Nathalie Gasser ISLAM, GENDER, INTERSEKTIONALITÄT

Bildungswege junger Frauen in der Schweiz 
Nathalie Gasser

Islam, Gender, Intersektionalität 
Für die Frauen, die hinter den Pseudonymen Zara, Xhemile, Esma, Duaa, Ardita, Velika, Adea, Aieta, Maide, Suad, Sahar, Zoya, Rahima, Lane, Malia, Raime, Fijona, Illana, Rhea, Hannan und Mira stehen.

Nathalie Gasser, geb. 1974, lehrt und forscht an der Pädagogischen Hochschule Bern mit den Schwerpunkten soziale Ungleichheit und Dominanzverhältnisse im Kontext von Bildung, Othering, Intersektionalität, Bildungsbiografien und Islamdiskurs sowie rassismuskritische Bildung. Sie studierte Sozialanthropologie an der Universität Bern und promovierte in Religionswissenschaft an der Universität Luzern. 
Nathalie Gasser

\section{Islam, Gender, Intersektionalität}

Bildungswege junger Frauen in der Schweiz 
Das religionswissenschaftliche Seminar der Kultur- und Sozialwissenschaftlichen Fakultät der Universität Luzern hat diese Studie unter dem Titel »Einen Weg finden. Bildungsbiografien junger Musliminnen in der Deutschschweiz im Kontext des gegenwärtigen Islamdiskurses« am 26. August 2019 auf Antrag der beiden Gutachtenden, Prof. Dr. Martin Baumann (Religionswissenschaftliches Seminar, Universität Luzern) und Prof. Dr. Angela Stienen (Institut für Forschung und Entwicklung, Pädagogische Hochschule Bern, IFE PHBern) als Dissertation angenommen.

Die Dissertation wurde von der Pädagogischen Hochschule Bern (PHBern) gefördert.

\section{$\underset{\text { patagegische tochsshule }}{\text { PHern }}$}

Publiziert mit Unterstützung des Schweizerischen Nationalfonds zur Förderung der wissenschaftlichen Forschung.

\section{FNSNF}

SCHWEIZERISCHER NATIONALFONDS

ZUR FÖRDERUNG DER WISSENSCHAFTLICHEN FORSCHUNG

Auszüge aus dem Kapitel »Expertin für Islam« erschienen 2019 unter dem Titel: Gasser, Nathalie (2019): »Frau Ibrahimi, was sagt der Islam dazu?« Die Differenzkategorie »Muslimin« als soziale Deutungspraxis im pädagogischen Kontext. In: Zeitschrift für Religionskunde (ZFRK) 7, S. 7-17.

\section{Bibliografische Information der Deutschen Nationalbibliothek}

Die Deutsche Nationalbibliothek verzeichnet diese Publikation in der Deutschen Nationalbibliografie; detaillierte bibliografische Daten sind im Internet über http://dnb.d-nb.de abrufbar.

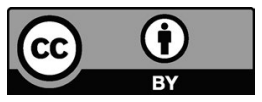

Dieses Werk ist lizenziert unter der Creative Commons Attribution 4.0 Lizenz (BY). Diese Lizenz erlaubt unter Voraussetzung der Namensnennung des Urhebers die Bearbeitung, Vervielfältigung und Verbreitung des Materials in jedem Format oder Medium für beliebige Zwecke, auch kommerziell. (Lizenztext: https://creativecommons.org/licenses/by/4.o/deed.de)

Die Bedingungen der Creative-Commons-Lizenz gelten nur für Originalmaterial. Die Wiederverwendung von Material aus anderen Quellen (gekennzeichnet mit Quellenangabe) wie z.B. Schaubilder, Abbildungen, Fotos und Textauszüge erfordert ggf. weitere Nutzungsgenehmigungen durch den jeweiligen Rechteinhaber.

\section{Erschienen 2020 im transcript Verlag, Bielefeld (C) Nathalie Gasser}

Umschlaggestaltung: Maria Arndt, Bielefeld

Druck: Majuskel Medienproduktion $\mathrm{GmbH}$, Wetzlar

Print-ISBN 978-3-8376-5318-2

PDF-ISBN 978-3-8394-5318-6

EPUB-ISBN 978-3-7328-5318-2

https://doi.org/10.14361/9783839453186

Gedruckt auf alterungsbeständigem Papier mit chlorfrei gebleichtem Zellstoff.

Besuchen Sie uns im Internet: https://www.transcript-verlag.de

Unsere aktuelle Vorschau finden Sie unter www.transcript-verlag.de/vorschau-download 


\section{Inhalt}

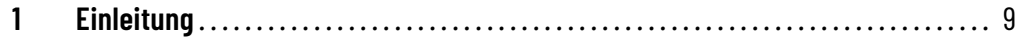

2 Theoretische Rahmung ........................................ 17

2.1 Der Islamdiskurs in der Schweiz und die Differenzkategorie »Muslimin «.......... 18

2.1.1 $»$ Religiöses Othering « ................................................................ 19

2.1.2 Die diskursive Differenzkategorie »Muslimin « ............................. 21

2.1.3 Weitere in der Deutschschweiz relevante Diskurse ............................26

2.2 Intersektionelle Perspektive in Bezug auf den Zugang zu Bildung.................. 36

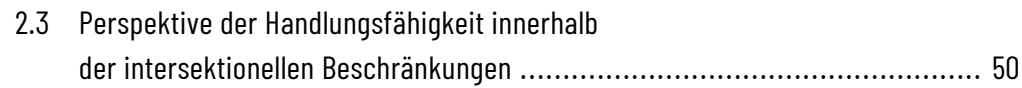

3 Annäherung an das Forschungsfeld .......................... 59

3.1 Musliminnen und Muslime in der Schweiz: ein Überblick...............................59

3.2 Anknüpfungspunkte: Forschung zu adoleszenten Secondas*os muslimischen Glaubens im Kontext des gesellschaftspolitischen Islamdiskurses in der Schweiz .............................64

3.3 Schweizerisches Bildungssystem im Kontext von sozialer Ungleichheit .............72

3.3.1 Überblick: Gliederung des Bildungssystems in der Schweiz ..................72

3.3.2 Jugendliche mit »Migrationshintergrund « in Übergängen im Bildungssystem in der Schweiz............................................ 76

4 Methodisches Vorgehen...................................... 87

4.1 Sample: Forschen zu Musliminnen im Spannungsfeld zwischen »methodological Islamism « und »strategical essentialism « ...................... 88

4.2 Zugang zum Feld: Multi-Sited Ethnography ...........................................95

4.3 Biografisch-narrative, themenzentrierte Interviews .............................. 105 
4.4 Codierung und kontinuierliche Auswertung:

datengeleitete Theoriebildung nach der Grounded-Theory-Methodologie

(GTM) kombiniert mit einer fallzentrierten Perspektive

5 Bildungsbiografische »Taktiken « junger religiös orientierter Secondas muslimischen Glaubens in der Deutschschweiz ........................ 115

5.1 Typus 1: »Taktik « der kämpferischen Selbstbehauptung als Muslima ............. 117

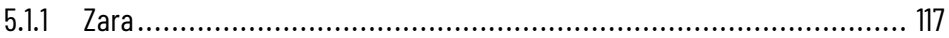

5.1.2 Bildungsbiografisches Bestehen durch die »Taktik« der kämpferischen Selbstbehauptung als emanzipierte bzw. dezidiert religiöse Muslima .................................................................. 122

5.2 Typus 2: »Taktik « des zielstrebigen Aufsteigens ....................................... 155

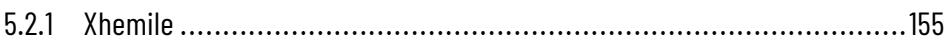

5.2.2 Bildungsbiografisches Bestehen durch die »Taktik«

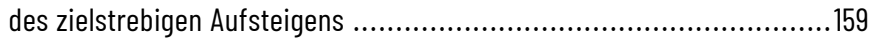

5.3 Typus 3: »Taktik« der religiösen Vergemeinschaftung ............................. 193

5.3.1 Esma...................................................................................... 193

5.3.2 Bildungsbiografisches Bestehen durch die »Taktik«

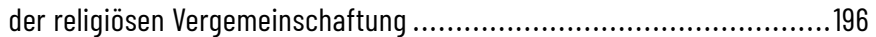

5.4 Typus 4: »Taktik« der widerständigen Mikropraktiken .............................. 222

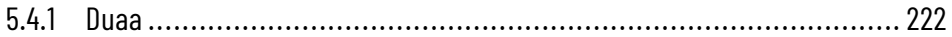

5.4.2 Bildungsbiografisches Bestehen durch die »Taktik« der widerständigen Mikropraktiken ............................................. 226

6 Exkurs: Religionsverständnis, religiöse Praxis und religiöse

Selbstrepräsentation junger Secondas muslimischen Glaubens im Wandel... 251

7 Zusammenfassung und Schlussdiskussion: Die doppelte Rolle der Religion in Bildungsbiografien junger Secondas muslimischen Glaubens ......... 265

7.1 Religion als Differenzkategorie: Manifestationen

der Differenzkategorie »Muslimin « in Bildungsbiografien

7.2 Religion als Ressource: Manifestation von religiöser Praxis, religiöser

Selbstrepräsentation und religiöser Vergemeinschaftung als Ressource

in Bildungsbiografien .................................................................. 290

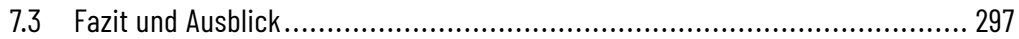

Dank .......................................................... 301 
Literaturverzeichnis.

Transkriptionsregeln Interviews. 343 



\section{Einleitung}

In den letzten Jahren ist in gesellschaftspolitischen Diskursen ein Trend auszumachen, Differenzen vermehrt entlang religiöser Grenzen zu konstruieren (Sökefeld 2011: 271). Mecheril und Thomas-Olalde (2011) sprechen in diesem Zusammenhang von der diskursiven Praxis des »religiösen Otherings (ebd.: 45), welche das Ziel verfolgt, die Grenze zwischen einer $»$ - mehr oder weniger expliziten - Wir-Gruppe $<$ und `den Andern $<$ zu markieren und zu verobjektivieren « (ebd.: 46). >Religion« wurde in diesem Diskurs zunehmend zu einer zentralen Interpretationskategorie für negativ und positiv betrachtete individuelle und kollektive Handlungsweisen, insbesondere derer von Migrant"innen ${ }^{1}$ (Behloul 2010: 45). Im homogenisierenden Islamdiskurs wird die Abgrenzung gegen >den Islamく immer stärker mit dem Verweis auf hierarchische Geschlechterverhältnisse begründet, die als unveränderbares Wesensmerkmal >des Islam dargestellt werden (Marx 2008: 55, Allenbach/Müller 2017: 273). Hierbei lässt sich eine dominante differenzkategoriale Geschlechtskonstruktion beobachten, nämlich das Bild einer von Zwang dominierten "armen, unterdrückten muslimischen Frau« und ihrem Pendant, einem unterdrückenden, Zwang ausübenden »frauenfeindlichen muslimischen Mann« (Kaya 2012: 120). Innerhalb dieser diskursiven Formation wird die Markierung "Muslimin« zur Differenzkategorie (vgl. Kap. 2.1.2).

Muslimische Frauen scheinen diskursiven Zuschreibungen und dem damit einhergehenden »dauernden Rechtfertigungsdruck (Tunger-Zanetti 2013a: 224) besonders ausgesetzt zu sein (vgl. u.a. Baghdadi 2012, 2010, Schild 2010, Kap 2.1.2). Schild behauptet gar, muslimische Frauen in der 
Schweiz seien in der Ausformulierung einer "positiven >muslimischen Identität`, deren Anerkennung durch die Mehrheitsgesellschaft sie anstreben«, nicht »frei««. Vielmehr müssten sie sich fortwährend mit kursierenden Repräsentationen und negativen Zuschreibungen auseinandersetzen, diese »unablässig berichtigen, korrigieren und entkräften« (Schild 2010: 181).

Trotz des mit hoher Emotionalität geführten aktuellen Diskurses über Muslim*innen in der Schweiz wurde bisher auffallend wenig zu deren biografischen Erfahrungen geforscht, insbesondere zu denen von Frauen der sogenannten zweiten Generation ${ }^{2}$. Dabei scheinen es gerade die biografischen Erfahrungen zu sein, anhand derer die subjektive Verarbeitung und die Auseinandersetzung mit der gesellschaftlichen Komplexität in transnationalen Lebenswelten $^{3}$ besonders nachvollzogen werden kann (vgl. Wensierski und Lübcke 2012, 2011, 2007; Lübcke 2007: 313). Deutsche Studien legen nahe, dass sich die sogenannte »zweite Generation« hinsichtlich ihrer identitären Aushandlungsprozesse in einem Spannungsfeld befindet: Einerseits müssen sich die jungen Secondas*os innerhalb der Gesellschaft (im Kontext des gegenwärtigen Islamdiskurses) als Muslim*innen verorten, anderseits müssen sie sich gegenüber ihrer Elterngeneration positionieren (vgl. u.a. Bendixsen 2013, 2005, Nökel 2002, 1999, Schiffauer 2004). Diese Aufgabe wird gemäss Schiffauer dadurch erschwert, dass "sowohl von der Einwanderergesellschaft wie von der ersten Generation das Verhältnis von seuropäischer Kultur < und Islam als Verhältnis von Eigenem und Fremden konstruiert« wird (2004: 354) und somit als »ein Verhältnis von Opposition« (ebd.). Dieses Verhältnis wiederum ist durch eine Machtasymmetrie der Etablierten gegenüber den Zugewanderten bestimmt (ebd.: 354).

Junge (muslimische) Secondas*os stehen in ihren adoleszenten Individuationsprozessen insofern vor einer doppelten Herausforderung - King und Koller sprechen von einer »verdoppelten Transformationsanforderung« (2009b: 12): Einerseits müssen sie sich in der adoleszenten Auseinandersetzung mit den Welt-, Selbst- und Sachbezügen (Helsper et al. 2009: 26)

2 Zur Proble
pitel 4.1.

3

Mit»transnationalen sozialen Räumen « werden in der Migrationsforschung plurilokale Aktionsfelder von Personen »mit Migrationshintergrund« angesprochen, die mehr oder weniger zeitgleich wirksam sind und biografisch als zusammengehörig betrachtet werden. Der soziale Raum als verdichteter Kommunikations- und Interaktionszusammenhang besteht aus mehreren Schauplätzen, die institutionell völlig unterschiedlich strukturiert sind (Pries 2008). 
befassen, andererseits stehen sie zusätzlich vor der Anforderung, mit »der zugeschriebenen und erlebten Differenz« (Allenbach et al. 2011: 18) einen Umgang zu finden.

Was bedeutet das nun für religiös orientierte junge Secondas muslimischen Glaubens in der Deutschschweiz?

Die voranstehend skizzierten Spannungsfelder lassen vermuten, dass gerade religiös orientierte Secondas - als muslimische Frauen, Migrantinnen und Angehörige der zweiten Generation - in besonderem Masse von der Anforderung betroffen zu sein scheinen, mit zugeschriebener Differenz einen Umgang $\mathrm{zu}$ finden und sich gesellschaftlich und der Elterngeneration gegenüber zu behaupten. Eine solche Ausgangslage lässt die Frage aufkommen, ob diese Spannungsfelder auch Einfluss auf den Bildungsbereich haben, bspw. auf Position und Positionierung junger religiös orientierter Secondas im schweizerischen Bildungssystem.

Untersuchungen zu identitären Aushandlungsprozessen von adoleszenten Musliminnen der sogenannten zweiten Generation im Kontext von Schule und Ausbildung stellen in der Schweiz jedoch eine eigentliche Forschungslücke dar. Internationale Studien bieten zwar interessante Anknüpfungspunkte, sind jedoch nur bedingt übertragbar: Erstens nimmt die Berufsbildung im Dualen Bildungssystem der Schweiz einen wesentlich höheren Stellenwert ein als in den europäischen Nachbarländern, zweitens gilt das schweizerische Inkorporationsregime im Vergleich als überdurchschnittlich streng und assimiliationistisch (Gianni 2009) und drittens unterscheidet sich die muslimische Bevölkerung in der Schweiz durch ihre Heterogenität deutlich von denjenigen der Nachbarländer (Nielsen et al. 2012). Diese Faktoren legen nahe, dass sich in der Schweiz eine besondere Perspektive auf die identitären Aushandlungsprozesse und Strategien im Zusammenhang mit Bildungsentscheidungen, insbesondere adoleszenter muslimischer Frauen, eröffnet.

Deutsche Studien lassen zudem vermuten, dass speziell Kopftuch tragende Frauen im Bildungssystem durchaus mit wirkmächtigen Bildungsbarrieren konfrontiert sein könnten und das Tragen eines Kopftuchs bspw. bei einer Lehrstellenvergabe als Ausschlusskriterium gewertet werden könnte (vgl. bspw. Scherr et al. 2015: 150-151).

Diese Ausgangslage führte mich zu meiner Fragestellung: Das zentrale Erkenntnisinteresse der vorliegenden Untersuchung resultierte in der Frage, 
ob und wie sich der Islamdiskurs auf die Bildungsbiografien junger, religiös orientierter Secondas muslimischen Glaubens ${ }^{4}$ der Deutschschweiz auswirkt.

Ein besonderer Fokus wurde hierbei zunächst auf (bildungs-)biografische Übergänge ausgerichtet, so z.B. auf den Übergang von Volksschule zum nachobligatorischen Ausbildungssystem sowie auf die erste Selektionsschwelle (vgl. Kap. 3.3). Ausgangspunkt dieser Fokussierung bildete die auf neuere jugendsoziologische Studien abgestützte Annahme, dass in bildungsbiografischen Übergängen Neuaushandlungs- und Repräsentationsprozesse nicht nur stattfinden (King 2004, Schittenhelm 2010, 2005), sondern überdies stereotypen gesellschaftlichen Zuschreibungen besonders ausgesetzt sind (vgl. bspw. Scherr et al. 2015). Ziel der Arbeit war es zu untersuchen, wie religiös orientierte Secondas muslimischen Glaubens ihre (bildungs-)biografische Positionierung aushandeln, darstellen und reflektieren, und welche Rolle die Religion sowie die (diskursive) Differenzkategorie »Muslimin« hierbei spielen und ob und wie diese Faktoren den berufsbiografischen Prozess bzw. die Wahl der nachobligatorischen Ausbildung beeinflussen.

Hierbei waren folgende Teilfragen leitend:

- Wie wirken (diskursive) Zuschreibungsprozesse auf junge religiös orientierte Secondas im Kontext von Schule und (Berufs-)Ausbildung?

- Welche Differenzdimensionen wirken in Bildungsbiografien? Wirken sie intersektionell?

- Wie konstituiert und manifestiert sich die Differenzkategorie »Muslimin« in Bildungsbiografien?

- Wie gelingt es den jungen Secondas muslimischen Glaubens bildungsbiografisch »einen Weg zu finden«? Wie erlangen sie (mehr) Agency in Bildungsbiografien?

Um den jungen Frauen Raum für die Darstellung eigener Relevanz- und Deutungssysteme innerhalb ihrer sozialen Räume zu geben, wurde für das Forschungsvorhaben ein ethnografischer Ansatz gewählt. Kern des Zugangs zum Feld bildete die Methodik einer multi-sited Ethnography, wie Marcus (1995) sie in Abgrenzung zur klassisch ethnografischen Vorgehensweise vorschlug. Wie bei einer ethnografischen Herangehensweise üblich, kam bei der Datenerhebung ein Methodenmix zum Zuge: Die Basis der empirischen Untersuchung

4 Zur Gestalt des Samples sowie der Problematisierung und Definition von Begrifflichkeiten in der Fragestellung vgl. Kap. 4.1. 
bestand aus einem zirkulären Verfahren von teilnehmender Beobachtung in multiplen sozialen, aber auch virtuellen Feldern, verbunden mit themenzentrierten (bildungs-)biografischen Interviews sowie einer diskursiven Dokumentenanalyse in Bezug auf die Differenzkategorie »Muslimin«.

Die Befragung zu bildungsbiografischen Übergangsprozessen erfolgte retrospektiv. Das Sample bestand aus religiös orientierten, muslimischen Frauen $^{5} »$ mit Migrationshintergrund $\aleph^{6}$, die in der Schweiz geboren, resp. als Kleinkinder mit ihren Eltern zugewandert sind und zum Zeitpunkt der Forschung in der Deutschschweiz wohnten. Die Frauen waren zum Zeitpunkt der Datenerhebung 18 bis 32 Jahre alt und somit in einem Alter, in dem Menschen einerseits - wie erfahrene Biografieforschende festgestellt haben - in der Lage sind »kritisch ihre soziale Position, ihren Akteur-Spielraum und ihr Selbst im Verhältnis zu andern [zu] reflektieren" (Nökel 2002: 19; vgl. hierzu auch Rosenthal 1995: 104, 135 Lucius-Hoene/Deppermann 2002: 298), andererseits die zu rekonstruierende bildungsbiografische Lebensphase noch nicht zu weit zurück liegt.

In Interviews, welche die Feldforschung begleiteten, wurden die Frauen gebeten, narrativ über ihre Überlegungen zur Berufswahl bzw. zum Übergang von Schule zu nachobligatorischem Ausbildungssystem sowie zu anderen Bildungsentscheidungen Auskunft zu geben, dabei wurden der Stellenwert allfälliger religiöser Orientierungen sowie gesellschaftliche Zuschreibungsprozesse für ihr bildungs- bzw. berufsbiografisches Selbstverständnis angemessen thematisiert (vgl. Stienen/Bühler/Gasser/Tamcan 2011). Die kontinuierliche, zirkuläre Auswertung erfolgte mittels Grounded Theory (Strauss/Corbin 1996) und wurde durch eine fallzentrierte, biografische Perspektive ergänzt. In einer späteren Phase der Untersuchung wurde in folge des zirkulären Prozesses der Grounded Theory die Fragestellung angepasst und die forschungslogische Entscheidung getroffen, die diskursive Differenzkategorie "Muslimin« nicht nur hinsichtlich von bildungsbiografischen Übergängen, sondern in Bezug auf die gesamte erhobene Bildungsbiografie zu betrachten. Eine erste Auswertung der bildungsbiografischen Narrationen zeigte nämlich, dass sich sowohl eingeschlagene Bildungswege wie auch Religionsverständnis, religiöse Praxis und religiöse Selbstrepräsentation in der frühen Adoleszenz im Spannungsfeld zwischen »methodological Islamism«(Brubaker 2012: 6) und einem »strategic use of (...) essentialism « (Spivak 1993: 5, Herv. im Orig.) vergleiche Kap. 4.1. 
noch stark verändern und gegenseitig beeinflussen können. Der ausschliessliche Blick auf bildungsbiografische Übergänge hätte mögliche Aussagen verkürzt und die Bildungsverläufe im Rahmen des heute flexibilisierteren und durchlässigeren schweizerischen Bildungssystems nur eingeschränkt darstellen lassen.

In der theoretischen Ausrichtung der Forschung folgte ich der Tradition einer postkolonialen, feministischen Migrationsforschung, die (Fremd-)Konzeptionen von Frauen/Migrantinnen/Musliminnen als "passive Opfer« und damit einhergehenden Rettungsdiskursen (vgl. Kap. 2.1.2) kritisch gegenüber steht (vgl. Abu-Lughod 2013, 2002, Allenbach 2016, Marx 2008). Die theoretische Perspektive der vorliegenden Forschung hatte denn auch zum Ziel, den Blick auf die Selbstpositionierungen und die Handlungsfähigkeit (Agency) der jungen Frauen zu richten, ohne jedoch die strukturellen Einschränkungen ihrer Bildungsbiografien zu negieren. In theoretischer Hinsicht interessierten hierbei insbesondere das Zusammenspiel von Handlung und Struktur, also die Handlungsspielräume innerhalb der potenziell intersektionell wirkenden strukturellen Beschränkungen der Bildungswege der jungen Frauen: Es sollte rekonstruiert werden, auf welche Strategien religiös orientierte Secondas zurückgreifen, um sich als handelnde Subjekte aktiv gesellschaftlichen Differenzierungs- und Schliessungsprozessen zu stellen oder diesen zu trotzen (vgl. Kap. 5).

Zunächst wird in Kapitel 2 die Rahmung des Projekts näher erläutert. Hierbei wird auf den Islamdiskurs, wie er sich gegenwärtig in der Schweiz zeigt, eingegangen. Angesichts der Forschungsfrage wird der diskursiven Differenzkategorie »Muslimin« (Kap. 2.1.2) in diesem Zusammenhang besondere Beachtung geschenkt. Ebenso wird in Kapitel 2 die doppelte theoretische Perspektive, die eingenommen wird, näher erläutert. Es handelt sich um eine Verbindung einer intersektionellen Perspektive (Kap. 2.2), welche die potenziellen (strukturellen) Beschränkungen der Bildungswege der jungen Frauen in den Blick nehmen soll, mit einer Perspektive der Handlungsfähigkeit (Agency) (Kap. 2.3), die eben diese (innerhalb der strukturellen Beschränkungen) der jungen Frauen fokussiert.

In Kapitel 3 wird das Forschungsfeld näher umrissen. Dahingehend wird zunächst auf die muslimische Bevölkerung in der Schweiz eingegangen (Kap 3.1), um sodann den Forschungsstand bzw. Anknüpfungspunkte zu bestehenden Forschungen zu skizzieren (Kap. 3.2). Schliesslich wird das schweizerische Bildungssystem im Kontext von sozialer Ungleichheit beschrieben (Kap. 3.3). 
In Kapitel 4 folgt eine Darlegung des methodischen Vorgehens der Untersuchung. In einem ersten Schritt wird das Sample umrissen und auf das Dilemma des Forschens zu Musliminnen im theoretischen Spannungsfeld von "methodological Islamism« (Brubaker 2012: 6) und einem »strategic use of (...) essentialism« (Spivak 1993: 5, Herv. im Orig.) eingegangen (Kap. 4.1). Anschliessend erläutere ich die ethnografische Herangehensweise und den Zugang zum Feld (Kap. 4.2). In zwei weiteren Unterkapiteln gehe ich einerseits auf die methodische Durchführung biografisch-narrativer, themenzentrierter Interviews (Kap. 4.3) und schliesslich auf die Codierungs- und Auswertungsstrategie ein (Kap. 4.4).

Kapitel 5 bildet das eigentliche Kernstück der Arbeit. Hier werden anhand empirischer Fallbeispiele vier habituell verankerte »Taktiken (De Certeau 1988: 89) rekonstruiert, mittels derer die jungen Frauen versuchen, in ihren intersektionell beschränkten »Möglichkeitsräumen« (Holzkamp 1983) mehr Agency in ihren Bildungsbiografien zu gewinnen. Es handelt sich hierbei um die "Taktik der kämpferischen Selbstbehauptung als Muslima« (Kap. 5.1), die »Taktik des zielstrebigen Aufsteigens« (Kap. 5.2), die »Taktik der religiösen Vergemeinschaftung« (Kap. 5.3) sowie die »Taktik der widerständigen Mikropraktiken« (Kap. 5.4). Die Kapitel werden jeweils einleitend mit einem kurzen exemplarischen, bildungsbiografischen Portrait versehen. Die typisierten, habituell verankerten »Taktiken« (De Certeau 1988: 89) werden dann anhand des a) Herkunftsmilieus, b) der Rolle der Religion und der Differenzkategorie »Muslimin« hinsichtlich der Bildungsbiografie sowie c) der gesellschaftlichen Selbstpositionierung unter Einbezug weiterer Fälle und unterschiedlicher Ausprägungen verdeutlicht.

Mit Kapitel 6 und 7 folgt der Schlussteil der Arbeit. In einem Exkurs in Kapitel 6 werden sieben, teilweise genderspezifische Thesen zum Wandel des Religionsverständnisses, den religiösen Praxen und der religiösen Selbstrepräsentation junger Secondas muslimischen Glaubens hinsichtlich ihrer Elterngeneration aufgestellt. Dieses Themenfeld bildete zwar nicht den Hauptfokus der Arbeit, kristallisierte sich aber im Zuge der Forschung so deutlich heraus, dass an dieser Stelle näher darauf eingegangen werden soll.

In Kapitel sieben folgt eine Zusammenfassung der Untersuchung und die Schlussdiskussion der Ergebnisse: Ich argumentiere, dass »Religion« in Bildungsbiografien junger Secondas muslimischen Glaubens eine doppelte Rolle einnimmt. Einerseits eine bildungsbiografisch einschränkende Rolle als intersektionell wirkende Differenzkategorie (Kap. 7.1) und andererseits als "gelebte Religion« (>lived religion`McGuire 2008) die Rolle einer Ressource (Kap. 
7.2). Des Weiteren schlage ich anlehnend an Walgenbach (2012c, Gender als interdependente Kategorie) vor, Religion theoretisch als interdependente Kategorie zu denken. Eine solche Perspektive soll einen intersektionellen Blick auf religionswissenschaftliche Daten ermöglichen, der bspw. auf spezifische Erfahrungen religiöser Frauen in subalternen gesellschaftlichen Positionen fokussieren kann, ohne die damit einhergehenden komplexen Überlagerungen struktureller Dominanzverhältnisse zu unterschlagen. Mit einem Fazit und weiterführenden Forschungsdesideraten schliesse ich $a b$.

An dieser Stelle noch eine Anmerkung zur Anonymisierung: Bei den verwendeten Namen der Frauen handelt es sich selbstverständlich um Pseudonyme. Um mögliche Rückschlüsse auf reale Personen zu vermeiden, wurden wenn möglich neben der Anonymisierung der Namen auch Anzahl von Geschwistern, Kindern sowie Berufsbezeichnungen von Interviewten und deren Eltern durch analoge Erwerbstätigkeiten verfremdet. Um im Hinblick auf die Struktur des Bildungssystems, der Bildungswege und Zugänge, aber auch hinsichtlich von Genderaspekten und gesellschaftlicher Positionierung grösstmögliche Analogien zwischen realen und anonymisierten Bildungsbiografien zu schaffen, wurde das Berufsberatungs- und Informationszentrum Bern (BIZ Bern) beigezogen.

Abschliessend noch eine Bemerkung zu den Interviewstellen: Die Bezeichnungen hinter den Interviewstellen (z.B. A 51) beziehen sich auf die betreffenden Codierabschnitte in den MAXQDA-Dateien. Die direkten Zitate aus Interviews sind wörtlich in Standarddeutsch übersetzt, bis auf wenige kursiv geschriebene Mundartausdrücke, die sich schwer übersetzen liessen. Diese werden jeweils in einer Fussnote erklärt. 


\section{Theoretische Rahmung}

Diskurse $\mathrm{zu}>$ Islam ${ }^{1}$ und $>$ Muslim ${ }^{*}$ in-Sein $<$ verlaufen in der Schweiz in der Post9/11-Zeit innerhalb unterschiedlicher Formationen: Einerseits werden Muslim*innen unter den Vorzeichen eines New Orientalism bzw. Otherings verhandelt, d.h., sie werden als das >fremde Andere`, als monolithisches spiegelbildliches Gegenüber zum >Eigenen` rezipiert (Kap. 2.1.1). Innerhalb dieses diskursiven Rahmens ist auch weitgehend die Differenzkategorie »Muslimin« angesiedelt (vgl. Kap. 2.1.2). Andererseits werden Muslim*innen zunehmend unter dem Aspekt eines \Sicherheitsproblems besprochen (Allenbach/Sökefeld 2010:19; vgl. Frisina 2010 in Bezug auf Italien). Weitere diskursive Felder in der Deutschschweiz bilden die Thematik sichtbarer religiöser Symbole im öffentlichen Raum: bspw. die für die Schweiz bezeichnende Debatte um die im November 2009 angenommene sogenannte Minarettinitiative (»Initiative gegen den Bau von Minaretten «) oder die gegenwärtig ${ }^{2}$ diskutierte Volksinitiative zum Verhüllungsverbot (»Initiative Ja zum Verhüllungsverbot«). Auch im Bildungsbereich werden Debatten geführt; so wird bspw. - mitunter seit vielen Jahren - auch juristisch darüber gestritten, inwiefern Lehrpersonen und Schülerinnen im Unterricht Kopftuch tragen dürfen oder unter welchen Bedingungen aus Glaubensgründen ein Dispens vom Schwimmunterricht erfolgen kann oder eben nicht (vgl. Kap. 2.1.3).

Innerhalb dieses diskursiven Gefüges müssen sich junge muslimische Frauen gesellschaftlich behaupten. In Bezug auf ihre Bildungsbiografien - so argumentiere ich in der vorliegenden Untersuchung - manifestieren sich unterschiedliche Differenzdimensionen, die im Zusammenspiel auf als diskursive Konstrukte und nie als essenzialisierte Entitäten verstanden (vgl. Marx 2008: 65).

2 Die beschriebenen Ereignisse bilden den Forschungsstand im Sommer 2017 ab. 
den Zugang zu Bildung wirken (vgl. Kap. 2.2). Neben strukturellen Beschränkungen wird in der vorliegenden Untersuchung indes gerade auch die Handlungsfähigkeit der jungen Frauen in den Blick genommen. Diese entwickeln verschiedenste Strategien, mit welchen sie auf dominante Diskurse, zugeschriebene Differenzen und strukturelle Beschränkungen reagieren bzw. sich diesen widersetzen und mehr Handlungsfähigkeit entwickeln. Innerhalb des Islamdiskurses, welcher den Rahmen der Untersuchung bildet, argumentiere ich theoretisch aus einer doppelten Perspektive: Zur Erklärung der strukturellen Beschränkungen in Bezug auf den Zugang zu Bildung wird eine intersektionelle Perspektive eingenommen (vgl. Kap. 2.2), die auf das Wechselspiel verschiedener Differenzdimensionen zur Beleuchtung der Handlungsstrategien der Frauen fokussiert - ein Ansatz, welcher die Handlungsfähigkeit in den Blick nimmt, ohne jedoch deren strukturellen Einschränkungen zu negieren (Perspektive der Handlungsfähigkeit vgl. 2.3). Bei der Theoretisierung von Agency lehne ich mich an das auf De Certeau rekurrierende Konzept der »alltäglichen Taktiken und Strategien« (1988: 87ff.) an, mit dem auf dominante Diskurse reagiert werden kann.

\subsection{Der Islamdiskurs in der Schweiz und die Differenzkategorie "Muslimin"}

Jugendliche Migrant*innen stehen in ihren adoleszenten Individuationsprozessen vor einer doppelten Herausforderung - King und Koller sprechen von einer »verdoppelten Transformationsanforderung« (2009a, 2009b: 12): Einerseits müssen sie sich in der adoleszenten Auseinandersetzung mit den Welt-, Selbst- und Sachbezügen (King/Koller 2009b, Hummrich 2009: 28) befassen, andererseits stehen sie zusätzlich vor der Anforderung, mit »der zugeschriebenen und erlebten Differenz« (Allenbach et al. 2011: 18) einen Umgang zu finden. Kontext der Studie bildet der gesellschaftspolitische Islamdiskurs, ausgehend von der Annahme, dass dieser sich auf die Identifikations- und Repräsentationsstrategien (Allenbach et al. 2010: 2) und somit auch auf (Bildungs-)Biografien junger Muslim*innen auswirkt. Im Folgenden soll es nicht darum gehen, die laufenden Diskurse in all ihren Facetten vollständig auszuleuchten, sondern darum, das diskursive Feld abzustecken, in dem Muslim*innen in der Deutschschweiz ihre Bildungsentscheidungen fällen müssen. 
In politischen und medialen Debatten um Migration und Integration in der Schweiz erfährt der Islam seit einigen Jahren eine ungleich hohe Beachtung. Gegenstand dieser Debatten sind in der Schweiz nicht ausschliesslich die Ausgrenzung >des Islam auch die (Re-)Formulierung von seigenen kulturellen Werten (vgl. »Leitkultur«-Diskussion in Deutschland Marx 2008: 55). In der 2016 geführten sogenannten >Händeschüttelaffäre`, in deren Rahmen sich ein Schüler der Sekundarstufe in Therwil (Kanton Baselland), auf den Islam rekurrierend, weigerte, der Lehrerin die Hand zu geben, wurde bspw. schweizweit intensiv diskutiert, inwiefern >Schweizer Werte (hier aufgefasst als: der Lehrperson am Eingang des Schulzimmers die Hand zu geben) für alle gelten sollen (vgl. auch Bleisch 2016). Die Dringlichkeit und Emotionalität, mit welcher diese Diskussion geführt wurde, zeigte sich bspw. daran, dass sich gar die Bundesratsrätin Simonetta Sommaruga in die Debatte einmischte, die Forderung, »der Händedruck gehört zu unserer Kultur«, platzierte und dies als nicht verhandelbar bezeichnete (Sommaruga zit.n. Jürgensen 2016). Dabei ist es eher selten, dass sich ein*e Bundesrät*in als Vorsteher*in eines eidgenössischen Departements in eine Angelegenheit einbringt, die theoretisch in den Zuständigkeitsbereich der Schulleitungsebene fällt. Die neuesten Entwicklungen des Falls gehen dahin, dass es seitens der Kantonsregierung Baselland insbesondere der Bildungsdirektorin Monica Gschwind Bestrebungen gibt, »die Akzeptanz hiesiger Werte und Rituale« und davon abzuleitende »bürgerliche Pflichten « in die Verfassung einschreiben zu lassen, ein entsprechendes Gesetz befindet sich zur Zeit in der Vernehmlassung (Loser 2017).

\subsection{1 "Religiöses Othering"}

In den letzten Jahren besteht in gesellschaftspolitischen Debatten die Tendenz, Differenzen vermehrt entlang religiöser Grenzen zu konstruieren (Sökefeld 2011: 271). Die Gründe hierfür werden meist in den Ereignissen des 11. Septembers 2001 gesehen (vgl. bspw. Behloul 2009a: 104, Ettinger et al. 2011: 14). Sökefeld (2011: 271) markiert für den angelsächsischen Raum den Beginn eines solchen Trends jedoch bereits Ende 1980er-Jahre mit der »RushdieAffäre $\aleph^{3}$. Im Zuge dieser Affäre bezogen sich viele Muslim*innen verstärkt auf 
den Islam und wurden "gleichzeitig von der nicht-muslimischen Mehrheitsgesellschaft als nicht kompatibel mit >westlichen « Werten ausgegrenzt « (Sökefeld 2011: 271). Mecheril und Thomas-Olalde (2011) sprechen in diesem $\mathrm{Zu}$ sammenhang von der diskursiven Praxis eines »religiösen Othering[s]« (ebd.: 45), um die Grenze zwischen einer » - mehr oder weniger expliziten - >WirGruppe und `den Andern` zu markieren und verobjektivieren« (ebd.: 46). Aktuelle öffentliche und politische Debatten sind zudem wesentlich von einer essenzialistischen Einheitssemantik geprägt, die sich um ein vermeintlich unveränderbares Wesen des Islam dreht (Behloul 2009a: 106, Allenbach et al. 2010: 8). Religion wurde zunehmend $\mathrm{zu}$ einer zentralen Interpretationskategorie für negative und positive individuelle und kollektive Handlungsweisen, insbesondere derer von Migrantinnen und Migranten (Behloul 2010: 45). Behloul konstatiert denn auch einen »discours total« (2009c). Allenbach et al. (2010: 22) sehen den anti-muslimischen Diskurs gar als integrationsverhindernd, Tezcan (2007: 71) überspitzt mittels der Konstruktion eines »homo islamicus«, Schiffauer mittels »Muslim-Other« (2004: 354).

Um die Jahrtausendwende etablierten sich im Zuge der Ereignisse des 11. Septembers in der öffentlichen Kommunikation »Differenzsemantiken« (Ettinger/Imhof 2011: 6), die diskursiv eine >muslimische Minderheit< konstruierten und deren Verhältnis zur >Mehrheitsgesellschaft< thematisierten sowie insbesondere problematisierten (ebd. vgl. auch Behloul 2005, Behloul/Lathion 2007). Die überraschende Annahme der Minarettinitiative am 29. November 2009 lässt darauf deuten, dass auch in der Schweiz kulturelle Differenzdiskurse zunehmend anhand religiöser Symbole konstruiert werden (Behloul 2011: 127; vgl. auch nachstehend die Kontroverse um die Initiative "Ja zum Verhüllungsverbot«). So gelangen Ettinger und Imhof (2011) zum Schluss, dass »im Zuge dieser Entwicklung (...) die ursprünglichen, auf die nationalen Herkunftskontexte der Immigranten bezogenen Typisierungen durch eine religiöse Typisierung überformt und verdrängt« (Ettinger/Imhof 2011: 1) wurden. Oder wie Illana, die ich im Zuge der Feldforschung kennenlernte, plakativ ausdrückt: »Früher waren wir die bösen Albaner, heute sind wir die bösen Muslime« (Feldprotokoll, Februar 2016).

zu, Rushdie mittels einer Fatwa am 14. Februar 1989 wegen Blasphemie zum Tode zu verurteilen. Khomeini rief die Muslime in aller Welt zur Vollstreckung dieses Urteils auf. Um dessen Durchführung Nachdruck zu verleihen, setzte er ein Kopfgeld von drei Millionen US-Dollar aus. Dieses Fatwa löste eine riesige Kontroverse aus (vgl. Talal 1990). 


\subsubsection{Die diskursive Differenzkategorie »Muslimin«}

Wie Allenbach und Müller (2017: 289) zeigen konnten, stehen Geschlechtsdiskurse zunehmend »im Brennpunkt des Kampfs um Anerkennung von religiösen Minderheiten« und müssen »als Argument für den Ausschluss von Zugewanderten herhalten" (Allenbach/Müller 2017: 273). Symbolische Grenzen zwischen Etablierten und Aussenseitern werden demnach vermehrt durch »Gleichheitsnormen als kultureller Marker des Westens« verhandelt (ebd.: 289). Dies zeigt sich in Bezug auf den Islam bspw. anhand differenzkategorialer Geschlechtskonstruktionen, die - meist mit dem Verweis auf hierarchische Unterdrückungsverhältnisse - als unveränderbares Wesensmerkmal >des Islam< dargestellt werden (Allenbach/Müller 2017: 273, Marx 2008: 55). Innerhalb dieses diskursiven Rahmens wird die Markierung »Muslimin« zur Differenzkategorie.

Die Differenzkategorie »Muslimin« zeigt sich in der Schweiz diskursiv besonders deutlich an den medialen und politischen Auseinandersetzungen um das Tragen eines Kopftuchs bzw. eines Niquabs oder eines Burkinis, wie bspw. in der sog. Burkadebatte ${ }^{4}$, in zahlreichen, teilweise auch medial geführten Diskussionen um Kopftuch tragende Schülerinnen und Lehrpersonen, um angemessene Kleidung und Burkinis im Schwimmbad und Schwimmunterricht. All diesen Debatten ist gemeinsam, dass den muslimischen Frauen unter den Bedingungen einer stereotypen Geschlechterkonstruktion die freie Wahl über ihren eigenen Körper zu entscheiden, abgesprochen wird (Kaya 2012: 124).

Weiter ist der Diskursformation über Geschlechtskonstruktionen und >den Islam^ eigen, dass `der Westen als (H)ort der Aufklärung, Freiheit und Toleranz sowie gleichberechtigter, emanzipatorisch strukturierter Geschlechterverhältnisse dargestellt und `dem Islam Zuschreibungen " (Marx 2008: 8) diametral entgegengesetzt wird. Kaya bezeichnet diese Diskursformation als kolonial (2012: 118), Dietze als $»$ neoorientalistisch" (2006: 234). In der Schweiz liegen nur wenige empirische Forschungen zu Strategien von jungen religiös orientierten muslimischen Frauen im Umgang mit Zuschreibungen vor - insbesondere was den Bildungsbereich anbelangt. Dabei manifestieren sich in der Schweiz Debatten 
um das Tragen des Kopftuchs nicht nur, aber besonders deutlich im Bildungskontext (vgl. Schnewly-Purdie/Tunger-Zanetti 2015: 562). Sie drehen sich bspw. darum, ob Kopftuch tragende Frauen als Lehrpersonen tätig sein oder als Schülerinnen in der Schule das Kopftuch tragen dürfen. Was für Auswirkungen diese stereotypen diskursiven Genderbilder auf die Selbstrepräsentation und -positionierung junger religiös orientierter Musliminnen und ihre Bildungsbiografie haben, ist Teil der vorliegenden empirischen Untersuchung.

Wie aus dem voranstehend Ausgeführten bereits deutlich geworden sein dürfte, werden Geschlechterdiskurse hinsichtlich des Islam meist (jedoch nicht ausschliesslich) unter Einbezug oder mit Hinweis auf das Tragen eines Kopftuchs geführt. Im Folgenden gehe ich auf zentrale Positionen der sogenannten >Kopftuchdebatten ${ }^{5}$ und ihre dahinter stehenden Geschlechterkonzepte ein, nicht zuletzt deshalb, weil religiös orientierte Muslim*innen - Bedeckte wie Nicht-Bedeckte - im an- oder ablehnenden Sinne diskursiv immer wieder auf diese gesellschaftlich diskutierten Positionen zurückgreifen.

An Marx (2008: 57ff.) anlehnend argumentiere ich, dass sich innerhalb der (feministischen) Debatten um die Bedeckung der muslimischen Frau in der Schweiz unterschiedliche »Rettungsszenarien« (also Szenarien »zur Errettung « muslimischer Frauen) rekonstruieren lassen: Marx geht - in Bezug auf Deutschland und die Niederlande - von drei unterschiedlichen »Rettungsszenarien« aus, die sich im Spannungsfeld von Geschlechterkonzepten und Islam bewegen und denen unterschiedliche Konzeptionen von >dem Islam aber auch von Geschlechtskonstruktionen (und Feminismus) zugrunde liegen (ebd.). Marx' Rettungsszenarien lassen sich meines Erachtens auf die Positionen in der Kopftuch- und Burkadebatte in der Schweiz übertragen. Im Folgenden werden sie kurz beschrieben und in Zusammenhang mit den in der Schweiz geführten Debatten gebracht:

Im Folgenden summiere ich unter >Kopftuchdebatten< Debatten zur Verschleierung der Frau, sei es durch einen Hijab, Niqab oder durch eine Burka. Mit Burkadebatte nehme ich Bezug auf die spezifische Schweizer Debatte zum Verhüllungsverbot, die unter diesem Namen geläufig ist. 
1 Rettungsszenario: Die Rettung »der unterdrückten Muslimin« vor dem "orientalistischen Patriarchat «

Im Rahmen dieses ersten (feministischen) Rettungsszenarios wird >der Islam anknüpfend an orientalistische Vorstellungen (Said 1995) im Sinne eines »wesenhaften >orientalistischen Patriarchats« (Marx 2008: 57) begründet. Eine solche essenzialisierende Konzeption des Islam basiert auf der Vorstellung, dass >der Islam^ per se repressiv gegenüber Frauen sei. »Das Kopftuch« als primärer symbolischer Ausdruck dieser »Unterdrückung« lehnen Vertreter*innen dieses Rettungsszenarios ab (ebd.).

Rekurrierend auf ein Verständnis der Emanzipation, das sich mit dem Tragen des Kopftuchs nicht vereinen lässt, werden Kopftuch tragende, sich als emanzipiert verstehende Musliminnen als »Scheinfemninistinnen« (ebd.) verstanden, die sich ihrer unterdrückten Position nur unzureichend bewusst seien. Diese abwertende Haltung gegenüber Kopftuch tragenden Frauen basiert auf einer Viktimisierung und Entsubjektivierung und weist den rettenden Akteur*innen eine paternalistische Rolle zu (ebd.). Als prominente feministische Vertreterin dieses Rettungsszenarios im deutschsprachigen Raum (mit Strahlung in die Schweiz) lässt sich Alice Schwarzer und der Umgang der Zeitschrift Emma mit dem Thema Islam/Islamismus anführen (vgl. Schwarzer 2017). Auf diese Position im Allgemeinen und auf die Äusserungen von Schwarzer im Besonderen wird von den jungen religiös orientierten Musliminnen im Feld oft (meist in ablehnender Weise) Bezug genommen.

Die beschriebene Position lässt sich zudem anhand der in der Schweiz gegenwärtig geführten Debatte um die Volksinitiative »Ja zum Verhüllungsverbot« veranschaulichen (vgl. bspw. Gujer 2016). Wie die feministische Theologin Strahm bereits 2007 sarkastisch zu der Politisierung der Kopftuchdebatte bemerkt: »Da werden selbst SVP-Vertreter plötzlich zu veritablen Feministinnen und verteidigen ein angeblich egalitär-frauenfreundliches Christentum gegen ein scheinbar frauenfeindliches Geschlechterkonzept im Islam« (Strahm 2007: 1). Bracke beobachtet in den Niederladen ähnliche Dynamiken überraschender Schulterschlüsse rechter Politiker mit liberalen Feministinnen: »a complicity between white chevaliers saving oppressed Muslim woman, and liberal feminists seeing feminism as the affirmation of Western liberal values conceived against >cultural claims« (Bracke 2011: 36). 
2 Die Rettung islamkritischer Feminist*innen vor »multikulturalistischen Tabus» Abweichend von Rettungsszenario eins steht bei diesem Szenario primär der eigene (>westliche`) Handlungskontext im Zentrum. Vertreter*innen dieses Rettungsszenarios kritisieren nicht >den Islam^als solchen, sondern richten sich gegen mulitkulturalistische bzw. kulturrelativistische Vorstellungen, die »nach Ansicht der RetterInnen dieses Szenarios, [sic!] eine >falsche Toleranz etablieren bzw. mit ihrer >Solidarität den Fundamentalismus, die Intoleranz salonfähig‘ machen« (Toker 1993b zit.n. Marx 2008: 58). Vor diesem Hintergrund rufen Vertreter*innen dieses Rettungsszenarios zu einer »Enttabuisierung der Kritik am Islam« auf und fordern eine Verteidigung sogenannter »westlicher Errungenschaften« (ebd.). Oder wie Strahm (2007: 3) eine solche Position umschreibt: Die Trennung von Staat und Religion solle endlich konsequent erfolgen und Frauenunterdrückung dürfe nicht im Namen einer falschen Toleranz geduldet werden (ebd.). Diese Art von Positionierung lässt sich ebenso in der gegenwärtig geführten Debatte um die Volksinitiative »Ja zum Verhüllungsverbot« nachweisen (vgl. bspw. Jenny 2016).

3 Die Rettung der emanzipierten Muslimin vor »Zwangsverwestlichung « und Assimilationsanforderung

Beim dritten Szenario handelt es sich um ein Szenario, das »den Ursachen einer (Re-)Orientierung von Muslim*innen am Islam auf den Grund gehen und eine islamische Orientierung als Ressource einer emanzipatorischen Identitätsdefinition und Lebensgestaltung begreifen« will (Marx 2007: 61). Musliminnen werden nach dieser Position als handlungsfähige Subjekte begriffen, die »über ein eigenes Verständnis von Feminismus sowie eines zu beschreitenden Emanzipationsweges verfügen« (ebd.). Eine am Islam ausgerichtete Lebensführung kann diesem Szenario zufolge »auch das Tragen eines Kopftuches beinhalten « und dennoch als "potentielle emanzipatorische und widerständige Erweiterung von Handlungsmöglichkeiten« (ebd.) eingestuft werden.

In den Augen der Retter*innen dieses Szenarios sollen die Musliminnen vor »leitkulturellen « integrationspolitischen Assimilationsforderungen einerseits, andererseits aber insbesondere auch von universalistisch, eurozentristisch ausgerichteten Feminist*innen, also quasi vor den Retter*innen der Szenarien 1 und 2 in Schutz genommen werden. Auch diese Position ist in der Schweiz bei Gegner*innen der Initiative »Ja zum Verhüllungsverbot« 
und der damit einhergehenden, sogenannten >Burkadebatte $<$ u finden (vgl. bspw. Landolt 2016a).

Marx' Rettungsszenarien lassen sich meines Erachtens in Bezug auf die Kopftuch- und Burkadebatte auf die Schweiz übertragen. Zudem lassen sie sich in zwei zentrale, diametral entgegengesetzte (feministische) Positionen unterteilen: zum einen in eine »neo-koloniale« Position (Szenario 1 und 2) zum anderen in eine "post-koloniale« Position (Szenario 3). Neo-koloniale Positionen verweisen auf einen universal und in diesem Sinne hegemonial begriffenen, eurozentristischen Feminismus oder einen unilinear verstandenen Evolutionismus. Vertreter*innen dieser Position verstehen das Kopftuch als Symbol der Unterdrückung, aber auch eines politischen und fundamentalistischen Islam, zudem als integrationshemmend bis -verhindernd (Strahm 2007: 3). Durch diese Auffassung wird ein hegemoniales, islamkritisches (feministisches) >Wir $<$ als Gegenbild zu einer diametral entgegengesetzten >orientalischen< Gesellschaft geschaffen, das den eigenen Emanzipationsweg als einzig möglichen Weg Richtung Freiheit begreift - in einem solchen Verständnis sind Kopftuch tragende Frauen fremdbestimmt und manipuliert, während >westliche Frauen emanzipiert und frei sind.

Postkoloniale Positionen hingegen verstehen Emanzipation und das Tragen eines Kopftuchs nicht als zwingenden Widerspruch und lehnen eine kollektive Viktimisierung und Entsubjektivierung von (muslimischen) Frauen sowie eine Idealisierung des >westlichen Geschlechterverhältnisses ab. Sie anerkennen Widersprüche im westlichen Emanzipationskonzept und weisen darauf hin, dass Kopftuch tragen auch sgegen den Strich werden kann, nämlich bspw. als eine » öffentliche (...) Inszenierung eines andern Frauseins« (Strahm 2007: 7), als ein sich Verwehren gegen westliche Dominanz- und Assimilationsansprüche (ebd.). Postkoloniale Positionen betonen die Handlungsfähigkeit (Agency) der Akteur*innen und lehnen die Konzeption der Muslimin als passives Opfer ab (vgl. bspw. Allenbach/Müller 2017: 288).

Do Muslim Woman really Need Saving? fragte 2002 die in Columbia lehrende, postkoloniale feministische Sozialanthropologin Abu-Lughod einst programmatisch vor dem politischen Hintergrund der damals stattfindenden Afghanistan-Offensive der Amerikaner. Diese Frage richtete sich primär gegen die voranstehend erwähnte Konzeption der muslimischen Frau als zu rettendes hilfloses Opfer. Im Anschluss daran warf sie die ketzerische Behauptung auf, dass die Befreiung beziehungsweise >Rettung der afghanischen Frau primär als Kriegsrechtfertigungsgrund für den von George W. Bush im 
Anschluss an 9/11 losgetretenen »War on Terror« diene. In diesem viel beachteten Aufsatz und in ihrem 2013 erschienenen Buch Do Muslim women need saving? plädiert Abu-Lughod dafür, dass anstelle solcher Rettungsdiskurse eine ernsthafte Würdigung und Anerkennung der Unterschiede von Frauen in der Welt als Produkte differierender Geschichte, verschiedener Umstände und Manifestationen unterschiedlich strukturierter Bedürfnisse stattfinden soll (Abu-Lughod 2002: 783). Sie fordert dazu auf, simplizistische kulturalistische Erklärungsmuster zu dekonstruieren und anstelle derer die Diversität muslimischer und anderer Frauen in den Blick zunehmen - d.h., muslimische Frauen nicht durch Gewalt und implizierte Überlegenheit erretten zu wollen (Abu-Lughod 2013).

In der theoretischen Ausrichtung dieser Forschung folge ich der Tradition einer postkolonialen, feministischen Migrationsforschung und stehe der Konzeption der >Muslimin als passives Opfer, das gerettet werden muss $<$ im Anschluss an Abu-Lughod $(2013,2002)$ kritisch gegenüber. Dass die Konzeption der weiblichen Migrantin als passives, hilfloses Opfer auch in der Schweiz (und zudem im Bildungskontext) immer noch äusserst aktuell ist, verdeutlichte Allenbach anlehnend an Abu-Lughod in ihrem kürzlich erschienenen Beitrag Do Muslim Girls Really Need Saving? Boundary-Making and Gender in Swiss Schools (2016). Hier beschreibt Allenbach die vorherrschende stereotype Sicht auf Geschlechterrollen im Islam als Grenzziehungsprozess, der Muslim*innen als homogene Gruppe rezipiert und als Opfer darstellt. Sie stellt in Bezug auf muslimische Mädchen in der Schweiz fest, dass diese mit starken Elendsdiskursen (»discourses of misery«, 2016: 44) konfrontiert seien, die ihnen das Elend bescheinigen würden, passive Opfer zu sein und quasi von Bildungsinstituten und der Gesellschaft »gerettet « werden zu müssen. Anhand ethnografischer Beispiele von jungen muslimischen Mädchen, die mit der Schule in Bezug auf den Schwimmunterricht in Konflikt geraten, gelingt es Allenbach aufzuzeigen, was den jungen Frauen in der Konzeption als passives Opfer oft abgesprochen wird, nämlich dass sie durchaus über Agency (Handlungsfähigkeit) verfügen und durchaus aktiv an Aushandlungsprozessen über ihre Wünsche und Bedürfnisse teilnehmen (2016: 44).

\subsubsection{Weitere in der Deutschschweiz relevante Diskurse}

Frisina (2010: 560) beobachtete in Italien, dass Muslim*innen vermehrt unter dem Aspekt eines >Sicherheitsproblems verhandelt würden. Auch in der Schweiz lassen sich solche Tendenzen rekonstruieren (vgl. Allenbach/Söke- 
feld 2010: 19). Insbesondere im Zusammenhang mit islamistisch motivierten Anschlägen in Europa ${ }^{6}$ ist in den Schweizer Medien und im öffentlichen Diskurs eine zunehmende Fokussierung auf Muslim*innen als spotenzielles Sicherheitsproblem $<\mathrm{zu}$ beobachten. Öffentlich diskutiert wird bspw. darüber, ob und inwiefern Schweizer Muslim*innen den sogenannten Islamischen Staat (IS) unterstützen und ob und inwiefern Verbindungen von ihnen zu radikalen Gruppen existieren (vgl. bspw. Jurinak 2015). Auch wird debattiert, inwiefern in gewissen Schweizer Moscheen Jugendliche radikalisiert werden und/oder gar zu Jihad-Reisen ermuntert werden. Im Zusammenhang mit derartigen Vorhaltungen und dem Vorwurf des >Gewähren-Lassens`mutmasslich radikal predigender Imame kamen einzelne Moscheen als (H)orte zukünftiger Jihad-Reisender in Verruf (vgl. bspw. Baumgartner 2016). Auch in der sogenannten Burkadebatte wurden unter anderen sicherheitspolitische Argumente angeführt (vgl. bspw. Egerkinger Komitee/Wobmann 2015, siehe unten).

Es gilt festzuhalten, dass der Islamdiskurs in verschiedenen Ländern Europas jeweils leicht unterschiedlich gelagert und thematisch besetzt ist (Behloul 2009b: 257, vgl. auch Kopftuchdebatten in Europa Kortweg/Yurdakul 2016). Wie Schnewly-Purdie und Tunger-Zanetti (2015: 562) feststellen, hat die Eigenheit des schweizerischen Systems, nämlich die Kombination einer repräsentativen Demokratie mit einer starken Partizipationsmöglichkeit der Bürger*innen durch direkt-demokratische Mittel grossen Einfluss auf Fragen, die im Zusammenhang mit dem Islam öffentlich diskutiert werden: Im schweizerischen System ist es möglich, dass Entscheide des Parlaments oder der Kantone durch eine Volksinitiative gekippt werden können und dass der sogenannte >Volkswille via Volksinitiative durchgesetzt werden kann. So können Vorlagen in Gesetzen oder in der Verfassung auch gegen den Willen der Regierung und des Parlaments festgeschrieben werden, wie dies bei einigen den Islamdiskurs betreffenden Themen, bspw. bei der Minarettinitiative (2009) geschehen ist (ebd., Tunger-Zanetti 2013b: 285). Durch ein fehlendes Verfassungsgericht hat zudem keine juristische Instanz die rechtliche Befugnis, Gesetzesartikel, die gegen international geltendes Recht verstossen, aufzuheben (Schnewly-Purdie/Tunger-Zanetti 2015: 562).

Die politischen Diskurse in der Schweiz rund um den Islam drehen sich zudem vermehrt auch um sichtbare religiöse Symbole. Baumann und TungerZanetti (2011: 154) stellten die These auf, dass der öffentliche Raum ein umgrösseren Anschläge zwischen 2010 und 2016 zu nennen. 
kämpftes Terrain darstelle, in dem »neue Religionsbauten von gesellschaftlich ausgegrenzten religiösen Gruppen zu Kristallisationspunkten von Protest und Abwehr« (ebd.) würden. Als das Beispiel hierfür kann die 2009 angenommene Volksinitiative »Gegen den Bau von Minaretten« genannt werden. Mit beinahe 115000 Unterschriften reichte das Egerkinger Komitee rund um den SVP-Nationalrat Walter Wobmann am 8. Juli 2008 diese Initiative ein (Müller 2009: 61). Das Initiativkomitee begründete die Initiative damit, dass das Minarett keinen ausschliesslich religiösen Charakter aufweise, sondern vielmehr Symbol eines religiös-politischen Machtanspruchs sei (ebd.). >Der Islam` stelle die Religion über den Staat und dieser Anspruch stehe im Widerspruch zur schweizerischen Verfassung und Rechtsordnung. Unter dem Vorwand der Religionsfreiheit würden so die Grundrechte anderer, insbesondere der Rechtsgleichheit, bestritten. Ein Minarettverbot sorge dafür - so die Argumentation des Initiativkomitees -, dass die in der Verfassung festgehaltene Gesellschafts- und Rechtsordnung zukünftig garantiert bleibe (ebd.). Die deutliche Annahme der Volksinitiative mit 57.5 Prozent bei einer überdurchschnittlich hohen Stimmbeteiligung von 53.8 Prozent (Tunger-Zanetti 2013b: 285) kam für Befürworter*innen wie Gegner*innen der Initiative überraschend und rückte die Schweiz für kurze Zeit ins Licht der Weltöffentlichkeit (Baumann/Tunger-Zanetti 2011: 152). Die im Vorfeld dazu geführte sehr emotionale Debatte und das »Gemenge aus diffusen Ängsten und Ohnmachtsgefühl, Populismus und Skepsis gegenüber Ausländern und >Fremden<, sowie einem weitgehend stereotypen Islam-Negativbild in den Medien ( (ebd.: 153) beeinflussten die Abstimmung nachhaltig (ebd.). Die teilweise schon fast islamophobe Debatte im Vorfeld der Abstimmung führte im Inund Ausland zu grosser Resonanz - nicht nur unter Muslim*innen (ebd.: 152, für eine ausführliche Darstellung siehe Wäckerling 2014). Die Minarettdebatte gipfelte also schliesslich in einem Minarettbau-Verbot, das in der Schweizer Bundesverfassung festgeschrieben wurde.

Im Zuge dieses Abstimmungskampfs wurde vom Bieler Konvertiten Nicolas Blancho der Islamische Zentralrat Schweiz (IZRS) gegründet, mit dem Ziel »auf den anti-islamischen Diskurs zu reagieren" (IZRS 2010). Obwohl der salafistisch ausgerichtete IZRS mit seinen rund 3000 Mitgliedern einen verhältnismässig kleinen Teil der vereinsgebundenen organisierten Muslim*innen der Schweiz umfasst - verglichen mit den geschätzten 95200 Mitglie- 
dern ${ }^{7}$ der muslimischen Dachverbände - verfügt er in öffentlich geführten Debatten um den Islam durch geschickte Provokation in den letzten Jahren über eine überdurchschnittliche mediale Präsenz. Eine vergleichbar grosse mediale Präsenz in diesen Themen nimmt fast nur noch das ideologisch dem IZRS diametral entgegengesetzte Forum für fortschrittlichen Islam (FFI) ein, das sich in zahlreichen Fernseh- und Zeitungsauftritten in hart geführten Diskussionen Vertreter*innen des IZRS mit ähnlich pointierten Aussagen entgegen stellt. Diese duale Konstellation prägte in den letzten Jahren die mediale Debatte über Islam in der Deutschschweiz, lässt sie sich doch ideal inszenieren und verspricht beiden Vereinen eine konstante Medienpräsenz und nicht zuletzt Mitglieder*innen-Werbung.

Als weiterer grosser Player und politischer Akteur in der Debatte um den Islam tritt die rechtskonservative Schweizerische Volkspartei (SVP) auf. Die SVP versteht es, die anti-muslimischen Diskurse um Sicherheit, Sichtbarkeit und Verhüllung (neuerdings auch Einbürgerung) mit ihren politischen Vorstössen und ihrer Propaganda zu vereinigen. Während die Partei rund um das Egerkinger Komitee in ihrer Werbekampagne um die Minarettinitiative primär Argumente der Überfremdung und die damit verbundenen Ängste in Othering-Diskurse verpackt, bindet sie bei der Verhüllungsinitiative erfolgreich das Argument der (bedrohten) Sicherheit mit ein. Indem sie ein allgemeines Verhüllungsverbot fordert, dass ebenso die Vermummung z.B. von Demonstranten einschliesst, lässt sie das Sicherheitsargument einfliessen und grenzt sich zudem in gleichem Zuge vom Vorwurf ab, die Initiative richte sich ausschliesslich gegen muslimische Frauen. In dem Abstimmungskampf um die parlamentarische Initiative für die erleichterte Einbürgerung der sog. »dritten Migrationsgeneration « ${ }^{8}$, welche die SVP vehement bekämpfte, griff ein SVP-nahes Komitee um den als Hardliner bekannten SVP-Nationalrat Andreas Glarner in den Abstimmungskampf ein und verknüpfte bildsprachlich das in der Verhüllungsinitiative aufgebaute >Feindbild der Niqab tragenden Frau mit der Diskussion um die erleichterte Einbürgerung. Dies mittels eines Werbeplakats, das eine verhüllte Frau mit dem Slogan »Unkontrolliert einbürgern? - Nein!« präsentierte (vgl. Glarner 2017). Auch hier zeigte sich die Bedeutung der sichtbaren religiösen Symbole in den (ZRF), Universität Luzern (Feldprotokolle 9.4.2015).

8 Über die Initiative wurde am 12. Februar 2017 abgestimmt; sie wurde vom Volk angenommen (Bundesrat 2017). 
geführten (politischen) Debatten. Baumanns und Tunger-Zanettis voranstehend angeführte These in Bezug auf sichtbare religiöse Symbole im öffentlichen Raum (2011: 154) könnte also ebenso auf die sog. Burkadebatte ${ }^{9}$ übertragen werden: Auch in der Burkadebatte wird der öffentliche Raum zum umkämpften Terrain und zum Kristallisationspunkt von Protest und Abwehr.

Seit das Egerkinger Komitee am 15. März 2016 eine nationale Volksinitiative für ein Verhüllungsverbot lanciert hat (Initiativkomitee »Ja zum Verhüllungsverbot « 2015), ist die in der Schweiz seit vielen Jahren schwelende Burkadebatte wieder neu entflammt. Die Volksinitiative fordert ein Verhüllungsverbot, mittels dessen in der Verfassung festgeschrieben wird, dass niemand sein Gesicht im öffentlichen Raum verhüllen darf (Schweizerische Bundeskanzlei 2017). Der zweite Absatz lautet: »Niemand darf eine Person zwingen, ihr Gesicht aufgrund ihres Geschlechts zu verhüllen« (ebd.). Das Gesetz sieht aber Ausnahmen vor, diese beinhalten u.a. »Gründe (...) des einheimischen Brauchtums« (ebd.). Ausnahmen aus religiösen Gründen ausser »in Sakralstätten « sind ausgeschlossen (ebd.). Das Verhüllungsverbot richtet sich somit in erster Linie gegen Niqab-Tragende, aber auch gegen vermummte Demonstranten. Auffällig und für die momentane Stimmung kennzeichnend ist, dass die öffentliche Debatte sozusagen ausschliesslich zum Niqab (vulgo: »Burka«) geführt wird.

Zwischen 2006 und 2011 befasste sich das Parlament mehrfach mit Verhüllungsverboten. Sowohl eine Standesinitiative aus dem Kanton Aargau (Bundesversammlung 2010) wie auch Vorstösse von Christoph Darbellay (CVP, VS) (Bundesversammlung 2009), Hans Fehr (SVP, ZH) (Bundesversammlung 2011a) und Oskar Freysinger (SVP, VS) (Bundesversammlung 2011b) forderten ein Verbot. Mit Ausnahme des Vorstosses der CVP forderten alle Eingaben ein generelles Verhüllungsverbot, d.h., sie waren nicht nur gegen Niqab tragende Frauen, sondern auch gegen vermummte Demonstrant*innen gerichtet. Der Bundesrat lehnte alle entsprechenden Vorstösse $\mathrm{ab}$, mehrheitlich mit der Begründung, dass ein Verbot gegen Art. 15 BV (Glaubens- und Gewissensfreiheit) verstossen würde. Der Nationalrat hatte die Vorstösse für ein generelles Verhüllungsverbot unterstützt, gescheitert waren sie jeweils am Ständemehr (Bundesversammlung 2011a, b).

Am 22. September 2013 nahm der Kanton Tessin mit 65.4 Prozent eine Volksinitiative für ein Verhüllungsverbot an, das nun in der Tessiner Kantonsverfassung verankert ist (Repubblica e Cantone Ticino 2016). Der Bun-

9 Zum ^Naming^der Debatte vgl. Fussnote 4. 
desrat, der sich jahrelang gegen entsprechende Vorstösse aus dem Parlament gewehrt hatte, musste das Tessiner Burkaverbot am 12. November 2014 zähneknirschend als »bundesrechtskonform « anerkennen (Bundesrat 2014), hielt jedoch in seiner Medienmitteilung fest, dass er ein solches Verbot wegen der geringen Anzahl Niqab tragender Frauen in der Schweiz nicht als sinnvoll erachte (ebd.). Das Gesetz ist seit dem 1. Juli 2016 in Kraft (Repubblica e Cantone Ticino 2016). Auch in anderen Kantonen sind zum Zeitpunkt der vorliegenden Untersuchung weitere ähnlich gelagerte Volksbegehren anhängig.

In der öffentlich geführten, damals erneut aufgeflammten Debatte waren im Wesentlichen die drei zuvor beschriebenen Marx'schen Rettungsszenarien (Marx 2008) bzw. die neo-kolonialen und postkolonialen Haltungen in Bezug auf muslimische Frauen zu erkennen. Sowohl Befürworter*innen als auch Gegner*innen argumentieren mit Menschenrechten, Erstere werten Toleranz gegenüber der Ganzkörperverschleierung als Toleranz gegenüber der Unterdrückung betroffener Frauen (vgl. bspw. Jenny 2016, Gujer 2016), Letztere betonen das Selbstbestimmungsrecht von (muslimischen) Frauen (vgl. bspw. Landolt 2016a).

Vermehrt wird ebenfalls über die Eingliederung(-sfähigkeit) von Muslim*innen in die Schweizer Gesellschaft unter dem Begriff der »Integration " debattiert (der Begriff der "Integration « löste hierbei den Begriff der »Assimilation« ab, vgl. Allenbach/Müller 2017: 2). Von einem Teil der politischen Akteure wird Muslim*innen gar die Fähigkeit, sich gesellschaftlich einzugliedern, pauschal abgesprochen (Allenbach/Sökefeld 2010: 19). Wie Allenbach und Sökefeld jedoch unterstreichen, ist "Integration « ein hochnormatives Konzept, mittels dessen Gruppen pauschal diskursiv ausgegrenzt und als »Problemgruppen " (Allenbach/Sökefeld 2010:19) markiert werden. Allenbach und Sökefeld (2010: 19) legen plausibel dar, weshalb sie das Konzept der »Integration « für ungeeignet befinden, Prozesse der Eingliederung analytisch zu erfassen. Sie schlagen stattdessen vor, Eingliederungsprozesse (von Muslim*innen) analytisch mit dem Konzept der Inkorporation von Soysal (1994) zu begreifen. Das Konzept der Inkorporation geht davon aus, dass verschiedene Staaten unterschiedliche »Inkorporationsregimes« bereitstellen. »Inkorporation « wird im Gegensatz zu »Integration« nicht als einseitiger, sondern als wechselseitiger Eingliederungsprozess verstanden und setzt sich aus Inkorporationsbemühungen (z.B. seitens (muslimischer) Organisationen) und Inkorporationsbedingungen (z.B. politische Vorgaben zu Einwanderung und Einbürgerung, aber auch frauen- oder fremdenfeindliche Einstellungen oder allgemeine Bedingungen in verschiedenen Lebensbereichen, wie 
Bildung, Arbeit, Wohnen etc.) zusammen (Allenbach/Müller 2017: 276, Allenbach/Sökefeld 2010: 19). Allenbach und Sökefeld sehen demzufolge die in der Schweiz wohnhaften Muslim*innen mit zwei zentralen Inkorporationsbedingungen konfrontiert: einerseits mit den sehr heterogenen rechtlichen und politischen Inkorporationsbedingungen in verschiedenen lokalen und kantonalen Kontexten der Schweiz, andererseits mit dem zuvor beschriebenen homogenisierenden Islamdiskurs, der sie pauschal als problematisch und »monoidentitär« klassifiziert (Allenbach/Sökefeld 2010:19-20).

Auch der Bildungsbereich bleibt nicht vom öffentlichen Diskurs rund um >den Islam` gefeit. Wie bereits erwähnt, drehen sich die Debatten hierbei einerseits um die Frage, ob sich Frauen bzw. Mädchen als Schülerinnen bedecken dürfen, zum anderen, ob Lehrpersonen Kopftuch tragen dürfen. Als weiteres den Bildungsbereich speziell betreffendes Thema kann die Diskussion rund um den Besuch bzw. Dispens des obligatorischen Schwimmunterrichts in der Schule bezeichnet werden.

Die den Bildungsbereich betreffenden Debatten werden in erster Linie aus juristischer Perspektive entlang der relevanten Gerichtsurteile geführt. Im Folgenden wird, ohne die (ausufernde) Debatte umfassend darzustellen, kurz auf wesentliche gerichtliche Beschlüsse eingegangen, die den Diskurs in Bezug auf den Umgang mit dem Kopftuch im Bildungsbereich massgeblich beeinflussten und formten.

In der Schweiz sind für die den Schulunterricht betreffenden >Kopftuchfragen grundsätzlich die Kantone zuständig. Die Bundesverfassung garantiert die Glaubens- und Gewissensfreiheit, die auch die weltanschauliche Neutralität der öffentlichen Schulen umfasst (Bundesverfassung 1999, Art. 15).

Gemäss der heute gängigen Schweizer Praxis dürfen sich Schülerinnen während des Unterrichts bedecken, nicht jedoch Lehrpersonen. Diese Praxis geht auf folgende zwei Bundesgerichtsentscheide zurück, die in der Öffentlichkeit breit debattiert wurden: Da ist zum einen der Bundesgerichtsentscheid von 1997 (BGE 123 I 296), als eine konvertierte Genfer Primarlehrerin gegen den Genfer Staatsrat Beschwerde einlegte, der von ihr verlangte, dass sie im Unterricht ihr Kopftuch ablege. Das Bundesgericht gab in einem ausführlich begründeten Urteil dem Genfer Staatsrat Recht (ebd.). Er anerkannte zwar die Einschränkung der Religionsfreiheit der Lehrerin durch den Entscheid, gewichtete jedoch das öffentliche Interesse in diesem Fall höher (ebd.). Der Europäische Gerichtshof für Menschenrechte (EGMR), wohin sich die betreffende Lehrerin letztinstanzlich wandte, stützte das Urteil des Bun- 
desgerichts (EGMR-Urteil 15. Februar 2001, Nr. 42393/98). Während das Urteil des Bundesgerichts in Genf kaum Aufsehen erregte, wurde es auf nationaler Ebene kritisch diskutiert. Stellvertretend für die eine Sicht - die Befürworter des Urteils - soll hier eine Stellungnahme des Völkerrechtlers Kälin stehen: Kälin stellte sich auf die Position, dass Lehrpersonen »in der Einwanderungsgesellschaft (...) zugemutet « werden darf, »auf Kleidung mit starker religiöser Symbolwirkung zu verzichten « (Kälin 2000: 168), währenddessen das Tragen des Hijabs bei Schülerinnen Teil ihrer Privatsphäre sei (ebd.: 167). Augsburger, die stellvertretend für die gegenteilige Sicht hier stehen soll, hielt dem entgegen, dass ein Kopftuch im Gegensatz zum Kruzifix nicht ein religiöses Symbol darstelle, sondern lediglich ein Kleidungsstück sei, das einen Hinweis auf die Religionszugehörigkeit der Trägerin gebe und als solches den Schutz der Religionsfreiheit geniesse (Augsburger 2005: 31). Im Gegensatz zu einem an die Schulzimmerwand gehängten Kruzifix bringe die religiös motivierte Kleidung der Lehrerin die Haltung eines Individuums zum Ausdruck und könne dem Staat nicht zugerechnet werden (ebd.). Solange die Lehrperson ihre religiösen Überzeugungen nicht propagiere, verstosse sie nicht gegen das Gebot der religiösen Neutralität der Schule (ebd.). Vom Kopftuch der Lehrerin gehe objektiv gesehen für die Lernenden kein Zwang aus, es verletze deshalb weder ihre Glaubensfreiheit noch stelle es einen »Eingriff in die Grundrechte Dritter« dar (ebd.) Die Juristin und Sozialanthropologin Augsburger klassifizierte infolgedessen ein Kopftuchverbot »ohne konkrete Gefährdung anderer Rechtsgüter« als »unverhältnismässig« (ebd.).

Den zweiten Grundsatzentscheid in Bezug auf das Kopftuchtragen im Bildungsbereich fällte das Bundesgericht am 11. Dezember 2015. Es bestätigte in diesem Entscheid das Urteil des St. Galler Verwaltungsgerichts, dass ein Mädchen der Schulgemeinde St. Margarethen das Kopftuch in der Schule tragen darf (BGE 142 I 49). Die Schulgemeinde hatte dies dem Mädchen zunächst verboten, eine dagegen gerichtete Beschwerde hiess das Verwaltungsgericht jedoch 2014 gut. Das Bundesgericht stützte das Urteil des Verwaltungsgerichts mit der Begründung, dass das Verbot sich nicht mit der Glaubens- und Gewissensfreiheit vereinbaren lasse (ebd.).

Auch dieser Entscheid wurde breit und heftig öffentlich debattiert. Auf der einen Seite standen die Befürworter*innen dieses Urteils und auf der anderen Seite wurde meist im rechts-konservativen politischen Lager die Meinung vertreten, dass ein Kopftuchverbot an Schulen einem so massgeblichen öffentlichen Interesse entsprechen würde, dass es einen Eingriff in die Religions- und Glaubensfreiheit rechtfertigen würde. Die Walliser 
SVP startete gar eine Initiative, welche die Kopfbedeckung an öffentlichen Schulen verbieten soll (Kucera 2016).

Ungeachtet der heftigen Debatten gelten diese Urteile des Bundesgerichts im schulischen Umfeld als momentane Leitlinie, hielten sich doch bisher schweizweit alle Gerichte an diese wegweisenden Urteile (humanrights.ch 2016). Auch auf der Ebene der tertiären Bildungsinstitutionen gelten diese Urteile trotz möglichen rechtlichen Handlungsspielraums als richtungweisend, dies zeigt bspw. die kürzlich von der Pädagogischen Hochschule Bern (PHBern) verdeutlichte Praxis, wonach zwar Schülerinnen im Unterricht ein Kopftuch tragen dürfen, Lehrpersonen bzw. Studierende in einem Praktikum jedoch nicht (Feldprotokoll 8.12.2016).

Ein weiteres im Bildungsbereich debattiertes Themenfeld ist die Dispensation vom obligatorischen schulischen Schwimmunterricht. Dieses Themenfeld, das eigentlich wie die >Kopftuchfrage in der Schule in den kantonalen Zuständigkeitsbereich gehören würde, zeichnet sich durch eine Kehrtwende der öffentlichen Meinung aus (Allenbach 2016: 37). Auch in dieser Debatte wurde vornehmlich aus einer juristischen Perspektive argumentiert. Der erwähnte Umschwung der öffentlichen Meinung soll im Folgenden kurz anhand von vier wegweisenden Gerichtsurteilen illustriert werden.

1993 wurde einem 12-jährigen Mädchen aus einer türkischen Familie vom Bundesgericht eine Ausnahmeregelung gewährt. Sie durfte sich vom gemischtgeschlechtlichen Schwimmunterricht dispensieren lassen (PfaffCzarnecka 2009; BGE 119 la 178). 2008 wurde zwei 9- und 11-jährigen Jungen kein Dispens vom koedukativen Schwimmunterricht gewährt (Wyttenbach 2013; BGE 135 I 79). 2013 verweigerte das Bundesgericht einem 14-jährigen Mädchen ebenfalls die Dispensation des schulischen Schwimmunterrichts (BGE 2C_1079/2012). Gleichfalls 2008 wollte ein Schweiz-türkischer Doppelbürger seine beiden 9- und 7-jährigen Töchter vom Schwimmunterricht dispensieren lassen. Da das baselstädtische Gesetz die Dispensation erst ab der Geschlechtsreife vorsieht, klagte die Familie vor Bundesgericht, wo die Beschwerde 2012 (BGE 2C_666/2011) abgelehnt wurde. Daraufhin zog die Familie vor den Europäischen Gerichtshof für Menschenrechte (EMGR) weiter. Dieser gelangte nach einer ausführlichen Analyse am 10. Januar 2017 zu dem Schluss, dass das Interesse der Kinder an einem kompletten Unterricht die Integration fördere und höher als das Interesse der Eltern an einem Schwimmdispens aus religiösen Gründen zu gewichten sei (EGMR-Urteil 10. Januar 2017, Nr. 29086/12). 
Die über Schwimmdispense geführte - in erster Linie juristische - Debatte ist sehr komplex (für eine detaillierte Übersicht vgl. Allenbach 2016: 37ff.) Die Sozialanthropologin Allenbach unterstreicht in einer Analyse dieser Debatte insbesondere zwei Aspekte, nämlich dass einerseits auffallend sei, dass das Bundesgericht 1993 die >Integration< der Familie in die Gesellschaft als Argument dazu nutzte, einen Dispens zu stützen, während sich 2008 und 2013 jedoch eine Praxiswende vollzog und das >Integrations-Argument< als Gegenargument für einen Dispens hinhalten musste. Zweitens - so unterstreicht Allenbach - wurde ab 2013 deutlich, dass der Schwimmunterricht für muslimische Mädchen selbst in der Pubertät obligatorisch sei, falls die Schule den »Pubertätsfaktor « einbeziehe - sprich - bspw. die Mädchen getrennt von den Jungen unterrichtet würden und es erlaubt sei, einen Burkini zu tragen, sowie gewährleistet würde, dass kein Körperkontakt zu einem etwaigen männlichen Schwimmlehrer bestehe (Allenbach 2016: 38). Diese erneuerte Praxis wurde durch den neuesten Entscheid von Januar 2017 gestützt (EGMR-Urteil 10. Januar 2017, Nr. 29086/12).

Auch diese neueren Entscheide wurden öffentlich heftig debattiert. Menschenrechtsexpertin Doris Angst begrüsst dieses Urteil bspw. und würdigt es als ausgewogen: Sie sieht dadurch auf der einen Seite die integrativen Aufgaben der Schule gewürdigt und auf der anderen Seite komme das Urteil den Eltern entgegen, indem es flankierende Massnahmen, wie bspw. das Tragen eines Burkinis, vorsähe (Schutzfaktor-m.ch 2017). Seit 2010 wird auf der politisch entgegengesetzten Seite hingegen die Erlaubnis, Burkinis im Schwimmunterricht zu tragen, als »>Burkini<-Kniefall« (Pastega 2010) bezeichnet. SVPNationalrat und Rechtwissenschaftler Hans-Ueli Vogt kritisiert nach dem Urteil 2017 gar das >multireligiöse Weltbild « der Strassburger Richter (Gafner 2017).

Ein weiteres diskursrelevantes Ereignis, das den Bildungsbereich betraf und in der schweizerischen Öffentlichkeit breit diskutiert wurde, ist die zuvor beschriebene sogenannte »Händeschüttelaffäre«. Durch sie wurde eine im Bildungsbereich oft diskutierte Geschlechtskonstruktion männlicher muslimischer Schüler und deren Väter deutlich: Im Bildungsbereich wird immer wieder darüber diskutiert, inwiefern mit der >dem Islam`zugeschriebenen »Machohaftigkeit« von Vätern von Schüler*innen oder von männlichen Schülern umgegangen werden soll. Ebenso kann in Diskussionen mit Angehörigen des Schulwesens die Tendenz beobachtet werden, dass unerwünschtes (provokatives) Verhalten, insbesondere von männlichen Schülern mit »Migrationshintergrund « anstatt bspw. der Adoleszenz primär und teilweise vor- 
schnell >dem Islam $\prec$ zugeschrieben wird (Feldprotokolle ${ }^{10}$ ). Betrachtet man die Entwicklung des Islamdiskurses, erstaunt es wenig, dass sich >der Islam^auch im Bildungsbereich als wirkmächtige Zuordnungs- und Differenzkategorie manifestiert (vgl. in Bezug auf Deutschland, siehe Lingen-Ali 2012).

Diese allgemeine Zuspitzung des gesellschaftspolitischen anti-muslimischen Diskurses geht nicht spurlos an jungen Schweizer Muslim*innen vorbei (Baumann et al. 2017: 32): Junge Muslim*innen sehen sich mit einer zunehmenden Verschärfung zugeschriebener Differenz konfrontiert, was sich einerseits auf ihre Selbstrepräsentation (Allenbach et al. 2010: 2), andererseits aber auch auf ihre Bildungsbiografien auswirkt, wie die vorliegende Untersuchung aufzeigen soll.

\subsection{Intersektionelle Perspektive in Bezug auf den Zugang zu Bildung}

Während in Kapitel 2.1. der diskursive Kontext, in dem sich die jungen Frauen meines Samples positionieren müssen, dargestellt worden ist, wird in diesem Kapitel darauf eingegangen, wie unterschiedliche Differenzdimensionen in ihrem Zusammenspiel wirken und wie dieses Zusammenspiel theoretisch bzw. intersektionell - gedacht werden kann.

Im Anschluss an Le Bretons Bezugsrahmen zur Erklärung sozialer Ungleichheit und Strukturmerkmalen sozialer Ausschliessung (Le Breton 2011: 73ff.) verstehe ich die bildungsbiografische Situation von jungen, religiös orientierten Secondas muslimischen Glaubens als »Folge eines spezifischen historischen, politischen und geographischen Prozesses« (ebd.: 73), »in dessen Zusammenhang soziale Differenzsetzungen konstitutiv für die Reproduktion gesellschaftlicher Verhältnisse« werden (ebd.). Um diese Differenzsetzungen in den Blick zu nehmen, möchte ich eine intersektionelle Perspektive einnehmen, die im Folgenden umrissen werden soll.

10 Hierbei handelt es sich unter anderen um Feldprotokolle zu Diskussionen mit Lehrpersonen im Anschluss an die Veranstaltungsreihe »Islam und Schule - ohne Vorurteile« der Pädagogischen Hochschule Bern (PHBern) sowie um Feldprotokolle zu dem sich an ein pädagogisches Feld richtenden Workshop Muslimische Jugendgruppen in der Schweiz des Zentrums für Religionsforschung (ZRF) der Universität Luzern (2014). Beide Veranstaltungs(-reihen) wurden im Rahmen des vorliegenden Projekts besucht und teilnehmend beobachtet, stattfindende Diskussionen protokollarisch festgehalten. 
Die feministische Bildungsforscherin Walgenbach (2012a: 81) definiert Intersektionalität folgendermassen:

»Unter Intersektionalität wird (...) verstanden, dass soziale Kategorien wie Gender, Ethnizität, Nation oder Klasse nicht isoliert voneinander konzeptualisiert werden können, sondern in ihren >Verwobenheiten oder >Überkreuzungen (intersections) analysiert werden müssen. Additive Perspektiven sollen überwunden werden, indem der Fokus auf das gleichzeitige Zusammenwirken von sozialen Ungleichheiten gelegt wird. Es geht demnach nicht allein um die Berücksichtigung mehrerer sozialer Kategorien, sondern ebenfalls um die Analyse ihrer Wechselwirkungen« (Walgenbach 2012a: 81).

Allen Intersektionalitätsansätzen ist gemeinsam, so unterstreicht Walgenbach weiter, dass sie »Macht-, Herrschafts- und Normierungsverhältnisse, die soziale Strukturen, Praktiken und Identitäten reproduzieren«, fokussieren (2012b: o. S.).

Ohne den Anspruch zu haben, den Forschungsstand erschöpfend darzustellen, möchte ich auf zentrale Diskussionsstränge der mitunter ausladenden Diskussion um diese Forschungsperspektive eingehen. Gewicht lege ich hierbei auf die Entwicklung des Konzepts im deutschsprachigen Raum und in Europa. In der feministischen Geschlechterforschung ist das Konzept in Europa nämlich leicht differierend zu ihrem Entstehungskontext in den USA rezipiert worden. Aufgrund der historischen Entwicklung konnten bspw. die in den USA anders konnotierten Kategorien race und class nicht einfach unproblematisch in den europäischen Kontext überführt werden (für eine ausführliche Übersicht über die unterschiedlichen Entwicklungen vgl. Davis 2008). Dennoch möchte ich zunächst kurz auf die konstitutiven Ursprünge des Konzepts, die in den USA zu finden sind, eingehen: Meist werden Ursprünge des Intersektionalitätskonzepts im angloamerikanischen Kontext Black Feminism und der Critial Race Theory gesehen (u.a. Knapp 2005, Lutz/Davis 2005). Obwohl es auch dahingehende Einflüsse und Diskussionen in Europa gab, stand im Mittelpunkt der genealogischen Debatte um Intersektionalität doch der Vorwurf schwarzer Feministinnen ${ }^{11}$ an den weissen, bürgerlichen Feminismus, dass dieser sich ausschliesslich um die Interessen weisser, westlicher,

11 >Weiss male, sondern beziehen sich auf eine ideologische Konstruktion von Hautfarbe und auf damit korrespondierende, zugeschriebene sozial-historische Positionen (vgl. Lutz et al. 2013: 10, Walgenbach 2005a). 
heterosexueller, nicht behinderter weiblicher Subjekte aus der Mittelschicht kümmere (vgl. Walgenbach 2012c: 28).

Als diesbezüglich historische Zäsur gilt die Gründung des Combahee River Collectives 1974 in Boston (ebd.: 27). Dieses Kollektiv verfasste ein Statement A Blacks Feminist Statement - worin sich die Autorinnen als schwarze, lesbische und sozialistische Feministinnen positionierten und sich für die Entwicklung einer integrierten Analyse von »simultaneous oppressions (Combahee River Collective 1981: 210) stark machten. Wegbereitend waren auch die Publikationen von Andalùa und Moraga (1981) This Bridge Called my Back: Writings by Radical Woman of Color, sowie von Hull, Bell Scott et al. (2010 [1982]) All the Woman are White, All the Blacks Are Men, But Some of Us are Brave: Black Women's Studies. Diese und andere Studien (vgl. Walgenbach 2012b: o. S.) übten in den 7oerund 8oer-Jahren umfassende Kritik am etablierten Feminismus. Die schwarze Kulturtheoretikerin hooks [sic!] bspw. warf weissen Feministinnen vor, eine exklusive Gruppe zu sein und als diese im Namen saller Frauen $\mathrm{zu}$ sprechen, dabei jedoch nur die eigenen Partikularinteressen im Blick zu haben und Ressourcen wie Universitäten, Verlage oder Massenmedien zu nutzen, die wiederum exklusiv ihnen und nicht allen Frauen zugänglich seien (Walgenbach 2012b, hooks 1981, 1984).

Der eigentliche Begriff der Intersektionalität geht jedoch auf die amerikanische Juristin Crenshaw (1989) zurück, die auf Basis juristischer Fallanalysen untersuchte, wie sich verschiedene Diskriminierungsformen überschneiden. Sie gelangte zum Schluss, dass amerikanische Antidiskriminierungsgesetze entweder zugunsten schwarzer Männer oder weisser Frauen operieren würden, die spezifischen Probleme schwarzer Frauen jedoch aussen vor bleiben würden. Sie bediente sich dabei der Metapher einer Strassenkreuzung, an welcher der Verkehr aus mehreren Richtungen kommen kann (Crenshaw 1989: 149):

»Nehmen wir als Beispiel eine Strassenkreuzung, an der der Verkehr aus allen vier Richtungen kommt. Wie dieser Verkehr kann auch Diskriminierung in mehreren Richtungen verlaufen. Wenn es an einer Kreuzung zu einem Unfall kommt, kann dieser von Verkehr aus jeder Richtung verursacht worden sein - manchmal gar von Verkehr aus allen Richtungen gleichzeitig. Ähnliches gilt für eine schwarze Frau, die an einer sKreuzung ` verletzt wird; die Ursache könnte sowohl sexistische als auch rassistische Diskriminierung sein«.

Später ergänzt sie in einem Interview, dass nach diesem symbolischen Unfall weder die herbeigeeilte »Gender-Ambulanz« noch die »Race-Ambulanz« die 
schwarze Frau mitnehmen würden, da sie beide nicht ausmachen konnten, ob sie zuständig seien und die verunfallte Frau keine befriedigende Antwort darauf geben könnte (Crenshaw zit.n. Walgenbach 2012c: 49).

Eines der Fallbeispiele, welches die Juristin Crenshaw dazu anführte, stammte aus dem Jahr 1976. Es handelte sich hierbei um eine Klage von schwarzen Frauen gegen General Motors in Bezug auf ihr Vergütungssystem, welches sich an der Dauer der Betriebszugehörigkeit orientierte. Die Klägerinnen argumentierten, dass bei General Motors vor dem Civil Rights Act 1964 aufgrund der rassistischen Segregation in den USA gar keine schwarzen Frauen eingestellt wurden, durch das Senioritätsprinzip jedoch die Folgen der Diskriminierung aufrechterhalten würden. Auch eine Entlassungswelle 1970 betraf schwarze Frauen bei General Motors ungleich schwerer, da sich diese an der Dauer der Betriebszugehörigkeit orientierte. Das Gericht wies die Klage mit der Argumentation ab, dass es sich hierbei nicht um eine geschlechtliche Diskriminierung handle, da General Motors vor 1964 bereits mehrere weisse Frauen beschäftigt hatte. Auch dem Vorwurf der rassistischen Diskriminierung wollte das Gericht nicht nachgehen, sondern empfahl den Klägerinnen sich mit einer Sammelklage gegen General Motors aufgrund rassistischer Diskriminierung zusammenzutun. Das Gericht anerkannte den Anspruch der Frauen, als schwarze Klägerinnen aufzutreten, also nicht an (>Genderund Race-Ambulanz‘, vgl. oben). Das Gericht sah zwar Handlungsbedarf bei genderspezifischer oder rassistischer Diskriminierung, nicht jedoch bei einer Kombination von beiden (Walgenbach 2012b: o. S.). In diesem juristischen Fall wurde den Frauen also verweigert, ihre Klage als schwarze Frauen zu formulieren. Crenshaw zufolge sind schwarze Frauen demnach nur solange rechtlich geschützt, als ihre Anliegen sich entweder mit denen weisser Frauen oder schwarzer Männer decken (Crenshaw 1989: 141ff.). Das Verletzungspotenzial schwarzer Frauen ist demzufolge laut Crenshaw deutlich höher, da sie in der Metapher der zuvor beschriebenen Strassenkreuzung nicht nur von den Autos, die aus der einen Richtung kommen (rassistische Diskriminierung) oder aus der anderen (sexistische Diskriminierung), verletzt werden können, sondern auch noch von einer Kombination von beiden. Sie verdeutlicht anhand weiterer Fälle, dass amerikanische Antidiskriminierungsgesetze dem Aspekt der Intersektionalität nicht gerecht werden können, da sie als single-issue-framework (Crenshaw 1989: 152) konzipiert seien. Die Erfahrungen schwarzer Frauen sind also laut Crenshaw mehr als die Summe rassistischer und sexistischer Diskriminierung; nämlich die Verwobenheit der beiden Differenzdimensionen. 
Walgenbach zufolge lassen sich Crenshaws theoretische Interventionen allerdings nicht wie manchmal in den deutschsprachigen Genderstudies geschehen, auf die Metapher der Strassenkreuzung reduzieren, vielmehr zählt sie drei Bedeutungsebenen von Crenshaws Intersektionality-Begriff nach (Walgenbach 2012b: o. S.):

- 1. Ebene: Intersektionalität nimmt Bezug auf die Überkreuzung von Differenzkategorien und Herrschaftsstrukturen (race/gender und racism/sexism).

- 2. Ebene: Intersektionalität konzeptualisiert als die Positionierung schwarzer Frauen innerhalb sich überlappender Systeme (overlapping systems) von Subordinationen.

- 3. Ebene: Intersektionalität als politisches Identitätskonzept, das sich nicht auf eine Kategorie beschränkt (multiple identities).

Auch Chebout (2016) kritisiert die Tendenz der auf die Strassenkreuzung verkürzten Rezeption von Crenshaws Arbeit.

In neueren europäischen Publikationen zu Intersektionalität wird betont, dass auch in der europäischen Geschlechterforschung vergleichbare theoretische (und politische) Debatten geführt wurden und sich die Diskussion über Intersektionalitäten »nicht als US-Import abtun« lässt (Walgenbach 2012b: o. S., vgl. auch Rommelspacher 2009a: 81). Lutz et al. (2013:12) führen den Umstand, dass europäische Impulse eines `Gründungsnarratives` weitgehend ausser Acht gelassen werden, darauf zurück, dass in Europa »multiple Genealogien« (ebd.) für eine Intersektionalitätsdebatte Impulse setzten. Obwohl es in den europäischen Genderstudies durchaus vielversprechende Ansätze, die auf Fragen sozialer Heterogenität abzielten, gab, konnte keiner dieser Ansätze eine vergleichbare Anzahl Wissenschaftler*innen zusammenführen wie das »Paradigma Intersektionalität« (Walgenbach 2012b: o. S.). Wissenschaftsgeschichtlich gesehen ist es laut Lutz et al. (2013: 13) zumindest interessant, dass Crenshaws Metapher der Strassenkreuzung eine solch schnelle Verbreitung erfuhr und Eingang in ganz unterschiedliche Forschungsbereiche, aber auch in die Politik fand, wohingegen anderen theoretischen Konzepten, die ähnliche inhaltliche Ziele verfolgten, eine solche Schlagkraft verwehrt blieb (ebd.). Walgenbach (2013: 275) sieht die Schlagkraft einer Intersektionalitätsperspektive hierin, dass diese genug offen sei, einen gemeinsamen Orientierungsrahmen zu bieten, innerhalb dessen es möglich sei, ganz unterschiedliche Fragen, theoretische Ansätze, Analyseebenen und soziale Kategorien mitein- 
ander zu verbinden. Theoretische Entwürfe, die zumindest ein ähnliches Ziel verfolgten, jedoch nicht im selben Umfang aufgenommen worden waren, sind laut Lutz et al. (2013: 13) und Walgenbach (2013: 26) bspw. folgende: Doing Difference (Festermaker/West 1995), Achsen der Ungleichheit (Klinger/Knapp 2007) oder die dreifache Vergesellschaftung (Lenz 1995), aber weder diese noch der von Collins generierte Begriff der Interlocking Systems of Oppression (1990) sowie das von Anthias und Yuval-Davis entwickelte Konzept der Racialized Boundaries (1992), mit dessen Hilfe sie die Verflechtungen der Kategorien »Rasse«, Nation, Klasse, Geschlecht und Hautfarbe aufzeigen wollten, noch Kings Konzept der Multiple Jeopardies (Mehrfachgefährdungen) (1988) wurden im Gegensatz zu Crenshaws Vorschlag international aufgegriffen.

Ungeachtet der breiten Rezeption muss Crenshaws Vorschlag, Intersektionalität in der Metapher einer Strassenkreuzung zu sehen, im Kontext ihrer Entstehung im juristischen Kontext betrachtet werden. Der Intersektionalitätstheoretikerin Walgenbach (2012b: o. S.) ist beizupflichten, wenn sie es als problematisch ansieht, diese Metapher aus ihrem Entstehungskontext zu lösen und auf die Sozialwissenschaften zu übertragen. Zweifelsohne wurde durch Crenshaws Arbeiten die Diskussion über Mehrfachdiskriminierung sowohl in den USA wie auch in Europa inspiriert und angestossen, dennoch kann die Metapher der Strassenkreuzung und ihre Folgemodelle, z.B. das im deutschen Sprachraum viel beachtete Modell der Achsen der Ungleichheit - Achsen der Differenz (Klinger/Knapp 2007, Klinger/Knapp 2005, Klinger 2003) als zu eindimensional kritisiert werden (Walgenbach 2012b: o. S., Rommelspacher 2009a: 89 etc.). Insbesondere dann, wenn diese aus dem juristischen Kontext gelöst und in einen sozialwissenschaftlichen Kontext übertragen werden (Walgenbach 2012b: o. S.).

In ihrem Achsenmodell gehen Klinger und Knapp bspw. in einer linearen Logik von Achsen als institutionalisierte Gefüge sozialer Relationen aus (Klinger/Knapp 2007: 20), sie beziehen sich dabei auf die Kategorien »Rasse«, Klasse und Geschlecht, die sie als gleichgewichtig bzw. symmetrisch betrachten. Ihr Anliegen ist es, "unproduktive Frontstellungen« zwischen »sozialer Ungleichheit vs. gesellschaftlicher Entstrukturierung; kulturellen vs. ökonomischen Faktoren; System vs. Akteursperspektive zu überwinden« (Klinger/Knapp 2007: 21-22). Wie Rommelspacher (2009a: 89) kritisiert, geben sie jedoch wenig Aufschluss darüber, in welcher Weise dies geschehen soll.

Auch Modelle, die mit Begriffen wie Überkreuzungen, Überschneidungen oder Schnittpunkten operieren, lassen sich der Logik einer "LineaturenMethapher« (Walgenbach 2012b: o. S.) zuordnen (ebd.). Kritisiert werden 
diese Folgemodelle der Crenshaw'schen 'Strassenkreuzungs-Methaper insbesondere dahingehend, dass Machtverhältnisse nicht als >Linien oder >Relationen konzeptualisiert werden sollten, da sie so suggerieren würden, dass die Differenzkategorien sich nur überschneiden würden und nicht gegenseitig voneinander durchdrungen seien (ebd.: 11).

Eine weitere theoretisch debattierte Frage ist, wie offen Kategorien gedacht werden sollen oder wie sie sich konstituieren und wie ihr $\mathrm{Zu}$ sammenspiel sich gestaltet. McCall (2005) differenziert hierbei zwischen drei verschiedenen Zugangsweisen $\mathrm{zu}$ Intersektionalität: zwischen antikategorialen, inter-kategorialen sowie intra-kategorialen Zugängen. Bei antikategorialen Zugängen wird die Berechtigung einer bestimmten Kategorie per se in Frage gestellt, ein inter-kategorialer Zugang nimmt die Wechselwirkung unterschiedlicher (vorausgesetzter) Kategorien in den Blick (z.B. das Achsenmodell von Klinger/Knapp 2007) - während ein intra-kategorialer Zugang danach fragt, wer eigentlich mit der jeweiligen Kategorie gemeint ist - wie dies etwa Crenshaw (1989) tut. McCalls Einteilung wird jedoch auch kritisiert, so stellt bspw. Yuval-Davis (2013: 207) fest, dass sich intraund interkategoriale Ansätze nicht ausschliessen und plädiert »für einen Intersektionalitätsansatz, der die Sensibilität und Dynamik des intrakategorialen Ansatzes mit der sozioökonomischen Perspektive des interkategorialen Ansatzes kombiniert« (ebd.).

In Alternative zu den intra-, inter- und antikategorialen Ansätzen schlägt Walgenbach gemeinsam mit Dietze, Hornscheidt und Palm das interessante Konzept der »interdependenten Kategorie« vor (Walgenbach et al. 2012), auf das ich mich in dieser Arbeit beziehe. Walgenbach will mit ihrem Vorschlag eine »integrale Perspektive« auf soziale Kategorien entwickeln (2012c: 58, Herv. im Orig.), welche »die gegenseitige Abhängigkeit von sozialen Kategorien fokussiert und damit die komplexen Beziehungen von Dominanzverhältnissen in den Vordergrund stellt« (Walgenbach 2012b: o. S., Herv. im Orig.). Sie problematisiert beim bisherigen Begriffsangebot anhand der Kategorie Gender, dass bisherige Konzeptionen, auch solche, welche Kategorien nicht als isoliert betrachten, tendenziell von einem sgenuinen Kern der sich mit anderen Kategorien verkette oder verschränke. Diese Annahme von Entitäten, die sich verbinden würden, stabilisiere solche Essenzialismen eher als sie zu hinterfragen, so ihre Kritik. Aufgrund dieser und der weiter zuvor angeführten Kritik an der Logik einer »Lineaturen-Methapher « schlägt Walgenbach anstelle des Intersektionlitätsbegriffs vor, von Interdependenzen auszugehen (2012c: 61, Herv. im Orig.). Sie sieht den Vorteil einer solchen 
Begrifflichkeit darin, dass »die gegenseitige Abhängigkeit und die komplexen Beziehungen von Dominanzverhältnissen in den Vordergrund « (ebd.) gestellt würden, da es unmöglich sei, Kategorien losgelöst von deren Interdependenzen zu denken. Um dies zu unterstreichen, schlägt sie den Begriff der interdependenten Kategorie (Walgenbach 2012c) vor. Sie geht somit nicht von Interdependenzen zwischen Kategorien aus, sondern von interdependenten Kategorien - in dieser Konzeption werden die Verbindungen also bereits innerhalb einer Kategorie mitgedacht (ebd.: 61.).

Welche Aspekte formieren demzufolge nun eine interdependente Kategorie? Dies ist laut Walgenbach einerseits von den Erkenntnisinteressen und andererseits vom Gegenstandsfeld abhängig. Sie schlägt vor, anschliessend an die kontextuelle Definition

»nach den relevanten Feldern und Ebenen zu suchen, welche die Kategorie Gender in dem ausgewählten Kontext aufspannen. Um die interdependente Struktur einer Kategorie zu fassen gilt es, deren interne Architektur in ihrer Komplexität möglichst umfassend auszuleuchten. Dabei hebt unser sanalytischer Spotlight z zeitweise bestimmte Aspekte hervor, während andere in den Hintergrund treten müssen« (Walgenbach 2012c: 63, Herv. im Orig.).

Ist der Kontext definiert, wäre also auf der Suche nach inhaltlichen Bestimmungen nach relevanten Feldern und Ebenen zu suchen, welche eine interdependente Kategorie in dem ausgewählten Kontext aufspannen. Die Innovation einer solchen Konzeption ist laut Autorin zudem darin zu sehen, dass auf eine Aufzählung gängiger Differenzkategorien verzichtet, also das »EceteraProblem« (ebd.: 64) teilweise gelöst werden könne. Insgesamt zeichnet sich dieser Ansatz meines Erachtens insbesondere durch seine anti-essenzialistische Konzeption bzw. die Verlagerung der komplexen Architektur von Differenzbeziehungen in das Innere der Kategorie aus, und ist meines Erachtens deswegen und durch seine explizite Bezugnahme auf einen »analytischen Spotlight (ebd.: 63) theoretisch als gewinnbringend zu betrachten.

Auch Winker und Degele bemängeln, dass in intersektionellen Ansätzen weitgehend Konzepte fehlen, welche die Wechselwirkungen zwischen den Kategorien berücksichtigen (2009: 23). Der zentrale Kritikpunkt von Winker und Degele betrifft jedoch die Ebenen, auf der sich die intersektionellen Analysen bewegen. Sie bemängeln, dass sich - strukturell gesehen - weitgehend die meisten intersektionellen Analysen auf einer einzigen Ebene befinden und Konzepte fehlen würden, die entsprechenden Ebenen zu verbinden (ebd.). Sie schlagen deshalb eine intersektionale Mehrebenenanylse (Winker/De- 
gele 2009: 25-62) vor, die folgende drei miteinander in Wechselwirkung stehende Ebenen einbezieht: die Struktur-, die Repräsentationsebene und die Ebene der Identitätskonstruktion (ebd.). Sie kritisieren, dass die meisten intersektionalen Studien ausschliesslich auf der Mikroebene angesiedelt seien. Nach Winker und Degele (ebd.) sind die drei von ihnen vorgeschlagenen Ebenen zwar nicht neu, würden jedoch in der wissenschaftlichen Diskussion nicht ausreichend verbunden. Die auf der Strukturebene angesiedelten relevanten Kategorien sind nach Winker und Degele begrenzt, nämlich Klasse, >Rasse`, Geschlecht und Körper. Diese Kategorien liessen sich aus der gesellschaftlichen Analyse eines modernen Kapitalismus deduktiv ableiten. Auf der Repräsentations- und der Identitätskonstruktionsebene müsse eine prinzipielle Offenheit unterschiedlicher Differenzkategorien angenommen werden. Diese würden jedoch induktiv aus dem Forschungsprozess gewonnen (ebd.: 28). Mit Verweis auf Bourdieu (ebd.: 63ff.) setzen sie, um die Komplexität des Ansatzes zu bewältigen, an den sozialen Praxen der Individuen an, durch welche die drei Ebenen miteinander verbunden sind, und rekonstruieren anhand dieser Effekte Wirkungen und Hervorbringungen von Differenzkategorien:

»Mit Blick auf die Verwobenheiten von Praxen und Diskursen analysieren wir soziale Praxen in Form von Handlungen einschliesslich sprachlicher Interaktionen und untersuchen die dort vorfindbaren Differenzierungskategorien vor allem in ihren Wechselwirkungen. Ausgehend vom empirischen Handeln und Sprechen von Personen fragen wir nach den Identitäten, die sie herstellen, sowie Strukturen und Normen, auf die sie rekurrieren « (ebd.: 67).

Für die Auswertung des empirischen Materials entwerfen sie ein iterativ angelegtes Acht-Schritte-Analyseprogramm. Die Analyseschritte werden teilweise auf einem sehr hohen Abstraktionsniveau formuliert. In Schritt fünf wird bspw. vorgeschlagen Identitätskonstruktionen $\mathrm{zu}$ vergleichen und zu clustern (ebd.: 80). Kritiker*innen dieses Ansatzes, so z.B. Riegel (2016a: 139) werfen Winker und Degele ein allzu starres mechanistisches Vorgehen vor, das »dem dialektischen Wechselspiel und der Interdependenz der Ebenen und der verschiedenen Ungleichheitsverhältnisse nicht hinreichend gerecht werden kann« (ebd.). Weiter wirft Riegel den Autorinnen der intersektionalen Mehrebenenanalyse vor, dass sie zumindest in den ersten vier ihrer Analyseschritte »auf den verschiedenen Ebenen getrennt nach der Thematisierung von Differenz- und Ungleichheitsverhältnissen« (ebd., Herv. im Orig.) fragen und so die Gefahr bestehe, »dass auf unterschiedlichen 
Ebenen jeweils verschiedene Kategorien aufgespürt werden, aber gerade die Konsequenzen und die Folgen des intersektionalen Zusammenspiels aus dem Blick geraten« (ebd.). Trotz dieser meines Erachtens berechtigten Kritik an Winkers und Degeles Ansatz lässt sich allerdings nicht bestreiten, dass deren Mehrebenenanalyse bedeutende Impulse für die methodologische Debatte der Intersektionalitätsforschung gesetzt hat (Walgenbach 2016: 52, Le Breton 2011: 81).

Eine weitere kontrovers geführte Diskussion in der Intersektionalitätsdebatte - hauptsächlich in deren europäischer Rezeption - bildet die Auswahl und Gewichtung von Differenzkategorien (Walgenbach 2014: 68ff., Winker/Degele 2009: 15). Traditionell wurden Crenshaw folgende drei Kategorien - race, class, gender - in der US-amerikanischen Intersektionalitätsdiskussion verwendet. Diese Triade gehört wohl - ergänzt durch ein »hilflos wirkendes etc.« (Walgenbach 2012b: o. S.) - nach wie vor zu den häufigsten Aufzählungen (ebd.). Dieses »etc.« wurde bereits von Butler (1991: 210) ironisch kommentiert und als ein nie enden wollender Bezeichnungsprozess von Subjekten interpretiert. Die prinzipielle Unabgeschlossenheit der Kategorien bildet denn auch Probleme; Winker und Degele (2009: 16) betonen, dass die Entscheidung für diese oder jene Differenzkategorie grundlegend vom untersuchten Gegenstand einerseits und von der untersuchten Ebene andererseits abhängt (ebd.).

In der europäischen Debatte werden neben den klassischen gender, class, race (bzw. Ethnizität) - »The Big Three« (Davis 2008: 24) - verschiedene Kategorien wie Alter, Sexualität, Nation (und/oder Körper) diskutiert (Davis 2008, Walgenbach 2012b). Lutz und Wenning schlagen nicht weniger als dreizehn, in späteren Veröffentlichungen gar fünfzehn bipolare Differenzlinien vor, denen jeweils ein Gegensatzpaar zuzuordnen ist (Lutz/Wenning 2001: 20, Lutz/Leiprecht 2003). Die von ihnen vorgeschlagenen 15 bipolaren hierarchischen Differenzlinien lauten wie folgt (Lutz/Leiprecht 2003: 121, Abb. 1): 


\begin{tabular}{|c|c|}
\hline Kategorie & Grunddualismus \\
\hline Geschlecht & männlich-weiblich \\
\hline Sexualität & hetero-homo \\
\hline$>$ Rasse $<$ / Hautfarbe & weiss - schwarz \\
\hline Ethnizität & $\begin{array}{l}\text { dominante Gruppe - ethnische Minderheit(en) = } \\
\text { nicht ethnisch - ethnisch }\end{array}$ \\
\hline Nation / Staat & Angehörige-Nicht-Angehörige \\
\hline Klasse / Sozialismus & >oben<->unten< / etabliert - nicht etabliert \\
\hline Religion & säkular-religiös \\
\hline Sprache & überlegen-unterlegen \\
\hline Kultur & zzivilisiert<->unzivilisiert< \\
\hline Gesundheit & nicht behindert-behindert \\
\hline Alter & Erwachsene-Kind / alt-jung \\
\hline $\begin{array}{l}\text { Sesshaftigkeit/ } \\
\text { Herkunft }\end{array}$ & $\begin{array}{l}\text { sesshaft-nomadisch / angestammt- } \\
\text { zugewandert }\end{array}$ \\
\hline Besitz & reich/wohlhabend-arm \\
\hline Nord-Süd/West-Ost & the West - the rest \\
\hline $\begin{array}{l}\text { Cesellschaftlicher } \\
\text { Entwicklungsstand }\end{array}$ & $\begin{array}{l}\text { modern-traditionell (fortschrittlich- } \\
\text { rückständig, entwickelt - nicht entwickelt) }\end{array}$ \\
\hline
\end{tabular}

Lutz/Leiprecht 2003: 121, Abb. 1

Kritisiert werden können bei diesem analytischen Modell einerseits die linear gedachten Kategorien, andererseits lässt sich auch die doch weitgehend (und gerade hinsichtlich der Kategorie Religion) eher eurozentristisch und essenzialistische Konzeption der Differenzlinien infrage stellen, auch wenn die Autor*innen festhalten, dass es sich hierbei nur um die Erfassung eines Spannungsverhältnisses handelt (Lutz/Leiprecht 2003: 121). Insgesamt kann - betrachtet man die Diskussion um die Auswahl der Kategorien - BeckerSchmidt jedoch unschwer beigepflichtet werden, wenn sie feststellt, dass Intersektionalität ein solch hybrides Forschungsparadigma darstellt, dass es sich nur »arbeitsteilig bewältigen lässt« (2007: 57).

Ein weiterer Aspekt einer intersektionellen Perspektive - so zeigt sich laut Davis in deren europäischer Rezeption - ist, dass sie sich ideal eignet, um 
essenzialistische Konstruktionen von Identität $\mathrm{zu}$ vermeiden und »situated, critically reflexive feminist knowledge« (2008: 30) zu produzieren.

Hinsichtlich der Vermeidung von essenzialistischen Konstruktionen von Identität entwirft die finnische Sozialanthropologin Anthias einen interessanten Ansatz (Anthias 2009a, 2009b, 2008). Anthias (2003: 36) setzt zunächst dem Identitätsbegriff den als Prozessbegriff angelegten Terminus der »sozialen Positionierung«(ebd.: 29) entgegen. Auf subjektive Positionalität kann Anthias zufolge in sozialwissenschaftlich generierten »Erzählungen über Zugehörigkeit «bzw. »Verortungen« zugegriffen werden (ebd.: 25). Anthias verfolgt hiermit ein »anti-statisches Plädoyer gegen die naturalisierte Festschreibung von Identitäten durch Differenzkategorien« (Bauschke-Urban 2010: 138). Um Positionierungen im Spannungsfeld von Selbstverortungen und der Zuweisung von Positionen im Geflecht verschiedener, miteinander verschränkter Dimensionen von Zugehörigkeit nachvollziehbar zu machen, schlägt sie vor, verschiedene Differenzkategorien (z.B. Klasse, Gender, Ethnizität oder soziale Herkunft) nicht gesondert, sondern prozessual in ihrem Zusammenspiel zu analysieren (Anthias 2008: 5). Differenzkategorien werden so als sich gegenseitig beeinflussende soziale Räume gesehen, die soziale Prozesse und soziale Beziehungen hervorbringen, die sich unter bestimmten Umständen zu bestimmten Konfigurationen zusammenfügen (ebd.). Anthias spricht hierbei von »translokaler Positionalität«:

»A translocational positionality is one structured by the interplay of different locations relating to gender, ethnicity, race and class (amongst others), and their at times contradictory effects. Positionality combines a reference to social position (as a set of effectivities: as outcome) and social positioning (as a set of practices, actions and meanings: as process). That is, positionality is the space at the intersection of structure (social position/social effects) and Agency (social positioning/meaning and practice). The notion of >location< recognises the importance of context, the situated nature of claims and attributions and their production in complex and shifting locales (Anthias 2008: 15, Herv. im Orig.).

Wie in dem Zitat deutlich wird, denkt Anthias Differenzkategorien nicht starr oder essenziell, sondern prozessual und schlägt basierend auf dem Intersektionalitätsgedanken das Konzept der »translokalen Positionalität «vor, das eine Verbindung der Kategorien impliziert (2009a, 2009b, 2008).

In meiner theoretischen Perspektive beziehe ich mich neben Walgenbachs theoretischem Vorschlag der interdependenten Kategorie (Walgenbach 2012c) 
weitgehend auf einen neueren intersektionellen Ansatz aus dem deutschsprachigen Raum - auf die von Riegel vorgeschlagene intersektionale Heuristik (Riegel 2016a: 61ff. und 136ff., Riegel 2010a: 67ff.). Riegel geht von der Annahme aus, dass das Konzept der Intersektionalität im Sinne eines sensitizing concepts (2016a: 137) zu betrachten sei und sieht diese Perspektive als »eine offen fragende, wie auch als eine (vorherrschende Verhältnisse) kritisch-hinterfragende« (ebd.) Perspektive an. Durch eine solche Perspektive werde "potentiell dem Anspruch feministischer Wissenschaftskritik (...) ebenso entsprochen wie dem herrschaftskritischen Impetus feministischer und postkolonialer Forschung« (ebd.). Riegel schlägt eine »intersektionale Heuristik« (ebd.) vor, die aus zwei Analyseinstrumenten besteht - einerseits aus einem intersektionalen Analyserahmen, der »verschiedene Dimensionen und Ebenen von sozialen Ungleichheits- und Dominanzverhältnissen aufzeigen soll und der Analyse zugänglich machen soll« (ebd.) und auf der anderen Seite aus intersektionalen Fragedimensionen »im Sinne einer analytisch aufschliessenden und hinterfragenden Forschungsperspektive - für die konkrete Analyse des empirischen Materials und dessen sozialem und situativem Kontext« (ebd.). Riegel unterstreicht insbesondere auch das kritische und dekonstruktivistische Potenzial einer solchen Perspektive (ebd.: 140). In ihrem intersektionalen Analyserahmen nimmt sie einerseits die Interdependenz von verschiedenen Machtund Ungleichheitsverhältnissen in den Blick: Die Interdependenz »von asymmetrischen Geschlechter-, Klassen-, Ethnizitäts- und Körperverhältnissen, bzw. (Hetero)Sexismen, Klassismen, Rassismen und Ableismen in internationalen, globalisierten kapitalistischen Gesellschaftsverhältnissen« (ebd.: 138). Zum anderen will Riegels Analyserahmen die Verbindungen der sozialen Ebenen, auf denen die Differenzkategorien manifest werden, in den Blick nehmen: Sie unterscheidet hier zwischen a) der Ebene der gesellschaftlichen Bedingungen und b) der Ebene der sozialen Diskurse und institutionalisierten Praktiken, sowie c) der Ebene des Subjekts bzw. des subjektiv begründeten Handelns und subjektiven Orientierungen (ebd.).

In ihrem zweiten Analyseinstrument, den intersektionalen Fragedimensionen, entwickelte sie für die Analyse folgende heuristische Fragen an den Forschungsgegenstand und an das empirische Material:

- »Wie werden soziale Differenzkonstruktionen und Dominanzordnungen (situativ, habituell, diskursiv) hergestellt und reproduziert?

- Welche sozialen Differenzkonstruktionen sowie Macht- und Herrschaftsverhältnisse werden (wie) relevant? Wie wirken diese zusammen? 
- Was wird dabei sichtbar (gemacht), was in den Hintergrund gerückt?

- Aus welcher sozialen Positionierung heraus werden Differenzkonstruktionen vorgenommen und in welchem Kontext erfolgt dies?

- Welche Funktionen und welche Folgen hat dies für die beteiligten Subjekte und für die hegemoniale soziale Ordnung?

- In welcher Weise (und in welchen Kontexten) zeigen sich dabei gegenüber hegemonialen Strukturen, Diskursen und Repräsentationen affirmative, hinterfragende, widerständige oder verschiebende Praktiken?« (ebd.: 2016: 141).

Riegel (ebd.: 139) stellt klar, dass es sich bei ihrem intersektionalen Analyserahmen eben gerade nicht, wie Winkel und Degele dies mit ihrer Mehrebenenanalyse (Winker/Degele 2009: 25-62) verfolgten, um eine forschungsmethodische Anleitung oder Aufforderung handelt, das Material auf verschiedenen Ebenen systematisch auf das Auftauchen von Differenzkategorien $\mathrm{zu}$ untersuchen, sondern um eine »Heuristik zur empirischen Untersuchung und Kontextualisierung « von Diskursen, Praktiken und Interaktionen (Riegel 2016a: 139, Herv. d. Verfasserin).

Was bedeutet nun die voranstehend dargelegte theoretische Diskussion für die vorliegende Untersuchung? Riegel (2016a: 137) betont im Anschluss an viele andere Forschende, dass Intersektionalitätsforschung keine bestimmte Forschungs- oder Auswertungsmethode, sondern eine Perspektive auf einen Forschungsgegenstand darstellt. Im Anschluss an Riegel verstehe ich Intersektionalität in erster Linie als Analyseperspektive bzw. als sensitizing concept (ebd., Knapp 2013: 251, vgl. auch Phoenix 2013: 183, Le Breton 2011: 73, Walgenbach 2012b: o. S., Davis 2008 etc.). Anthias (2008: 15) folgend verstehe ich Kategorien - bzw. Differenzdimensionen, wie ich sie nenne - zudem nicht als starr, sondern als prozessual. Vor diesem Hintergrund möchte ich den Blick auf die Wirkmächtigkeit und »interne Architektur« (Walgenbach 2012c: 63) der Differenzkategorie »Muslimin« richten.

Ich möchte mittels einer intersektionellen Perspektive auf meine Daten aufzeigen, wie und ob die Differenzkategorie »Muslimin« eine Rolle bei sozialen und (bildungs-)biografischen Positionierungsprozessen von jungen religiös orientierten Secondas spielt und inwiefern sie im Zusammenspiel von verschiedenen Differenzdimensionen intersektionell in Bildungsbiografien wirken kann. Auf der anderen Seite möchte ich die Perspektive auf den Handlungsspielraum bzw. die Handlungsfähigkeit (Agency) innerhalb ihres intersektionell beschränkten »Möglichkeitsraums« (Holzkamp 1983) ausrichten und re- 
konstruieren, mittels welcher Strategien sich die jungen Frauen als handelnde Subjekte aktiv gesellschaftlichen Differenzierungs- und Schliessungsprozessen stellen. Auf diese letztere theoretische Perspektive der Agency wird im folgenden Kapitel eingegangen.

\subsection{Perspektive der Handlungsfähigkeit innerhalb der intersektionellen Beschränkungen}

Neuere feministisch orientierte, sozialanthropologische Studien zeigen, dass eine intersektionelle Perspektive erkenntnisgenerierend mit Handlungstheorien (Agency-Theorien) verbunden werden kann (Lingen-Ali 2013, Le Breton 2011 u.a.). Während sich eine intersektionelle Perspektive besonders dazu eignet, gesellschaftliche Einschränkungen aufzuzeigen, fokussieren AgencyTheorien gerade auf das Gegenteil, nämlich auf den Handlungsspielraum bzw. die Handlungsfähigkeit der Akteur*innen. Eine Kombination einer intersektionellen Perspektive mit einem handlungstheoretischen Ansatz bietet sich demnach meines Erachtens als theoretische Rahmung für das vorliegende Projekt an: Es ist mir ein Anliegen, nicht nur die intersektionellen Einschränkungen der bildungsbiografischen Wege von jungen religiös orientierten Musliminnen aufzuzeigen, sondern insbesondere auch die (oft sehr kreativ genutzten) Handlungsspielräume innerhalb des gegebenen $»$ Möglichkeitsraums $\aleph^{12}$ (Holzkamp 1983: 334ff.). Durch die Kombination der beiden theoretischen Perspektiven soll vermieden werden, die jungen Frauen ausschliesslich rals passive Opfer $<$ intersektionell wirkender gesellschaftlicher Beschränkungen darzustellen. Im folgenden Kapitel möchte ich vorschlagen, wie der handlungspraktische Umgang mit gesellschaftlichen Zwängen theoretisch gedacht werden könnte.

Agency-Theorien sind in verschiedenen sozialwissenschaftlichen Feldern entwickelt worden, um Menschen als aktive Gestalterinnen ihrer Lebenssituation zu betrachten. Dahinden und Stants stellten bereits vor einigen Jahren ein »Wiederauftauchen des Konzepts der Agency« in der Migrationsforschung

12 Das Konzept des »Möglichkeitsraums«stammt aus der kritischen Psychologie und geht auf Holzkamp (1983) zurück. Holzkamp geht davon aus, dass die soziale Positionierung eines Individuums einerseits durch objektive, anderseits durch subjektive Handlungsmöglichkeiten und -einschränkungen geprägt ist (ssubjektiver und objektiver Möglichkeitsraum`) (ebd.: 334ff.). Speziell zur Analyse von Möglichkeitsräumen adoleszenter Migrant*innen vgl. bspw. King/Koller 2009b, Riegel 2004: 72ff. und 118ff.). 
fest - dies in Form einer Neuorientierung, durch welche die bisherige >Passivität ‘ der weiblichen Migrantinnen aufgehoben wird (2006: 36). Le Breton zufolge (2011: 108) ist diese Neuorientierung des Agency-Konzepts für die Analyse von Frauen in Migrationsprozessen besonders aufschlussreich, da es "Menschen als aktiv handelnde Subjekte ins Blickfeld rückt und nicht nur Zwangslagen thematisiert, denen Migrantinnen unterliegen, sondern ebenso die eingeschränkten - Spielräume, worüber sie verfügen und die es ihnen ermöglichen, eigene Lebenskonzepte zu entwerfen« (ebd.). Agency stellt gemäss Le Breton in dieser Neuorientierung »einen der neueren sozialtheoretischen Versuche dar, der unter Berücksichtigung philosophischer Grundannahmen über das Subjekt eine paradigmatische Neuorientierung von strukturfunktionalistischen zu praxistheoretischen Theoriekonzepten vorgenommen hat « (Le Breton 2011: 114). Neuere Ansätze, die auf diesen umfassenderen Zugang zu Agency abzielen, basieren zwar auf früheren dichotomen Gegenüberstellungen, die zwischen Agency und Struktur differenzieren; sie lehnen jedoch eine dualistische Gegenüberstellung ab und gehen davon aus, dass sich Struktur und Agency gegenseitig bedingen (Lingen-Ali 2013: 29-30). Als wichtige Vertreter*innen und ausschlaggebend in dieser Debatte gelten neben Anthony Giddens und Pierre Bourdieu auch Jürgen Habermas und die Soziologin Margret Archer (vgl. Le Breton 2011: 114). Abgesehen von der Vielfalt dieser Ansätze lassen sich Ziegler (2008) zufolge drei zentrale gemeinsame Perspektiven herauslesen: „Erstens zeichnen sie individuelle und strukturelle Handlungsspielräume aus der Perspektive der Handlungsformen und Handlungsoptionen der Akteure nach. Zweitens betrachten sie Handeln im konstitutiven Wechselspiel mit strukturellen Bedingungen. Drittens gehen sie von der grundsätzlichen Veränderbarkeit menschlichen Handelns aus« (Ziegler 2008: 83). Wie Le Breton betont, bildet der Vorteil einer solchen Perspektive, dass "die Deutungen der AkteurInnen, deren Kompetenzen und Ressourcen, sowie auch Begrenzungen sowohl auf individueller, wie auch auf struktureller Ebene« (2011: 110) ins Blickfeld rücken.

Um eine solche Perspektive einzunehmen, möchte ich die Ebene des alltäglichen Handelns in den Blick nehmen. Bei der Theoretisierung des alltäglichen Handelns stütze ich mich auf den Kulturtheoretiker Michel De Certeau, der eine subtile Perspektive auf allägliche Praktiken entwickelt hat, die er in seinem Werk die »Kunst des Handelns" (1988) darlegt. Es lag nicht in De Certeaus Absicht, ein abgeschlossenes theoretisches System zu entwickeln, im Gegenteil, er wehrt sich vehement gegen »die dominierende Vorstellung, das Ziel der Kulturanalyse sei die Produktion allgemeiner, theoretischer In- 
terpretationen, die dann auf jedes Beispiel anwendbar« seien (Winter 2007: 25). Vielmehr richtet er seinen Blick auf das anonyme »Gemurmel der Gesellschaften « (De Certeau 1988: 9) - auf die Praktiken, welche das Alltagsleben hervorbringt. Mittels kritischer Kulturanalyse theoretisiert De Certeau alltägliche »Strategien und Taktiken « (ebd.: 87ff.) und nimmt so quasi eine >praxeologische Perspektive auf das alltägliche Handeln »Aktivitäten von Verbrauchern, die angeblich zu Passivität und Anpassung verurteilt sind« (ebd.: 11, Herv. im Orig.) stets im Fokus. Diese will er innerhalb der gesellschaftlichen und kulturellen Ordnung neu verorten (Krönert 2009: 49). Für De Certeau erschöpft sich das alltägliche Handeln des Konsumenten »nicht in den Zwängen geistiger und materieller Reproduktion, sondern ist selbst als eine Fähigkeit zur Produktion, als >Kunstfertigkeit< zu begreifen« (Füssel 2001: 105). In Abgrenzung zu Bourdieus Studien (z.B. zu Bourdieu 1983), welche die Reproduktion bestehender sozialer Strukturen und das habituelle Eingebunden sein ins Zentrum rücken, und im Gegensatz zu Foucaults Theorien zu Macht (1976a,b) möchte De Certeau die »Kombinationsmöglichkeiten von Handlungsweisen« (De Certeau 1988: 12), welche Alltagspraktiken hervorbringen, die in der Regel sunsichtbar bleiben, einbeziehen.

De Certeau kritisiert an Foucaults Machtanalyse eine Überbetonung der Herrschaftsverhältnisse, er selbst richtet den Blick vielmehr auf »die unsichtbaren Praktiken, mittels derer sich die Subjekte den organisierten Raum wieder aneignen« (Krönert 2009: 52). Bei Bourdieus Theorien bemängelt er insbesondere in dessen frühen Arbeiten die Starrheit des Habituskonzepts (De Certeau 1988: 124-25). Füssel umschreibt De Certeaus Kritik an Bourdieu wie folgt:

»Was ihn an Bourdieus Analysen irritiert, ist dabei nicht die Annahme einer sunbewussten ‘ Strukturierung von Erfahrungen und Praktiken, sondern das Cewicht, das dem Habitusbegriff als eine Art sinterpretative Master key< (Ahearne 1995: 153) zukommt. In den Augen Certeaus [sic!] tendiert der Begriff des Habitus dazu, die Heterogenität der Praktiken zu nivellieren, indem sie unter einen universellen Begriff subsumierbar werden« (Füssel 2001: 106).

De Certeau stellt also weder Macht noch die soziale Ordnung ins Zentrum seiner Überlegungen, sondern den »listigen« Widerstand »von unten« durch autonome Aneignungsweisen alltäglicher Praktiken. Dadurch rückt er die Handlungsfähigkeit (Agency) von Individuen in subalternen Positionen gegenüber etablierten Strukturen ins Zentrum. De Certeau spricht von der 
Kunst des Handelns (1988) als »Kunst des Gebrauchs derjenigen Produkte, die ihr aufgezwungen werden « (1988: 81). Produktion und Konsum verhalten sich De Certeau zufolge wie Lesen und Schreiben (ebd.: 26). Wie die Leser*innen beim Lesen ihren eigenen Text produzieren, indem sie ihm Bedeutung verleihen, »bieten Alltagspraktiken Raum für autonome Aneignungsweisen« (Füssel 2001: 106). De Certeau entdeckt in alltäglichen Handlungen wie Lesen, sich Unterhalten, Kochen, Spazieren gehen oder Fernsehkonsum "listvolle Praktiken der Wiederaneignung eines durch Machtstrategien und funktionalistische Rationalität organisierten Systems« (Winter 2008: 310). Alltagspraktiken sind nach De Certeau immer auch Aneignungspraktiken, welche auf einem eigensinnigen »Gebrauch « des Gegebenen basieren (De Certeau 1988:13):

»Das Gegenstück zur rationalisierten, expansiven, aber auch zentralisierten, lautstarken und spektakulären Produktion ist eine andere Produktion, die als `Konsum< bezeichnet wird: diese ist listenreich und verstreut, aber sie breitet sich überall aus, lautlos und fast unsichtbar, denn sie äussert sich nicht durch eigene Produkte, sondern in der Umgangsweise mit den Produkten, die von einer herrschenden ökonomischen Ordnung aufgezwungen werden« (De Certeau 1988: 13, Herv. im Orig.).

De Certeau sieht den »gemeinen Mann« als »Held[en] des Alltags« (ebd.: 9), der durch seine kulturellen Aneignungs- und Umdeutungsprozesse Widerstand leistet. Der Kampf um die legitimen Aneignungsweisen von Praktiken führt dabei zu einer »Politisierung der Alltagspraktiken« (Füssel 2001:106), die sich jedoch nicht (oder zumindest nicht zwingend) im Sinne eines politischen Kampfs abspielt. Die Kunst der Aneignung besteht vielmehr in einer gelebten und erfahrenen Subversivität, die nicht primär mit politischen Vorstellungen wie z.B. dem Klassenkampf etc. verbunden ist oder im Opponieren gegen ideologische Strukturen wie bspw. bei Hall (1996), sondern dadurch dass (kulturelle) »Texte« in etwas Eigenes verwandelt werden. Eine solche Perspektive öffnet nicht zuletzt auch den Blick für die Kreativität des alltäglichen Handelns.

Nach De Certeau setzt sich das »Alltägliche aus allen möglichen Arten des Wilderns zusammen « (1988: 12, Herv. im Orig.). Winter spricht in diesem Zusammenhang von einer "widerständigen Sozialität« (2008: 299). De Certeau weist jedoch darauf hin, dass die Künste des alltäglichen Handelns nicht etwa als eine Gegenkultur oder individualistisch verstanden werden dürfen, sondern als relationales Konstrukt (ebd.: 311). Für ihn ist das Alltagsleben Ort der 
Auseinandersetzung und der Verhältnisbestimmung der Prozeduren und des »Kräftefelds«, in das sie eingreifen (De Certeau 1988: 20). Dieses Verhältnis ist ihm zufolge theoretisch mittels einer »kriegswissenschaftlichen Analyse der Kultur« (ebd.: 20) zu denken. Eine solche Analyse hat zum Ziel, »der Widerspenstigkeit populärer Praktiken Rechnung [zu tragen] ohne die disziplinierende Macht der herrschenden Verhältnisse auszublenden« (Krönert 2009: 51).

Unter Rückgriff auf Clausewitz unterscheidet er zwischen »Strategien« und »Taktiken«. Unter »Strategie« versteht er folgendes:

»Als Strategie bezeichne ich die Berechnung (oder Manipulation) von Kräfteverhältnissen, die in dem Moment möglich wird, wenn ein mit Willen und Macht versehenes Subjekt (ein Unternehmen, eine Armee, eine Stadt oder eine wissenschaftliche Institution) ausmachbar ist. Sie setzt einen Ort voraus, der als etwas Eigenes beschrieben werden kann und somit als Basis für die Organisierung einer Exteriorität dienen kann, seien dies Stossrichtungen oder Bedrohungen (Kunden oder Konkurrenten, Feinde, das Umland der Stadt, Forschungsziele und -gegenstände etc.)« (De Certeau 1988: 87, Herv. im Orig.).

Als Beispiel für eine »Strategie« führt Winter (2007: 31) das von Foucault analysierte Bentham'sche Panopticon an, bei dem durch den Überwachungsblick ein Ort beherrscht wird. Als zweites Beispiel nennt er die ")Macht des Wissens` von Medizinern und Psychologen, die Kraft ihres Wissens, das durch Machtverhältnisse ermöglicht wurde, definieren, was >normales $<$ und was >abweichendes« Verhalten ist« (ebd.: 31). »Strategien« weisen also auf (gesellschaftlich) etablierte Handlungsmuster hin, die aus einer privilegierten und mit Macht, ökonomischen Ressourcen ausgestatteten Position Kräfteverhältnisse (mit)bestimmen können.

Im Gegensatz dazu sind »Taktiken« Handlungsmuster aus einer subalternen Position heraus, in denen eine Umdeutung etablierter Strukturen stattfinden kann. »Taktiken« sind jedoch abhängig von einer vorhandenen >Infrastruktur<, bspw. eines Diskurses:

»Im Gegensatz zu den Strategien (...) bezeichne ich als Taktik ein Handeln aus Berechnung, das durch das Fehlen von etwas Eigenem bestimmt ist. Keine Abgrenzung einer Exteriorität liefert ihr also die Bedingung einer Autonomie. Die Taktik hat nur den Ort des Anderen. Sie muss mit dem Terrain fertigwerden, das ihr so vorgegeben wird, wie es das Gesetz einer fremden 
Cewalt organisiert. Sie ist nicht in der Lage, sich bei sich selbst aufzuhalten, also auf Distanz, in einer Rückzugsposition, wo sie Vorausschau üben und sich sammeln kann: sie [sic!] ist eine Bewegung sinnerhalb des Sichtfeldes des Feindes ' wie Bülow sagte (14), die sich in einem von ihm kontrollierten Raum abspielt. (...). Sie profitiert von >Gelegenheiten $<$ und ist von ihnen abhängig; (...) Dieser Nicht-Ort ermöglicht ihr zweifellos die Mobilität - aber immer in Abhängigkeit von den Zeitumständen -, um im Fluge die Möglichkeiten zu ergreifen, die der Augenblick bietet. Sie muss wachsam die Lücken nutzen, die sich in besonderen Situationen der Überwachung durch die Macht der Eigentümer auftun. Sie wildert darin und sorgt für Überraschungen. Sie kann dort auftreten, wo man sie nicht erwartet. Sie ist die List selber « (De Certeau 1988: 89, Herv. im Orig.).

Ein illustrierendes Beispiel für eine »Taktik« im Sinne De Certeaus aus meiner Feldforschung wäre bspw. die »listige« subkulturelle Aneignung der ursprünglich in der weissen Mittelschicht fussenden Hipsterbewegung (»Ort des Andern«) durch deren »Muslimisierung« als »Mipsterz«-Bewegung. Mipster setzt sich zusammen aus "Muslim(a)« und "Hipster« (Feldprotokoll 16.07.2014) - also muslimische* $r$ Hipster. Ein Zeugnis dieser Aneignung ist bspw. das im Dezember 2013 im Internet veröffentliche Video ${ }^{13}$ MIPSTERZ der beiden amerikanischen Filmemacher Abbas Rattani und Habib Yazdi, welches sich viral unter jungen Muslim*innen in Amerika und Europa, aber auch im Nahen Osten verbreitete.

De Certeau unterscheidet also zwischen »Strategien« der Disziplinierung und »Taktiken« der Aneignung (Füssel 2001: 106). »Taktiken« sind für ihn ein »Ort des Andern« bzw. ein »Nicht-Ort«, eine »Kunst der Schwachen« (ebd.: 107), die einen beständigen, alltäglichen und unsichtbaren Kampf in einem dominierten »Kräftefeld « führen. Wie Füssel (2001: 107) zu Recht festhält, beinhaltet seine Privilegierung der Aneignungsweisen jedoch keine romantische Sichtweise auf die handelnden Akteure, es sind die Vorgehensweisen und Handlungsmuster, die ihn primär interessieren »und nicht das Subjekt, das Urheber oder Träger derselben ist «(De Certeau 1988: 12). Im Zentrum seiner Denkfigur »steht eine >Kunst der Schwachen<, die wie eine Art unsichtbarer Guerilla permanente Kämpfe im Kräftefeld der Kultur führt « (Füssel 2018: 103).

13 https://vimeo.com/100475946. 
Wie Winter (2007: 21) und andere festhalten, ist das Potenzial der Theorie der »Kunst des Handelns« von De Certeau bisher unzureichend beachtet worden - ist sie doch nach wie vor äusserst aktuell, und eignet sich hervorragend, um »widerständische Sozialiät im postmodernen Alltagsleben « (Winter 2008: 299) $\mathrm{zu}$ beschreiben. De Certeau ist im deutschsprachigen Raum einerseits in der Städteforschung, andererseits aber auch in der Medien- und Geschichtsforschung und in der Kulturwissenschaft rezipiert worden. Krönert (2009: 55) betont, dass eine Auseinandersetzung mit De Certeaus Ansatz gerade auch »im Bereich des Religiösen« (ebd.) fruchtbar wäre, da er »der Gebrochenheit individualisierter Religiosität Rechnung [trage] und damit zugleich die Dichotomie zwischen der These der Säkularisierung auf der einen und der >Wiederkehr des Religiösen auf der anderen Seite [überwinde]« (ebd.). De Certeau verweist auf die etablierte Ordnung im »religiösen Raum«, deren populärer Gebrauch so weit gehen könne, dass er die »Funktion von Religion « verändern könne (De Certeau 1988: 59). Eine solche Perspektive sehe ich für die vorliegende Forschung als äusserst interessant an, da sie eine Betrachtungsweise zulässt, welche individuelle Aneignungsweisen (etablierter) religiöser Praxen fokussiert.

Die italienische Sozialanthropologin Frisina (2010:560) bezieht sich in der Beschreibung von den (in Bezug auf den herrschenden Islamdiskurs) widerständigen »identification tactics and strategies« (2010: 560) von jungen Muslim*innen in Italien ebenfalls auf De Certeau, sie kombiniert ihre Perspektive allerdings nicht mit intersektionellen Überlegungen. Frisina betont jedoch, dass es sich bei diesen "Taktiken « und »Strategien « nicht um rationale und bewusste Handlungen handelt:

»Talk of tactics and strategies should not be misleading, however, giving us the impression of rational agents who opportunistically plan their moves. A capacity for reflection is not always needed to grasp the opportunities afforded by different situations; it is more a case of wise ignorance and practical capabilities« (Frisina 2010: 560).

Was heisst dies nun für vorliegende Untersuchung? Die von De Certeau vorgeschlagene »kriegswissenschaftliche« Perspektive des alltäglichen Handelns eignet sich meines Erachtens sehr gut, um alltägliche »Taktiken« junger religiös orientierter Secondas zu rekonstruieren und im Hinblick auf ihre Bildungsbiografien - innerhalb intersektioneller Beschränkungen theoretisch zu denken. Die Kombination einer solch handlungstheoretischen mit einer intersektionellen Perspektive, wie sie in Kapitel 2.2. beschrieben 
worden sind, schlage ich folgendermassen vor: Hinsichtlich der strukturierenden Beschränkungen der bildungsbiografischen Wege der jungen Frauen wird eine intersektionelle Perspektive eingenommen. In der Theoretisierung der Agency der jungen Frauen, also der Art wie sie innerhalb des vorstrukturierten »Möglichkeitsraums (Holzkamp 1983) bildungsbiografisch »einen Weg finden«, greife ich auf das Konzept der alltäglichen »Taktiken«, von De Certeau (1988) zurück (vgl. Typologie Kap. 5). »Strategien« und »Taktiken« bezeichnen nach De Certeau Kräfteverhältnisse und sind als solche relational zu verstehen (Füssel 2018: 104). Das Potenzial von De Certeaus Konzept der »Taktiken« besteht meines Erachtens insbesondere darin, potenziell »listige« Alltagspraktiken $\mathrm{zu}$ analysieren, auf welche religiös orientierte Secondas zurückgreifen, um sich hegemonialen gesellschaftlichen Machtverhältnissen als handelnde Subjekte entgegen zu stellen. Unter "Strategien« versteht De Certeau in der Regel Strukturen, die auf Kontrolle zielen und mittels derer soziale Ordnung hergestellt werden soll. Hierbei kann es sich jedoch auch um kurzfristig festgelegte Anordnungen handeln (Winter 2018). Sie bilden den Referenzrahmen bzw. das »Kräfteverhältnis« (De Certeau 1988: 87), innerhalb dessen sich die »Taktiken« verorten. Sie verhalten sich relational zu »Taktiken« (ebd.: 89). »Taktiken« sind zunächst soziale Praktiken, die von Individuen oder Gruppen ergriffen werden können (Winter 2018). Da sich eine intersektionelle Perspektive als analytisch sensibilisierendes Konzept meines Erachtens besser eignet, um die subtilen Machtverhältnisse, die einschränkend auf Bildungsbiografien wirken, zu analysieren, habe ich auf die Weiterführung des »Strategie«-Begriffs als Gegensatz zum Begriff der »Taktik« nach De Certeau (1988: 87) verzichtet. Als referenziellen Rahmen der »Taktiken" auf der Ebene der »Strategien" verwende ich stattdessen intersektionelle Differenzdimensionen. Dies jedoch ohne den relationalen Aspekt zwischen "Taktiken" und intersektionellen Einschränkungen (bzw. "Strategien«) zu vernachlässigen. Den Begriff der »Taktiken«, wie De Certeau ihn als konzeptuelle Beschreibung von »Alltagssubversion « (Füssel 2018: 107) konzipiert, sehe ich als geeignet an, um Agency aus subalternen Positionen heraus in einem intersektionell beschränkten, bildungsbiografischen "Möglichkeitsraum« (Holzkamp 1983) theoretisch zu fassen. Ich gehe mit Frisna (2010: 560) davon aus, dass es sich bei »Taktiken« grösstenteils um unbewusste Handlungsmuster handelt. Auch Winter (2017) ist der Ansicht, dass sich "Taktiken « in der Regel nicht diskursiv artikulieren, sondern oft unterbewusst in den Kontexten ihrer Entstehung verankert sind. Sie sind jedoch - so Winter (ebd.) - nicht unterbewusst im Freud'schen Sinne, sondern 
können durchaus bewusst gemacht werden, wie es bspw. Giddens mit dem Begriff des "praktischen Bewusstseins" vorschlägt (Giddens 1997).

Die Art, wie sich eine »Taktik« zeigt oder welche »Taktik« zum Zuge kommt, sehe ich schliesslich als habituell verankert (Bourdieu 2006). Ich beziehe mich hierbei auf eine spätere Arbeit von Bourdieu (2006: 164ff.), in der er auf die durchaus berechtigte Kritik von De Certeau und anderen an der Starrheit seines Habitusbegriffs in seinem Frühwerk (1983a, 1979) reagierte. In »Reflexive Anthropologie« (2006) modifizierte Bourdieu sein Habituskonzept und unterstrich, dass ein Habitus nicht nur zur Reproduktion von Herrschaftsverhältnissen beiträgt, sondern auch $\mathrm{zu}$ »neuen Spielzügen« fähig ist (Winter 2017). Genau in diesem Spannungsfeld sehe ich De Certeaus Begriff der »Taktiken«, wie ich ihn in vorliegender Arbeit zu verwenden gedenke, angesiedelt: als habituell bedingte und dennoch kreative Spielzüge innerhalb eines durch intersektionelle Prozesse begrenzten bildungsbiografischen »Möglichkeitsraums« (Holzkamp 1983) - als Aneignungsmöglichkeiten von Handlungspraktiken innerhalb einer »Geographie des Möglichen« (Winter 2008: 312). 


\section{Annäherung an das Forschungsfeld}

\subsection{Musliminnen und Muslime in der Schweiz: ein Überblick}

Im Jahr 2000 zählte die letzte umfassende Volkszählung in der Schweiz 310 ○o० Muslim*innen (Bovay 2004). Während der Anteil von Muslim*innen an der Bevölkerung der Schweiz 1970 erst 0.26 Prozent betrug, waren es 1980 0.89 Prozent (ebd.). Mit der kriegsbedingten Zuwanderung von Personen aus Ex-Jugoslawien stieg der Anteil der Muslim*innen in der Schweiz in den 1990er-Jahren sprunghaft an - von 1990 2.21 Prozent auf 4.26 Prozent in 2000 (ebd.). Neuere, gesicherte Zahlen liegen keine vor, der Grund dafür besteht darin, dass das System der »Volkszählung« aus politischen und ökonomischen Gründen sistiert wurde. Von 1850-2000 wurde alle zehn Jahre eine Volkszählung vorgenommen, die eine Frage nach Religionszugehörigkeit einschloss. Heute werden die Bevölkerungszahlen über die Gemeinderegister erhoben (Schneuwly Purdie/Tunger-Zanetti 2015: 574, für entsprechende Zahlen vgl. BFS 2017c). Nicht alle Gemeinden erheben jedoch Informationen über Religionszugehörigkeit, denn die Kategorisierung »Religionszugehörigkeit « und deren statistische Erhebung ist aufgrund der vorgegebenen Zuordnungen und der Zuschreibungen nicht unproblematisch. Dies zeigt sich bspw. an der Frage, wer überhaupt als Muslim*in definiert wird und wer nicht: Wie wäre z.B. eine religiös sozialisierte Tochter einer Sunnitin und eines Schiiten statistisch $\mathrm{zu}$ »klassifizieren«? Als »Sunnitin«, "Schiitin« oder »Konfessionslose«? Dieselbe Problematik stellt sich natürlich auch bei der Zugehörigkeit (bzw. Nichtzugehörigkeit) zu anderen Religionsgemeinschaften, so wie bei den Söhnen und Töchtern von Eltern, die unterschiedlichen Religionsgemeinschaften angehören. Eine weitere Schwierigkeit besteht zudem darin, dass einzelne Gemeinden nur staatlich anerkannte Religionsgemeinschaften als Kategorien der Selbstdeklaration aufführen (Schnewly-Purdie/Tunger-Zanetti 2015: 574, Fussnote 36). 
Dessen ungeachtet wurde im Jahr 2014 gemäss Schätzungen, die auf statistischen Hochrechnungen ${ }^{1}$ beruhen, von ca. 450000 Muslim*innen in der Schweiz ausgegangen, das entspricht ca. 5.5 Prozent der Gesamtbevölkerung, wovon gut ein Drittel unter 20 Jahre alt ist (Schneuwly Purdie/Tunger-Zanetti 2017: 682). 80 Prozent der Muslim*innen in der Schweiz sind Sunnit*innen, 7 Prozent Schiit*innen, 11 Prozent türkische Alevit*innen, die restlichen Prozente sind Angehörige von Minderheiten wie verschiedenen Sufiorden oder den Ahmadiyya (ebd.: 683). Gemäss Schneuwly Purdie und Tunger-Zanetti (2017: 683) verteilt sich die Bevölkerung geografisch unterschiedlich auf die verschiedenen Sprachregionen der Schweiz: Während in der deutschsprachigen Schweiz 76.7 Prozent der muslimischen Bevölkerung der Schweiz wohnen, leben in der französischsprachigen Schweiz 21.6 Prozent und im Tessin 1.7 Prozent (vgl. hierzu auch BFS 2017c). Zudem existieren gut 240 Moscheen und 24 Muslim*innen vorbehaltene Begrabungstätten auf Gemeindefriedhöfen (Schneuwly Purdie/Tunger-Zanetti 2017: 683-684). Ein stark wachsender Teil der Muslim*innen besitzt die Schweizer Staatsangehörigkeit, 2014 waren es 34 Prozent, inklusive ein paar tausend Konvertit*innen (ebd.: 682).

In Bezug auf Herkunft, Sprache und soziokulturelle Zugehörigkeiten zeichnen sich Muslim*innen in der Schweiz im Gegensatz zu der muslimischen Bevölkerung der europäischen Nachbarländer durch eine grosse Heterogenität aus (Scharbrodt et al. 2017, Allenbach/Sökefeld 2010, Gianni 2010, Behloul/Lathion 2007). Der grösste Teil der Muslim*innen (39 Prozent) stammt ursprünglich aus dem Balkan, gefolgt von 13 Prozent aus der Türkei (Aleviten eingeschlossen), 4 Prozent aus Nordafrika und 3 Prozent aus dem

1 Die Zahlen beruhen auf einer Hochrechnung des Bundesamts für Statistik (BFS) mit einem Sample von 200000 Personen. Die genaue offizielle Zahl der Muslime für 2014 ist 346208 (Schneuwly Purdie/Tunger-Zanetti 2017: 682) - anzufügen ist jedoch, dass ein nicht unerheblicher Teil der Bevölkerung aus dieser Erhebung ausgeschlossen wurde: Das Sample, auf dem die Hochrechnung beruht, umfasst nur permanent in der Schweiz niedergelassene Personen über 15 Jahre, die in privaten Haushalten wohnten - ausgeschlossen davon sind Asylsuchende, Geflüchtete, Diplomaten und eine beträchtliche Anzahl von sog. Expatriierten, die in der Schweiz arbeiten, sowie Gefängnisinsassen und Menschen, die in sozialen und medizinischen Institutionen wohnen (SchnewlyPurdie/Tunger-Zanetti 2015: 574). Rechnet man die Zahlen aufgrund durchschnittlicher Geburts- und Zuwanderungsraten hoch und schliesst unter 15-Jährige und Aleviten mit ein - wie Schneuwly Purdie und Tunger Zanetti dies taten, kommt man auf die Zahl von ca. 450000 (Schneuwly-Purdie/Tunger-Zanetti 2017: 682). 
Nahen Osten; weitere 3 Prozent aus EU-Staaten, 2 Prozent aus der afrikanischen Sub-Sahara, I Prozent aus Zentralasien und I Prozent aus Ostasien (Schneuwly Purdie/Tunger-Zanetti 2017: 683).

Die Heterogenität der muslimischen Bevölkerung in der Schweiz kann, wie Allenbach und Sökefeld unterstreichen, angesichts des homogenisierenden Islamdiskurses nicht genug betont werden (2010: 17). Es handelt sich hierbei um eine Heterogenität hinsichtlich Ethnizität, »Migrationshintergrund«, Sprache und Glaubenstradition (Müller 2013: 52). Diese Heterogenität kommt nicht zuletzt in einer grossen Pluralität von Formen gelebter Religiosität (>lived religion`, McGuire 2008: 12-13) zum Ausdruck (Allenbach/Sökefeld 2010: 16, Schneuwly Purdie 2010, Schneuwly Purdie et al. 2009). Im Gegensatz zu den USA und Kanada, wo Muslim*innen häufig der Mittelschicht angehören, gehört die muslimische Bevölkerung der Schweiz überdurchschnittlich oft der Unterschicht an (Allenbach/Sökefeld 2010: 14).

Lediglich ein kleiner Teil der in der Schweiz lebenden Muslim*innen kann als >religiös aktiv bzw. sogenannt spraktizierend (De Flaugergues 2016, Gianni et al. 2015). Eine kategoriale Einteilung in die Dichotomie >praktizierend vs. >nicht praktizierend wissenschaftlicher Sicht jedoch ohnehin obsolet oder zumindest subjektiv, die Grenzen scheinen vielmehr fliessend $\mathrm{zu}$ verlaufen (vgl. neue Typologie religiöser Profile ${ }^{2}$ Stolz et al. 2014: 65-78, aber auch Endres et al. 2013: 10, Stolz/Baumann 2007:35-36). Endres et al. schätzen den Anteil der Muslim*innen, welche die Religionsausübung als »lebensbestimmend« verstehen, unter Einräumung des zuletzt genannten Einwands auf 10-15 Prozent (Endres et al. 2013: 10).

Der Aufbau einer religiösen Infrastruktur setzte mit dem Familiennachzug von muslimischen Gastarbeitern ein und kann als Prozess des »HeimischWerdens« gedeutet werden (Allenbach/Müller 2017: 279, D’Amato 2015). Die Mehrheit der religiös aktiven Muslim*innen unter den Zugewanderten ist in Vereinen organisiert, die sich meist entlang ethnischer und sprachlicher Grenzen ausrichten und Moschee-gebunden sind (Zurlinden 2015: 179, Endres et al. 2013: 11). Diese Vereine verfügen in der Regel über Räumlichkei-

2 Stolz et al. (2014: 65-78) sprechen in ihrer Typologie von 4 religiösen Profilen innerhalb eines sozialen Felds, welches innerhalb der Dimensionen »institutionelle Religiosität« und »alternative Spiritualität« aufgespannt wird: 1. Institutionelle 2. Alternative 3. Distanzierte 4. Säkulare. 
ten, die einerseits der Ausübung religiöser Praxen, andererseits aber auch als Treffpunkte für vielfältigste Aktivitäten dienen - von folkloristischen Volkstanzgruppen über Frauengruppentreffen bis hin zur Hilfe bei Hausaufgaben und Bewerbungsschreiben (eigene Beobachtungen, Endres et al. 2013:13, Baumann 2012: 46-52, Behloul 2005: 157). Behloul bezeichnet Moschen gar als "polyfunktionale Dienstleistungszentren«(Behloul 2005: 157, 2004). Meistens sind diese räumlich in der (städtischen) Peripherie angesiedelt und äusserlich nicht als religiöse Lokale erkennbar (eigene Beobachtungen, vgl. auch Allenbach/Müller 2017: 279, Müller 2013: 54).

Institutionell hatte sich die Bandbreite muslimischer Vereine in den vergangenen Jahrzehnten ausdifferenziert, nicht zuletzt durch die Gründung der Dachorganisationen (Endres et al.: 2013: 12). Auch das zunehmende Gewicht von Secondas*os und von Konvertit*innen ${ }^{3}$ in religiösen Vereinen dürfte hierbei eine Rolle gespielt haben. Moschee-ungebundene Organisationen, welche primär vor allem von religiösen Akteur*innen der zweiten Generation von $\mathrm{Zu}$ gewanderten frequentiert werden, sind meist nicht mehr entlang sprachlichethnischer Gruppen organisiert. Kommunikationssprache ist Deutsch und es wird Wert darauf gelegt, dass ein Islamverständnis repräsentiert wird, das sich mit einem Leben in der hegemonialen schweizerischen Gesellschaft vereinen lässt (zum Wandel von Religionsverständnis, religiöser Praxis und religiöser Selbstrepräsentation junger Secondas muslimischen Glaubens gegenüber der Elterngeneration vgl. Thesen in Kapitel 6).

Auf gesamtschweizerischer Ebene gibt es seit längerem Bestrebungen, verschiedene Vereine in einem Dachverband zusammenzufassen. Es gibt zwei Dachverbände mit repräsentativem Anspruch: 1978 wurde die KIOS (Koordination Islamischer Organisationen Schweiz) gegründet, gemäss Schneuwly Purdie und Tunger-Zanetti (2017: 686) scheint dieser Verband jedoch zurzeit nicht mehr aktiv zu sein. 2006 folgte die Gründung der Föderation Islamischer Dachorganisationen (FIDS) als repräsentativer gesamtschweizerischer Dachverband, der laut Selbstdeklaration rund 170 muslimische Vereine repräsentiert (FIDS 2017). Die muslimischen Dachverbände haben sich zunächst auf regionaler (kantonaler) und erst in einem zweiten Schritt auf nationaler Ebene mit dem Ziel gebildet, die Vielfalt stärker vertreten, als es ihrer recht kleinen Zahl entsprechen würde (Endres et al. 2013: 12). 
der muslimischen Vereine $\mathrm{zu}$ bündeln, um einerseits einen Verständigungsprozess untereinander einzuleiten, andererseits aber auch, um eine Ansprechstelle für staatliche Stellen zu schaffen (Allenbach/Sökefeld 2010: 17). Tunger-Zanetti schätzt die Mitglieder aufgrund einer Hochrechnung von muslimischen Vereinen innerhalb und ausserhalb der Dachverbände ${ }^{4}$ auf gesamthaft ca. 100000 (Tunger-Zanetti 2017). Allenbach und Müller (2017: 279) zufolge befinden sich diese Organisationen momentan in einer Etablierungsphase, welche nach Ansicht der Autorinnen in erster Linie von den Kindern von Zugewanderten getragen wird, denen es um die Verortung der religiösen Gemeinschaft in der »Aufenthaltsgesellschaft" gehe (ebd.: 278). Als deutliches Zeichen hierfür können laut Autorinnen die Pläne der beiden grössten muslimischen Dachverbände FIDS und KIOS betrachtet werden »eine öffentlich-rechtliche Anerkennung des Islam anzustreben und dadurch die faktische Gleichstellung mit den beiden christlichen Landeskirchen $\mathrm{zu}$ erreichen « (ebd.: 279). Baumann (2012: 45) stellte bereits im Rahmen eines Syntheseberichts zum Nationalen Forschungsprogramm »Religionsgemeinschaften, Staat und Gesellschaft“ (NFP58) fest, dass Vertreter*innen nichtchristlicher Religionen immer häufiger »den Wunsch nach gleichberechtigter gesellschaftlicher Akzeptanz und öffentlich-rechtlicher Anerkennung ihrer Religion, der Möglichkeit von eigenem Religionsunterricht an öffentlichen Schulen und der Zulassung der Errichtung repräsentativer, >würdiger Religionsbauten« äussern (ebd.).

Allenbach und Müller stellen zudem ein zunehmendes Eindringen von Frauen in die »institutionelle Sphäre von Religion « fest (Allenbach/Müller 2017: 287). Frauen übernehmen laut den Autorinnen in religiösen Organisationen von Zugewanderten neue Aufgaben (ebd.). Neuere religionswissenschaftliche Forschungsergebnisse weisen in eine ähnliche Richtung: Baumann (2012: 61) konnte bspw. hinsichtlich der religiösen Organisation von zugewanderten vietnamesischen Buddhist*innen und tamilischen Hindus aufzeigen, dass ein Mangel an religiösen Spezialisten neue Räume für Frauen im rituellen Bereich öffnet, die ihnen in den Herkunftsländern verwehrt bleiben würden (ebd.). Dass sich im rituellen Bereich in Moscheen neue Räume für Frauen eröffneten, konnte ich auch in meiner Feldforschung beobachten, insbesondere im Zusammenhang mit etablierten Frauengruppen und der Einweisung von jungen Mädchen in religiöse Riten

4 Für eine detaillierte Übersicht der muslimischen Verbände siehe Schneuwly Purdie/Tunger-Zanetti 2017: 686-687. 
und Schriften. Zudem stellte ich fest, dass Frauen teilweise auch repräsentative Aufgaben übernehmen, bspw. Führungen an Anlässen wie am »Tag der offenen Moschee« bzw. der »Nacht der Religionen« oder dass gar eine Moschee an einem »runden Tisch der Religionen « durch eine Frau vertreten wurde (Feldprotokoll 8.11.2014). Bei den Frauen, die repräsentative Aufgaben übernahmen, handelte es sich - wohl nicht zuletzt aufgrund ihrer fundierten Deutschkenntnisse - fast ausschliesslich um Secondas oder aber Konvertitinnen. An der rituellen Einweisung von jungen Mädchen und Frauen waren, wie ich beobachten konnte, auch Frauen der sog. »ersten Generation« von Zugewanderten beteiligt.

\subsection{Anknüpfungspunkte: Forschung zu adoleszenten Secondas*os muslimischen Glaubens im Kontext des gesellschaftspolitischen Islamdiskurses in der Schweiz}

Wie bereits erläutert, wurde trotz des mit hoher Emotionalität geführten aktuellen Islamdiskurses bisher in der Schweiz auffallend wenig zu biografischen Erfahrungen von adoleszenten Muslim*innen geforscht, insbesondere zu denen von jungen Frauen der sogenannten »zweiten Generation«. Unzureichende Untersuchungen zu bildungsbiografischen Verläufen von religiös orientierten adoleszenten Secondas ergeben die eigentliche Forschungslücke. Dabei bildet gerade das »adoleszente Suchen nach Neuem« (Mey/Rorato 2010: 14) unter den Bedingungen von Migration eine (bildungs-)biografische Herausforderung (vgl. hierzu auch King/Koller 2009b). Nicht zuletzt deshalb, weil diese Suche eingebunden ist in »soziale Verhältnisse, in denen nicht nur Kapitalien, sondern auch soziale Anerkennung ungleich verteilt und vielfache Mechanismen der Reproduktion von sozialer Ungleichheit am Wirken sind« (ebd.). Anlehnend an King (2004: 28ff.) begreife ich die Phase der Adoleszenz als »Möglichkeitsraum« (Holzkamp 1983), in welcher in Auseinandersetzung mit dem >bisherigen eigenen Leben - und besonders mit der familialen Herkunft(-sgeschichte) - in Umgestaltungsprozessen potenziell neue, eigene Lebensentwürfe entwickelt und neue Perspektiven gewonnen werden können (King 2004: 28ff.).

Ungeachtet der eher bescheidenen Forschungslage in der Schweiz zu biografischen Erfahrungen religiös orientierter Secondas muslimischen Glaubens im Kontext von Bildungsprozessen existieren etliche Studien, an welche die vorliegende Untersuchung anschliessen kann. Zentrale Anknüpfungs- 
punkte bilden sozialwissenschaftliche Untersuchungen $\mathrm{zu}$ muslimischen Frauen der sog. »ersten Generation" von Zugewanderten in der Schweiz (Schild 2010, Baghdadi 2012, 2010) sowie neuere religionswissenschaftliche und sozialanthropologische Studien, welche die Vielfältigkeit der Zugehörigkeiten und Grenzziehungsprozesse von jugendlichen Muslim*innen in der Schweiz untersuchen (Allenbach/Müller 2017, Allenbach 2016, 2012, 2011, Allenbach/Herzig 2010, Baumann 2019 (im Erscheinen), Baumann et al. 2017, Dahinden et al. 2012, 2011, 2010, Endres et al. 2013, Müller, 2013, 2010).

Es bestehen Hinweise darauf, dass der gesellschaftspolitische Islamdiskurs einen starken Einfluss auf identitäre Aushandlungsprozesse und Repräsentationsstrategien junger Muslim*innen hat (vgl. dazu Baumann 2019 (im Erscheinen), Behloul 2011; Allenbach et al. 2010: 2). Dass sich solche Zuschreibungsprozesse verstärkt auf die Selbstrepräsentationen junger Muslim"innen auswirken, können die Ergebnisse dreier Projekte des Nationalen Forschungsprogramms »Religionsgemeinschaften, Staat und Gesellschaft» (NFP58) aufzeigen (Allenbach et al. 2010; Dahinden et al. 2010, Behloul 2011):

Die Forschungsgruppe um Giordano (Allenbach et al. 2010: 9) stellt fest, dass adoleszente Muslim*innen als Reaktion auf ihre Ausschlusserfahrungen aufgrund ihrer Religionszugehörigkeit verschiedenste Strategien entwickeln, um ihren multiplen Zugehörigkeiten (multiple belonging) Sinn zu verleihen. So setzen sie bspw. unterschiedliche Aspekte ihrer Zugehörigkeiten (»Muslim«; »Ausländerin«, »eingebürgert« etc.) flexibel ein, um sie je nach Kontext und Situation zu betonen und sich zu >Insidern $\mathrm{zu}$ machen (ebd.: 10).

Dahinden et al. (2010: 9) untersuchen in einer weiteren empirischen Studie ebenfalls Strategien von jungen Muslimen, mit etablierten Differenzlinien umzugehen. Sie typisieren hierbei vier derartige Umgangsstrategien: (1) der Versuch, hierarchische Machtverhältnisse der Differenz umzudeuten und dadurch das prekäre gesellschaftliche Anerkennungsverhältnis zu unterlaufen, bspw. durch die positive Aufladung der eigenen Herkunft, die als kulturell bereichernd dargestellt wird (Dahinden et al. 2010: 9) oder (2) die Mobilisierung einer reaktiven Männlichkeit, bspw. durch die provokative offene Infragestellung der Geschlechtergleichheit, mithilfe derer junge Männer versuchen, ihr prekäres Anerkennungsverhältnis zu unterlaufen, um über ihren Status als Mann mehr Selbstbewusstsein zu demonstrieren (»reaktive Ethnizität«) (ebd.: 10) oder schliesslich (3) Grenzüberschreitungen bzw. Assimilationsbemühungen, die sich dadurch auszeichnen, dass die Jugendlichen versuchen, sich vollkommen von der eigenen Herkunft zu distanzieren (ebd.: 10). Besonders hervorzuheben ist das Ergebnis der Forschungsgruppe, dass die eta- 
blierten Differenzlinien von den Jugendlichen nicht etwa als solche infrage gestellt werden; hiermit wird deutlich, welche starken Machtkonstellationen mit solchen »Grenzziehungsprozessen« einhergehen (ebd.: 9).

Eine neuere Studie gelangt diesbezüglich jedoch zu einem anderen Ergebnis: In ihrer Untersuchung zu transnationalisierten Peer-Communities in Bern West stossen Oester und Brunner auf Jugendliche, welche die Differenzlinien des dominanten Diskurses zwischen Etablierten und Aussenseitern nicht akzeptieren und einen Gegendiskurs generieren (Oester/Brunner 2015: 127, Oester/Brunner 2014: 101, 115).

Behloul (2011) zeigt schliesslich auf, wie der Islamdiskurs auch unter Muslim*innen selbst zu unerwarteten Abgrenzungsstrategien führen kann, im Sinne einer strategischen Aufwertung ethnischer bzw. religiöser Zugehörigkeit. Die Repräsentationsstrategien bosnischer muslimischer Gruppierungen der Schweiz in Bezug auf den Islamdiskurs zeigen, wie diese den spezifisch europäischen Charakter des bosnischen Islam $<$ betonen und diesen als eine Art `Garantie gegen religiösen Extremismus` akzentuieren (2011: 316).

Mittlerweile liegt eine Handvoll Studien vor, die sich explizit mit der (religiösen) Verortung jugendlicher Muslim*innen der zweiten Generation in der Deutschschweiz befassen: Eine religionswissenschaftliche Studie des Zentrums für Religionsforschung der Universität Luzern (ZRF) zu muslimischen Jugendgruppen und Bildung von zivilgesellschaftlichem Sozialkapital in der Schweiz (Endres et al. 2013) fokussiert auf die Organisation und gesellschaftliche Partizipation junger Muslim*innen. Aufbauend auf den theoretischen Ansatz des zivilgesellschaftlichen Sozialkapitals (civic social capital) von Stepick kann die Untersuchung belegen, dass muslimische Jugendgruppen eigendefinierte Räume bilden, in denen sich die Jugendlichen vielfältige Unterstützung holen können, aber auch Ausschlusserfahrungen verarbeiten sowie nützliche persönliche Fähigkeiten in selbstdefinierter Weise erlernen bzw. erwerben können. Die Studie zeigt auf, dass eine Einbindung in religiöse Jugendgruppen die gesellschaftliche Partizipation junger Muslim*innen eher fördert als - wie von manchen politischen Akteuren befürchtet - behindert (Endres et al. 2013: 77-79).

Eine neuere Studie des Zentrums für Religionsforschung (ZRF) der Universität Luzern (Baumann et al. 2017) befasst sich mit der Frage, an welchen religiösen Autoritäten sich junge Muslim*innen in der Schweiz orientieren. Die Ergebnisse zeigen, dass junge Muslim*innen verschiedenste Angebote und Medien nebeneinander nutzen. Zudem weisen die Forschenden nach, dass Erklärungen und Auslegungen von Eltern, Freunden und Vertrauens- 
personen gegenüber dem Einfluss von Imamen oder Internetpredigern eine bisher unzureichend beachtete, bedeutungsvolle Rolle spielen. Die Jugendlichen entwickeln laut dem Autor*innenteam auf der Suche nach »Autoritätsangeboten «klare, selbstständige Kriterien und interpretieren die Religion der Eltern individuell, kritisch und eigenständig (2017: 2).

Für die vorliegende Untersuchung äusserst relevant ist auch die Studie Migration und Religion (2013) der Sozialanthropologin Müller. Müller (2013) zeigt in ihrer umfassenden, theoretisch reichhaltig untermauerten Untersuchung zu männlichen jugendlichen Muslimen und Hindus der zweiten Generation auf, dass diese sich mitunter zwangsläufig im Spannungsfeld zwischen »fremd« und »eigen« verorten müssen. Die Jugendlichen bedienen sich Müller zufolge dafür unterschiedlichster Strategien: Während die einen sich Aufgrund von Ausschlusserfahrungen einer ethnischen bzw. religiösen Gesellschaft annähern, »wobei sich die Fremdzuschreibungen zu einer Sichselbsterfüllenden-Prophezeiung zu entwickeln scheinen « (ebd.: 282), stellen andere Jugendliche die dominanten Differenzlinien infrage und leisten mittels ihrer Positionierung Widerstand (ebd.). Müller unterstreicht die von Schiffauer (2004) aufgezeigte Tendenz, dass sich die Aushandlungsprozesse zwischen den Generationen unter den Bedingungen der Migration für die Jugendlichen weiter verkomplizieren würden (Müller 2013: 284), insbesondere da seitens der »ersten Generation« die Tendenz besteht, die eigenen Werte zu bewahren (ebd.). Ebenfalls analysiert Müller die Narrationen der Jugendlichen über deren Zugehörigkeit. Sie regt diesbezüglich an, zwischen einer emotionalen und einer zivilgesellschaftlichen Ebene von Zugehörigkeit zu unterscheiden (ebd.: 282-283) und illustriert dies an der von den Jugendlichen verwendeten Zuschreibung der »Eidgenossen« (ebd.: 282) vs. Schweizer Bürger: Die männlichen Jugendlichen, welche den Begriff des »Eidgenossen« als Zuschreibung verwenden, verstehen sich laut Müller durchaus als Bürger der Schweiz, jedoch nicht als »Eidgenossen«. Die Zuschreibung »Eidgenosse« symbolisiert für die Jugendlichen die »Einheimischen« ohne »Migrationshintergrund« (ebd.: 283). Als weiteres Resultat weist Müller nach, dass die von ihr untersuchten männlichen Jugendlichen sich fortwährend mit dem stereotypisierenden Verdacht der Frauenunterdrückung konfrontiert sehen. Sie versteht die vehemente Befürwortung der Gleichberechtigung der Geschlechter als Strategie dieser Jugendlichen, sich dieser Zuschreibung entgegen $\mathrm{zu}$ stellen und ihre Zugehörigkeit zur Schweizer Gesellschaft zu untermauern (ebd.: 284). Auch kann Müller nachweisen, dass die Religionsausübung für die Jugendlichen eine sehr unterschiedliche Rolle einnimmt. Sie sieht hierbei 
Stolz' These der Deinstitutionalisierung (Stolz 2012) bestätigt. Ebenfalls kann sie in Bezug auf Zugehörigkeit feststellen, dass die untersuchten muslimischen und hinduistischen jungen Männer ihre Religionszugehörigkeit »bewusst wahrnehmen, da sie diese im Migrationskontext immer wieder erneuern, vergegenwärtigen und begründen müssen« (Müller 2013: 283).

Abschliessend gelangt Müller zu dem interessanten Ergebnis, dass bei hinduistischen männlichen Jugendlichen im Gegensatz zu den untersuchten muslimischen Jugendlichen weniger die Religion als die Hautfarbe als Kriterium des sozialen Ausschlusses dient (ebd.). Daraus zieht sie folgenden Schluss: "Die Beobachtung, dass sich Religion zu einem wichtigen gesellschaftlichen Differenzfaktor entwickelt hat, scheint sich also in der Schweiz nur für Muslime zu bewahrheiten, nicht jedoch für Hindus« (ebd.).

Ausserhalb der Schweiz untersuchen zahlreiche empirische Studien identitäre Aushandlungsprozesse und Identifikationen muslimischer Frauen der ersten oder der zweiten Generation sowie ihre Religiosität und religiöse Praxis. Als weitgehender Konsens der Studien kann resümiert werden, dass Secondas*os ein unterschiedliches Verhältnis zu Religion haben, und dass sich nur ein kleinerer Teil als »religiös« bezeichnet. Die Soziologin Nökel untersucht in einer vielbeachteten Studie Identitätskonstruktionen adoleszenter religiös orientierter Musliminnen der sog. »zweiten Generation« in Deutschland (2002). Sie rekonstruiert einen spezifischen Typus adoleszenter Kopftuch tragender Muslim*innen - »Neo-Muslimas« (ebd.: 31) -, deren Islamisierung sie als »weibliche Identitätsstrategie« beschreibt (ebd.: 25). »Neo-Muslimas« setzen Nökel zufolge auf einen »Wandel bzw. eine Ausdifferenzierung innerhalb des in Deutschland lokalisierten Islam und auf ein selbstbewusstes Verständnis als Muslimas« (ebd.: 16) und verstehen ihre Islamisierung als »Akt der persönlichen Selbstsouveränität«. Die Religionswissenschaftlerin Klinkhammer (2000) untersucht in einer Studie im Anschluss an Weber die >religiöse Lebensführung، sunnitischer Türkinnen der zweiten Generation in Deutschland und stellt fest, dass die von ihr befragten Frauen ihre Auseinandersetzung mit dem Islam rekurrierend auf die Fremdzuschreibung als Türkinnen und Muslim*innen führen (Klinkhammer 2000: 284).

Schröter analysiert in einer über weite Strecken äusserst kulturalistisch anmutenden Studie - Mohammeds deutsche Töchter (2002) - Bildungsprozesse junger Musliminnen in Deutschland »bei Kulturwechsel« (ebd.: 11). Sie kommt zu dem Ergebnis, dass sich die meisten jungen Frauen hinsichtlich ihrer Bildungswege kritisch mit religiösen Bezügen auseinandersetzen (ebd.: 275-76). 
Hummrich eröffnet in ihrer Studie Bildungserfolg und Migration (2009) eine Perspektive, die weg von einer defizitorientierten Sichtweise hin zu einer ressourcenorientierten, »chancenhaften Betrachtung« (Hummrich 2009: 248) von Religiosität im Zusammenhang mit (Bildungs-)Biografien führen soll. Sie konstatiert, dass »auch in kollektiven Orientierungen bei Migranten jugendliche Religiosität mit einer reflexiven Auseinandersetzung mit gesellschaftlicher Pluralisierung einhergeht, die neben individuellem Bewältigungspotenzial auch kollektive Orientierungsmuster bietet « (ebd.: 248-249).

Bezüglich der gesellschaftlichen Selbstverortung und der Rolle der Religion in biografischen Prozessen finden sich in Deutschland auch Studien, die diese identifikatorischen Aushandlungsprozesse zu typisieren versuchen (Wensierski/Lübcke 2012, 2011, 2007; Karakaşoğlu-Aydin 2000; Tietze 2001). Ausgehend von der erkenntnisleitenden Hypothese, dass »der religiös-kulturelle Kontext der muslimischen Herkunftsmilieus der Jugendlichen einen prägenden und strukturierenden Einfluss auf die Alltags- und Lebenswelten, die Orientierungsmuster und die biografischen Lebensentwürfe der Jugendlichen hat « (Wensierski/Lübcke 2011: 94), befragen Wensierski und Lübcke in einer grossangelegten qualitativen Studie 107 muslimische Jugendliche der zweiten Generation in Bezug auf ihre Aufwachsprozesse, die Struktur und Prozesse der Jugendphase, sowie Alltags- und Jugendkulturen (Wensierski/Lübcke 2012, 2011, 2007, Lübcke 2007). Sie erstellen eine Typologie, welche den Pluralismus dieser Jugendbiografien zum Ausdruck bringen soll (Wensierski/Lübcke 2011: 94-95): Basierend auf der nicht unproblematischen Annahme $e^{5}$ eines »muslimischen Habitus« (Kelek 2002: 64) konstruieren sie fünf Typen muslimischer Jugendbiografien: 1. säkularisierter jugendbiografischer Verselbstständigungsprozess, 2. bi-kulturelle Identitätsproblematik, 3. Re-Islamisierung im Gefolge der Adoleszenz, 4. islamisch-selektiv modernisierte Jugendbiografie und 5. anomisch-delinquente Migrantenbiografie. Wensierski und Lübcke argumentieren, dass muslimischen Jugendbiografien »das Spannungsfeld zwischen Mehrheitsgesellschaft und Migrantencommunity als biografisches Problem zwischen säkularer Mehrheitskultur und islamischer Herkunftskultur« (Wensierski/Lübcke 201: 95) inhärent sei. Sie suchen mittels Fallanalysen zu belegen, wie biografische Identitätskrisen im Verlauf der Adoleszenz ausgetragen und entschieden werden (ebd.). 
Auch in Österreich existiert eine Reihe von (allerdings quantitativ ausgerichteten) soziologischen Studien, die sich mit der gesellschaftlichen Teilhabe der »zweiten Generation « von Muslim*innen in Österreich befassen (Weiss et al. 2016, 2014, Weiss 2007).

Weitere Anknüpfungspunkte bieten Killian und Johnson (2006), die identitäre Aushandlungsprozesse von Maghrebinerinnen der sog. »ersten Generation« von Zugewanderten in Paris untersuchen. Die Forscherinnen stellen fest, dass muslimische Frauen in Frankreich besonders gewichtigen, historisch bedingten »Othering «- Prozessen ausgesetzt sind und als »the ultimate >other« konstruiert werden (2006: 61). Im Laufe ihrer Interviews bemerken sie, dass auffällig viele Gesprächspartnerinnen, wenn sie nach einer Selbstbeschreibung gefragt wurden, speziell betonen und insistieren, sie seien nicht >immigrants` (ebd.: 72). Kilian und Johnson argumentieren, dass die Frauen, indem sie sich explizit von der Zuschreibung simmigrant< distanzieren, mithilfe einer »Not-me«-identity« eine gesellschaftliche Fremdzuschreibung zurückweisen, welche sie einer Gruppe mit niedrigem sozialen Status zuschreiben und ihnen so keinen Raum für Aushandlung lassen würde (ebd.). Durch die Ablehnung dieser Zuschreibung versuchen sie sich einer identitären Fremdverortung zu widersetzen und Kontrolle über diese Zuschreibungsprozesse zu erlangen (ebd.: 75). Die Ergebnisse von Kilian und Johnson zu Muslim*innen der sog. »ersten Generation« in Paris sind ungeachtet unterschiedlicher Zugänge und Forschungskontexte äusserst ähnlich zu den Ergebnissen der Studien von Schild (2010) und Baghdadi (2012, 2010) zu Muslim*innen der »ersten Generation« von Zugewanderten in der Schweiz: Die Befragten rekurrieren in ihrer Selbstpositionierung auf das stereotype Bild »der Muslimin«, um sich selbst davon abzugrenzen.

Eine neuere Ethnografie von Bendixsen über junge Musliminnen in Berlin (Bendixsen 2013) bildet einen weiteren zentralen Anknüpfungspunkt für die vorliegende Untersuchung. Bendixsen zeigt auf, wie die Verortung als »religious subject « (ebd.: 283) die jungen Frauen vor vielfältige Herausforderungen stellt:

»Nonetheless, crafting the Self as a religious subject brings with it restrictions, obligations, and (potential) group identification, which are all reinforced by the excessive public focus on Muslim woman and the headscarf. For these women, the crafting of a religious Self also takes place within a context of representing Islam, at the local, national and global level. (...). As young women are deepening their religious orientation, they face their own 
and others' expectations that they also take on a role as representatives and transmitters of the meaning of Islam in twenty-first century Cermany. The consequences that this responsibility has in the youths' everyday life however, cannot be overstated. Social pressure from themselves, their peers, and other Muslims becomes a component of their efforts to develop into Good Muslims, as defined by an Islamic discourse situated in a sociohistorically defined context« (ebd.).

Bendixsen unterstreicht, dass ein stereotypisierendes Bild einer (nicht-liberalen) religiösen jungen Muslimin, die von patriarchalen religiösen Strukturen gefangen und unterdrückt und somit handlungsunfähig sei, komplett ignoriere, welch komplexe Prozesse und "politics of the religious self « der religiösen Identifikation bei den jungen Musliminnen der sog. »Zweiten Generation« stattfinde (ebd.: 290).

Bendixsen verdeutlicht, wie die jungen Frauen als Strategie eine von ihnen als "puren Islam« beschriebene Religion zu leben versuchen, um sich vom »ethnisierten«, traditionellen Islam ihrer Eltern abzugrenzen (ebd.: 281, 286). Sie sieht dies einerseits als gesellschaftliche (generationale) Selbstpositionierungsstrategie der religiösen Muslimas unter den Bedingungen des Islamdiskurses, andererseits aber auch als urbanes Phänomen (ebd.: 287). Sie erkennt im anonymen urbanen Raum grössere Möglichkeiten für die jungen Frauen, sich einerseits in einem vom religiösen Umfeld ihrer Eltern losgelösten religiösen Milieu zu bewegen. Andererseits biete der urbane Raum Möglichkeiten, religiöse Lebenspraxis und jugendkulturellen Lifestyle $\mathrm{zu}$ verbinden (ebd. 287, 288).

Von spezieller Bedeutung für vorliegendes Projekt - auch in Bezug auf die theoretische Herangehensweise - ist der Artikel der deutschen Erziehungswissenschaftlerin Riegel (2011), der sich speziell mit Religion als Differenzmarker im pädagogischen Bereich befasst. Riegel analysiert darin die Herstellungsprozesse von Differenz im (sozial-)pädagogischen Sprechen über Jugendliche mit »Migrationshintergrund « im deutschen Kontext (2011: 319). Hierbei nimmt sie auf die theoretischen Konzepte der Intersektionalität und Interdependenz Bezug. Sie gelangt zu dem Schluss, dass »Prozesse des Othering sowie anti-muslimische, rassistische, heterosexistische Diskurse und Repräsentationen« (ebd.: 337) in (sozial-)pädagogischen Prozessen allgegenwärtig seien und dass diese Differenzmarker nicht einzeln, sondern ineinander verschränkt auftreten und sich so "gegenseitig beeinflussen und bestärken« (ebd.). Als ein weiteres Ergebnis streicht sie heraus, dass in den 
von ihr untersuchten Erzählungen der Jugendarbeiter*innen über Jugendliche mit »Migrationshintergrund « Differenzlinien vor allem entlang kulturellreligiöser Grenzen konstruiert würden. Riegel zeigt auf, wie Religion in diesem Kontext zum Differenzmarker wird: Sie stellt fest, dass in Erzählungen von Jugendarbeiter*innen speziell muslimische Jugendliche als »von der >deutschen Kultur< (...) abweichend« (ebd.: 321) konstruiert wurden. Ebenso verdeutlicht sie, wie sich diese Differenzen anhand gängiger Differenzmarker manifestieren, so zum Bespiel anhand von Erzählungen über sunterdrückteく muslimische Mädchen, patriarchale Geschlechterrollenvorstellungen und gewalttätige Konflikte.

Inwiefern sich religiös orientierte Secondas muslimischen Glaubens in der Deutschschweiz ebenfalls mit der Differenzkategorie »Muslimin« im Bildungskontext konfrontiert sehen und wie sich dies auf ihre Bildungsbiografien auswirkt, ist Gegenstand der vorliegenden Untersuchung.

\subsection{Schweizerisches Bildungssystem im Kontext von sozialer Ungleichheit}

Im Folgenden soll in einem Überblick kurz auf das Bildungssystem der Schweiz eingegangen werden (Kap. 3.3.1). In einem zweiten Kapitel (Kap. 3.3.2) werden Forschungen $\mathrm{zu}$ Jugendlichen mit »Migrationshintergrund « in schulischen Übergängen fokussiert, um dergestalt die institutionellen Bedingungen zu umreissen, innerhalb derer sich junge Secondas behaupten müssen.

\subsection{1 Überblick: Gliederung des Bildungssystems in der Schweiz}

Das schweizerische Bildungssystem zeichnet sich in erster Linie durch seine föderalistische Organisation und durch seine frühe Selektion aus. Das Bildungswesen in der Schweiz ist von der obligatorischen Schule bis zur Tertiärstufe (Hochschulen und höhere Berufsbildung) zwar Staatsaufgabe, die Verantwortung für die Bildungsgänge liegt jedoch aufgrund des Föderalismus primär bei den Kantonen. Im nachobligatorischen Bildungsbereich, der allgemeinbildende Schulen, Berufsbildung und Hochschulen umfasst, teilen sich Bund und Kantone die Verantwortung für das öffentliche Bildungswesen (BFS 2017a). 
Die dezentralisierte Organisation des Bildungswesens erklärt die relativ grosse Heterogenität seiner Strukturen. Die strukturelle Vielfalt des Bildungssystems beinhaltet ihrerseits neben positiven Aspekten wie der Angepasstheit an lokale Bedürfnisse auch die Problematik der Vergleichbarkeit, der Mobilität und der Chancengerechtigkeit (SKBF 2014: 43). Die Bundesverfassung verpflichtete deshalb die Kantone im Jahre 2006 durch die neu in die Verfassung aufgenommenen »Bildungsartikel« zur Harmonisierung hinsichtlich des Schuleintrittsalters, der Schulpflicht, der Dauer und Ziele der Bildungsstufen sowie der Übergänge und der Anerkennung von Abschlüssen (ebd.; BV Art. 62, Abs. 4). Mit dem anschliessend verabschiedeten sogenannten HarmoS-Konkordat - einer interkantonalen Vereinbarung über die Harmonisierung der obligatorischen Schule - gab die schweizerische Konferenz der kantonalen Erziehungsdirektoren (EDK) 2007 ihrem Willen zur Umsetzung dieser »Bildungsartikel« Ausdruck (ebd.). Das Konkordat trat 2009 in Kraft und legte eine Frist von sechs Jahren bis zur Umsetzung fest, welche am 31. Juli 2015 ablief (SKBF 2014: 43).

Im Folgenden soll eine Übersicht des EDK das schweizerische Bildungssystem schematisch darstellen. Die Grafik zeigt in vereinfachter Form das Bildungssystem der Schweiz mit nebenstehender Klassifizierung gemäss der internationalen Standardklassifikation der Bildung (International Standard Classification of Education «, ISCED $2011^{6}$ ). Es wird zwischen folgenden Bereichen des Bildungssystems unterschieden:

- Vorschulstufe (ISCED o),

- Primarstufe (ISCED 1),

- Sekundarstufe I (ISCED 2),

- Sekundarstufe II (ISCED 3 und 4),

- Tertiärstufe (ISCED 5 und 6),

- Heil- und Sonderpädagogik.

Der Besuch der öffentlichen Schule erfolgt in der Schweiz unentgeltlich. 95 Prozent der Kinder besuchen eine öffentliche Schule, lediglich 5 Prozent lassen sich in einer Privatschule ausbilden (educa.ch 2017a).

6 Die »International Standard Classification of Education« (ISCED) ist ein Klassifizierungssystem der UNESCO, das Schultypen und Schulsysteme entlang einheitlicher »Level« (1-6) zugunsten einer internationalen Vergleichsmöglichkeit charakterisiert und klassifiziert (Unesco 2012). 
Abbildung 1: Diese Grafik wurde von der Schweizerischen Konferenz der kantonalen Erziehungsdirektoren (EDK) mit freundlicher Genehmigung zur Verfügung gestellt (vgl. EDK 2017a). Der EDK obliegt das uneingeschränkte Copyright.

\section{DAS BILDUNGSSYSTEM SCHWEIZ}

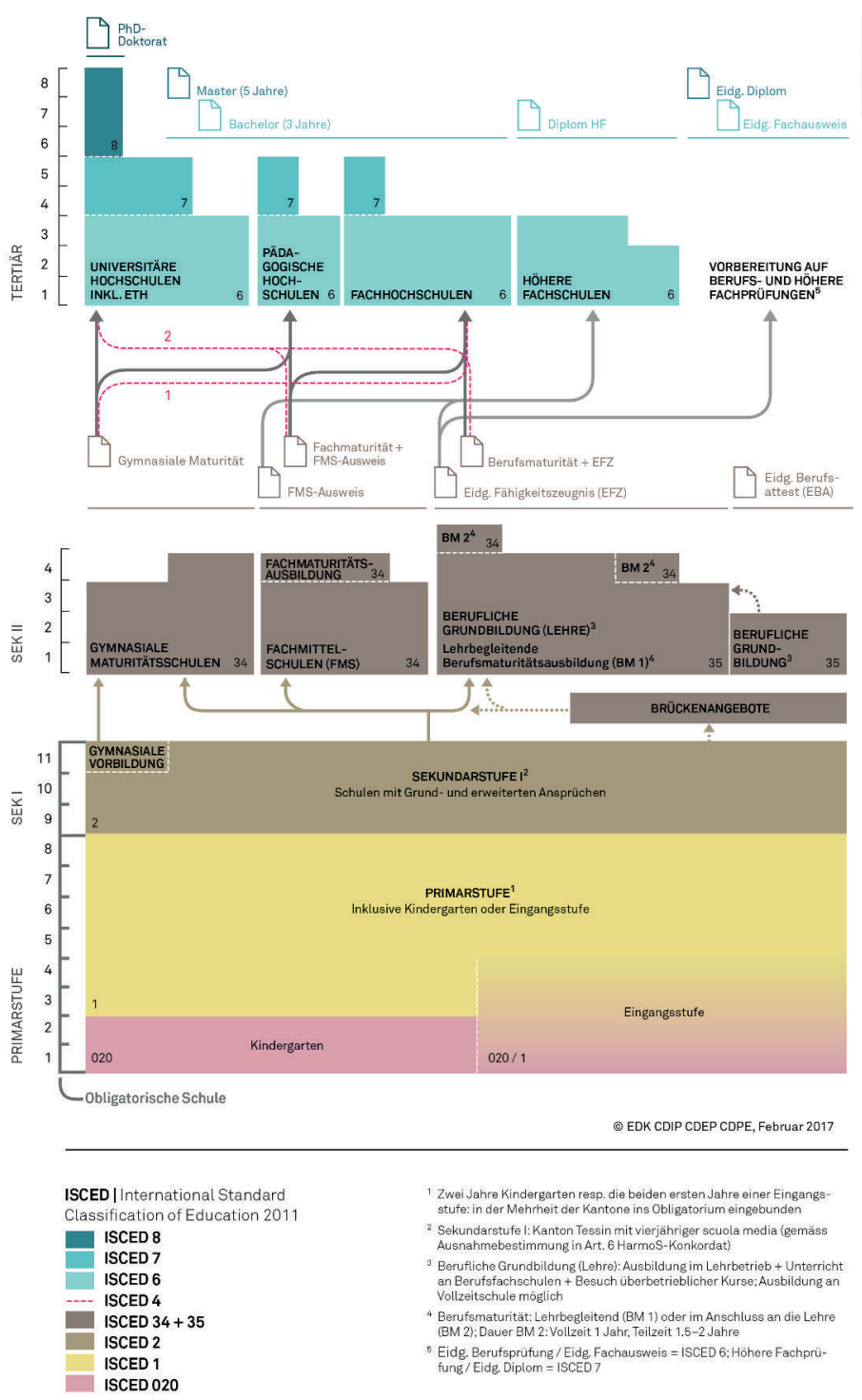

: Passerelle 2: Berufsmaturität ode Hochschule $\rightarrow$ Universitare

; Passerelle 1: Gymnasiale 1. Maturität $\rightarrow$ Fachhochschule (Berufs praktikum 
Beim Kindergarteneintritt sind die Lernenden in der Regel vier Jahre alt. Die Schulpflicht ${ }^{7}$ dauert elf Jahre und umfasst die Vorschul- und Primarstufe (acht Jahre, inkl. der in den meisten Kantonen obligatorischen zwei Jahre Kindergarten) und die Sekundarstufe I (drei Jahre; ausser im Kanton Tessin, wo diese vier Jahre umfasst) (ebd.).

Anschliessend erfolgt der Übertritt in die Sekundarstufe II. Unterteilen lässt sich die Sekundarstufe II in allgemeinbildende und berufsbildende Ausbildungsgänge (educa.ch 2017b).

Die Mehrheit der Jugendlichen begibt sich in eine berufsbildende Ausbildung, in der sie einen Beruf erlernen (ebd.). Mehrheitlich absolvieren die Jugendlichen eine Berufslehre in Betrieben, die mit schulischem Unterricht in der Berufsschule ergänzt wird (sog. Duales System der Berufsbildung). Eine Berufslehre kann jedoch auch im Vollzeitangebot in schulischen Einrichtungen stattfinden (ebd.) Die Duale Berufsausbildung mit den Lernorten Betrieb und Schule ist traditionell stark im deutschschweizerischen Bildungssystem verankert (Imdorf 2011: 261). Berufsausbildungszertifikate regulieren den Eintritt in den qualifizierten Arbeitsmarkt; die Arbeitsmarktchancen von Arbeitnehmer*innen ohne Berufsqualifikation haben sich in den letzten Jahrzehnten massiv verschlechtert. Eine abgeschlossene berufliche Ausbildung garantiert zwar keine Stelle, stellt jedoch einen entscheidenden Faktor für die späteren beruflichen Möglichkeiten der Ausgebildeten dar (ebd.).

Die allgemeinbildenden Ausbildungsgänge umfassen Gymnasien und Fachmittelschulen, sie qualifizieren ihre Abgänger*innen nicht direkt für einen Beruf, sondern bereiten auf die Tertiärstufe vor (educa.ch 2017b).

Die Tertiärstufe schliesst eine relativ breite Palette von Ausbildungen entweder an Hochschulen oder im Rahmen von höherer Berufsbildung ein. Die Schweiz verfügt über drei Typen von Hochschulen: universitäre Hochschulen, Fachhochschulen und Pädagogische Hochschulen. Die Zulassung an Hochschulen erfolgt in der Regel durch eine Maturität oder durch die eidgenössische Berufsmaturität (andere Zulassungen sind möglich) (educa.ch 2017c). Die höhere Berufsbildung auf der anderen Seite beinhaltet eine Spezialisierung bzw. ein Vertiefen des Fachwissens nach abgeschlossener beruflicher Grundbildung. Die höhere Berufsbildung schliesst eidgenössische Berufsprüfungen und eidgenössische höhere Fachprüfungen und Abschlüsse höherer Fachschulen ein (ebd.). 
Kinder und Jugendliche mit besonderem Bildungsbedarf werden bis zum 20. Lebensjahr mittels sonder- bzw. heilpädagogischen Angeboten und Massnahmen unterstützt. Die Regelung dieser Angebote erfolgt kantonal (educa.ch 2017d).

Kennzeichnend für das schweizerische Bildungssystem ist dessen frühe Selektion: Neben Deutschland selektiert kaum ein Land so früh und so stark wie die Schweiz (Müller 2013: 66). Auf der anderen Seite zeichnet sich das Bildungssystem der Schweiz durch seine hohe Durchlässigkeit aus. Es existieren ganz unterschiedliche Wege, in eine Ausbildung oder Schule ein- oder überzutreten oder eine Ausbildung nachzuholen (EDK 2017b).

Die für den Bildungsverlauf relevanteste Selektion geschieht in der Sekundarstufe I, die sich je nach Kanton in zwei bis vier verschiedene Schultypen gliedert. Grob können zwei Typen unterschieden werden: Solche, die in "Grundanforderungen« ausbilden, und solche, die »erweiterten Anforderungen« und Ansprüchen gerecht werden und die im Gegensatz zu den Schultypen mit »Grundanforderungen« den Zugang zu Maturitäts- und Fachmittelschulen eröffnen (Müller 2013: 66). Diese frühe Selektion unterminiere die Chancengerechtigkeit, so die Kritik (z.B. u.a. Haenni Hoti 2015, Becker 2010, Hupka-Brunner et al. 2011, Kronig 2007). Als weitere Schlüsselstelle der Selektion gilt der Eintritt in die nachobligatorische Ausbildung auf Sekundarstufe II, also die Schwelle zur nachobligatorischen Ausbildung. Müllers Einschätzung (2013: 66.) ist beizupflichten, wenn sie feststellt, dass die Ausbildung auf Sekundarstufe II in den letzten Jahren zur Selbstverständlichkeit geworden ist und »als weitere Schlüsselstelle für die Zukunft der Auszubildenden« (ebd.) betrachtet werden kann.

\subsubsection{Jugendliche mit »Migrationshintergrund « in Übergängen im Bildungssystem in der Schweiz}

Als besondere Herausforderung in Bezug auf Bildungswege gelten die schulischen Übergänge bzw. die schulische Selektion. Die Art und Weise, wie bildungsbiografische Übergänge gemeistert wurden, spielte denn auch eine zentrale Rolle in den bildungsbiografischen Narrationen der untersuchten jungen Frauen in vorliegender Studie.

In diesem Kapitel soll es nicht darum gehen, den Forschungsstand des breit beforschten Feldes über bildungsbiografische Übergänge von Jugendlichen mit »Migrationshintergrund« vollumfänglich auszuleuchten, sondern darum, das für die vorliegende Untersuchung relevante Feld zu umreissen. 
Wie verschiedenste Studien zeigen, manifestieren sich in Übergängen unterschiedliche Mechanismen der Reproduktion sozialer Ungleichheit besonders deutlich; gleichzeitig werden Prozesse der Ausdifferenzierung und Hierarchisierung wirksam, die Chancen entlang bestimmter Differenzkategorien (wie z.B. Schicht, Klasse, Geschlecht, »Migrationshintergrund«, Wohnort etc.) ungleich verteilen (Hadja/Hupka-Brunner 2013, Becker et al. 2013, Becker/Solga 2012, Kronig 2013, Kronig 2007, Kronig et al. 2000).

Etliche Studien verdeutlichen denn auch übereinstimmend, dass Lernende »mit Migrationshintergrund ${ }^{8}$ der »zweiten Generation« verglichen mit solchen ohne »Migrationshintergrund « in den höheren Bildungsstufen unterund in den niedrigen Bildungsstufen überrepräsentiert sind (u.a. BFS 2017b, Hadjar/Hupka-Brunner 2013a, Meyer 2009 etc.).

Im Jahre 2015 hatten gemäss Definition ${ }^{9}$ des BFS (2017b) 36 Prozent der Bevölkerung $a b 15$ Jahren einen »Migrationshintergrund «. Ein Drittel dieser Bevölkerungsgruppe besass 2015 die Schweizer Staatsangehörigkeit (ebd.); vier Fünftel der Personen mit »Migrationshintergrund« gehören der sogenannten ersten Generation an (d.h., sie sind selbst zugewandert), während ein Fünftel in der Schweiz geboren wurde (dazu zählen Zugewanderte der

8 Das Kriterium der Nationalität, auf dem die statistischen Bildungsanalysen des Bundesamtes für Statistik (BFS) in der Schweiz traditionell beruhen, erwies sich zunehmend als unbrauchbar, um die Bildungswege von Zugewanderten und deren Nachkommen zu erfassen (Bader/Fibbi 2012: 5). Das etwas neuere Kriterium »mit Migrationshintergrund «stellt jedoch gleichermassen ein Problem dar: Gerade in Bezug auf Bildungsstatistiken ist es äusserst relevant, wie der Begriff definiert wird, beziehungsweise, wen dieser Begriff umschliesst - sind hier Jugendliche, die in der Schweiz geboren worden sind, gemeint, die einen ausländischen Pass haben, oder (auch) Jugendliche, die einen Schweizer Pass haben, deren Eltern jedoch im Ausland geboren sind? Wie verhält es sich mit Jugendlichen mit Schweizer Pass, die im Ausland geboren wurden? Je nachdem, wie diese Gruppe definiert wird, fallen die Bildungsstatistiken unterschiedlich aus. Das Bundesamt für Statistik schlägt folgende Definition der Kategorie »mit Migrationshintergrund« vor: »Alle Personen ausländischer Staatsangehörigkeit, die eingebürgerten Schweizerinnen und Schweizer (mit Ausnahme der in der Schweiz geborenen Eingebürgerten mit Eltern, die beide in der Schweiz geboren wurden), sowie die gebürtigen Schweizerinnen und Schweizer mit Eltern, die beide im Ausland geboren wurden« (BFS 2017b).

9 »Alle Personen ausländischer Staatsangehörigkeit, die eingebürgerten Schweizerinnen und Schweizer (mit Ausnahme der in der Schweiz geborenen Eingebürgerten mit Eltern, die beide in der Schweiz geboren wurden), sowie die gebürtigen Schweizerinnen und Schweizer mit Eltern, die beide im Ausland geboren wurden« (BFS 2017b). 
sog. zweiten Generation sowie gebürtige und eingebürgerte Schweizer*innen) (ebd.). Gemäss BFS (ebd.) stellt bei fast 50 Prozent das höchste Bildungsniveau die Sekundarstufe II dar, gefolgt von 30 Prozent, deren höchster Bildungsabschluss auf der Tertiärstufe angesiedelt ist und von 20 Prozent, die lediglich über einen Abschluss der obligatorischen Schule verfügen (bei diesen Zahlen ist jedoch zu beachten, dass viele Personen zwischen 15 und 30 sich noch in Ausbildung befinden und noch über keinen höchsten Bildungsabschluss verfügen) (ebd.). Die Bevölkerung »ohne Migrationshintergrund« (gemäss der Definition des BFS 2017b) ist verglichen mit der Gesamtbevölkerung auf der Sekundarstufe II und der Tertiärstufe übervertreten und in der obligatorischen Schule untervertreten (16 Prozent). Mit 28 Prozent und 40 Prozent sind demgegenüber Personen mit »Migrationshintergrund « im Verhältnis gleichmässig auf die drei Bildungsniveaus verteilt (BFS 2017b). Bei der sog. »zweiten Generation«, um die es in dieser Studie in erster Linie geht, erreichen verhältnismässig mehr Personen einen Abschluss der obligatorischen Schule als höchstes Bildungsniveau, während solche mit einem Tertiärabschluss im Vergleich zur Gesamtbevölkerung einen tieferen Anteil aufweisen (ebd.). Verschiedene Autor*innen unterstreichen allerdings, dass der Befund, dass Lernende mit »Migrationshintergrund « in höheren Bildungsstufen unter- und in den niedrigen Bildungsstufen überrepräsentiert sind, ganz unterschiedlichen Faktoren geschuldet ist, resp. unter Einbezug verschiedenster Faktoren gelesen und entsprechend relativiert werden müsse (Müller 2013: 67, Bader/Fibi 2012, Riphan/Bauer 2007, Mey et al. 2005, Bolzmann et al. 2003). Beispielsweise muss hinsichtlich der Bildungsbeteiligung zwischen der sog. »ersten« und »zweiten Generation« von Zugewanderten unterschieden werden: Jugendliche von Zugewanderten der »zweiten Generation« sind zwar verglichen mit gebürtigen Schweizer*innen leicht schlechter positioniert, jedoch deutlich besser als Zugewanderte der »ersten Generation« (BFS 2017b, Müller 2013: 67, Mey et al. 2005). Zudem müssen hierbei die eingebürgerten Jugendlichen der sog. »Zweiten Generation« berücksichtigt werden, was das Bild relativiert, denn insbesondere im oberen Bildungssegment sind diese Jugendlichen sogar besser positioniert als die gleichaltrigen gebürtigen Schweizer*innen (BFS 2017b, Mey et al. 2005). Die statistischen Resultate fallen also insgesamt tiefer aus, wenn Eingebürgerte unter die Kategorie der Einheimischen subsumiert werden, insbesondere wenn wie in älteren Studien nach dem Kriterium der nationalen Zugehörigkeit unterschieden wird. Zudem kann davon ausgegangen werden, dass eine Einbürgerung bei höherer Bildung wahrscheinlicher ist (Müller 2013: 67). Auch zeigen Mey et al. (2005) 
auf, dass Jugendliche älterer Zuwanderungsgruppen im Bildungssystem tendenziell schlechter positioniert sind als Jugendliche neuerer Zuwanderungsgruppen. Diese Aussage gilt jedoch nicht für jugendliche Zugewanderte aus Deutschland, die partiell besser als junge Schweizer"innen positioniert seien (ebd.).

Ebenfalls muss, wie etliche Studien aufzeigen, berücksichtigt werden, dass die schlechteren Positionierungen von Jugendlichen mit »Migrationshintergrund « im Vergleich zu gebürtigen Schweizer Jugendlichen primär sozialer (und nicht »kultureller«) Natur sind (Müller 2013: 69). So stammen Jugendliche mit »Migrationshintergrund « der zweiten Generation überdurchschnittlich oft aus sogenannten »unteren Gesellschaftsschichten« und sind dadurch einerseits vermehrt verschiedensten Mechanismen sozialer Ausschlüsse ausgesetzt (ebd.). Bildungsstatistiken müssen nicht zuletzt auch deshalb unter Berücksichtigung der sozialen Herkunft gelesen werden. Eine solche Lesart wirft ein neues Licht auf die Bildungsabschlüsse von Jugendlichen mit »Migrationshintergrund«: Verschiedenste Studien belegen, dass Kinder von $\mathrm{Zu}$ gewanderten unter Einbezug der sozialen Herkunft ihre Bildungsmöglichkeiten besser nutzen als die Kinder von Einheimischen (Riphan 2007, Mey et al. 2005: 96, Bolzmann et al. 2003). Der schulische Erfolg von Jugendlichen der zweiten Generation scheint, wie Müller (2013: 69) ausführt, mit der überdurchschnittlich hohen Aufstiegsmotivation der Jugendlichen zusammenzuhängen; für diese stellt Bildung oft der einzige Weg des sozialen Aufstiegs dar. Umgekehrt könne diese Aufstiegsmotivation jedoch auch zu »überhöhten Mobilitätserwartungen, unrealistischen Bildungszielen sowie zu einem hohen Druck seitens der Eltern führen« (ebd.).

Es herrscht weitgehend Einigkeit darüber, dass komplexe Prozesse und Strukturen für das Scheitern oder den Erfolg von Bildungskarrieren ausschlaggebend sind. Das Bildungssystem trägt seinerseits über verschiedenste Mechanismen und Selektionsprozesse zur Reproduktion und Stabilisierung sozialer Ungleichheit bei (Felouzis/Charmillot 2017, Gomolla/Radke 2009, Kronig 2007, Solga 2005, Bourdieu/Passeron 1987). Die »Persistenz herkunftsbedingter Ungleichheit« (Mey 2015: 236) ist im europäischen Vergleich in Deutschland und in der Schweiz gar besonders ausgeprägt (ebd., Kronig 2013).

Wie Kronig (2013: 45ff., 2007: 211f., 2005) verdeutlicht, wirkt das Schulsystem ungeachtet entgegenlaufender bildungspolitischer Bemühungen diskriminierend. Bei Selektionsentscheiden manifestiert sich dies besonders markant: Wie Kronig empirisch zeigt, sind Selektionsentscheide nicht in ers- 
ter Linie von Leistungen abhängig, sondern werden massgeblich von anderen Faktoren wie bspw. Zugehörigkeiten geprägt. Zu den leistungsfremden Faktoren zählen weiter die Differenzkategorien Geschlecht, soziale Herkunft, Wohnort sowie nationalstaatliche Zugehörigkeit (Kronig 2005: 13). Diese Differenzkategorien beeinflussen die Benachteiligung entsprechender Gruppen (ebd.). Gleiche Leistungen führen, das gilt mittlerweile als unbestritten, nicht zum selben Bildungserfolg. Gomolla und Radke (2009) bringen diesbezüglich das Konzept der institutionellen Diskriminierung ein. Ihr Modell basiert auf verschiedenen sozialen Ungleichheitsachsen (einschliesslich derjenigen von Kronig 2005). Die institutionelle Diskriminierung stellt nach Gomolla und Radke eine besondere Form von Diskriminierung dar, wobei die Ursachen der Diskriminierung im organisatorischen Handeln gesellschaftlicher Institutionen (wie z.B. auch das Bildungssystem) lokalisiert sind. Sie differenzieren zwischen direkter und indirekter institutioneller Diskriminierung (ebd.: 48f.). Bei der direkten institutionellen Diskriminierung handelt es sich um regelmässige, intentionale Handlungen welche zur Routine geworden sind, bei der indirekten institutionellen Diskriminierung um eine ganze Bandbreite von institutionellen Mechanismen, die bestimmte Gruppen überproportional treffen (ebd.).

Bislang gibt es nur vereinzelt ethnografische Studien, die soziale Selektionsprozesse und Praktiken des Schulpersonals im Umgang mit sozial ungleichen Kindern und deren Eltern untersuchen. In einer fundierten, neueren ethnografischen Studie untersucht Hofstetter, wie das Bildungspersonal und die Bildungsteilnehmenden hinsichtlich von Bildungsentscheidungen zusammenspielen (Hofstetter 2017). Aufgrund seines Materials schlägt er vor, die Schule als eigenständige Akteurin zu konzipieren, welche Schüler*innenströme lenkt und als Organisation eigene Interessen verfolgt. Er legt dar, dass sich das Schulsystem nicht selbst reguliert, sondern dass »quasi durch eine unsichtbare Hand alljährlich ungefähr gleich viele Kinder ihrer Herkunft entsprechend auf die vorhandenen Plätze der hierarchisierten Sekundarstufe I verteilt werden« (ebd.: 292). Er beleuchtet verborgene Zusammenhänge und Praktiken, die zur allmählichen Entstehung von Bildungsentscheidungen führen, wie bspw. »Mikro-Entscheidungen«. Solche fortwährend von schulischen Akteur*innen getroffenen »Mikro-Entscheidungen« führen gemäss Hofstetter in der Summe dazu, dass »tendenziell soziale Ungleichheiten in Bildungsungleichheiten transformiert werden und dabei Kinder für den ihnen zugewiesenen Klassenzug >passend gemacht werden« (ebd.: 293).

Weiter kann in Bezug auf Bildungsübergänge einerseits an in der Schweiz durchgeführte Studien zum Übergang von der Volksschule zum 
nachobligatorischen Ausbildungssystem von jugendlichen Migrant*innen angeknüpft werden (vgl. Mey 2015, Mey/Rorato 2010, Müller R. 2009, Mey et al. 2005, Imdorf 2005, Fibbi et al. 2003 etc.), andererseits an internationale jugendsoziologische Arbeiten, die den Übergangprozess von der Schule zur nachobligatorischen Ausbildung als Prozess einer potenziellen Umorientierung konzipieren (vgl. bspw. King/Koller 2009a,b, King 2004, Schittenhelm 2010, 2005). Auch auf Ergebnisse der Schweizer Jugendpanelstudie TREE (vgl. Scharenberg et al. 2016, Hadjar/Hupka-Brunner 2013a, Bergman et al. 2012, Sacchi et al. 2011; Hupka/Stalder 2011a,b u.a.) kann zurückgegriffen werden: Ergebnisse der Schweizer TREE-Studie unterstreichen ebenfalls die voranstehend dargelegten Befunde, dass nicht nur Leistungen, sondern auch individuelle und strukturelle Merkmale eine Rolle bei Übertritten spielen (z.B. Hupka-Brunner et al. 2011a). Beispielsweise haben Knaben aus sozioökonomisch besser gestellten Familien höhere Chancen auf einen direkten Übertritt in die Sekundarstufe II - bei gleichen Leistungen wie Knaben aus sozioökonomisch schlechter gestellten Familien. Ebenso haben Lernende aus einem Schultyp mit tieferem Anforderungsniveau geringere Chancen für einen Direktübertritt in die Sekundarstufe II als Schulabgänger*innen von Ausbildungstypen mit erweiterten Anforderungen - bei denselben schulischen Leistungen (ebd.). Hupka-Brunner et al. (2011b) konnten zudem in einer weiteren vergleichenden Studie über bildungsbenachteiligte Jugendliche des Schweizer TREE-Surveys sowie des Deutschen DJI-Übergangspanels belegen, dass insbesondere die Faktoren Geschlecht, "Migrationshintergrund « und Schulleistung bei Übergängen in die nachobligatorische Schulbildung ins Gewicht fallen. Sie legen dar, dass insbesondere junge Frauen, Jugendliche mit »Migrationshintergrund « und Jugendliche mit schlechteren Schulnoten ein höheres Risiko für einen nicht erfolgreichen Übergang haben (ebd.: 75).

Etliche Studien weisen nach, dass die betriebliche Erstausbildung, welche das Tor zum qualifizierten Arbeitsmarkt im Dualen Berufsbildungssystem der Schweiz darstellt, für Jugendliche mit »Migrationshintergrund « nicht in gleichem Masse zugänglich ist wie für Jugendliche ohne »Migrationshintergrund« (vgl. Imdorf 2011: 262). Imdorf (2011) legt dar, mittels welcher Mechanismen in der Deutschschweiz jugendliche Schulabgänger*innen mit »Migrationshintergrund« benachteiligt werden: Er zeigt auf, dass die Reproduktion sozialer Ungleichheit insbesondere bei der Lehrlingsselektion, also bei Vergabe der Lehrstellen für die betriebliche Erstausbildung, erfolgt. Die Ursache in der Benachteiligung von Schulabgänger*innen mit »Migrationshintergrund « verortet Imdorf in der Funktionsweise und Organisationslogik der Betriebe 
selbst und der für sie relevanten Welten, zu denen die Betroffenen keinen Zugang haben (ebd.). Diese Bildungsbarriere kann ihre Wirkmächtigkeit in erster Linie deshalb entfalten, da die Vergabe von Lehrstellenplätzen nicht staatlich geregelt ist und die Betriebe quasi in Eigenregie über den Abschluss eines Ausbildungsvertrags entscheiden können (ebd.: 274).

Mey und Rorato (2010) stellen in Bezug auf Übergänge »Prozesse der Ernüchterung nach Abschluss der Volksschule« (ebd.: 5) fest. Mit dem »Verlust des Status als Volksschüler« (ebd.) und mit der beruflichen Positionierung würden sich soziale (Ungleichheits-)Positionen verfestigen und gesellschaftlichen Ungleichheits- und Differenzierungsprozessen kein Einhalt mehr geboten (ebd.). Mey (2015) untersuchte in einer weiteren Studie die Passung zwischen eigenen Wünschen und Zielen von Jugendlichen mit »Migrationshintergrund « und der Nachfrage des Arbeitsmarkts. In ihrem bezeichnenden Artikel Wege in die Arbeitswelt - dorthin, wo noch Platz ist (Mey 2015) verweist sie in Bezug auf Übergänge in die nachobligatorische Bildung auf starke Momente der Fremdbestimmung. So führt sie anhand von Fallbeispielen aus, wie der Übergang bildungsbenachteiligte Jugendliche in Branchen und Berufe führen kann, die ihren Neigungen und Wünschen wenig entsprechen und die tendenziell die wenig privilegierte Stellung ihrer Eltern im Arbeitsmarkt reproduzieren. Sie gelangt zu einem interessanten Nebenergebnis in Bezug auf die Rolle von Berufspraktika in »Brückenangeboten«: Jugendliche wurden durch diese Praktika als Alternative zu einer antizipierten drohenden Arbeitslosigkeit tendenziell in unbeliebte Berufe hineinberaten, deren Lehrstellen noch nicht besetzt werden konnten (ebd.: 251-252).

Schittenhelm konzipiert den Übergang zwischen Schule und beruflicher Ausbildung schliesslich als »Statuspassage« (2010: 40, 2005). Diese bringe Veränderungen bestehender sozialer und institutioneller Einbindungen mit sich und sei in ihrem Ausgang ungewiss, da sie für die betreffenden Personen oft mit Such- und Neuorientierungsprozessen einhergehe (2005: 25). Vor diesem Hintergrund versteht Schittenhelm den Statusübergang von Schule $\mathrm{zu}$ einer beruflichen Ausbildung als »Orientierungsanforderung« (ebd.: 17), die es $\mathrm{zu}$ bewältigen gelte und während derer sich junge Erwachsene neu positionieren, orientieren und verorten müssten. Auch Schittenhelm unterstreicht, dass die Bewältigung dieser Anforderung für junge Erwachsene mit »Migrationshintergrund « besonders weitreichende Folgen habe. Sie spricht von "mehrdimensionalen Statuspassagen« (2010: 40), die sich in Bezug auf das Schulsystem, Migration, Generationenbeziehungen sowie Partnerschaft und Familiengründung (ebd.: 40-41) finden. Insbesondere für weibliche Mi- 
grantinnen würden diese Statuspassagen eine vergleichsweise grössere Herausforderung darstellen als etwa für junge Erwachsene ohne »Migrationshintergrund « (Schittenhelm 2005: 19; Granato 2006, 2003: 117). Studien zeigen, dass sich bei jungen Frauen mit »Migrationshintergrund « die benachteiligenden Effekte kumulieren (Häberlin et al. 2004), beziehungsweise die Differenzdimensionen Gender und »Migrationshintergrund « ungünstig zusammenspielen.

Bader und Fibbi (2012: 11) arbeiten basierend auf einer Analyse einschlägiger Fachliteratur fünf relevante Einflussbereiche auf Bildungsbiografien von Jugendlichen mit »Migrationshintergrund« heraus. Es sind dies die Migrationslaufbahn, das familiäre Umfeld, die Bildungsstrukturen, das soziale Kapital und die psychosozialen Ressourcen. Sie betonen insbesondere die Wichtigkeit des sozialen Kapitals und die zentrale Rolle der Lehrpersonen für die Laufbahn der Jugendlichen als Vorbilder bei der Suche nach Orientierung (ebd.: 55).

Oester (2008: 50-51) nimmt die widersprüchliche Funktion des Bildungssystems in Bezug auf soziale Ungleichheit in den Fokus. Sie spricht von der »doppelten Funktion des Bildungssystems« (ebd.: 50): Diese bestehe einerseits in der Funktion der sozialen Nivellierung und der Homogenisierung des Bildungssystems, welche die Gemeinschaftsbildung mittels assimilativer bzw. integrativer Prozesse zum Ziel habe und das soziale Lernen in der Vordergrund stelle, andererseits in der Funktion der sozialen Hierarchisierung, die Differenzierungsprozesse über das akademische Lernen in den Vordergrund stelle und dem leistungsbezogenen Wettbewerb verpflichtet sei (ebd.). Oesters Modell der »doppelten Funktion des Bildungssystems« führt sie zudem zu einer interessanten Erklärung für die Reproduktion von Bildungsungleichheiten im Zusammenhang mit sozialräumlicher Segregation: Sie führt aus, wie diese doppelte Funktion unter dem Aspekt der sozialräumlichen Segregation dazu führen kann, dass Schulen an weniger privilegierten Schulstandorten, wo der soziokulturelle Wandel demografisch am höchsten ist, »riskieren (...), sich zum Nachteil des akademischen Lernens auf ihren Assimilationsauftrag zu beschränken« (ebd.: 65), während privilegierte Schulstandorte mit einem stabilen Mittelstand sich auf die Aufbau akademischer Leistung konzentrieren können und somit die höchsten Wettbewerbschancen haben (ebd.). Oester und Brunner zeigen zudem auf, wie das Bildungssystem in transnationalisierten sozialen Räumen mittels Selektionsprozessen und assimilativen Forderungen die adoleszenten Peerwelten und deren Einund Ausgrenzungslogiken prägt (Oester/Brunner 2015). 
Mit Riegel (2017: 11, 2016a, b) kann der widersprüchliche Umgang des Bildungssystems mit migrationsgesellschaftlicher Pluralität und sozialer Ungleichheit abschliessend folgenderweise zusammengefasst werden: Einerseits liegt dem Bildungssystem zwar eine Gleichheits- und Leistungsideologie zugrunde, nach der zumindest der theoretische Anspruch auf Gleichbehandlung besteht und Leistung die primäre Grundlage zum Bildungserfolg sein sollte. Der Anspruch zu Gleichheit und leistungsbasiertem Bildungserfolg steht jedoch in faktischem Widerspruch zu diskriminierenden Mechanismen des Bildungssystems, wie a) der starken Selektivität, b) der kulturellen Hegemonie und nationalstaatlichen Zentrierung von Bildung, die dazu führt, dass sich Differenz- und Normalitätskonstruktionen in Organisationsformen, Bildungsinhalten und pädagogischem Handeln materialisieren sowie c) institutionalisierten Formen von Diskriminierung (Riegel 2017: 11). Folge davon ist, dass es der Institution Schule trotz anderslautender Ansprüche und Bemühungen nicht gelingt, Verhältnisse sozialer Ungleichheit zu durchbrechen. Dies führe einerseits zur »Beteiligung und Reproduktion von hegemonialen Dominanz- und Differenzverhältnissen) (ebd.: 12) andererseits zu ungleichen Chancen im Bildungssystem durch »Benachteiligungen, Verletzungen und fehlende Repräsentation von denjenigen, die der hegemonialen Normalitätskonstruktion (als bürgerlich, weiss, schweizerisch, männlich, heterosexuell, gesund konzeptualisiert) nicht entsprechen« (ebd.).

Einen solchen Fokus einnehmend, stellt sich nun in Bezug auf die vorliegende Untersuchung die Frage, wie es sich mit der Bildungsbeteiligung religiös orientierter Musliminnen und der Differenzkategorie »Muslimin« in einem so konzeptualisierten Bildungssystem verhält? Entsprechende, systematische Studien liegen meines Wissens für die Schweiz bisher keine vor. International existieren zwar vereinzelt Studien, diese sind jedoch aufgrund unterschiedlich strukturierter Bildungssysteme, Inkorporationsbedingungen (Soysal 1994, Allenbach/Müller 2017: 276, Allenbach/Sökefeld 2010: 19) sowie der unterschiedlichen Zusammensetzung der muslimischen Bevölkerung lediglich beschränkt auf die Schweiz übertragbar. Ethnografische Untersuchungen zu religiös orientierten jungen Secondas muslimischen Glaubens im Kontext von Bildung stellen mit Ausnahme vielleicht von Allenbach (2016) in der Schweiz ebenso weitgehend eine Forschungslücke dar. Allenbach (2016) befasst sich mit Agency und Grenzziehungsprozessen von jungen muslimischen Mädchen in Bezug auf den obligatorischen schulischen Schwimmunterricht und zeigt auf, wie die jungen Frauen durchaus vielfältige Handlungsmöglichkeiten besitzen, dominante (gegenderte) Differenzlinien und damit einherge- 
hende Machtkonstellationen infrage zu stellen und ihre Positionierung dazu auszuhandeln (ebd.: 43f.). Sie verweist auf eine zunehmende Bedeutung eines "muskulären Liberalismus« in Bezug auf Muslim*innen in der Schweiz, der die Grenzen zwischen »uns« und »den Andern" primär entlang Geschlechtervorstellungen zieht (ebd.)

International existieren vereinzelt neuere sozial- bzw. bildungsanthropologische Studien über religiös aktive junge muslimische Frauen (und Männer) in Bildungskontexten (vgl. bspw. Jaffe-Walter 2016, Giliam 2015, Mir 2014). Die dänische Bildungsanthropologin Gilliam untersucht in ihrem ethnografischen Beitrag Beeing a Good, Relaxed or Exaggerated Muslim (2015) bspw. wie "Muslim*in sein" von Jugendlichen in sozialen Kontexten von dänischen Schulen konstruiert und ausgehandelt wird.

In Coercive Concern untersucht Jaffe-Walter (2016) in einer ethnografisch fundierten Studie, wie Stereotypen von muslimischen Zugewanderten in liberalen westlichen Gesellschaften tägliche Interaktionen an öffentlichen Schulen beeinflussen und das Bild, wie muslimische Jugendliche von Lehrpersonen und Peers gesehen werden, prägen. Sie führt weiter aus, wie Schulen als Orte von nationalstaatlicher Steuerung funktionieren, und wie der (gesellschafts-)politische Überfremdungsdiskurs im Bildungssystem reproduziert wird und auf diese Weise das Leben der Jugendlichen, die unter ständiger sozialer Beobachtung stehen, prägt (ebd.).

Die amerikanische Anthropologin Mir (2014) schliesslich untersucht das Campusleben junger Musliminnen in den Vereinigten Staaten. Sie gelangt zum Schluss, dass junge muslimische Frauen in der Post-9/11-Ära in ihren identitären Aushandlungsprozessen einem doppelten Erwartungsdruck ausgesetzt sind: einerseits dem Erwartungsdruck der muslimischen Community und andererseits dem der dominanten nicht-muslimischen Gesellschaft. Mir (2014) verdeutlicht in ihrer ethnografischen Studie, wie eine Gruppe junger sich als Musliminnen identifizierender Frauen ihre Identität in diesem Spannungsfeld konstruieren und im Kontext des universitären Campuslebens aushandeln.

Die erwähnten Studien zeigen allesamt den engen Bezug des Bildungswesens zum jeweiligen nationalstaatlichen System einerseits und zu dominanten gesellschaftspolitischen Diskursen und Zuschreibungen andererseits: Das Bildungssystem reproduziert die gesellschaftlich und politisch dominierenden Differenzkonstruktionen; die jugendlichen Muslim*innen sehen sich folglich (auch) im Bildungswesen mit stereotypisierenden Ausschlussprozessen konfrontiert. Unterstrichen wird jedoch ebenfalls, dass die jungen Frauen 
(und Männer) mit vielgestaltigen Strategien auf diese Gegebenheiten reagieren.

Zusammenfassend kann konstatiert werden, dass sich Bildungsungleichheiten bei Jugendlichen mit »Migrationshintergrund« in einem »defizitorientierten, früh selektionierenden Bildungssystem « (Oester/Brunner 2015: IV) anhand unterschiedlicher Differenzdimensionen manifestieren. Dies verdeutlicht sich besonders nachdrücklich bei bildungsbiografischen Übergängen. Die Einnahme eines intersektionellen Blicks auf das Zusammenspiel dieser verschiedenen Differenzdimensionen in migrationsgesellschaftlichen Verhältnissen kann sich hierbei als äusserst sinnvoll erweisen (vgl. bspw. Riegel 2016a, b, 2010b Hadjar/Hupka-Brunner 2013b, zum theoretischen Rahmen vgl. Kap. 2).

Ob und wie sich die Differenzkategorie "Muslimin« als intersektionell wirkende Kategorie in bildungsbiografischen Übergängen in einem Bildungssystem manifestiert, das von Jugendlichen mit »Migrationshintergrund « nach wie vor primär Assimilationsleistung erwartet, ist Gegenstand dieser Untersuchung. 


\section{Methodisches Vorgehen}

Das gewählte methodische Vorgehen orientierte sich an der Fragestellung des Forschungsvorhabens: Mittels sozialanthropologischer Forschungsmethoden sollten Sinnzusammenhänge und Relevanzsysteme der Akteurinnen analysiert werden. Durch eine solche Forschungsstrategie lassen sich Rückschlüsse auf gesellschaftliche Bedingungen des (bildungs-)biografischen Handelns der jungen Frauen ziehen und im Sinne Bourdieus verstehen (vgl. Bourdieu 1997). Ziel hierbei war es, aus einer Akteurinnenperspektive die Bedeutung der Differenzkategorie »Muslimin« in Bildungsbiografien zu rekonstruieren und »Taktiken« (De Certeau 1988: 89) zu eruieren, mittels derer die jungen Secondas ihre Agency im Zusammenhang mit ihren Bildungsbiografien erweitern.

Es wurde ein ethnografischer Ansatz gewählt, welcher den Akteurinnen Raum für die Darstellung eigener Relevanz- und Deutungssysteme innerhalb von (sozialen) Räumen geben sollte. Der Vorteil einer ethnografischen Forschungsstrategie ist nicht zuletzt, dass "Aspekte des Handelns und Denkens beobachtbar werden, die in Gesprächen und Dokumenten - gleich welcher Art - (...) nicht in dieser Weise zugänglich wären « (Lüders 2011: 151). Kern des Zugangs zum Feld bildete die Methodik einer multi-sited Ethnography, wie Marcus (1995) sie in Abgrenzung zur klassisch ethnografischen Vorgehensweise vorschlägt.

Wie bei einer ethnografischen Herangehensweise üblich, kam bei der Datenerhebung ein Methodenmix zum Zuge: ein zirkuläres Verfahren von teilnehmender Beobachtung ${ }^{1}$ in multiplen (sozialen) Feldern, themenzentrier-

Die Methodik der teilnehmenden Beobachtung, die »Königsmethode der Sozial- bzw. der Kulturwissenschaft« (Girtler 1989:104) wird bereits seit längerer Zeit fruchtbar im religionswissenschaftlichen Kontext bzw. in der Religionsforschung eingesetzt (Baumann 1998; für eine Übersicht vgl. bspw. Franke/Maske (2011: 108ff.). Ein ethnografischer Zugang im Sinne einer »multi-sited Ethnography« umfasst jedoch mehr als teil- 
ten (bildungs-)biografischen Interviews sowie einer diskursiven Dokumentenanalyse in Bezug auf die Differenzkategorie »Muslimin«.

Die kontinuierliche, zirkuläre Auswertung fand mittels Grounded Theory (Strauss/Corbin 1996) statt und wurde durch eine fallzentrierte, biografische Perspektive ergänzt. Die Darstellung der Resultate erfolgte schliesslich entlang einer Typologie ${ }^{2}$ von alltäglichen »Taktiken «(De Certeau 1988: 89), welche bei jungen Musliminnen in der Deutschschweiz in Bezug auf ihre Bildungsbiografien und ihre gesellschaftliche Selbstpositionierung manifest werden (siehe Kap. 5).

\subsection{Sample: Forschen zu Musliminnen im Spannungsfeld zwischen "methodological Islamism" und "strategical essentialism"}

Die Ausgangslage des Samplings gestaltete sich ziemlich komplex. Das Vorhaben bestand darin, von einer Arbeitsdefinition auszugehen und anschliessend in kontinuierlich kontrastierendem Verfahren theoretisch zu sampeln (Strauss/Corbin 1996). Die Arbeitsdefinition des Samples lautete zunächst wie folgt:

»Untersucht werden sollen junge muslimische Frauen mit »Migrationshintergrund « der zweiten Ceneration in der Deutschschweiz, die sich als >muslimisch bezeichnen (Selbstdeklaration) und in der Schweiz geboren, resp. als Kleinkind in die Schweiz gekommen sind. Die zu Befragenden sollen zwischen 18-24 Jahre alt sein und damit in einem Alter, in dem sie einerseits - wie erfahrene Biografieforschende festgestellt haben - in der Lage sind, »kritisch ihre soziale Position, ihren Akteur-Spielraum und ihr Selbst im Verhältnis zu andern [zu] reflektieren « (Nökel 2002: 19; vgl. hierzu Rosenthal 1995: 104, 135 Lucius-Hoene/Deppermann 2002: 298), andererseits die zu rekonstruierende Lebensphase noch nicht zu weit zurück liegt«.

nehmende Beobachtung, hier kommt meist ein Methodenmix, der u.a. teilnehmende Beobachtung beinhaltet, zum Zuge (vgl. Falzon 2009:1).

2 Hier lehne ich mich an das von Kelle und Kluge (2010) vorgeschlagene Verfahren zur Typisierung an. Wichtig zu betonen ist jedoch, dass es sich bei der Typologie nicht um die Darstellung eines Weberschen Idealtypus (Weber, Max (1995 [1904]) handelt, sondern um eine Typisierung von »Taktiken« (De Certeau 1988:89). Infolgedessen können innerhalb einer Bildungsbiografie je nach Lebensabschnitt unter Umständen verschiedene »Taktiken« (ebd.) zum Zuge kommen. 
Bereits in der frühen Erhebungsphase taten sich jedoch drei verschiedene Problemfelder bezüglich dieser Arbeitsdefinition auf: 1) sich als "muslimisch « bezeichnen (Selbstdeklaration), 2) die Konzeption »zweite Generation« in der Migrationsforschung und 3) die Altersspanne. Diese Punkte mussten reflektiert, hinterfragt und teilweise umdefiniert werden. Dieser Prozess soll im Folgenden kurz beschrieben werden.

Bereits in der frühen Erhebungsphase wurde deutlich, dass >Muslima sein situativ konstruiert wird und selbst eine »Selbstdeklaration« kontextuell variieren kann. Dies soll kurz am Beispiel der einundzwanzigjährigen Lane illustriert werden:

In den meisten Situationen, insbesondere jedoch in nicht-religiös konnotierten Kontexten, wie z.B. der Arbeitswelt - bezeichnet sich Lane, wie sich in der Feldforschung anhand der teilnehmenden Beobachtung zeigte - als Muslima ${ }^{3}$.

Lanes Familie ist aus Südosteuropa eingewandert; sie wurde als eines von fünf Geschwistern in der Deutschschweiz geboren und wurde »distanziert « religiös sozialisiert ${ }^{4}$ (vgl. »Vier Gestalten des (Un)-Glaubens«, Stolz et al. 2014: $75 \mathrm{ff}$.). Die ältere Schwester von Lane fand in der Pubertät durch Schulkameraden zu einer dezidiert religiösen muslimischen Jugendgruppe, begann religiöse Schriften zu lesen und bedeckte sich fortan mit einem Hijab - ein Schritt, dem Lane grossen Respekt zollt und den sie sehr bewundert, wie sie immer wieder unterstreicht. Der grosse Respekt, den Lane für diese Entscheidung aufbringt, rührt vom Mut her, den es in Lanes Augen erfordert, sich

3 Der Vorteil einer ethnografischen Zugangsweise ist unter anderem, dass mittels teilnehmender Beobachtung Aspekte der Selbstrepräsentation erfasst werden können, die in Interviews und Dokumenten nicht in derselben Weise zugänglich wären; vgl. hierzu auch Lüders 2011: 151

4 Es gestaltet sich schwierig, die religiöse Sozialisation von Lane in dieser Kürze darzustellen. Lane umschreibt ihre religiöse Sozialisation folgendermassen: »Meine Mutter, sie hat uns Kinder eigentlich auch nicht so religiös erzogen. Sie hat uns immer gesagt, ja es gibt einen Cott, es gibt einen Allah, ihr dürft das nicht machen oder so wie bei Euch im Chris..., ich weiss nicht was du bist, Entschuldigung (NG lacht) eh so wie im Christentum halt, so die zehn Gebote sind, ihr dürft das nicht und so, ist ja bei uns ähnlich, hat sie uns dieses Zeug erklärt, hat sie uns ein paar kurze Suren beigebracht, so vor dem Einschlafen, damit wir keine Angst haben. Aber so richtig ihr müsst beten und so, hat sie uns nie beigebracht« (Lane, Interview 27.05.2015, A 36). Gemäss des in der schweizerischen Religionswissenschaft vielbeachteten Modells der Typen von Religiosität (»Vier Cestalten des (Un)-Glaubens«) von Stolz et al. (2014) würden Lanes Eltern wohl am ehesten dem Typus der »Distanzierten« (Stolz et al. 2014: 75ff.) entsprechen. 
in einem tendenziell islamkritischen gesellschaftlichen Umfeld als religiöse Muslima zu »outen « und dadurch bspw. in Kauf zu nehmen, dass Jobchancen vermindert werden. Inspiriert von ihrer ältesten Tochter vertieft sich auch die Mutter mehr in religiöse Themen und bedeckt sich erneut, nachdem sie den Hijab, als sie in die Schweiz kam, dem Vater zuliebe abgelegt hatte. Diesen hatte sie zuvor, wie Lane mir erklärte, eher aus Gründen einer familiären Tradition denn als Zeichen von Religiosität angelegt. Der Vater hingegen, der nicht sehr religiös orientiert ist, und die Mutter überredete, den Hijab abzulegen, als sie in die Schweiz kamen, steht ihrer Tendenz, sich nun wieder vermehrt der Religion zuzuwenden, skeptisch gegenüber. Lane selbst schliesst eine allfällige Bedeckung als Zukunftsprojekt nicht aus, möchte sich jedoch im Moment ausserhalb der Moschee, die sie auch ab und an besucht, nicht bedecken. Sie bemüht sich jedoch darum, mehr oder weniger regelmässig das Pflichtgebet zu verrichten, besucht die Moschee und ist passiv Mitglied einer muslimischen Jugendorganisation. Gleichzeitig legt sie, wie ich beobachten konnte, Wert auf eine nicht-religiös konnotierte, trendig-modische äusserliche Erscheinung, ist oft stark geschminkt und zieht sich gerne figurbetont an. Nicht zuletzt deshalb steigt der Druck seitens ihrer Schwester und deren religiösen Freundinnen, sie solle sich doch bedecken oder zumindest anders anziehen. Dadurch sieht sich Lane mit dem Dilemma konfrontiert, sich zu positionieren. Sie löst das Problem so, dass sie sich im familiären Kontext, insbesondere in Bezug auf die Kreise ihrer älteren Schwester, explizit als »Nicht-Muslima bezeichnet und positioniert, so muss sie sich der Definition und den Ansprüchen, die ihre Schwester an das >Muslima- sein koppelt, nicht stellen, resp. sich nicht in ihrem eigenen >Muslima- sein $<$ anpassen. Im beruflichen Kontext jedoch positioniert sie sich tendenziell eher als Muslima, um ihre (religiöse) Zugehörigkeit zu markieren und gleichzeitig bspw. auf das Einhalten von Speisegeboten pochen zu können. Das heisst, Lane konstruiert $>$ Muslima-sein situativ, je nach dem in welchem Umfeld sie sich bewegt.

Dass einem solch situativ konstruierten >Muslim(a)-sein< unzureichend Rechnung getragen wird und der Begriff »Muslim*in« weitgehend essenzialistisch verwendet wird, wirft Brubaker (2012) der exponentiell zunehmenden Forschung zu Islam und Muslimen vor. Er spricht in diesem Zusammenhang anlehnend an Wimmer und Glick-Schiller (2002) von einem »methodological Islamism« (Brubaker 2012: 6). Insbesondere kritisiert er die unzureichende resp. unreflektierte Verwendung von Muslim*in als »Kategorie der Analyse« (ebd.). Er schlägt vor, "Muslim"in« als »Kategorie der Analyse« fallen zu lassen und ausschliesslich auf der Ebene einer »Kategorie der Praxis«, also 
einer Kategorie, welche die Akteur*innen im Feld benutzen, zu verwenden, und so dem Umstand Rechnung zu tragen, dass es sich bei Muslim*innen um eine sehr heterogene Gruppe und keine homogene Entität handelt (ebd.).

Modood und andere (Meer/Modood 2013, Modood 1998) halten dagegen, dass durch eine solch radikal anti-essenzialistische Dekonstruktion von Gruppenidentitäten deren politische Anerkennung verunmöglicht wird. Modood zeigt im Zusammenhang mit Muslim*innen als religiöser Minorität in Grossbritannien bspw. auf, dass auf politischer Ebene, ohne homogenisieren $\mathrm{zu}$ wollen, marginalisierte Gruppen benannt werden müssen, um ihre (religiöse) >Identität $\mathrm{zu}$ schützen und politisch anerkannt zu werden (Modood 2013, 2011, 2010, 1998). Die postkoloniale, feministische Philosophin Spivakfordert in diesem Zusammenhang in einem Text der Subaltern Study Group einen »strategic use of (...) essentialism « (Spivak 1993: 5, Herv. im Orig.) längst einen »strategischen Essentialismus«. Müller (2013: 119) resümiert hinsichtlich des dargelegten Spannungsfelds, dass in letzter Konsequenz »eine radikale anti-essentialistische Perspektive (...) weder Politik noch Gesellschaft oder ein kohärentes Selbst « zulasse. Durch die enge Verwobenheit von sozialer Praxis und sozialwissenschaftlicher Theorie komme es bei Forschenden diesbezüglich $\mathrm{zu}$ »Problematiken einer konstruktivistischen und anti-essentialistischen Perspektive, die man auch als Dilemmata bezeichnen kann« (ebd.).

Vor einem solch »anti-essentialistischen Dilemma« stand ich in vorliegender Untersuchung: Einerseits sah und sehe ich mich theoretisch einer konstruktivistischen und anti-essenzialistischen Perspektive verpflichtet, auf der anderen Seite war es mir ein zentrales Anliegen, allfällige (strukturelle) Diskriminierungen und Einschränkungen junger muslimischer Frauen in Bezug auf das Bildungswesen sichtbar zu machen - gerade auch hinsichtlich des gesellschaftlichen Islamdiskurses und der diskursiven Differenzkategorie »Muslimin«. Ein solches Vorhaben würde, Modoods Argumentationslinie folgend, durch eine konsequent anti-essenzialistische Perspektive verunmöglicht.

Schliesslich entschied ich mich, im Sinne eines »strategischen Essentialismus« (Spivak 1993: 5) nicht vollständig darauf zu verzichten, Muslim*in als Kategorie der Analyse und Praxis zu verwenden, dies jedoch in stetigem Bewusstsein und in Reflexion der zuvor benannten Problematik der situativen und fluiden Konstruiertheit von Selbst- und Fremdzuschreibungen. Die ursprünglich vorgesehene Voraussetzung zur Teilhabe am Sample, nämlich die einer Selbstdeklaration als Muslimin wurde also im weitesten Sinne beibe- 
halten, jedoch unter den ausgeführten Überlegungen reflektiert und flexibel gehandhabt (bspw. wurde Lane schliesslich dem Sample zugerechnet, obwohl sie sich nicht in allen erforschten Kontexten als Muslima deklarierte).

Zweitens tat sich hinsichtlich des Samples die Frage auf, wie der Begriff »zweite Generation« umrissen und definiert werden sollte: Verschiedentlich haben Forschende auf die Problematik der Verwendung des Generationsbegriffs in der Migrationstheorie hingewiesen (vgl. bspw. Müller 2013: 61ff. Aumüller 2010, Juhasz/Mey 2003: 18ff.). Kritisiert wurde unter anderem, dass der Generationsbegriff einerseits empirisch unscharf sei und andererseits dazu führe, dass der Status als »Ausländer*in« direkt auf die nächste Generation übertragen würde (D’Amato 2010: 177) und drohe »zu einem Verdikt zu werden, das die Betroffenen zur strukturellen Marginalität verurteilt« (Aumüller 2010 o. S.).

In der Schweizer Migrationsforschung (und im öffentlichen Diskurs) wird zunehmend die ursprünglich auf den schweizerisch-irakischen Filmemacher Samir ${ }^{5}$ zurückgehende Begrifflichkeit der Seconda*o (D’Amato 2010: 178-179) rezipiert. Anders als der Generationenbegriff bezieht der Begriff Seconda*o seine Legitimität daraus, dass er ein politisches Projekt darstellt und darauf abzielt, Menschen mit gemeinsamen Forderungen zu vereinen (Allenbach 2016: 34, D’Amato 2010: 178-179, Juhasz/Mey 2003:18). Müller (2013: 57) zufolge bildete die medial inszenierte Beschuldigung von Jugendlichen mit »Migrationshintergrund « an Sachbeschädigungen während der 1. Mai-Demonstration 2002 den Ausgangspunkt für die politische Bewegung der Secondas*os in der Schweiz (ebd.). Als Reaktion gegen diese öffentliche Stigmatisierung versuchten Secondas*os sich zu organisieren und eine Art »Gegen-Stereotyp« (ebd.) zu etablieren im »Kampf gegen das negative Image, den sie mithilfe der Betonung ihres sozioökonomischen Erfolges und ihrer Zugehörigkeit zur Schweiz führten« (ebd.). Die Bezeichnung Seconda*o stellte also zunächst einen politischen Kampfbegriff oder zumindest eine Art Selbstbezeichnung von Jugendlichen mit »Migrationshintergrund« der sog. "zweiten Generation« dar. Bis heute sind in der Schweiz verschiedene lokale Gruppierungen existent, die sich unter dem Namen »Secondas*os« oder »Second@s plus« politisch vereinen und betätigen, so bspw. »Secondas Zürich « ${ }^{6}$. Bis vor kurzem existierte aber auch als politisches Konzept versteht (D'Amato 2010: 178; www.dschointventschr.ch/de/movies/documentaries/babylon-2). 
zudem ein schweizerischer Dachverband - „Second@s Plus Schweiz«, der sich jedoch mangels zeitlicher Ressourcen der engagierten Mitglieder 2016 auflöste (Landolt 2016b).

In der Migrationsforschung wurde die Begrifflichkeit Seconda*o relativ rasch aufgenommen und etabliert sich teilweise (vgl. bspw. u. v.a. Allenbach 2016, 2011, D’Amato 2010, Mey 2010, Bolzman et al. 2003, Juhasz/Mey 2003:1819 etc.). Laut Müller vermochte sie sich jedoch noch nicht gänzlich durchzusetzen (Müller 2013: 59). In vorliegendem Projekt werden die Begriffe Seconda"o und "zweite Generation « synonym verwendet und anlehnend an Juhasz/Mey (2003:18-19) wie folgt definiert: Unter »Seconda*o« oder »zweiter Generation « werden Jugendliche verstanden, die in der Schweiz geboren oder als Kleinkinder in die Schweiz gekommen sind und bei denen beide Eltern im Ausland geboren sind. Eingeschlossen hierin sind sowohl eingebürgerte wie auch nicht eingebürgerte Jugendliche.

Drittens zeigte sich im Verlaufe der Untersuchung, dass es der Beantwortung der Forschungsfrage zuträglich war, die ursprüngliche Altersspanne des Samples von 18-24 etwas auszuweiten bzw. flexibel zu handhaben. Es zeichnete sich $\mathrm{ab}$, dass Bildungsentscheidungen nicht zuletzt wegen des sehr >durchlässigen schweizerischen Bildungssystems bis weit in die Adoleszenz und ins junge Erwachsenenleben hinein gefällt werden und Prozesse einleiten, die meines Erachtens in die Analyse einbezogen werden müssen (vgl. hierzu auch King/Koller 2009a, King 2004). Ebenso wurde deutlich, dass sich sowohl eingeschlagene Bildungswege, -entscheidungen wie auch Religionsverständnis, religiöse Praxis und religiöse Selbstrepräsentation in der Adoleszenz noch stark verändern können. Die Begrenzung auf eine Altersspanne von 18-24 hätte mögliche Analysen verkürzt und bildungsbiografische Verläufe im Rahmen des heute relativ flexibilisierteren und durchlässigeren schweizerischen Bildungssystems nur eingeschränkt darstellen lassen.

Die Arbeitsdefinition und Ausgangslage des Samples wurde also angesichts der drei zuvor reflektierten Punkte dahingehend angepasst, dass erstens zwar nicht auf »Muslimin« als Kategorie der Analyse verzichtet wurde, dies jedoch einzig aus Gründen eines »strategischen Essentialismus« (Spivak 1993: 5). Zweitens wird der Begriff der »zweiten Generation« ebenfalls kritisch reflektiert, in Anführungsstrichen verwendet, um die oben geschilderten Vorbehalte zu unterstreichen und gegebenenfalls durch die Begrifflichkeit der Seconda*o ersetzt. Und schliesslich drittens wurde die ursprünglich vorgesehene Alterspanne von 18-24 Jahren flexibel gehandhabt. Im Sample befinden sich nun Frauen zwischen 18-35 Jahren. 
Während der gesamten Feldforschungsphase wurden geeignete Interviewpartnerinnen gesampelt und für ein (bildungs-)biografisches Interview über Berufswahl und Phase des Übergangs von Volksschule zur nachobligatorischen Ausbildung angefragt. Die kontinuierliche Weiterentwicklung des Samples erfolgte, wie gemäss Grounded-Theory-Methodologie üblich, schrittweise mittels des Verfahrens des Theoretical Samplings (Strauss/Corbin 1996: 148ff.). Dieses zielt nicht auf eine statistische Repräsentativität $a b$, sondern auf eine konzeptuelle: Theoretisch gesampelt wird also mit dem Ziel, alle Fälle und Daten $z u$ erheben, die »für eine vollständige analytische Entwicklung sämtlicher Eigenschaften und Dimensionen der in der jeweiligen Grounded Theory relevanten Konzepte und Kategorien erforderlich sind « (Strübing 2011: 155). Zentral hierbei ist, dass auf ein deduktives, vorab bestimmtes Sample zugunsten einer kontinuierlichen Entwicklung des Samples verzichtet wird, das sich an der iterativ sich entfaltenden Theorie orientiert (Strübing 2011: 154).

Mittels des Verfahrens des Theoretical Samplings (Strauss/Corbin 1996: 148ff.) wurden die Interviewpartnerinnen in vorliegendem Projekt kontinuierlich kontrastierend ausgewählt, beispielswiese nach (berufs-)biografischem Verlauf, Art der (religiösen) Vergemeinschaftung, Herkunftsmilieu, Wohnort (Stadt/Land) etc. Ziel dieses Vorgehens war es, eine möglichst grosse Varianz des empirischen Datenmaterials zu erzeugen.

Eng zusammenhängend mit der Konzeption des theoretischen Samplings ist das Kriterium der theoretischen Sättigung (vgl. Strübing 2011: 155). Das Sampling gilt dann als beendet, wenn eine sogenannte Theoretische Sättigung erreicht ist, das heisst, »wenn im Zuge weiterer Vergleichsprozesse keine neuen Einsichten erfolgen und die Modifikationen nur noch zur Verbesserung der internen Konsistenz nötig sind« (Mey/Mruck 2011: 29). Oder mit anderen Worten:

»Ging es zunächst darum, in Bezug auf das untersuchte Phänomen möglichst homogene Fälle zu untersuchen, so wird nach dem Erreichen der theoretischen Sättigung diese Strategie des minimalen Vergleichs durch eine Strategie des maximalen Vergleichs ersetzt, d.h. es werden nun systematisch Daten zu Falldomänen ausgesucht, die gute Chancen haben, abweichende Ausprägungen des Phänomens aufzuweisen« (Strübing 2011: 155).

Im vorliegenden Projekt begannen sich nach rund fünfzehn biografischen Interviews und nach rund zwei Jahren Feldforschung erste Anzeichen einer Theoretischen Sättigung abzuzeichnen. Um zu überprüfen, ob »im Zuge weiterer Vergleichsprozesse keine neuen Einsichten erfolgen« (Mey/Mruck 2011: 
29), wurden vier weitere biografische Interviews sowie weitere informelle Gespräche geführt. Gesamthaft wurden schliesslich neunzehn biografische Interviews digital aufgezeichnet und transkribiert. Zusätzlich wurden diverse formelle und informelle Expert*innen-Interviews geführt. Punktuelle Feldaufenthalte fanden während des gesamten Forschungsprozesses statt.

\subsection{Zugang zum Feld: Multi-Sited Ethnography}

Ausgehend von der Kritik einer räumlichen Verortung von Kultur in der Sozialanthropologie der 9oer-Jahre und von einem dynamischen, nicht- essenzialistischen Kulturverständnis im Zuge der Globalisierung »and its cousin, transnationalism« (Falzon 2009: 6) kam es zu einer »Neudefinition des ethnografischen Feldes und der Feldforschung jenseits einer lokal verankerten Örtlichkeit« (Halbmayer 2017: 1). In einer globalisierten Welt, so lautete das zentrale Argument von Marcus, könne das ethnografische »Feld« nicht länger »single-sited « definiert werden, sondern müsse global agierende Lebenswelten ethnografisch erforschen können und so "multi-sited « ${ }^{7}$ erfolgen (Marcus 1995: 98). Marcus wiedersetzte sich dem Bild des Felds als homogener im Vorfeld abgeschlossener Einheit: Subjekte sind nach ihm mehrfach bzw. vielfach verortet und mobil, Ziel einer »multi-sited Ethnography« soll es hierbei sein, diese Vielfachverortungen oder multiplen »Felder « miteinander in Beziehung zu setzen (ebd.: 96-97). In dieser Perspektive ist das Feld nicht einfach örtlich vorhanden, sondern wird mittels Feldforschung erst konstruiert (vgl. Amit 2000).

Marcus schlägt sechs Strategien vor, wie »multi-sited« ethnografisch vorgegangen werden soll (Marcus 1995: 106:ff.):

- "Follow the people«: Diese Strategie richtet sich nach Bewegungen und Entwicklungen von Personen oder Personengruppen aus. Den Akteur*in-

Das englische Wort »site« eröffnet im Deutschen, wie Weissköppel (2005: 49) ausführt, geradezu ein semantisches Feld, das verdeutlicht, was mit diesem Begriff im Cegensatz zum früheren »field « unterstrichen werden soll, nämlich ein Kulturverständnis, das nicht auf abgeschlossener Lokalität beruht, sondern »Kultur (...) als potentiell mobile, weil kognitiv und interaktiv einzubringende Ressource des Denkens und Handels zu betrachten, die an ganz unterschiedlichen Stellen und Plätzen ebenso durch unterschiedliche Medien zum Einsatz kommen kann oder zur Schau gestellt, inszeniert wird« (ebd.: 2005 49-50, Herv. im Orig.). 
nen wird in ihrer (sozial)räumlichen Mobilität gefolgt. Diese Strategie hat sich insbesondere in der Migrationsforschung etabliert (Weissköppel 2005: 53). Die »Follow-the-people«-Strategie bildet Marcus zufolge die üblichste und konventionellste Form eine »multi-sited Ethnography« zu materialisieren (Marcus 1995:106).

- "Follow the thing«: Bei dieser Strategie geht es um das Verfolgen von Zirkulationsprozessen und der (historischen) Verbreitung einer Sache, z.B. von Konsumgütern, aber auch von Medienproduktionen etc. (ebd.). Als Beispiel erwähnt Marcus hier Mintz' (1985) kulturhistorische Analyse des Zuckers.

- "Follow the methaphor«: Als weitere Strategie bezeichnet Marcus die Strategie, Metaphern zu folgen, wobei er insbesondere auf assoziative Techniken verweist, welche verschiedene, nicht auf den ersten Blick miteinander verbundene Felder verknüpfen (Marcus 1995: 108). Er erörtert in diesem Zusammenhang Martins Untersuchung der »Flexible Bodies« (1994), in welcher dieser die Darstellung des Immunsystems als Metapher zum Ausgang nimmt, wie dieses in verschiedenen (sozialen) Feldern der amerikanischen Gesellschaft gedacht wird. Hierbei verknüpft sie Darstellungen des Immunsystems in Massenmedien, "auf der Strasse«, im Zusammenhang mit Aids, im Bereich alternativer Therapietechniken sowie unter Wissenschaftler"innen (Marcus 1995: 108).

- „Follow the plot, story or allegory«: Bei dieser Strategie werden Geschichten oder Allegorien, die in einem Feld zum Ausdruck kommen, als Ausgangspunkt genommen, um ein »multi-sited« Forschungsprojekt in Angriff zu nehmen (Marcus 1995: 109). Hierbei geht es darum, wiederkehrende Erzählmuster aufzuspüren, um »moderne Mythenbildung oder Praktiken des kollektiven Gedächtnisses zu rekonstruieren« (Weissköppel 2005: 53).

- „Follow the life or biography«: Bei dieser Strategie wird die Lebensgeschichte zum Ausgangspunkt genommen, um unterschiedliche soziale Räume, Orte oder ethnografische Felder miteinander in Beziehung zu setzen und dadurch Verbindungen und Fragmentierungen zwischen verschiedenen (sozialen) Feldern sichtbar zu machen (Marcus 1995: 109). 
- "Follow the conflict«: Last but not least zählt Marcus die Strategie des "Follow-the-conflict « auf. Die vorgeschlagene Vorgehensweise besteht hierbei darin, unterschiedlichen Parteien in Konflikten zu folgen (ebd.: 110).

Schliesslich definiert Marcus eine siebte Strategie, die allerdings meines Erachtens nicht ganz auf derselben Ebene wie die anderen Strategien angesiedelt ist, nämlich die »strategically situated (single-site) Ethnography« (1995: 110), mit welcher er nicht etwa die Rückkehr zur klassischen Feldforschung meint, sondern »die gezielte Auswahl eines Ortes, der im Sinne einer Schaltstelle oder eines Knotenpunktes moderner, komplexer Schaltstellen funktioniert« (Weissköppel 2005: 54).

Weissköppel zufolge betrachtete Marcus die aufgeführte Liste der möglichen Strategien stets als ausbaufähig und unabgeschlossen und regte zu einer Kombination verschiedener Strategien an (ebd.).

Marcus' Entwurf einer Multi-sited Ethnography löste grosses Echo aus und wurde breit rezipiert, kommentiert, teilweise weiterentwickelt, kombiniert (vgl. bspw. Falzon 2009, Weissköppel 2005, Hannerz 2003, Gustavson/Cytrynbaum 2003) oder hinsichtlich unterschiedlicher Kontexte adaptiert (vgl. bspw. Stienen 2016 Fieldwork under forced protection).

Unter anderem fachte Marcus' Vorschlag die methodologisch-theoretische Debatte um das »ethnografische Feld« neu an. Diese drehte sich um folgende Fragen: Was ist ein Forschungsfeld? Sind »Felder « geografische Territorien oder soziale Konstruktionen? Was ist lokal? Was ist multilokal und translokal? Können lokale Praktiken in Verbindung mit globalen strukturellen Prozessen untersucht werden? Weissköppel argumentiert, dass Marcus' Begriff »multi-sited« keinesfalls dahingehend missverstanden werden dürfe, dass Feldforschung an verschiedenen Orten betrieben werde, sondern dass mit »multi-sited « eine Bandbreite an Forschungsstrategien gemeint ist, mittels derer sich die/der Forschende »across multiple sites of cultural meaning production « (2005: 45, 52-53) bewegt. Die meisten Forschenden, die über »multisitedness « geschrieben haben, würden diese methodologisch wohl von »multi-country research « unterscheiden - obwohl die verschiedenen Felder sehr wohl geografisch auch weit auseinander liegen können (Falzon 2009: 13). Dennoch ist die Spannbreite der Positionen gross. Sie könnte hier mit Falzon (2009: 2) wie folgt umrissen werden: während für die einen ein »multi-sited field« eine Form von (geografisch)-dezentriertem Raum darstellt, begreifen andere »site« gar nicht mehr räumlich im geografischen Sinne, sondern nur 
noch als »Perspektive«. Bei beiden Positionen handelt es sich um Extreme, welche die Spannbreite der Positionen auffächern, unbestritten bleibt jedoch, dass die mittlerweile in der Sozialanthropologie etablierte erkenntnistheoretische Prämisse, dass Raum sozial (vs. geografisch) wie auch transnational (vs. national abgeschlossen) konstruiert ist, zu methodologischen Konsequenzen führen musste (vgl. ebd.: 4). Marcus' Vorschlag einer multi-sited Ethnography stellte einen, wenn auch nicht den ersten, bedeutenden Vorstoss in diese Richtung dar (vgl. z.B. Mintz 1985). Weissköppel spricht bezüglich Diasporaund transnationalen Studien geradezu von einem »Boom« dieses Forschungsstils (Weissköppel 2005: 46).

Eine besondere Stärke von Marcus' vorgeschlagener Vorgehensweise ist meines Erachtens, dass er mit seinem Ansatz den Weg dafür bereitete, nicht nur geografische, transnationale, sondern auch soziale und insbesondere virtuelle Felder miteinander zu verknüpfen. In einem solchen Verständnis wird die Forschende »zur Spurensucherin (...), die kreuz und quer reist und recherchiert« (Weissköppel 2005: 52), wobei dieses Reisen eben nicht nur räumlichgeografisch zu verstehen ist, sondern auch als Reise im sozialen und medialen Raum, der bspw. auch internetbasierte soziale Räume und Diskurse umfassen kann.

Jeder Ansatz hat selbstredend auch seine Schwächen. So wäre vielleicht als Nachteil der Forschungsstrategie einer multi-sited Ethnography zu erwähnen, dass bei einer insgesamt gleichbleibenden Feldforschungsdauer die einzelnen der zahlreichen »Felder« nur vergleichsweise kurz und oberflächlich untersucht werden können im Vergleich zu einer klassischen ethnografischen Forschung, die in der Regel einen mindestens einjährigen »single-site « Aufenthalt »im Feld« erforderte. Falzon fasste die Kritik an dieser Forschungsstrategie als »the >Lack of Depth charge« zusammen (Falzon 2009: 7). Der Vorwurf der mangelnden Tiefe führte weiter auch zur Kritik an den aus dieser Forschungsstrategie angeblich resultierenden »travelling anthropologists« (Halbmayer 2017: 2). Diese würden sich, anstatt sich in einer Sache bzw. einem Feld zu vertiefen, als Folge dieser »multi-sited«-Forschungsstrategie ständig »reisend « zu neuen Feldern bewegen, so der Tenor dieser Kritik.

Demgegenüber besteht der im Zuge der zunehmenden Transnationalisierung und Globalisierung unbestrittene Vorteil einer systematischen Verknüpfung unterschiedlicher Felder, die sozialräumlich und manchmal ebenfalls geografisch weit voneinander entfernt sein können. Auch schärft der systematische Kontextwechsel den Blick »für Wiederkehrendes, Musterhaftes, was im einzelnen Kontext als Banalität untergehen würde« (Weissköp- 
pel 2005: 64). Nichtsdestotrotz bleiben kontinuierliche Forschungsbeziehungen, wenn auch an verschiedenen Orten, an verschiedenen "sites « zentral für das Gelingen einer solchen Forschungsstrategie (ebd. 64-65).

In der vorliegenden Untersuchung verstehe ich »Feld« in erster Linie sozialräumlich; dies umschliesst für mich jedoch auch unterschiedliche geografisch und sozial auseinanderliegende Orte und - wie Marcus (1995: 95) vorweg nahm - den virtuellen (sozialen) Raum. Bei vorliegendem Projekt kamen insbesondere zwei von Marcus vorgeschlagene Strategien zum Zuge: Die Strategie des Follow-the-people, sowie die Strategie des Follow-the-thing. Wobei bei letzterer Strategie der »the thing«-Begriff im Vergleich zu Marcus leicht ausgedehnt wurde.

Die Follow-the-people-Strategie bildete zunächst den Ausgangspunkt meiner ethnografischen Forschung. In einer ersten, explorativen Phase gelang es mir, durch Einzelkontakte den Zugang zum Forschungsfeld zu schaffen, sowie sog. key persons (vgl. Beck et al. 2005) zu eruieren.

Anschliessend ging es darum, das Forschungsfeld $\mathrm{zu}$ >erschliessen Ich liess mich »kreuz und quer" (Weissköppel 2005) `treiben drei Schlüsselpersonen über ca. ein halbes Jahr hinweg durch verschiedene sozialräumliche, geografische sowie virtuelle Felder. Wie Breidenstein et al. treffend feststellten, führt die »Forschungsstrategie, den Teilnehmern in ihren Relevanzen $\mathrm{zu}$ folgen, nicht zu methodischer Anarchie« (Breidenstein et al. 2015: 38), sondern »stützt sich hier auf theoretische Annahmen über den Gegenstandbereich: Kulturelle Felder verfügen über eine Eigenlogik, eine eigene Ordnung, die auch einen Beobachter, der sich treiben lässt, an die Hand nimmt und führt« (ebd., Herv. d. Verfasserin).

Ausgehend von diesen key persons gelang mittels der Follow-the-peopleStrategie der Aufbau eines relativ breiten Netzes an Feldkontakten und potenziellen Interviewpartnerinnen. Eine Folge dieser Vorgehensweise war, dass ich mich dadurch vorübergehend vor allem in den sozialen Netzwerken dieser ersten drei Schlüsselpersonen bewegte - weil diese vergleichsweise gut sozial, gemeinschaftlich und virtuell vernetzt waren und deshalb einem zunächst »feldfremden" Menschen wie mir auch gut zugänglich. Eine grössere Herausforderung bildete dann das Erschliessen von im Sinne eines Theoretical Samplings (Strauss/Corbin 1996) kontrastierenden Kontakten, denen in einem zweiten Schritt "gefolgt« werden sollte. Vergleichsweise schwierig gestaltete sich z.B. das Finden von den Sampling-Kriterien entsprechenden Frauen mit ausschliesslich informellen Netzwerken. Dies gelang via Bildungsinstitutionen durch Hinweise von Peers. Schliesslich war es 
möglich, gezielt und kontinuierlich diejenigen Frauen auszusuchen, denen ich im Rahmen meiner zeitlichen Möglichkeiten ${ }^{8}$ partiell »folgen « wollte. Ziel hierbei war es, im Sinne Bourdieus zu verstehen (vgl. Bourdieu 1997), wie sich die unterschiedlichen Lebenswelten von jungen, religiös orientierten Secondas muslimischen Glaubens konstruieren und wie ihre Referenz- und Deutungssysteme strukturiert sind.

Die Follow-the-People-Strategie führte mich über zwei Jahre hinweg in ganz unterschiedliche soziale und virtuelle Räume: in Familien- oder WG-Küchen, durch Chatforen, in Universitätsbibliotheken, Coiffeursalons, Kinderzimmer, durch Facebook-Threads, in biologische Labors, in Whats-App-Gruppen, an Podiumsdiskussionen, in Wohnzimmer, an muslimische Modeschauen, in Frauenräume in Moscheen, in Hijabläden, an Garagenverkäufe; ins Frauenbad (Sisters only), auf YouTube-Kanäle sowie an Veranstaltungen muslimischer Jugendgruppen und Freitagsgebete; an Iftar-Anlässe und an Hochzeiten; durch Bewerbungsprozesse und Gespräche um zukünftige Kindernamen; sowie in eine sich regelmässig treffende muslimische Frauengruppe einer Moschee. Kurzum - ich versuchte an den unterschiedlichen Lebenswelten der Frauen, denen ich »folgen« durfte - hier gebührt ihnen nochmals ein ganz herzlicher Dank! - im Rahmen der gegebenen Möglichkeiten möglichst umfassend und »multi-sited« teilzunehmen.

Die Follow-the People-Strategie verschaffte mir schliesslich Zugang $\mathrm{zu}$ einer Art gegendertem transnationalem (religiösem) Sozialraum, in dem (neue) Vorstellungen von Glauben und Glaubensgemeinschaft ausgehandelt sowie (religiöse) Selbstverständnisse und Selbstrepräsentationen von jungen Muslimas konstruiert werden. Die Follow-the-people-Strategie diente mir da$\mathrm{zu}$, Relevanz- und Deutungssysteme und (religiöses) Selbstverständnis der untersuchten Akteurinnen zu erfassen und (sprachliche) Codes zu verstehen.

Parallel zu der Follow-the-people- kam die Follow-the-thing-Strategie zum Zuge. Den »the thing «-Begriff weitete ich in Bezug auf Marcus (1995: 107) etwas aus, in dem ich eine weitgehend entmaterialisierte Kategorie als die zu verfolgende Sache festmachte: Als ein »the thing (bzw. Sachstrang) definierte ich einerseits die Differenzkategorie »Muslimin« - die »Follow-the-Thing«-Strategie wurde hier zu einer Diskursanalyse: In Medien, Presse und virtuellen Medien verfolgte ich die Diskussion und Manifestation der Differenzkategorie »Muslimin« im Islamdiskurs in der Deutschschweiz. Dies mit besonderem Fokus 
auf den Bildungsbereich und auf die Lebenswelt von Frauen (z.B. Kopftuchdebatten im Zusammenhang mit der öffentlichen Wahrnehmung von muslimischen Frauen, insbesondere den Berufs-und Bildungsbereich betreffend). Auch wurden der wissenschaftliche Diskurs und neuere Publikationen zum Thema systematisch gesichtet sowie versucht, die Differenzkategorie »Muslimin « in Bezug auf die neueren tagespolitischen Ereignisse, die den Islamdiskurs in der Schweiz befeuerten, zu situieren (vgl. u.a. Kapitel 2.1).

Auf der anderen Seite verfolgte ich als zweiten Sachstrang (»thing«) (virtuell) kursierende Themen, welche die jungen Musliminnen beschäftigen, gemäss der iterativen und offenen Vorgehensweise GroundedTheory-Methodologie (Strauss/Corbin 1996). Diese Themen eruierte und verfolgte ich relativ breit: einerseits über einschlägige Websites, Facebookeinträge/-kommentare, YouTube-Filme, Social-Media-Plattformen und andere Kommunikationsplattformen, aber auch in grauer Literatur, Newslettern, Flyern und anderen Felderzeugnissen, die kontinuierlich gesichtet wurden. Zum anderen eruierte ich diese Themen aber auch in Gesprächen bei Besuchen in »analogen« sozialen Feldern.

Mittels der Follow-the-thing-Strategie kam ich bspw. der Thematik der Unterscheidung von Kultur/Tradition vs. Religion - hier nicht verwendet im analytischen Sinne, sondern als Akteur*innenbegriffe - auf die Spur, welche sich durch diverse (virtuelle) Felder zog (vgl. ausführlich, Kap. 6). Andererseits brachten mich die Suche und das Verfolgen von Themen, die adoleszente Muslimas beschäftigen, insbesondere auch zu interessanten Einsichten in Fragen der (religiösen) Selbstrepräsentation (bspw. ob/wie/wann zeige ich mich als gläubige Muslima), der gesellschaftlichen Selbstpositionierung sowie des (religiösen) Selbstverständnisses. In Fragen der (religiösen) Selbstrepräsentation war die ethnografische Forschungsstrategie besonders hilfreich. Sie führte mich zu interessanten Einsichten bspw. bezüglich situativ variierender (religiöser) Selbstrepräsentation (vgl. Bsp. Lane) und führte teilweise Aspekte zutage, welche die geführten Gespräche kontrastierten (vgl. hierzu Lüders 2011: 151).

Weiter führte mich die Suche nach Themen, die religiös orientierte Secondas beschäftigen, auch zu Lifestyle-Fragen (z.B. Kopftuch-Tutorials, »Muslima-gerechtes« Schminken, Fashion-Labels, Musikvideos etc.). Lifestyle-Fragen sind oft eng verwoben mit Fragen religiöser Selbstrepräsentation und der gesellschaftlichen Selbstbehauptung und Positionierung.

Schliesslich wurde die gesamte Feldforschung kontinuierlich dokumentiert; einerseits in Beobachtungsprotokollen (»Feldprotokolle«), andererseits 
durch die Anlage einer Film- und Fotodatenbank, einer Sammlung weiterer Felderzeugnisse (bspw. Flyer, Newsletter, Werbeartikel von Organisationen etc.) sowie Internet- und Zeitungsartikeln. Die Reflexion der Feldeindrücke fand entsprechend der Grounded-Theory-Methodologie laufend in sog. Memos statt (vgl. Strauss/Corbin 1996).

\section{Exkurs: Ethnografische Forscherin in einem politisch umkämpften, religiösen Feld}

Khawaja und Mørcks stellten in ihrem Aufsatz Researchers Positioning: Muslim Otherness and Beyond (2009) fest:

»A key point (...) is the importance of constant awareness of and reflection on the multiple ways in which one's positioning as a researcher influences the research process. Studying the others calls for close reflections on one's own position, theoretically, personally, and politically, taking into account one's complicity in either overcoming or reproducing processes of othering and marginalisation« (ebd.: 28).

Als ethnografisch Forschende in einem hochpolitisierten »Feld «, wie dies das Erforschen von Lebenswelten junger Musliminnen derzeit darstellt, wurde ich von Anfang an von verschiedensten Seiten her immer wieder nolens volens dazu gezwungen mich theoretisch, politisch und persönlich zu positionieren (vgl. hierzu Khawaja/Mørck 2009). Einerseits ereilte mich dieser »Positionierungszwang« (Riegel 2004: 338) im öffentlich-professionellen Bereich, andererseits aber auch in meinem privaten Umfeld, sowie »im Feld « gegenüber den jungen Frauen selbst. Mannigfaltige Ansprüche und (Vor-)Urteile kumulierten bei diesen erforderlichen Positionierungsprozessen. Einerseits wurde ich in die Rolle der »Expertin für Islam « und alles dem Islam Zugeschriebene gedrängt, andererseits aber auch in die Rolle der "Anwältin aller Musliminnen«, die alles und jedes zu rechtfertigen hat, was (meist gerade in globaler Hinsicht gesehen) der sog. »Rolle der Frau im Islam« zugeschrieben wird. Kurzum, ich wurde selbst demjenigen »dauernden Rechtfertigungsdruck «(Tunger-Zanetti 2013c, Tunger-Zanetti 2013a: 224) ausgesetzt, der als gesellschaftlich omnipräsenter Druck auf den jungen muslimischen Frauen »im Feld« lastet (vgl. Kapitel 5.4). Auch die Rolle der »Expertin für Islam« ist manchen Frauen, die ich untersuchte, nicht fremd. Insbesondere diejenigen, welche eine nachobligatorische schulische Ausbildung besucht haben, beklagten sich, dass sie in der Erwartungshaltung von Lehrpersonen und Peers nicht nur über sämtliche religiöse Belange, sondern auch über jegliche, »dem Islam« und der »arabi- 
schen Kultur« zugeschriebene Dinge (wie z.B. Mädchenbeschneidung oder aber auch weltpolitische Konflikte sowie tagespolitische Ereignisse) Auskunft geben können und eine Meinung haben sollten (vgl. Kapitel »Expertin für Islam«, S. 178ff.). Gleiches galt im übertragenen Sinne für mich als Forscherin. Ich kann nun sehr gut nachvollzeihen, dass die Zuschreibung einer solchen Expert"innenrolle äusserst unangenehm sein kann. Hinzu kommt, dass die zu beantwortenden »Fragen zum Islam « meist in einem hochnormativen, politisch und emotional aufgeladenen Kontext geäussert werden und ich erlebte ansatzweise, was die jungen Frauen hinsichtlich dieser Rolle beschrieben: Nämlich dass eine solche Rolle zwangsläufig zu einem Gefühl der Überforderung einerseits und zu einem Gefühl des Scheiterns an vorgefassten Meinungen und nicht erfüllbaren Ansprüchen andererseits führt.

Weiter erforderten auch »das Feld« bzw. die Menschen im Feld eine konstante Positionierung, Reflexion und Klärung von sozialen, politischen und religiösen Zugehörigkeiten (vgl. hierzu auch Weissköppel 2005: 56, zum ethnografischen Forschen im »religiösen Feld« vgl. auch Blanes 2006). Zum einen stiegen mit zunehmender ethnografischer Nähe die Ansprüche seitens der Frauen, denen ich »folgte«, mich politisch, persönlich aber auch hinsichtlich meiner Religionszugehörigkeit zu positionieren. So wurde ich mit zunehmender Dauer meiner Forschung und Bekanntheit meiner Person in entsprechenden religiös konnotierten Feldern z.B. gefragt, ob bzw. wann ich (endlich) konvertieren wolle (vgl. hierzu auch Weissköppel 2005: 56, Blanes 2006). So kam ich in die Lage, meine Zugehörigkeit zum Christentum zu markieren; dies "mehr [als] ein rettender Anker in der Rollenkonfusion als ein Überzeugungsakt« (Weissköppel 2005: 56). Die Erfahrung, dass von einer ethnografisch Forschenden in einem dezidiert »religiösen Feld« bezüglich religiöser Zugehörigkeiten eine Positionierung erwartet wird, habe ich bereits in einem anderen Forschungsprojekt im Kontext von evangelikalen Jugendlichen machen können (vgl. Steinen/Bühler/Gasser/Tamcan 2011). Insofern ist Blanes beizupflichten, wenn er seinem Artikel The Atheist Anthropologist: Believers and non-believers in anthropological fieldwork (2006) feststellt: "personal belief ( (..) can be restaged from a peripheral to a central position within anthropological and ethnographic projects concerning religious phenomena (ebd.: 225). Interessant war für mich insbesondere die Erkenntnis, dass zwar meine Positionierung in beiden Forschungen demselben Zweck diente, nämlich mich allzu missionarischem Eifer seitens »des Feldes $z$ zu entziehen; situativ musste diese jedoch - trotz gleichbleibender Intention - kontextuell erfolgen und somit im meinem Falle diametral entgegengesetzt: Während ich im 
Kontext der vorliegenden Forschung meine religiöse Zugehörigkeit tendenziell eher unterstrich, musste ich sie im Falle der erwähnten Forschung im Kontext von evangelikalen Adoleszenten eher abschwächen. Auch die Erfahrung der situativ kontextuellen Betonung/Abschwächung bezüglich (religiöser) Zugehörigkeiten teile ich mit den jungen Frauen, die ich untersuchte. Die Forschungsgruppe um Giordano (Allenbach et al. 2010: 9) stellte wie zuvor bereits erwähnt fest, dass junge Muslim*innen unterschiedliche Aspekte ihrer (religiösen) Zugehörigkeiten flexibel einsetzten, um sich je nach Kontext und Situation zu positionieren (ebd.: 10).

Weiter musste ich als ethnografisch Forschende auch wiederholt meine Rolle klären und die Erwartungen dämpfen, welche mit zunehmender Dauer der Forschungsbeziehungen im sozialen Bereich entstanden. So wurde z.B. mit der Zeit von einigen Frauen eine reziproke Beziehung in Bezug auf soziale Kontakte erwartet, was sich etwa daran zeigte, dass ich wiederholt aufgefordert wurde, bei der Jobsuche zu vermitteln, in Bewerbungsprozessen zu helfen oder aber auch meine Familie mitzubringen, z.B. zu einem Abendessen oder einem Iftar. Dies erforderte eine Rollenklärung. Auch im politischen Bereich wurde von mir immer wieder implizit oder explizit eine Positionierung erwartet, z.B. nach tagespolitischen Ereignissen, wie z.B. dem Verbot der Jahresversammlung des IZRS im November 2014, welche von vielen jungen Muslim*innen weit über die Kreise des IZRS hinaus mit relativ grosser Emotionalität verhandelt wurde. Als weitere Frage stellte sich, wie ich mich als Forschende bezüglich der Geschlechterordnungen in religiösen Kontexten positionieren sollte (z.B. was das Bedecken des Haars in religiösen Kontexten anbelangt oder das Einhalten von genderspezifischen Sitzordnungen, wo gegeben etc.). Hier versuchte ich einen pragmatischen Weg zu gehen und in Absprache mit den Frauen, denen ich »folgte«, auszuhandeln, welches Verhalten kontextuell angemessen und wo ich durch meine Rolle als Forschende zwecks Erkenntnisgewinns geschlechtskonforme Verhaltensweisen auch einmal etwas strapazieren konnte.

Stellte diese kontinuierlich erforderliche »Positionierungsleistung« anfänglich in allen Bereichen eine grosse Herausforderung dar, wurde es einerseits durch fortwährende (theoriegeleitete) Reflexion, aber andererseits auch durch eine sich einstellende Routine mit der Zeit einfacher, Möglichkeiten und Grenzen meiner professionellen Rolle als Forscherin zu kommunizieren und dennoch tragfähige Forschungsbeziehungen zu entwickeln. 


\subsection{Biografisch-narrative, themenzentrierte Interviews}

Als Erhebungsmethode der neunzehn ausführlichen (bildungs-)biografischen Interviews kam eine Mischung zwischen biografisch- narrativen und themenzentrierten Einzelinterviews zum Zuge, es handelte sich hierbei um offene Gespräche, die einerseits einer biografischen Linie folgten, andererseits aber auch themenzentrierte Frageblöcke beinhalteten (vgl. Kurth/Lehmann 2011). Es wurden gesamthaft neunzehn biografische Interviews geführt, digital aufgezeichnet und transkribiert sowie diverse formelle und informelle Expert"innen-Interviews geführt.

Die Einstiegsfrage bestand aus einer erzählgenerierenden Frage ${ }^{9}$ : Die Interviewten wurden gebeten, ihre Überlegungen zur Berufswahl bzw. zum Übergang von Schule zur nachobligatorischen Ausbildung Auskunft zu geben. Hierbei lag interviewtechnisch gesehen der Fokus auf dem Prinzip der Narrativität (Kurth/Lehmann 2011:135) und somit auf »der freien, erzählerischen Darstellung von selbst Erlebtem« (ebd.). Gleichzeitig wurde dem Prinzip der Offenheit (ebd.) Rechnung getragen, gemäss dessen den Befragten ermöglicht werden soll »ihre persönlichen Erfahrungen, Sichtweisen und Motive in ihrer eigenen Logik, Sprache und Relevanzsetzung darzustellen« (ebd.).

Einer biografisch-narrativen Linie folgend wurden im Laufe der Interviews der Stellenwert allfälliger religiöser Orientierungen sowie gesellschaftliche Zuschreibungsprozesse für das (berufliche) Selbstverständnis bzw. den Bildungsweg angemessen thematisiert (vgl. Stienen/Bühler/Gasser/Tamcan 2011). In einem Nachfrageteil wurden mittels fokussierten Nachfragens nicht oder nur am Rande erwähnte, für die Forschungsfrage jedoch relevante Aspekte thematisiert.

Die biografischen Interviews fanden an unterschiedlichen Orten, jedoch in den allermeisten Fällen bei den Interviewten zu Hause oder in deren privatem Umfeld statt. In zwei Fällen wurden die Interviews an Bildungsinstitutionen geführt. In den Expert*innen Interviews wurden Expert*innen

9 In den Interviews wurde mit einer gleichbleibenden Einstiegsfrage gearbeitet. Anschliessend wurde der Logik eines natürlichen Gesprächsverlaufs folgend mit Themenblöcken gearbeitet, die je nach Verlauf in unterschiedlicher Reihenfolge thematisiert werden konnten. Nach dem Interview kam zudem ein biografischer Fragebogen zum Zug, mithilfe dessen herkunftsmilieuspezifizierende Fragen in Bezug auf den Bildungsstand der Eltern, Partner, Geschwistern, Grosseltern, ggf. Kinder etc.) erhoben werden konnten. 
aus unterschiedlichen (Bildungs-)Bereichen einerseits mit Zwischenresultaten konfrontiert und gebeten, diese $\mathrm{zu}$ kommentieren, andererseits hinsichtlich Sachfragen und möglicher Lücken im Datenmaterial befragt. Die Expert*innen-Interviews fanden an den jeweiligen Arbeitsorten der Interviewten statt. Unmittelbar nach dem Interview erstellte ich ein sogenanntes "post comment interview sheet", wie das Miles und Hubermann (1984 zit.n. Mey/Mruck 2007: 495) vorschlagen, wo ich erste Eindrücke festhielt, das mir aber auch als »self-monitoring tool« (ebd.: 495) dazu dienen sollte, eigenen Konzepten auf die Spur zu kommen und deren Einfluss zu limitieren oder zumindest $\mathrm{zu}$ reflektieren.

Die Interviews wurden in Mundart geführt und anschliessend in Standardsprache übersetzt (Transkriptionsregeln siehe Anhang). Dabei wurde versucht, den Sinn des Satzes möglichst unverändert zu lassen. Es gilt hierbei jedoch im Hinterkopf zu behalten, dass, wie Bourdieu feststellte, »auch die wörtlichste Verschriftlichung bereits eine wirkliche Übersetzung oder zumindest eine Interpretation ist« (Bourdieu 1997: 797).

\subsection{Codierung und kontinuierliche Auswertung: datengeleitete Theoriebildung nach der Grounded-Theory-Methodologie (GTM) kombiniert mit einer fallzentrierten Perspektive}

Der gesamte Erhebungs- und Analyseprozess folgte der iterativen, offenen Vorgehensweise der Grounded-Theory-Methodologie (Strauss/Corbin 1996), deren wichtigste Technik das Vergleichen bzw. die Suche nach Ähnlichkeiten und Unterschieden ist. Das Grounded-Theory-Verfahren geht ursprünglich auf die beiden Soziologen Anselm Strauss und Barney Glaser zurück (vgl. Glaser/Strauss 1967, Strauss 1994, Strauss/Corbin 1996) und wurde seither immer wieder ergänzt und weiterentwickelt (vgl. bspw. Mey/Mruck 2007). Das Verfahren der Grounded Theory ist in der soziologischen Theorietradition des symbolischen Interaktionismus begründet, welche »die Wechselwirkung von Gesellschaft und Individuen berücksichtigt und darauf zielt, Mechanismen der (Re-)Konstruktion der sozialen Wirklichkeit aufzudecken « (Müller 2013: 154). Es lässt sich somit ideal mit der theoretischen Einnahme einer sozialkonstruktivistischen Perspektive, wie sie vorliegendem Projekt zugrunde liegt, vereinen. 
Ziel der Grounded-Theory-Methodologie $\left(\mathrm{GTM}^{10}\right)$ ist »eine »regelgeleitete, kontrollierte und prüfbare 'Entdeckung، von Theorie aus Daten/Empirie« (Mey/Mruck 2011:11). Der eigentliche Forschungsprozess nach Grounded Theory erfolgt zirkulär; das heisst, dass Datenerhebung, -analyse und Theoriegenerierung miteinander verschränkt sind. Die renommierten GTM-Forschenden Mey und Mruck gehen von drei Essentials der GTM aus (Mey/Mruck 2009: 108), die zum Standard genommen werden sollen, wenn Forschende für sich beanspruchen, eine auf der Grounded-Theory-Methodologie basierende Studie durchgeführt zu haben (ebd.). Es sind dies: 1) Konzeptbildung statt Beschreibung; 2) Theoretical Sampling und Theoretische Sättigung und 3) das Schreiben von Memos (ebd.: 108ff.).

Die Basis für die GTM ist demnach eine Auseinandersetzung mit Daten, die von Beginn weg nicht auf eine rein deskriptive Art erfolgen soll. Das technische Vorgehen bei der Datenanalyse versteht sich als "theorie-orientiertes Kodieren« (ebd.:108), bei dem gefragt wird, wofür der einzelne, empirische Vorfall steht bzw. welchen theoretischen Gehalt er besitzt.

Der Datenkorpus der vorliegenden Untersuchung bestand aus Feldprotokollen, neunzehn formell aufgezeichneten, biografischen Interviews, diversen Expert*innen-Interviews, einer Foto- und Filmdatenbank, einer Sammlung weiterer Felderzeugnisse (bspw. Flyer, Newsletter, Werbeartikel von Organisationen etc.) sowie Internet- und Zeitungsartikeln. Hinzu kamen zahlreiche »Memos« (vgl. Strauss/Corbin 1996: 169ff.), die den rollenden Forschungsprozess dokumentierten, reflektierten und kommentierten. Bei der Analyse wurde der in der Grounded-Theory-Methodologie geltenden >Faustregek »all is data« (Glaser 2004, Abschnitt 3.3) gefolgt. Die Offenheit für neue, aus den Daten erschlossene Themen ist denn auch ein Charakteristikum ethnografischer Analyseprozesse mittels Grounded Theory - in welcher die »Heuristik der Entdeckung« nicht nur für die Erhebungsphase, sondern auch für die Phase der Analyse gilt (Breidenstein et al. 2015: 119).

Um die Akteurinnenperspektive der befragten Frauen anschliessend im Einzelfall wie auch fallübergreifend zu analysieren, wurde auf ein kombiniertes Verfahren zurückgegriffen: Einerseits wurden die Interviews in einer (bildungs-)biografischen, fallzentrierten Perspektive analysiert (vertikale Dimension), andererseits wurde das gesamte Datenmaterial in einem daten-

10 Mey und Mruck unterscheiden zwischen Grounded-Theory-Methodologie (GTM) als gesamtem Forschungsansatz und Grounded Theory (CT) als Produkt dieser Vorgehensweise (Mey/Mruck 2009: 108). Dieser Unterscheidung wird hier gefolgt. 
und theoriegeleiteten Codegenerierungsprozess im Hinblick auf die Erarbeitung transversaler Themen untersucht (horizontale Dimension) ${ }^{11}$. Durch die fallzentrierte Perspektive - die vertikale Dimension - sollten (bildungs-)biografische Prozesse im Zusammenhang mit gesellschaftlichen Strukturen und/oder Einschränkungen ermittelt werden. Durch die Einnahme einer transversalen Perspektive - horizontale Dimension - hingegen sollten Themen ermittelt werden, welche den Relevanzen des Felds vergleichend folgten und so eruieren sollten, welche Bedeutung der diskursiven Differenzkategorie »Muslimin« in den Bildungsbiografien der jungen Frauen zukommt und ob und inwiefern sich diese auf bildungsbiografische Verläufe auswirkte.

Um die Daten saufzubrechen<, zu reduzieren und zu ordnen, wird in der klassischen GTM-Vorgehensweise zwischen offenem, axialem und selektivem Codieren unterschieden (Strauss/Corbin 1996, Strauss 1994). Der gesamte Codierprozess dient dem Ziel einer datengeleiteten Theoriebildung (Mey/Mruck 2011: 24) und erfolgt zirkulär, weil die am Material gebildeten Codes und Kategorien und deren Zusammenhänge kontinuierlich an neuem Material geprüft und verfeinert werden (Mey/Mruck 2009: 116).

In dem Auswertungsprozess folgte ich in weiten Teilen dieser klassischen, zirkulären Vorgehensweise: Ich codierte laufend während des Erhebungsprozesses das neue Datenmaterial ${ }^{12}$. Das sogenannte offene Codieren dient dem >Auseinanderbrechen des Texts, wobei die Idee dahinter ist, den tieferliegenden Gehalt der Daten zu ergründen. Beim offenen Codieren werden bspw. ein Interview oder ein Feldprotokoll, aber auch visuelle Dokumente Zeile für Zeile bzw. Szene für Szene analysiert und es werden provisorische Codes ${ }^{13}$ vergeben. Während der offenen Codierung soll sich gemäss der GTM allmählich ein Verständnis dafür entwickeln, wie die einzelnen Kategorien zusammenhängen und welche Codes zentral sind. Hierbei kann zwischen soziologisch konstruierten Codes ${ }^{14}$ einerseits und In-vivo-Codes andererseits unterschieden werden (Müller 2013: 155). Während die soziologisch konstruierten Codes aus der Literatur abgeleitet werden, entsprechen In-vivo-Codes der Terminologie

\footnotetext{
11 Eine ähnliche Auswertungsstrategie schlägt Müller (2013: 154ff.) vor.

12 Technisch erfolgte die Codierung mittels der Codierungssoftware MAXQDA.

13 Analog zu Codes wird manchmal auch von Konzepten gesprochen, um zu unterstreichen, dass es nicht um eine Deskription, sondern um eine Konzeptbildung geht (vgl. Mey/Mruck 2009: 114).

14 Diese Art von Codes wird auch als »geborgte Codes« bezeichnet, »geborgt« im Sinne von auf Fachwissen bzw. Vorwissen zurückgreifend (Mey/Mruck 2009: 114).
} 
»des Feldes«. Ein Beispiel für einen offenen In-vivo-Code wäre »steihert zrüggdiss ${ }^{15}$ «. Unter diesen Code fallen empirische Vorfälle, die zu folgendem von mir erstellten Code-Beschrieb passen: »Widerstand leisten gegen empfundenes Unrecht, meist im Zusammenhang mit Ausschlusserfahrungen. Steht im Kontrast zu der Haltung, sich (bedingungslos) anzupassen, wobei Anpassen als >uncook verstanden wird. « Ein Beispiel für aus der Literatur abgeleitete, sogenannte soziologisch konstruierte Codes wäre: »Ausbildung als Aufstiegsprojekt« oder »soziales Kapital« im Anschluss an Bourdieu.

Die Vergabe von Codes ist nach GTM am Anfang noch ganz nahe am Datenmaterial. In einem zweiten Schritt erfolgt als weiterer Abstraktionsschritt das axiale Codieren, das auf Erarbeitung von Zusammenhängen abzielt. Ziel des axialen Codierens ist es, die Codes miteinander zu vergleichen, nach inhaltlichen Kriterien in Kategorien zusammenzufassen und zu benennen (Mey/Mruck 2009: 115). Kategorien verweisen auf "Konzepte höherer Ordnung« (ebd.); auch hier kann wiederum zwischen soziologisch konstruierten und In-vivo-Bezeichnungen unterschieden werden (ebd.). Das axiale Codieren kommt meist in mittleren bis späteren Stadien des Forschungsprozesses zur Anwendung (Müller 2013: 156). Ein Beispiel für einen axialen In-vivoCode aus vorliegender Forschung wäre »es zeigen«: Diese Kategorie beschrieb ich zunächst folgendermassen: "Sich an ein (imaginäres) gesellschaftliches 'Gegenüber richtende Handlungen und Äusserungen, die dazu dienen, ostentativ zzu zeigen<, dass die Person als Frau bzw. Muslima nicht etwa so ist/denkt/handelt, wie vom gegenderten Islamdiskurs antizipiert«.

Beim selektiven Codieren schliesslich geht es als letztem Codierungsschritt um die Sichtung und Sortierung von Codelisten, Kategorien und zusammenfassenden Memos (ebd.).

Beim selektiven Codieren folgte ich dem von Breidenstein et al. (2015) konzipierten Prinzip der »doppelten Relevanz ethnographischer Themen« (2015:

15 Dieser Terminus entstammt dem jugendumgangssprachlichen Berndeutschen Dialekt. Er ist sehr schwierig ihn adäquat in Standardsprache zu übersetzen; wörtlich könnte »steihert zrüggdisse« etwa mit »knallhart zurückgeben« (im sprachlichen Sinne verstanden) übersetzt werden. Beim Teilwort »-disse « handelt es sich um eine >Eindeutschung des englischen Slang-Terminus' »to diss someone « (abgeleitet von »to disrespect someone«), der vor allem in der Hiphop-Szene gebräuchlich ist, um jemandem seinen »disrespect«sprachlich auszurücken (vgl. Urban Dictionary 2017). In der HiphopSzene wird dieses Wort auch benutzt, um den rivalisierenden Sprechgesang auf der Bühne zu bezeichnen (ein*e Rapper"in »disst« die andere) (ebd.). 
118). Mit »doppelter Relevanz« meinen Breidenstein et al. Themen, die einerseits »in den Daten in den erkennbaren Relevanzen des Feldes gründen« und andererseits »für den wissenschaftlichen Diskurs anschlussfähig« sind (ebd., Herv. im Orig.). Um die Codierung zu systematisieren, sowie Metakategorien und analytische Themen »doppelter Relevanz« zu eruieren, wurde parallel zum offenen Codierungsprozess ein grosses Übersichtsdokument erstellt. Mithilfe dieses Dokuments wurde angestrebt, die auf MAXQDA vorgenommenen Codierungen unter Oberkategorien zu systematisieren.

Es besteht eine gewisse Schwierigkeit darin, einen zirkulären Forschungsprozess »linear« darzustellen. Deshalb beschreibe ich nun untenstehend die parallel zur Codierung verlaufenden Memoing- und TheoreticalSampling-Prozesse, mit dem Hinweis darauf, dass diese während des ganzen Forschungsprozesses zirkulär immer wieder zum Zuge kommen:

Parallel und basierend auf dieser fortwährenden Codierung sampelte ich theoretisch nach neu auftauchenden Kriterien kontinuierlich junge Frauen, denen ich teilweise in Marcus' vorgeschlagenem Sinne mittels der »Followthe-people-Strategie« (Marcus 1995:106) »folgte« (mithilfe des bereits in Kapitel 4.1 beschriebenen Verfahrens des Theoretical Samplings, Strauss/Corbin 1996: 148ff.).

Ein weiterer zentraler Aspekt der iterativen Vorgehensweise der GTM ist das fortwährende Schreiben von sogenannten Memos (»Memoing«). Diese Vorgehensweise erwies sich als sehr sinnvoll: Laufend wurde der Codierungsprozess unterbrochen, um Auswertungsschritte, Gedanken, theoretische Ideen und Konzepte in Memos festzuhalten. Glaser und Strauss weisen beide auf den zentralen Stellenwert des »Memoing« in der GTM hin und unterstreichen hierbei die Bedeutung einer kontinuierlichen Dokumentation und Reflexion für den Forschungsprozesses. Glaser beschreibt dies wie folgt:

»Theory articulation is facilitated through an extensive and systematic process of memoing that parallels the data analysis process in GT. Memos are theoretical notes about the data and the conceptual connections between categories. The writing of theoretical memos is the core stage in the process of generating theory. If the analyst skips this stage by going directly to sorting or writing up, after coding, he/she is not doing GT « (Glaser, Barney G. with assistance of Judith Holton 2004: Abschnitt 3.14).

Es ist Glaser beizupflichten, wenn er den »Memoing «-Prozess als zentral einstuft. In vorliegendem Projekt arbeitete ich intensiv mit verschiedenen Arten von Memos. Grob könnten diese in Auswertungs-, Theorie-, Planungs-, Me- 
thoden - und Reflexionsmemos eingeteilt werden. Des Weiteren erstellte ich auch eine thematische Sammlung von Konzept-Memos im Zusammenhang mit meiner Feldforschung.

Während die unzähligen Memos sich zu Beginn des Forschungsprozesses noch nicht auf einem sehr hohen Abstraktionsniveau befanden, verdichteten sie sich während des laufenden Forschungsprozesses stetig, wurden überarbeitet, systematisiert oder wieder verworfen. Sie bildeten schliesslich Vorstufen zum vorliegenden Manuskript.

Während beim Analyseprozess das offene Codieren zunächst als Instrument für die Feinanalyse - für das `Auseinanderbrechen der Daten verwendet wurde und die Codes anschliessend durch das axiale Codieren miteinander in Verbindung gebracht wurden (horizontale Dimension) kam an zweiter Stelle wiederum die Falldimension (Bildungsbiografie) ins Spiel (vertikale Dimension, siehe oben): Flick spricht bei einem kombinierten fallorientierten Vorgehen anlehnend an Grounded Theory von »thematischem Codieren« (Flick 2010: 402). Aufbauend auf das von ihm vorgeschlagene Verfahren trug ich in einem ersten Schritt folgende offene, thematisch orientierte Fragen an die bildungsbiografischen Fälle heran - diese Fragen orientierten sich nicht zuletzt auch am zuvor beschriebenen intersektionellen Zugang als »sensitizing concept«:

- Welche Themen/Handlungsmuster sind für den einzelnen Fall zentral, welche nicht?

- Wie zeigt sich der Verlauf der Bildungsbiografie, welche Ereignisse, Strukturen, Handlungsweisen sind ausschlaggebend?

- Welche Differenzdimensionen (Herkunftsmilieu (»class«), »Migrationshintergrund«, Gender, Religion, sichtbare religiöse Symbole (z.B. Hijab), religiöse Selbstrepräsentation, Körper (z.B. Hautfarbe etc.) kommen im vorliegenden Fall in Bezug auf den Bildungsweg zum Tragen und wie, welche nicht und warum?

- Welche Rolle spielt hierbei die Differenzkategorie »Muslimin« und der gesellschaftspolitische Islamdiskurs?

- Wie wirken diese Differenzdimensionen intersektionell in Bezug auf Bildungsbiografien?

- Welche Rolle spielen hierbei das religiöse Selbstverständnis, die religiöse Selbstrepräsentation und eine allfällige religiöse Vergemeinschaftung? Welche Rolle spielen die generationalen Beziehungen?

- Welche Rolle kommt dem Bildungssystem zu? 
Mittels dieser Fragen kristallisierten sich auf der Ebene der Handlungsmuster unterschiedliche »Taktiken« (De Certeau 1988: 89) von jungen Frauen in Bezug auf den Bildungszugang und das bildungsbiografische Bestehen heraus. Diese »Taktiken« erschienen mir bezüglich der zuvor beschriebenen Handlungstheorie von De Certeau (1988, vgl. Kap. 2.3) sowie einer intersektionellen Perspektive als theoretisch anschlussfähig im Sinne von Breidenstein et al. als Prinzip der »doppelten Relevanz ethnographischer Themen« (2015: 118).

Da sich im fallkontrastierenden Vergleich verschiedene sich repetierende, ähnliche Handlungsmuster innerhalb ähnlicher struktureller Bedingungen zeigten, lag eine Typisierung nahe. Bei der Typenbildung löste ich mich jedoch im Gegensatz zu Flicks Vorschlag (2010: 402ff.) von der Ebene der Personen und typisierte stattdessen auf der Ebene von Handlungsmustern ${ }^{16}$ (vgl. Kelle/Kluge 2010: 111ff.).

Wie Kelle und Kluge (2010: 47ff.) vorschlagen, folgte ich auch in der Typisierung der kontinuierlich konstatierenden Vorgehensweise der GroundedTheory-Methodologie. In einem weiteren Schritt fragte ich also, welche habituell verankerten »Taktiken« am ehesten als "prototypisch« (ebd.: 105) aufgefasst werden können und welche diesen kontrastierend entgegengesetzt werden können. In Abgrenzung zum »Weberschen Idealtypus« (vgl. Weber 1995 [1904]), der »einem zugespitzten, für die Analyse konstruierten Gedankenbild gleichkommt « (Müller 2013: 157) beruhen »Prototypen« auf realen Fällen, welche die Charakteristika eines jeden zu typisierenden Handlungsmusters am besten repräsentieren (Kelle/Kluge 2010: 105): An ihnen soll das Typische aufgezeigt werden und die individuellen Besonderheiten dagegen abgegrenzt werden (ebd.). Selbstverständlich bleibt eine Typenbildung jeglicher Art ein heuristisches Instrument zum Sichtbarmachen von Ergebnissen. Die Kehrseite dieser Darstellungsform ist, dass zugunsten der Gewinnung trennscharfer, analytischer Kategorien zur differenzierenden Wahrnehmung sozialer Wirklichkeiten und Prozesse gewisse Finessen einzelner Fälle unterbeleuchtet bleiben. Dem einzelnen Fall kann eine Typologie - so betrachtet nie ganz gerecht werden. In vorliegender Untersuchung habe ich mich, im Wissen um die Grenzen dieser Darstellungsform dennoch für eine Typisierung zum Zwecke der Kommunizierbarkeit und Sichtbarmachung von strukturellen und strukturierenden Bedingungen sozialer Prozesse entschieden.

16 Durch die habituelle Einbettung dieser »Taktiken« (vgl. Kap. 2.3) wurde jedoch gleichzeitig der Aspekt der soziostrukturellen Verankerung der Handlungsmuster berücksichtigt. 
Die Typologie soll dazu beitragen, dieses komplexe Forschungsfeld zu fassen. Die Art der Illustration der Typologie anhand von auf realen Fällen beruhenden »Prototypen« soll garantieren, dass dennoch eine möglichst differenzierte Sichtweise, in die auch die Feldforschung und teilnehmende Beobachtung und somit von den Interviews allenfalls abweichende Arten der Selbstrepräsentation einfliessen, stattfindet.

Konkret bildet das Ergebnis der vorliegenden Untersuchung also eine Rekonstruktion von habituell verankerten »Taktiken«, die bei bildungsbiografischen Zugängen, Entscheidungen und Wegen von jungen religiös orientierten Secondas muslimischen Glaubens zum Tragen kommen. Weiter wurde rekonstruiert, an welche strukturellen Bedingungen diese »Taktiken" geknüpft sind und wie und ob sich diese in ihrer (religiösen) Selbstrepräsentation artikulieren.

Die Darstellung der Ergebnisse im folgenden Kapitel gestaltet sich wie folgt: Da ich »Taktiken«, wie in Kapitel 2.3 ausführlich dargelegt, als habituell verankert sehe, werden die einzelnen Typen von »Taktiken « anhand eines »Prototyps « (Kelle/Kluge 2010: 115) bzw. eines prototypischen Fallbeispiels dargestellt. Einzelne, in dem "prototypischen" Fallbeispiel nicht zum Zuge kommende Aspekte, die für die zu typisierende »Taktik« ebenfalls relevant sind, werden unter Einbezug weiterer Fälle dargestellt. 



\section{Bildungsbiografische "Taktiken « junger religiös orientierter Secondas muslimischen Glaubens in der Deutschschweiz}

Ausgehend vom Datenmaterial wurden verschiedene »Taktiken« (De Certeau 1988: 89) hinsichtlich der Bildungsbiografien religiös orientierter Secondas muslimischen Glaubens analysiert und typisiert. Analysiert wurde, welche habituell verankerten »Taktiken« bei bildungsbiografischen Zugängen, Entscheidungen und Wegen zum Tragen kommen und wie sich die jungen Frauen unter den Bedingungen des laufenden homogenisierenden Islamdiskurses gesellschaftlich positionieren.

Insgesamt wurden vier Typen von »Taktiken « gesellschaftlicher Selbstpositionierung in Bezug auf Bildungsbiografien rekonstruiert - teilweise wurden innerhalb eines Typus unterschiedliche Ausprägungen hinsichtlich der (religiösen) Selbstrepräsentation ausgemacht. 
Typologie von » Taktiken gesellschaftlicher Selbstpositionierung in Bezug auf (Bildungs-)Biografien«:

Typus 1: Bildungsbiografisches Bestehen durch die »Taktik« der kämpferischen Selbstbehauptung als Muslima

- Religiöse Selbstrepräsentation: Emanzipierte Muslima

- Religiöse Selbstrepräsentation: Dezidiert religiöse Muslima

Typus 2: Bildungsbiografisches Bestehen durch die »Taktik« des zielstrebigen Aufsteigens

- Religiöse Selbstrepräsentation: Pragmatische Muslima

- Religiöse Selbstrepräsentation: Engagierte Muslima

Typus 3: Bildungsbiografisches Bestehen durch die »Taktik« der religiösen Vergemeinschaftung

- Religiöse Selbstrepräsentation: Muslima in/durch Cemeinschaft

Typus 4: Bildungsbiografisches Bestehen durch die »Taktik« der widerständigen Mikropraktiken

· Religiöse Selbstrepräsentation: Muslima im Verborgenen

Die Darstellung der Typen erfolgt zunächst anhand eines einführenden Portraits der jeweils exemplarisch dargestellten Frauen, bei welcher sich die typologische »Taktik« rekonstruieren liess. Anschliessend werden einzelne Aspekte der »Taktiken« unter Beiziehung weiterer Fälle vertieft und anhand folgender Kapitel strukturiert:

a) Herkunftsmilieu im Zusammenhang mit der »Taktik«,

b) Die Rolle der Religion Differenzkategorie »Muslimin« hinsichtlich der Bildungsbiografie,

c) »Taktik« gesellschaftlicher Selbstpositionierung bezüglich der Bildungsbiografie. 
Innerhalb dieser Kapitel werden allfällige Ausprägungen religiöser Selbstrepräsentation differenziert.

\subsection{Typus 1: "Taktik « der kämpferischen Selbstbehauptung als Muslima}

\subsubsection{Zara}

Zara (34) lernte ich an einem »Tag der offenen Moschee« kennen. Sie stand vorne im Gebetsraum, erklärte Besucherinnen und Besuchern die Moschee und beantwortete deren Fragen. Die besagte Moschee öffnete das erste Mal ihre Türen - dies geschah auf Initiative von Zara, wie ich im Nachhinein erfuhr. Ihr ist es ein Anliegen, wie sie später erzählt, dass die Moschee mehr »Sichtbarkeit« erfährt.

Zara selbst - das fällt sofort auf - ist eine Respekts- und Autoritätsperson: Wenn es Probleme im Ablauf der Veranstaltung gab oder Besucherfragen von anderen Moscheevereinsmitgliedern nicht sofort geklärt werden konnten, wandten sich die Blicke der Verantwortlichen an Zara. Auch bei kritischen Fragen zu Hijab und »Stellung der Frau im Islam« wirkte sie routiniert in ihrer Argumentation. Sie ergriff das Wort und konterte; das Publikum hörte ihr aufmerksam zu und nickte, selbst ein anwesender Islamwissenschaftsprofessor schien beeindruckt. Die Kopftuch tragende Frau in engen Jeans so lässt sich anhand der Beobachtungen erahnen - ist es gewohnt, öffentlich aufzutreten.

In den Pausen beobachtete ich, wie sie von Menschen, die ihr Fragen stellten, umringt wurde. Sie schien unter den Anwesenden Ansehen und Respekt $\mathrm{zu}$ geniessen, immer wieder huschten verschiedene Leute vorbei und flüsterten ihr kurz etwas ins Ohr oder stellten eine Frage. Aus diesen Routinen liess sich schliessen, dass Zara in der Moschee so etwas wie eine Autoritätsperson ist.

Zara ist, so erfahre ich später, Repräsentantin ihrer Moschee in diversen interreligiösen Gefässen. Auch leitet sie die örtliche Frauengruppe der Mo-

$1 \quad$ Alle Namen wurden anonymisiert. Die Berufe wurden zwecks grösserer Anonymisierung jeweils durch andere Berufe, die hinsichtlich Ausbildung, Einkommen und Prestige derselben Berufsgruppe zugeordnet werden können (vgl. BFS 2017d) ausgetauscht, ebenso wurden die Anzahl Ceschwister und eigener Kinder etc. verändert. 
schee und übt eine Funktion in einem überregionalen muslimischen Verein aus. Sie verfügt über eine tertiäre Ausbildung im interkulturellen Bereich und ist in verschiedensten Integrationsprojekten engagiert, sowohl in unabhängigen, von NGOs initiierten, wie auch in staatlichen.

Dieser Werdegang war nicht von Anfang an in Zaras Bildungskarriere angelegt, er äussert sich jedoch exemplarisch in der von ihr bedienten »Taktik« der kämpferischen Selbstbehauptung als Muslima.

Sie - die früh heiraten sollte, erhielt stets wenig Unterstützung von ihrer Familie in Bildungsbelangen. Trotz guter Noten entschied sie sich - auf sich alleine gestellt - für den Weg in die Realschule, da sie sich nicht von ihren Peers trennen wollte. Weder vonseiten der Eltern noch vonseiten der Schule und Lehrpersonen wurde korrektiv auf diese Bildungsentscheidung, die, wie sich später herausstellte, unter dem Leistungsniveau von Zara lag, Einfluss genommen.

Zaras Eltern sind aus einem Staat in Südosteuropa in die Schweiz gezogen, ihr Vater selbst ging acht, ihre Mutter sechs Jahre zur Schule. Als Zara Ende ihrer obligatorischen Schulzeit langsam erkannte, was ein Realschulabschluss für ihre zukünftige Berufswahl bedeutete, wurde ihr bewusst, dass sie sich anstrengen musste, wenn sie einen weiterführenden Bildungsabschluss erreichen wollte. An Motivation für eine nachobligatorische Ausbildung fehlte es Zara jedoch nicht: Zentraler Punkt ihrer Bildungsmotivation war es, niemals (finanziell) so abhängig von einem Mann zu sein, wie dies ihre Mutter von ihrem Vater war.

Zara fand auf Anhieb eine Lehrstelle im unteren Dienstleistungsbereich, sah sich jedoch hinsichtlich einer nachobligatorischen Ausbildung mit starkem Widerstand ihrer Eltern konfrontiert: Sie waren der Ansicht, dass eine solche sich für eine Frau nicht lohne, da sie sowieso bald heiraten würde und zu Hause Mann und Kinder versorgen werde.

Bereits in dieser frühen bildungsbiografischen Phase zeigten sich erste Anzeichen der von Zara in Anspruch genommenen »Taktik« einer kämpferischen Selbstbehauptung - sie musste ihren nachobligatorischen Bildungszugang erkämpfen: Entgegen dem Willen ihrer Eltern nahm sie die Lehrstelle an - unter den Lehrvertrag setzte sie kurzerhand die gefälschte Unterschrift ihrer Eltern. Sie hoffte diese mithilfe ihrer älteren Schwestern während der Sommerferien zu überzeugen. Ihre Rechnung ging auf: Die Eltern liessen sich überzeugen und überwanden zudem anfängliche Bedenken, dass Zara täglich alleine unterwegs sein würde. Zara behauptete sich also erfolgreich gegenüber dem traditionellen Rollenbild ihrer Eltern und erkämpfte sich den Zu- 
gang zu einer nachobligatorischen Ausbildung. Sie startete ihre Ausbildung und schloss sie mit Bestnoten ab. Bei einer anschliessenden Weiterbildung konnte sie, wie sie erzählte, zwischen zahlreichen Angeboten lokaler Firmen aussuchen.

In dieselbe Zeit fiel Zaras Wieder- bzw. »Neuentdeckung« des Islam. Zara wurde, wie sie sagt, "auf traditionelle Weise« religiös sozialisiert; empfand »den Islam« jedoch stets als erzieherisches Mittel ihrer Eltern und primär als Instrument zur Disziplinierung. Insbesondere der Mutter wirft Zara das Beharren auf konservativen Rollenbildern unter Vorschiebung der Religion vor. Durch einen überzeugten evangelikalen Christen, den sie kennenlernte, erfuhr sie, dass Religion auch »etwas Schönes« sein könne. Das gab ihr den Anstoss, sich näher mit dem Islam auseinanderzusetzen und zu erkunden, ob es ein anderes Religionsverständnis als das ihrer Eltern gibt.

In den Herbstferien während ihrer Weiterbildung verliebte sie sich in einen gleichaltrigen jungen Mann, der in dem Ex-Staat von Jugoslawien, in dem ihre Eltern geboren waren, lebte. Sie war zunächst sehr skeptisch, da dieser, wie sich herausstellte, sehr gläubig war. Sie, die den Islam im Zusammenhang mit ihrem Milieu stets als Disziplinierungsinstrument erfahren hatte, stellte ihren Freund »auf die Probe«; versuchte ihn zu provozieren, indem sie bspw. öfter und länger als üblich mit ihren Freundinnen ausging. Als eine negative Reaktion ausblieb, war sie sehr erstaunt, denn sie führte Unterdrückung und Disziplinierung der Frau stets auf »den Islam« zurück. Dass ein tiefreligiöser Mensch ihr sämtliche Freiheiten lassen könnte, passte nicht in ihr damaliges Religionsverständnis. Angespornt durch die Erkenntnis, dass Religion und ein emanzipiertes Rollenverständnis sich nicht ausschliessen müssen, begann sie sich noch intensiver mit dem Islam zu befassen.

Bei der Wahl ihres zukünftigen Mannes musste sich Zara ebenfalls durchsetzen, sich erneut gegen die Vorstellungen ihrer Familie behaupten und sich von elterlichen Vorstellungen emanzipieren: Die Eltern waren von Anfang an gegen die Heiratspläne ihrer Tochter, da Zaras zukünftiger Mann aus einem sehr konservativen ländlichen Dorf stammte. Insbesondere Zaras Vater hatte zunächst grosse Bedenken, dass seine »rebellische« jüngste Tochter leiden könnte, wenn sie mit einem religiösen Mann verheiratet wäre. Zara jedoch vertraute ihren »Tests « und drohte sich anderenfalls gegen den Willen der Eltern zu verheiraten. Kurz vor der Hochzeit gelang es ihr jedoch zur eigenen Erleichterung, ihren Vater zu überzeugen und sie heiratete mit dem Einverständnis der Eltern ihren jetzigen Mann. 
Zara emanzipierte sich bereits vor ihrer Heirat in der frühen Adoleszenz zunehmend vom elterlichen Religionsverständnis, das sie als einengend empfand. Sie fand zu einer neuen Art von religiösem Selbstverständnis, das sich grundlegend von dem elterlichen, als traditional wahrgenommenen Islam unterschied. Befördert wurde dies auch durch ihren Mann und dessen für Zara völlig neue Auslegung seines Glaubens. Zara begann das tägliche Gebet zu praktizieren. Im Laufe der Zeit störte sie sich zunehmend an dem Spagat, sich nur während des Gebets und in der Moschee zu bedecken. Der Entscheid zum Tragen des Hijabs begann im Stillen zu reifen. Gleichzeitig änderte sie ihren Kleidungsstil und verzichtete immer mehr auf ärmellose T-Shirts und trug längere Hosen. Unmittelbar nach der Geburt des ersten Kindes Ende zwanzig begann Zara sich zu bedecken. Ihren Mann bezog sie in ihre Überlegungen zu diesem Entscheid nicht mit ein - sie stellte ihn vor vollendete Tatsachen.

Zara war sich stets bewusst, so erzählte sie, dass dieser Beschluss einschneidende gesellschaftliche Konsequenzen haben könnte. Dass er ihr eine Rückkehr in den erlernten Beruf komplett verunmöglichte, war jedoch auch für sie eine überraschende Konsequenz ihres Entscheids. Zahlreiche Bewerbungen und Anfragen führten ins Leere, eine Rückkehr in den Arbeitsmarkt schien trotz bester Zeugnisse und Referenzen aussichtslos. Immer wieder wurde ihr gesagt, ja, sie könne kommen, sehr gerne sogar, aber ohne Kopftuch.

Zara, die sich eine Hausfrauenrolle wie die ihrer Mutter nicht vorstellen konnte und unbedingt wieder arbeiten wollte, begann sich freiwillig in Integrationsprojekten zu engagieren. Ihr Mann war zunächst von Zaras stillschweigendem Entscheid, sich zu bedecken überrascht, unterstützte sie jedoch, wie bereits zuvor, in jeglicher Hinsicht. Nach wie vor teilen sich die beiden die Familienarbeit, ihr Mann reduzierte seine Anstellung nach der Geburt des ersten Kindes und beaufsichtigte die Kinder, damit Zara sich engagieren konnte. Die Arbeit in Integrationsprojekten war zwar anfänglich schlecht bezahlt, bereitete Zara jedoch grossen Spass und war sinnstiftend; bald ergab ein Engagement das andere. Zara verstand es dank ihrer »Taktik« der kämpferischen Selbstbehauptung gut, sich dem stereotypen Bild der bedeckten Muslimin konterkarierend zu repräsentieren; aufgrund ihrer gegenstereotypischen Art der Selbstrepräsentation wurde sie von NGOs regelrecht »entdeckt « und konnte sich vor Anfragen kaum retten. Gerne präsentiert sie sich in Schulen, auf Podiumsdiskussionen und in Integrationsgremien als selbstbewusste, von traditionellen Rollenbildern emanzipierte Muslima, die nie um 
eine schlagfertige Antwort verlegen ist. Selbst die hoch provozierenden Fragen von pubertierenden Schüler*innen kontert sie in ihren Klassenbesuchen prompt und einfallsreich und lässt, wie ich mehrfach beobachten konnte, auf Veranstaltungen verblüffte und in ihren stereotypen Bildern irritierte Menschen zurück.

Diese Art von kämpferischer Selbstbehauptung als Muslima, die das Kernstück der »Taktik« von Typus eins bildet, bedient in ihrer Ausprägung des Selbstverständnisses als emanzipierte Muslima (vgl. Tabelle oben) die politischen Ziele von linken NGOs, Integrationsgremien und auch der linken Presse. Durch ihre anti-stereotypische Selbstrepräsentation wurde Zara zu einer Art »Vorzeige-Muslima« von Integrationspolitiker*innen, Bildungsinstitutionen und NGOs, was ihr schliesslich gar berufsbiografisch zugute kam: Sie wurde eigens von einer Studiengangleiterin für einen Studiengang auf Tertiärstufe in Kulturmediation angefragt, ob sie nicht teilnehmen wolle, da sie »von muslimischer Seite her« gut hineinpassen würde und wurde schliesslich »sur dossier« aufgenommen.

Die »Taktik« der (emanzipierten) kämpferischen Selbstbehauptung führte also im Endeffekt direkt dazu, dass Zara trotz ihres Realabschlusses eine tertiäre Ausbildung machen konnte.

Charakteristisch für die »Taktik«, welche hier als Typus eins bezeichnet wird, ist, wie durch eine kämpferische Selbstbehauptung als Muslima eine gesellschaftliche Selbstpositionierung erfolgte, die einen positiven Einfluss auf die Bildungsbiografie zur Folge hatte. Frauen, die sich diese »Taktik« zunutze machen, können bildungsbiografisch trotz intersektionell stark wirksamer Einschränkungen durch die Differenzdimensionen Gender, »class«, »Migrationshintergrund « und Religion mehr Handlungsfähigkeit (Agency) erlangen und sich beruflich schliesslich verwirklichen.

Hinsichtlich der religiösen Selbstrepräsentation, mittels derer bei dieser »Taktik« schliesslich grössere berufsbiografische Handlungsfähigkeit erlangt werden kann, lassen sich zwei Ausprägungen rekonstruieren (vgl. Tabelle 1 oben). Die Selbstrepräsentation als emanzipierte Muslima (wie Zara) und die Selbstrepräsentation als dezidiert religiöse Muslima, unten an dem Fallbeispiel von Mirjeta illustriert. Ein weiteres zentrales Element dieses Typus besteht in der klaren Emanzipation vom elterlichen Religionsverständnis zur Klärung eigener identifikatorischer Fragen. 


\subsubsection{Bildungsbiografisches Bestehen durch die "Taktik" der kämpferischen Selbstbehauptung als emanzipierte bzw. dezidiert religiöse Muslima}

Nach diesem einleitenden Portrait wird die »Taktik« des Bildungszugangs durch kämpferische Selbstbehauptung als Muslima nun unter Beiziehung weiterer Fälle und anhand der folgenden Kapitel spezifiziert, es sind dies: a) Herkunftsmilieu im Zusammenhang mit der »Taktik«; b) Die Rolle der Religion und der Differenzkategorie »Muslimin « hinsichtlich der Bildungsbiografie und c) »Taktik" gesellschaftlicher Selbstpositionierung bezüglich der Bildungsbiografie. Bei den beiden Untertypen dieser »Taktik « - ich bezeichne diese hier als Ausprägungen - handelt es sich einerseits um die »Taktik« des Bildungszugangs durch kämpferische Selbstbehauptung als semanzipierte Muslima und anderseits um die »Taktik« des Bildungszugangs durch kämpferische Selbstbehauptung als >dezidiert religiöse Muslima (vgl. Tabelle 1, oben). Die Ausprägungen unterscheiden sich insbesondere anhand der religiösen Selbstrepräsentation der Frauen und der daraus folgenden unterschiedlichen gesellschaftlichen Selbstpositionierung. Aus diesem Grund werden sie im Unterkapitel 5.1.2c, in welchem die religiöse Selbstrepräsentation thematisiert wird, getrennt aufgeführt.

\section{a) Herkunftsmilieu im Zusammenhang mit der "Taktik "}

Die interviewten Frauen, bei denen die »Taktik« der kämpferischen Selbstbehauptung rekonstruiert werden konnte, gehören in der Regel Familien von ehemaligen Gastarbeitern an, die über wenig Bildungskapital verfügen. Das tägliche finanzielle Bestehen der Eltern war von grossen Anstrengungen geprägt - die Familien waren in der Kindheit der interviewten Frauen stets vom Prekariat (Pelizzari 2009: 49) bedroht. Die Eltern der Frauen pflegten in der Regel eine sogenannte klassische Rollenteilung, bei welcher der Mann als Alleinverdiener für das familiäre Einkommen zuständig ist und die Frau sich im Gegenzug um Hausarbeiten und Kinder kümmerte. Sie konnten ihre Kinder in Bildungsbelangen entweder kaum unterstützen oder hielten die schulische und ausbildungsbezogene Unterstützung ihrer Töchter aufgrund von traditionellen Rollenvorstellungen für vernachlässigbar.

Zara stammt aus einem solchen Milieu. Ihre Eltern wanderten aus Südosteuropa als Gastarbeiter ein. Zaras Vater fand in der Schweiz als Kleingewerbler Arbeit, ihre Mutter blieb zu Hause und kümmerte sich um die Kinder. Das Geld war stets knapp, ihre Mutter musste den Vater als Verwalter der fa- 
miliären Finanzen um alles bitten. Als Jüngstes von drei Kindern lehnte sich Zara im Gegensatz zu ihren älteren Geschwistern früh gegen elterliche, patriarchale Vorstellungen auf, die sie als traditionell bezeichnet. Motivation für eine nachobligatorische Ausbildung war für Zara somit auch primär die eigene Selbstständigkeit als Frau und ihre zukünftige Unabhängigkeit von einem Mann - also eine Emanzipation vom elterlichen Rollenbild. Nie wollte Zara so abhängig von einem Mann werden, wie sie ihre Mutter abhängig von ihrem Vater empfand:

»Äh also habe ich eigentlich schon immer gewusst, ich will mein Geld verdienen und ich will selbstständig sein. Vor allem als ich gesehen habe wie, ja, wie ich das Verhältnis auch von Mutter und Vater zuhause erlebt habe, dass er das Celd heimgebracht hat und somit auch das Sagen gehabt hat und meine Mutter natürlich fast nichts in der Hand gehabt hat. //Mhm// und für jeden Penny hat fragen müssen: Gibst du mir? Gibst du mir, oder? //Mhm// und das hat mir eigentlich nie gefallen. Das ist für mich sehr klar gewesen, von Anfang an, dass ich das nie so haben möchte (Zara, A 50). ${ }^{2}$

Wie aus dem Zitat deutlich wird, erlebte Zara das Verhältnis von ihrer Mutter und ihrem Vater als asymmetrisch. Sie sieht den Grund hierfür in erster Linie darin, dass der Vater als Alleinverdiener der Familie eine Machtposition gegenüber der Mutter einnehmen konnte. Ihre Mutter ist dadurch in eine Abhängigkeit des Vaters geraten, der sie »fast Nichts« entgegensetzen konnte und die zum Verlust jeglicher (finanzieller) Autonomie führte. Zara war schon früh klar, dass sie sich ein solch asymmetrisches Verhältnis in einer späteren Beziehung nicht vorstellen kann - sie sich davon emanzipieren will.

Bereits als Schülerin begann sie, Wochenjobs anzunehmen, 1- bis 2-mal pro Woche kleinere Aushilfsarbeiten zu machen, um ihr Taschengeld aufzubessern und unabhängiger vom Vater zu sein. Bereits hier zeigten sich erste Bestrebungen der Selbstbehauptung und Emanzipation.

Die interviewten Frauen, bei denen die »Taktik« der kämpferischen Selbstbehauptung als emanzipierte Muslima rekonstruiert werden konnte, erhielten wenig bis gar keine Unterstützung in schulischen Belangen von ihrer Familie. Bereits an der ersten Selektionsschwelle wurde Zaras Bildungs-

2 Die Bezeichnungen hinter den Interviewstellen (hier: A 50) beziehen sich auf die betreffenden Codierabschnitte in den MAXQDA-Dateien (Transkriptionsregeln siehe Anhang). 
biografie durch die Differenzkategorien »Migrationshintergrund $\aleph^{3}$ und »class und "Gender « begrenzt. Dieses Zusammenspiel zeigte sich einerseits darin, dass die Eltern als Zugewanderte (»Migrationshintergrund«) das Bildungssystem ungeachtet sprachlicher Übersetzungsbemühungen vonseiten der Institutionen zu wenig kannten, um die weitreichende, bildungsbiografische Bedeutung von komplexen Selektionsprozessen auf Bildungslaufbahnen vollständig nachvollziehen zu können. Auf der anderen Seite erschien ihnen, die selbst nur über basale schulische Bildung verfügten (»class«) die Ausbildung ihrer Tochter als Mädchen, das früh heiraten sollte, nicht prioritär (»Gender«).

Aufgrund dieser Umstände blieb Zara bereits bei der ersten Selektionsschwelle am Übergang von der Primar- zur Sekundarstufe auf sich alleine gestellt und entschied sich für den Verbleib in der Realstufe. Retrospektiv gesehen bereute sie ihre Entscheidung und führte sie darauf zurück, dass sie diese allein treffen musste und von niemandem "gepusht« wurde:

»Also wenn man mich ein bisschen gepusht hätte und wenn man mir ein bisschen klar hätte zeigen können, was das eigentlich alles bedeutet $/ / \mathrm{mhm} / /$ hätte ich äuä viel mehr schaffen können (...). Und die Chance habe ich mir entgehen lassen $/ / \mathrm{mhm} / /$ also ich habe mir sogar ääh, äh, die Sek entgehen lassen, nur, weil ich einfach gute Freundinnen in $\operatorname{der~Prim}^{4}$ gehabt habe und bin gar nicht erst an die Prüfung gegangen. Weil ich habe gedacht, dann gehe ich nachher zu den Strebern //mhm// und dann verliere ich meine Freundinnen. Das sind meine Gedanken gewesen und im Nachhinein könnte ich die Wände hinaufgehen (lacht) aber, es ist natürlich viel zu spät oder« (Zara, A 62).

Auf sich alleine gestellt, traf Zara ihre Bildungsentscheidung aufgrund der Argumente der Peergroup ${ }^{5}$ : Erst während der Berufswahlphase wurde Zara langsam bewusst, was es für ihre Berufswahl bedeutete, keinen Sekundarschulabschluss zu haben und ärgerte sich über den Entschluss.

An dieser ersten Selektionsschwelle am Übergang zur Sekundarstufe war Zara also aus einer intersektionellen Perspektive als junges Mädchen mit

3 Wenn ich die konzeptionalisierten Kategorien als Differenzdimensionen fasse, die einen Einfluss auf den Verlauf einer Bildungsbiografie haben, werden sie kursiv geschrieben (vgl. hierzu auch Kap. 7.1).

4 Die Realstufe wurde früher in einigen Kantonen der Schweiz als Primarstufe bezeichnet: kurz: »Prim«.

5 Zu Peerwelten in transnationalen sozialen Räumen und deren Ein- und Ausgrenzungslogiken im Zusammenhang mit der schulischen Selektion vgl. Oester/Brunner (2015). 
»Migrationshintergrund « aus der Unterschicht im Bildungssystem gleich mehrfach belastet, erstens durch die mangelnde Kenntnis des Schulsystems aufgrund des »Migrationshintergrunds« der Eltern (»Migrationshintergrund«) sowie durch deren Gender-bedingte Zukunftsplanung. Ebenfalls spielte bei diesem Übergang die Reproduktion der sozialen Klasse (»class") eine Rolle. Das Bildungssystem versagte zudem als Korrektiv. Der Entscheid in der Realstufe bei ihren Peers zu verbleiben ist aus Sicht eines jungen Mädchens durchaus nachvollziehbar. Neuere Studien zeigen jedoch, dass junge Lernende, aber auch Jugendliche bei Bildungsentscheidungen auf die Unterstützung von glaubwürdigen Bezugspersonen angewiesen sind, so z.B. Eltern oder Lehrpersonen (Neuenschwander 2011). Hierbei nehmen die Eltern als >significant others (Woelfel et al. 1971 zit.n. Bader/Fibbi 2012: 24) eine zentrale Rolle ein. Es wird belegt, dass gerade für Schüler*innen mit »Migrationshintergrund« das soziale Kapital ungleich wichtiger ist, um die Möglichkeiten und das Potenzial von Bildungsentscheidungen im Rahmen der kognitiven Fähigkeiten auszuschöpfen, als für Schüler*innen ohne »Migrationshintergrund« (vgl. etwa Bader/Fibbi 2012, Zhou et al. 2008). Potenziell hätten also glaubwürdige Bezugspersonen seitens des Bildungssystems korrektiv auf Zaras Bildungsentscheidung Einfluss nehmen und sie auf einem in Bezug auf ihre Herkunft eigenständigen, ihren kognitiven Fähigkeiten entsprechenden Bildungsweg unterstützen können. Zaras Selektionsentscheid an der ersten Selektionsschwelle zeigt jedoch im Einklang mit einschlägigen bildungsbiografischen Forschungen die Wirkmächtigkeit von leistungsfremden Faktoren auf Bildungsverläufe auf, wonach durch das Bildungssystem tendenziell der soziokulturelle Hintergrund der Eltern reproduziert wird. In Übergängen, so belegen zahlreiche Studien, manifestierten sich unterschiedliche Mechanismen der Reproduktion sozialer Ungleichheit besonders deutlich; gleichzeitig werden Prozesse der Ausdifferenzierung und Hierarchisierung wirksam, die Chancen entlang bestimmter Differenzkategorien ungleich verteilen (Hadja/Hupka-Brunner 2013, Becker et al. 2013, Becker/Solga 2012, Kronig 2013, Kronig 2007, Kronig et al. 2000).

Ungeachtet der eher bescheidenen bildungsbiografischen Unterstützung seitens glaubwürdiger Bezugspersonen meisterte Zara die zweite Selektionschwelle - den Übergang von der obligatorischen zur nachobligatorischen Ausbildung - dann mittels der rekonstruierten »Taktik« der kämpferischen Selbstbehauptung. Behaupten musste sich Zara einerseits auf dem Arbeitsmarkt, andererseits gegen elterliche Rollenvorstellungen: Sie trat zunächst im Rahmen des obligaten schulischen Berufswahlprozesses in einem Detail- 
handelsgeschäft im Luxussegment eine Schnupperlehre an, die ihr sehr gut gefiel. Es gefiel ihr, dass sie hier in Kontakt »mit einer sehr neue[n] Welt« (A 51) kam, die sich so sehr von ihrem Herkunftsmilieu unterschied. Dennoch machte sie sich wenig Hoffnung auf eine Lehrstelle, da der Geschäftsführer diese angeblich bereits besetzt hatte. Überraschenderweise wurde sie, wie sie erzählt, eine Woche nach ihrer Schnupperlehre dennoch kontaktiert und für eine Lehrstelle angefragt:

»Und dann hat er mich so komisch gefragt, ob das für ihn...ein Problem sei, wegen dem B-Ausweis ${ }^{6}$ oder? Ob, ob das für ihn irgendwie speziell etwas bedeutet, was er da müsse. Weil die haben nie Ausländer mit B-Ausweis dort gehabt. //Mhm// und dann habe ich gesagt: Nein, wenn ich keine Probleme mache, dann gibt es auch keine Probleme« (Zara, A 52).

Obwohl der Geschäftsführer zunächst Bedenken wegen ihres Aufenthaltsstatus hatte, behauptete sich Zara selbstbewusst gegen die Vorurteile ihres zukünftigen Arbeitsgebers und räumte seine Bedenken aus. Sie wurde schliesslich als erste »Ausländerin« in diesem Geschäft für eine Lehrstelle angefragt. Sie freute sich sehr, ihre Freude währte jedoch nur kurz, da ihr ihre Eltern verboten, die Lehrstelle anzunehmen:

»(..) meine Mutter hat gesagt: Für was auch? In zwei, drei Jahren wirst du vielleicht heiraten, bist schon, achtzehn, neunzehn oder? Und dann brauchst du doch keine Lehrstelle. Geh lieber da ein bisschen arbeiten im Supermarkt. (...). Verdiene ein bisschen Geld, das du mal eben ein bisschen auf der Seite hast, wenn du heiratest und so, und ääh was bringt dir schon ein Beruf zu erlernen?«(Zara, A 56).

Die Mutter begründet die elterliche Entscheidung mit der Logik eines traditionellen Rollenbilds. Zara, der eine spätere (finanzielle) Unabhängigkeit als Frau von einem zukünftigen Mann dringendstes Anliegen war, sah diese nun durch die elterlichen Vorstellungen gefährdet und war der Überzeugung: »Ich vermassle so meine Zukunft, wenn ich nichts mache« (A 62). So entschloss sie sich zu einem drastischen Schritt: Sie setzte die gefälschte Unterschrift der Eltern unter ihren Lehrvertrag und hoffte, dass sie diese während der bis

6 Der Ausweis B stellt eine Aufenthaltsbewilligung dar, die in der Regel fünf Jahre gültig ist und auf Nachweis einer unbefristeten Anstellung oder mindestens 365 Tage dauernden Anstellung (bzw. eines Elternteils) erfolgt. Für Details zu den unterschiedlichen Aufenthaltsbewilligungen in der Schweiz siehe POM (2017). 
zum Lehrbeginn verbleibenden Sommerferien mithilfe ihrer älteren Schwestern umstimmen könne.

Hier werden wiederum die intersektionell wirkenden strukturellen Beschränkungen (»class«; »Migrationshintergrund«, Gender) deutlich, mit denen sich Zara am Übergang zur nachobligatorischen Ausbildung (und bereits zuvor) konfrontiert sah. Ebenfalls wird bereits in diesem früheren Stadium ihrer Bildungsbiografie offenbar, wie Zara ihre emanzipatorischen Bestrebungen nötigenfalls kämpferisch durchsetzt, auch aus einer subalternen Position heraus. Mittels der »Taktik« der kämpferischen Selbstbehauptung setzte sich Zara erfolgreich zur Wehr und lehnte sich zudem gegen das elterliche Rollenbild auf. Hierzu verbündete sie sich mit ihren älteren Schwestern gegen die Eltern. Die Schwestern, die selbst über keine nachobligatorische Ausbildung verfügten, hatten die Folgen einer fehlenden Berufsausbildung im Arbeitsmarkt bereits drastisch selbst erfahren. Sie arbeiteten beide seit der obligatorischen Schule im Supermarkt an der Kasse und mussten sich »untendurch schlagen« (Zara, A 69). Dennoch verdienten sie stets weniger als Arbeitskolleg*innen, die über einen Berufsabschluss verfügten. Die Folgen der intersektionell wirkenden Bildungsbarrieren kamen also bei den Schwestern von Zara bereits voll zum Tragen. Die Schwestern wollten nicht, dass Zara dasselbe Schicksal drohte und versuchten sie nach Kräften zu unterstützen, damit sie eine Lehrstelle antreten konnte. Gemeinsam mit ihren Schwestern gelang Zara die Auflehnung gegen die Eltern, sie konnte zunächst die Mutter und dann auch den Vater umstimmen.

\section{b) Die Rolle der Religion und der Differenzkategorie "Muslimin" hinsichtlich der Bildungsbiografie: Hijab als Bildungsbarriere}

Frauen, bei denen die »Taktik« der kämpferischen Selbstbehauptung als Muslima rekonstruiert werden konnte, tragen entweder seit ihrer Kindheit ein Kopftuch oder haben sich im Laufe der Adoleszenz dazu entschieden, sich zu bedecken. Konstitutionell für ihre Bildungsbiografien ist zudem, dass sich das Tragen des Hijabs auf ihren nachobligatorischen Ausbildungsweg substanziell auswirkt. Das Kopftuch tragen wirkte zunächst so stark als Bildungsbarriere, dass die Frauen zu einer beruflichen Neuorientierung oder einem Umweg gezwungen wurden. Sie fanden somit entweder aufgrund des Kopftuchtragens bereits keine Lehrstelle oder verloren eine solche, weil sie während der Ausbildung entschieden, sich zu bedecken oder aber sie 
mussten aufgrund des später in der Adoleszenz gefällten Entscheids, das Kopftuch zu tragen, ihre bisherige Berufslaufbahn aufgeben.

Dass der Entscheid, ein Kopftuch zu tragen, in der Adoleszenz gefällt wird, ist nicht unüblich. Das gilt, wie meine Daten zeigen, sowohl für religiös wie nicht religiös sozialisierte Frauen und lässt sich meines Erachtens mit der adoleszenten Auseinandersetzung mit »Welt-, Selbst- und Sachbezügen« (King/Koller 2009b, Hummrich 2009: 28) erklären, mittels derer in Umgestaltungsprozessen potenziell neue, eigene Lebensentwürfe entwickelt werden (King 2004: 28ff.). Berufsbiografisch ist für die jungen Frauen das strukturelle Zusammenfallen dieser adoleszenten Auseinandersetzung mit der nachobligatorischen Berufsbildungsphase äusserst ungünstig, denn sie werden hier durch ein folgenschweres Zusammenspiel der Differenzdimensionen Gender und Religion bildungsbiografisch eingeschränkt: Das Tragen eines Hijabs, so konnte in den Bildungsbiografien rekonstruiert werden, manifestiert sich in der Berufsbildung als wirkmächtige Bildungsbarriere (ausführlich vgl. Kap. 7.1).

Die interviewten Frauen, bei denen diese »Taktik« rekonstruiert werden konnte, traten allesamt als ersten Schritt in die nachobligatorische Ausbildung eine Berufslehre an oder planten, eine solche anzutreten. Wie sich aus den Erzählungen rekonstruieren lässt, sind speziell im Bereich der Berufslehren, aber auch in der Ausübung von Berufen die intersektionell wirkenden Beschränkungen in Bezug auf den Hijab besonders wirkmächtig. Systematische Studien zur Wirkmächtigkeit des Kopftuchs als Bildungsbarriere liegen in der Schweiz meines Wissens noch keine vor. Aufgrund der vorliegenden Daten können zwar keine generalisierten Aussagen getroffen werden, es ist jedoch augenfällig, dass keine Frau, die ich interviewte und die zum Zeitpunkt ihrer Bewerbung für eine Lehrstelle einen Hijab trug, eine Lehrstelle in einem von ihr angestrebten Berufssegment finden konnte.

Auffällig ist, dass in all den analysierten ablehnenden Argumentationslinien (potenzieller) Arbeitgeber*innen nie das Argument eines Defizits auf dem Niveau der Qualifikation angeführt wird. Im Gegenteil, laut den bildungsbiografischen Narrationen der jungen Frauen wird seitens der Arbeitgebenden meist unverblümt kundgetan, dass der Grund einer Nichtanstellung bzw. Kündigung einzig und allein im Tragen eines Kopftuchs liege. Dies, obwohl es sich faktisch hierbei um institutionelle Diskriminierung handelt. So wurde Zoja, einer anderen Frau meines Samples, bspw. offen gesagt, dass sie eine Lehrstelle bekommen würde, falls sie diese ohne Kopftuch antrete: 
»Ähm (...) ich trug in der Schule äh ein Kopftuch, und als ich schnuppern ging, hat man mir, (...) hat mir die äh Chefin gesagt ähm..., wenn sie ihren $\mathrm{Hudu}^{7}$ ablegen, dürfen sie unterschreiben und hat mir den Vertrag so hingeschoben (halbes Lachen), ja, der Hudu« (Zoja, A 32).

In dieser Erzählung wird deutlich, dass der jungen Frau in Aussicht gestellt wurde, eine Lehrstelle zu bekommen, falls sie das Kopftuch ablegen würde; der Vertrag lag bereits vor ihr. Die potenzielle zukünftige Chefin machte Zoya in aller Deutlichkeit klar, dass sie einzig und allein den Hijab als Hinderungsgrund für einen Lehrstellenvertrag sähe. In der abwertenden Formulierung $\mathrm{Hudu}$ wird deutlich, mit welch starken Stigmata die Ausbildende das Kopftuch belegte und mit welch diskriminierenden Zuschreibungen sich die junge Frau konfrontiert sah. Auch aus dem nachgeschobenen »ja, der Hudu« mit halbem Lachen kann geschlossen werden, dass die abwertende Bezeichnung verletzend auf die junge Frau gewirkt haben muss.

Während bereits mehrfach nachgewiesen wurde, dass das Duale Berufsbildungssystem der Schweiz für Schulabgänger*innen mit »Migrationshintergrund« nicht in gleichem Masse zugänglich ist wie für solche ohne »Migrationshintergrund « (vgl. bspw. Imdorf 2011: 261), lassen meine Daten vermuten, dass sich der Hijab als sichtbares religiöses Symbol im Zuge des gegenwärtigen Islamdiskurses als zusätzliche wirkmächtige Bildungsbarriere manifestiert. Durch das Zusammenspiel der Differenzdimensionen Religion und Gender anhand des sichtbaren religiösen Symbols des Hijab besteht für junge Musliminnen, "für die das Kopftuch ein nicht verzichtbarer Ausdruck ihrer Identität ist « (Scherr et al. 2015: 149) eine wirkmächtige Bildungsbarriere im Bereich der Berufsbildung und oder -ausübung (ausführlich vgl. Kap. 7.1). Hinsichtlich der beruflichen Möglichkeiten entfaltet die Differenzkategorie »Muslimin« für Frauen anhand des sichtbaren religiösen Symbols Hijab in der Berufsbildung also eine bildungsbiografisch hindernde Wirkmächtigkeit.

Anhand frauenspezifischer Diskriminierungserfahrungen aufgrund sichtbarer religiöser Symbole wird meines Erachtens besonders deutlich, weshalb Religion als Differenzkategorie theoretisch intersektionell bzw. interdependent gedacht werden muss: um Ausschlusserfahrungen religiös orientierter Frauen nicht zu unterschlagen oder unter anderen Kategorien zu subsumieren (vgl. hierzu ausführlich Kap. 7.1). den mit diesem Wort Putzlappen, Stofffetzen oder ähnliches bezeichnet. Umgangssprachlich wird es manchmal auch für »billiges Kleidungsstück« verwendet. 
Nicht nur im bildungsbiografischen Abschnitt der Berufsbildung, sondern auch in dem der Berufsausübung wird deutlich, dass der Hijab hindernd für eine weitere berufliche Karriere oder schon nur auch für eine Anstellung sein kann.

Zara hatte ihre Lehre noch ohne Kopftuch absolviert. Als sie sich nach der Geburt ihres Kindes entschloss, einen Hijab zu tragen, blieb ihr eine Rückkehr in den Dienstleistungsbereich verwehrt. Auch ihr wurde in aller Deutlichkeit gesagt, dass es ausschliesslich an ihrer Kopfbedeckung liege:

»Und das haben sie mir auch direkt gesagt, also sie haben mir wirklich gesagt: Nein, mit Kopftuch nicht, und sonst ja. (...). Super Zeugnisse habe ich vorweisen können von super Geschäften, hier in A. Nie eine Lücke in meinem Lebenslauf, also immer wirklich, von guter Stelle zu nächster guter Stelle mit immer wieder guten Zeugnissen, also von meiner Lehrzeit, und nachher die zwei, drei Jahre und (...) wirklich erwünschenswerte Zeugnisse... (...) ...und trotzdem hat es nicht geklappt. Es hat immer geheissen: ohne Kopftuch ja, und mit Kopftuch nein« (Zara, A 80).

Durch die Aufzählung und das Unterstreichen des bisher erreichten, »super Zeugnisse (...) von super Geschäften« in ihrer Bildungsbiografie wird deutlich, wie stolz Zara auf das bisher Erreichte ist, das sie sich trotz schwieriger Umstände hart erkämpft hat. Solche Zeugnisse vorweisen zu können, trotz der in ihrer Bildungsbiografie bereits früh intersektionell wirkenden Beschränkungen ist keine Selbstverständlichkeit. Zudem wird in dieser Aussage eine gewisse Frustration darüber deutlich, wenn trotz guter Zeugnisse und einwandfreier Berufslaufbahn das berufliche Weiterkommen einzig an der Diskriminierung aufgrund des Tragens des Hijabs scheitert - zugespitzt von ihr auf den Punkt gebracht: »ohne Kopftuch ja und mit Kopftuch nein«.

Diese Form der starken Wirkmächtigkeit der Differenzkategorie »Muslimin« via Hijab haben alle Frauen, bei denen die »Taktik« der kämpferischen Selbstbehauptung als Muslima rekonstruiert wurde, erfahren: Sie sahen sich aufgrund des Tragens des Hijabs früher oder später in ihrer Bildungskarriere mit einem Punkt, der eine scheinbare bildungsbiografische »Endstation« bedeutete, konfrontiert. Durch das Tragen eines Hijabs stand eine berufsbiografische komplette Neuorientierung an, welche durch die intersektionell wirksamen bildungsbiografischen Beschränkungen der Differenzdimensionen Religion und Gender strukturell quasi erzwungen wurde. Ein aus diesem bildungsbiografischen Punkt resultierendes konstitutives Element für die »Taktik« der kämpferischen Selbstbehauptung als Muslima bildet die di- 
rekte oder indirekte Politisierung der Frauen durch diese Ausschlusserfahrung. Bei Frauen findet infolgedessen eine bildungsbiografische Neuorientierung durch politisierte kämpferische Selbstbehauptung als Muslima statt, die schliesslich zu einer spezifischen Neuausrichtung der religiösen Selbstrepräsentation führt, welche im folgenden Kapitel beschrieben wird.

\section{c) "Taktik“ gesellschaftlicher Selbstpositionierung hinsichtlich der Bildungsbiografie: Agency durch religiöse Selbstrepräsentation}

Während im vorhergehenden Kapitel insbesondere die bildungsbiografischen Einschränkungen der Frauen, bei denen die "Taktik« der kämpferischen Selbstbehauptung als Muslima rekonstruiert werden konnte, thematisiert wurden, wird in diesem Kapitel das Augenmerk auf die »Taktik« ausgerichtet, mittels welcher sie ihre bildungsbiografische Agency vergrössern: In erster Linie steigern sie diese durch die Art ihrer religiösen Selbstrepräsentation.

Wie bereits dargelegt, bildet ein konstitutives Element für die Bildungsbiografien der interviewten Frauen, dass sie aufgrund ihres meist in der Adoleszenz erfolgten Entscheids sich zu bedecken, einen einschneidenden berufsbiografischen Umweg bzw. eine berufsbiografische Neuorientierung vornehmen mussten. Diese berufsbiografische Neuorientierung wurde, wie im Folgenden aufgezeigt werden soll, entscheidend durch die religiöse Selbstrepräsentation und die damit einhergehende religiöse Vergemeinschaftung der Frauen beeinflusst. Hierbei lassen sich zwei Ausprägungen differenzieren: einerseits die kämpferische Selbstbehauptung als semanzipierte Musli$m a$ (illustriert am prototypischen Fallbeispiel von Zara) und andererseits die kämpferische Selbstbehauptung als >dezidiert religiöse` Muslima (illustriert am prototypischen Fallbeispiel von Mirjeta).

\section{Ausprägung: Selbstrepräsentation als emanzipierte Muslima}

Ein konstitutives Moment für die Ausprägung der religiösen Selbstrepräsentation als emanzipierte Muslima ist eine Emanzipation vom elterlichen Religionsverständnis bzw. eine Neuauslegung des religiösen Selbstverständnisses gegenüber jenem der Eltern zur Klärung eigener (religiöser) Identifikationsfragen hinsichtlich des Genderbilds.

Frauen, die sich wie Zara dieser »Taktik« bedienen, wurden in »traditionellem Sinne« religiös sozialisiert. Dies will hier meinen, dass in der Familie 
religiöse Praxis in Form von »lived religion ${ }^{8}$ (McGuire 2008) tradiert wurde, die von Bräuchen und (Glaubens-)Traditionen des Umfelds, in dem die Eltern geboren wurden, geprägt ist.

Zara nennt noch einen weiteren zentralen Aspekt ihrer religiösen Sozialisation. Nämlich den Aspekt der Disziplinierung:

»a, zum Beispiel hat meine Mutter immer gesagt, eben du bist, wir sind Muslime, es, es geht nicht, dass du einfach fortgehst. Dass ich einfach in die Stadt gehen konnte, einkaufe oder mit Freundinnen unterwegs sein können, hat sie immer argumentiert mit: Wir sind Moslems, das machen wir nicht« (Zara, A 158).

Islam, »Moslem sein«, so wird aus dem Zitat ersichtlich, wurde von den Eltern, speziell von ihrer Mutter, dann als Erklärung bemüht, wenn es darum ging, Verhaltens- und Erziehungsregeln durchzusetzen - insbesondere hinsichtlich des von ihr erwünschten Rollenverhaltens. Wollte die Mutter nicht, dass Zara mit ihren Freundinnen in die Stadt einkaufen ging, argumentierte sie mit religiösen Geboten bzw. Verboten, laut denen sich das nicht gehöre. Lange verband Zara Religion bzw. »Islam« somit in erster Linie mit Regeln, die ihre Eltern ihr vorschrieben; sie nahm ihn primär als Instrument der Disziplinierung wahr. Sie lehnte »Religion« somit zunehmend $a b$ :

»Und somit habe ich auch einen Hass entwickelt gegen meine Religion, weil ich habe gedacht: Was ist das für eine Religion? Wir sind alle aus Fleisch und Blut. Und mein Bruder, wieso soll er mehr wert sein als ich? Und wieso soll er mehr dürfen als ich? Das habe ich auch nicht als gerecht empfunden und habe mich eigentlich auch distanziert von der Religion, weil ich gedacht habe, so eine Religion brauche ich nicht. Oder so einen Cott brauche ich auch nicht (Zara, A 189).

Aus dem Zitat wird deutlich, wie Zara eine »Religion« ablehnt, die sie als Instrument zur Rechtfertigung von Geschlechterungleichheit wahrnimmt. In der Formulierung »habe ich auch einen Hass entwickelt« wird deutlich, wie

»Lived religion « ist ein Konzept, das auf die US-amerikanische Religionsanthropologin McGuire (2008) zurückgeht. McGuire kritisiert mit dem Konzept ein (Forschungs-)Verständnis von Religiosität, das ausschliesslich religiöse Institutionen und deren Religionsverständnis fokussiert, vielmehr will sie die religiöse Praxis und deren subjektive Bedeutung für Akteur*innen in den Blick nehmen. »Lived religion« richtet den Aufmerksamkeit auf die Verwobenheit von Kultur und Religion, wie sie sich im Alltagsleben manifestiert und stellt so eine ideale Grundlage zur ethnografischen Erforschung religiöser Praxis dar (vgl. hierzu auch Allenbach 2017: 283, Giordano et al. 2010: 6). 
stark sie die als Disziplinierungsinstrument wahrgenommene Religion zurückweist. Sie brauche »so eine Religion nicht«, welche die elterliche Argumentationsgrundlage dafür bilde, dass ihr Bruder mehr dürfe als sie und somit die Basis der von ihr abgelehnten elterlichen Rollenvorstellungen darstelle.

Während Zara zunächst die elterliche Religionsauslegung als »Religion« per se wahrnimmt und ablehnt, kommt sie in der Adoleszenz, als sie sich mit Religion vertiefter auseinandersetzt, zu dem Schluss, dass es sich nicht um »den Islam« als Ganzen, sondern um das elterliche Religionsverständnis handelt, das sie ablehnt:

»Und ich habe das Gefühl gehabt, dass es stimmt, dass das von der Religion kommt, bis ich nachher eben irgendwo auch ein bisschen erwachsener geworden bin und gesagt habe: Ok, jetzt musst du dich selber mal ein bisschen erkundigen. Was will deine Religion von dir? Dort ist eigentlich so dieser erste Schritt gewesen, als ich gesagt habe: Ich muss meine Religion besser kennenlernen und habe gemerkt: Nein, das, was meine Eltern sagen ist einfach eine Tradition, eine Kulturfrage und nicht eine Religionsfrage oder?« (Zara, A 159).

In der in dem Zitat vorgenommenen diskursiven Trennung zwischen "Religion« vs. »Tradition« wird deutlich, dass Zara zum Schluss kommt, dass es sich bei der elterlichen Auslegung von Religion, „das was meine Eltern sagen«, nicht um »eine Religionsfrage« handelt, sondern dass ihre Eltern mit »Tradition« argumentieren - einer »Kulturfrage«.

Frauen, bei denen die »Taktik« der kämpferischen Selbstbehauptung als Muslima rekonstruiert werden konnte, emanzipieren sich dezidiert vom elterlichen als traditionell wahrgenommenen Religionsverständnis und positionieren sich durch eine Umdeutung des Religionsverständnisses gegenüber der Elterngeneration als eine neue Generation ${ }^{9}$. Die Emanzipation vom elterlichen Religionsverständnis geht mit einer dezidierten diskursiven Trennung

9 Bei den Frauen, bei denen sich diese »Taktik« rekonstruieren liess, lässt sich die Emanzipation vom elterlichen Religionsverständnis besonders deutlich ausmachen. Meine Daten legen jedoch die Vermutung nahe, dass es sich bei der diskursiven Trennung von »Religion« und »Kultur « nicht zuletzt auch um ein sich wandelndes, spezifisches Religionsverständnis der sogenannten »zweiten Generation« in Abgrenzung gegenüber dem ihrer Eltern handelt (vgl. ausführlich Kap. 6). 
von »Religion $\ll^{10}$ vs. »Kultur/Tradition« einher, die sich nicht nur, aber auch gegen ein »der Kultur « zugeschriebenes Genderbild und die damit verbundene Disziplinierung der jungen Frauen in traditionelle Geschlechterrollen wendet. Sie finden dadurch einen Weg, sich trotz der Ablehnung des elterlichen, durch Religion begründeten Rollenbilds als gläubige Muslimas eigenständig $\mathrm{zu}$ behaupten.

Die Beobachtung einer auffälligen diskursiven Unterscheidung zwischen »Religion« und »Kultur«, wobei die Vorstellung von »Religion« als »etwas Reinem « und »Kultur« als »etwas (die Religion) Verunreinigendem« besteht, teilen diverse Untersuchungen zu jungen Muslim*innen ausserhalb der Schweiz in Europa (vgl. in Bezug auf Frankreich, wie auch allgemein: Roy 2010, 2006, in Bezug auf Deutschland: Bendixsen 2013, John 2007, ausführlicher in Kapitel 6). Die interviewten Frauen, die sich diese »Taktik« zu Eigen machen, nehmen für sich in Anspruch, einen »reinen«, nicht-traditionalen, von »Kultur« losgelösten und in dieser Hinsicht »universellen« Islam zu vertreten. Diese Deutung von Islam ist Teil der »Taktik« der kämpferischen Selbstbehauptung als Muslima und hat einen emanzipatorischen Aspekt: Die diskursive Trennung von »Kultur/Tradition« vs. »Religion« ermöglicht religiös orientierten Secondas nicht nur eine Emanzipation vom elterlichen Religionsverständnis, indem sie dieses der »Kultur/Tradition« zuschreiben, sondern gleichzeitig auch die Zurückweisung des elterlichen, konservativen Rollenbilds als »kulturell/traditionell«. Sie finden durch diese Unterscheidung einen Weg, sich sowohl als »religiöse« wie auch als »(von kulturellen Traditionen) emanzipierte« Muslima zu behaupten und lehnen damit eine Zuschreibung konservativer Rollenbilder zur Religion ab. Hiermit trotzen sie dem im Islamdiskurs omnipräsenten vorherrschenden geschlechtskategorialen Stereotyp, der >religiösen, ergo zwingend unterdrückten Muslimin<.

Dies wird auch in der Aussage von Velika, einer anderen Frau meines Samples, deutlich:

»Als albanisches Mädchen zum Beispiel, ist es so ein bisschen die Tradition (...) musste ich zu Hause sein, also eben so ein bisschen die Hausarbeit machen und so Sachen kennenlernen. Und ich finde, dass...für mich ist es nicht etwas, das ich für richtig halte, weil ich finde, der Islam sagt, Männer und

10 Hierbei handelt es sich um »Kategorien der Praxis«, also um Akteur"innenkonzepte und nicht um »Kategorien der Analyse«(vgl. Brubaker/Cooper 2007: 52-55). Um dies zu verdeutlichen, werden Akteur*innenkonzepte in doppelten Anführungsstrichen verwendet, vgl. bspw. »Kultur«, »Religion«, »Tradition«. 
Frauen sind gleich. Ich kann genau das machen, was ich will. Und von dem her ist es für mich wie so kein Argument gewesen, als Mädchen darfst du das nicht machen. Das habe ich als Argument einfach nicht akzeptiert zu Hause $/ / \mathrm{mhm} / /$ wenn es die Religion nicht sagt (...) dann ist es etwas anderes, als wenn-wenn- wenn es irgendwie, wenn es die Kultur sagt //mhm// V: auch von dem her ist das Argument, ja du darfst nicht, weil du ein Mädchen bist. Das habe ich einfach nicht akzeptiert« (Velika, A 97).

Velika schreibt das Argument »ja du darfst nicht, weil du ein Mädchen bist« implizit »der Kultur« zu. Dadurch, dass sie diese elterliche Argumentationslinie nicht als religiöses Gebot, sondern als »das, was die Kultur sagt«, deutet, ist sie in der Lage, diese abzulehnen und »einfach nicht « zu akzeptieren und sich dennoch als gläubige bzw. religiöse Muslima selbst zu behaupten. Die Ablehnung des elterlichen Genderbilds durch die diskursive Unterscheidung von »Kultur« und »Religion« bildet einen zentralen Punkt bei dieser »Taktik«, wobei das elterliche Rollenmodell der »Kultur/Tradition« zugeschrieben wird, der »Religion« kontrastierend dazu ein emanzipatorischer Aspekt innewohnt. Velika gelingt im Rahmen der Hinwendung zur Religion also eine Art »sanfte Emanzipation« (Strahm 2007: 13) vom elterlichen Genderbild. Die Hinwendung zur Religion wird insofern für Velika und die anderen Frauen, bei denen diese »Taktik« rekonstruiert werden konnte, zur emanzipatorischen Ressource; ein Umstand, der dem homogenisierenden, diskursiven Bild einer sich der Religion zuwendenden Muslimin diametral entgegensteht.

Die »listige "1 $^{11}$ Aneignung der Deutung von »Religion« vs. »Kultur« und die damit einhergehende religiöse Selbstrepräsentation als emanzipierte Muslima macht den Kern der »Taktik« der kämpferischen Selbstbehauptung als Muslima in der Ausprägung der emanzipierten Muslima aus. Nach De Certeau handelt sich bei »Taktiken « um listige autonome Aneignungsweisen von Alltagspraxen, in denen eine Umdeutung etablierter Strukturen stattfinden kann (De Certeau 1988: 89). Indem die Frauen also die diskursive Unterscheidung von »Religion« und »Kultur « im Zusammenhang mit dem Geschlechterverhältnis vornehmen, eignen sie sich eine Deutung des »Muslima seins« an, die es ihnen erlaubt, sich gleichzeitig vom religiös begründeten elterlichen

11 Nach De Certeau (1988: 89) muss eine Taktik Lücken nutzen, die sich ihr in besonderen »Situationen der Überwachung durch die Macht der Eigentümer« auftun. Die Taktik, so De Certeau, sucht nach »Celegenheiten« und ist gleichzeitig »von ihnen abhängig« (ebd.): »Sie ist die List selber« (ebd.). 
Rollenbild zu emanzipieren und sich dennoch als (religiöse) Frau sowie Muslima selbst zu behaupten und somit im intersektionell beschränkten »Möglichkeitsraum« (Holzkamp 1983) mehr Handlungsfähigkeit zu erlangen.

Diese Art des religiösen Selbstverständnisses wirkt sich selbstredend auf die religiöse Selbstrepräsentation einerseits und auf die Art der religiösen Vergemeinschaftung andererseits aus:

Frauen, die sich der »Taktik« der kämpferischen Selbstbehauptung als emanzipierte Muslima bedienen, sind sehr glaubensgewiss, sie sehen Religion als umfassende Lebensordnung an. Gleichzeitig reflektieren sie Glaubensinhalte kritisch - diskutieren religiöse Gebote und handeln damit verbundene alltägliche Situationen aus. Wie ich beobachten konnte, finden solche religiösen Aushandlungsprozesse auch im Kollektiv statt wie bspw. unter Freundinnen oder in Frauengruppen von Moscheen.

Das Tragen des Hijabs ist für Frauen dieser »Taktik« nicht verhandelbarer Teil ihrer religiösen Selbstidentifikation. Die religiöse Selbstrepräsentation als eine vom elterlichen Genderbild emanzipierte Muslima, welche sich als »Schweizer Muslima« der zweiten Generation versteht und von der Gleichwertigkeit aller Religionen ausgeht, macht Frauen, welche sich dieser »Taktik« bedienen, äusserst anschlussfähig und interessant für eine Zusammenarbeit mit NGOs und interreligiösen Gefässen ${ }^{12}$. Die »Taktik« der kämpferischen Selbstbehauptung als emanzipierte Muslima besteht schliesslich darin, durch eine »listige« Umdeutung (De Certeau 1988: 89) des »Muslima seins« Zugang zu einer Alternativkarriere bzw. Bildungszugang zu erlangen. Das Stigma »Hijab« und die Differenzkategorie »Muslimin« wird in diesem Kontext zum »Charisma« (Lipp 2010), wie sich auch an Zaras Bildungsbiografie verdeutlichen lässt:

Die Erfahrung der Verunmöglichung einer Rückkehr in den Dienstleistungsbereich aufgrund des sichtbaren religiösen Symbols Hijab kam für Zara in diesem Ausmass überraschend - sie war enttäuscht: »weil ich habe nicht einmal einen Aushilfsjob (...) oder so erhalten, wo eigentlich die Kunden vorwiegend Migranten sind« (Zara, A 78). Zunächst versuchte sie, wie sie erzählt,

12 Dieses Engagement in interreligiösen Cefässen grenzt Frauen der Taktik mit der Ausprägung der religiösen Selbstrepräsentation als emanzipierte Muslima gleichzeitig auch von Frauen ab, welche sich der Taktik mit der Ausprägung der Selbstrepräsentation als religiöse Muslima bedienen. Letztere gehen ostentativ von einer Überlegenheit der eigenen Religion aus und haben nicht zuletzt dadurch einen gewissen Missionsanspruch. 
»die brave Hausfrau [zu] spielen« (Zara, A 78). Sie habe aber dann »nach etwa drei, vier Monaten gemerkt, dass ich das nicht wirklich bin (lacht)« (ebd.): $\mathrm{Zu}$ Hause sei ihr die »Decke auf den Kopf gefallen« (ebd.). So begann Zara nach neuen Möglichkeiten zu suchen und baute ein zunächst nebenberuflich ausgeführtes Engagement als Mentorin für junge Migrantinnen aus. Dieses Engagement war an eine feministisch orientierte NGO gebunden, die Zaras Anliegen und Rollenbild, junge Frauen trotz schlechter Bedingungen in ihrem berufsbiografischen Weg zu unterstützen, entgegenkam. Sie umschreibt ihr Engagement wie folgt:

"Also so quasi ein bisschen ein Motivationsmotor spielen für diese Frauen, um sie zu motivieren, trotz schlechten Deutschkenntnissen und trotz Schwierigkeiten nicht aufzugeben und an sich zu arbeiten und zu kämpfen für eine Ausbildung oder dafür, einfach etwas zu machen. Und das habe ich fast drei Jahre gemacht, einfach nebenbei immer, auf Termin. Und dort bin ich eigentlich so, das ist so mein erster Schritt gewesen (...) (Zara, A 166).

Die Formulierung "Motivationsmotivator spielen« deutet an, dass es einen Aspekt ihrer Rolle als "Motivationsmotivator « gab, den sie »spielen« musste. Selbst sich in einer ebenfalls prekären, beruflichen Situation befindend, in der unklar war, wie und ob sie sich beruflich weiterentwickeln konnte. Dennoch war es ihr ein Anliegen, junge Frauen dazu zu bringen, »trotz Schwierigkeiten nicht aufzugeben«, für sie selbst stellte »aufgeben« ebenfalls keine Option dar. Sie ermutigte die Frauen stets zum Kampf und zu »kämpfen für eine Ausbildung«. Hier wird einmal mehr deutlich, dass für Zara »kämpfen« das Mittel der Wahl war, Zugang zu Bildung zu erlangen - auch dies ein konstitutives Element dieser »Taktik«. Teil der »kämpferischen Selbstbehauptung« von Zara war es, sich vom elterlichen Rollenbild $\mathrm{zu}$ emanzipieren, nicht als »Hausfrau« $\mathrm{zu}$ Hause $\mathrm{zu}$ bleiben, sondern hauptsächlich »einfach etwas $\mathrm{zu}$ machen«. Im Nachhinein wurde deutlich, dass dies lediglich ein »erster Schritt« gewesen war. Denn durch dieses Engagement wurde Zara nach und nach bekannter in NGO-Kreisen. Sie wurde auf Veranstaltungen eingeladen, auf denen sie Leute sah und kennenlernte, was wiederum neue Anfragen mit sich brachte:

»Das hat mir so gutgetan. (...) und dann lernt man eben auch Leute kennen von diesen verschiedenen Organisationen, Institutionen und dann kommt mal hier eine Anfrage und dort eine Anfrage« (Zara, A 166).

Zara zog Befriedigung aus ihrem Engagement, welches ihr die berufliche Sinnhaftigkeit und die Anerkennung stiftete, welche ihr, sobald sie den Hijab 
zu tragen begonnen hatte, in ihrem ursprünglichen Berufsfeld sprichwörtlich von einem Tag auf den anderen verwehrt geblieben worden war. Dass ihre eigenen teilweise schwierigen bildungsbiografischen Erfahrungen nun auf diesem Weg zu etwas Nutze waren, tat ihr »so gut«. Durch die damit einhergehende zunehmende Akkumulation von sozialem Kapital (Bourdieu 1983b) »kommt mal hier eine Anfrage und dort eine Anfrage« gelang ihr der Aufbau eines relativ breiten (beruflichen) Netzwerks. Zunächst engagierte sie sich in NGOs und interreligiösen Gremien; schliesslich wurde sie auch vermehrt von Bildungsinstitutionen angefragt, sie wurde in Schulklassen eingeladen, machte Moscheeführungen für Studierende, sprach auf Podien und an Fachhochschulen; zu guter Letzt wurde sie gar Mitglied eines politischen Integrationsgremiums. Parallel zu ihrer öffentlichen Präsenz nahm sie zunehmend eine wichtigere Stellung innerhalb ihres Moscheevereins ein, wo sie sich aktiv daran beteiligte, Deutsch als Sprache für religiöse Handlungsfelder zu propagieren, um die Moschee für Leute der »zweiten Generation« attraktiv zu machen. Gleichzeitig initiierte sie, dass die Moschee mit »Tage der offenen Tür« gegen aussen an »Sichtbarkeit gewinnt« (Feldprotokoll), indem sie ihre Tore für Nachbarschaft und weitere Interessierte öffnete und mit Vorträgen zentrale Glaubensinhalte erklärte. Auch gründete die engagierte junge Frau eine aktive Frauengruppe in der Moschee. Wenig erstaunlich wurde sie bald darauf auch von der Presse »entdeckt«, wo sie in ihrer symbolischen Rolle als Hijab tragende junge Muslima der zweiten Generation zu interreligiösen Themen oder quasi als »Expertin« als muslimische Frau befragt wurde. Sie ist selbst überrascht über das Potenzial, das ihr zunächst nebenberufliches Engagement barg:

»Ähm habe aber nie gedacht, dass das eigentlich so äh ganz eine wichtige Sache sein wird, habe das einfach gewollt, weil ich mich einfach nebenbei habe engagieren wollen. Auch für junge Frauen und so« (Zara, A 146).

Aus ihrem Engagement »für junge Frauen und so« wurde also aufgrund der speziellen Dynamik, welche das Aufeinandertreffen ihrer religiösen Selbstrepräsentationsstrategie als emanzipierte Muslima mit den Interessen linker NGOs in dem politisch stark umkämpften Feld des laufenden Islamdiskurses und des damit einhergehenden Genderbilds auslöste, eine "ganz (...) wichtige Sache«. Ein Umstand, der Zara selbst erstaunt. Sie habe sich einfach »nebenbei engagieren wollen«. Ihre ursprüngliche Motivation, sich für junge benachteiligte Frauen »einfach nebenbei« einzusetzen, führte schliesslich zu einer Alternativkarriere. 
Konstitutiv für die »Taktik« der kämpferischen Selbstbehauptung als emanzipierte Muslima ist es, dass die religiöse Selbstrepräsentation als emanzipierte Muslima Zugang $\mathrm{zu}$ einer beruflichen Weiterentwicklung schafft. Im Umfeld der linken NGOs und interreligiösen Integrationsgremien wurde die Differenzkategorie »Muslimin« (sichtbar gemacht anhand des Symbols Hijab) für Zara plötzlich nicht mehr zum verhindernden Stigma, sondern im Gegenteil zu ihrem Charisma stilisiert (vgl. Lipp 2010). Ihre Selbstrepräsentation als selbstbewusste, selbstbestimmte, kämpferische und dennoch religiöse Muslima fasziniert Öffentlichkeit, Feministinnen, NGOs, Presse, Bildungsinstitutionen gleichermassen - eine neue Rolle, die Zara sichtlich auch geniesst, die »ein bisschen eine Sucht geworden« ist (Zara, A 166). Schliesslich führte sie ihre »Taktik« gar zu einem bildungsbiografischen Qualifikationsschritt -einem tertiären Ausbildungsgang: Sie wurde von einer Fachhochschule eigens angefragt, ob sie eine Ausbildung als »Kulturmediatorin« (CAS »Kulturvermittlung«) machen wolle:

»Und sie haben mich eigentlich darauf angesprochen, sie haben mich angerufen (...), ob ich nicht Lust habe, weil sie möchten gerne auch gemischte Klassen zusammenstellen, von verschiedenen Religionen Leute drin haben, und von der muslimischen Seite würden sie mich sehen, haben sie gesagt. Ob ich Lust habe« (Zara, A 102).

Aus der Aussage »und sie haben mich eigentlich darauf angesprochen« wird deutlich, dass Zara sich hier zunächst in einer passiven Rolle befand. In der Regel werden Studiengänge auf Initiative der Studierenden besucht. Aufgrund ihrer religiösen Selbstrepräsentation wurde Zara jedoch angefragt. Aus der Formulierung »von der muslimischen Seite würden sie mich sehen« geht hervor, dass Zara von der Fachhochschule als (akkurate) Vertreterin und Repräsentantin »der muslimischen Seite« wahrgenommen und in dieser zugeschriebenen Rolle eigens dafür angefragt wurde, ob sie an dem Studiengang teilnehmen wolle. Gleichzeitig spricht ein autoritärer Duktus aus der Formulierung »würden sie mich sehen«, der klar ausdrückt, wer die Wahl trifft und dass die Macht in diesen Selektionsprozessen (ungleich) verteilt ist. Zara nahm den Vorschlag jedoch an, lieh sich die nicht unerheblichen Studiengebühren und schloss die Ausbildung ab. Die »Taktik« der kämpferischen Selbstbehauptung als emanzipierte Muslima und die damit einhergehende Aneignung der Differenzkategorie »Muslimin« durch ihre religiöse Selbstrepräsentation ermöglichte der Realschulabgängerin also schliesslich einen tertiären Studiengang. 
Andere Frauen fanden gleichermassen durch die voranstehend beschriebenen, religiösen Selbstrepräsentationen erneuten Zugang zu Bildung und zum Arbeitsmarkt, der ihnen aufgrund des Hijab-Tragens anderswo verwehrt blieb. Sie gingen bspw. einen Weg in die berufliche Selbstständigkeit, wo die Differenzkategorie »Muslimin« und deren Sichtbarkeit anhand des sichtbaren religiösen Symbols Hijab nicht wie zuvor zum berufsbiografischen "Stigma« wurde, sondern wie bei Zara zum Fundament der beruflichen Weiterentwicklung. Dies geschah durch die (religiöse) Selbstrepräsentation und Emanzipation vom elterlichen, klassischen Rollenbild, das eine ausschliessliche Rolle als »Hausfrau« vorsah. Beispiele für solche durch die »Taktik« geformten Berufsbiografien sind bspw. die Lancierung eines muslimischen Modelabels oder die Selbstständigkeit als Fahrlehrerin speziell für muslimische Frauen oder aber die Eröffnung einer Hijab-Boutique. Lutz und Davis haben in ihrem Aufsatz Geschlechterforschung und Biografieforschung: Intersektionalität als biografische Ressource am Beispiel einer aussergewöhnlichen Frau anhand des Fallbeispiels einer südafrikanischen Anti-Apartheids-Aktivistin bereits dargelegt, wie unter gewissen Umständen intersektionell wirkende Mehrfachdiskriminierungen nicht nur nachteilig wirken, sondern auch zur biografischen Ressource werden können (Lutz/Davis 2005: 228-247). Wie hier verdeutlicht werden sollte, kann dies unter gewissen Umständen auch bei Bildungsbiografien der Fall sein.

Obwohl die »Taktik« der kämpferischen Selbstbehauptung als emanzipierte Muslima eine wirkmächtige Gegenstrategie zur hegemonialen Repräsentation (Hall 2004: 161) darstellt, muss jedoch mit Hall festgehalten werden, dass damit »die Widersprüche der binären Struktur« alltagskultureller »Stereotypisierung nicht überwunden« (ebd.) sind, sondern vielmehr reproduziert werden.

\section{Ausprägung: Selbstrepräsentation als dezidiert religiöse Muslima}

Bei der Ausprägung der Selbstrepräsentation als dezidiert religiöse Muslima stellt sich die Ausgangslage hinsichtlich des Herkunftsmilieus ähnlich wie bei der Ausprägung der religiösen Selbstrepräsentation als emanzipierte Muslima dar. Wie bei ersterer Ausprägung gelangen die interviewten Frauen, die sich als dezidiert religiöse Muslima selbst repräsentieren, berufsbiografisch aufgrund des sichtbaren religiösen Symbols Hijab an eine Grenze, die eine berufliche Um- oder Neuorientierung erfordert. Wie bei der voranstehend beschriebenen Ausprägung wirken auch hier die Differenzdimensionen Gen- 
der, »Migrationshintergrund«, »class« und Religion (speziell anhand sichtbarer religiöser Symbole) intersektionell einschränkend auf die Bildungsbiografie. Beide Ausprägungen religiöser Selbstrepräsentation beinhalten als zentrales, übergeordnetes Element die »listige« Aneignung (De Certeau 1988: 89) der Deutungsweise der Differenzkategorie »Muslimin« durch eine spezifische religiöse Selbstrepräsentation. Bei beiden Ausprägungen hatte die Art der religiösen Selbstrepräsentation entscheidenden Einfluss auf den weiteren Verlauf der Bildungsbiografie: Während es den interviewten Frauen mit religiöser Selbstrepräsentation als emanzipierte Muslima gelingt, sich durch die »Taktik« der kämpferischen Selbstbehauptung gesellschaftspolitisch zu positionieren und eine Alternativkarriere in interreligiösen und/oder interkulturellen NGOs zu machen oder sich durch berufliche Selbstständigkeit mittels eines (religionsrelevanten) Nischenangebots zu positionieren, werden Frauen, bei denen eine religiösen Selbstrepräsentation als dezidiert religiöse Muslima rekonstruiert wurde, durch die Ausschlusserfahrung politisiert und lehnen sich durch jugendkulturelle Verszenung ${ }^{13}$ im $»$ Kampf gegen Islamophobie " gesellschaftlich auf. Letztere vergrössern ihre bildungsbiografische Agen$c y$, wie im Folgenden dargelegt werden soll, mittels eines »sozialisatorische[n] Effekt[s] szeneinterner Vergemeinschaftung (Meinert/Seeliger 2013: 49)

Mirjeta, bei welcher die Selbstrepräsentation in der Ausprägung als dezidiert religiöse Muslima nachgezeichnet werden konnte, und an deren prototypischem Fall diese Ausprägung illustriert werden soll, stammt aus einem ähnlichen Milieu wie Zara. Sie plante zunächst aufs Gymnasium zu gehen, scheiterte jedoch aufgrund ihrer für das gymnasiale Niveau ungenügenden deutschen Sprachkenntnisse und trat stattdessen eine Lehrstelle als Chemielaborantin in einem industriellen Betrieb an. Im Laufe der Lehrzeit begann sie sich wie Zara vermehrt mit dem Islam zu befassen, dies geschah ebenfalls nicht zufällig in der Adoleszenz, sondern nicht zuletzt auch aufgrund der Klärung eigener (religiöser) Identifikationsfragen und solchen hinsichtlich ihres Elternhauses. In dieser Zeit entschloss sich Mirjeta einen Hijab zu tragen, weshalb ihr ihre Lehrstelle gekündet wurde. Mirjetas »Taktik« mit diesem berufsbiografischen Einschnitt umzugehen, gestaltete sich jedoch leicht anders als die von Zara: 
Wie die »Taktik« von Zara beinhaltet auch die »Taktik« von Mirjeta die in De Certeaus Sinne (1988) »listige« Aneignung der Deutung der Differenzkategorie »Muslimin«. Diese »listige« Aneignung bzw. Umdeutung der Differenzkategorie »Muslimin« aus einer subalternen Position heraus geschieht jedoch durch die kämpferische Selbstbehauptung als dezidiert religiöse Muslima:Zentrales Moment dieser »Taktik« ist die ostentative Betonung alltagsreligiöser Praxen (wie bspw. Beten, Geschlechtertrennung etc.) und Kleidung als Zeichen des Widerstands gegen Gesellschaft und Elternhaus, sowie eine auf dieser religiösen Selbstrepräsentation aufbauende subkulturelle Vergemeinschaftung mit jugendkulturellem Charakter. Ihre religiöse Selbstrepräsentation hatte wie bei Zara indirekt einen klaren Einfluss auf den Bildungsweg, da ein »sozialisatorischer Effekt szeneinterner Vergemeinschaftung« (Meinert/Seeliger 2013: 49) der jugendkulturellen Szene, in der sich Mirjeta vergemeinschaftete, eine islamisch begründete Pflicht zur (Weiter-)Bildung beinhaltete.

Als Mirjeta sich im Laufe der Lehre dazu entschied ein Kopftuch zu tragen, war ihr bewusst, dass sie aufgrund ihres Entscheids, sich zu bedecken, ihre Lehrstelle verlieren würde, da ihr dies der Lehrmeister angekündigt hatte, als sie ihn danach fragte. Sie nahm dies jedoch in Kauf, obwohl sie von der Ansage ihres damaligen Vorgesetzten zunächst ziemlich niedergeschlagen war:

»Ich war dann einfach dort und ganz eingesackt also ganz eingeschüchtert und so. Ich war in dieser Zeit auch sehr scheu und habe mich gar nicht gewehrt« (Mirjeta, A 44).

Aus der Aussage wird deutlich, wie Mirjeta sich damals verunsichern liess und nicht in der Lage war, sich zu wehren. Ein Umstand, der sich später ändern sollte. Mirjeta wurde durch diese Erfahrung politisiert. Nach drei Monaten, in denen sie zu Hause geblieben war und sich »auf sich besonnen« (Mirjeta, A 44) hatte, sah sie ein klares Ziel vor Augen: Sie wollte ein Kopftuch tragen können, den Islam praktizieren und so ihre Lehre beenden und kam zur Ansicht: » Es kann nicht sein, dass es nicht zusammen geht« (Mirjeta, A 44). Hier wird bereits ein erster Ansatz ihrer »Taktik« der kämpferischen Selbstbehauptung als Muslima deutlich. Bei einer selbstständig tätigen Frau (mit sog. »Migrationshintergrund«) fand sie nach längerer Suche schliesslich einen Ort, wo sie ihre Lehre mit Kopftuch beenden konnte. Mirjeta imponierte ihre neue Chefin, die »Leidenschaften oder die Charaktereigenschaft« hatte. Ebenso beeindruckte sie, »dass für sie Nichts unmöglich ist« (Mirjeta, A 47). 
Parallel zu dieser Begegnung wurde ihr damals gegen Abschluss der Lehrzeit, wie sie erzählt, der Islam zur Maxime ihrer Bildungsmotivation und -aspiration:

»Der Islam schreibt vor, dass die Leute in der Bildung das Höchstmögliche anstreben sollen« (Mirjeta, A 47).

Für Mirjeta, die sich zunehmend mit der Religion auseinandersetzte, wurde der Islam immer wichtiger. Sie fasste neue Ziele und strebte »das Höchstmögliche« an: Nach ihrer Lehre wollte sie studieren. Sie begründet ihre Bildungsaspiration religiös. Berufsbegleitend holte sie die Hochschulzulassung nach, was »eine stressige Zeit« (A 51) war, wie sie sagt. Parallel dazu gewann für Mirjeta die Vergemeinschaftung mit jungen, gebildeten Muslim*innen und die Verszenung (Gebhardt 2018, Gebhardt et al. 2007: 213) an Bedeutung.

Obwohl es an dieser Stelle zu weit führen würde, detailliert auf muslimische, jugendkulturelle Szenen in Europa einzugehen, sei doch auf einige wichtige Beobachtungen bezüglich neueren transnationalisierten, muslimischen jugendkulturellen Strömungen in der Deutschschweiz hingewiesen ${ }^{14}$ :

In Westeuropa existiert eine breite Palette an spezifisch muslimischen Jugend- und Subkulturen, Szenen, Moden und Musikstilen (Herding 2013); Grüner Pop (Müller et al. 2010), »Pop-Muslime« (Gerlach 2010), religiöse Szenen der Neo-Muslimas (Nökel 2002), muslimische Modeszenen (bspw. Modellabel Style Islam), Taqwacore (Punk-Islam) etc. Neuere jugendkulturelle Entwicklungen werden zunehmend transnationalisiert und gewinnen an Bedeutung (vgl. bspw. muslimische Mode oder Fernseh-Prediger ${ }^{15}$ etc.).

In Bezug auf die Frage, welche Bedeutung der Teilnahme an religiösen Gruppierungen (muslimische Jugendgruppen, Frauenvereine, Moscheevereine) resp. der Absenz davon in Bildungsbiografien zukommt, wurden im Anschluss an die Ergebnisse des Projekts über muslimische Jugendgruppen des ZRF (Zentrum für Religionsforschung Luzern) und deren fundierte Charakterisierung der muslimischen Jugendgruppen in der Schweizer Gesellschaft (Endres et al.: 2013) zunächst neuere jugendkulturelle Entwicklungen sowie muslimische Jugend- und Frauengruppen in der Deutschschweiz in den (ethnografischen) Blick genommen. Das Projekt des ZRFs lautete »Muslimische Jugendgruppen und Bildung von zivilgesellschaftlichem Sozialkapital in der Schweizer Gesellschaft « und wurde 2011-2013 durchgeführt (vgl. Jürgen Endres, Andreas TungerZanetti, Samuel Behloul und Martin Baumann 2013). Das dem religionswissenschaftlichen Seminar der Universität Luzern angegliederte Zentrum für Religionsforschung (ZRF) stellte eine wichtige Kooperationspartnerin meines Dissertationsprojekts dar. 
Wie sich in der Feldforschung zeigte, werden neuere muslimische jugendkulturelle soziale Praktiken auch in der Schweiz aufgegriffen und reproduziert. So fand z.B. im November 2013 der erste schweizerische muslimische Poetry-Slam (I-Slam) organisiert von >UMMAH - Muslimische Jugend Schweiz statt und es existiert mittlerweile auch in der Schweiz eine kleine muslimische Modeszene mit eigenen Labels und Fashion Shows. YouTubeFilme von sogenannten $» H i j a b$-Bloggerinnen ${ }^{16}$ mit Hijab-oder Get-ready-forEid-Make-up-Tutorials ${ }^{17}$ sowie Musikvideos von Mipsterz (muslimische Version von Hipsters, vgl. Kap. 2.3), aber auch "pop-muslimische« Starprediger (Gerlach 2010) finden in der Schweiz ihr Publikum. Hierbei nehmen das Internet und Social-Media-Kanäle eine zentrale Bedeutung ein (vgl. hierzu auch in Bezug auf Europa Herding 2013, auf die Schweiz Endres et al. 2013: 39).

In der Feldforschung wurden unter anderem moschee-ungebundene Gruppierungen, in deren Umfeld sich neuere, transnationalisierte, jugendkulturelle Einflüsse in erster Linie verorten lassen, in den Blick genommen, so z.B. die in Zürich stationierte muslimische Jugendorganisation >UMMAH - Muslimische Jugend Schweiz‘, die einen jährlichen U-Day ${ }^{18}$ (UMMAH-Day) organisiert mit deutschschweizweiter Ausstrahlung. Aber auch andere moschee-ungebundene Jugendorganisationen oder Organisationen, die primär von Adoleszenten frequentiert werden, organisieren regelmässig Anlässe (wie bspw. $\mathrm{MSAZ}^{19}, \mathrm{MSAB}^{20}, \mathrm{IZRS}^{21}, \mathrm{VIJS}^{22}$ etc.). Die von muslimischen

16 Bezeichnung vgl. Hannan, A 637.

17 Sehr beliebt ist bspw. Hijabhills aus England, die viele Styling-Filme ins Netz stellt, von Every-Day-Make-up-Tutorial über Cet-ready-for-Eid bis zum Hijab-for-Beginners (Folge 13): https://www.youtube.com/results?search_query=Hijabhills [Stand: 15.11.2017]. Diese Art von YouTube-Filmen entsprechen dem gegenwärtigen jugendkulturellen Trend sich Make-up und Styling-Filme auf YouTube anzuschauen, in denen sich Menschen privat dabei filmen, wie sie sich zurecht machen. Mittlerweile werden oft angeklickte Filme auch von Werbefirmen mit Produktwerbung oder Produkten gesponsert.

18 An dem alljährlichen U-Day (UMMMAH-Day) vom 18.10.2014 zeigten sich die Einflüsse deutscher muslimischer jugendkultureller Selbstrepräsentation deutlich: So war das deutsche Fashionlabel Styleislam (bekannt für seine T-Shirts mit Aufdrucken wie bspw. »I love my Prophet« oder »Smile - It's Sunnah«) präsent und mit Ausnahme von Tarik Ramadan waren fast ausschliesslich deutsche Referenten*innen und Musiker*innen geladen, vgl.: www.u-day.ch/, zuletzt geprüft am 30.06.2015.

19 Muslim Students Association Zurich.

20 Muslim Students and Alumni Association Bern.

21 Islamischer Zentralrat Schweiz.

22 Vereinigung Islamische Jugend Schweiz. 
Jugendorganisationen organisierten Aktivitäten haben eher selten einen ausschliesslich religiösen Charakter - Ausnahmen bilden vielleicht gemeinsame Iftar ${ }^{23}$-Anlässe im Ramadan. Meist werden jedoch jugendliche Freizeitaktivitäten wie Fussballtourniere, I-Slam, Konzerte, (Wander-)Ausflüge, Jugendlager, aber auch Podiumsdiskussionen etc. organisiert (vergleichbar mit organisierten Aktivitäten von Vereinen mit freikirchlichem Hintergrund, wie bspw. der >ICF - International Christian Fellowship ; Stienen/Bühler/Gasser/Tamcan 2011, Walthert 2010). Hier kann als gläubige(r) Muslim*in Gemeinsamkeit erfahren werden (Ansprechformel »Geschwister im Islam«). Muslimische Jugendorganisationen und -gruppen sind allerdings auch Orte, wo Ausschlusserfahrungen thematisiert und ausgetauscht ${ }^{24}$ werden können (vgl. hierzu auch Endres et al. 2013), ältere Jugendliche und junge Erwachsene dienen hierbei nicht selten als Vorbilder, Rollenmodelle oder Ratgeber*innen. Im Zuge dieser Ausschlusserfahrungen werden teilweise auch politische Podiumsdiskussionen mit geladenen Gästen lanciert und organisiert.

Die Jugendorganisationen sind ebenfalls im Netz präsent (Website aber auch Social Media) und verfügen in der Regel über einen regelmässig aufdatierten Webauftritt, der sich an einer zeitgemässen Bildsprache mit jugendkulturellem Charakter orientiert.

Mirjeta bewegt sich in einer "Szene $\varkappa^{25}$ (Hitzler/Niederbacher 2010: 15-16) junger Menschen, die eine dezidierte, eher konservative Auslegung des Islam

23 Abendliches Mahl des Fastenbrechens im Ramadan.

24 Aufgrund der erhobenen Daten kann angenommen werden, dass verschiedene Organisationen unterschiedliche Strategien des Umgangs mit Ausschlusserfahrungen »bedienen «. Während Organisationen wie >UMMAH - Muslimische Jugend Schweiz bemüht sind, ihren Mitgliedern Wege aufzuzeigen, resp. sich gegenseitig auf der Suche darin zu bestärken, sich als gläubige( $r$ Muslim*in gesellschaftlich zu integrieren und betonen, dass Integration als gemeinsamer/gegenseitiger Prozess zu verstehen sei, stellen Organisationen wie bspw. der IZRS (Islamischer Zentralrat Schweiz) tendenziell eher Identifikationsangebote für junge Frauen (und Männer) bereit, welche in ihren Assimilationsbemühungen als gläubige Muslim*innen in der Schweizer Cesellschaft enttäuscht wurden.

25 Hitzler und Niederbacher definieren Szene wie folgt: » Eine Form von lockerem Netzwerk; einem Netzwerk, in dem sich unbestimmt viele beteiligte Personen und Personengruppen vergemeinschaften. In eine Szene wird man nicht hineingeboren oder hineinsozialisiert, sondern man sucht sie sich aufgrund irgendwelcher Interessen selber aus und fühlt sich in ihr eine Zeit lang mehr oder weniger szu Hause،. Eine Szene weist typischerweise lokale Einfärbungen und Besonderheiten auf, ist jedoch nicht lokal begrenzt, sondern, zumindest im Prinzip, ein weltumspannendes, globales - und ohne intensive Internet-Nutzung der daran Beteiligten zwischenzeitlich auch kaum noch überhaupt 
leben. Diese Szene weist jugend-, aber auch subkulturelle Züge auf: Die jungen Menschen identifizieren sich mit dieser Szene über eine normierende soziale Praxis, die sich unter anderem in einer ausgeprägten Gruppensymbolik, in der Sprache, einer (religiös geprägten) Kleidung, (tolerierter) Musik, eigenen Social-Media-Kanälen und Gruppen, alltagsreligiösen Praxen sowie politischer Haltung und religiöser Weltanschauung artikuliert (vgl. hierzu auch ebd.: 190ff.).

Im Zuge dieser Vergemeinschaftung wird »der Islam« zunehmend der Schlüssel von Mirjetas alltäglicher Lebensführung:

»Also der Islam ist eigentlich das Höchste in meinem Leben. Ich versuche,

Alles dem Islam unterzuordnen. //Mhm// weil ähm das ist das Einzige, was für mich Sinn macht« (Mirjeta, A 77).

Mirjeta ist glaubensgewiss, »der Islam« in einer dezidierten, konservativen ausgelegten Variante wird zunehmend zur Richtschnur ihrer Lebensführung. In der Formulierung »das Einzige, was Sinn macht « wird gleichzeitig der ausschliessliche Charakter, der sich als oberste Maxime ihrer Lebensordnung manifestiert, deutlich.

Mirjetas religiöse Selbstrepräsentation manifestiert sich einerseits in einem religiösen Kleidungsstil und andererseits anhand einer kompromisslosen Handhabung (alltags-)religiöser Praxen. Sie kleidet sich bewusst, wie sie sagt »islamisch«. Als Ausdruck dessen zieht einen Khimar dem Hijab vor. Zudem ist sie, wie die weiblichen Peers der Szene, in der sie sich bewegt, meist ganz schwarz oder dunkelbraun gekleidet - ein Umstand, der ihr, wie ich verschiedentlich beobachten konnte, ablehnende Reaktionen von Menschen, denen sie auf der Strasse begegnet, einbringt.

Auch in der Handhabung religiöser Praxen ist sie äusserst konsequent. Als ich sie bspw. neben einigen informellen Gesprächen formell mit laufendem Band interviewe, unterbricht sie das Interview ostentativ für das Gebet.

Die Irritation, die eine selbstbewusste religiöse Selbstrepräsentation in einer sich als säkular verstehenden Gesellschaft auslöst, begründet Mirjeta mit deren »Islamophobie«:

vorstellbares - Cesellungsgebilde bzw. eine sglobale Mikrokultur«. Und natürlich gibt es in einer Szene keine förmlichen Mitgliedschaften« (2010: 15-16, Herv. im Orig.). 
»(...) die Menschen sowieso islamophob sind und Kopftücher nicht gerne haben, Bärte nicht gerne haben und ein selbstbewusstes Auftreten sowieso (...). Der Sündenbock für alles ist der Islam« (Mirjeta, A 100).

Mirjeta verortet Islamophobie insbesondere in der gesellschaftlichen Ablehnung sichtbarer religiöser Symbole. Insbesondere würden die Menschen eine religiöse Selbstrepräsentation ablehnen, so Mirjeta, wenn diese (wie bei ihr und ihren Peers), an ein, wie sie es nennt, "selbstbewusstes Auftreten« gekoppelt ist.

Genau dieses Moment eines >selbstbewussten Auftretens` mit ostentativem Charakter ist hinsichtlich der »Taktik« der kämpferischen Selbstbehauptung in der Ausprägung als >dezidiert religiöse Muslima konstitutiv: Die ostentative (religiöse) Selbstrepräsentation besteht einerseits aus einer dezidierten, konservativen Auslegung des Islam und einer kompromisslosen Handhabung sowie Betonung religiöser Praxen, andererseits aber auch aus der Politisierung der damit einhergehenden Ausschlusserfahrungen und dem daraus folgenden »Kampf« gegen die »islamophobe Gesellschaft«. Kern dieser »Taktik« bildet der politische Kampf gegen die »islamophobe Gesellschaft » als verantwortliche Instanz für das vorläufige Scheitern der eigenen Bildungsbiografie am sichtbaren religiösen Symbol des Hijab. Teil dieses »Kampfes gegen die Islamophobie« ist das Antreiben und Befördern einer »höchstmöglichen« Bildung aller Muslim*innen (vgl. unten).

Frauen, bei denen die »Taktik« der kämpferischen Selbstbehauptung in der Ausprägung der religiösen Selbstrepräsentation als dezidiert religiöse Muslima nachgezeichnet werden konnte, werden durch die ihnen aufgrund des Hijabs widerfahrende berufsbiografische Ausschlusserfahrung in ihrer Erstausbildung politisiert. Anders als bei der Ausprägung der religiösen Selbstrepräsentation als emanzipierte Muslima manifestiert sich die »Taktik« der kämpferischen Selbstbehauptung nicht im Dialog mit gesellschaftlichen Gremien, sondern durch (politischen) Widerstand gegen die Schweizer Gesellschaft. Anders als Zara sieht Mirjeta keinen Nutzen darin, die Gesellschaft »aufzuklären«, vermittelnd in interreligiösen Gefässen oder Schulklassen tätig zu sein, vielmehr widmet sie sich dem »Kampf gegen die Islamophobie«. Aufgrund dieser Tatsache erstaunt es nicht, dass im Kontext des gegenwärtigen geführten Islamdiskurses die offensiv-ostentativ ausgelebte Religiosität von diesen Frauen einerseits eine »Irritation der säkularen Gesellschaft« (Strahm 2007: 9) bewirkt, anderseits aber bisweilen auch eine (meist negative) Reaktion des Elternhauses hervorruft. Diese Irritation einer dem Selbst- 
verständnis nach säkularen Gesellschaft durch eine »selbstbewusst gelebte und öffentlich präsentierende Religiosität muslimischer Frauen« (ebd.) wird von den Frauen jedoch intendiert oder zumindest in Kauf genommen. Bei Ausschlusserfahrungen gilt es, - so die Maxime der Szene, in der sich Mirjeta bewegt - nicht zu kuschen, sondern wie Lane ${ }^{26}$ das Handeln der Szene, der ihre Schwestern angehören, beschreibt (Feldprotokoll Mai 2015): »steihert zrüggdisse« - knallhart verbal zurückzugeben.

Der »Kampf gegen die Islamophobie« bzw. die Politisierung der jungen Frauen aufgrund ihrer Ausschlusserfahrungen wird entscheidend befördert durch die Vergemeinschaftung mit gleichgesinnten religiösen Musliminnen und Muslimen in einer Szene, die jugendkulturelle Züge trägt. >Klassische religiöse Vergemeinschaftung in moschee-gebundenen Jugend- oder Frauengruppen, wie sie Frauen, der Ausprägung der religiösen Selbstrepräsentation als emanzipierte Muslima bevorzugen, lehnt Mirjeta ab. Wie sie betont, ist sie enttäuscht von Imamen und Moscheevereinen, die in ihren Augen skuschen<, wenn der Islam gesellschaftlich negativ diskutiert wird, und die ihrer Ansicht nach »möglichst nicht auffallen und sich nahezu dafür entschuldigen, dass man überhaupt Muslim[in] ist (Mirjeta, A 90). Zoja, eine andere Frau meines Samples, bringt es während eines Gesprächs prägnant auf den Punkt: Sie will nicht wie ihre Eltern »sorry und danke für die Moschee im Keller«sagen. Als Schweizer Muslima fordert sie »ein Gotteshaus, das auch wirklich eins ist «, vergleichbar mit einer Synagoge oder einem Tempel (Feldprotokoll Dez. 2015; aber auch Zoja, A 81, 82).

Mirjeta versteht sich als Teil einer religiösen Gemeinschaft, die Gesellschaftskritik übt und die in dieser Rolle zwangsläufig auf Widerstand stösst, denn »unser Spiegel gegen die Gesellschaft, das mag fast niemand ertragen in der Schweiz« (Mirjeta, A 90). Mirjeta wirft der hegemonialen Gesellschaft vor, dass sie Muslim"innen, die wie sie »eine eher konservative Auslegung vom Islam fordern« und sich dafür einsetzen, regelrecht »aus dem Diskurs herauskicken« (Mirjeta, A 91) will, indem die Gesellschaft sie in die Ecke des Radikalismus stellen würde, »wo man uns noch radikal, möglichst radikal und vom Radikalen in das Gefährliche bringt« (Mirjeta, A 92). Frauen, bei denen diese »Taktik« rekonstruiert werden konnte, geraten - obwohl fernab davon aufgrund der ostentativ gelebten Religiosität nicht selten unter Terrorismusverdacht; dies entweder vonseiten ihres familiären Umfelds oder aber auch seitens der Presse oder der (virtuellen) Öffentlichkeit. Ausgeprägt äusserte 
sich dies bspw. bei Adea, einer anderen Frau des Samples. Adea stammt aus einem säkularen Haushalt. ${ }^{27}$ Als sie sich im Laufe ihrer Adoleszenz dazu entschloss, einen Hijab zu tragen und zunehmend in einer religiösen Szene mit jugendkulturellen Zügen verkehrte, war die Familie, insbesondere der Vater alarmiert:

»Nachher hat er mir gesagt, nimm das scheiss Kopftuch weg. So seine Wortwahl. Er hat es so gesagt« (Adea, A 103).

Wie diesem Zitat zu entnehmen ist, war der Vater gar nicht erfreut, dass Adea nun ein Kopftuch trägt. Aus ihrer Aussage »so seine Wortwahl« wird die Befremdung über diese Aussage deutlich. Adea fügt sich für drei Wochen den Wünschen des Vaters, danach beginnt sie jedoch definitiv den Hijab zu tragen. Anders als das stereotype Bild der »unterdrückten Muslimin«, die "gezwungen wird, ein Kopftuch zu tragen«, trägt Adea den Hijab gegen den Willen ihres Vaters. Als ich sie kennenlernte, zog sie den Hijab während der Arbeit jedoch noch aus.

Als sie begann, zu Vorträgen in Moscheen zu gehen, befürchtete ihr Vater - alarmiert durch den laufenden Islamdiskurs - gar eine Radikalisierung. Er verbot ihr, weiterhin Moscheen zu besuchen. Als ich sie ein halbes Jahr später im Umfeld der jugendkulturellen Szene, die ich teilnehmend beobachtete, zufällig wieder treffe, trägt sie einen Khimar. Sie schildert mir, dass sie ihren Job an der Kasse eines Kaufhauses aufgeben musste, weil sie ihren Hijab dafür nicht mehr ausziehen wolle und wie schwierig es sei, nun eine Anstellung zu finden. Mittlerweile sei auch die Verwandtschaft in Südosteuropa davon überzeugt, dass Adea sich auf dem Weg zur Radikalisierung befinde, erzählt sie augenzwinkernd. Ihre Verwandten hätten diesbezüglich besorgt ihre Mutter angerufen, nur weil sie am 8. März, dem weltweiten »Tag der Frau« auf Facebook postete »dass der Prophet sagte, man solle die Frauen gut behandeln, gut zu ihnen schauen ja«. Sie räumt jedoch umgehend ein: »ich habe schon provoziert « (Adea, A 142). Ihre Provokation galt ihrer Tante, der sie vorwarf, sie rufe ihre Mutter zwar am »Tag der Frau« an, nicht jedoch an religiö-

27 Wie D’Amato (2010: 183) feststellt: »Wenn auch viele dieser Jugendlichen aus einem eher säkularen Haushalt stammen, spielt für sie die Religion mehr als für ihre Eltern die Rolle des Identitätsmarkers«. Dies mag nicht zuletzt eine Art »reaktive Religiosität« (vgl. »reaktive Ethnizität « Portes/Rumbaut 2001: 284-86) in Bezug auf den laufenden Islamdiskurs sein, der Differenzen zugunsten religiös verlaufender Trennlinien konstruiert (Sökefeld 2011: 271) und weniger wie zuvor entlang den konstruierten Differenzlinien Nationalität bzw. Ethnizität. 
sen Feiertagen. Diese Art der bewussten Provokation ist ebenfalls konstitutiv für die »Taktik« der kämpferischen Selbstbehauptung als Muslima in der Ausprägung der religiösen Selbstrepräsentation als dezidiert religiöse Muslima. Sie findet nicht nur, aber auch in virtuellen Räumen statt. Es kommt jedoch vor, dass solche Provokationen Missverständnisse und weitreichende öffentliche Debatten zur Folge haben, die sich schwer kontrollieren lassen: Mirjeta erzählt, dass eine Aussage auf Social Media, die ihr, wie sie sagt, fälschlicherweise zugeschrieben wurde, an die Öffentlichkeit gelangte und sie zum Ziel einer Presse-Kampagne machte, infolge derer sie massiv persönlich bedroht wurde.

Innerhalb der subkulturellen Szene mit jugendkulturellen Zügen, in der sich die beiden Frauen bewegen, werden Erlebnisse, bei denen teilweise durch bewusste Provokation und ostentativ befolgte religiöse Praxen Irritationen hervorgerufen werden, wie ich beobachten konnte, teilweise als Beweis der Gruppenzugehörigkeit herumgereicht und detailreich erzählt: Diese Art des Teilens dieser (manchmal auch durch bewusste Provokation herbeigeführten) Ausschlusserfahrungen wirkt identitätsstiftend, bestärkt die Gruppe und politisiert die Vergemeinschafteten weiter im »Kampf gegen Islamophobie«.

In der jugendkulturellen Verszenung, die Teil der »Taktik« der kämpferischen Selbstbehauptung als dezidiert religiöse Muslima bildet, sind hinsichtlich des provokativen Auftretens, aber auch hinsichtlich der Politisierung der Szenegänger*innen durchaus Parallelen zu anderen jugendkulturellen Bewegungen mit subkulturellen Zügen auszumachen, wie bspw. zur Punkbewegung. Was Meinert und Seeliger (2013) in ihrer sozial- und kulturwissenschaftlichen Betrachtung der deutschen Punkszene feststellen, lässt sich auch auf die religiöse Szene, in der sich Mirjeta und Adea bewegen, übertragen:

»Ein (...) zentraler Bezugspunkt in der Kultur des Punk ist die Kommentierung und Cestaltung gesellschaftspolitischer Strukturen und Prozesse. (...). Im Hinblick auf die Punkkultur lässt sich (...) ein sozialisatorischer Effekt szeneinterner Vergemeinschaftung anführen, welcher sich auch in der Politisierung eines Grossteiles der Szenegänger niederschlägt. Gleichzeitig haben politische Bezüge aber auch eine identitätsstiftende Bedeutung (...)« (Meinert/Seeliger 2013: 48,49).

Wie der Punkbewegung ist auch der jugendkulturellen Szene, in der sich Mirjeta und Adea bewegen, die Kommentierung (und Gestaltung) hegemonialer gesellschaftlicher Prozesse aus ihrer subalternen Position heraus ein zentrales Anliegen. Ähnlich wie in der Punkkultur wird diese durch einen offensiv 
inszenierten Kleidungsstil und (gesellschaftlich-provokative) Selbstrepräsentation, der auf die Ideologie (bzw. hier Religion) hinweist, sichtbar gemacht. Ebenfalls lässt sich ein »sozialisatorischer Effekt« dieser Vergemeinschaftung ausmachen, die sich in der Politisierung einerseits und in seiner identitätsstiftenden Wirkung andererseits niederschlägt.

Mirjeta findet in der Szene eine Art Antwort auf die gesellschaftliche Anerkennungsverweigerung (Hagedorn 2008: 12): Wie Hagedorn (2008) in einer Untersuchung über Jugendkulturen feststellt, ist entscheidendes Element der jugendkulturellen Vergemeinschaftung und Selbstrepräsentation der Versuch einer Umkehrung der Machtverhältnisse (ebd.: 12) und »eine Antwort auf die Anerkennungsverweigerung, die von der dominanten Mehrheitskultur ausgeht« (ebd.).

Im Islamischen Zentralrat Schweiz (IZRS) findet Mirjeta im Gegensatz zu den Moscheevereinen die Form einer religiösen Vergemeinschaftung, die ihr vorschwebt:

»Okay, jetzt beim IZRS also in erster Linie ist es mal islamisch ... Dass man etwas macht für den Islam für die islamische Gemeinschaft. Die Muslime in der Schweiz sind ja so schlecht organisiert oder es gibt fast gar keine Institutionen und vor allem im Kampf gegen Islamphobie. Ich selbst habe das miterlebt, dass ich aufgrund des Kopftuches aus der Lehre geschmissen wurde« (Mirjeta, A 86).

Aus dem Zitat wird ersichtlich, dass Mirjeta beim IZRS auf ein Identifikationsangebot trifft, das ihr entspricht. Ebenso hebt sie politisch vergemeinschaftende Aspekte positiv hervor. Als grösste (islamophobe) Ausschlusserfahrung, so wird in dem Zitat ebenfalls deutlich, erlebte Mirjeta den »Rausschmiss « aus ihrer Lehre durch ihren in der Adoleszenz gefällten Entscheid, fortan ein Kopftuch zu tragen. Beim IZRS findet sie die Unterstützung, die sie im Kampf gegen solch »islamophobe« Akte sucht, denn der IZRS entziehe sich dem »Kampf gegen die Islamophobie« nicht, im Gegensatz zu den sonst schlecht organisierten Muslim"innen.

Das Argument, dass der IZRS die einzige Institution sei, die sich wehre und (medial) dem laufenden Islamdiskurs dezidiert entgegentrete, ist ein vielzitiertes Argument junger religiös orientierter Secondas"os in der Deutschschweiz. Diesem Engagement wird gemeinhin grosser Respekt gezollt, auch von jungen Frauen und Männern, die in der Auslegung ihrer Religion durchaus nicht auf der Linie des IZRS liegen. Mirjeta hingegen ist vom IZRS in jeder Hinsicht beeindruckt: 
»Mir hat es gefallen, dass sie ähm gut organisiert sind, dass sie gebildet sind und dass sie sich medial, also mit den Medien [zusammenarbeiten] (Mirjeta, A 83).

Mirjeta beeindrucken insbesondere die Organisationsformen, der gebildete Habitus und die Medieninszenierung des IZRS. Insbesondere imponieren ihr »der Präsident« und die gebildete Führungsriege. Bildung würde von dieser grossgeschrieben und islamisch begründet, die Mitglieder würden angehalten, sich (weiter) zu bilden:

»Der Islam schreibt vor, dass die Leute in der Bildung das Höchstmögliche anstreben sollten //mhm// und da (...) also ich bin dann zu dieser Zeit an Vorträge gegangen, als es auch um Bildung gegangen ist und der Präsident hat auch oft gesagt, dass Muslime nur weiterkommen, wenn sie auch gebildet sind (...). Und das hat mich in dieser Zeit geprägt und ich habe gedacht, wieso eigentlich nicht. Weil Chemielaborantin ist schon gut gewesen, aber es auch nicht etwas gewesen, auf dem ich (...) bleiben wollte. Das hat so mein Entschluss gefasst, dass ich dann studieren gehe« (Mirjeta, A 47-48).

Wie aus dem Zitat ersichtlich wird, stellt eine islamisch begründete grösstmögliche Bildungsaspiration Teil der Sozialisation durch die religiöse Vergemeinschaftung dar. Der Bildungsweg als politisierte Muslima soll konsequent weiterverfolgt werden, es gilt »das Höchstmögliche an[zu]streben«. Mirjeta imponieren diese Vorträge über Bildung. Was der Präsident wiederholt betont, leuchtet ihr ein, nämlich dass »Muslime nur weiterkommen, wenn sie auch gebildet sind «. Bildung ist in der Szene, in welcher sich Mirjeta bewegt, neben der Politisierung ein massgeblicher »sozialisatorischer Effekt szeneinterner Vergemeinschaftung « (Meinert/Seeliger 2013: 49). Sich zu bilden wird zum Teil der religiösen Selbstrepräsentation und zum Teil des »Kampfes gegen die Islamophobie«. Dies hat Mirjeta, wie sie sagt, "geprägt« und sie fasst den Entschluss an einer technischen Hochschule studieren zu gehen, den sie unter grösster persönlicher Anstrengung berufsbegleitend umsetzt.

Frauen, bei denen die »Taktik« der kämpferischen Selbstbehauptung in der Ausprägung der religiösen Selbstrepräsentation als dezidiert religiöse Muslima rekonstruiert werden konnte, verschaffen sich also wie Mirjeta über einen Umweg Zugang zu Bildung: Die Szene, in der sie sich als dezidiert religiöse Muslima kämpferisch selbstbehauptet, beinhaltet den »sozialisatorische[n] Effekt« (Meinert/Seeliger 2013: 49) - eine konsequente Verfolgung des »höchstmöglichen« Bildungsziels. Durch die szeneartige Gemeinschaft 
erfährt sie Unterstützung in der ursprünglichen Bildungsaspiration, die ihr zuvor verwehrt geblieben ist und setzt sie mit ungleich grosser Anstrengung fort. Unterstützt wird sie hierbei von ihren Peers. Bei »islamophobem« Widerstand und gesellschaftlichen Bildungsbarrieren greift die religiöse Gemeinschaft ${ }^{28}$ zudem unterstützend und notfalls auch mit juristischen Mitteln ein. Dies insbesondere falls wegen einer dezidiert religiösen Lebensführung (wie z.B. dem Tragen eines Kopftuchs) der berufsbiografische Weg nicht verfolgt werden kann.

\section{Zusammenfassung "Taktik« Typus 1}

Die interviewten Frauen, bei denen die »Taktik« des Bildungszugangs durch kämpferische Selbstbehauptung als Muslima rekonstruiert werden konnte, erfahren aus einer intersektionellen Perspektive starke Einschränkungen ihrer Bildungsbiografie durch das Zusammenspiel der Differenzdimensionen Gender, »Migrationshintergrund«, »class « und Religion, insbesondere hinsichtlich der sichtbaren religiösen Symbolik religiöser Kleidung (wie bspw. Hijab, Khimar). Bei diesen Frauen manifestieren sich an der ersten Selektionschwelle zur Sekundarstufe wirkmächtige Bildungsbarrieren aufgrund des Zusammenspiels einer fehlenden Unterstützung der Eltern und deren Genderbild einerseits sowie der mangelnden Unterstützung von Lehrpersonen und der sich dabei ungehemmt entfaltenden reproduktiven Wirkung des Bildungssystems andererseits (vgl. Kronig 2005).

Die Frauen des Samples, bei denen sich die »Taktik« der kämpferischen Selbstbehauptung als Muslima rekonstruieren liess, machten als ersten Schritt in die nachobligatorische Ausbildung eine Lehre. Hierbei wirkte die Differenzkategorie »Muslimin« anhand des sichtbaren religiösen Symbols Hijab zu einem Zeitpunkt der nachobligatorischen Bildungsbiografie so stark als Bildungsbarriere, dass diese eine berufliche Neuorientierung oder einen Umweg erforderte. Die interviewten Frauen fanden entweder keine Lehrstelle oder mussten ihre bisherige Berufslaufbahn oder Ausbildungsstelle aufgeben. In der Art des Umgangs mit bildungsbiografischen Hindernissen zeigt sich die »Taktik« der kämpferischen Selbstbehauptung als Muslima:

Zentral für die »Taktik« der kämpferischen Selbstbehauptung als Muslima ist die »listige« Aneignung der Deutungsweise der Differenzkategorie »Musli-

28 Auch bei der Taktik des Typus 3 spielt die religiöse Vergemeinschaftung eine entscheidende Rolle hinsichtlich des Bildungszugangs jedoch nicht im Sinne eines »sozialisatorische[n] Effekts« (Meinert/Seeliger 2013: 49). 
min«. Nach De Certeau sind »Taktiken« listige, autonome Aneignungsweisen alläglicher Praktiken von Individuen aus subalternen Positionen, in denen eine Umdeutung etablierter Strukturen stattfinden kann (De Certeau 1988: 89). Eine »Taktik«

»... profitiert von `Gelegenheiten « und ist von ihnen abhängig; (...). Sie muss wachsam die Lücken nutzen, die sich in besonderen Situationen der Überwachung durch die Macht der Eigentümer auftun. Sie wildert darin und sorgt für Überraschungen. Sie kann dort auftreten, wo man sie nicht erwartet. Sie ist die List selber« (De Certeau 1988: 89).

Die »Taktik« manifestiert sich bei zwei Untertypen, ich nenne sie Ausprägungen, leicht unterschiedlich. Die beiden Ausprägungen unterscheiden sich anhand der religiösen Selbstrepräsentation: Bei der einen handelt es sich um die religiöse Selbstrepräsentation als »emanzipierte Muslima«, bei der anderen um die religiöse Selbstrepräsentation als »dezidiert religiöse Muslima«. Die »Taktik« beinhaltet zwar bei beiden Ausprägungen die »listige« Aneignung der Differenzkategorie »Muslimin«; diese manifestiert sich jedoch dann auf leicht unterschiedliche Weise: Bei der Ausprägung der religiösen Selbstrepräsentation als emanzipierte Muslima lässt sich eine Aneignung der Differenzkategorie »Muslimin « erkennen, in welcher die Inszenierung einer »Gegenstrategie der Repräsentation« (Hall 2004: 161) hinsichtlich des dominanten diskursiven Rahmens ersichtlich wird. Dagegen manifestiert sich diese Aneignung bei der anderen Ausprägung (Selbstrepräsentation als dezidiert religiöse Muslima) durch das ostentative Bedienen des diskursiven Stereotyps durch die Inszenierung als dezidiert religiöse Muslima.

Durch beide Arten der religiösen Selbstrepräsentation erlangen die Frauen, die sich diese »Taktik « zunutze machen, mehr Handlungsfähigkeit (Agen$c y)$ : Der ersteren Ausprägung gelingt es, sich mithilfe (religiöser) Selbstrepräsentation als emanzipierte Muslima gesellschaftspolitisch zu positionieren und eine Alternativkarriere in interreligiösen und/oder interkulturellen NGOs zu machen oder sich durch berufliche Selbstständigkeit mittels eines (religionsrelevanten) Nischenangebots (z.B. Hijab-Verkäuferin, Fahrlehrerin für muslimische Frauen) zu positionieren. Kraft der »Taktik« letzterer Ausprägung (Selbstrepräsentation als dezidiert religiöse Muslima) wird der Bildungszugang auf Umwegen erlangt: Der durch die Stigmatisierung als Kopftuch tragende Muslima erzwungene berufliche Umweg führt zur Politisierung. Die »Taktik« der kämpferischen Selbstbehauptung als dezidiert religiöse Muslima beinhaltet die islamisch begründete Bildungsaspiration als Teil des 
»Kampfes gegen die Islamophobie«: Der Bildungsweg als politisierte Muslima wird konsequent weiterverfolgt - islamisch begründete grösstmögliche Bildungsaspiration stellt neben der Politisierung einen »sozialisatorische[n] Effekt szeneinterner Vergemeinschaftung « (Meinert/Seeliger 2013: 49) dar. Bei »islamophobem« Widerstand der Gesellschaft in der Verfolgung dieser Bildungsaspiration greift die religiöse Gemeinschaft zudem unterstützend und notfalls auch mit juristischen Mitteln ein, falls wegen einer dezidiert religiösen Lebensführung der berufsbiografische Weg nicht verfolgt werden kann.

Die »Taktik« der kämpferischen Selbstbehauptung und Selbstrepräsentation als Muslima - quasi des »sich zu Nutze Machens « oder der Umdeutung einer stigmatisierenden Differenzkategorie ist bei beiden Ausprägungen identisch. Dank der »Taktik« der kämpferischen Selbstbehauptung als Muslima, transformieren Frauen, welche sich diese »Taktik« zunutze machen, die Differenzkategorie »Muslimin« bildungsbiografisch gesehen von der intersektionell wirkenden Kategorie zur Ressource einer gesellschaftlichen Selbstpositionierung. Sie eignen sich die Differenzkategorie in De Certeaus Sinne (1988: 89) an und deuten sie um.

\subsection{Typus 2: "Taktik « des zielstrebigen Aufsteigens}

\subsubsection{Xhemile}

Als ich Xhemile (24) das erste Mal in ihrer Wohnung in einem grossen Block treffe, stellt sie sich vor und meint plötzlich, ich könne sie auch Simone nennen - die meisten Schweizer*innen könnten sich ihren Namen nicht merken, deswegen habe sie sich einen Schweizer Vornamen für sich ausgedacht. Auf die Idee gekommen sei sie im Gymnasium als sich der Biologielehrer ihren Namen nie merken konnte und sie deshalb kaum aufrief.

Als Xhemile ein Kleinkind war, holte ihr Vater die Mutter und die anderen drei Geschwister aus Südosteuropa in die Schweiz, wo er eine Stelle als Imam innehatte. Xhemile ist als Kind quasi »in der Moschee aufgewachsen «, wie sie erzählt. Die Moschee habe ihr als »Zufluchtsort « gedient, insbesondere im Grundschulalter, als sie sich noch sehr fremd in der Schweiz fühlte. Jeden Tag nach der Schule ging sie direkt zur Moschee des Vaters, welche nur drei Minuten vom Elternhaus entfernt lag. Später besuchte sie dort jedes Wochenende den religiösen Unterricht. 
Xhemile stammt aus einem Milieu, in dem Bildung grossgeschrieben wird. Von Kindsbeinen an wurde ihr insbesondere vom Vater vermittelt, dass sie sich in der Schule anstrengen soll und lernen, um etwas zu erreichen. Ihr Vater arbeitet als engagierter Imam und verfügt über einen Studienabschluss in Islamwissenschaften aus einem arabischen Land. Beide Grossväter, mütterlicher- und väterlicherseits, sind ebenfalls Imame. Xhemiles Mutter verfügt kaum über schulische Bildung, sie kümmert sich um die Kinder und den Haushalt, besuchte jedoch intensiv Deutschkurse, es ist ihr wichtig, sich $\mathrm{zu}$ integrieren.

Obwohl das Milieu, aus dem Xhemile stammt, bildungsaffin ist, hatte sie - als älteste Tochter und erstes eingeschultes Kind der Familie - aufgrund der Migrationssituation zunächst grosse Schwierigkeiten, sich im Bildungssystem und dem frühen Selektionsverfahren zurecht zu finden. Ihre Eltern kannten das schweizerische Schulsystem kaum und konnten sie nicht unterstützen. Sie musste sich, wie sie erzählt, alles »autodidaktisch« beibringen. So musste sie z.B. einen Weg finden, ein Diktat zu lernen, da ihr niemand vorlesen konnte. Ihre Geschwister hätten dann, wie sie erzählt, später von ihren Erfahrungen profitieren können und es deshalb viel leichter gehabt.

Wie Xhemile erzählt, habe sie schon als Kleinkind gewusst, was sie beruflich einmal erreichen wolle: Lehrperson werden. Sie sieht diesen Beruf als ihre Berufung an. Von Anfang an richtete sie ihre ganze Schulkarriere auf dieses Bildungsziel aus: Xhemiles »Taktik« des Bildungszugangs durch zielstrebiges Aufsteigen zeigte sich denn auch bereits an der ersten Selektionsschwelle, in der Mittelstufe. So wurde sie zunächst in die Real eingestuft; als sie jedoch realisierte, dass sie die Sekundarstufe erreichen musste, wenn sie Lehrerin werden wollte, strengte sie sich an und krempelte den Selektionsentscheid zielstrebig mittels grösster Anstrengung innert weniger Monate um und schaffte es, in die Sekundarstufe aufgenommen zu werden. Bereits früh traf sie ihre Bildungsentscheidungen auf sich allein gestellt und mittels im Vergleich zu privilegierten Lernenden ungleich grösserer Anstrengung zielgerichtet und stets mit ihrem Plan, Lehrerin zu werden, vor Augen.

Ausschlusserfahrungen im Schulsystem aufgrund ihres "Migrationshintergrundes« begegnete Xhemile ebenfalls mit der »Taktik « der Zielstrebigkeit: Als ihr der Schulleiter sagte, sie solle nicht auf das Gymnasium gehen, das sei zu schwierig für sie und Englisch solle sie besser auch nicht belegen, es sei eine Fremdsprache zu viel, nahm sie das als gegenteiligen Ansporn und schaffte zielstrebig schliesslich die beste Empfehlung für das Gymnasium als Einzige ihrer Klasse erreichte sie die Maximalpunktezahl. Ihre Zielstrebig- 
keit führte sie bis zur strategischen Auswahl von Peers: Bereits während der Schulzeit tat sie sich mit denjenigen Schülerinnen zusammen, die viel lernten und nicht »in den Ausgang" gingen. Mit den Schulkolleginnen, die aus demselben Land in Südosteuropa zugewandert waren wie ihre Eltern und von denen sie sagte, sie würden sich nur für Kleidung und ihr Äusseres interessieren, wollte sie nichts zu tun haben. Heute ist der grösste Teil ihres Freundeskreises akademisch gebildet, was sie in dem Moment, als ich sie nach der Zusammensetzung ihres Freundeskreises frage, selbst erstaunt feststellt.

Xhemile wurde religiös sozialisiert. Sie ist glaubensgewiss und ist als Tochter eines studierten Imam in religiösen Belangen auch formal hochgebildet - sie spricht und liest den Koran auf Arabisch. Religiöse Praxis sowie religiöse Vergemeinschaftung bilden für Xhemile zudem eine habituell verankerte Selbstverständlichkeit. Wie ihr Vater vertritt sie einen intellektuellen Zugang zum Islam; sie reflektiert Glaubensinhalte kritisch. Obwohl sie sehr glaubensgewiss ist, hat Xhemile einen pragmatischen Zugang zur religiösen Praxis, sie tradiert die pragmatische Haltung ihres Vaters gegenüber religiösen Pflichten - im Zweifelsfalle ordnet sie diese ihrem Bildungs- und Aufstiegsprojekt unter. Als die Moschee-Besuche und die religiöse Bildung mit ihrer schulischen Ausbildung zeitlich zu konkurrieren beginnen, ist der Vater sofort bereit, Xhemile von diesen Verpflichtungen zu entbinden: Ihr zielstrebiges Aufsteigen soll nicht durch religiöse Pflichten behindert werden. Ein Grundsatz, auf den auch Xhemile sehr bedacht ist: Ihrer Mutter, die es gerne sehen würde, dass Xhemile sich bedeckt, erklärt sie kurzerhand, dass sie nicht so lange studiert habe, um sich dann ihr berufliches Ziel durch ein Kopftuch zunichte machen zu lassen.

Aufgrund ihrer pragmatischen Haltung gegenüber religiöser Praxis betont sie, sie sei »nicht so der Vorzeigemoslem«. Ihr Scheitern am konsequenten Verrichten des täglichen Gebets vergleicht sie mit einer Diät. Immer wieder nähme sie es sich vor, aber dann gelinge es nach ein paar Tagen nicht mehr. Dennoch: Das Freitagsgebet lasse sie nie aus, wie sie unterstreicht. Für regelmässige Besuche in der Moschee oder persönliches Engagement in religiösen Vereinen fehle ihr die Zeit.

Auch bezüglich ihrer Ausbildung und ihres zukünftigen Berufs lebt Xhemile ihren Glauben pragmatisch: In der Lehrerinnen- und Lehrerbildung lässt sie sich mühelos darauf ein, sich von religiösen Dogmen zu distanzieren und Wissensinhalte, die sich von ihrem persönlichen Glauben unterscheiden, zu unterrichten. 
Nicht nur im schulischen, sondern auch im privaten Bereich geht Xhemile zielstrebig vor. Als sie sich in einen Mann in Südosteuropa verliebt, der für ihre Familie nicht infrage kommt, setzt sie alles daran, ihr Ziel, ihn in die Schweiz zu holen und - notfalls gegen den Willen der Familie - zu heiraten. Sie nimmt dafür einen emotional sehr belastenden zeitweiligen Bruch mit dem Vater und den totalen Bruch mit dem Grossvater in Kauf. Dieses Erlebnis ist für sie biografisch sehr einschneidend, sie weint, wenn sie von dieser Zeit erzählt. Dennoch erreichte Xhemile ihr Ziel: Sie holte ihren zukünftigen Mann in die Schweiz, schlug sich ohne finanzielle Unterstützung ihrer Eltern neben ihrem Studium mit Aushilfejobs durch und arbeitete monatelang sieben Tage die Woche, um sich und ihrem zukünftigen Mann das Leben zu finanzieren. Sie erreichte ihr Ziel und heiratete den Mann ihrer Träume schliesslich ohne Anwesenheit der Eltern. Nach einer schwierigen ersten Phase arrangierte sich der Vater mit seinem neuen Schwiegersohn.

Selbst in dieser anstrengenden Zeit verlor Xhemile ihre Bildungsaspiration nie aus den Augen und mittels ihrer »Taktik« des zielstrebigen Aufsteigens gelang es ihr in dieser grossen Belastungsphase den Vorkurs zur Pädagogischen Hochschule zu absolvieren, sie lernte in "Nachtschichten«.

Die interviewten Frauen, bei denen sich die »Taktik« des Bildungszugangs durch zielstrebiges Aufsteigen nachzeichnen liess, wurden meist religiös sozialisiert. Sie sind glaubensgewiss und verfügen zudem über ein fundiertes, formales religiöses Wissen. Ihre Eltern sind in der Regel in moscheegebundenen religiösen Vereinen aktiv. Sie sind hinsichtlich der Ausbildung ihrer Kinder - Töchter wie Söhne - aufstiegsorientiert. Die jungen Frauen tradieren das elterliche Aufstiegsprojekt und verhalten sich hinsichtlich der elterlichen Bildungsaspirationen angepasst. Konstitutiv für die »Taktik« des Bildungszugangs durch zielstrebiges Aufsteigen ist der Versuch des Kompensierens von strukturellen Ausschlusserfahrungen durch eine ungleich zielstrebige Aufstiegsorientierung.

Die Ausübung alltäglicher, religiöser Pflichten in Zusammenhang mit Bildungsbelangen (z.B. Kollision Gebetszeiten mit Vorlesungszeiten) handhaben die interviewten Frauen pragmatisch. Im Zweifelsfalle ordnen sie ihre religiöse Praxis dem Bildungs- und Aufstiegsprojekt unter. Anders als bei der »Taktik« des Typus 1 wird die religiöse Selbstrepräsentation von den Frauen nicht zur gesellschaftlichen Positionierung genutzt, sondern Religion und religiöse Praxis dient in erster Linie als persönliche Ressource. Unter den Frauen befinden sich sowohl solche, die sich bedecken als auch solche, die sich dagegen 
entschieden haben oder nur situativ, in religiös konnotierten Kontexten wie bspw. bei Moscheebesuchen einen Hijab tragen.

Die gesellschaftliche Marginalisierung von Muslim*innen in der Schweiz wird von den Frauen zwar durchaus wahrgenommen und problematisiert, sie besitzt jedoch gemäss ihren biografischen Erzählungen wenig persönliche Relevanz im tertiären Umfeld, in dem sich die Frauen bewegen. Ausschlusserfahrungen im Kontext von Bildungsinstitutionen werden zwar gemacht, jedoch durch hartnäckige Zielverfolgung und durch verstärkte Anstrengungen im Erreichen der (Bildungs-)Ziele kompensiert. Die Differenzkategorie »Muslimin« kommt bei diesen Frauen im Vergleich zu Bildungsverläufen, die mit der »Taktik« des Typus 1 einhergehen, als Bildungsbarriere deutlich weniger stark zum Tragen.

\subsubsection{Bildungsbiografisches Bestehen durch die "Taktik" des zielstrebigen Aufsteigens}

Nach diesem einleitenden Portrait von Xhemile wird die »Taktik« des Bildungszugangs durch zielstrebiges Aufsteigen nun unter Beiziehung weiterer Fälle und anhand der folgenden Kapitel spezifiziert, es sind dies: a) Herkunftsmilieu im Zusammenhang mit der »Taktik«; b) Die Rolle der Religion und der Differenzkategorie "Muslimin " hinsichtlich der Bildungsbiografie und c) "Taktik" gesellschaftlicher Selbstpositionierung bezüglich der Bildungsbiografie.

Es konnten zwei unterschiedliche Ausprägungen religiöser Selbstrepräsentation ausgemacht werden: Es handelt sich um die Ausprägung der religiösen Selbstrepräsentation als >pragmatische Muslima einerseits (hier am Fallbeispiel von Xhemile illustriert) und andererseits um die Ausprägung der religiösen Selbstrepräsentation als sengagierte Muslima (aufgezeigt anhand der prototypischen Fallbeispiele von Sahar und Hannan). Die Ausprägungen unterscheiden sich insbesondere in der Art, wie die religiöse Praxis ihrer Eltern tradiert wird: Während bei der Ausprägung der religiösen Selbstrepräsentation als pragmatische Muslima die Bedeutung der religiösen Praxis gegenüber der Elterngeneration abnimmt, wird bei der Ausprägung der religiösen Selbstrepräsentation als engagierte Muslima die religiöse Praxis der Eltern, insbesondere das Engagement in religiösen Vereinen tradiert.

\section{a) Herkunftsmilieu im Zusammenhang mit der "Taktik "}

Die interviewten Frauen, bei denen sich die »Taktik« des zielstrebigen Aufsteigens rekonstruieren liess, stammen aus bildungsorientierten Milieus. In 
der Regel verfügen beide Elternteile oder mindestens ein Elternteil über einen tertiären Bildungsabschluss, der jedoch in der Schweiz nicht anerkannt wird oder aber über eine höhere religiöse Ausbildung. Die Eltern von Frauen wünschen sich eine »bessere Zukunft« für ihre Kinder. Das Erreichen dieses Ziels sehen sie in erster Linie durch eine bestmögliche Ausbildung ihrer Kinder gewährleistet: Bildungsorientierung stellt für sie eine habituell verankerte Selbstverständlichkeit dar, auch wenn sie ihre Kinder im hiesigen Schulsystem kaum unterstützen können. Die Bildungsaspiration der Eltern wird von den Frauen tradiert: Sie verfolgen ein tertiäres Ausbildungsziel.

Als Xhemile knapp 5-jährig war, holte ihr Vater ihre Mutter und ihre Geschwister aus Südosteuropa per Familiennachzug in die Schweiz. Bereits als junges Schulkind hat Xhemile ein klares Berufsziel vor Augen: Sie will Lehrerin werden.

»]a ich weiss - ich habe eigentlich immer Lehrerin werden wollen - von klein an, meine Mutter hat mir auch schon immer erzählt, als sie mich gefragt haben, die Verwandten, was ich werden will, immer von klein an immer gewusst: Lehrerin. Das hat sich eigentlich durchgesetzt, jahrelang, also...« (Xhemile, A 37).

Zielstrebig und allen Widerständen zum Trotz verfolgt sie ihr früh gefasstes Bildungsziel jahrelang: heute studiert sie an einer pädagogischen Hochschule (vgl. Kap. 5.2.2 c).

Sie beschreibt, wie wichtig es ihrem Vater war, dass sie eine gute Ausbildung absolviert und wie er sie und ihre Geschwister dazu angespornt habe. Wenn sie und ihre Geschwister sich bspw. beklagt haben, dass sie nicht lernen können, wenn sie zu viert ein Zimmer teilten, liess er das Argument nicht gelten und beschrieb ihnen, wie er während seines gesamten Islamwissenschaftsstudiums in einem Schlaftrakt mit siebzig Studenten gelebt habe und so habe lernen müssen (Feldprotokoll, September 2014). Er spornte Xhemile von Anfang an dazu an, aufs Gymnasium zu gehen, obwohl er, wie sie erzählt, zu dieser Zeit das schweizerische Schulsystem kaum kannte, und nicht genau wusste, wie ein Bildungsweg darin aussehen könnte. Er habe einfach von anderen Vätern gehört, es sei gut, aufs Gymnasium zu gehen (Xhemile, A 59) und war stets bemüht, Xhemiles Bildungserfolg im Rahmen seiner Möglichkeiten zu unterstützen. So war er bspw. sofort bereit, sie von dem Koranunterricht in seiner Moschee zu entbinden, als sie die Zeit fürs Lernen beanspruchte.

Xhemile stammt aus einer in der männlichen Abstammungslinie religiös gebildeten Familie: Beide Grossväter sowohl mütterlicher- wie auch väterli- 
cherseits sowie einer ihrer Onkel sind Imame. Xhemiles Vater hat als Imam, wie sie erzählt, in der Schweiz »ziemlich (...) Karriere gemacht « (A 145). Nach einer Ausbildung an einer arabischen Hochschule in Islamwissenschaften migrierte er in die Schweiz und ist nach verschiedenen Jobs heute in einer grossen Moschee in der Deutschschweiz als leitender Imam tätig. Er gilt als engagierter, sogenannt »liberaler« Imam, der sich öffentlich für einen interreligiösen Dialog einsetzt. Das Bemühen um die Integration von Muslim*innen in der Schweiz ist sein oberstes Credo, er ruft dazu auf, dass Integration auch Anpassung an die Lebensumstände in der Schweiz erfordere und begründet dies mit seinem Religionsverständnis.

Xhemiles Mutter verfügt über keine Ausbildung, sie übernimmt zunächst die Rolle einer Familienfrau, arbeitet indessen später, als die Kinder älter sind, in einer Reinigungsfirma. Sie tradiert zwar eine klassische Frauenrolle, übernimmt jedoch den Integrationsanspruch ihres Mannes:

» (...) sie hat so Deutschkurse gemacht, ja sie hat sich auch integrieren wollen, also sie hat sich immer bemüht, dass wir vorankommen, also dass wir auch u-unsern Platz hier in der Schweiz finden, ähm... ja sie hat die Fahrprüfung nachher auch gemacht hier, dass sie ziemlich auch selbstständig wird...«(Xhemile, A 145).

In der Schilderung von Xhemile wird deutlich, wie sehr die Mutter sich darum bemüht, sich gesellschaftlich zu integrieren und durch die Fahrprüfung Mobilität und eine gewisse Unabhängigkeit von ihrem Mann zu erlangen. Hierin durchbricht sie die traditionelle Frauenrolle ein kleines bisschen. Gleichzeitig wird in dem Zitat eine gewisse Aufstiegs- bzw. Zielorientierung der Mutter deutlich, denn sie habe sich immer bemüht »dass wir vorankommen«. Dieses (familiale) »Vorankommen« beinhaltet »auch« Integration - verdeutlicht durch die Aussage »dass wir unsern Platz hier in Schweiz finden«.

Xhemiles Eltern, das ist typisch für das Milieu, aus dem Frauen dieser »Taktik« stammen, legen grossen Wert auf eine Integration in die hegemoniale Gesellschaft. Diese Integration soll nicht nur, so die Vorstellung, aber insbesondere auch durch Aus- und Weiterbildung erfolgen. Die Frauen ihrerseits orientieren sich entweder an den elterlichen Bildungswünschen oder tradieren elterliche Bildungsaspirationen, welche den Eltern selbst aufgrund der Migrationssituation oder der Anerkennung von Bildungstiteln verwehrt blieben. Die elterliche Bildungsorientierung und deren Aufstiegswille sind habituell verankert. Anders als bei der »Taktik« des Typus 1 bestehen seitens der Eltern dieser Frauen kaum genderstereotype Vorstellungen bezüglich der 
nachobligatorischen Ausbildung. So gilt die elterliche Bildungsaspiration für ihre Kinder gleichermassen für Mädchen wie für Jungen.

Betrachtet man bei Xhemile die Tradierung der Berufe in der Familie väterlicherseits, könnte man die These aufstellen, dass der Lehrberuf die grösstmögliche Annäherung an den Beruf des Vaters ist, Imamin stellt für sie als Frau keine Option dar. Der Vater ist für Xhemile eine zentrale Identifikationsfigur. Sie tradiert den Bildungsweg ihres Vaters und transformiert ihn in den Lehrberuf. Als älteste Tochter übernimmt Xhemile eine Pionierrolle (dies nicht nur im Bildungssystem), sie orientiert sich eindeutig nicht an der Mutter - ihr Vorbild ist der Vater. Sie übernimmt quasi die klassische Männerrolle, holt ihren Mann aus der serbischen Provinz und nicht umgekehrt. Auch bei der Berufswahl zielt sie wie die Mehrheit der männlichen angehenden Lehrpersonen auf die Oberstufe.

Bei Frauen, bei denen die »Taktik« des zielstrebigen Aufsteigens rekonstruiert werden konnte, wirken hinsichtlich des Herkunftsmilieus insbesondere die Differenzdimensionen »Migrationshintergrund « und »class« intersektionell. Aufgrund der Nichtanerkennung der Bildungsabschlüsse der Eltern in der Schweiz sind die Familien der Frauen zudem in einer ökonomisch prekären Situation (Intersektion »class « und »Migrationshintergrund«) und können sich gesellschaftlich nicht so positionieren (»class«), wie es ihnen zuvor möglich war. Die Differenzdimension »Migrationshintergrund « wirkt insofern einschränkend, dass die Eltern das Schulsystem unzureichend kennen und aus diesem Grund und aufgrund anfänglich mangelnder Sprachkenntnisse ihre Töchter in ihren Bildungsentscheidungen insbesondere hinsichtlich der ersten frühen Selektionsschwelle nicht ausreichend unterstützen können.

\section{b) Die Rolle der Religion und der Differenzkategorie "Muslimin" hinsichtlich der Bildungsbiografie: "Expertin für Islam»}

In diesem Kapitel wird nun zunächst kurz die religiöse Sozialisation der Frauen beschrieben, die sich bei beiden analysierten Ausprägungen nahezu identisch zeigte. Dann wird auf die Tradierung der religiösen Praxis, die sich bei den beiden Ausprägungen unterschiedlich gestaltet, getrennt eingegangen, um dann abschliessend wiederum auf die bei beiden Ausprägungen kongruente Bedeutung der Differenzkategorie »Muslimin« in der Bildungsbiografie einzugehen.

In Bezug auf die Wirkung der Differenzkategorie »Muslimin« in der Bildungsbiografie lässt sich bei beiden Ausprägungen Ähnliches rekonstruieren: 
Während sich die Differenzkategorie »Muslimin« in der Mittelschule insbesondere hinsichtlich einer zugeschriebenen Rolle der »Expertin für Islam« manifestiert, verliert sie später im tertiären Umfeld nahezu komplett als Relevanz. Da sich die Frauen zum Zeitpunkt der Datenerhebung allesamt in einer tertiären Ausbildung befanden, kann über die Phase des (noch folgenden) eigentlichen Berufseinstiegs keine Aussage erfolgen. Es besteht jedoch Grund zu der Annahme, dass gerade bei Frauen, bei denen eine religiöse Selbstrepräsentation als engagierte Muslima rekonstruiert werden konnte und welche einen Hijab tragen, die Wirkmächtigkeit der Differenzkategorie »Muslimin« aufgrund des späteren Einstiegs in das Berufsfeld biografisch nach hinten verschoben werden könnte.

Die interviewten Frauen, bei denen die »Taktik« des zielstrebigen Aufsteigens rekonstruiert werden konnte, waren in der Regel bereits als Kinder durch Familienmitgliedschaft Teil eines religiösen Vereins ${ }^{29}$; ihre religiöse Sozialisation zeichnete sich durch starke Vereinsgebundenheit aus. Die Eltern der Frauen waren oder sind zumeist in entsprechenden Vereinen aktiv; sie verfügten zudem innerhalb dieser über eine höhere soziale Stellung und waren teilweise sozial engagiert. So wie bspw. die Mutter von Maide: Sie ist bis heute Leiterin einer Moschee-gebundenen Frauengruppe und organisiert (Tanz-)Anlässe für junge Frauen aus der Moschee. Oder Hannans Mutter bei Hannan liess sich ebenfalls diese »Taktik« rekonstruieren - die kein offizielles »Vereinsamt « in dem Sinne innehat, die aber durch grosses religiöses Wissen und ihre langjährige Mitgliedschaft insbesondere unter den Frauen hohes Ansehen geniesst und ein Label für muslimische Spielsachen lanciert hat, oder eben Xhemiles Vater, der ein engagierter Imam ist.

Die Frauen wurden von Kindsbeinen an in die jeweiligen religiösen Vereine ihrer Eltern hineinsozilaisiert. Xhemile beschreibt ihre religiöse Bildung wie folgt:

»Es ist immer präsent gewesen, also die Religion, wir haben auch jeden Samstag - Vormittags sind wir in die Moschee gegangen und haben den Koran gelesen also ja - gelernt zu lesen und auch diverse andere Dinge so...die Schrift und uns mit der Schrift auseinandergesetzt, mit Versformen mit...äh ...ja es ist eigentlich immer ja es hat uns durch das ganze Leben eigentlich begleitet« (Xhemile, A 183).

29 Da es sich beim Islam in der Schweiz nicht um eine öffentlich nicht anerkannte Religionsgemeinschaft handelt, müssen die Muslim*innen, die sich organisieren wollen, dies in Vereinen oder Stiftungen tun. 
Als Tochter des Imam wurde Xhemile mitunter auch durch einen langjährigen formalen regelmässigen Religionsunterricht religiös sozialisiert, sie vertritt dementsprechend einen intellektuellen Zugang zum Islam und setzte sich intensiv mit »der Schrift« auseinander, in Originalsprache.

\section{Ausprägung religiöse Selbstrepräsentation als pragmatische Muslima}

Im Folgenden werden die religiöse Praxis und die religiöse Selbstrepräsentation von Frauen wie Xhemile beschrieben, bei denen »die »Taktik« des zielstrebigen Aufsteigens gekoppelt mit einer religiösen Selbstrepräsentation als pragmatische Muslima rekonstruiert werden konnte.

Xhemiles Eltern lebten ihr eine konsequente religiöse Praxis vor, bspw. verrichteten sie ihr Gebet fünfmal am Tag. Anders als in ihrer Kindheit übt Xhemile als erwachsene Frau ihre religiöse Praxis pragmatisch aus:

»Das Freitagsgebet mache ich, den Rest schaffe ich wie nicht, aber vielleicht überwinde ich mich auch nicht so wirklich...im Moment habe ich das Gefühl, ich bin so belastet, dass mir...dass ich nicht noch Zeit habe dafür //mhm// es ist einfach, ich könnte es schon...ich könnte es mir schon einrichten irgendwie, würde es schon gehen, aber ich glaube ich vernachlässige es ein bisschen so...konzentriere mich auf andere Dinge im Moment« (Xhemile, A 200).

Als Werkstudentin, die ihr Studium an der pädagogischen Hochschule mit zwei verschiedenen Jobs finanzieren muss, ist Xhemile zeitlich sehr ausgelastet. Aus der Aussage, dass sie das ein bisschen vernachlässige und sich »auf andere Dinge im Moment « konzentriere, wird deutlich, dass im Moment der Fokus auf diese »anderen Dinge« (es kann im Zusammenhang des Interviews davon ausgegangen werden, das sie hier die Ausbildung meint) gegenüber der religiösen Praxis eine höhere Wichtigkeit erhält.

Xhemile spricht einen weiteren Aspekt an, welcher das Verrichten der täglichen Gebete erfordert, nämlich die aufzubringende Disziplin. Sie bringt dies prägnant auf den Punkt, indem sie das Einhalten der religiösen Pflichten mit dem Befolgen einer Diät vergleicht:

»Also ich bin immer noch religiös (halbes Lachen), also der Clauben ist immer noch vorhanden, ich bete nur nicht...ich bete jeden Freitag...(...)...finde ich schade ich möchte eigentlich schon, ich nehme es mir immer vor, aber so ja...wie Diät halt, man nimmt es sich vor macht es zwei drei Mal, nachher 
findet man immer etwas, (hebt Stimme) ich habe keine Zeit für das (halbes Lachen) - Ausreden halt!« (Xhemile, A 201)

Xhemile beteuert, als ob ihr dies jemand absprechen wolle, sie sei, »immer noch religiös « und doppelt nach, "also der Glauben ist immer noch vorhanden«, um dann gleich anzufügen, dass sie »nur« nicht bete bzw. nur am Freitag bete. Ebenfalls in der Aussage wird ein gewisses Bedauern darüber deutlich, dass dies nicht konsequenter gelingt, denn sie "möchte eigentlich schon«. Schliesslich bringt sie den Aspekt der erforderlichen Disziplin mit ins Spiel. Als Begründung für ihre Inkonsequenz führt sie zwar zuerst die (zeitliche) Belastung an, räumt jedoch umgehend ein, dass das letztlich "Ausreden halt« seien. In ihrer Aussage zeichnet sich eine gewisse Pragmatik $a b$, Xhemile impliziert zwar Bedauern (»schade«), dass es nicht gelingt, konsequenter zu sein, dennoch hat das Beten für sie den Anstrich einer (mühsamen) Pflicht, die konsequentes Handeln erfordert, wie eine Diät.

Typisch für Frauen, bei denen sich die »Taktik« in der Ausprägung der Selbstrepräsentation als pragmatische Muslima nachzeichnen liess, ist, dass sie ihr zielstrebiges Aufstiegsprojekt der religiösen Praxis überordnen. Da sie sehr glaubensgewiss sind, geht dies häufig mit einem schlechten Gewissen bzw. einem gewissen Bedauern einher. Neben ihrem engagierten Bildungsprojekt, das oft zusätzlich mit einer Erwerbstätigkeit als Werkstudentin einhergeht, bringen die interviewten Frauen gemäss ihren Erzählungen die Zeit (und die Motivation) für eine konsequente religiöse Praxis, wie bspw. für das tägliche Gebet, nicht auf.

Bei diesen Frauen nimmt die religiöse Praxis gegenüber der Elterngeneration $\mathrm{ab}$ - hierin unterscheiden sie sich deutlich von den Frauen, bei denen dieselbe »Taktik« in der Ausprägung der religiösen Selbstrepräsentation als engagierte Muslima rekonstruiert werden konnte: Letztere tradieren die religiöse Praxis und das elterliche Engagement in religiösen Vereinen.

Religion und religiöse Praxis nutzen Frauen, bei denen diese »Taktik« in der Ausprägung als pragmatische Muslima rekonstruiert werden konnte, in erster Linie als persönliche Ressource. Die religiöse Vergemeinschaftung dient allenfalls der Pflege von sozialen Beziehungen oder der Regenerierung und Zerstreuung, wenn neben der Ausbildung genügend Zeit bleibt. Gleichzeitig genügen sie den eigenen (bzw. durch die Eltern geprägten) Ansprüchen als Muslima nicht, was sich besonders deutlich an der Aussage von Maide, einer anderen Frau meines Samples zeigt. Maide bezeichnet sich in Abgren- 
zung zur Elterngeneration als »nicht so der Vorzeigemoslem « und bringt ihre Prioritäten folgendermassen auf den Punkt:

»Ich bin eigentlich nicht so der Vorzeigemoslem, aber... bei so Sachen helfe ich sehr gerne und... Ich bin gerne dabei (...). Also aktiv...wie meine Mutter nicht. Aber... Ich bekomme natürlich immer mit von meiner Mutter, wann gerade der nächste Anlass ist, und so. Und in der Regel, wenn ich...gerade gar nichts Brennendes habe, irgendwie für Prüfungen lernen oder so, bin ich eigentlich immer dabei« (Maide, A 166, 180).

Es lässt sich aus dem Gesagten rekonstruieren, dass ein »Vorzeigemoslem« in der Deutung von Maide im Verein stark engagiert ist (wie ihre Mutter). Sie hingegen ist bezüglich der Vereinsaktivitäten pragmatisch eingestellt: Gerne hilft sie ab und zu bei »so Sachen« mit, die sie »immer« von ihrer Mutter mitbekommt; gleichzeitig macht sie sogleich ihre Prioritäten deutlich, nämlich, dass sie dann »dabei« ist, wenn sie "gerade gar nichts Brennendes« habe, »wie für Prüfungen lernen oder so«. »Brennend « gegenüber den religiösen Vereinsaktivitäten, resp. mit diesen konkurrierend, sind demnach insbesondere Ausbildungsbelange.

Was schon bei Xhemile anklingt, sollte anhand des Zitats von Maide nochmals verdeutlicht werden: Im Zweifelsfall ordnen die interviewten Frauen mit der Ausprägung der religiösen Selbstrepräsentation als pragmatische Muslima ihre Ausbildung der religiösen Praxis und einem Engagement im religiösen Verein ihrer Eltern über. Diese Priorisierung ist jedoch nicht zu verwechseln mit einer Bedeutungslosigkeit der jeweiligen Vereine in der Lebenswelt der Frauen. Wie ich beobachten konnte, sind sie an den bedeutenderen Anlässen ihrer Moscheevereine meistens präsent und helfen teilweise mit und/oder übernehmen im Auftrag der Eltern einige Aufgaben.

Die Pragmatik hinsichtlich der religiösen Selbstrepräsentation kommt bei Xhemile nicht nur hinsichtlich der religiösen Praxis, sondern auch in Bezug auf ihre Ausbildung(-sinhalte) und ihre Berufsrolle zum Ausdruck. Im Lehrberuf lässt sie sich darauf ein, sich von religiösen Dogmen zu distanzieren. So bereitet ihr der Gedanke an das zukünftige Unterrichten der Evolutionstheorie keine Schwierigkeiten:

»Adam und Eva, das ist so das Grundsystem und plötzlich, dass wir von den Affen abstammen und solche Dinge...habe ich eigentlich nie geglaubt, aber... ich muss ja das nachher später unterrichten (lacht), das ist wie...ich habe mich nachher so für mich gesagt, ok...es... man muss ja nicht seinen eige- 
nen Glauben weitergeben... //mhm// einfach das wissenschaftlich und das, was eigentlich...in den Büchern steht...und für das bin ich verpflichtet und mehr muss ich ja nicht //mhm// also...ich kann mit dem leben, wenn ich den anderen das muss, wenn ich das weitergebe, was ich gelesen habe, was ich gelernt habe... //mhm// wenn das auch nicht mit meinem Glauben übereinstimmt //mhm// diesen Kompromiss habe ich geschlossen für mich« (Xhemile A 243-244).

Die Evolutionstheorie zu unterrichten, stellt die glaubensgewisse Xhemile zwar vor das Dilemma, (später) etwas unterrichten zu müssen, das ihrem Glauben diametral widerspricht: etwas an das sie selbst nicht glaubt. Hinsichtlich ihrer Berufsrolle kommt sie sachbezogen zum Schluss: "man muss ja nicht seinen eigenen Glauben weitergeben«. Sie löst ihr Dilemma unter der zu Hilfenahme von Lehrmitteln, und indem sie das Wissenschaftliche fokussiert, das, was »in den Büchern steht« vermittelt. Mit Verweis auf ihre (professionelle) Verpflichtung fügt sie pragmatisch an »mehr muss ich ja nicht«. Sie hat für sich diesen Kompromiss geschlossen, und »kann mit dem leben.« Auch hier ordnet sie ihren Glauben ihrem Bildungsziel und ihrem professionellen Berufsanspruch unter.

In einer Studie, welche die Vereinbarkeit von Religiosität mit dem Professionalitätsanspruch der Lehrer*innenbildung untersuchte, konnte bei einigen dezidiert gläubigen christlichen Studierenden dasselbe Dilemma, wie Xhemile es beschreibt, rekonstruiert werden (Stienen/Bühler/Gasser/Tamcan 2011): das Dilemma, als professionelle Lehrperson Inhalte vermitteln zu müssen, welche unter Umständen dem eigenen Glauben wiedersprechen. Die Art, wie dieses Dilemma von christlichen Studierenden gelöst wurde, wurde in erwähnter Studie typologisiert. Ein spezifischer Typus erinnert stark an Xhemiles Vorgehen: Diesem Typus von glaubensgewissen Studierenden gelang es nämlich, den Anspruch der heutigen Lehrerinnen- und Lehrerbildung auf wissenschaftliche Reflexivität (die Gewissheiten kritisch befragt), als selbstverständlichen Teil der Ausbildung und der Professionalität als Lehrperson anzunehmen und sich darauf einzulassen. Mittels wissenschaftlicher Reflexivität waren diese Studierenden in der Lage, Distanz zum eigenen Glauben einzunehmen, Spielräume auszuloten und - wie Xhemile - Kompromisse einzugehen. Diese Kompromisse konnten sie einerseits (auch dies eine identische Strategie von Xhemile) durch das Beiziehen von standardisiertem Lehrbuchwissen als Hilfestellung eingehen, »andererseits durch die Akzeptanz, dass das eigene Glaubensbekenntnis, das als absolute Wahrheit angesehen 
wird, nicht von allen als solche betrachtet wird« (ebd.: 13). Im Kontext der Schule zu missionieren bzw. den Glauben weiterzugeben, wurde von solchen Studierenden "nicht nur als Neutralitätspflicht, sondern grundsätzlich ausgeschlossen« (ebd.), da es dem professionellen Anspruch an eine Lehrperson nicht genügt.

Bei Xhemile kann meines Erachtens ähnlich wie bei der zuvor geschilderten Vorgehensweise eine Verknüpfung des Aufbaus eines wissenschaftlichreflexiven professionellen Habitus mit einem habituell verankerten, intellektuellen Zugang zur Religiosität erkannt werden, der eine pragmatische Handhabung religiöser Glaubensinhalte im beruflichen Kontext zulässt.

Die pragmatische Handhabung religiöser Praxis zeigt sich bei Xhemile auch hinsichtlich des Kopftuchtragens. Xhemiles Mutter hätte gerne, dass ihre Tochter einen Hijab tragen würde. Wie ich beobachten konnte, trägt Xhemile den Hijab jedoch nur situativ, nämlich ausschliesslich im Kontext religiöser Vergemeinschaftung oder in der Moschee. Sie begründet dies wie folgt:

»(..) und das Kopftuch habe ich nicht an, das ist (lacht) meine Mutter hätte das gerne, aber (lacht) ich konnte mich immer wehren (lacht), dagegen wehren, so...(...) ich finde es nicht einmal schlimm, also, also ich würde mich schon sehen...im Kopftuch, a-aber ich stelle es mir...das Einzige, ha-, was ich gesagt habe ist, ich habe doch nicht studiert so lange und habe dann am Schluss nicht das machen können, was ich möchte und ich denke das Kopftuch würde mich daran hindern (...) weil ich möchte eigentlich schon etwas erreichen, jetzt habe ich...am Schluss hätte ich nachher für Nichts studiert, das Ganze...dann hätte ich mich für etwas Anderes entscheiden müssen, wo das Kopftuch...ja...erlaubt ist, akzeptiert wird...«(Xhemile, A 203-204).

Xhemile spielt hier auf die in der Schweiz gängige Praxis an, dass Lehrpersonen im schulischen Kontext kein Kopftuch tragen dürfen. Diese ist auf den Bundesgerichtsentscheid von 1997 (BGE 123 I 296) zurückzuführen ${ }^{30}$ (vgl. Kap. 2.1.3). Auch auf der Ebene der tertiären pädagogischen Bildungsinstitutionen gilt dieses Urteil trotz eines möglichen, rechtlichen Handlungsspielraums teilweise als richtungsweisend, dies zeigt sich bspw. in der an der Pädagogischen Hochschule Bern (PHBern) gängigen Praxis, wonach Studierende in

30 Es handelt sich um das in Kapitel 2.1.3 beschriebene Urteil, bei dem eine konvertierte Genfer Primarlehrerin gegen den Genfer Staatsrat Beschwerde einlegte, der von ihr verlangte, dass sie im Unterricht das Kopftuch ablege. Ihre Beschwerde wurde abgelehnt. 
einem Praktikum kein Kopftuch tragen dürfen (Feldprotokoll 8.12.2016). Andere Hochschulen wiederum loten den rechtlichen Handlungsspielraum, den dieses Urteil zulässt, eher aus (vgl. bspw. PH Zürich 2014). Der bei Xhemile rekonstruierten »Taktik« des zielstrebigen Aufsteigens würde ein Entscheid für das Tragen eines Hijabs diametral entgegenstehen: Sie ordnet, dies ein Kernstück der »Taktik« in dieser Ausprägung, die religiöse Praxis der Verfolgung ihres Bildungsziels unter.

Die religiöse Selbstrepräsentation als pragmatische Muslima, die für diese Ausprägung charakteristisch ist, zeichnet sich zusammenfassend durch zwei zentrale folgende Aspekte aus: erstens durch eine Abnahme der Bedeutung der religiösen Praxis auf der Generationsebene der Töchter im Vergleich zu den Eltern und zweitens durch die pragmatische Unterordnung der religiösen Praxis und religiösen Selbstrepräsentation hinsichtlich der Bildungsbiografie. Die interviewten Frauen bedecken sich dementsprechend wie Xhemile in aller Regel im Kontext der Ausbildung oder Berufsausübung nicht. Die Entscheidung, einen Hijab im Alltag zu tragen, könnte allenfalls ein nicht auszuschliessendes Zukunftsprojekt sein, kommt jedoch während der Berufsphase nicht infrage - nicht zuletzt, um dem zielstrebigen bildungsbiografischen Aufsteigen keine Hindernisse in den Weg zu legen.

\section{Ausprägung religiöse Selbstrepräsentation als engagierte Muslima}

Im Folgenden werden die religiöse Praxis und die religiöse Selbstrepräsentation von Frauen, bei denen die "Taktik« des zielstrebigen Aufsteigens in der Ausprägung der religiösen Selbstrepräsentation als engagierte Muslima rekonstruiert werden konnte, beschrieben. Dies soll anhand der prototypischen Fallbeispiele von Sahar und Hannan exemplarisch verdeutlicht werden.

Sahar verfügt über eine vergleichbare religiöse Sozialisation wie Xhemile. Wie Xhemiles Eltern sind auch Sahars Eltern bildungs- und aufstiegsorientiert. Der Vater verfügt über eine gymnasiale Bildung und eine Fachausbildung in einem hochspezialisierten medizinischen Beruf und hat sich in der Schweiz zum Berufsbildner hochgearbeitet, die Mutter verfügt über ein Medizinstudium mit Spezialisierung, konnte ihren Beruf in der Schweiz jedoch wegen mangelnder Sprachkenntnisse und fehlender Anerkennung der Ausbildung nicht ausüben. Sie blieb infolgedessen zu Hause und kümmerte sich um Kinder und Haushalt und berät ihren Bekanntenkreis informell bei medizinischen Problemen. Wie Xhemiles zeichnet sich auch Sahars religiöse Sozialisation durch eine starke Vereinsgebundenheit aus. Sahars Eltern, 
insbesondere die Mutter, nehmen innerhalb der religiösen Gemeinschaft eine zentrale Rolle ein und die ganze Familie lebt eine konsequente religiöse Praxis. Sahar bedeckt sich wie ihre Schwestern - anders als Xhemile tradiert sie die religiöse Praxis ihrer Eltern weitgehend. Dies bildet den zentralen Unterschied zu Frauen, bei denen die »Taktik« in der Ausprägung der religiösen Selbstrepräsentation als pragmatische Muslima nachgezeichnet werden konnte: Frauen mit der Ausprägung der religiösen Selbstrepräsentation als engagierte Muslima tradieren nicht nur die religiöse Orientierung der Eltern; das elterliche Engagement im Religionsverein wird ebenfalls tradiert und nicht, wie bei Frauen mit der Ausprägung der religiösen Selbstrepräsentation als pragmatische Muslima, abgeschwächt.

Bei diesen Frauen besteht seitens der Eltern eine hohe Erwartung an den Bildungsweg ihrer Kinder. Diese elterliche Bildungsaspiration wird von den Töchtern übernommen und sie absolvierten, angespornt durch den tradierten elterlichen Aufstiegswillen, das Gymnasium oder eine Mittelschule stets im Hinblick auf ihr Bildungsziel: eine Tertiärbildung. Sahar umschreibt dies wie folgt:

»Und deswegen hat es uns auch, es hat uns geprägt also irgendwie habe ich schon das Cefühl, dass es wegen meinen Eltern ist, warum ich dann auch in die [spezielle Sekundarschule mit erhöhten Anforderungen] ${ }^{31}$ ging oder in der Schule gut war oder zum Bespiel dann auch am Gymnasium mich immer angestrengt habe, weil ich einfach immer wusste, meine Eltern legen grossen Wert darauf« (Sahar, A 22).

Dass die Eltern grossen Wert auf Bildung legten, sieht Sahar in der Retrospektive als prägend für ihre Bildungsbiografie an. Um den Stellenwert der Bildung für den Vater weiter zu unterstreichen, beschreibt sie dessen Engagement in Bildungsbelangen für die Kinder wie folgt:

»Wenn es (...) um Bildung geht, dann würde er auch 1000 Franken ausgeben, wenn es irgendwie um Schulbücher geht oder sonst etwas geht, dann kennt er keine Grenzen von Celd oder irgendetwas sonst, dann sagt er immer

31 Der genaue Name des Schulmodells wird aus Anonymisierungszwecken nicht genannt. Da die Schulmodelle und deren Bezeichnungen in der Schweiz sogar innerhalb der Kantone variieren, ist eine relativ genaue Zuordnung des Schulorts durch die Bezeichnung des Schulmodells möglich. Beim genannten Modell handelt es sich, allgemein formuliert, um eine spezielle Sekundarstufe mit erhöhten Ansprüchen und Anschluss ans Cymnasium. 
Bildung kommt als erstes, auch wenn du für die Bildung nach China musst, (lacht) ähm, das kommt als erstes« (Sahar, A 22).

Für den Bildungsweg ist kein Weg und kein (finanzieller) Aufwand zu scheuen, so die väterliche Haltung, sprichwörtlich illustriert an der Aussage: »auch wenn Du für die Bildung nach China musst«. Mit Sahars Ausführungen lässt sich die elterliche Bildungsaspiration von Frauen, bei denen sich diese »Taktik« rekonstruieren liess, exemplarisch verdeutlichen: Sie stellt einen habituell verankerten Anspruch dar.

Sahars Bildungsweg führte sie schliesslich - mit dem Blick auf Bourdieus Habitustheorie wenig verwunderlich (Bourdieu 1983a, b) - ebenfalls in das medizinische Berufsfeld, wo sie nun eine tertiäre Ausbildung an einer höheren Fachhochschule absolviert. Anders als die Eltern von Zara unterschieden Sahars Eltern bei ihren erwünschten Bildungsaspirationen für ihre Kinder nicht nach genderspezifischen Kriterien zwischen ihren Töchtern und Söhnen. Im Gegensatz zu Zara, die nach elterlichem Wunsch keine nachobligatorische Ausbildung absolvieren, sondern früh heiraten sollte, war es Sahars Eltern ein grosses Anliegen, dass sie, wie auch ihre jüngeren Brüder, die bestmöglichste Ausbildung absolvieren soll. Dies stellt einen deutlichen Unterschied zum familiären Habitus von Frauen, bei denen die »Taktik« des Typus eins rekonstruiert werden konnte, dar. Und dürfte nicht zuletzt mit einen Grund darstellen, weshalb sich die Wirkmächtigkeit der Differenzdimension Gender hinsichtlich der Bildungsbiografie bei Sahar und Hannan nicht so einschränkend entfalten konnte, wie bei Frauen der »Taktik« des Typus eins (vgl. hierzu ebenfalls Bourdieu 1982a, b).

Auch Hannan wurde sehr ähnlich sozialisiert wie Sahar und Xhemile. Sie stammt aus einem bildungs- und aufstiegsorientierten Elternhaus; ihr Vater verfügt über eine universitäre Bildung in einem industriellen Beruf, ihre Mutter studierte Kunst in einem aussereuropäischen Land. Der Vater hat sich in der Schweiz zum Informatiker umschulen lassen, die Mutter illustriert muslimische Kinderbücher. Wie Sahars und Xhemiles religiöse Sozialisation zeichnet sich auch diejenige von Hannan durch eine starke Vereinsgebundenheit aus und stellt eine habituell verankerte, fraglose Selbstverständlichkeit dar. Wie die beiden anderen ist auch Hannan äusserst glaubensgewiss und verfügt über ein fundiertes, formales religiöses Wissen, das sie von Kindsbeinen an erworben hat. Anders als Xhemile tradiert sie jedoch die Handhabung der religiösen Praxis der Eltern weitgehend. So stellt es für sie bspw. eine fraglo- 
se Selbstverständlichkeit dar, dass sie die täglichen Gebete verrichtet und wie ihre Mutter und ihre ältere Schwester, Hijab trägt:

»Also meine Schwester (...) als sie zuerst kam, also meine Eltern haben sie gefragt, ob sie gerne ein Kopftuch tragen möchte oder nicht. Und sie sagte damals, dass sie ein Kopftuch tragen möchte, weil sie wollte damals wie die Mutter sein und die Mutter ist halt immer wie ein Vorbild //mhm// und alle wollen eigentlich sein wie die Mutter und ja sie sagte, dass sie gerne das Kopftuch tragen möchte und ja und ich habe dann auch einfach getragen, also das kam einfach so //mhm// wie automatisch also, es war wie automatisch, ja« (Hannan, A 171-178).

Aus dem Zitat wird deutlich, wie das Tragen eines Hijabs für Hannan eine fraglose Konsequenz ihrer religiösen Sozialisation darstellte. In dem Ausdruck »automatisch« spiegelt sich die habituelle Selbstverständlichkeit.

Frauen, bei denen sich die »Taktik« des Typus zwei rekonstruieren liess und sich als engagierte Muslima religiös selbstrepräsentieren, sind in der Regel Hijab tragend. Anders als Frauen der »Taktik« des Typus eins, welche sich im Dualen Berufsbildungssystem durch das Tragen des Hijabs mit wirkmächtigen Bildungsbarrieren konfrontiert sehen, sind die Bildungsbiografien von Frauen der »Taktik« des Typus 2 intersektionell gesehen vergleichsweise weniger eingeschränkt. Sie können ihre berufliche Selbstverwirklichung im Vergleich uneingeschränkt ins Zentrum ihrer bildungsbiografischen Überlegungen setzen. So stellt es früh Hannans Ziel dar »einen Beruf erlerne[n], der mir auch Spass macht und bei dem ich mir auch vorstellen kann, das auch mein ganzes Leben zu tun« (Hannan, A 421-423). In Hannans Fall fand sie dieses Ziel im Studium der Architektur.

Bemerkenswert hierbei ist, dass bei diesen Frauen, obwohl sie einen $\mathrm{Hi}$ jab tragen, die Differenzkategorie »Muslimin« keine vergleichbare Relevanz als schulische Bildungsbarriere entfalten kann, wie dies in der Berufsbildung (vgl. Typus 1) der Fall ist. Aufgrund des Zusammentreffens der sozialen Praxis des Bedeckens mit unterschiedlichen institutionellen Strukturen des Bildungssystems (Berufsbildung vs. Mittelschule, tertiärer Bereich) machen die Frauen ganz unterschiedliche Erfahrungen im Zusammenhang des Kopftuchtragens und ihrer Bildungsbiografien. Während bei Frauen, bei denen die »Taktik« des Typus eins rekonstruiert werden konnte, die Frage der Bedeckung zur berufsbiografisch existenziellen Frage wird und sie sich zwischen dem Tragen eines Kopftuchs und dem beruflichen Fortkommen entscheiden müssen, kann die Differenzkategorie »Muslimin« im tertiären, schulischen 
Umfeld, in dem sich Frauen der »Taktik« des Typus 2 bewegen, nicht annähernd dieselbe Wirkmächtigkeit entfalten. Im Gegenteil: Sie entwickelt kaum an berufsbiografischer Relevanz. Ausschlusserfahrungen werden von den interviewten Frauen, die sich in einem tertiären Umfeld bewegen, laut ihren Aussagen kaum gemacht. Die gesellschaftliche Marginalisierung der Muslim*innen im Zuge des laufenden Islamdiskurses nehmen Hannan und Sahar zwar sehr wohl wahr und problematisieren sie; die Differenzkategorie »Muslimin« hat jedoch aufgrund vorherrschender schulkultureller Sinnesordnung (Budde 2012) wenig persönliche Relevanz im tertiären Umfeld. Sahar konstatiert diesbezüglich:

»Aha so, also ich persönlich habe immer positive Erfahrungen gemacht, also mir hat noch nie jemand gesagt ähm, dass so wieso...wieso ziehst du ein Kopftuch an oder es ist ja mega komisch. Also etwas Negatives hat mir noch nie jemand gesagt«(Sahar, A 25).

Die interviewten Frauen, bei denen die »Taktik« des zielstrebigen Aufsteigens in der Ausprägung der religiösen Selbstrepräsentation als emanzipierte Muslima rekonstruiert werden konnte, die einen Hijab tragen, werden zwar in der Öffentlichkeit teilweise für ihr Kopftuch tragen angefeindet und machen Ausschlusserfahrungen. Sie tendieren dessen ungeachtet jedoch dazu, diese zu bagatellisieren. Für Hannan geht diese Erfahrung gar soweit, dass es für sie schwierig ist, überhaupt nachzuvollziehen, dass andere Personen einschneidende Ausschlusserfahrungen machen. Sie erlebte ihr schulisches und Ausbildungsumfeld stets unterstützend:

»Und darum kann ich es auch nicht verstehen, wenn so andere sagen, es sei $u$ schlimm ${ }^{32}$ hier und $/ / \mathrm{mhm} / /$ ja ich finde es noch schwierig $/ / \mathrm{mhm} / /$ weil ich es selber nicht sehe oder keine Ahnung« (Hannan, A 273-275).

In dem tertiären Umfeld, in dem sie sich bewegt, ist sie so weit davon entfernt, dass sie es selbst "nicht sehe«. Falls sie jedoch dennoch angefeindet wird, ist sie meist in der Lage, sich selbstbewusst für die habituell verankerte selbstverständliche Religiosität zu wehren. Oder wie Sahar es ausdrückt: »Wenn man Bildung hat, kann man sich immer wehren « (Sahar, A 26). Gegebenenfalls werden Ausschlusserfahrungen, wie ich beobachten konnte, zusätzlich in der religiösen Gemeinschaft diskutiert und verarbeitet, resp. Strategien des Umgangs damit besprochen.

32 Umgangssprachliche schweizerdeutsche Wendung für »sehr schlimm«. 
Es stellt sich jedoch die Frage, wie die Situation sich dann nach dem Studium, bei dem gegenüber der Lehre verzögerten Eintritt ins Berufsleben, darstellen wird. Aufgrund der Altersbegrenzung meines Samples steht diese den Frauen noch bevor. Erfahrungen mit der Differenzkategorie »Muslimin« thematisieren sie fast ausschliesslich im Rahmen der Zuschreibung einer Expertinnenrolle »für Islam« seitens Lehrpersonen und Peers, die sie nicht zuletzt aufgrund ihrer Permanenz im schulischen Alltag als sehr unangenehm empfanden. Diese Art der Erfahrung mit der Differenzkategorie »Muslimin« teilen alle interviewten Frauen, die sich zu »Taktik« 2 zuordnen liessen. Sie wird im folgenden Kapitel beschrieben (Kap. »Expertin für Islam«, S. 178ff.).

Hannan und Sahar sind konsequent in der Handhabung ihrer religiösen Praxen. Sie verrichten bspw. pflichtbewusst die täglichen Gebete. Anders als Mirjeta (»Taktik«1), die sich ostentativ der Befolgung religiöser Praxen zuwendet, verzichten sie jedoch auf demonstratives Befolgen religiöser Gebote: Sie finden in ihrer Ausbildung und beruflichen Situation Wege, ihre habituell verankerte religiöse Praxis konsequent zu verfolgen, indem sie versuchen, Kompromisse zu finden, ohne in Konflikt mit ihren bildungs- und berufsbezogenen Aktivitäten zu kommen. So würde es bspw. für Hannan bei Kollisionen von Unterrichts- und Gebetszeiten keine Option darstellen, eine Vorlesung für ein Gebet zu unterbrechen oder gar zu verschieben. Lieber betet sie die verpassten Gebete zu Hause nach. Auch Sahar, die in einem Krankenhaus arbeitet, verrichtet ihre täglichen Gebete nach der Arbeit zu Hause:

»Und dann mache ich es so, wenn ich nach Hause komme, hole ich die, die ich verpasst habe so wie nach. So mache ich das, weil es nicht möglich ist dort, wo ich arbeite, (...) dass ich das Gebet mache. Weil wir nur eine halbe Stunde Pause haben mit diesen Kleidern und der Ort und so, das ist wirklich nicht //mhm// ideal, deswegen mache ich es jeweils, wenn ich nach Hause komme, hole ich es so wie nach«(Sahar, A 23).

Ebenso wie die religiöse Praxis wird auch das intensive elterliche Engagement im religiösen Verein tradiert: Sie sind meist sogar in mehreren religiösen Vereinen engagiert. Einerseits im elterlichen Verein, andererseits vergemeinschaften sie sich auch in bildungsbezogenen Jugendorganisationen. Sahar beschreibt die Mitglieder in ihrem Jugendverein wie folgt:

»Es haben fast alle - es gibt so viele von uns, die das Cymnasium gemacht haben oder dran sind und es gibt noch mehr, die an der Uni sind zum Beispiel $/ / \mathrm{mhm} / /$ und bei uns ist allen die Bildung sehr wichtig auch wenn wir Frauen 
sind und Männer, also bei uns ist die Bildung wirklich gleichberechtigt hier« (Sahar, A 26).

An dieser Aussage lassen sich zwei Aspekte der religiösen Vergemeinschaftung von Sahar verdeutlichen, die exemplarisch für die »Taktik« dieser Ausprägung sind: Einerseits vergemeinschaften sie sich im tertiären Umfeld mit Muslim*innen, die denselben Bildungshintergrund aufweisen (bspw. in universitären muslimischen Student*innengruppen oder in muslimischen Jugendgruppen, in denen sich vorwiegend junge Gymnasiast*innen und Student"innen treffen). Andererseits - so unterstreicht Sahar in dieser Aussage - wird innerhalb dieser religiösen Vergemeinschaftung im tertiären Umfeld hinsichtlich der Bildung nicht nach Genderaspekten unterschieden. Innerhalb dieser religiösen Gruppen wird also die habituell verankerte Bildungsaspiration von Frauen als "gleichberechtigt« zusätzlich bestärkt. Die Mitgliedschaft und das Engagement in (bildungsbezogenen) religiösen Vereinen stellen eine zusätzliche Ressource beim Verfolgen ihres Bildungsziels dar. Dadurch, dass einerseits seitens der Elterngeneration und andererseits seitens der (religiösen) Peers im tertiären Umfeld keine oder zumindest im Vergleich zu Frauen der »Taktik« des Typus 1 wenig genderspezifische Vorbehalte hinsichtlich der Bildungsbiografien bestehen, kann die Differenzdimension Gender aus intersektioneller Sicht bei der »Taktik« des Typus zwei nicht dieselbe Wirkmächtigkeit entfalten, wie bei Frauen, bei denen die »Taktik« des Typus eins rekonstruiert werden konnte.

Die religiöse Selbstrepräsentation der Frauen zeichnet sich durch ein starkes Engagement in religiösen Vereinen (z.B. Öffentlichkeitsarbeit) und/oder zugunsten von religionsrelevanten Eigeninitiativen (wie Design von muslimischen Spielsachen, karitative Initiativen muslimischer Wohlfahrt etc.) aus. Einige Frauen engagieren sich zusätzlich für Themen, die mit jugendlichem (religiösem) Lifestyle von jungen Muslim*innen zu tun haben. Sie vertreiben bspw. Konsumgüter, die in der Schweiz im öffentlichen Handel nicht einfach zu finden sind (z.B. muslimische Mode oder Halal-Süssigkeiten etc.).

Dieses Engagement stellt die leitende Beschäftigung neben der Ausbildung dar. Hannan engagiert sich bspw. neben der Vergemeinschaftung im elterlichen Verein in verschiedenen muslimischen Vereinen dafür, dass jungen Musliminnen »casual-elegante« Mode, wie sie es nennt (Hannan, A 707), zur Verfügung steht. Sie ist der Ansicht, dass es in der Schweiz keine »stylische« Mode für junge Musliminnen zu kaufen gebe. Deshalb nähten sie und ihre Schwestern jeweils gekaufte Kleider für sich so um, dass sie einerseits 
den muslimischen Kleidungsvorschriften entsprechen und andererseits ihren modischen Ansprüchen und verschiedenen »Styles« (Hannan, A 646) gerecht wurden. Als sie merkte, dass viele modebewusste junge Glaubensschwestern vor demselben Problem stehen wie sie, gründete sie kurzerhand mit ihrer Schwester ein eigenes muslimisches Frauenmodelabel. Sie importierte bunte Hijabs und stellte ihre erste Kollektion eigener Kleider an einem UMMAHDay $^{33}$ aus (Feldprotokoll 18.10.2014). Modische muslimische Kleidung für junge Frauen scheint in der Tat eine Marktlücke zu sein. So sind, wie ich beobachten konnte, an den meisten grösseren Anlässen von muslimischen Jugendvereinen Stände zu finden, wo junge Frauen selbstgenähte oder importierte Kleidung feilbieten ${ }^{34}$. Hannan geht noch einen Schritt weiter: Sie vertreibt ihre Produkte an »Schwestern« nicht nur an Vereinsanlässen, sondern zusätzlich auf diversen Internetkanälen. So bietet ihr Label nicht nur auf einer eigenen Website und einer Facebook-Seite Waren an, sondern setzt auch auf Mittel wie Produkteplatzierung durch sog. Influencer ${ }^{35}$ : Das Label engagierte eigens eine sogenannte »Hijab-Bloggerin ${ }^{36}$, die als Influencerin wirbt.

Sahar hingegen engagiert sich auf andere Weise für ihre Gemeinschaft. Sie ist in der Öffentlichkeitsarbeit für den elterlichen Religionsverein tätig. Ihr Engagement beschreibt sie wie folgt:

33 Jährliche Crossveranstaltung des Vereins >UMMAH - Muslimische Jugend Schweiz‘. An den sog. »UMMAH-Days« werden einerseits Referate und Workshops abgehalten, andererseits werden aber auch viele Dinge zum Kauf angeboten wie bspw. religiöse Schriften, junge muslimische Mode, muslimische Lifestyle-T-Shirts (z.B. mit dem Aufdruck »Keep smiling - it's Sunnah« oder »l love my prophet«), »Halal«- Süsswaren, muslimische Spielsachen und Kinderbücher oder aber palästinensisches Olivenöl etc. (Feldprotokoll 18.10.2014).

34 Auch der IZRS (Islamischer Zentralrat Schweiz) nahm diese Marktlücke wahr und führte zu diesem Zweck mehrere Jahre hintereinander die »Islamic Lifestyle and Fashion Show« (ILFS) durch. Der Anlass wurde von Frauen für Frauen organsiert (»Sisters only! «). Diese Fashionshow genoss nicht nur unter Anhängerinnen des IZRS regen Zulauf (Feldprotokoll, 6.9.2015). Auch an diesen Anlässen konnte die gezeigte Mode teilweise gekauft werden.

35 Beim Influencer-Marketing werden gezielt Personen eingesetzt, die über eine hohe Präsenz und ein hohes Ansehen in sozialen Netzwerken und Medien verfügen, um ein Produkt so zu platzieren und zu vermarkten (vgl. Online Marketing Lexikon 2018).

36 »Hijab-Bloggerinnen« (Bezeichnung vgl. Hannan, A 637) sind junge bedeckte Frauen, die über ihr Leben mit Hijab im Internet bloggen. Meist behandeln sie in erster Linie Lifestyle-Themen. 
»Also meine Mutter hat ja die Position, die (ich) vorher gesagt habe und ich habe jetzt zusammen mit einer anderen (...). Wir zwei sind äh so zuständig so ein wenig für den interreligiösen Dialog. //Mhm// und wir haben dann auch jeweils so Tabligh ${ }^{37}$ - Veranstaltungen, also Tabligh heisst so wie, unsere-unsere Religion den anderen Menschen hier zu zeigen, vorstellen wer wir sind, so ein wenig das, organisieren ich und sie zusammen so eine Veranstaltung und dann halten wir da wirklich so zum Beispiel zwei kleine Vorträge darüber, wer wir sind und über irgend ein Thema das gerade aktuell ist. (...) Weil wir versuchen ganz stark mit diesen-diesen Veranstaltungen und dem interreligiösen Dialog uns abzugrenzen von diesen Extremisten, das war so die Botschaft«(Sahar, A 25).

Wie aus dem Zitat deutlich wird, ist Sahar im elterlichen Verein zusammen mit einer anderen jungen Frau für den »interreligiösen Dialog « zuständig. Sie organisiert »Tabligh«-Veranstaltungen, die zum Ziel haben, die religiöse Gemeinschaft in der Öffentlichkeit zu positionieren. Tabligh beinhaltet jedoch gleichzeitig auch einen gewissen Missionsanspruch (vgl. hierzu auch Wiedl 2008: 35-36). Die »Botschaft« soll in erster Linie sein, zu vermitteln (und dafür $\mathrm{zu}$ werben), dass ihre Religionsgemeinschaft sich im interreligiösen Dialog engagiert und sich dezidiert »von (...) Extremisten« abgrenzt. Es geht Sahar also darum, sich dafür zu engagieren, ihre Religionsgemeinschaft unter den Bedingungen des gegenwärtigen islamkritischen Diskurses zu positionieren.

Die »Taktik« des zielstrebigen Aufsteigens in der Ausprägung der religiösen Selbstrepräsentation als engagierte Muslima zeichnet sich zusammenfassend durch die folgenden Aspekte aus: Erstens durch eine Tradierung der religiösen Praxis und der Aufstiegsorientierung der Elterngeneration und zweitens durch ein starkes Engagement in religiösen Vereinen als zentrale Beschäftigung neben der Ausbildung. Sowohl die Tradierung der Bildungsaspiration der Eltern, die bei ihren Kindern bei Bildungszielen nicht nach genderspezifischen Kriterien unterscheiden, als auch die Vergemeinschaftung in religiösen Vereinen bilden eine zusätzliche Ressource beim Verfolgen des Bildungsziels. Die religiöse Selbstrepräsentation dieser Ausprägung befeuert also die ohnehin schon durchschlagekräftige »Taktik« des zielstrebigen Aufsteigens zusätzlich. 


\section{"Expertin für Islam «}

Die dominante Manifestation der Differenzkategorie »Muslimin«, wie sie sich in den bildungsbiografischen Erzählungen der Interviewten präsentiert, variiert in den Mittelschulen und in der Berufsbildung deutlich: Während in der Dualen Berufsbildung Differenz primär anhand sichtbarer religiöser Symbolik (in erster Linie dem Hijab) konstruiert wird (vgl. Typus 1), wird Differenz in der mittelschulischen, insbesondere in der gymnasialen Bildung mehr über die Zuschreibung einer Expertinnenrolle, einer »Expertin für Islam« seitens der Lehrpersonen, aber auch der Peers hergestellt (vgl. Typus 2). Diese soll in diesem Kapitel beschrieben werden.

Die interviewten Frauen, bei denen die »Taktik« des Typus des zielstrebigen Aufsteigens rekonstruiert werden konnte, befinden sich wie erwähnt in einem tertiären Ausbildungsgang oder streben einen solchen an und absolvierten mindestens eine Mittelschule. Die Manifestation der Differenzkategorie »Muslimin« in Form eines zugeschriebenen Expertinnentums gestaltet sich in den Bildungsbiografien der Frauen beider Ausprägungen religiöser Selbstrepräsentation des Typus zwei vergleichbar und soll deshalb in diesem Kapitel gemeinsam beschrieben werden.

Die Pädagogisierung von Differenz durch eine zugeschriebene Rolle einer »Expertin für Islam« führt gemäss der Erzählungen der jungen Frauen zu einer als permanent beschriebenen Erwartungshaltung seitens Lehrpersonen und Peers, gemäss dieser die in diese Rolle gedrängten Frauen nicht nur über sämtliche religiösen, sondern auch über jegliche, »dem Islam« und der »arabischen Kultur« zugeschriebenen Belange (wie z.B. Mädchenbeschneidung oder aber auch weltpolitische Konflikte, sowie tagespolitische Ereignisse) Auskunft geben können sollten. Verstärkt in die Rolle einer »Expertin« hineingedrängt werden die Frauen jeweils, wenn gesellschaftspolitische Ereignisse oder Debatten, aber auch terroristische Anschläge die Tagespresse dominieren. Velika, eine andere Frau meines Samples, bei welcher diese »Taktik« nachgezeichnet werden konnte, bringt diese Art von Zuschreibung auf den Punkt, indem sie ihre Rolle im Gymnasium hinsichtlich der Debatte um die Minarettinitiative (»Initiative gegen den Bau von Minaretten«) beschreibt:

»Und dann plötzlich wo es aufgekommen ist, wo die Debatte aufgekommen ist, bin ich sozusagen das Angriffsschild gewesen, weil alle das Gefühl hatten, ja ich müsste das doch alles wissen. Ich meine, ich komme ja von dort. Ich bin ja so jemand, ich bin ja Muslim[in], ich bin ja Ausländer[in], ich müsste es eigentlich wissen //mhm// und darum bin ich die ganze Zeit so mit Fragen 
bombardiert worden. (...) Und dann, wo die Leute zuerst auf mich zugekommen sind und mich gefragt hatten, ja, was...was sagst denn du dazu? Und stimmt das überhaupt, kann das überhaupt sein, und was sagt der Koran dazu? Ist es nicht so, dass Frauen unterdrückt werden? Und dann bin ich so gewesen, woow, das stimmt also überhaupt nicht //mhm// und dann ja...habe ich selber angefangen, mich einzulesen. Aber nicht weil ich gefunden habe, ich will jetzt unbedingt, sondern eher weil ich gefunden habe, ich muss, um zu wissen, was ich sagen muss (Velika, A 50).

Velika beschreibt, wie sie während des Abstimmungskampfs zum »Angriffsschild« wurde. In dem Ausdruck »Angriffsschild« spiegelt sich die Dynamik der emotional aufgeladenen politischen Debatte im Vorfeld der Abstimmung, die bis in das Klassenzimmer hineinreichte und deren (gegnerische) Argumentationslinien sich über der Gymnasiastin entladen haben. Sie schildert, wie die von ihr wahrgenommene Erwartungshaltung ihres schulischen Umfelds dahingehend verlief, dass sie über alles dem Islam Zugeschriebene Auskunft geben müsse, »weil alle das Gefühl hatten, ja ich müsste doch alles wissen«. Sie beschreibt die wahrgenommene Zuschreibung als »ich komme ja von dort«. Dieses »von dort« ist jedoch in ihrer Aussage nicht näher definiert und unterstreicht das Diffuse dieser Fremdverortung: Es gibt dieser Fremdverortung zufolge einen Ort, »von dort« kommen »Muslim*innen«. Es zeigt, wie die intersektionell wirkende Differenzkategorie »Muslimin/Ausländerin« mit einem imaginären, fremden Ort verbunden ist, von wo die »Expertin für Islam« kommen soll. Wie Lingen-Ali und Mecheril feststellen, gehen Prozesse der religiösen Fremdzuschreibungen oft mit territorialen Referenzen einher, die "vermeintlich eindeutig« sind (Lingen-Ali/Mecheril 2016: 22). In dieser Zuschreibungspraxis werden die Frauen »auf eine Herkunft festgelegt, deren exotisierte Eigenart sie situativ repräsentieren müssen « (Purtschert 2012: 107). Reale Lebenswelten sowie der Umstand, dass Velika in der Schweiz geboren und aufgewachsen ist, zählen in der Fremdzuschreibung »ich komme ja von dort« nicht. Lingen-Ali und Mecheril (2016: 19) sprechen hierbei von »Praktiken der Ausgrenzung« (ebd.): »Die religiös Andern sind different und weil sie different sind, fraglos nicht am richtigen Platz« (ebd.). Religion wird somit zur sozialen Deutungspraxis (vgl. ebd.) im pädagogischen Feld.

Weiter präzisiert Velika die Fremdzuschreibung, indem sie ausführt, wie sie in erster Linie als »so jemand « wahrgenommen wird und präzisiert dann, »ich bin ja Muslim[in], ich bin ja Ausländer[in]«, um gleich auf die damit verbundene Erwartungshaltung einzugehen, »ich müsste es ja eigentlich wis- 
sen«. Velika beschreibt, wie sie von ihrem schulischen Umfeld »die ganze Zeit so mit Fragen bombardiert « wurde und wie die Leute zu ihr kamen und von ihr eine Expertise zu jeglichen, dem Islam zugeschriebenen Aspekten erwarteten. Sie stellten Fragen wie, »ja stimmt das überhaupt « und »was sagt der Koran dazu « und »ist es nicht so, dass Frauen unterdrückt werden?«. Letztere Frage führte bei Velika dazu, dass sie sich nolens volens dazu entschloss sich (intellektuell) zu wehren. Sie begann sich vertiefter einzulesen und beschreibt, dass es sich hierbei nicht um ein intrinsisches Bedürfnis handelte (»nicht weil ich gefunden habe, ich will jetzt unbedingt«), sondern wie sie sich gezwungen sah, die fremdzugeschriebene Expertinnenrolle anzunehmen und mehr noch - auszufüllen: Sie begann sich vermehrt einzulesen »um $\mathrm{zu}$ wissen, was ich sagen muss«. Die zugeschriebene Rolle der »Expertin für Islam« führte also bei Velika dazu, dass sie sich gezwungen sah, sich vermehrt mit ihrer Religion auseinanderzusetzen. Die daraus folgende Akkumulierung von Wissen sollte ihr letztlich dazu verhelfen, eine fremdzugeschriebene Rolle auszufüllen, die sie sich gar nicht aussuchte:

»]a. Sobald es um die arabische Kultur gegangen ist, bin ich plötzlich als Expertin betitelt worden (...) und von dem her haben sie mich immer auf das angesprochen, und dann schauen sie dich auf einmal alle an. Was du jetzt sagst //mhm// und dann...weisst du, du willst ja auch nichts Falsches sagen $/ / \mathrm{mhm} / /$ aber es wird etwas von dir erwartet //mhm// aber ich meine, wenn ich die anderen Frage, ja warum feierst du Weihnachten? Die wissen das nicht einmal. Warum feierst du Ostern? Die haben keine Ahnung, was an Ostern so wichtig ist //mhm// aber bei ihnen ist das vollkommen okay, wenn sie das nicht wissen, aber, wenn ich etwas nicht weiss (lacht), dann, warum denn nicht? Du bist ja Muslim[in] //mhm// aber ich meine in meinem Freundeskreis wissen so viele nicht, weshalb man Ostern feiert. Zum Teil wissen sie nicht einmal, dass Ostern einen viel... einen höheren Feiertag ist als Weihnachten. Das wissen viele nicht //mhm// und dann finde ich, von mir wird immer erwartet, dass ich alles weiss und begründen kann. Aber sobald man sie selber fragt, ist es vollkommen irrelevant $/ / \mathrm{mhm} / /(. .$.$) ist dann so etwas$ wie...aber Entschuldigung....das ist doch nicht fair!« (Velika, A 155).

Velika, deren Eltern in Südosteuropa geboren wurden, sieht sich plötzlich in der Rolle als »Expertin für arabische Kultur« gedrängt. Aus ihrer Aussage »und dann schauen sie dich auf einmal alle an« wird auch der fordernde (Rechtfertigungs-)Druck des Umfelds deutlich. Es wird nicht nur erwartet, dass sie zu allem, das dem Islam und »der arabischen Kultur« zugeschrieben 
wird, Auskunft geben kann, sondern auch eine Meinung haben soll. Die damit einhergehende Erwartungshaltung führt, wie Velika beschreibt, zu einem erhöhten Anspruch an sich selbst, wenn sie beteuert »weisst du, du willst ja auch nichts Falsches sagen«. In dieser Aussage wird eine gewisse Ohnmacht deutlich, $z u$ der eine solch zugeschriebene Rolle führen kann. Es besteht einerseits der Erwartungsdruck des >Publikums an die >Expertin (»es wird etwas von dir erwartet«) und anderseits die Angst davor, dass es als persönliche Unzulänglichkeit gewertet werden könnte, wenn sie eine Auskunft nicht geben kann (oder auch nicht geben will). Darauf führt sie aus, was bei anderen Frauen meines Samples ebenfalls oft thematisch wurde, nämlich die Ungerechtigkeit (»das ist doch nicht fair«), dass seitens der Lehrpersonen, aber auch der Peers an sie ganz andere Ansprüche gestellt werden als an christlich sozialisierte Schüler*innen, bei denen es »okay« sei, wenn sie etwas nicht wüssten. Bei ihr tauche indes, wenn sie etwas nicht wisse, gleich die Frage auf: »Warum denn nicht? Du bist ja Muslim[in]«. Aus dieser Aussage wird deutlich, wie diese stereotypisierende Zuschreibung mit einem essenzialistischen Religionsbegriff einhergeht, welcher den Blick auf die realen Lebenswelten der jungen Frauen versperrt (vgl. hinsichtlich Kultur, Kalpaka 2006). Velika beschreibt, wie viele ihrer christlich sozialisierten Freund*innen bspw. nicht wüssten, weshalb man Ostern feiere und oft die zentralen Feiern des Christentums nicht kennen würden, während von ihr erwartet wird »dass ich alles weiss und begründen kann«. Die Lebenswelten der christlich sozialisierten Jugendlichen und ihr Verhältnis zu Religion werden von den Lehrpersonen hingegen als selbstverständlich plural und pluralisiert angesehen. Von ihnen wird nicht erwartet, dass sie auch nur Grundzüge »ihrer Religion « - falls sie überhaupt einer solchen zugschreiben werden - kennen. Velika bemängelt, dass verschiedene Ansprüche an sie und ihre Peers gestellt werden und schildert, wie sie damit abgespeist würde, dass »es vollkommen irrelevant« sei, wenn sie im Gegenzug ähnliche Fragen zum Christentum stelle. Der ungleiche Anspruch an sie vs. ihre Peers empfindet sie als sehr ungerecht, führt er doch zu einer Reproduktion gesellschaftlicher Ungleichheitsverhältnisse im schulischen Kontext.

Kalpaka (2006) beschreibt in ihrem Aufsatz Pädagogische Professionalität in der Kulturalisierungsfalle. Über den Umgang mit ,Kultur in Verhältnissen von Differenz und Dominanz die Wirkung von Kulturalisierung und die ausschliessenden Effekte eines statischen Kulturbegriffs im pädagogischen Kontext. Sie legt dar, wie ein geschlossener statischer Kulturbegriff verhindert, dass Personen und ihre Handlungsgründe differenziert wahrgenommen werden. Ei- 
ne solcher Kulturbegriff führt das Handeln von Schülerinnen und Schülern monokausal auf Kultur zurück, und dadurch wird »meistens verhindert, das Handeln als Antwort auf erlebte Widersprüche aufzufassen und weitere Fragen bezüglich der erlebten Widersprüche zu stellen, so dass bedeutsame Lebensbedingungen zum Teil unerkannt bleiben« (ebd.: 396). Analog dazu lässt sich meines Erachtens die zugeschriebene Rolle als »Expertin für Islam« auf einen geschlossenen Religionsbegriff zurückführen. Dass sich neben der von Kalpaka georteten »Kulturalisierungsfalle« nun auch eine »Religiosisierungsfalle« im pädagogischen Feld eröffnet $\mathrm{zu}$ haben scheint, erstaunt angesichts des gesellschaftspolitischen, diskursiven Trends, dass Differenzen vermehrt entlang religiöser Grenzen konstruiert werden (Sökefeld 2011: 271), nicht.

Insbesondere die Allgegenwärtigkeit der Rollenzuschreibung einer »Expertin« für Fragen, welche dem Islam zugeschrieben werden, seitens Lehrpersonen wird von den interviewten Frauen als irritierend beschrieben. Velika schildert, wie sie im Unterricht permanent angesprochen worden ist; immer und immer wieder habe es geheissen: »Was sagen Sie dazu, Frau Hoxha? Was ist ihre Meinung dazu? Was sagt der Islam dazu?«(Velika, A 166). Auch Hannan beschreibt den Positionierungszwang im Unterricht als omnipräsent in ihrer Mittelschulzeit: »es war eigentlich schon vom ersten Tag an so « (Hannan, A 838-839). Sei es bei politischen Ereignissen, welche dem Islam zugeschrieben wurden, oder sei es, wenn im Deutschunterricht eine Lektüre, wie »Nathan der Weise« von Lessing, anstand: »dann musste ich immer meinen Kommentar abgeben « (Hannan, A 808). Sie erlebte die dauernde Adressierung durch eine Lehrperson einerseits als Stichelei, andererseits aber auch als diffus. Sie konnte deren Ziel und Absicht nicht recht einordnen:

»ich kann selbst nicht genau sagen, ob es Interesse ist, oder auch ein bisschen so sticheln, so ein bisschen //mhm// es war vielleicht so ein Mischmasch ${ }^{38}$ halbes Lachen) //mhm// oder ob sie auch wollte, dass ich ein bisschen mehr über Religion, über meine Religion erzähle im Unterricht oder ich weiss auch nicht« (Hannan, A 816-819).

Einige der Frauen beschreiben den permanenten Rechtfertigungszwang auch als bewusste Provokation seitens der Lehrpersonen, so z.B. Velika:

»Wir hatten auch einen Deutschlehrer gehabt, (...) er hat es geliebt zu provozieren. Er hat...er hat es wirklich gerne gemacht gehabt. Und mich gera- 
de direkt angesprochen, dann bin ich sozusagen ganz allein gewesen. Und plötzlich sind alle Stimmen laut geworden, damit er so ein bisschen...Diskussion provozieren konnte. Und er einfach sozusagen nur zuschauen konnte« (Velika, A 54).

Velikas Schilderung lässt keinen Zweifel offen, dass die Lehrperson sie mit ihrer Vorgehensweise in eine für sie äusserst unangenehme Situation brachte. Aus der Aussage »dann bin ich sozusagen ganz allein gewesen « wird offenbar, dass dieser Positionierungszwang im pädagogischen Kontext als Ausschlusserfahrungen zu deuten ist - als Reproduktion des kollektiven gesellschaftlichen »Rechtfertigungsdrucks« (vgl. u.a. Baumann 2015: 17, Tunger-Zanetti 2013a: 224, Tunger-Zanetti 2013c, Schild 2010: 181), sich ständig als muslimische Frau rechtfertigen bzw. legitimieren zu müssen. Velika beschreibt ergänzend, wie es ihrem Deutschlehrer dadurch gelungen ist - quasi als pädagogischen Kniff auf Velikas Kosten -, in der Klasse eine Diskussion zu provozieren, der er nur noch zuschauen musste.

Obwohl für die Betroffenen meist sehr unangenehmen, ist davon auszugehen, dass die Zuschreibung der Rolle einer »Expertin für Islam« durch Lehrpersonen und Peers wohl kaum ausschliesslich in negativer Intention vorgenommen wird. Das Pädagogisieren der Differenzkategorie »Muslimin« in Form der Zuweisung einer Expertinnenrolle kann zumindest in gewissen Kontexten sicherlich auch als (unbeholfene) »Form des Verstehen-Wollens« (Kalpaka 2006: 396) ${ }^{39}$ gedeutet werden, die ihrerseits in begegnungspädagogischen Ansätzen fusst. Mecheril und Thomas-Olalde betonen, dass »begegnungspädagogische Ansätze (...) immer jene Differenzen voraus[setzen], auf die sie pädagogisch zu reagieren suchen, wodurch diese Ansätze zu einer Praxis der Herstellung von Differenz werden « (Mecheril \& Thomas-Olalde 2018, S. 194). Wie in den bildungsbiografischen Narrationen der jungen Frauen rekonstruiert werden konnte, werden durch solche Praxen gesellschaftliche Ausschlusserfahrungen im pädagogischen Kontext reproduziert.

Buchhardt (2014: 179) geht in Bezug auf eine ethnografische Schulforschung in Dänemark davon aus, dass Religion von der Institution Schule (mit) produziert wird, wie sie anhand ihrer Daten schlüssig mittels der omnipräsenten Dichotomie »Muslimness« vs. »Danishness/Christianess« analysiert. Sie gelangt schliesslich zu dem Schluss: jedoch im pädagogischen Kontext von »Kulturalisierung als eine Form des VerstehenWollens« (2006: 396). 
»(..) the culturalized category of sreligion (...) not only functions as a metaform of the concept of race (...) the culturalized category of sreligion « may be explained as micro-identity politics (...) internalizing social classification and social distribution. (...) >To be Muslim< and >to be UniversalChristian-Danish< are indeed things you can learn in school« (Buchardt 2014: 180).

Wie die oben ausgeführten Beispiele zeigen, wird in den biografischen Erzählungen der Frauen anhand der zugeschriebenen Rolle der »Expertin für Islam« die Konstruktion "Ausländer*in/Muslim*in« vs. "Schweizer*in/Christ*in « deutlich. Die verschiedenen Ansprüche, die mit dieser Kategorisierung einhergehen, können wie Buchardt (ebd.) für den dänischen Kontext darlegt, meines Erachtens ebenso mit »micro-identity-politics« erklärt werden, welche die gesellschaftliche soziale Klassifikation und soziale Ungleichheit (re)produzieren.

\section{c) "Taktik " gesellschaftlicher Selbstpositionierung hinsichtlich der Bildungsbiografie: Agency durch Aneignung des meritokratischen Prinzips}

Die interviewten Frauen, bei denen die »Taktik« des zielstrebigen Aufsteigens rekonstruiert werden konnte, erlangen mehr Handlungsfähigkeit durch eine zielstrebige kompensatorische Aneignung des meritokratischen Leistungsprinzips (Becker/Hadjar 2017, Hadjar 2008, Solga 2005, Young 1961) - dies bei beiden Ausprägungen religiöser Selbstrepräsentation. Die »Taktik« des zielstrebigen Aufsteigens zeigt sich besonders deutlich, wenn es zu strukturellen Ausschlusserfahrungen kommt, die dann mittels Zielstrebigkeit und Leistung kompensiert werden. Im Folgenden möchte ich nun exemplarisch am Übergang der ersten Selektionschwelle von Xhemile aufzeigen, wie sich diese »Taktik« bildungsbiografisch manifestiert.

In der Rolle als Erstgeborene in der Migrationssituation konnte Xhemile zunächst von ihren Eltern, die gerade erst daran waren, sich in der Berufswelt der Schweiz zu etablieren und das Schulsystem noch nicht kannten, keine grosse Unterstützung in schulischen Belangen erwarten. Sie war auf sich allein gestellt. Als ältestes Kind der Familie im schweizerischen Schulsystem kam ihr zudem eine gewisse Vorreiter*innenrolle $\mathrm{zu}$ :

»Und bis dann...ist einfach, ich bin die Älteste gewesen, ich habe gar keine Ahnung gehabt, wie es weiter geht also - dass man ausgesondert wird...selektioniert, Sek-Real, was ist das überhaupt und das ist mir gar nicht bewusst 
gewesen und ich habe keine Ahnung gehabt...was muss ich machen dass ich in die Sek oder was bringt mir die Sek und was ist Real //mhm// so bis dort und es ist mir eigentlich so egal gewesen, also ni-nicht besonders angestrengt«(Xhemile, A 55).

Aus dieser Aussage lässt sich schliessen, dass Xhemile die grosse Bedeutung der ersten Selektionsschwelle im schweizerischen Schulsystem nicht bewusst war. Aufgrund ihres fehlenden Bewusstseins der Bedeutung dieser Selektionsschwelle hat sich Xhemile in der Folge nicht besonders angestrengt und wurde zunächst in die Realschule eingestuft. Retrospektiv wird sie sich bewusst, dass es Wissen über das System braucht, um in der Schullaufbahn erfolgreich zu sein. Sie konstatiert an anderer Stelle, dass es ihre Geschwister diesbezüglich viel leichter gehabt hätten, weil sie später von ihren Erfahrungen und ihrem Wissen über die Institutionen, aber auch von autodidaktischen Lerntechniken profitieren konnten (z.B. A 159). Diese aus intersektioneller Sicht wirksame Bildungsbarriere an der ersten Selektionsschwelle manifestiert sich ähnlich wie bei Frauen der »Taktik« des Typus 1: Als junge Mädchen waren Xhemile wie Zara bei der ersten Selektionsschwelle am Übergang von der Primar- zur Sekundarstufe auf sich alleine gestellt und entschieden sich für den Verbleib in der Realstufe (Intersektion der Differenzdimensionen "class« und »Migrationshintergrund«). Wie bei Zara wirkte das Schulsystem bei der ersten Selektionsschwelle zunächst hinsichtlich der gesellschaftlichen Position der Eltern in der Schweiz reproduktiv (vgl. Kronig 2005).

Anders als Zara hatte Xhemile jedoch bereits damals ein klares Berufsziel vor Augen: Sie wollte Lehrerin werden. Ihre Familie befürwortete, anders als bei Zara, dieses Bildungsziel zumindest ideell, auch wenn sie wenig praktische Unterstützung bieten konnten. Als Xhemile realisierte, dass sie in die Sekundarschule eingestuft werden musste, wenn sie Lehrerin werden will, strengte sie sich an und krempelte den Selektionsentscheid innerhalb von zwei Monaten um:

»Und nachher, als es mir bewusst geworden ist, dass ich [die] Sek[undarstufe] brauche, ja damit ich Lehrerin werden kann...bin nachher in Sek also (...) nach zwei Monaten nachher wieder in der Sek eingestuft, Math und äh...Französisch und Deutsch //mhm// das ist wirklich zügig gegangen, ich habe wirk- 
lich Vollgas gegeben, habe immer Sechser, Fünfeinhalber ${ }^{40}$ gemacht (halbes Lachen) - ja...«(Xhemile, A 57-59).

Das prototypische Element der »Taktik« des zielstrebigen Aufsteigens lässt sich sehr deutlich anhand des zuvor aufgeführten Zitats veranschaulichen: Das Bildungssystem wirkt in den Bildungsbiografien dieser jungen Frauen in Bezug auf die soziale Ungleichheit zunächst reproduktiv, insbesondere hinsichtlich der intersektionell wirkenden Differenzdimensionen »Migrationshintergrund « und »class«. Mittels der »Taktik« des zielstrebigen Aufsteigens gelingt es ihnen jedoch, mit im Vergleich zu privilegierten Lernenden ungleich grösserem, kompensatorischen Arbeitsaufwand - mittels kompensatorischer Aneignung des meritokratischen Prinzips (Becker/Hadjar 2017, Hadjar 2008, Solga 2005, Young 1961) - Selektionsschwellen zu meistern.

Xhemile verfolgt ihr Bildungsziel konsequent, schon früh trifft sie ihre Bildungsentscheidungen notfalls alleine, stets das Ziel vor Augen, Lehrerin zu werden. Von der ersten Selektionsstufe an ordnet Xhemile all ihre Bildungsentscheidungen und -bemühungen einem einzigen Ziel unter: Lehrerin $\mathrm{zu}$ werden. Auch später sieht sie den Grund einer gymnasialen Bildung einzig durch ihr Berufsziel gerechtfertigt:

»Und ich habe einfach unbedingt in den Gymer ${ }^{41}$ wollen, aber heute im Nachhinein denke ich, es ist wahrscheinlich, also wenn ich nicht Lehrerin hätte werden wollen, wäre es wirklich eine dumme Entscheidung gewesen...unnötig...«(Xhemile, A 59).

Aus dem Zitat lässt sich die Zielorientiertheit rekonstruieren, die ebenfalls prägend für Xhemiles Bildungsbiografie war. Sie habe »einfach unbedingt in den Gymer wollen«. Den Zweck einer gymnasialen Bildung sieht sie jedoch zumindest aus der Retrospektive einzig durch ihr Ziel, Lehrerin zu werden, gerechtfertigt. Sie ist gar der Ansicht, dass es "wirklich eine dumme Entscheidung ...unnötig« gewesen wäre, das Gymnasium zu besuchen, hätte sie es nicht für das Erreichen ihres Bildungsziels benötigt. Ein Interesse an Allgemeinbildung »sui generis« gab es für Xhemile in ihrer Bildungslaufbahn demnach nicht. Es ging ihr einzig darum, zielstrebig ihr Bildungsziel zu erreichen und dafür traf sie die erforderlichen Bildungsentscheidungen.

40 Die schweizerische numerische Schulnotenskala reicht von 1-6, wobei 6 die Höchstnote darstellt.

41 Schweizerische umgangssprachliche Bezeichnung für Gymnasium. 
Besonders deutlich lässt sich die »Taktik« des zielstrebigen Aufsteigens nachzeichnen, wenn es zu bildungsbiografischen Ausschlusserfahrungen kommt. Xhemile beschreibt ein Gespräch mit ihrem damaligen Schulleiter über einen allfälligen Übertritt ins Gymnasium wie folgt:

»Der Schulleiter hat mir dazumal gesagt gehabt, ich solle es nicht probieren (...), weil es sei zu schwierig für mich und ich soll probieren lieber, ich solle auch Englisch nicht nehmen, weil das sei zu viel ((wäre))) und das hat mich so dann angespornt, weiterzumachen, weil das hat mich so genervt, dermassen genervt, dass er so etwas sagt...(...) Er hat das Cefühl gehabt, ich-ich denke es, ich weiss es nicht warum, aber so Migrantenkinder und (...) wahrscheinlich schafft sie das nicht...(...) vielleicht hat es den Andern hat es...Mut weg...äh also genommen...das schon mal zu probieren ${ }^{42}$ und ich habe gedacht, nein, dem zeige ich es mal!«(Xhemile, A 66-72, Unterstrichenes wurde laut betont ausgesprochen).

Die Erfahrung, dass ihr der Schulleiter einen gymnasialen Übertritt nicht zutraute, deutete Xhemile retrospektiv als Ausschlusserfahrung aufgrund von Vorurteilen gegenüber Lernenden mit »Migrationshintergrund«. Ihr ist bewusst, dass dies eine Erfahrung ist, von der sich Andere hätten entmutigen lassen und davon abgesehen hätten, einen gymnasialen Übertritt ins Auge $\mathrm{zu}$ fassen. Xhemile jedoch begegnete Ausschlusserfahrungen im Schulsystem mit verstärktem Einsatz und noch grösserer Zielstrebigkeit und liess sich nicht beirren: »(...) und ich habe gedacht, nein, dem zeige ich es mal!«. Sie nahm diese Unterredung mit dem Schulleiter zum Ansporn und schaffte mittels kompensatorischer Aneignung des meritokratischen Prinzips (Becker/Hadjar 2017, Hadjar 2008, Solga 2005, Young 1961) schliesslich die beste Empfehlung für das Gymnasium, indem sie als Einzige ihrer Klasse die Maximalpunktezahl erreichte.

Bei Xhemiles Übergang in das nachobligatorische Bildungssystem kann meines Erachtens besonders deutlich aufgezeigt werden, wie Xhemile durch die »Taktik« des zielstrebigen Aufsteigens aus einer subalternen Position heraus mehr Handlungsfähigkeit (Agency) erlangen konnte. De Certeau beschreibt treffend, innerhalb welcher Gegebenheiten eine »Taktik« zum Zuge kommt, eine »Taktik« »muss mit dem Terrain fertigwerden, das ihr so vorgegeben wird, wie es das Gesetz einer fremden Gewalt organisiert « (De Certeau 1988: 89), in diesem Falle stellt dies die Konfrontation mit 
einem »defizitorientierten, früh selektionierenden Bildungssystem « (Oester/Brunner 2015: IV) dar. Die "Taktik« des zielstrebigen Aufsteigens ist ein Handlungsmuster, mittels dessen es Xhemile gelingt, aus einer subalternen Position heraus mehr Agency zu erlangen, indem sie ihr Ziel nicht aus den Augen verliert und preisgibt. Sie lässt sich nicht dahingehend überzeugen, den gymnasialen Übertritt gar nicht erst »zu probieren«. Es gelingt ihr, »im Fluge die Möglichkeiten zu ergreifen, die der Augenblick bietet« (De Certeau 1988: 89), die etablierten Strukturen umzudeuten und für Überraschungen zu sorgen (maximale Punktzahl für den gymnasialen Übertritt). De Certeau zufolge sorgt eine »Taktik«»für Überraschungen. Sie kann dort auftreten, wo man sie nicht erwartet« (De Certeau 1988: 89).

In De Certeaus Sinne (1988: 89) besteht das konstitutive Element der »Taktik« des zielstrebigen Aufsteigens in der kompensatorischen Aneignung des meritokratischen Prinzips (Becker/Hadjar 2017, Hadjar 2008, Solga 2005, Young 1961). Trotz bestehender Bildungsungleichheiten besteht, wie Becker/Hadjar (2017) aufzeigen, in westlichen Gesellschaften ein verbreiteter Glaube an einen "meritokratischen, herkunftsunabhängigen Zugang zu Bildung« (ebd.: 35). In der Vorstellung einer meritokratischen Gesellschaft »wird die soziale Schichtung nach sozialer Herkunft scheinbar durch eine soziale Schichtung nach individueller Leistung ersetzt« (Becker/Hadjar 2017: 34). Hierbei legitimiert das Leistungsprinzip die Struktur der sozialen Ungleichheit, d.h. die ungleiche Verteilung von Bildung, Status und Einkommen wird einzig durch die ungleiche Leistung von Individuen gerechtfertigt (ebd.: 33-34). In dieser Vorstellung spiegelt sich nicht zuletzt eine »liberale Ideologie individueller Freiheit und dem [sic!] Verständnis von Chancen- statt Ergebnisgleichheit wieder [sic!]« (ebd.: 36). Die Vorstellung einer Chancengleichheit durch gleiche Leistung hält - wie unzählige bildungssoziologische Studien verdeutlichen - einer empirischen Überprüfung nicht stand (z.B. Kronig 2007, vgl. hierzu ausführlich Kapitel 3.3). Das meritokratische Prinzip hat sich dennoch im Zuge der Bildungsexpansion zu einem wirkmächtigen Legitimationsprinzip sozialer Ungleichheiten und ungleicher Bildungschancen entwickeln können (Hadjar 2008, Solga 2005).

Xhemiles Zielstrebigkeit wirkt sich gar auf die Wahl ihres Freundeskreises aus. Der grösste Teil ihres Freundeskreises ist akademisch gebildet, sie hat »einfach Kolleginnen, die auch studiert haben....̈hm...oder einfach eine Fachhochschule gemacht haben « (Xhemile, A 226). Ihren Freundeskreis beschreibt sie wie folgt: 
»Ich habe mich immer an solchen angehängt, die (...) zielorientiert gewesen sind, zielstrebig gewesen sind, die etwas im Leben erreichen wollten« (Xhemile, A 213).

Mit Schulkolleginnen, die andere Interessen hatten, als »etwas im Leben erreichen«, wollte sie jedoch nichts zu tun haben:

»Ich wollte mich eigentlich nicht mit denen abgeben (halbes Lachen), sagen wir es so, ein bisschen fies...ähm, weil sie haben andere Interessen gehabt, Schminken, Ausgang...Parties...ja und das habe ich nicht gewollt, also...« (Xhemile, A 217).

Xhemiles strategisch anmutende Auswahl der Peers zeigt sich auch darin, mit wem sie sich nicht »abgeben « wollte. In der Aussage schwingt eine gewisse Scham mit - sie ist sich bewusst, dass die Beschreibung der Peers, von denen sie sich abgrenzt, »ein bisschen fies « sei, beziehungsweise eine Zuschreibung und Stereotypisierung, die mit einer Abwertung verbunden ist.

Während der Ausbildungszeit schlug sich Xhemile mit Hilfsjobs in Reinigungsfirmen ohne die finanzielle Unterstützung ihrer Eltern durch, mit denen sie aufgrund ihrer Partnerwahl im Zwist lag. Auch in dieser aufreibenden Zeit verlor sie ihr Berufsziel nie aus den Augen und es gelang ihr selbst in dieser grossen Belastungsphase noch den Vorbereitungskurs zu absolvieren und die Prüfung an der Pädagogischen Hochschule zu bestehen:

»Während des Vor[bereitungs] kurses...äh gerade nach der Hochzeit [habe ich] Aufnahmeprüfungen gehabt, eine eigene Wohnung in diesem Jahr gesucht, einen Job - es ist wirklich so viel gewesen...ich habe nichts gelernt, in der letzten Woche, eine Woche vor der Aufnahmeprüfung habe ich angefangen, alle zwölf Fächer zu lernen //mhm// für die Prüfung, es ist wirklich schwer gewesen, ich bin wirklich um acht aufgestanden, bis um zwölf in der Nacht habe ich gelernt... //mhm// bin schlafen gegangen und wieder am nächsten Tag und das sieben Tage nacheinander habe ich das durchgezogen und nachher die Prüfungen bestanden « (Xhemile, A 286, Unterstrichenes wurde laut betont ausgesprochen).

Aus der Aussage wird die Belastung deutlich, die Xhemile während der Zeit des Vorbereitungskurses und der anschliessenden Zulassungsprüfung an die Pädagogische Hochschule auszuhalten hatte. Doch durch ihre Zielgerichtetheit war sie einmal mehr in der Lage, auch in einer schwierigen Ausgangslage ihren Ehrgeiz und sämtliche Kräfte zu mobilisieren und sich mithilfe 
von Nachtschichten in einer Woche so vorzubereiten, dass sie die Prüfung bestand - stets das Ziel bzw. ihren Beruf vor Augen. Mit viel Arbeit, Disziplin und Durchhaltewillen und mittels der oben beschriebenen Aneignung des meritokratischen Prinzips hat sie es geschafft, obwohl sie als »Migrantenkind« (Xhemile, A 68), schwere strukturelle Hindernisse des Schulsystems zu überwinden hatte.

Zentrales Element der »Taktik« des zielstrebigen Aufstiegs ist es, dass die Frauen, welche sich diese »Taktik« zu Eigen machen, wie Xhemile, jeglichem (strukturellen) Widerstand mit der Intensivierung der Anstrengungen zur Erreichung höherer Leistung und der Fokussierung auf das Ziel begegnen. Mehr Agency hinsichtlich ihres Bildungswegs erlangen die jungen Frauen dadurch, dass es ihnen gelingt, mittels - im Vergleich zu privilegierten Lernenden - ungleich grösserer Anstrengung aus ihren subalternen Positionen heraus nach dem meritokratischen Prinzip die intersektionell wirkenden Barrieren auszuhebeln und ihre habituell verankerte Bildungsaspiration in einer tertiären Bildung umzusetzen. In der Koppelung dieser kompensatorischen Aneignung des meritokratischen Prinzips mit der Ressource einer elterlichen Bildungsaspiration, welche nicht nach genderspezifischen Kriterien unterscheidet, entwickelt diese »Taktik« hinsichtlich der untersuchten Bildungsbiografien eine grosse Durchschlagskraft. Zusätzlich ist diese »Taktik« noch durch eine ausgeprägte Zielfokussierung gekennzeichnet.

\section{Zusammenfassung "Taktik" Typus 2}

Die interviewten Frauen, bei denen die »Taktik« des Bildungszugangs durch zielstrebiges Aufsteigen rekonstruiert werden konnte, erfahren aus einer intersektionellen Sicht Einschränkungen ihrer Bildungsbiografie durch das Zusammenspiel der Differenzdimensionen »Migrationshintergrund«, »class« und Religion. Hinsichtlich der Berufsbiografie erweist sich die Differenzdimension Gender jedoch als weniger wirkmächtig in dem intersektionellen Zusammenspiel als bei Frauen der »Taktik« des Typus 1. Dies zeigt sich insbesondere anhand zweier Aspekte: Erstens kann die Differenzdimension Gender hinsichtlich der Bildungsbiografie bei den interviewten Frauen dieser »Taktik« weniger Wirkmächtigkeit entfalten, da die Eltern in ihren Bildungsaspirationen, die von den Töchtern tradiert werden, nicht nach genderspezifischen Kriterien unterscheiden. Die Eltern fördern ihre Töchter und ihre Söhne hinsichtlich ihrer Bildungsbiografie gleichermassen; sie verfechten bspw. nicht, wie die Eltern von Frauen der »Taktik« 1 ein klassisches Rollenbild, nachdem 
ihre Töchter früh heiraten sollen und deshalb keine gute Ausbildung benötigen. Im Gegenteil: Sie erwarten von ihren Kindern - genderunabhängig einen gesellschaftlichen Aufstieg durch Bildung. Eine Vorstellung, die habituell bei den Töchtern verankert ist und tradiert wird. Zweitens kann bei den Frauen, bei denen die »Taktik« 2 rekonstruiert wurde und die einen Hijab tragen, die Differenzdimension Gender im Zusammenspiel mit Religion aufgrund der vorherrschenden schulkulturellen Sinnesordnung (Budde 2012) im tertiären (und zuvor im mittelschulischen) Umfeld, in dem sich die Frauen bewegen, nicht dieselbe berufsbiografisch einschränkende Wirkmächtigkeit entfalten wie in der Berufsbildung. Die Differenzkategorie »Muslimin«manifestiert sich in diesem Umfeld zwar in Form eines zugeschriebenen Expertinnentums (»Expertin für Islam«), macht jedoch keine einschneidende berufsbiografische Umorientierung erforderlich, wie dies bei der »Taktik« 1 der Fall ist.

Bei den Frauen der »Taktik« 2 konnten zwei unterschiedliche Ausprägungen religiöser Selbstrepräsentation rekonstruiert werden: Es handelt sich hierbei einerseits um die religiöse Selbstrepräsentation als "pragmatische Muslima« und andererseits um die religiöse Selbstrepräsentation als »engagierte Muslima«: Während bei der Ausprägung der religiösen Selbstrepräsentation als "pragmatische Muslima« die Bedeutung der religiösen Praxis gegenüber der Elterngeneration abnimmt, wird bei der Ausprägung der religiösen Selbstrepräsentation als »engagierte Muslima« die religiöse Praxis der Eltern, insbesondere das Engagement in religiösen Vereinen, tradiert.

Die Ausprägungen unterscheiden sich insbesondere in der Art, wie die religiöse Praxis ihrer Eltern weitergegeben wird, haben aber keinen sich gross voneinander unterscheidenden Einfluss auf die Bildungsbiografie. Dies ist insofern bemerkenswert, da bei Frauen, bei denen die religiöse Selbstrepräsentation als »engagierte Muslima « rekonstruiert werden konnte und die einen Hijab tragen, keine vergleichbaren bildungsbiografischen Einschränkungen rekonstruiert werden konnten, wie in der Berufsbildung bei Frauen der »Taktik« 1. Allerdings muss dieser Befund dahingehend relativiert werden, dass den Befragten aufgrund ihres Alters der Berufseintritt nach dem tertiären Ausbildungsgang noch bevor steht. Es ist nicht auszuschliessen, dass dort dann intersektionell wirkende Barrieren auftreten könnten, die in der schulkulturellen Sinnesordnung des tertiären Umfelds kaum Relevanz entwickeln konnten.

Aus intersektioneller Sicht waren die jungen Frauen beider Ausprägungen der »Taktik« 2, bildungsbiografisches Bestehen durch zielstrebiges Auf- 
steigen, in ihrer frühen Bildungsbiografie zwar belastet: Als junge Lernende wurden sie durch strukturelle Barrieren im Bildungssystem insbesondere aufgrund des Zusammenspiels »Migrationshintergrund«, »class« und (weniger stark, aber auch durch Religion und Gender) benachteiligt. Bildungsbiografisch zeigt sich das insbesondere hierin, dass sie als Lernende von Exponent*innen des Bildungssystems in Selektionsentscheidungen hineinberaten wurden, die weder ihren kognitiven Fähigkeiten noch ihren Bildungswünschen und -zielen entsprechen. Ihre Eltern waren trotz hoher Bildungsaspirationen für ihre Töchter aufgrund fehlender Kenntnisse des Schulsystems und der Bedeutung der frühen Selektion nicht in der Lage, sie zu unterstützen. Die »Taktik« des zielstrebigen Aufsteigens erwies sich jedoch trotz dieser Bildungsbarrieren als äusserst durchschlagekräftig: Konstitutives Element der »Taktik « 2 ist es, dass jeglichem (auch strukturell bedingtem) Widerstand mit der Intensivierung der Zielstrebigkeit und der Leistung begegnet wird. In De Certeaus Sinne (1988: 89) besteht das zentrale Element der »Taktik« des zielstrebigen Aufsteigens in der Aneignung des meritokratischen Prinzips (vgl. Becker/Hadjar 2017). Mehr Agency erlangen die jungen Frauen paradoxerweise dadurch, dass sie sich dasjenige Prinzip aneignen, mittels dessen Bildungsungleichheit in modernen Gesellschaften normativ gerechtfertigt wird (Solga 2005). Es gelingt ihnen, durch - im Vergleich zu privilegierten Lernenden ungleich grössere Anstrengung aus ihren subalternen Positionen heraus die intersektionell wirkenden Barrieren auszuhebeln und ihre habituell verankerte Bildungsaspiration in einer tertiären Bildung umzusetzen. Sie eignen die Deutung ihres »Möglichkeitsraums« (Holzkamp 1983) also mittels des meritokratischen Prinzips an, wonach »die soziale Schichtung nach sozialer Herkunft scheinbar durch eine soziale Schichtung nach individueller Leistung ersetzt« wird (Becker/Hadjar 2017: 34).

Die Aneignung des meritokratischen Prinzips in der Koppelung mit der im Vergleich zur »Taktik« des Typus 1, 3 und 4 weniger wirkmächtigen Wirkungsweise der Differenzkategorie »Muslimin« aufgrund der weniger starken Manifestation der Differenzdimension Gender macht diese »Taktik« $2 \mathrm{zu}$ einer, hinsichtlich der Bildungsbiografie äusserst effektiven »Taktik«. Die Tradierung der elterlichen Bildungsaspiration, die nicht nach genderspezifischen Kriterien unterscheidet, bildet eine nicht zu unterschätzende, zusätzliche Ressource beim Verfolgen des Bildungsziels. Die habituell verankerte religiöse Praxis und der ebenfalls habituell verankerte, intellektuelle Zugang zu Religion ermöglichen es den Frauen, eine reflexive Distanz zu religiösen Dogmen einzunehmen, wenn der Zugang zu Bildung es erfordert 
(Bsp. Lehrer*innenbildung). Religion und religiöse Praxis manifestieren sich bei dieser »Taktik« in erster Linie als Ressource in Privatem und dienen nicht (wie bei »Taktik« 1 und 3) der gesellschaftlichen Positionierung.

\subsection{Typus 3: „Taktik» der religiösen Vergemeinschaftung}

\subsubsection{Esma}

Esma (35) kam per Familiennachzug mit ihrer Mutter und ihren drei Geschwistern aus einem Land aus Südosteuropa in die Schweiz, wo der Vater bereits seit Jahrzehnten als Gastarbeiter (»Saisonnier«) lebte und auf dem Bau arbeitete. Esma betont, dass weder Krieg noch »das Finanzielle« sie in die Schweiz geführt hätten, sondern dass sie als Familie zusammenleben wollten. Eine Anekdote aus ihrer ersten Zeit als Schulkind in der Schweiz, die Esma mir mehrmals erzählte, ist, wie sie in der Schule »das erste Mal in meinem Leben« mit der Thematik der Religionszugehörigkeit konfrontiert wurde. Nämlich als eine Lehrperson sie fragte, welcher Religion sie angehöre und Esma es nicht wusste. Sie sagte der Lehrperson, sie müsse ihren Vater fragen. Sie ging also nach Hause und fragte ihren Vater, welcher Religion sie angehöre und dieser sagte: Wir sind Muslime. Der Lehrer habe selbstverständlich bereits Bescheid gewusst, es sei eine rhetorische Frage gewesen, erzählt Esma. Und da habe sie verstanden: Aha - ich habe einen anderen Glauben als die Andern. Esmas erste Begegnung mit der Differenzkategorie »Muslimin« fand also durch eine Lehrperson statt.

Esma stammt nicht aus einem besonders religiösen Elternhaus. Das elterliche, familiale Milieu war geprägt durch konservative, traditionelle Wertehaltungen und Rollenbilder - religiöse Praxis spielte für die Familie jedoch eine untergeordnete Rolle. Im Gegenteil, die Eltern hätten nicht viel Ahnung von Religion gehabt, erzählt Esma, viel mehr als Ramadan und Fastenbrechen hätte sie nicht vermittelt bekommen. Erst sehr viel später, inmitten einer existenziellen Ehe- und Lebenskrise begann sie, sich selbst intensiv mit Religion auseinanderzusetzen.

Ihr beruflicher Traum, so erzählt Esma, sei immer gewesen, Dolmetscherin zu werden. Für die Eltern, die beide nur über geringe Schulbildung verfügten, war eine nachobligatorische Schulbildung ihrer Tochter undenkbar. Sie waren der Ansicht, dass Esma sich nicht weiterbilden müsse, da sie sowieso bald heiraten und Kinder kriegen würde. Ihre Mutter war zeitlebens 
Hausfrau und das sollte auch für Esma gut genug sein, so die elterliche Vorstellung.

Zum Ende der Schulkarriere in der neunten Klasse der Realschule, die Noten waren sehr gut, versuchte Esma dennoch, auf sich allein gestellt eine Lehrstelle als Kosmetikerin oder Damenschneiderin zu bekommen. Dies gelang ihr jedoch nicht. Die Gründe hierfür sieht sie darin, dass sie sich einerseits zu wenig im Bewerbungssystem zurecht fand und andererseits keine Unterstützung vonseiten der Eltern, die das schweizerische Bildungssystem kaum kannten, erhielt. Eine Lehrperson versuchte noch, die Eltern von einem zehnten Schuljahr für Esma zu überzeugen - vergeblich: eine weiterführende, nachobligatorische Ausbildung kam nicht infrage.

Ein halbes Jahr ergab sich nichts, Esma fand keine Anschlusslösung nach der Schule. Auch weitere Bewerbungen liefen ins Leere. Der Übergang zu einer nachobligatorischen Ausbildung gelang im Alleingang nicht, Esma drohte bildungsbiografisch »durch die Maschen« zu fallen. Eine Nachbarin vermittelte ihr schliesslich einen Aushilfejob in einer kleinen Tankstelle. Innerhalb zweier Wochen übergab ihr der Chef die Schlüssel und schenkte ihr sein Vertrauen, erzählt sie stolz, zwei Jahre später, mit siebzehn, war sie Geschäftsführerin und konnte den Laden selbst verwalten. Dennoch, so wurde ihr bald klar, hatte sie ohne Ausbildung keine weitere berufliche Perspektive. Ein Berufswechsel ohne nachobligatorische Ausbildung schien aussichtslos - Esma sah sich bildungsbiografisch "parkiert « und langweilte sich.

Was das Rollenbild anbelangte, passte sie sich den elterlichen Vorstellungen an, heiratete früh einen Mann, den sie schon seit ihrer Kindheit kannte, bekam drei Kinder. Als ihre Ehe durch eine existenzielle, psychische Krise ihres Mannes herausgefordert wurde und Esma eine Trennung erwog, setzten sie ihre Eltern unter Druck bei ihrem Mann zu bleiben: Eine Trennung stellte im konservativen Weltbild der Eltern keine Option dar. Esma fühlte sich in die Enge getrieben. Das Leben erschien ihr an diesem Punkt gänzlich perspektivlos, wie sie erzählt.

Im Moment der völligen Ausweglosigkeit, beruflich »parkiert«, in einer existenziellen Ehekrise, ohne Unterstützung ihrer Familie, suchte Esma Zuflucht im Glauben und entdeckte ihre persönliche »Beziehung zu Gott«. Durch einen neuen, zufälligen Bekannten ihres Mannes fand sie Anschluss an eine Glaubensgemeinschaft, durch die sie gemeinsam mit ihrem Mann eine neue Perspektive in ihrem Leben entdeckte. Ihr Mann überwand mithilfe der Religion als Orientierungspunkt nach und nach seine psychischen Probleme. 
Die neu entdeckte »Beziehung zu Gott« als Erweckungserlebnis verleiht den gesellschaftlich erfahrenen Benachteiligungen nachträglich plötzlich eine Sinnhaftigkeit: Sie werden von ihr retrospektiv umgedeutet als Weg, der gegangen werden musste, um zu Gott zu finden. Auf der sozialen Ebene fand Esma in der religiösen Vergemeinschaftung neuen Sinn und erhielt Selbstvertrauen sowie Halt. In der Frauengruppe der Moschee traf sie auf einen Freundeskreis - „Freunde fürs Leben« wie sie sagt und mit denen sie sich über alle möglichen Dinge austauscht, nicht nur über religiöse, wie sie betont. Wie ich beobachten konnte, pflegen die Frauen dieser Gruppe einen sehr familiären Umgang miteinander: Sie necken oder trösten sich, besprechen Namen ihrer zukünftigen Kinder, feiern Geburten, religiöse Feste und freuen sich gemeinsam über berufliche Erfolge. Gemeinsam unternehmen sie Reisen zu religiösen Stätten, besprechen (glaubensrelevante) Dilemmata oder Probleme in Beruf, Familie und Beziehung. Nicht erstaunlich ist es deshalb, dass die Frauen sich gegenseitig in (berufs-)biografischen Belangen unterstützen, sich austauschen, einander Ressourcen zugänglich machen. Sie unterstützen sich bei Bewerbungen und machen sich gegenseitig Netzwerke zugänglich. Diese berufsbiografische Unterstützung durch das akkumulierte soziale Kapital (Bourdieu 1983b) durch die religiöse Gemeinschaft ist essenziell für die »Taktik« der religiösen Vergemeinschaftung als Bildungszugang. Denn diese kommt bei Frauen zum Zuge, bei denen Bildungsentscheidungen ohne jegliche Optionen anstehen und deren Berufsbiografien im besten Falle Wege sind, die dorthin führen, »wo noch Platz ist « (vgl. Mey 2015: 235). Die religiöse Vergemeinschaftung und das dadurch akquirierte soziale Kapital (Bourdieu 1983b) wird an einem aussichtslosen (berufs-)biografischen Punkt existenziell für die weitere Lebensführung, indem sie den Frauen durch sozial vorhandene Ressourcen hilft, sich gesellschaftlich und berufsbiografisch zu entwickeln, in dem Moment wo Staat, Bildungssystem und Elternhaus versagen und eine substanzielle Krise droht.

Durch die Vermittlung einer Frau der Frauengruppe der Moschee gelangt Esma schliesslich an eine für Migrant"innen konzipierte Dolmetscherinnenschule für »kulturelle Übersetzung«, wo sie die langersehnte Ausbildung machen kann und nun regelmässig in Gefängnissen, für die Polizei und in Spitälern übersetzt. Die Ausrichtung an der Religionsgemeinschaft stiftet Esma innere und äussere Orientierung und dient ihr als Ressource zur gesellschaftlichen Selbstbehauptung und berufsbiografischen Positionierung.

Anders als bei Frauen, bei denen die »Taktik« des Typus 1 in der Ausprägung der Selbstrepräsentation als dezidiert religiöse Muslima rekonstru- 
iert werden konnte (vgl. Fallbeispiel Mirjeta), steht bei der »Taktik« des Typus 3 nicht die Bildungsaufstiegsorientierung als "sozialisatorischer Effekt szeneinterner Vergemeinschaftung " (Meinert/Seeliger 2013: 49) im Vordergrund, sondern eine von der Herkunftsfamilie unabhängige Akkumulation von sozialem Kapital (Bourdieu 1983b), durch die eine berufliche Weiterentwicklung stattfinden konnte, welche den Frauen ansonsten verwehrt geblieben wäre.

\subsubsection{Bildungsbiografisches Bestehen durch die "Taktik" der religiösen Vergemeinschaftung}

Nach diesem einleitenden Portrait von Esma wird nun die »Taktik« des Bildungszugangs durch religiöse Vergemeinschaftung näher ausgeführt und anhand der folgenden drei Kapitel spezifiziert: a) Herkunftsmilieu im Zusammenhang mit der »Taktik«; b) Die Rolle der Religion und der Differenzkategorie »Muslimin« hinsichtlich der Bildungsbiografie und c) "Taktik" gesellschaftlicher Selbstpositionierung bezüglich der Bildungsbiografie. Die Frauen erlangten mehr Agency hinsichtlich ihrer Bildungsbiografie durch das soziale Kapital (Bourdieu 1983b), das sie durch die Hinwendung zu einer Religionsgemeinschaft akkumulieren konnten.

Bei den Frauen dieser »Taktik« konnten hinsichtlich der religiösen Selbstrepräsentation keine unterschiedlichen Ausprägungen (bzw. Untertypen) ausgemacht werden.

\section{a) Herkunftsmilieu im Zusammenhang mit der "Taktik"}

Die Frauen der »Taktik« 3 gehören in der Regel Familien von ehemaligen sog. »Saisonniers « ${ }^{43}$ an und gelangten via »Familiennachzug« in die Schweiz.

43 Saisonniers kamen zunächst mit einer Kurzaufenthaltsbewilligung (für eine »Saison«, daher der Name) während max. neun Monaten durch das sogenannte »Saisonnierstatut « in die Schweiz. Das Saisonnierstatut wurde 1934 mit dem Bundesgesetz über Aufenthalt und Niederlassung in der Schweiz eingeführt (Arlettaz 2012: O. S.). Das Statut entstand im Kontext einer Migrationspolitik, die sich einerseits den wirtschaftlichen Bedürfnissen des Arbeitsmarkts anpassen und gleichzeitig dem politischen Druck fremdenfeindlicher Kreise entsprechen wollte (ebd.). Die Idee hinter dem Saisonnierstatut war eine utilitaristische: Durch billige Arbeitskräfte aus dem Ausland sollte ein »Konjunkturpuffer im Wohlfahrtsstaat (D’Amato 2005: 61) geschaffen werden, indem bei einer Rezession ausländische Arbeitskräfte wieder abgeschoben werden und die Arbeitsplätze durch »Einheimische« besetzt werden konnten (Coppola 2013: 122ff.). 
Die überwiegende Zahl der Arbeitsmigranten aus Südosteuropa waren Männer ${ }^{44}$ und arbeiteten wie Esmas Vater auf Baustellen, im Gastgewerbe oder in Niederigstlohnsegmenten (Aarburg/Gretler 2011: 287). Aarburg und Gretler erkennen die primären Gründe dafür, dass die Arbeitsmigration aus Südosteuropa fast ausschliesslich männlich dominiert war, darin, dass die »Institution der Grossfamilie« es ermöglichte, »ihre in der Heimat gebliebenen Angehörigen in geschützter familiärer Obhut zu wissen« (ebd.).

Die meisten »Saisonniers« kamen innerhalb von Jahren oder wie Esmas Vater Jahrzehnten jede Saison in die Schweiz, lebten sich ein und wurden in ihren Herkunftsländern, wo sie ihre Kinder und Frauen zurückliessen, zunehmend zu Fremden (vgl. hierzu auch Mahnig und Piguet 2003). Für das Familienleben hatte diese Art utilitaristischer Migrationspolitik einschneidende Auswirkungen. So beschreibt denn auch Esma die Rolle des Vaters in ihrer frühen Kindheit wie folgt:

»]a, zuerst ist mein Vater, eigentlich in Deutschland gewesen und nachher in die Schweiz gekommen und das ist, also ich...ich bin sagen wir mal auf die Welt gekommen ohne meinen Vater. Mein Vater ist immer Ausland gewesen. Er ist nur in die Ferien manchmal gekommen. (...). Und meinen Vater habe ich nur dann gekannt und er ist der beste Vater der Welt gewesen, weil er alles für uns gemacht hat natürlich« (Esma, A 60-61).

Esma wuchs wie viele Kinder der »Saisonniers« quasi ohne ihren Vater auf. Sie sah ihn nur dann, wenn er für drei Monate nach Hause kam, um Urlaub zu machen und die Möglichkeit zu haben, den Arbeitsvertrag in der Schweiz zu erneuern. Eine temporäre Aufenthaltsbewilligung für »Saisonniers« war nämlich an eine zwingende Ausreise und eine frühestens nach drei Monaten erfolgende Wiedereinreise (und natürlich an einen bestehenden Arbeitsvertrag) gekoppelt (Coppola 2013: 122). Esma beschreibt, wie sie ihn in dieser kurzen Zeit, in der sie ihn jährlich sah, als »de[n] beste[n] Vater

Coppola sieht deshalb im Saisonnierstatut das Sinnbild einer »utilitaristischen Migrationspolitik« (ebd.: 120), welche sich wie ein roter Faden durch die Geschichte der Migration der Schweiz ziehe. Wicker spricht in diesem Zusammenhang gar davon, dass die Idee des temporären Aufenthalts von Menschen, die als Arbeitskraft, nicht jedoch als Staatsbürger in der Schweiz willkommen seien, zum »Prototyp des neuen Zuwanderers«(Wicker 2003: 17) wurde.

44 Im Gegensatz existierten durchaus auch weibliche Saisonnierarbeiterinnen, diese stammten jedoch vorwiegend aus Italien und Portugal und waren in der inzwischen weitgehend verschwundenen Textilindustrie tätig (Aarburg/Gretler 2011: 287). 
der Welt« wahrnahm, weil er die Kinder, wenn er sie denn sah, verwöhnte. Die tägliche (Erziehungs-)Arbeit oblag hingegen Esmas Mutter und der ländlichen Grossfamilie, in der sie aufwuchs. Die Art des Lebens als »transnationale Familie« (Bryceson/Vuorela 2002), die nationalstaatliche Grenzen überspannt und in diesem Sinne als »deterritorialisiert « bezeichnet werden könnte (vgl. auch Aarburg/Gretler 2011: 222ff.) hatte weitreichende Folgen sowohl für Frauen und Kinder wie auch für die Männer: Eine gesellschaftliche Integration der »Saisonniers« in der Schweiz oder ein Familiennachzug war zunächst im Saisonnierstatut nicht vorgesehen und wurde später an teilweise harte Bedingungen geknüpft ${ }^{45}$. Gewerkschaften kritisierten, dass mit dem Saisonnierstatut ein neues Prekariat geschaffen wurde, das unter vielgestaltigen Diskriminierungen litt. So wurden die »Saisonniers« jährlich einer sogenannten "grenzsanitarischen Untersuchung « unterzogen; diejenigen, welche den gesundheitlichen Ansprüchen nicht genügten, wurden zurückgeschickt (Schweizerischer Gewerkschaftsbund 2014: o. S.). »Saisonniers« hatten zudem keinen Anspruch auf Familienzusammenführung, wurden bei den Sozialversicherungen diskriminiert und hatten kein Recht auf einen Wechsel des Arbeitsplatzes und der Branche vor Ablauf der Saison (ebd.). Aus struktureller Sicht waren sie somit auf »Gedeih und Verderb« ihren vertragsgebenden Arbeitgebern ausgeliefert. Erst nach zehn Jahren hatten die »Saisonniers« die Möglichkeit, eine Niederlassungsbewilligung (mit Recht auf Familiennachzug) zu beantragen (Coppola 2013: 122).

Anfang der 9oer-Jahre kam es zu einer vorübergehenden Lockerung der rechtlichen Stellung der Zugewanderten, die zu dem Einsetzen eines grossen Familiennachzugs seitens langjähriger »Saisonniers« führte (ebd.: 122-123). Esmas Eltern entschlossen sich, im Zuge dieser Entwicklungen eine Aufenthaltsbewilligung zu beantragen und in der Schweiz als Familie zusammenzuleben:

Beispielsweise musste ein »Saisonnier« gemäss dem bis 2007 gültigen alten Ausländergesetz über eine »angemessene Wohnung « sowie über »genügend finanzielle Mittel für den Unterhalt seiner Familie« verfügen, damit er seine Familie nachkommen lassen durfte (BVO Art. 39 zit.n. Aarburg/Gretler 2011: 288). Die Interpretation dessen, was eine angemessene Wohnung sowie genügend finanzielle Mittel waren, führte allerdings zu teilweise sehr unterschiedlicher Handhabung in den Kantonen (ebd.). Zahlreiche Kinder lebten deshalb als sog. »versteckte Kinder « in der Schweiz in IIlegalität und verliessen am Tag kaum die Wohnungen (Frigerio 2014: 20). 
»Und nachher hat er entschieden mit meiner Mutter, eben, dass wir in die Schweiz kommen. Also mein Vater hat, wie gesagt über 20-30 Jahre hier gelebt. (...) Dann sind wir eben das erste Mal in die Schweiz gekommen. Und zwar - ganz normal. Nicht irgendwie Krieg oder so, sondern nur durch Entscheidung von meinen Eltern, wo sie entschieden haben, wir wollen gemeinsam jetzt leben und nicht so hin und her« (Esma, A 61).

Auch wenn Familienzusammenführungen nach so langer Zeit wie bei Esmas Familie meist die Erfüllung eines lange gehegten Wunschs war, nämlich dem transnationalen familiären »hin und her « zu entkommen und gemeinsam $\mathrm{zu}$ leben, stellten sie nicht selten extrem schwierige biografische Erfahrungen für alle Beteiligten dar: Auf der einen Seite war die Entfremdung der Ehemänner von deren Frauen und Kindern ein Problem - plötzlich und oft zum ersten Mal lebten sie mit engen Angehörigen ein kleinfamiliäres Leben, während sie vorher jahrzehntelang ein relativ eigenständiges Dasein führten (Aarburg/Gretler 2011: 292-293). Auf der anderen Seite kannten Frauen und Kinder die Schweiz kaum, waren in der Regel nicht der Landesprache mächtig und deshalb vollständig auf den Ehemann bzw. Vater angewiesen. Zudem wurden sie oft relativ unvorbereitet aus einem ländlichen Grossfamilienverband herausgerissen und in ein kleinfamiliäres Leben in der Stadt verfrachtet (ebd.). So dürfte es auch Esmas Mutter gegangen sein, die es anfänglich sehr ungewohnt fand, den ganzen Tag isoliert von anderen Erwachsenen in einer kleinen Wohnung am Rande einer schweizerischen Kleinstadt zu verbringen.

Hinzu kamen bei den meisten nachgezogenen Familien finanzielle Probleme. Während der Lohn eines »Saisonniers« relativ gut reichte, um eine Grossfamilie in der Ferne zu versorgen, wurde er nach dem Familiennachzug plötzlich knapp, als es galt plötzlich eine Frau und mehrere Kinder in der Schweiz zu ernähren. Aus diesem Grund lebten zusammengeführte Familien meist in prekären ökonomischen Situationen, in überbelegten Wohnungen und in wenig privilegierten Gegenden (ebd.).

Esmas Mutter hielt sich, wie viele andere nachgereiste Frauen und Mütter auch, im Zuge dieser biografischen Unsicherheiten am Bekannten fest: an den Werten der traditionell-patriarchal geprägten, ländlichen Grossfamilie und dem damit einhergehenden Rollenbild.

Aus Esmas Erzählungen wird deutlich, wie das mütterliche Rollenverständnis beschaffen war:

»Frau ist mehr so Hausfrau gewesen...nicht gross Ausbildung, sondern mehr eben...Familie, Kinder...Kochen, Putzen, Garten und so« (Esma, A 49). 
Das Genderbild der Eltern der Frauen, bei denen diese »Taktik« rekonstruiert wurde, beschränkte sich auf die Rolle der Frau als Hausfrau, Ehefrau und Versorgerin der Kinder und Hauses. Auch für Esma sahen die Eltern eine solche Rolle vor. Trotz guter Noten und obwohl sich Lehrpersonen noch für eine weiterführende Ausbildung nach der Realschule für Esma einsetzten, kam für sie eine nachobligatorische Ausbildung bzw. ein zehntes Schuljahr nicht infrage (vgl. ausführlich Kapitel 5.3.2c). Dass sie sich zunächst ungeachtet anders lautender Träume den elterlichen Wünschen fügte, war fragloser Bestandteil von Esmas Sozialisation.

Das von einer ländlich-patriarchalen Welt geprägte mütterliche Rollenbild sowie die mütterlichen Lebenserfahrungen und Wertvorstellungen waren Esma und den anderen interviewten Frauen jedoch in der Migrationssituation wenig nützlich und vermochte eine Integration in das soziale und berufliche Leben nicht zu fördern. Was Aarburg und Gretler rekurrierend auf Bourdieu hinsichtlich der zugewanderten Väter in diesem Kontext feststellten, gilt auch für die Frauen: »Das soziale und kulturelle Kapital« der Mütter war »in der neuen Umgebung weitgehend wertlos geworden« (Aarburg/Gretler 2011: 333).

Dass Esma dem für sie vorgesehenen Rollenbild kritisch gegenüberstand, verdeutlicht folgende Aussage:

»(...) zwar man hat gehört, ja nein das darf man, das darf man nicht...Aber daran habe ich immer Zweifel gehabt, weil da habe ich gedacht: Ach komm, das sind nur Männer-Entscheidungen oder Manne- Mannesköpfchen, die sich das so wünschen (...). Also ich weiss noch von den Kindheitserlebnissen in der Familie und so und da habe ich gesagt: Hey Frauen, wehrt euch doch! Es kann doch nicht sein, dass ihr nur Hausfrauen sein dürft« (Esma, A 50).

Esma ist sich (retrospektiv) bewusst, dass das Genderbild ihrer Kindheit sehr konservativ geprägt war. Sie ortet ein asymmetrisches Machtverhältnis zwischen den Geschlechtern und ein Rollenbild, gegen das sie seit ihrer Kindheit aufbegehren wollte, als sie den Frauen zurief, dass es nicht sein könne, dass sie nur Hausfrauen sein dürfen.

Wider besseren Wissens sah sie sich dennoch aufgrund ihrer strukturell bedingten, prekären Lage damals noch nicht imstande, den Wertvorstellungen und dem Rollenbild, in das sie sozialisiert wurde, etwas entgegenzusetzen. Später, im Kontext der religiösen Vergemeinschaftung, wird Esma in der Lage sein, auch gegen aussen ein kritisches Rollenbild zu vertreten und sich den Anordnungen männlicher, religiöser Vertreter zu widersetzen, auch dann, wenn andere Frauen diese als fraglos gegeben hinnehmen. 
Damals fügte sich Esma jedoch und heiratete dem elterlichen Wunsch entsprechend früh einen Partner, der per Heiratsmigration aus dem Land, in dem die Eltern geboren waren, zu ihr in die Schweiz zog.

Eine von der Familie arrangierte Heirat mit einem Partner aus Südosteuropa bildete nach der erneuten Verschärfung der Einreisebestimmungen meist die einzige Möglichkeit für Grossfamilien, transnationale Bindungen zu festigen oder neu zu knüpfen (vgl. Aarburg/Gretler 2011: 233). Denn eine Einreise in die Schweiz zwecks Arbeitsmigration war für Menschen aus dem Balkan nach 1991 faktisch quasi nicht mehr möglich: 1991 kam es zu einer erneuten Verschärfung und $\mathrm{zu}$ einem grundlegenden Wandel in der schweizerischen Migrationspolitik: zur Einführung des sogenannten »DreiKreise-Modells«, das sich an der Vorstellung der »kulturellen Distanz« zum Einwanderungsland orientierte. Es wurde zwischen einem »inneren Kreis« (EU/EFTA), zwischen einem »mittleren Kreis« (Kanada, USA, Osteuropa) und einem »äusseren Kreis« (alle übrigen Länder) differenziert: Personen aus dem dritten Kreis konnten also de facto ab 1991 nur noch per Asylgesuch (und nicht mehr als Arbeitsmigrant*innen) einreisen (Müller 2013:28). Später wurde es zu einem »Zwei-Kreise«-Modell gewandelt, welches die Auswahlkriterien für migrantische Arbeitskräfte nochmals verschärfte (Coppola 2013: 123). Seit 2002 trat das Personenfreizügigkeitsabkommen zwischen der EU und der Schweiz schrittweise in Kraft, wonach Staatsangehörige der EU/EFTAStaaten von der vollen Personenfreizügigkeit profitieren (Müller 2013: 29). Das Saisonnierstatut wurde im Zuge dieser Entwicklung durch den Kurzaufenthaltsstatus ersetzt, der temporäre Aufenthalte von Arbeitsmigrant*innen regelt (Coppola 2013: 123).

Im Laufe dieser Entwicklungen heiratete Esma ihren Mann. Strukturell gesehen stand das Paar von Beginn an unter doppeltem Druck: Einerseits waren sie den wachsamen Augen der Migrationsbehörden ausgesetzt, die darauf erpicht waren, "missbräuchliche Eheschliessungen« (sog. "Scheinehen«) zu orten und verhindern (Kurt/Shy Chau 2013: 13), andererseits bestand Druck zum Gelingen der Ehe seitens der Eltern, die an einer Stärkung der transnationalen Familienbande interessiert waren und die ein allfälliges Scheitern der Ehe als Option gar nicht erst in Betracht zogen. Das junge Paar war also, strukturell gesehen, gleich in zweifacher Hinsicht "verdammt zum Eheglück«, wie der Migrationsrechtsspezialist Spescha (2011: 1) das »Paarleben unter dem Damoklesschwert der Migrationsbehörden« etwas pointiert auf den Punkt bringt (ebd.). 
Das Paradoxe an Esmas Situation im Anschluss an diese Heirat bestand darin, dass sie sich plötzlich in einer ähnlichen Rolle wie ihr Vater bei der Familienzusammenführung wiederfand: Sie war sowohl für die finanzielle Versorgung ihres Ehepartners zuständig wie für zahlreiche andere Aspekte, die seine Integration in die schweizerische Gesellschaft befördern sollten, da er die Lebensumstände seiner Ehefrau kaum kannte und keine Landessprache sprach. Esma, wie auch die anderen interviewten Frauen, bei denen diese »Taktik« rekonstruiert wurde und für welche eine klassische Hausfrauenrolle vorgesehen war, die in der elterlichen Vorstellung keine Erwerbsarbeit beinhaltete, befanden sich infolge der transnationalen Heiratsmigration plötzlich de facto in einer klassischen Ernährerinnenrolle in Bezug auf ihre angeheirateten Ehemänner, die neu in die Schweiz migriert waren. Diese unter strukturellen Zwängen erfolgte Umkehrung der klassischen tradierten Rollenbilder führte nicht selten zu erheblichen innerfamiliären Spannungen (vgl. hierzu auch Aarburg/Gretler 2011: 333).

Auch in Esmas Ehe zeigten sich bald erste Risse. Das junge Paar bekam rasch aufeinanderfolgend drei kleine Kinder. Dass sich Secondas hinsichtlich ihres neu zugewanderten Ehemanns in der Ernährerinnenrolle befanden, hiess nicht automatisch, dass sie auch im Haushalt die klassische, für Männer vorgesehene Rolle einnahmen, im Gegenteil, meist führte eine solche Situation zu erheblichen Mehrfachbelastungen für die Frauen, so auch bei Esma. Esmas Mann geriet zudem in eine zunehmend schwere psychische Krise, wohl nicht zuletzt auch ausgelöst durch den permanenten strukturellen Druck und eine erfolglose Arbeitssuche sowie geprägt vom Verlust der traditionellen Männerrolle als stützende und kontrollierende Autorität. Seine psychischen Probleme nahmen schliesslich überhand, dominierten das familiäre Leben und hatten eine existenzielle Ehekrise zur Folge. Als Esma eine Trennung von ihrem Mann erwog, weil sie ein Zusammenleben mit ihrem kranken Partner auch angesichts ihrer kleinen Kinder kaum mehr aushielt, setzten sie ihre Eltern unter Druck: Eine Scheidung passte nicht in die Wertvorstellungen der konservativen Familie. Zudem bestanden strukturelle Zwänge hinsichtlich des Aufenthaltsstatus ihres Manns: Er hätte unter Umständen sein Aufenthaltsrecht in der Schweiz verloren (Kurt Shy Chau 2013: 28). In dieser für Esma schier ausweglos scheinenden Situation, die durch sehr starke Fremdbestimmung geprägt war, fand sie zur Religion und zur Religionsgemeinschaft (vgl. Kap. 5.3.2b).

Die interviewten Frauen der »Taktik« 3 waren also hinsichtlich ihrer (Bildungs-)Biografie aus intersektioneller Perspektive gleich mehrfach belastet, 
erstens aufgrund des »Migrationshintergrunds«, der sie strukturell gesehen benachteiligte und ein transnationales Familienleben mit anschliessender Familienzusammenführung nötig machte, sowie den gesellschaftlichen Dynamiken aufgrund derer sie in der Schweiz der Unterschicht (»class«) zugeordnet wurden. Zweitens wirkten, wie anhand von Esmas biografischen Erzählungen deutlich wird, starke Gender-bedingte Einschränkungen hinsichtlich der Bildungsbiografie; insbesondere aufgrund eines traditionellen Rollenbilds, das eine frühe Heirat erforderte und eine Trennung auch bei grossen ehelichen Schwierigkeiten ausschloss, sowie die damit einhergehenden elterlichen Vorstellungen der Hinfälligkeit einer nachobligatorischen Ausbildung für Frauen. Bereits in der Schule wurden die Frauen zudem mit der Differenzkategorie Religion als soziale Deutungspraxis konfrontiert. Dies wird im folgenden Kapitel näher ausgeführt.

\section{b) Die Rolle der Religion und der Differenzkategorie "Muslimin" hinsichtlich der Bildungsbiografie: als Muslimin markiert}

Wie zuvor geschildert, ist Esmas Sozialisation stark durch traditionelle Familien- und Rollenbilder geprägt. Demgegenüber nahm die religiöse Sozialisation, wie Esma schildert, eine eher untergeordnete Rolle ein:

»]a vom Glauben her, wie gesagt, meine Familie ist nicht so religiös. Klar man hat gelebt, wie alle anderen, meine Mutter zieht ein Kopftuch an....Aber (...) sie haben auch nicht so viel Ahnung von der Religion. Sie haben das mehr [so] kulturell gemacht«(Esma, A 44).

Esma beschreibt ihre Familie als eher »distanziert« religiös (vgl. Stolz et al. 2014: 75ff.). Das Kopftuch tragen der Mutter schreibt sie mehr einem tradierten, kulturellen Brauch zu als einer primär religiös motivierten Praxis. Sie geht gar davon aus, dass ihre Eltern in religiösen Belangen nicht sehr bewandert sind und ein eher »kulturelles« Verständnis von Religion haben. Diese Aussage kann dahingehend gedeutet werden, dass Esma die religiöse Praxis ihrer Eltern retrospektiv vor dem Hintergrund ihres eigenen, neu erworbenen Religionsverständnisses als Seconda in der Schweiz deutet. Ihr eigenes Religionsverständnis geht, wie das vieler Secondas/os, mit einer Abgrenzung zur Religiosität der Elterngeneration einher sowie einer zunehmenden Intellektualisierung bzw. Systematisierung der eigenen Religiosität (ausführlicher in Kap. 6, vgl. zu diesem Prozess auch Schlieter et al. 2011: 8 bei tibetischen Migrant*innen der zweiten und dritten Generation in der Schweiz). In ihrer Aussage wird zudem deutlich, dass auch Esma implizit von einer Trennung 
von »Kultur« und »Religion« ausgeht und vor der Vorstellung, dass die Elterngeneration eine von »Kultur« durchsetzte bzw. mit »Kultur« durchsetzte »Religion $\aleph^{46}$ praktiziere und tradiere (auf diese ebenfalls oft bei Secondas/os anzutreffende diskursive Unterscheidung wird in Kapitel 6 eingegangen). Dementsprechend schildert sie ihre religiöse Sozialisation wie folgt:

»(..) ich habe gewusst, wir machen Ramadan, wir fasten, wir tun ähm... wir brechen das Fasten ja und ähm...was haben wir noch? (...). Mehr von meinem Glauben habe ich gar nicht so richtig gewusst. //Mhm// Einfach nur die Rituale, die man gemacht hat. Man hat von den Eltern etwas gesehen oder von den Crosseltern etwas gesehen, aber so richtig erklärt ist mir das eigentlich nie worden« (Esma, A 42).

Ähnlich wie Frauen der »Taktik« des Typus 1 wurde auch in Esmas Familie eine Form von »lived religion« (McGuire 2008) gelebt und tradiert, die von Bräuchen und (Glaubens-)Traditionen des Umfelds, in dem die Eltern geboren wurden, geprägt wurde. Ihre Eltern besuchten im Alltag weder die Moschee noch waren sie Mitglieder eines religiösen Vereins, dementsprechend verfügten die Frauen der »Taktik« des Typus 3 als Kind auch nicht über eine grosse formelle religiöse Bildung. Im Gegensatz dazu wurden Frauen, bei denen die »Taktik« des Typus 2 rekonstruiert wurde, mittels eines intellektualisierten Religionsverständnisses sozialisiert, das mit einer Mitgliedschaft in einem religiösen Verein verbunden war, und mit dem Erwerb von breitem, formal religiösem Wissen einherging.

Esma bringt mit der folgenden Aussage zudem einen weiteren Aspekt ihrer religiösen Sozialisation ins Spiel, nämlich dass es für sie als Kind eine Selbstverständlichkeit darstellte, unterschiedliche >Gotteshäuser zu kennen und auch an unterschiedlichen Orten zu beten. Im Dorf, in dem Esma ihre frühe Kindheit verbrachte, lebten Muslim*innen und Christ*innen ihren Glauben Seite an Seite:

»Ich habe beides noch ein bisschen gekannt. (...). Aber da wir, ähm... in unserem Dorf auch Kirchen haben, habe ich natürlich auch viel Kirchen besucht und ich bin auch dort beten gegangen« (Esma, A 42).

46 Ich führe diese Begriff hier in Anführungsstrichen, um zu unterstreichen, dass es sich hierbei um Akteur*innen-Konzepte handelt, die von geschlossenen Begriffen von »Kultur« und »Religion« ausgehen, die ich auf der Ebene der Analyse so nicht verwende (vgl. Unterscheidung der »Kategorien der Analyse« und den »Kategorien der Praxis« Brubaker/Cooper 2007: 52-55). 
Esma verfügte also durch ihre religiöse Sozialisation über einen offenen $\mathrm{Zu}$ gang zu Glaubenstraditionen und religiöser Praxis und nicht über ein geschlossenes Religionsverständnis, das sich auf eine einzige, in sich »abgeschlossene« religiöse Tradition beschränkte. Auch in der Schweiz behielt sie diese offene Haltung hinsichtlich religiöser Praxis bei, so beschreibt sie, wie sie jeweils auf ihrem Schulweg zu einer katholischen Madonnenstatue betete:

»Als ich den Weg zur Schule gegangen bin, hat es dort eine Kirche gehabt. (...) und draussen hat es...so wie ein...Monument oder wie sagt man dem [gehabt]. Ich weiss nicht, ob es Nonne oder Maria gewesen ist, weiss ich nicht. (...) und jedes Mal, wenn ich in der Schule gewesen bin, weil damals habe ich auch Deutsch nicht so richtig gekonnt, habe ich dort angehalten und zu Gott gebetet. Durch die Statue, habe ich irgendwie das Gefühl gehabt, die hört mich und schickt das weiter (lacht) (Esma, A 43).

Wie aus dieser Aussage einerseits deutlich wird, spielte es für Esma aufgrund ihrer religiösen Sozialisation keine Rolle, an welchen religiösen »Monumenten « und unter zu Hilfenahme welcher Symbolik sie ihre religiöse Praxis ausübte. Aus ihrer Perspektive war es relevant, dass sie mittels eines religiösen Symbols zu Gott beten konnte. Das Symbol bzw. die Statue diente ihr als Vermittlerin zu Gott und verlieh ihr das Gefühl, dass ihre Botschaft gehört wird, im Glauben die Staute »schickt das weiter«. Aus dem lachenden Erzählen dieses letztgenannten Satzes wird deutlich, wie sich Esma retrospektiv etwas von dieser Annahme ihrer Kindheit distanziert. Andererseits nimmt diese Aussage eine spätere für Esma biografisch relevante Strategie vorneweg, nämlich dass sie sich in biografisch schwierigen Situationen vermehrt dem Glauben zuwandte. So kann diese Aussage ebenfalls dahingehend gedeutet werden, dass Esma aus der religiösen Praxis Kraft schöpfte. Dass sie direkt an die Aussage »jedes Mal, wenn ich in der Schule gewesen bin »die etwas überraschende Aussage anschliesst, »weil damals habe ich auch Deutsch nicht so richtig gekonnt«, kann dahingehend interpretiert werden, dass diese erste Anfangszeit in der Schule für sie aufgrund der noch spärlichen Deutschkenntnisse nicht ganz einfach gewesen sein musste. Das tägliche Ritual des Betens zu Gott auf dem Schulweg durch ein religiöses Symbol »ob es Nonne oder Maria gewesen ist « verlieh ihr in dieser ersten schwierigen Anfangszeit in der Schule ohne grosse Deutschkenntnisse Halt und das Gefühl »gehört« zu werden.

Hinsichtlich dieser offenen Auslegung religiöser Praxis und eines offenen Religionsverständnisses sollte Esma jedoch bald eines Besseren belehrt werden: Die Zuschreibung zu einer (einzigen) religiösen Tradition erfolgte für 
Esma erstmals fremdbestimmt: durch einen Lehrer ihrer Realschulklasse in der Schweiz. Sie schildert dieses Erlebnis heute als Teil ihrer religiösen Sozialisation:

»Das Lustige ist gewesen, als wir in die Schweiz gekommen sind. (...). Das erste $\mathrm{Mal}$ in meinem Leben bin ich konfrontiert worden mit meinem Glauben sozusagen. Und das weiss ich noch, als mich mein Lehrer gefragt hat: Was ist dein Glauben?...Und ich so...äh...Ja, Gott? (lacht). Das war mein Glauben, ich glaubte an Gott. Dann sagt er: Nein. Jeder Mensch hat seine eigene Richtung oder versucht mir ein bisschen zu erklären und dann habe ich gesagt: Ich weiss es nicht, ich muss meinen Vater fragen (lacht). Und nachher bin ich nach Hause gegangen und habe gesagt: Du Papi, was haben wir für einen Glauben? Und nachher sagt er, ja Moslem. Und ich sage ja, der Lehrer hat Moslem und Islam erwähnt und nachher sage ich, aber Moslem und Islam was ist denn das? Und dann sagt er: Ja, das ist das gleiche eigentlich. Nachher sage ich: Aber wieso weiss ich von dem gar nichts? (lacht). Danach sagt er, ja das ist wie selbstverständlich, du bist dort geboren und du lebst das einfach weiter (lacht)... Ja, es ist wirklich so lustig damals gewesen und danach bin ich eben in die Schule gegangen und habe ein bisschen erzählt, ja das ist mein Claube. Der Lehrer hat natürlich schon Bescheid gewusst, was es ist (lacht). Aber ich nicht so...und so...dann habe ich mich angefangen mehr so ein bisschen Gedanken zu machen, Aha...Ich habe doch einen anderen Clauben. Es ist Gott, also es ist ein Weg, Gottes Weg, aber trotzdem etwas anderes« (Esma, A 43).

Aus Esmas Perspektive als Kind und durch ihre offene religiöse Sozialisation stellte der Glaube in erster Linie einen >Glauben an Gott < dar. Dass der zweite Teil des Satzes als Frage formuliert ist (»Ja, Gott?«), kann dahingehend gedeutet werden, dass Esma bereits davon ausgehen konnte, dass die Antwort, sie glaube an Gott, die Lehrperson nicht befriedigen wird. Aufgrund ihrer bisherigen religiösen Sozialisation kam Esma bis anhin nicht in die Lage, gegenüber Dritten näher zu definieren, welcher religiösen Tradition sie sich zuordnete, bzw. was sie unter >Glauben an Gott « verstand. Durch die Konstruktion religiöser Differenz im Unterricht seitens der Lehrperson wurde Esma erstmals mit der Kategorie einer »Religionszugehörigkeit« (die sie erst einmal zu Hause erfragen musste) konfrontiert. Das Beispiel illustriert, wie durch eine Lehrperson der Prozess eines »religiöses Otherings« (Mecheril/ThomasOlalde 2011: 45, vgl. Kap. 2.2) eingeleitet wurde, in welchem Esma als Lernende mittels Religion als Zugehörigkeits- und Ausschlusscode im pädago- 
gischen Kontext markiert wurde (vgl. Lingen-Ali/Mecheril 2016: 18). Während sie selbst über ein offenes Verständnis von Religion verfügte, wurde sie seitens der Lehrperson jedoch klar in die Kategorie Islam gedrängt, sozusagen »fremdmuslimisiert«. Die Zuschreibung zur Kategorie »Muslimin« im Sinne einer Differenzkategorie erfolgte für Esma also erstmals im Schulzimmer durch Fremdzuschreibung. Wie anhand dieses Beispiels aufgezeigt werden kann, dient die Differenzdimension Religion nicht nur in politischen Debatten, sondern auch im pädagogischen Feld als Differenzmarker und als soziale Unterscheidungspraxis (ebd.). Hierbei ist das im Islamdiskurs vorherrschende Schema leitend (vgl. Kap. 2.1), wonach Musliminnen und Muslime pauschal als homogene Gruppe konstruiert werden und der Islam als »andere«, fremde Religion konstruiert wird, meist kommt hierbei noch der Antagonismus säkularer Westen vs. muslimische Länder zum Tragen (ebd.). Lingen-Ali und Mecheril weisen zudem auf den interessanten Aspekt hin, dass der Differenzmarker Religion primär für religiös orientierte Migrant*innen muslimischen Glaubens verwendet wird, während im Vergleich dazu religiös orientierte Migrant*innen christlichen Glaubens tendenziell eher Nationen zugeordnet werden (ebd.).

Obwohl Esma die Episode dieser Fremdzuschreibung lachend schildert, deutet doch der prominente Platz, der dieses Erlebnis innerhalb der Geschichte ihrer religiösen Sozialisation und in ihrer Migrationsgeschichte einnimmt, darauf hin, dass diese Fremdzuschreibung ein einschneidendes Erlebnis für sie darstellte; verschloss sie doch den Blick auf Esmas reale Lebensumstände bzw. lebensweltliche religiöse Praxis. Sie, die täglich betete, musste ihren Vater fragen gehen »aber Moslem und Islam was ist denn das?« und »wieso weiss ich von dem gar nichts?«. Gerade durch die lachende Schilderung dieser Erfahrung wird eine gewisse Irritation deutlich, die Esma hinter der Belustigung versteckt. Sie wird gewissermassen in die Ecke einer Unwissenden gedrängt, während ihr Vater ihr erklärt, dass sie nichts davon wisse, weil es »wie selbstverständlich sei«, es nie expliziert wurde, da sie so sozialisiert wurde (»du lebst das einfach weiter«).

Diese Art von religiöser Fremdzuschreibung respektive Differenzkonstruktion durch eine konstruierte Differenzkategorie Religion geht denn auch nicht selten einher mit einer Erwartungshaltung seitens der Lehrpersonen, Auskunft über »den Islam« geben zu können. Häufig führt das dazu, dass in diesem Kontext lebensweltlich relevante religiöse Praxen und das damit einhergehende tradierte Wissen seitens der Lernenden als defizitär wahrgenommen werden, was nicht selten wie auch bei Esma zu einer in- 
tensiveren Befassung mit der zugeschriebenen Religion führt. Esma sah sich also gezwungen, sich der sozialen Deutungspraxis und der schulischen Erwartungshaltung zu beugen und ging am nächsten Tag in die Schule und »habe ein bisschen erzählt, ja das ist mein Glaube«. Das »religiöse Othering« (Mecheril/Thomas-Olalde 2011: 45) der Lehrperson wurde von Esma also aufgenommen und reproduziert. Dies wird dadurch deutlich, dass sie sagt, "Aha...ich habe doch einen anderen Glauben. Es ist Gott, also es ist ein Weg, Gottes Weg, aber trotzdem etwas anderes«. Die Fremdzuschreibung führte demnach bei Esma dazu, ihren Glauben als »anders« anzusehen. Das "Aha« am Anfang des Satzes kann dahingehend gedeutet werden, dass diese Einsicht mit einer gewissen Überraschung einherging.

Die Art von Differenzkonstruktion via Religion, wie sie in Esmas Bildungsbiografie rekonstruiert werden konnte, lässt sich meines Erachtens nur auf dem Hintergrund eines geschlossenen Religionsbegriffs seitens der Lehrperson nachvollziehen. Dass ein geschlossener Religionsbegriff lebensweltlichen religiösen Praxen teilweise diametral entgegensteht, kann ebenfalls am Beispiel von Esma verdeutlicht werden: Das geschlossene Religionsbild der Lehrperson liess eine prinzipielle Offenheit, wie die von Esmas gelebter religiöser Praxis, nicht zu. Wie das Beispiel zeigt, verschliessen solche Fremdzuschreibungen den Blick zudem auf reale, lebensweltliche Umstände und religiöse Praxen, beruhen sie doch auf einem geschlossenen Begriff von Religion, der ein statisches Bild von Religion mit geschlossenen klar definierten Grenzen verficht (analog ${ }^{47}$ einem geschlossenen Kulturbegriff, wie ihn bspw. Welsch 2010: 2 beschreibt). Ein offenes Verständnis von gelebter religiöser Praxis, das von einem offenen Religionsbegriff (analog einem offenen Kulturbegriff, wie es bspw. das Konzept der Transkulturalität darstellt, vgl. ebd.: 3) ausgehen würde, würde den Blick auf die realen Lebensumstände bzw. religiösen Praxen der Lernenden öffnen können, da ein solcher eine gegenseitige Durchdringung und Verflechtung religiöser Konzepte umfasst. Lehrpersonen, die solche Zuschreibungen vornehmen, legen Lernende jedoch »auf eine vermeintliche Religionszugehörigkeit fest« (Lingen-Ali/Mecheril 2016: 22). Wie Lingen-Ali und Mecheril (ebd.) feststellen, suggeriert die Zuordnung bzw. Markierung von Menschen durch Religion (bzw. religiöse Traditionen), insbesondere durch »den Islam«, eine ungerechtfertigte Eindeutigkeit. Solche Kategorisierungen verschliessen jedoch den Blick vor »multireligiösen Familien«

47 Mit Geertz (1983: 44-95) gehe ich davon aus, dass Religion als kulturelles System betrachtet werden kann. 
und anderen »synchronen Vervielfältigungen und womöglich Verschmelzungen« sowie dem Abstandnehmen vom religiösen Glauben (ebd.: 22).

Die interviewten Frauen, bei denen sich die »Taktik« der religiösen Vergemeinschaftung rekonstruieren liess, so kann resümiert werden, stammten in der Regel aus (insbesondere hinsichtlich Genderrollen und -konzeptionen) eher traditionell orientierten Elternhäusern. Gleichzeitig waren die Eltern der Frauen entweder säkular ausgerichtet oder orientierten sich, wie Esmas Eltern, an einer Form von tradierter »lived religion« (McGuire 2008). Charakteristisch für die religiöse Sozialisation der Frauen war zudem, dass deren Eltern über keine enge Moscheeanbindung verfügten und keinem Religionsverein ${ }^{48}$ angehörten.

Die Differenzkategorie »Muslimin« manifestierte sich in den bildungsbiografischen Erzählungen dieser Frauen in erster Linie als »soziale Deutungspraxis« (Lingen-Ali/Mecheril 2016: 17) bzw. als soziale Deutungs- und Ordnungskategorie im pädagogischen Kontext. Aus einer intersektionellen Perspektive müssen hier die Differenzdimensionen Religion und »Migrationshintergrund « zusammengedacht werden: Es lässt sich in den sozialen Deutungspraxen nämlich ein Antagonismus zwischen einem westlich-(säkularen)-heimischen »Wir« gegenüber einem (vermeintlich) muslimisch-(religiösen)-migrantischen "Andern« (ebd.: 18) analysieren. Dieser Antagonismus stellt, wie am Beispiel von Esma verdeutlicht werden sollte, eine Fremdzuschreibung dar, die einerseits mit sozialen Ausschlussmechanismen einhergeht und andererseits den Blick auf reale lebensweltliche (religiöse) Praxen verschliesst.

48 Die Mehrheit der religiös aktiven Muslim*innen unter den Zugewanderten der sog. »ersten Generation « ist in Vereinen organisiert, die sich meist entlang ethnischer und sprachlicher Grenzen ausrichten und Moschee-gebunden sind (Zurlinden 2015: 179, Endres et al. 2013: 11). Diese Vereine verfügen in der Regel über Räumlichkeiten, die einerseits der Ausübung religiöser Praxen dienen, andererseits aber auch als Treffpunkte für vielfältigste Aktivitäten und von folkloristischen Volkstanzgruppen über Frauengruppentreffen bis hin zur Hilfe bei Hausaufgaben und Bewerbungsschreiben reichen (eigene Beobachtungen, Endres et al. 2013: 13, Baumann 2012: 46-52, Behloul 2005: 157). Moschee-ungebundene Organisationen, die tendenziell von religiösen Akteur*innen der zweiten Generation von Zugewanderten frequentiert werden, sind meist nicht mehr entlang sprachlich-ethnischer Cruppen organisiert. Primäre Umgangssprache in diesen Vereinen ist Deutsch. 


\section{c) "Taktik" gesellschaftlicher Selbstpositionierung hinsichtlich der Bildungsbiografie: Agency durch religiöse Vergemeinschaftung}

Esmas Bildungsbiografie wurde durch starke Momente der Fremdbestimmung und durch ein intersektionell wirksames Zusammenspiel verschiedener Differenzdimensionen (insbesondere Gender, »Migrationshintergrund «, "class" und Religion) geprägt. Mehr Handlungsfähigkeit (Agency) hinsichtlich ihrer (Bildungs-)Biografie erlangte Esma durch religiöse Vergemeinschaftung und das in diesem Zuge akkumulierte soziale Kapital (Bourdieu 1983b).

Nach ihrer Migration in die Schweiz durch Familiennachzug wurde Esma aufgrund ihrer noch mangelnden Deutschkenntnisse direkt in die Realstufe eingestuft ${ }^{49}$. Esma erwies sich als sehr gute Schülerin und lernte innerhalb kürzester Zeit Deutsch. Gerne hätte sie eine weiterführende Schule besucht. Ihr Traum war es, die Dolmetscherschule zu absolvieren, was sie auch mit einem Berufsberater diskutierte. Doch die Haltung der Eltern war klar: Eine nachobligatorische Ausbildung kam für Esma trotz guter Noten nicht infrage.

"Sondern du machst etwas, findest einen Job, heiratest nächstens und dann gründest [Du eine] Familie und dann schaut man auch für dich. So hat das eben geheissen« (Esma, A 75).

Dem elterlichen Wunsch zufolge sollte Esma eine Erwerbsarbeit finden, die Geld einbringt, um die Zeit zu überbrücken, bis sie ihr Wohl durch eine (frühe) Heirat in die Hände eines Ernährers legen konnte und sich aus Sicht ihrer Eltern ihrer eigentlichen Bestimmung, eine Familie zu gründen und die Kinder aufzuziehen, widmen konnte. Eine Lehrperson versuchte dennoch, die Eltern umzustimmen. Doch diese zeigten sich unnachgiebig. So war Esma nach dem neunten Schuljahr auf sich alleine gestellt. Sie beschreibt die Situation am Ende ihrer obligatorischen Ausbildung wie folgt:

»Also mein Vater ist Bauarbeiter, meine Mutter Hausfrau und dadurch, dass sie nie (...) gebildete Leute gewesen sind, haben sie mir das auch nie bieten können und sagen: Ey dieser Weg wäre richtig oder den könntest du machen oder das könntest du machen und ich bin in ein... anderes Land gekommen... mit so vielen Möglichkeiten und trotzdem habe ich nicht gewusst, was ich jetzt mache[n soll]« (Esma, A 73).

Aus dieser Aussage wird deutlich, wie Esma retrospektiv das geringe Bildungskapital der Eltern dafür verantwortlich macht, dass diese sie bei der

49 Esma kam im Vergleich zu anderen interviewten Frauen ein wenig später in die Schweiz (im Alter von ca. 11 Jahren). 
Suche nach einem beruflichen Weg nicht unterstützen konnten. Esma, die es gewohnt war, sich an der elterlichen Autorität orientieren zu können (und auch zu müssen), war in der Berufswahl plötzlich auf sich alleine gestellt, ohne dass ihr jemand einen Weg wies. Ihre Eltern hielten an den traditionell-patriarchal geprägten Wertvorstellungen und dem damit einhergehenden Rollenbild fest, was angesichts der zuvor beschriebenen, durch strukturelle Unsicherheiten geprägten Migrationssituation, nicht erstaunt. Sie waren nicht in der Lage, Esma einen Weg aufzuzeigen, welcher den beruflichen Möglichkeiten, die sie in der Schweiz als Seconda für sich sah, entsprach. So war Esma auf sich allein gestellt, als sie sich als Damenschneiderin und Kosmetikerin $\mathrm{zu}$ bewerben versuchte:

»...und ich habe damals auch nicht einmal richtig gewusst, wie das mit den Bewerbungen funktioniert« (Esma, A 73).

Ohne Unterstützung und mit mangelndem Wissen in Bezug auf das Bewerbungsverfahren bei Lehrstellen gelang es Esma nicht, sich im hart umkämpften Lehrstellenmarkt der neunziger Jahre durchzusetzen. Just in der Zeit, in der Esma ihre Schule abschloss, sah sich die Schweiz nämlich erstmals seit dem zweiten Weltkrieg mit einer ungewohnt hohen Arbeitslosigkeit konfrontiert und litt unter einem damit einhergehenden Lehrstellenmangel (Aarburg/Gretler 2011: 292; Ryser/von Erlach 2007: 48). Für Jugendliche mit "Migrationshintergrund «, die mehrsprachig waren und nicht Deutsch als Muttersprache hatten, war es in dieser Zeit gegenüber Eingesessenen ungleich schwerer an eine Lehrstelle $\mathrm{zu}$ gelangen. Esmas frühe Bildungsbiografie war zudem durch das Genderbild ihrer Eltern (und die damit einhergehenden Zukunftspläne) geprägt, das für sie eine zusätzliche manifeste Bildungsbarriere darstellte. Ferner waren ihre Eltern nicht in der Lage, sie im Einschlagen eines nachobligatorischen Bildungswegs zu unterstützen, einerseits durch die Migrationssituation und andererseits aufgrund ihres eignen geringen Bildungskapitals. Aus intersektioneller Sicht wirken bei den Frauen die Differenzdimensionen Gender, »class « und »Migrationshintergrund « gemeinsam als Bildungsbarriere. Ein Übergang in die nachobligatorische Ausbildung gelang keiner der interviewten Frauen, bei denen diese »Taktik« rekonstruiert werden konnte, auf Anhieb.

Auch Esma drohte bildungs- und berufsbiografisch im Arbeitsmarkt »durch alle Maschen« $\mathrm{zu}$ fallen. Trotz der Absicht $\mathrm{zu}$ arbeiten, »egal, was es ist « (Esma, A 75), ergab sich ein halbes Jahr nach Abschluss der obligatorischen Schulzeit keine Anschlusslösung für Esma. Dank der Vermittlung 
durch eine Nachbarin kam sie dann schliesslich als Hilfsarbeitskraft in einer Tankstelle unter:

»Ich bin hineingekommen, habe ich gesagt: Ok Esma, jetzt bist du da. Du hast null Ahnung von dem Ganzen, aber du kämpfst für das, was du jetzt da bist« (Esma, A 75).

Esma ergriff die Chance, die sich ihr bot und die sie davon bewahrte, gänzlich aus dem Berufsleben ausgeschlossen zu werden. Tatsächlich gelang es ihr, sich innerhalb von zwei Jahren an der Tankstelle ungeachtet fehlender Ausbildung zur Geschäftsführerin hochzuarbeiten, eine Errungenschaft, auf die sie bis heute sehr stolz ist.

Es gelang Esma durch soziales Kapital trotz fehlender nachobligatorischer Ausbildung vom Arbeitsmarkt nicht gänzlich ausgeschlossen zu werden und einen Weg in die Arbeitswelt zu finden, zumindest »dorthin, wo es noch Platz hat (vgl. Mey 2015: 235) ${ }^{50}$. Dennoch, so wurde bald deutlich, war sie nun beruflich "parkiert « - ohne Ausbildung ergaben sich für die ehemals ambitionierte, gute Schülerin im Arbeitsmarkt keine weiterführenden Anschlüsse. Dementsprechend langweilte sie sich.

Angekommen an einem Punkt, wo sich (berufs-)biografisch keine Anschlüsse mehr ergaben, gefangen in einer existenziellen Ehekrise, ohne Unterstützung ihrer Familie, suchte Esma (erneut) Zuflucht und Halt im Glauben. Sie schildert ein spirituelles Erlebnis, das sie auf dem Nullpunkt einer existenziellen Lebenskrise »rettete«:

»Als ich damals im Bett gelegen bin und geweint habe und gesagt habe: Cott hilf mir, ich habe einfach keine Kraft mehr //mhm// So kann ich nicht mehr. Es ist wirklich wie mein letzter Atemzug gewesen. //Mhm// Wirklich sozusagen und...ich weiss nicht wie ich das soll beschreiben aber, oder, oder zeigen...es ist so wie...wie als hätte mir etwas, also sie....mein...ich sage so mein Schutzengel oder meine Engel gewesen sind, wo mich wirklich wie... wie gestreichelt haben und gesagt haben....von Innen habe ich es gespürt, weil es ist so ein tiefes Emotionsgefühl gewesen, das mir gesagt hat - irgendetwas

50 Mey (2015: 235-236) bezeichnet stark fremdbestimmte Übergänge von Jugendlichen, die zwar gelingen, aber deren Chancen auf dem Arbeitsmarkt aus strukturellen Cründen eingeschränkt sind, und denen aus diesen Cründen wenig privilegierte Positionen in wenig privilegierten Branchen zugewiesen werden, als »Wege in die Arbeitswelt, dorthin, wo noch Platz ist« (ebd.). 
gesagt hat. Es wird alles in Ordnung kommen, mach dir keine Sorgen « (Esma, A 39).

Wie schon früher als Kind, als sie auf dem Schulweg zur Madonna betete, fand sie auch hier in einer schwierigen Lebensphase Zuversicht und Halt im Glauben. Ohne Hoffnung, am Ende ihrer Kräfte erfuhr sie ein spirituelles Erlebnis, das sie als Wendepunkt in ihrem Leben bezeichnet.

Etwa zur selben Zeit lernte Esmas Partner einen gläubigen Muslim kennen, der ihm ein Buch zum Lesen mitgab; auch er begann sich intensiver mit dem Glauben auseinanderzusetzen. Der Mann, den er kennengelernt hatte, wurde zum engen Freund und führte die Familie in seinen religiösen Verein ein, wo sie in einen neuen Bekanntenkreis gelangten, der sie und ihre Familie von Beginn an unterstützte:

»Die Menschen sind so, im Vergleich zu diesen Kollegen (...), die wir früher gehabt haben, die mehr so Interessen-Kollegen gewesen sind: Wenn $\mathrm{du}$ in Not bist, sind wir nicht da, aber wenn wir Interesse haben, sind wir da. //Mhm// Und dort haben wir gesehen, nein diese Kollegen sind anders. Sind wirklich andere Menschen und...dort haben wir nachher gesehen, die sind nicht für unsere Interessen da, sondern die sind auch für unsere Not da. //Mhm// Also dann, als wir sie am meisten gebraucht haben, sind sie für uns wirklich da gewesen. //Mhm// Und das hat uns nachher noch mehr gestärkt, dort hinein zu schauen, was ist das? Wieso haben sie...Wieso sind sie so oder? (...). Das hat mich mehr so richtig fasziniert dort drinnen, dass, (...) nachher in dieser Freundschaft, dass ich erkannt habe...das sind doch Freunde, die ich könnte nicht nur brauchen, weil ich jetzt in Not bin, sondern wirklich meine Lebensfreunde, sage ich mal so. (...) Aber wirklich, weil ich bemerkt habe, sie tun uns gut und die sind für uns gut da. Und das hat mich nachher mehr auch in die Religion hineingezogen und habe mich mehr interessiert«(Esma, A 46-47).

Wie aus voranstehender Aussage deutlich wird, beförderten sich das Finden dieses neuen Freundeskreises und die Suche nach einem religiösen Weg gegenseitig. Die Art, wie die Menschen dieses religiösen Vereins ihnen und ihrer Notsituation begegneten, beeindruckte Esma und ihren Mann sehr. Bald wollte Esma diese Gruppe, die ihr Halt gab, nicht mehr verlieren. Durch die Akkumulation von sozialem Kapital (Bourdieu 1983b) innerhalb dieser Religionsgemeinschaft stabilisierte sich die Situation von Esma und ihrer Familie allmählich. Getragen von stabilen sozialen Beziehungen und der Orientierung 
an der religiösen Praxis fand Esma einen Ausweg aus ihrer Lebenskrise. Das Überwinden einer (berufs-)biografischen Krise mittels der religiösen Vergemeinschaftung ist ein zentrales Element dieser »Taktik«. In Esmas Fall trug die Vergemeinschaftung gar zur Stabilisierung der ganzen Familie bei. Denn auch Esmas Partner überwand mithilfe der Religionsgemeinschaft allmählich seine tiefe psychische Krise und konnte Fuss fassen, trotz der massiven strukturellen Probleme, welche die Heiratsmigration mit sich brachte.

Entscheidenden Halt fand Esma insbesondere in der Frauengruppe der Moschee, wo ich sie während meiner teilnehmenden Beobachtung kennenlernte. Die Frauengruppe, in der Esma sich regelmässig mit anderen Frauen traf und trifft, ist Ort des Austauschs:

»Man geht dort, man beschäftigt sich nicht nur, eben auch das Thema Islam, sondern auch Alltag, also...(..) wir machen dort alles Mögliche. Also von Gesprächen her, ist es sehr offen, wo wir uns treffen. (...) aber unsere Frauengruppe ist mehr für mich wie eine...Freundschaftsgruppe, kann ich sagen. //Mhm// Wo ich mal, (...) wo ich mal den Alltag sein lassen kann und sagen: Jetzt gehe ich mich mal mit Frauen bequatschen (lacht)«(Esma, A 54).

Die Frauengruppe bildet für Esma einen ausseralltäglichen sozialen Raum. Esma betont, dass hier »nicht nur« religiöse Themen, »sondern auch Alltag« bzw. Alltagsfragen »bequatscht« werden könnten. Wie ich beobachten konnte, herrscht in diesen Frauengruppentreffen ein äusserst familiärer Ton. Nicht zuletzt dürfte diese Vertrautheit auch damit zusammenhängen, dass diese Gruppe seit längerem besteht, ihre Kernmitglieder sehr konstant sind und auch ausserhalb der Moschee privaten Kontakt pflegen (Feldprotokoll Nov. 2014). An den Gruppentreffen wird gescherzt, die Frauen nehmen einander auf den Arm, umgekehrt werden jedoch auch ernstere Themen diskutiert. Gleichzeitig bildet diese Frauengruppe auch einen selbstbestimmten und eigendefinierten Raum der kritischen religiösen Selbstsozialisation, wo Frauen mit »the realisation of a pius self« beschäftigt sind (Saba 2012: 128). Ebenso finden in muslimischen Frauengruppen Aushandlungsprozesse bezüglich der Legitimität religiöser Praxen statt (vgl. hierzu auch Bleisch Bouzar 2012: 292-294). Ich konnte bspw. beobachten, dass in diesem geschützten Rahmen Fragen religiöser Praxis mitunter kontrovers diskutiert werden, insbesondere frauenspezifische Auslegungen religiöser Gebote (Feldprotokoll Nov. 2014), die unter Ausschluss der >männlichen Welt « besprochen werden sollen. So z.B. Fragen, welche die >Reinheit der Frau betreffen. Auch konnte ich mehrfach beobachten, wie im Rahmen dieser Diskussionen männliche religiöse Auto- 
rität oder Entscheide von (männlichen) religiösen Autoritäten infrage gestellt wurden, beziehungsweise auf ihre lebensweltliche >Tauglichkeit ‘ geprüft und kritisch hinterfragt wurden. Gegenteilig zur Rezeption im öffentlichen Islamdiskurs können solche Gefässe durchaus emanzipatorischen Charakter haben und einen Raum für autonome kritische Fragen bilden. So wurde bspw. diskutiert, ob eine Frau, die in der Zeit einer Pilgerreise die Menstruation hatte, wirklich die Moschee, welche Ziel der Reise war, nicht betreten sollte, oder ob hier trotz anderslautender Weisungen von Gelehrten eine Ausnahme gemacht werden dürfe bzw. solle (Feldprotokoll Nov. 2014).

Esma gelingt es im Rahmen dieser Gruppe, eigene Gedanken zum elterlich eingeforderten Rollenbild und zu ihrem Bildungsweg bzw. ihren Bildungswünschen zu formulieren. Im geschützten Kreis der Frauengruppe reflektiert sie Genderbilder (wie bereits in ihrer Kindheit angelegt) kritisch und verficht in Debatten hinsichtlich religiöser Autoritäten autonome Positionen, die nicht alle Frauen teilen. So ist sie in der zuvor geschilderten Diskussion zur Pilgerreise bspw. der Ansicht, dass die Frau sich unbedingt der Ansicht der Gelehrten widersetzen und die Moschee betreten solle, denn es komme ja nicht auf die äussere, sondern auf die innere Reinheit, die Reinheit des Herzens an und die sehe sowieso nur Gott selbst, so ihre Position (Feldprotokoll, ebd.).

Esmas Berufswunsch war, wie angedeutet, Dolmetscherin, was ihr ob der beschriebenen Umstände verwehrt blieb. Dennoch dolmetschte sie bereits kurz nach dem Schulabschluss durch die Vermittlung einer Frau der Gemeinde gelegentlich für ein Integrationszentrum in verschiedenen Kontexten für andere Familien, z.B. in Gesprächen mit Lehrpersonen oder auf der Gemeinde. Ohne Ausbildung blieben diese Einsätze jedoch sehr sporadisch. Die Akkumulation des sozialen Kapitals in der Religionsgemeinschaft wird für Esma jedoch letztlich zur zentralen Ressource der Weiterentwicklung ihrer Bildungsbiografie und ermächtigt sie zum Wiedererlangen von mehr Handlungsfähigkeit (Agency) innerhalb ihres intersektionell eingeschränkten »Möglichkeitsraums« (Holzkamp 1983). Innerhalb der Frauengruppe der Moschee traf Esma gleich auf mehrere Frauen, die ihre Mehrsprachigkeit mangels anderer Optionen als berufliches Bildungskapital nutzten und sich zu sog. »interkulturellen Dolmetscherinnen« mit eidgenössischem Fachausweis ausbilden liessen. Sie alle besuchten eine Übersetzerinnenschule für Migrant*innen, die sich in Form einer Modularausbildung berufsbegleitend in zwei Jahren bewältigen lässt. Innerhalb dieser Ausbildung ist eine Migrationserfahrung Bedingung und wird, wie die Sprache, zur entscheidenden Ressource 
der Bildungsbiografie. Die Frauen der Frauengruppe ermutigten Esma, diese Ausbildung ebenfalls anzupacken.

»...und so plötzlich habe ich einfach äh...wie soll ich das ausdrücken? Mein Inneres verstärkt und bin mehr zum...zum Äusserlichen gekommen. Mehr so mich auch getraut zu zeigen, also ich bin ja da und, und ich kann etwas in meinem Leben erreichen. Obwohl ich immer hinten dran noch andere Probleme gehabt habe im Leben oder. Und so habe ich mir immer von tiefstem Herz gewünscht, hey es muss jetzt etwas in deinem Leben passieren (...) du brauchst jetzt irgendetwas was dich festigt, was du für dich selber etwas willst erreichen« (Esma, A 36).

Esma fasste durch die gewonnene innere Stärke neues Selbstvertrauen und den Entschluss, mehr Handlungsfähigkeit hinsichtlich ihrer (Berufs-)Biografie zu erlangen. Sie wünschte sich seit geraumer Zeit einen Ausweg aus ihrer beruflichen Langweile und bildungsbiografischen Sackgasse. Durch die Vergemeinschaftung im Religionsverein gelangte Esma zu neuer Entschlossenheit und packte diese Ausbildung berufsbegleitend erfolgreich an.

Wie aus der folgenden Aussage deutlich wird, ist sich Esma der Bedeutung ihres Freundeskreises für ihre (berufs-)biografische Entwicklung bewusst. Heute besitzt Esma zudem gar das Selbstbewusstsein, die Möglichkeiten zur persönlichen und beruflichen Entwicklung, von denen sie durch die Akkumulation von sozialem Kapital durch die Religionsgemeinschaft und die Frauengruppe profitierte, als reziprok anzusehen.

»Aber durch die Phasen in unserem Leben, wo sich ergeben haben... Haben wir genau dann, die Leute kennengelernt, wo ich jetzt sagen kann, (...) Cott hat es so gewollt, dass wir sie kennenlernen, weil durch sie...nicht nur uns aber auch denen sind vielleicht auch andere Tore aufgegangen« (Esma, A 53).

Was Esma retrospektiv bildungsbiografisch als göttliche Fügung deutet, kann aus sozialwissenschaftlicher Perspektive als das Wiedererlangen von mehr Handlungsfähigkeit (Agency) durch die Akkumulation von sozialem Kapital (Bourdieu 1983b) mittels der »Taktik« (De Certeau 1988: 89) der religiösen Vergemeinschaftung rekonstruiert werden. Im Einklang mit einschlägigen Forschungsergebnissen zeigte sich in den (Bildungs-)Biografien, dass Moscheen und deren Religionsvereine biografisch nicht »nur« als religiöse Stätte bzw. Orte der Ausübung religiöser Praxen fungieren, sondern im Sinne von »multifunktionellen Dienstleistungszentren« (Behloul 2005: 157, 2004) als Ausgangs- 
punkte für vielfältigste Aktivitäten dienen (vgl. hierzu auch: Endres et al. 2013: 13, Baumann 2012: 46-52, Martens 2010: 163,172-73, Marti/Kraft/Walter 2010: 46-47, Behloul 2010: 58, 2005: 157, Behloul/Lathion 2007: 201). Religionsgemeinschaften stellen für die Frauen vielmehr Netzwerke dar, die »eine soziale Infrastruktur, mit deren Hilfe sich auch ausserreligiöse Ziele verwirklichen lassen, zur Verfügung stellen« (Coleman 1990 zit.n. Traunmüller 2018: 917). Die Akkumulation von sozialem Kapital (Bourdieu 1983b) war für die weitere bildungsbiografische Entwicklung der interviewten Frauen entscheidend. Bader und Fibbi (2012: 55) weisen darauf hin, dass für Jugendliche mit »Migrationshintergrund « ein »soziales Kapital, welches breite und vielfältige Kontakte beinhaltet « ein entscheidender Vorteil ist, wenn es darum geht, beruflich $\mathrm{zu}$ bestehen. Religionsvereine bilden soziale Räume, mittels derer die Frauen dieser »Taktik« von der Herkunftsfamilie unabhängiges, soziales Kapital akkumulieren konnten. Anlehnend an King (2004: 28ff.) begreife ich die Phase der Adoleszenz und des frühen Erwachsenenlebens als »Möglichkeitsraum« Holzkamps (1983), in dem in Auseinandersetzung mit dem »bisherigen « eigenen Leben - und besonderes mit der familialen Herkunft(-sgeschichte) - in Umgestaltungsprozessen potenziell neue, eigene Lebensentwürfe entwickelt und neue Perspektiven gewonnen werden können (King 2004: 28ff.). So gelang es den interviewten Frauen in ihrer Adoleszenz durch die »Taktik« der religiösen Vergemeinschaftung mehr Handlungsfähigkeit (Agency) innerhalb ihres intersektionell beschränkten »Möglichkeitsraums« (Holzkamp 1983) zu erlangen. Durch die von der Herkunftsfamilie unabhängigen Akkumulation von sozialem Kapital konnten sie sich bis zu einem gewissen Grade von den durch das Elternhaus geprägten strukturellen Bildungsbarrieren emanzipieren (z.B. von der vom elterlichen Genderbild geprägten Hinfälligkeit einer nachobligatorischen Ausbildung wegen einer frühen Heirat) und eine weniger durch Fremdbestimmung geprägte Berufslaufbahn einschlagen.

Verschiedentlich ist bereits auf die gesellschaftlich integrierende Funktion religiöser Netzwerke von Migrant*innen hingewiesen worden (vgl. u.a. Baumann 2015, 2012; Endres et al. 2013, Nagel 2015, 2013, Pickel 2014). Nagel (2015, 2013) zeigt vor dem Hintergrund einer relationalen Netzwerkperspektive die vielfältigen gesellschaftlichen Einbindungen religiöser Migrantengemeinden und deren »zivilgesellschaftliches Potential« (Nagel 2014: 17ff.) auf. Baumann (2012: 47) unterstreicht zudem, dass Religionsgemeinschaften »mit ihrem Sprach-, Beratungs- und Bildungsangebot « Integrationsarbeiten leisten, »die sonst seitens des Staates oder der Zivilgesellschaft zu leisten wären« (ebd.). 
Der Religionssoziologe Pickel (2014) untersucht zudem in Bezug auf christliche Kirchen die Frage, inwiefern religiöse Netzwerke als "gesellschaftliche Integrationsressource« (2014: 41) wirken können. Rekurrierend auf die Sozialkapitalforschung Putnams spricht er von »religiösem Sozialkapital« (ebd.: 47). Religiöses Sozialkapital umfasst Pickel zufolge »freiwillige soziale Netzwerke, die auf religiösen Überzeugungen gründen (faith-based) oder in Beziehung zu einer Kirche stehen und dort entstehen (Bibelkreise, Jugendgruppen, Sozialhilfegruppen« (ebd., Herv. im Orig.). Weiter stellt er in einer empirischen Studie fest, dass »religiöses Sozialkapital strukturell brückenbildend« wirken kann (ebd.: 53). Dass ähnliche Mechanismen auch in nicht-christlichen religiösen Netzwerken zum Zuge kommen könnten und auch hinsichtlich Bildungsbiografien bedeutsam werden, lässt sich anhand der erhobenen Daten vermuten und in der berufsbiografischen Entwicklung von Esma exemplarisch verdeutlichen: Sie konnte mithilfe der »strukturell brückenbildenden« (Pickel 2014: 53) Wirkung der religiösen Vergemeinschaftung ihre (bildungs-)biografische Krise überwinden und fand dank des sozialen Kapitals, das sie akkumulieren konnte, einen Weg, eine nachobligatorische Ausbildung in Angriff zu nehmen. Heute arbeitet Esma dank ihrer neu erworbenen Ausbildung nur noch 50 Prozent in der Tankstelle, den anderen Teil ihres Einkommens kann sie mit Dolmetschen bestreiten. Sie übersetzt insbesondere für die Polizei, wo sie mittlerweile fest angestellt ist. Die Vergemeinschaftung im Religionsverein bildet mittlerweile seit Jahren den Mittelpunkt von Esmas (sozialem) Leben und die religiöse Praxis stellt für sie (und auch für ihre Familie) eine tägliche Selbstverständlichkeit dar. Auf Vermittlung der Frauengruppe der Moschee ist Esma nun ebenfalls in einem interkulturellen und interreligiösen Gremium engagiert.

Wie Mey und Rorato (2010) in einer Längsschnittstudie zu Bildungsbiografien von Jugendlichen mit »Migrationshintergrund « betonen, lassen sich die Qualität von Einbindungen in »herkunftsbezogene Communities« bildungsbiografisch keineswegs "auf einen blossen Ort des Rückzugs reduzieren « (ebd.: 4). Auch Endres et al. (2013: 78) stellen in ihrer empirischen Studie $\mathrm{zu}$ muslimischen Jugendgruppen fest, dass diese - anders als der vorherrschende gesellschaftspolitische Diskurs bisweilen suggeriert - nicht Nischengruppierungen darstellen, innerhalb derer junge Menschen von der Gesellschaft wegdriften:

»Vielmehr bilden sie eigendefinierte Räume, in denen sich Kinder, Jugendliche und junge Leute mit Migrationshintergrund wichtige Ressourcen holen 
können, die ihnen helfen, mit einer oft rauen sozialen Umwelt zurecht zu kommen« (ebd.).

Diese Art von Bedeutung von Religionsvereinen liess sich bei den interviewten Frauen ebenfalls feststellen. Die religiöse Vergemeinschaftung führte bei ihnen nicht zu einer gesellschaftlichen Separation - im Gegenteil: Die Religionsgemeinschaft wirkte integrativ und fing auf, wo Sozialstaat, Elternhaus und Bildungssystem nicht genügend Unterstützung bieten konnten und die Frauen durch das wirkmächtige Zusammenspiel der Differenzdimensionen Gender, "Migrationshintergrund« und »class« davon bedroht waren, bildungsbiografisch »aus dem System zu fallen«.

Religionsvereine und -gemeinschaften bildeten für diese Frauen also soziale Räume, wo sie Zugehörigkeit, Anerkennung und Unterstützung erfahren konnten und mithilfe derer sie gar mehr Handlungsfähigkeit (Agency) hinsichtlich ihrer (Bildungs-)Biografie (wieder-)erlangen konnten.

\section{Zusammenfassung "Taktik« Typus 3}

Die Bildungsbiografien der interviewten Frauen, bei denen die »Taktik« der religiösen Vergemeinschaftung rekonstruiert werden konnte, wurden zunächst durch starke Momente der Fremdbestimmung und durch ein intersektionell äusserst wirksames Zusammenspiel verschiedener Differenzdimensionen (insbesondere Gender, »Migrationshintergrund«, »class«) geprägt. Religion als Differenzdimension manifestierte sich in den Bildungsbiografien der jungen Frauen primär als »soziale Deutungspraxis« (Lingen-Ali/Mecheril 2016: 17) im pädagogischen Kontext im Zusammenspiel mit der Differenzkategorie Migrationshintergrund«). Mehr Handlungsfähigkeit (Agency) hinsichtlich ihrer Bildungsbiografie erreichten die Frauen schliesslich mittels der »Taktik« der religiösen Vergemeinschaftung und des im Zuge dieser akkumulierten sozialen Kapitals (Bourdieu 1983b).

Die Frauen lebten als Töchter von Gastarbeitern oder politischen Geflüchteten zunächst als transnationalisierte Familien (Bryceson/Vuorela 2002), bevor sie mit ihren Müttern und Geschwistern per sog. "Familiennachzug« in die Schweiz kamen.

Sie waren hinsichtlich ihrer (Bildungs-)Biografie aus intersektioneller Perspektive gleich mehrfach belastet, einerseits aufgrund des »Migrationshintergrundes«, der sie strukturell gesehen gesellschaftlich benachteiligte. Aufgrund der prekären arbeitsmarktlichen und gesellschaftlichen Position ihrer Eltern wurden sie in der Schweiz einer wenig privilegierten 
unterschichtenden »class« bzw. gesellschaftlichen Position zugerechnet. Andererseits wirkten auf die Frauen starke Gender-bedingte Einschränkungen hinsichtlich der (Bildungs-)Biografie; insbesondere das traditionelle elterliche Rollenbild, das eine frühe Heirat der Frauen vorsah, fungierte als Bildungsbarriere, ging es doch einher mit den elterlichen Vorstellungen einer generellen Hinfälligkeit einer nachobligatorischen Ausbildung für Frauen. Bereits in der Schule wurden die Frauen, die aus weitgehend säkularen Haushalten stammten, zudem mit der Differenzdimension Religion konfrontiert. Im pädagogischen Kontext wurden sie als Lernende mittels der Differenzkategorie »Muslimin« als Zugehörigkeits- und Ausschlusscode als »Andere« markiert (vgl. Lingen-Ali/Mecheril 2016: 18).

Bei (Bildungs-)Biografien von Frauen, bei denen diese »Taktik« rekonstruiert werden konnte, müssen also aus einer intersektionellen Perspektive die Differenzdimensionen Gender, »Migrationshintergrund « und »class« und Religion zusammen gedacht werden. Aufgrund des genderbasierten Rollenbilds und der fehlenden Unterstützung des Elternhauses blieb den Frauen eine nachobligatorische Ausbildung verwehrt. Im Alleingang gelang der Übergang von der Realschule in eine nachobligatorische Ausbildung nicht. Sie fanden sich nach längerer Übergangsphase ohne Ausbildung in wenig privilegierter Ausgangslage auf dem Arbeitsmarkt, in Arbeitsverhältnissen dort »wo es noch Platz hat« (Mey 2015: 235).

Sie heirateten früh und fügten sich zunächst den elterlichen Wünschen. Die Arbeit in einer schlecht qualifizierten Position, so die elterliche Vorstellung, war eigentlich als Provisorium bis zur Heirat gedacht und nicht von Dauer: Dieser elterliche Plan erwies sich jedoch als folgenträchtige Fehlkalkulation. Das Paradoxe an der berufsbiografischen Entwicklung der jungen Secondas war nämlich, dass sie, obwohl für sie eine klassische Hausfrauenrolle vorgesehen war, hinsichtlich einer arrangierten transnationalen Heirat ${ }^{51}$ de facto meist eher eine klassische Männerrolle einzunehmen hatten. Innerhalb dieser wurden sie - zumindest während einer gewissen Zeit - zur familialen Ernährerin und auch im ausserhäuslichen Bereich stellten sie die zentrale Orientierungsfigur ihrer angeheirateten Ehemänner dar, die zunächst nicht

$51 \quad$ Eine von der Familie arrangierte Heirat mit einem Partner aus Südosteuropa bildete nach 1991 wegen Verschärfung der Einreisebestimmungen meist die einzige Möglichkeit für Grossfamilien, transnationale Bindungen zu festigen oder neu zu knüpfen (vgl. Aarburg/Gretler 2011: 233). Eine Einreise in die Schweiz zwecks Arbeitsmigration war für Menschen aus dem Balkan nach 1991 faktisch quasi nicht mehr möglich. 
der Landessprache mächtig waren. Dadurch, dass sie durch eine fehlende Ausbildung in prekären Arbeitsverhältnissen standen, die am untersten Ende des Arbeitsmarkts angesiedelt waren, reproduzierten sie die prekäre elterliche soziale Stellung. Die Frauen wurden also mittels des Zusammenspiels dieser Differenzdimensionen gezwungen, einen Lebensweg einzuschlagen, der weder ihren Berufswünschen noch ihren schulischen Fähigkeiten entsprach, sondern tendenziell den sozioökonomischen Hintergrund der Eltern reproduzierte. Ein bildungsbiografisches Ausbrechen stellte für die interviewten Frauen, die sozialisiert waren, sich den elterlichen Wünschen zu fügen, zunächst keine Option dar.

Typisch für die »Taktik« der religiösen Vergemeinschaftung ist das Moment, in dem sich die Frauen (bildungs-)biografisch in einer Sackgasse sehen und aufgrund eines massiven strukturellen Drucks in eine scheinbar ausweglose (berufs-)biografische Krise geraten.

Vor dem Hintergrund dieser intersektionell wirksamen Beschränkungen lässt sich in diesem Typus die »Taktik« der religiösen Vergemeinschaftung rekonstruieren: Sie wenden sich einer Religionsgemeinschaft $\mathrm{zu}$, was in den biografischen Erzählungen der Frauen als Wendepunkt ihres Lebens dargestellt wird und teilweise im Zusammenhang mit einem von den Frauen geschilderten Erweckungserlebnis steht. Was die interviewten Frauen als "göttliche Rettung« aus der Krise deuten, kann aus sozialwissenschaftlicher Perspektive als das Wiedererlangen von mehr Handlungsfähigkeit (Agency) durch die Akkumulation von sozialem Kapital (Bourdieu 1983b) mittels der »Taktik« (De Certeau 1988: 89) der religiösen Vergemeinschaftung rekonstruiert werden. Um zu bestehen, mussten sich die interviewten Frauen von den elterlichen Wertevorstellungen lösen und darin bestärkt werden, sich (bildungs-)biografisch ungeachtet grossen strukturellen Drucks weiter zu entwickeln. Diese Ablösung gelang durch die »Taktik« der religiösen Vergemeinschaftung. Durch die von der Herkunftsfamilie unabhängige Akkumulation von sozialem Kapital gelang den Frauen eine berufliche Weiterentwicklung, die ihnen ansonsten verwehrt geblieben wäre.

Verschiedentlich ist auf die gesellschaftlich integrierende Funktion religiöser Netzwerke von Migrant*innen hingewiesen worden (vgl. u.a. Baumann 2015, 2012; Endres et al. 2013, Nagel 2015, 2013, Pickel 2014, Weissköppel 2008, Spickard 2005). Dass diese integrierende Funktion auch hinsichtlich von Bildungsbiografien Relevanz entwickeln kann, kann anhand der analysierten Fälle exemplarisch illustriert werden. 
Anders als der gesellschaftspolitische Diskurs suggeriert, wirkten bei diesen Frauen Religionsgemeinschaften nicht als Orte des Rückzugs in eine kompensierende Sinnwelt, sondern als integrierende Gemeinschaften. Hier konnten die Frauen für die Berufsbiografie entscheidendes soziales Kapital (Bourdieu 1983b) akkumulieren und dadurch mehr Handlungsfähigkeit (Agency) hinsichtlich ihrer (Bildungs-)Biografie wiedererlangen. Die Religionsgemeinschaft wirkte als »religiöses Sozialkapital« (Pickel 2014: 50) integrativ und fing auf, wo Elternhaus und Bildungssystem versagten und die Frauen durch das wirkmächtige Zusammenspiel der Differenzdimensionen Gender, »Migrationshintergrund« und "class« davon bedroht waren, bildungsbiografisch »aus dem System zu fallen«.

\subsection{Typus 4: »Taktik« der widerständigen Mikropraktiken}

\subsubsection{Duaa}

Duaa (27) wird mir durch eine ihrer Freundinnen, die mit ihr bei einem grossen Detailhändler zusammenarbeitet, als Gesprächspartnerin vermittelt. Die junge Frau, so fiel mir bereits bei der ersten Begegnung auf, trägt ihr Haar unter einem Tuch, das auf eine spezielle Art und Weise geschlungen ist: Es ist hinten im Nacken zusammengeknüpft. Das Tuch war sehr eng gebunden und an der Vorderfront stirnseitig prangte das goldene Emblem einer grossen prestigeträchtigen Modemarke. Ich war mir zunächst nicht sicher, ob es sich bei dem Tuch um ein Modeaccessoire oder ein religiöses Symbol handelte.

Duaa, so erzählte sie mir bei der ersten Begegnung, ist verheiratet und hat drei kleine Kinder, welche die Vorschul- und Primarstufe besuchen. Sie flüchtete mit ihrer Familie als Kleinkind aus einem kriegsgeplagten Land in der Sahelzone in die Schweiz, die Flucht dauerte mehrere Jahre und führte über ein arabisches Land auf Umwegen in die Schweiz. Duaas Vater war ursprünglich Ingenieur, auf dem langjährigen Fluchtweg und später in der Schweiz arbeitete er jedoch als Koranlehrer und Imam. Duaas Mutter verfügte über keine formale Schulbildung, sie war Familienfrau und kümmerte sich um die sechs Kinder und heute auch um ihre Enkelkinder. Zeitweise, als ihre Kinder noch nicht zum Familieneinkommen beitragen konnten, ging Duaas Mutter putzen, um zum knappen Familieneinkommen etwas beizusteuern.

Eigentlich, sagte Duaa, hätte sie immer gerne Köchin gelernt. Niemals, wirklich niemals, so erzählte sie, habe sie im Verkauf arbeiten wollen, so wie 
sie das heute täglich tut. Zentrales Hindernis einer Bewerbung auf eine Lehrstelle als Köchin war, dass Duaas Vater nicht begeistert war von den sehr unregelmässigen Arbeitszeiten und insbesondere vom Arbeitsweg, der teilweise in der Nacht hätte zurückgelegt werden müssen. Ihr Vater hätte dies einzig zugelassen, wenn er sie persönlich hätte holen können, dies war jedoch aufgrund seiner beruflichen Verpflichtungen nicht möglich. Duaa bewarb sich gemäss den Wünschen des Vaters infolgedessen nicht auf Kochlehrstellen und stellte ihren Berufswunsch zurück.

Während des zehnten Schuljahrs, welches Duaa an die Realschule anschloss, hatte sie ihren Traum, sich als Köchin zu bewerben, noch nicht ganz aufgegeben. Von der Lehrerin erhielt sie jedoch keine Unterstützung: Diese nahm Duaas Berufswunsch nicht ernst und "zwang« sie, wie Duaa es ausdrückt, sich bei einem grossen Detailhändler zu bewerben. Die Lehrerin fügte kurzum die Drohung an, wenn sie sich nicht dort bewerbe und keine Abstriche bei ihren Bildungswünschen mache, könne sie die Schule gleich verlassen, da sie mittlerweile eine der Einzigen sei, die keine Lehrstelle in Aussicht habe. Duaa wollte die Lehrstelle dennoch nicht, sie konnte sich eine Arbeit im Verkauf nicht vorstellen. Sich aktiv zu wehren, stellte für sie jedoch ebenfalls keine Option dar - sie ist stets bemüht, direkte Konfrontationen mit Repräsentant*innen der hegemonialen Gesellschaft möglichst zu vermeiden. So versuchte sie sich entsprechend mittels "widerständige[r] Mikropraktiken ${ }^{52}$ (Rothfuss 2012) zu wehren, was in diesem Fall bedeutete, dass sie absichtlich eine lausige Bewerbung verfasste: Sie hoffte, das Schicksal würde sich gnädig erweisen und der Detailhändler würde ihre Lehrstellenbewerbung ablehnen, wenn sie ein fehlerhaftes Motivationsschreiben abschicke, das voller »TippEx« sei. Ihre Hoffnung war jedoch vergeblich: Sie erhielt die Lehrstelle, die sie nie wollte, und nahm sie schliesslich an.

Während der Lehre, als Duaa an der Kasse arbeitete, fiel sie einer Journalistin auf, die einen Artikel über die Frau mit Kopftuch an der Kasse schrieb. Infolgedessen erliess die Chefetage des Unternehmens plötzlich ein generelles »Kopftuchverbot« für Angestellte. Duaa wurde von ihrem Vorgesetzten vor die Wahl gestellt: Entweder sie ziehe das Kopftuch aus, oder sie müsse

52 Als »(widerständige) Mikropraktiken« beschreibt Rothfuss (2012: 53ff.) auf De Certeaus Handlungstheorie rekurrierend, mikroskopische Taktiken, mittels derer sich brasilianische Favela- Bewohner*innen >fintenreich und >listig`gegen die fortwährende gesellschaftliche Stigmatisierung und Ausgrenzung der brasilianischen Mehrheitsgesellschaft zu wehren wissen (ebd.: 205ff.). 
die Lehre abbrechen. Gemeinsam mit ihren Eltern entschied sie, das Kopftuch während der Arbeitszeit auszuziehen. Auch hier war sie gezwungen, sich dem grossen strukturellen Druck durch intersektionelle Beschränkungen zu beugen. Unter diesen, durch starke Fremdbestimmung geprägten Umständen konnte Duaa schliesslich ihre Lehre beim Detailhändler abschliessen. Ihr eigentlicher (Lebens-)Plan bestand jedoch, wie sie beschrieb, seit dem Aufgeben ihres eigentlichen Berufswunschs darin, zu heiraten und »mit zwanzig Jahren ein Kind zu haben«. Ihre berufliche Entwicklung schrieb sie bereits in jungen Jahren $a b$ und verlegte ihre Ziele ausschliesslich ins Private. Sie lernte einen Mann auf einer Hochzeit ihrer erweiterten Familie kennen und heiratete ihn nach wenigen Monaten. Ihr Vater fand das ein bisschen übereilt, stimmte jedoch schliesslich zu. Kurz darauf gebar Duaa das erste von drei Kindern - genau wie sie es vorgesehen hatte - mit zwanzig Jahren.

Nach ihrem Lehrabschluss arbeitete sie an der Kasse des Detailhändlers weiter, wo sie fast täglich mit teilweise heftigen Anfeindungen hinsichtlich ihrer dunklen Hautfarbe konfrontiert wurde. Als eines Tages ein Kunde sich weigerte, seinen Korb auszuräumen und die Waren auf das Laufband zu stellen, mit dem Kommentar, sie könne das selbst tun, ging Duaa zu ihrem Vorgesetzten und bat ihn um eine Versetzung nach hinten ins Lager. Sich in direkter Konfrontation mit Kund*innen (als Repräsentant*innen der hegemonialen Mehrheitsgesellschaft) zu befinden, stellte für Duaa in der Regel aus ihrer subalternen (Spivak 1988) und mit wenig Macht ausgestatteten Position eigentlich keine Option dar, da sie von vornherein sals Verliererin feststehen würde. Deshalb versuchte sie mit allen Mitteln, eine solche zu vermeiden, in diesem Falle mittels der >Drohung sich zu wehren. Sie erreichte damit, was sie wollte: Der Vorgesetzte versetzte sie snach hinten teilung, fernab von den Blicken der Ladenbesucher*innen. Duaa, die peinlich genau auf die Einhaltung der Speisegebote achtet und all ihre Nahrung nur in Halal-Läden einkauft, ekelte sich zwar auf ihrem neuen Posten in der Fleischabteilung vor dem Schweinefleisch und zog deshalb immer gleich mehrere Handschuhe übereinander an, gleichzeitig sagte ihr die Arbeit aber auch zu, weil sie den stetigen Anfeindungen und Blicken, denen sie als Kopftuch tragende Muslima schwarzer Hautfarbe ausgesetzt war, im hinteren Lager entgehen und sich zurückziehen konnte. Andererseits gefiel ihr die Arbeit trotz ihres Ekels vor dem Fleisch recht gut, weil sie, wie sie erzählt, »das Hirn gebrauchen« konnte.

Duaa tradierte das Religionsverständnis ihrer Eltern, sie wurde traditionell religiös sozialisiert. Über ihren Vater, der als Koranlehrer tätig war, erhielt 
sie jedoch auch ein wenig formelle religiöse Bildung. Der Vater war jedoch sehr beschäftigt mit den sozialen Aufgaben, die sein Amt mit sich brachte und verbrachte kaum Zeit mit seinen Kindern. Dennoch war ihm die (Weiter-)Bildung seiner Tochter ein Anliegen: Regelmässig versuchte er Duaa zu überreden, eine weitere Lehre in Angriff zu nehmen, sich weiterzubilden. Der studierte Ingenieur kannte das schweizerische Schulsystem jedoch zu wenig, um seine Tochter von Beginn an zu unterstützen. Stets hatte er ihr und ihren Schwestern dessen ungeachtet eingeschärft, sie sollen etwas lernen, um unabhängig von einem Mann zu sein. Duaa sah in ihrem Vater dennoch keinen Referenzpunkt, zu oft war er abwesend in ihrer Kindheit. Längst sah sie keinen Sinn mehr in einer weiteren Ausbildung, sie verlagerte das Aufstiegsprojekt des Vaters in die nächste Generation. Ihre Kinder sollen es einmal besser haben, studieren können. Hierfür scheut sie keine Mühen und lernt in der Freizeit mit ihnen.

Obwohl ihr Vater in einer Moschee tätig ist und Duaa äusserst glaubensgewiss ihre religiösen Pflichten verrichtet, tut sie dies nur selten in Gemeinschaft; weder in dem religiösen Verein des Vaters noch im Rahmen einer anderen Vereinigung wie bspw. einer muslimischen Jugendgruppe. Der Vergemeinschaftung im Verein des Vaters geht sie regelrecht aus dem Weg. Zu sehr empfindet sie das Amt des Vaters als Bürde, der die soziale Kontrolle der Glaubensgemeinschaft über sie verstärkt und ihre Freiheiten einengt. Auch sonst verfügt Duaa über wenig Austausch und soziale Räume ausserhalb ihrer Familie, wo sie bspw. ihre Ausschlusserfahrungen reflektieren und teilen könnte. So hat sie den beinahe täglich gemachten Ausschlusserfahrungen kaum etwas entgegenzusetzen. Den weltpolitischen Entwicklungen im Zusammenhang mit terroristischen Anschlägen und den damit einhergehenden islamfeindlichen Zuschreibungen sieht sich Duaa als Kopftuch tragende Muslima ohnmächtig ausgeliefert. Eine von langer Hand geplante Paris-Reise sagte sie kurz zuvor, anlässlich des Charlie-Hebdo-Attentats, ab. Sie fürchtet sich vor Übergriffen auf sie als Muslimin. Als schwarze Kopftuch tragende Frau ist sie beinahe täglich alltagsrassistischen Anfeindungen ausgesetzt und versucht infolgedessen, wo immer es geht, direkte Konfrontationen mit Repräsentant*innen der hegemonialen Gesellschaft zu vermeiden.

Auch hinsichtlich religiöser Praktiken zieht Duaa eine Vermeidung einer direkten Konfrontation bzw. einer Sichtbarkeit in der Öffentlichkeit vor und versucht als religiös orientierte Muslima so wenig »sichtbar« wie möglich zu sein. Sie betet nicht am Arbeitsplatz und in der Öffentlichkeit, aus Angst >blöd angeschaut $<$ zu werden. Das Kopftuch trägt sie stets so, dass es als Modeacces- 
soire durchgehen könnte. Dies wiederum bringt ihr jedoch Kritik der Familie und ihrer Glaubensgemeinschaft ein. Lieber noch nimmt sie diese in Kauf, als öffentlich eindeutig als Muslima erkannt zu werden. Einzig die Speisegebote hält sie peinlichst genau ein. Als religiöses Handlungsfeld, das von aussen nicht sichtbar ist, kann sie dies tun, ohne aufzufallen. Die zunehmende Auswahl an veganen Lebensmitteln in grossen Supermärkten macht es für Duaa zudem einfacher, wie sie erzählt, halal einzukaufen, ohne auf die teuren Spezialgeschäfte ausweichen zu müssen.

Zentral für die »Taktik« der widerständigen Mikropraktiken, so kann zusammengefasst werden, sind die starken, intersektional wirkenden Einschränkungen der Bildungsbiografie. Neben Gender, »class«, »Migrationshintergrund « und Religion wirkt zusätzlich verstärkt einschränkend die Differenzdimension Körper (Hautfarbe). Die Religionszugehörigkeit wird für Duaa unter diesem einschneidenden strukturellen Druck zum Stigma innerhalb der hegemonialen Mehrheitsgesellschaft. Der Übergang zur nachobligatorischen Ausbildung ist bei Frauen, bei denen diese »Taktik« identifiziert werden konnte, zudem von starker Fremdbestimmung geprägt. Um Zugang zu Bildung zu erlangen und im Berufsleben stehen $\mathrm{zu}$ können, bleibt ihnen die Vermeidung einer direkten Konfrontation mit Repräsentant*innen der hegemonialen Gesellschaft, allenfalls begegnen sie strukturellem Druck mit der »Waffe der Schwachen« (Rothfuss 2012: 218) mit der »Taktik« der widerständigen Mikropraktiken, wie z.B. dem Verfassen einer fehlerhaften Bewerbung auf eine ungewollte Stelle.

\subsubsection{Bildungsbiografisches Bestehen durch die "Taktik" der widerständigen Mikropraktiken}

Nach diesem einleitenden Portrait von Duaa wird die »Taktik« des Bildungszugangs durch Vermeidung der direkten Konfrontation mittels Mikrowiderstands nun anhand der folgenden Kapitel dargelegt, es sind dies) Herkunftsmilieu im Zusammenhang mit der »Taktik«; b) Die Rolle der Religion und der Differenzkategorie "Muslimin « hinsichtlich der Bildungsbiografie und c) "Taktik" gesellschaftlicher Selbstpositionierung bezüglich der Bildungsbiografie.

Bei den interviewten Frauen der »Taktik« 4 konnten keine unterschiedlichen Ausprägungen (bzw. Untertypen) ausgemacht werden. 


\section{a) Herkunftsmilieu im Zusammenhang mit der "Taktik «}

Die interviewten Frauen, bei denen die »Taktik« der widerständigen Mikropraktiken rekonstruiert werden konnte, gehören Familien von anerkannten, politischen Geflüchteten an. Die Familien der Frauen wurden in den Ländern, von wo sie flüchteten, politisch verfolgt. So auch der Vater von Duaa, der mit seiner Familie anfangs der 90er-Jahre aus einem kriegsgebeutelten Land in der Sahelzone flüchtete. Ihre Eltern gehörten da der Opposition an oder standen ihr zumindest nahe.

Den unmittelbaren Anlass zur Flucht von Duaas Familie gab ein konkretes Gewalterlebnis im Zusammenhang mit dem tobenden Bürgerkrieg, das sich bis heute in Duaas Erinnerungen eingebrannt hat:

»Ich weiss, ich bin noch jung gewesen, noch klein, dreijährig, ich weiss nur, dass in unsere Küche eine Bombe eingeschlagen ist, denn wir haben dort ein Haus gehabt, wir haben in einem Haus gelebt und dann si-si-sind meine Eltern, haben alles zusammengepackt einfach das Wichtigste, das Nötigste, ähm, dann sind wir äh zum Nachbarhaus gerannt oder hingegangen und dort sind ganz viele Nachbarn miteinander gewesen. Und nachher äh sind wir weiter, weil mein Vater hat gesagt, hier in diesem Quartier, ich weiss die Orte nicht, wie sie ganz genau hiessen, hat er gesagt, hier sind wir nicht sicher, dann sind wir weiter gegangen in ein anderes Haus und dort haben wir ein paar Monate gelebt. Dann weiss ich nur noch, dass wir mit einem sehr grossen Schiff, ist glaube ich eine Yacht gewesen, keine Ahnung, ämu ein riesiges Teil von einem Schiff, sind wir dann nach [ein Land in Nordafrika] gegangen, ja. //Mhm// Und dort haben wir dann gelebt« (Duaa, A 40).

Duaa erzählt eine Fluchtgeschichte, wie sie oftmals bezeichnend für Flüchtende von Gewaltkonflikten ist, die versuchen, von Afrika nach Europa zu gelangen (vgl. u. v.a. Belloni 2016, 2015, Weissköppel 2008). Sie beschreibt ein Gewalterlebnis, das den Ausschlag für eine relativ abrupte Fluchtentscheidung gab. Diesem Aufbruch folgte eine jahrelange Migrations- bzw. Fluchtgeschichte, die sich als ein »biografisch offener Prozess« zeigte, »der mit mehrfachen Ortswechseln und geografischen Grenzüberschreitungen verbunden" war (Weissköppel 2008: 91). Wie Duaa schildert, versuchte ihre Familie zuerst an einen einigermassen sicheren Ort zu gelangen und dort in Erfahrung zu bringen, ob sich Optionen für eine Weiterreise ergeben. ${ }^{53}$ Eine längere Zeit,

53 Die transnationale Migrationssituation der Flüchtenden gestaltet sich oft fluid, vorübergehend, mulitilokal, variabel, unabgeschlossen und erfolgt »nicht unbedingt in 
an die sich Duaa noch erinnern kann, verbrachte sie als Kleinkind in einem Land in Nordafrika:

»Ich bin mit drei, wir sind vom [einem Land in der Sahelzone] nach [ein anderes Land in Nordafrika] gekommen und in [der Hauptstadt] bin ich auch noch dort in die Schule gegangen. Dort war ich dreijährig bis fünf, ja bis fünf sind wir dort in die Schule. Ich bin dort, wir haben dort zwei Jahre gelebt. Mein Vater hat dort als Koranlehrer gearbeitet« (Duaa, A 40).

Aus Duaas Erzählung wird deutlich, dass sich die Familie damals auf einen längeren Aufenthalt in Nordafrika einstellte. Dies wird insbesondere daran ersichtlich, dass die Kinder der Familie eingeschult wurden und der Vater eine Arbeit als Koranlehrer annahm.

Nicht zuletzt ist die Mobilität in der transnationalen Migration auch massgeblich davon beeinflusst, welche sozio-ökonomischen Möglichkeiten sich an einem (temporären) Aufenthaltsort ergeben. Weissköppel illustriert in ihrer Studie über transnationales Handeln in protestantischen Kirchgemeinden (Weissköppel 2008) anschaulich, wie Migrationsentscheide situativ erfolgen können und neben der Sicherstellung der ökonomischen und sozialen Kontinuität des familiären Systems nicht zuletzt, gerade bei Akademikern, auch bildungsbiografische Motive zum Tragen kommen können (ebd.: 91).

Auch für Duaas Vater brachte die Flucht entscheidende berufsbiografische Veränderungen mit sich. Als Akademiker, welcher der Opposition nahe stand, hatte er in einem durch einen dreissigjährigen Bürgerkrieg geprägten Land keinerlei Aufstiegschancen (vgl. hierzu auch Weissköppel 2008: 79). Auch später, als Geflüchteter, während der jahrelangen transnationalen Migration hatte er ohne Arbeitserfahrung und mangels Anerkennung seines Bildungsabschlusses keine Möglichkeit, seinen ursprünglichen Beruf als Ingenieur auszuüben. Weissköppel weist darauf hin, dass in der multilokalen Migrationssituation die jeweiligen Konstellationen »der sozialen, kulturellen und ökonomischen Kapitalformen den je spezifischen transnationalen Raum« aufspan-

Orientierung auf ein ausschliessliches Zielland«(Weissköppel 2008: 91). Innerhalb des Prozesses einer solchen sogenannten »chain-migration« (ebd.) werden unterschiedliche Aufenthaltsorte in Kauf genommen und situativ versucht, Ziele zu verwirklichen (ebd.). Belloni (2016: 55) weist zudem darauf hin, dass die Mobilität bzw. Weiterreise der Flüchtenden sehr eng mit transnationalen familialen Netzwerken und deren (ökonomischen Ressourcen) verbunden ist. 
nen und zeigt auf, wie diese in der Fluchtsituation als »Ressourcen« (ebd.: 92) mobilisiert werden. Als Aktivierung einer solchen »Ressource« kann die berufliche »Umorientierung « von Duaas Vater vom Ingenieur zum Koranlehrer gedeutet werden. In der Migrationssituation (bereits während der Flucht, später auch in der Schweiz) orientierte sich Duaas Vater neu und besann sich auf seine sozialisatorisch bedingte religiöse Bildung in der Koranschule zurück. In der Migrationssituation stellte diese plötzlich eine ökonomische Ressource dar, die es ihm ermöglichte als Koranlehrer und Imam seine Familie unabhängig von der Anerkennung seines akademischen Bildungsabschlusses und vom momentanen Aufenthaltsstatus sowie relativ unabhängig von der Arbeitsmarktsituation zu ernähren.

Schliesslich gelangte Duaa mit ihrer Familie in die Schweiz - mit dem Flugzeug, wie Duaa erzählt. Dort ersuchte ihr Vater um politisches Asyl. Es folgten wieder mehrere Jahre mit unterschiedlichen Aufenthaltsorten in verschiedenen Asylunterkünften in der Schweiz. Dem Vater war es jedoch ein grosses Anliegen, wie Duaa erzählt, möglichst bald auf eigenen Füssen zu stehen. Sobald der Aufenthaltsstatus der Familie geklärt war, suchte und fand er eine unabhängige Unterkunft für sich und seine Familie. Auch aus ökonomischer Perspektive war es den Eltern wichtig, unabhängig zu werden. Die Mutter fand eine Arbeit in einer Reinigungsfirma, während es dem Vater gelang, seine Tätigkeit als Koranlehrer und Imam weiterzuführen und zu intensivieren. Heute leitet er einen Moscheeverein in einer grösseren Deutschschweizer Stadt, wo er sich mit seiner Familie in einem Vorort nieder liess. Obwohl der Vater die ökonomische Grundlage seiner Familie, die mittlerweile sechs Kinder umfasste, dadurch relativ schnell und unabhängig absichern konnte, empfand Duaa die Arbeit ihres Vaters als alles andere als vorteilshaft für sie. Sie litt einerseits darunter, dass der Vater aufgrund der vielseitigen Verpflichtungen, welche das Amt als Imam mit sich brachte ${ }^{54}$, zu Hause kaum anwe-

54 Fragt man Imame in der Deutschschweiz nach ihrem Arbeitsalltag, beschreiben sie in der Regel einen Rund-um-die-Uhr-Job (Feldprotokoll 2014). Neben dem Leiten des Freitagsgebets zählen sie eine schier endlose Reihe weiterer Tätigkeiten auf: Religionsund Koranunterricht, manchmal auch Sprachunterricht für Kinder, Jugendliche und Erwachsene, Beantworten religionsbezogener Fragen der Gläubigen, Durchführung islamischer Eheschliessungen und Scheidungen, islamische Seelsorge in Spitälern und Gefängnissen, Totenwaschung und Totengebet, Trauerbegleitung, manchmal auch die Begleitung von Pilgerfahrten nach Mekka. Die Imame der Moscheevereine übernehmen jedoch weit mehr als religiöse Aufgaben im engeren Sinn: In zahlreichen Situationen werden sie zu Hilfe gerufen (dies verstärkt in der Migrationssituation), sei dies bei 
send war. Andererseits verstärkte die Tätigkeit des Vaters die soziale Kontrolle der (Glaubens-)Gemeinschaft über Duaa und ihre Geschwister:

»(..) in jeder Ecke kennen uns die Leute, wir kennen sie nicht. //Mhm// Und was mich jeweils nervt, ist, dass sie dann zu meinen Eltern gehen oder zu meinem Vater, ich habe deine Tochter gesehen, die ist dort und dort gewesen, um diese Uhrzeit. Es ist mühsam, //mhm// es nervt, du kannst nirgends hin, ohne dass du weisst, deine Eltern wissen es schon« (Duaa, A 50).

Wie aus dieser Aussage deutlich wird, störte es Duaa, dass sie und ihre Geschwister als Kinder des Imam beobachtet wurden und dass die (Glaubens-)Gemeinschaft somit die Funktion einer erweiterten, aber auch anonymen Kontrollinstanz einnahm und quasi als >verlängerter Arm< der Eltern ihre Handlungen kontrollierte und so auf ihre Lebenswelten Einfluss ausübte.

Sie erzählt, wie sie teilweise öffentlich zurechtgewiesen wurde, wenn sie gewisse, als Norm geltende Kleidervorschriften nicht einhielt. Ein Erlebnis ist ihr diesbezüglich in besonderer Erinnerung geblieben:

»Ich bin, vor ein paar Jahren (halbes Lachen) bin ich von einer arabischen Frau angesprochen worden, ob ich nicht die Tochter vom Imam bin. Normalerweise sage ich den Leuten einfach nein, gar nicht//ok// ich kenne die Leute nicht, weil es nervt mit der Zeit. //Ja// und dann habe ich, ich weiss nicht, warum ich dieser Frau ja geantwortet habe und die hat dann mich, so verflucht (lacht). Es war Sommer und ich habe das Kopftuch wie jetzt angezogen gehabt und (...) Ja, meinen Hals hat man ein wenig mehr gesehen und dann hat sie mich angefangen zämeschisse ${ }^{55}$, ich bin ihr einfach...einfach ihr davon gerannt. Weil ich habe gefunden, Kolleg ${ }^{56}$, ich weiss, was ich machen muss, ich kenne meine Religion, nur weil mein Vater Imam ist, heisst das nicht, dass du mich jetzt verurteilen musst« (Duaa, A 50).

der Bewältigung alltäglicher Lebensprobleme, zur Schlichtung innerfamiliärer Konflikte sowie bei Problemen mit Schulen und Behörden. Häufig, so schildern sie, werden sie auch mitten in der Nacht gerufen oder angerufen. Hinzu kommt noch eine Reihe repräsentativer Aufgaben, wie z.B. Öffentlichkeitsarbeit für die Moscheevereine oder die Mitarbeit in interreligiösen Cefässen (vgl. zu den Aufgaben von Imamen in Moscheevereinen in Deutschland auch Kamp 2007).

55 Wörtlich übersetzt =»zusammenscheissen«. Schweizer Mundartausdruck für verbales, starkes Massregeln, »zusammenstauchen«.

56 Umgangssprachliche, etwas saloppe Art, das Gegenüber anzusprechen, um auszudrücken, dass man sich auf derselben (Hierarchie-)Ebene sieht. 
Duaa entzieht sich dem Druck durch die gesellschaftliche Kontrolle als Tochter des Imam mittels der »Taktik « der widerständigen Mikropraktiken. »Normalerweise « sagt sie den Leuten, die sie ansprechen und die sie nicht kennt, nämlich einfach, sie sei nicht die Tochter des Imam. Sie widersetzt sich also der gesellschaftlichen Kontrolle, indem sie abstreitet, dass der Imam ihr Vater ist, und sich so der Massregelung entzieht.

An diesem Beispiel kann die »Taktik« der widerständigen Mikropraktiken besonders gut verdeutlicht werden: De Certeau konzipiert »Taktiken« resp. deren Kreativität als »Waffe der Schwachen« (Rothfuss 2012: 218): »Taktiken« sind Handlungsweisen, die aus subalternen Positionen hinaus »mit dem Terrain fertigwerden« müssen, das ihnen »so vorgegeben wird, wie es das Gesetz einer fremden Gewalt organisiert (De Certeau 1988: 89). Die Situation, in der Duaa von Gemeindemitgliedern angehalten wird, und potenziell zurecht gewiesen werden könnte, kann als Situation gedeutet werden, die durch »das Gesetz einer fremden Gewalt organisiert « (ebd.) und strukturiert ist - nämlich der sozialen Kontrolle der (für Duaa anonymen) Glaubensgemeinschaft. Mittels ihrer »Taktik« kann sich Duaa einer Normierung entziehen. Wie an dem Beispiel, das Duaa schildert, rekonstruiert werden kann, bietet diese »Taktik« aus der subalternen Position heraus die Möglichkeit, mehr Agency innerhalb eines stark begrenzten »Möglichkeitsraums« (Holzkamp 1983) zu erlangen - oder in De Certeaus Worten die Möglichkeit zur »Bewegung >innerhalb des Sichtfeldes des Feindes« (De Certeau 1988: 89). Wie De Certeau ausführt, muss eine »Taktik« »wachsam die Lücken nutzen, die sich in besonderen Situationen der Überwachung durch die Macht der Eigentümer auftun. (...) Sie kann dort auftreten, wo man sie nicht erwartet. Sie ist die List selber « (ebd.). Duaa nutzt also »listig« die Gunst des Augenblicks und entzieht sich. Wird der (strukturelle) Druck jedoch zu gross, wie die Begegnung mit der "arabischen Frau« illustriert, zieht sie sich zurück. Als sie einmal nicht zu der üblichen widerständigen Mikropraktik griff und nicht abstritt, dass sie die Tochter des Imam sei, wurde sie von einer Frau aufgrund von angeblich nicht eingehaltenen Kleidernormen verurteilt. Duaa blieb nichts anderes übrig, als davonzurennen, um sich einer direkten Konfrontation zu entziehen. Ein »Ausdiskutieren« bzw. offenes Bekunden des eigenen Standpunkts aus der subalternen Position heraus kommt nicht in frage. Die direkte Konfrontation in einem Konflikt stellt für Frauen, bei denen diese »Taktik « rekonstruiert werden konnte, aus ihrer subalternen gesellschaftlichen Position heraus keine Option dar. In dem Moment, in dem eine direkte Konfrontation droht, bleibt ihnen als Handlungsoption also einzig der (geordnete oder ungeord- 
nete) Rückzug, um in der taktischen, »kriegswissenschaftlichen« (De Certeau 1988: 20) Analyse De Certeaus zu verbleiben. Dass ein solcher >Rückzug wie es Duaas »Davonrennen« darstellt, nicht unbedingt nur als Kapitulation vor hegemonialen Überzeugungen gedeutet werden muss, kann aus dem folgenden Nachsatz von Duaa geschlossen werden: »Ich habe gefunden, Kolleg, ich weiss, was ich machen muss, ich kenne meine Religion, nur weil mein Vater Imam ist, heisst das nicht, dass du mich jetzt verurteilen musst...«. Die Aussage weist darauf hin, dass Duaa der Frau, vor der sie davonrennt, keinesfalls das Recht einräumt, so mit ihr zu sprechen, sie zu »verurteilen«. Implizit verdeutlicht wird dies zudem durch das Wort »Kolleg«, mit dem Duaa die Frau als Gegenüber imaginär anspricht: »Kolleg« kennzeichnet eine umgangssprachliche, etwas saloppe Art, ein Gegenüber anzusprechen, mit dem man sich auf derselben reziproken (Hierarchie-)Ebene, als »Kolleg*innen« sieht und nicht unterlegen. Dennoch bleibt eine direkte Konfrontation, ein direktes Aussprechen dieser Gedanken aus. Duaa rennt davon. Durch das Wegrennen entzieht sie sich erfolgreich einer Konfrontation, aus der sie als Suzbalterne potenziell »als Verliererin« hervorgegangen wäre.

Das Herkunftsmilieu von Frauen, bei denen die »Taktik« der widerständigen Mikropraktiken rekonstruiert werden konnte, zeichnet sich durch ständige Bedrohung einer Prekarisierung (Pelizzari 2009) aus. Die Eltern stehen meist in schlecht bezahlten, prekären Arbeitsverhältnissen und ihre Erwerbsbiografien sind von grossen (finanziellen) Unsicherheiten geprägt.

Auch für Duaas Eltern stellt die Finanzierung der Grossfamilie in Duaas Kindheit eine grosse Herausforderung dar. Durch die Erwerbstätigkeit sind sie zeitlich sehr ausgelastet - die Mutter putzt in einer Reinigungsfirma, der Vater ist täglich bis spät abends in der Moschee als Imam tätig; und dennoch ist das Geld stets knapp. Durch die Abwesenheit des Vaters und die ebenfalls grosse Arbeitsauslastung der Mutter sind die Geschwister oft auf sich alleine gestellt. Die grösseren Geschwister beaufsichtigen die Jüngeren. So erstaunt es auch nicht, dass für Duaa im Alltag ihrer Kindheit in erster Linie ihre älteren Geschwister und nicht die Eltern die entscheidenden Bezugspersonen darstellten.

Die langjährige transnationale Flucht über mehrere Aufenthaltsorte sowie die gesellschaftlich prekäre Situation führten bei Duaa zu einem Gefühl einer (sozialen) Deterritorialisiertheit und Heimatlosigkeit. Als Kopftuch tragende Muslima schwarzer Hautfarbe mit »Migrationshintergrund «, die mit einer wenig privilegierten gesellschaftlichen und ökonomischen Position vorlieb nehmen muss, ist Duaa aus intersektioneller Sicht mit wirkmächtigen 
Ausschlussmechanismen konfrontiert. Strukturell gesehen kommen infolge dieser Ausgangslage die Differenzdimensionen Gender, Religion, »Migrationshintergrund«, class und Körper gemeinsam zum tragen. Die zahlreichen gesellschaftlichen Ausschlusserfahrungen, denen sie sich aufgrund der sichtbaren Differenzmarker Hautfarbe (Körper) und Kopftuch (Religion und Gender) ausgesetzt sieht, verstärken das Gefühl einer mangelnden Zugehörigkeit. Nach einem Zwischenfall in einem Zug, bei dem Duaa, die zeit ihres Berufslebens hundert Prozent gearbeitet hatte, von einem älteren Herrn verbal heftig attackiert wird, sie liege doch nur dem Staat auf der Tasche, zieht sie gar in Erwägung, aus der Schweiz wegzuziehen:

»Eine Zeitlang hatte ich wirklich so eine Phase, ähm, was soll ich überhaupt hier in der Schweiz machen, ich werde ja nicht akzeptiert, ich bin in meinem...in meiner Heimat, bin ich ein[e] Ausländer[in], ich bin in der Schweiz ein[e] Ausländer[in]. //Mhm// Ich habe eigentlich gar keine Heimat. //Mhm// Ich habe nirgendwo, wo du, wo ich mich daran halten kann und sagen //mhm// $\mathrm{mou}^{57}$ hier gehöre ich hin. //Mhm// das habe ich gar nicht.« (Duaa, A 41).

Das Gefühl von Heimatlosigkeit spiegelt sich in Duaas Aussage im Ausdruck »Ausländer[in]«. Dieser dient ihr, um die mangelnde (soziale) Anerkennung zu markieren, die sie von der hegemonialen Mehrheitsgesellschaft erfährt, sowohl im Geburtsland ihrer Eltern als auch in der Schweiz und die sie zum Schluss führt, sie sei heimatlos. Wohl fühlt sie sich einzig in »arabischen Ländern«:

»Dann bleibt einem wirklich nichts anderes übrig als die arabischen Länder. (...) Ich, wie gesagt, ich gehöre zur Gesellschaft, es schaut mich niemand blöd an. Ich werde nicht ausgestossen wegen meiner Hautfarbe, meine Kinder können herumrennen, die, meine Kinder werden akzeptiert, das ist genauso wie hier ihr Schweizer, wenn ihr im Zug sitzt und eure Kinder am spielen sind, dass die anderen hinschauen und auch zulächeln euren Kindern« (Duaa, A 52).

Duaa schildert, wie sie im Urlaub Zugehörigkeit erfahren kann. Gleichzeitig wird aus dem Zitat besonders deutlich, wie Duaa insbesondere auch unter der Differenzdimension Körper (Hautfarbe) leidet, aufgrund derer sie gesellschaftlich »ausgestossen « und stigmatisiert wird. Sie hebt hervor, wie sie $\mathrm{Zu}$ -

57 Schweizerische Mundart für »doch«. 
gehörigkeit und Differenz anhand der Behandlung ihrer Kinder in der Öffentlichkeit erfährt. An anderer Stelle erwähnt sie, dass ihre Kinder sich stets besonders brav benehmen sollten und nicht herumrennen, weil sie sonst angefeindet wird, sie habe diese nicht im Griff. Mehrmals überlegt sie mit ihrem Mann, auszuwandern. Diese Pläne scheitern schliesslich am Veto ihres Vaters.

Riegel (2004) legt in ihrer Studie über Orientierungen und Handlungsformen junger Migrantinnen in Deutschland dar, dass Prozesse der sozialen Einund Ausgrenzung eng mit dem Kampf um gesellschaftliche Anerkennung und Zugehörigkeit verknüpft sind. Die Frage der Zugehörigkeit zur hegemonialen >Mehrheitsgesellschaft zielt nach Riegel nicht primär »auf formale Aspekte $a b$, sondern auf ihre soziale Anerkennung, Wertschätzung und ihre soziale und emotionale Einbindung (ebd.:353). Eng damit verbunden und zu verstehen ist Riegel zufolge die Konzeption der Frauen von Heimat, die nicht auf einer formellen Zugehörigkeit basiert, sondern auf der Sehnsucht nach einer sozialen Heimat, im Sinne »von affektiven Bindungen und sozialer Geborgenheit« (ebd.). Aus dem voranstehenden Zitat von Duaa kann rekonstruiert werden, dass auch sie sich nach einer sozialen Heimat sehnt und es hierbei nicht um eine formale Zugehörigkeit, sondern um einen Ort geht, an dem sie soziale Anerkennung erfahren kann, »wo ich mich daran halten kann und sagen (...) mou hier gehöre ich hin«. Die zahlreichen Ausschlusserfahrungen führen zu einem Gefühl der Heimatlosigkeit, der mangelnden Anerkennung und $\mathrm{Zu}$ gehörigkeit. Wie Riegel feststellt, setzt eine gelingende Anerkennung die »Bereitschaft der Mehrheitsgesellschaft voraus, die eigene Dominanz und damit verbundene Normalitätsvorstellungen aufzugeben und einem gleichberechtigten Aushandlungsprozess freizugeben« (ebd.: 358). Diese gesellschaftliche Bereitschaft ist aus Duaas Perspektive aufgrund der intersektionell wirkendenden, einschränkenden, hegemonialen Strukturen nicht erfahrbar, zu zahlreich sind ihre Ausschlusserfahrungen, die sie täglich macht.

\section{b) Die Rolle der Religion und der Differenzkategorie "Muslimin « hinsichtlich der Bildungsbiografie: als Muslimin stigmatisiert}

Duaa wurde in ihrer Familie religiös sozialisiert. Als Tochter eines Koranlehrers genoss sie zudem eine grundlegende formale religiöse Bildung. Sie ist glaubensgewiss und ihre Religiosität stellt für sie als sozialisatorisch erworbene Selbstverständlichkeit eine umfassende Lebensordnung dar. 
Im Gegensatz zu ihren Eltern ist Duaa nicht Mitglied in einem religiösen Verein, auch vergemeinschaftet sie sich nicht in virtuellen Feldern wie bspw. auf Social Media. Für so was habe sie keine Zeit, sagt sie, neben ihrem 100-\%Arbeitspensum sei sie froh, wenn sie genug Zeit finde, die sie mit ihren Kindern verbringen könne.

Gleichwohl ist Duaa auf der Suche nach einem Weg, wie sie als Musli$m a$ in der hegemonialen Mehrheitsgesellschaft bestehen kann. Aufgrund unterschiedlichster intersektionell zusammenwirkender Differenzdimensionen sieht sie sich fast täglich mit Ausschlusserfahrungen konfrontiert:

»Ich sehe es jeweils im Zug, es sitzt niemand neben mir //mhm// wenn ich das Kopftuch richtig an habe //mhm// Egal wie voll es ist. Es sitzt niemand neben mir. (...). Liegt es jetzt an meiner Hautfarbe, liegt es jetzt dran, dassdass ich ein Kopftuch an habe? (...) Ich weiss manchmal wirklich nicht, wie ich meine eigene Religion, hier in der Schweiz, //mhm// ausleben soll (...) ja, schau dir das hier an, ziehst du ein Kopftuch richtig an, wirst du behandelt, wie der letzte Dreck« (Duaa, A 51).

Als Hijab tragende Muslima schwarzer Hautfarbe ist Duaa zahlreichen Ausgrenzungsprozessen ausgesetzt. Sichtbar als gläubige Muslima im öffentlichen Raum wird Duaa insbesondere dann, wenn sie einen Hijab »richtig«, bzw. so dass auch der Hals bedeckt ist, anzieht. Durch das Tragen eines religiösen Symbols, das Frauen vorbehalten ist, entfaltet die Differenzkategorie »Muslimin« im Zusammenspiel Gender und Religion volle Wirksamkeit. Als Beispiel hierfür führt Duaa an, dass sie »wie der letzte Dreck«behandelt wird, wenn sie »ein Kopftuch richtig« anzieht.

Als glaubensgewisse Frau, für welche das Bedecken ihrer Haare »ein nicht verzichtbarer Ausdruck ihrer Identität ist « (Scherr et al. 2015: 149), kann sich Duaa aufgrund des intersektionellen Zusammenspiels der Differenzdimensionen Gender und Religion Ausschlusserfahrungen der Differenzkategorie »Muslimin« kaum entziehen. Hinzu kommt für Duaa noch die Differenzdimension Körper (Hautfarbe), aufgrund derer sie zusätzlichen rassistischen Anfeindungen ausgesetzt ist. Täglich erfahrbar wird das Zusammenspiel der Differenzdimensionen Gender, Religion und Körper für Duaa und die Frauen, bei denen diese "Taktik« rekonstruiert werden konnte, in kleinen alltagsrassistischen Handlungen von Repräsentant*innen der hegemonialen Gesellschaft - wie z.B. die von Duaa geschilderte Situation verdeutlicht, dass sich im Zug niemand neben sie setzten will, und zwar »egal wie voll es ist«. Unter diesen Vorzeichen ist auch die schon fast rhetorisch anmutende Frage 
zu lesen, ob es nun an der Hautfarbe oder am Kopftuch liege (dass niemand neben ihr sitzen wolle). Sie fragt sich weiter - auch diese Frage mutet rhetorisch an - wie sie unter diesen Umständen ihre »eigene Religion hier in der Schweiz (...) ausleben soll« bzw. als Hijab tragende Muslima schwarzer Hautfarbe bestehen soll.

Rommelspacher beschreibt solche alltagsrassistischen Grenzziehungsprozesse, wie sie diese Frauen täglich erfahren, als »Identifikationsrituale« mithilfe derer im Alltag »die Anderen als Fremde identifiziert werden« (Rommelspacher 2011: 31). Bei diesen und anderen gesellschaftlichen "Identifikationsritualen« (ebd.) werden die Frauen als gesellschaftlich »nicht zugehörig« bzw. »fremd« und »subaltern« markiert.

Durch solch intersektionelle stark wirksame Stigmatisierungen, die sich in zahlreichen alltagsrassistischen Ausschlusserfahrungen äussern, erstaunt es nicht, dass Duaa versucht, im öffentlichen Raum in der Schweiz so wenig wie möglich als Muslima sichtbar zu werden. Als Mittel sich zu wehren bleibt ihr als »Waffe der Schwachen« (Rothfuss 2012: 218) die »Taktik « der widerständigen Mikropraktiken. Besonders verdeutlicht werden kann die »Taktik« der widerständigen Mikropraktiken an der Art, wie Duaa ihr Kopftuch wickelt. Als ich sie darauf anspreche, lacht Duaa:

»]a, für mich ist mein Kopftuch, weil ich ziehe es modern an, weil momentan, man zieht so recht über den Islam, man zieht den Islam in den Dreck. Ich weiss nicht, wie ich mich verhalten soll. //Mhm// Ich würde gerne das Kopftuch richtig anziehen, aber ich habe Angst, dass mir irgendetwas passiert, nur weil ich richtig an habe. //Mhm.// Das ist momentan das. //Mhm.// Auch nach dem elften September, man hat nur noch über den Islam schlecht geredet. //Mhm.// Und dann weiss ich nicht, wie ich mich selber verhalten soll. //Mhm.// Zu meiner eigenen Religion. Es klingt traurig, //mhm// aber das ist wahr //mhm.// Ich möchte nicht draussen verprügelt werden für Menschen, die krank sind, die den Islam brauchen, um schlechte Dinge zu machen //Mhm// möchte ich nicht drunger cho ${ }^{58}$ « (Duaa, A 51).

Obwohl für Duaa ihre Religion eigentlich eine umfassende Lebensordnung darstellen würde, scheut sie, wie zuvor geschildert, Konfrontationen mit Repräsentierenden der hegemonialen Gesellschaft, da sie aus ihrer subalternen und mit wenig Macht ausgestatteten Position heraus im Vorhinein als

58 Schweizer Mundartausdruck wörtlich übersetzt »darunter kommen«. Sinngemäss könnte die Wendung mit »den Kürzeren ziehen« übersetzt werden. 
Verliererin feststehen würde. Duaa spricht einen weiteren Punkt an, der für sie alltäglich relevant wird, nämlich die Abhängigkeit ihrer Ausschlusserfahrungen von der geopolitischen Entwicklung und die damit gekoppelte Angst vor potenziellen antimuslimischen Übergriffen. Als ich sie am Tag nach dem Charlie-Hebdo-Attentat ${ }^{59}$ treffe, wirkt sie verstört. Sie hatte in der Vergangenheit immer wieder die Erfahrung gemacht, dass nach islamistischen Attentaten insbesondere in Europa ihre alltäglichen Ausschlusserfahrungen massiv zunahmen. Nun hatte sie zufällig genau in dieser Zeit eine Parisreise mit ihrer Schwester geplant. Aus Angst vor antimuslimischen Übergriffen sagte sie diese Reise nun kurzerhand ab.

Wie die geschilderte Episode aufzeigt und wie mir immer wieder, insbesondere von Hijab tragenden Frauen berichtet wurde, fühlen sich Musliminnen nach islamistisch motivierten Anschlägen verstärkt von »antiislamische[m] Rassismus « (Rommelspacher 2011: 28) bedroht. Kopftuch tragende Musliminnen sind also unmittelbar von der grassierenden Angst vor islamistischen Attentaten betroffen und werden via Religion als einer Gruppe zugehörig »markiert«, die potenziell ein Sicherheitsrisiko und somit eine Bedrohung darstellt. Zudem müssen sie sich von Vergeltungshandlungen fürchten. Dies spiegelt sich - verstärkt nach terroristischen Anschlägen - in einer Zunahme von alltagsrassistischen Übergriffen gegen Musliminnen und Muslime. Wie Lingen-Ali und Mecheril es treffend formulieren:

»Religion als Kategorie dient hierbei einer Markierung von Personen (...), die vor allem im Rahmen von Sicherheitspolitiken und -dispositiven sowie dem diesen zugeordneten (Alltags-)Denken funktional ist « (Lingen-Ali/Mecheril 2016: 22).

Der von Lingen-Ali und Mecheril dargelegte Zusammenhang zwischen Sicherheitspolitiken und dem diesen zugeordneten Alltagsdenken wird für die jungen von mir interviewten Musliminnen in ihrem Alltag lebenspraktisch oftmals unmittelbar relevant. Aufgrund der intersektionell äusserst

59 Terroranschlag auf die Redaktion der Satirezeitschrift Charlie Hebdo in Paris am 7. Januar 2015 mit zwölf Toten und mehreren Verletzten. Der Anschlag wird in Verbindung mit Al-Qaida-Jemen gebracht; als Motiv werden die zahlreichen vom Magazin veröffentlichten Mohammed-Karikaturen vermutet. Der Anschlag löste europaweit Bestürzung aus und entfachte eine beispielslose (online) Solidaritätsbewegung (und eine Kontroverse um diese), zu deren Symbol die Worte »]e suis Charlie« (»Ich bin Charlie«) geworden sind (Badouard 2016). 
wirkmächtigen strukturellen Einschränkungen durch die zusätzliche Differenzdimension Körper (Hautfarbe) erstaunt es nicht, dass Frauen, bei denen die »Taktik« 4 rekonstruiert wurde, besonders vulnerabel und abhängig von solchen Zuschreibungen und somit besonders der aktuellen sicherheitspolitischen Lage unterworfen sind. Eine junge Hijab tragende Frau erzählte mir eindrücklich, wie sie eines Morgens, ohne zuvor die Tagesgeschehnisse medial studiert zu haben, ein öffentliches Verkehrsmittel benutzte und einzig an den Reaktionen der anderen Fahrgäste feststellen konnte, dass sich ein Attentat ereignet haben musste (Feldprotokoll, Februar 2016).

Duaas Ausweg, sich solchen Konfrontation nicht (oder zumindest weniger) stellen zu müssen, besteht darin, ihr Kopftuch »modern« zu tragen, wie sie es im voranstehenden Zitat nennt. Sie räumt ein, dass sie das Kopftuch gerne »richtig« anziehen würde, es jedoch aus Angst bleiben lässt. Der Ausweg, den sie wählt, kann mit De Certeau (1988: 89) als das Erlangen von mehr Agency in einem intersektionell äusserst stark beschränkten »Möglichkeitsraum« (Holzkamp 1983) gedeutet werden. Nach De Certeau sind Alltagspraktiken immer auch Aneignungspraktiken, die auf dem eigensinnigen »Gebrauch « des Gegebenen basieren (De Certeau 1988:13). Ein solch eigensinniger Gebrauch des Gegebenen zeugt, wenn auch im mikroskopisch kleinen Bereich, wiederum vom Ausdruck einer subversiven Haltung gegenüber einer hegemonialen Deutungsmacht (vgl. Metzger 2013: 90). In dieser Semantik kann die Art, wie Duaa ihr Kopftuch schlingt, als (eigensinniger) »Gebrauch « des Gegebenen gelesen werden. Das »Gegebene« wäre hierbei einerseits, dass für Duaa die Bedeckung ihrer Haare ein unverzichtbarer Teil ihrer religiösen Identifikation ist, andererseits wäre das »Gegebene« das Zugehörigkeitsregime der hegemonialen Gesellschaft hinsichtlich Kopftuch tragender, (nicht weisser) Frauen. Duaa wählt jedoch eine widerständige Mikropraktik, die dies nicht (allzu) offensichtlich macht. In diesem Sinne stellt Duaas Art sich zu bedecken eine »Taktik« dar, die - in De Certeaus Worten - »wachsam Lücken« nutzt, welche »sich in besonderer Überwachung durch die Macht der Eigentümer auftun« (ebd.: 89). Die »Taktik« der widerständigen Mikropraktiken ermöglicht es ihr, eine komplette »Assimilation« an die hegemoniale Mehrheitsgesellschaft zu vermeiden und die öffentliche Sichtbarkeit als Muslima wenigstens teilweise zu umgehen oder mindestens uneindeutig zu halten und sich so vor einer Konfrontation mit Repräsentierenden der hegemonialen Mehrheitsgesellschaft zu schützen. Gleichzeitig umgeht sie damit eine komplette Aufgabe der Bedeckung ihrer Haare, die für sie ein unverzichtbarer Teil ihrer Identifikation als Muslima darstellt. 
Obwohl Duaa hinsichtlich des Hijabs quasi aus der Not eines intersektionell stark begrenzten »Möglichkeitsraums« (Holzkamp 1983) einen Kompromiss macht, gilt es doch festzuhalten, dass religiöse Gebote für Duaa, solange diese in der Öffentlichkeit nicht auffallen, eine umfassende Lebensordnung darstellen. So verzichtet Duaa auf das öffentliche Beten z.B. am Arbeitsplatz. Sie verlegt ihre religiöse Selbstrepräsentation quasi in die Verborgenheit oder das Private. Religiöse Gebote, die abseits der Öffentlichkeit befolgt werden können, hält sie jedoch peinlichst genau ein. Das zeigt sich bspw. bei den Speisegeboten:

»Ähm, wenn ich, ich habe noch nie Schwienigs ${ }^{60}$ gegessen, weil ich immer drauf wirklich schaue und dasselbe bei meinen Kindern, ähm, sie haben, so Süssigkeiten gehe ich immer beim [Spezialdetailhändler für Süssigkeiten] //mhm// gehe ich immer kaufen und das Vegetarische nehme ich oder vegan. Ich zahle lieber drauf, dafür kann ich $100 \%$ sicher sein, dass nichts Tierisches drin ist. Es ist manchmal mühsam //mhm// aber es bleibt mir nichts anderes übrig« (Duaa, A 44).

Duaa scheut keine (finanziellen) Mühen, halal Esswaren einzukaufen. Der gegenwärtige Trend des veganen Essen und der veganen Speisen machen es Duaa etwas leichter, auch ausserhalb der teuren Halal-Läden Speisen und z.B. Süssigkeiten für die Kinder einzukaufen. Diese Aussage zeigt auf, welche Bedeutung Duaa dem Einhalten religiöser Gebote eigentlich beimessen würde, würde sie nicht durch intersektionell wirksame Barrieren daran gehindert.

Die Differenzkategorie »Muslimin« fällt also bei Frauen, bei denen die »Taktik« der widerständigen Mikropraktiken rekonstruiert werden konnte, im Vergleich zu den anderen drei Typen ausserordentlich stark ins Gewicht. Ein Grund hierfür besteht darin, dass neben den intersektionell wirkenden Differenzdimensionen Gender, Religion, »Migrationshintergrund « und »class« eine weitere Differenzdimension, nämlich die des Körpers (hier in Gestalt der Hautfarbe), zusätzlich intersektionell verstärkend wirkt. Als weiterer Faktor für die besondere Wirksamkeit der von Duaa gemachten Ausschlusserfahrungen fällt zusätzlich der Umstand ins Gewicht, dass Duaa sich religiös nicht vergemeinschaftet. Religiöse Vergemeinschaftungen stellen Gefässe dar, innerhalb derer Ausschlusserfahrungen verarbeitet und Zugehörigkeit erfahren werden kann (vgl. bspw. »Taktik« des Typus 1 und 3).

60 Schweizer umgangsprachlicher Mundartausdruck für »Schweinefleisch«. 


\section{c) "Taktik" gesellschaftlicher Selbstpositionierung hinsichtlich der Bildungsbiografie: Agency durch widerständige Mikropraktiken} (Bildungs-)Biografien von jungen Frauen, bei denen die »Taktik« der widerständigen Mikropraktiken rekonstruiert werden konnte, zeichnen sich durch äusserst starke Momente der Fremdbestimmung aus. Der intersektionell begrenzte »Möglichkeitsraum« (Holzkamp 1983), innerhalb dessen sie - (bildungs-)biografisch gesehen - durch die »Taktik« der widerständigen Mikropraktiken mehr Handlungsfähigkeit (Agency) erlangen können, ist im Vergleich zum Handlungsspielraum der "Taktiken" von Typus 1, 2 und 3 nochmals stärker eingeschränkt: Neben den Differenzdimensionen Gender, »Migrationshintergrund « und »class« und Religion wirkt hier zusätzlich die Differenzdimension Körper (Hautfarbe) intersektionell verstärkend. Der intersektionell beschränkte Handlungsspielraum der Frauen ist zeitweise so verschwindend klein, dass selbst die »Taktik« als »Waffe der Schwachen« (Roth fuss 2012: 218) versagt und die Fremdbestimmung gänzlich obsiegt.

Im Zuge ihres bildungsbiografischen Verlaufs erlebte auch Duaa immer wieder entscheidende Konstellationen der Fremdbestimmung aufgrund ihrer wenig privilegierten Ausgangslage. Ihre Eltern kannten das Schulsystem kaum und konnten sie nicht unterstützen. Die bildungsbiografischen Momente der Fremdbestimmung lassen sich bei den Frauen besonders nachdrücklich am Übergang der obligatorischen zur nachobligatorischen Ausbildung $^{61}$ festmachen, wie im Folgenden exemplarisch verdeutlicht werden soll.

Duaa absolvierte neun Schuljahre in der Realstufe. Anschliessend konnte sie ihren langgehegten Berufswunsch Köchin nicht angehen, weil ihr Vater nicht wollte, dass sie als Mädchen spätnachts alleine von der Lehrstelle nach Hause fuhr (Feldprotokoll Januar 2015). Obwohl sich der Vater gegen eine Lehrstelle seiner Tochter mit unregelmässigen Arbeitszeiten aussprach, war er jedoch als Akademiker keineswegs für eine frühe Heirat und gegen eine Ausbildung seiner Töchter. Duaa schildert, wie der Vater sie von klein auf ermahnte:

"Schau, dass du weiterhin Geld verdienen kannst, schau, dass du niemals abhängig von einem Mann wirst. Auf dieser Welt kann alles passieren, du musst auf alles immer vorbereitet sein. (...). Meinem Vater ist es wichtig, dass wir nicht abhängig vo-von Männern werden, weil es ja in der Kultur,

61 Zu fremdbestimmten Übergängen von obligatorischer zu nachobligatorischer Ausbildung in Bildungsbiografien von Jugendlichen mit »Migrationshintergrund «vergleiche Mey (2015: 236). 
oder äh keine Ahnung, im [Land in der Sahelzone] sind eigentlich Männer vielviel mehr arbeiten gegangen, jetzt bei meinen, bei meinem Vater und bei meiner Mutter sind, seine Geschwister sind in die Schule gegangen. Die Ceschwister meiner Mutter sind auch in die Schule gegangen, studieren gegangen und alles. Ich weiss nicht, was er gesehen hat oder was er alles schon in seinem Leben erlebt hat. Aber er hat uns schon von klein auf gesagt, er hat einen Sohn, er weiss es, aber er schaut uns alle so an wie Knaben, schaut einfach, dass ihr niemals von einem Mann abhängig werdet« (Duaa, A 36).

Wie aus dem Zitat ersichtlich wird, besass der Vater klare Vorstellungen hinsichtlich der Ausbildung seiner Töchter. Diese richteten sich primär auf den Zweck einer finanziellen Unabhängigkeit aus, wohl nicht zuletzt aufgrund der Erfahrung der ständig prekären finanziellen Lage der Familie und der diesbezüglich drückenden Verantwortung. Duaa forderte er wie ihre Schwestern stets auf, »niemals abhängig« von einem Mann zu werden. Aus der Schilderung wird weiter deutlich, dass Duaa sich nicht genau im Klaren ist, weshalb der Vater diese Ansicht so dezidiert vertritt. Sie führt dies auf Erlebnisse des Vaters, die in der Vergangenheit liegen und die sie selbst nicht kennt, zurück. So begründet der Vater seine Ansicht auch mit unvorhersehbaren Lebensereignissen. Diese erfordern eine >Vorbereitung seiner Töchter und beinhalten laut Duaas Schilderungen insbesondere die (finanzielle) Unabhängigkeit von Männern. Diesbezüglich stellt er seine Töchter seinem einzigen Sohn gleich. Diese väterliche Sicht der Dinge ist für Duaa keineswegs selbstverständlich; sie empfindet sie als gesellschaftlich nicht unbedingt übliches Spezifikum der sozialen Herkunft der Eltern, die beide Akademikerfamilien entstammen.

Ungeachtet der väterlichen Ideen scheitert Duaas langgehegter Berufswunsch Köchin letztlich an den Bedenken des Vaters bezüglich des (nächtlichen) Arbeitswegs seiner Tochter, was sicherlich nicht zuletzt genderspezifische Gründe gehabt haben dürfte. Ein offenes Aufbegehren oder Infrage stellen dieser Entscheidung des Familienoberhaupts stellt für Duaa jedoch aufgrund ihrer Sozialisation keine Option dar. Duaas frühe Heirat und die Weigerung, eine vom Vater erwünschte weiterführende Ausbildung zu besuchen, kann jedoch auch als widerständige Mikropraktik gegen den durch starke Fremdbestimmung geprägten Übergang von Schule zu nachobligatorischer Ausbildung gelesen werden (vgl. unten).

Nachdem sie sich nicht auf Kochlehrstellen bewerben durfte, sank Duaas Interesse an der Berufswahl rapide. Im Alleingang und ohne substanzielle Hilfe von Bezugspersonen war sie nicht in der Lage, eine passende, weiter- 
führende Lösung nach der obligatorischen Schule zu finden. So besuchte sie nach der obligatorischen Schule als Übergangslösung ein berufsvorbereitendes, zehntes Schuljahr, ein sogenanntes »Brückenangebot«. »Brückenangebote sind kantonale, schulische Angebote, die sich an Jugendliche richten, die nach dem 9. Schuljahr keine Anschlusslösung gefunden haben und über keinen Abschluss auf der Sekundarstufe II verfügen (vgl. bspw. im Kanton Bern, ERZ 2018a). In einem solchen »Brückenangebot«, einem zehnten Schuljahr, das einen Lehrvertragsabschluss zum erklärten Ziel hatte (vgl. bspw. ERZ 2018b) wurde Duaa anschliessend, wie sie erzählt, von einer Lehrerin regelrecht dazu "gezwungen«, sich auf eine Lehrstelle zu bewerben, die sie keinesfalls wollte:

»Und somit musste ich das aufgeben und eh damals habe ich noch die BFF (10. Schuljahr) gemacht und die Lehrerin hat mich eben dazu gezwungen, bei XXX [grosse Schweizer Detailhandelsfirma] zu bewerben. (...) Entweder oder. Entweder bewerbe ich mich jetzt bei XXX oder ich-ich kann gerade mit dem, mit der Schule aufhören. (...). Dann habe ich so gedacht, easy (...), wenn man eine Stelle nicht möchte und nicht interessiert daran ist, dann schaut man auch, dass man nicht angenommen wird (halbes Lachen). Also habe ich durchgestrichen, tipexlet wirklich es war einfach eine hässliche Bewerbung. Weil ich einfach diesen Job nicht wollte« (Duaa, A 30).

Aus Duaas Schilderungen kann rekonstruiert werden, dass der Moment des Übergangs von der obligatorischen zur nachobligatorischen Ausbildung für sie gleich ein doppeltes Moment der Fremdbestimmung darstellte. Einerseits durch die Aufgabe ihres eigentlichen Berufswunschs Köchin, andererseits setzte sie die Lehrperson des 10. Schuljahrs, das sie besuchte, massiv unter Druck. Wie Mey (2015: 251-252) verdeutlicht, ist eine solche Art der Fremdbestimmung von Jugendlichen mit »Migrationshintergrund « am Übergang von obligatorischer zu nachobligatorischer Ausbildung mit wenig privilegierten Ausgangslagen nicht unüblich. Mey zeigt auf, dass Jugendliche teilweise durch berufsvorbereitende Praktika in »Brückenangeboten« in tendenziell unbeliebte Berufe »hineinberaten« werden, deren Lehrstellen nicht besetzt werden konnten; dies als Alternative zu einer antizipierten drohenden Arbeitslosigkeit (ebd.). Exakt in einer solchen von Mey beschriebenen Ausgangslage befand sich Duaa. Ihre Lehrperson »beriet« sie in eine Berufsrichtung, die Duaa nicht wollte. Sie fügte, wie Duaa erzählt, an, dass sie, wenn sie sich nicht bewerbe, erst gar nicht mehr zur Schule kommen müsse. Aus dieser »Drohung « kann rekonstruiert werden, dass die Lehrperson eine dro- 
hende Arbeitslosigkeit von Duaa antizipierte: Sie war offenbar der Ansicht, dass Duaa die von ihr vorgeschlagene (unbeliebte) Lehrstelle nicht als Chance betrachtete und sie keine andere Anschlusslösung finden würde, wenn sie sich nicht bewarb, und dass sie in diesem Falle gar nicht mehr zur Schule kommen müsse. Hatte doch das »berufsvorbereitende« 10. Schuljahr, das sie besuchte, wie viele andere »Brückenangebote« explizit einen Lehrvertragsabschluss zum Ziel (vgl. bspw. ERZ 2018b). ${ }^{62}$

Obwohl Duaa der Drucksituation ausgesetzt war, sich auf eine Lehrstelle bewerben zu müssen, die sie keinesfalls wollte, blieb sie zunächst noch zuversichtlich. Sie vertraute auf eine eigene selbstbestimmte Handlungsfähigkeit (Agency): »Wenn man eine Stelle nicht möchte und nicht interessiert daran ist, dann schaut man auch, dass man nicht angenommen wird«. Weil Duaa direkte Konfrontationen mit Repräsentanten der Mehrheitsgesellschaft jedoch scheut, da sie aufgrund ihrer mit wenig Macht ausgestatteten, subalternen Position im Vornhinein »als Verliererin« eines Machtkampfs feststehen würde, versuchte sie auch hier nicht, sich auf direktem (sprich: konfrontativem) Weg gegen die "Anordnung« der Lehrperson zu wehren. Dessen ungeachtet wehrte sie sich mittels der »Taktik« der widerständigen Mikropraktiken und erstellte absichtlich eine möglichst »hässliche Bewerbung«. Sie hoffte, damit zu ihrem Ziel zu kommen: nämlich ohne direkte Auseinandersetzung mit der Lehrperson den Job, den sie nicht haben wollte, auch nicht zu erhalten. Doch im Übergang zur nachobligatorischen Ausbildung versagte selbst ihre »Taktik« der widerständigen Mikropraktiken als »Waffe der Schwachen« (Rothfuss 2012: 218): Der Detailhändler, welcher über etliche, schwer zu besetzende Ausbildungsplätze verfügte, lud sie ein, prüfte sie und ihr wurde eine Lehrstelle

62 Jugendliche sind bei Bildungsentscheidungen auf die Unterstützung von glaubwürdigen Bezugspersonen - wie z.B. Eltern oder Lehrpersonen - angewiesen (Neuenschwander 2011). Eltern nehmen als ssignificant others (Woelfel et al. 1971 zit.n. Bader/Fibbi 2012: 24) eine zentrale Rolle in Bildungslaufbahnen und -entscheidungen von Kindern und Jugendlichen ein. Wie aus den erhobenen Bildungsbiografien rekonstruiert werden konnte, kennen die Eltern der Frauen des untersuchten Samples das Schulsystem in den allermeisten Fällen zu wenig und können deshalb bei schulischen Übergängen keine oder wenig Unterstützung bieten. Durch die soziale Positionierung der Frauen als Kinder von Migrant"innen der ersten Ceneration besteht für sie demzufolge eine überproportional grosse Abhängigkeit von professionellen Exponenten des Bildungssystems (Lehrpersonen, Berufsberater etc.). Hierbei besteht die Gefahr, dass Jugendliche in »Lösungen« hineinberaten werden, die weder ihren Berufswünschen noch kognitiven Fähigkeiten entsprechen, sondern tendenziell den sozioökonomischen Hintergrund der Eltern reproduzieren (vgl. hierzu Mey 2015). 
angeboten, die sie dann unter dem zu gross gewordenen strukturellen Druck zwangsweise annahm.

Duaas Wunsch nach einem eigenständigen Lebensentwurf und einer Lehrstelle als Köchin blieb also auf der Strecke und kam »durch das Zusammenwirken von wenig privilegierter Ausgangslage und forcierter beruflicher Platzierung « (Mey 2015: 237) in Bedrängnis. Duaa und die anderen Frauen, bei denen diese »Taktik« rekonstruiert werden konnte, fanden letztlich aufgrund erzwungener Platzierung den Weg in einen Beruf, den sie gar nicht wollten. Sie wurden entweder von Lehrpersonen, Bezugspersonen und Erwachsenen dazu gedrängt, unbeliebte Arbeitswege einzuschlagen, die kaum ihren Bedürfnissen entsprachen und tendenziell die wenig privilegierte soziale Stellung der Eltern reproduzierten (vgl. hierzu ebd.: 256).

Der Wunsch nach Eigengestaltung der Bildungsbiografie und nach autonomen Lebensentwürfen mussten Duaa und die anderen Frauen aufgeben. Oder wie Mey solche Ernüchterungsprozesse in »minimalen Möglichkeitsräume[n]« (ebd.: 250) umschreibt:

»Die Jugendlichen müssen realisieren, wie das internalisierte meritokratische Prinzip im Kontext sozialer Ungleichheitsverhältnisse - und dies bedeutet für sie: angesichts ihrer wenig privilegierten Ausgangslage und diskriminierender Praxen - ausgehebelt wird und ihre Anstrengungen zur Realisierung eigengesetzter Ziele ins Leere zu laufen drohen« (ebd.).

Duaa ergab sich schliesslich diesem Prozess eines durch Eltern und Lehrpersonen stark fremdbestimmten Übergangs in eine nachobligatorische Ausbildung. Sie verblieb anschliessend gar bis heute in dem Beruf, den sie nie wollte, selbst beim selben Arbeitgeber, bei dem sie ihre Lehre absolvierte. Dabei verlief ihre Berufsausbildung und die spätere Arbeitstätigkeit hinsichtlich intersektionell wirkender Ausschlusserfahrungen alles andere als unproblematisch. In ihrer weiteren Berufsbiografie gewannen nämlich neben den sich bereits bisher in ihrer Bildungsbiografie manifestierten Differenzdimensionen »class«, Gender, »Migrationshintergrund«, die Differenzdimensionen Religion und Körper zunehmend an Bedeutung:

»Und eh, ich weiss nicht, ich bin einmal an der Kasse gewesen, ist ein Journalist zu mir einkaufen gekommen und hat dann der XXX [Detailhandelfirma bei der Duaa ihre Lehre absolvierte] geschrieben und ähm...ich kann mich nur noch erinnern, dass der Filialleiter dazumal und der Vize mich ins Büro geholt haben. (...). Ja, somit musste ich dann das-das letzte Jahr, welches ich 
noch vor mir hatte, ohne Kopftuch machen. NG: Aber wie hat sich das denn abgespielt? Also dieser Journalist hat geschrieben //D: der hat geschrieben, ja// und sich beklagt? D: Eben, das weiss ich nicht, weil ich, dieses Schreiben habe ich nie zu Gesicht bekommen. Ich habe es nie gelesen oder es hat mir niemand etwas gezeigt. Sie sind dazumal zu mir gekommen, haben mich ins Büro gerufen, haben gesagt, ja, XXX [Detailhandelsfirma bei der Duaa ihre Lehre absolvierte] hat ein Kopftuchverbot gemacht« (Duaa, A 34).

Aus Duaas Schilderung dieser Episode spricht der Duktus einer Ohnmacht, der von hegemonialer Fremdbestimmung zeugt: Sie wird von ihren Vorgesetzen ins Büro zitiert und vor vollendete Tatsachen gestellt, nämlich dass die Firma XXX, wo sie ihre Lehre absolvierte und bei der es ihr in den zwei ersten Lehrjahren problemlos erlaubt war, einen Hijab zu tragen, plötzlich aufgrund einer Intervention ein »Kopftuchverbot « erliess. Obwohl sie weder Schreiben noch Anliegen des Journalisten kannte, musste sie die daraus resultierenden Konsequenzen tragen: Sie musste sich - wollte sie ihre Lehre beenden - dem Zwang beugen und ihr Kopftuch ausziehen.

Nach einer Absprache mit ihren Eltern fügte Duaa sich. Sie musste erfahren, dass es keinen Sinn macht, sich zu wehren, wenn sie von Anfang an als Verliererin der ungleichen strukturellen Verteilung von Macht und Anerkennung feststeht und kaum über Handlungsspielraum verfügt. Einmal mehr ist sie sozusagen auf »Gedeih und Verderb« dem intersektionellen Zusammenspiel der Differenzdimensionen Religion und Gender ausgeliefert, das sie anhand des religiösen Symbols Hijab als Muslima sichtbar und verletzbar macht. Wirkmächtig und unmittelbar erfährt sie den strukturellen Druck und das intersektionelle Zusammenspiel von Differenzdimensionen im Kontext der ungleichen Machtverteilung von Repräsentierenden der hegemonialen Gesellschaft (Chef, Vize, Journalist). In solchen Situationen wird der »Möglichkeitsraum« von Duaa so beengt, dass selbst widerständige Mikropraktiken versagen. Die beschriebene Erfahrung des Ausziehens des Hijabs im Zusammenhang mit ihrer Ausbildung dürfte nicht zuletzt zu Duaas Entscheidung beigetragen haben, das Kopftuch so zu tragen, wie sie es heute tut (vgl. Kap. $5.4 .2 b)$

Die Erfahrung eines wirkmächtigen, einschränkenden Zusammenspiels der Differenzdimensionen Gender, »Migrationshintergrund«, »class«, Religion und Körper (Hautfarbe) sollte sie während ihrer Lehrzeit nicht das letzte Mal machen. Täglich erlebt sie bei ihrer Arbeit an der Kasse rassistische Anfeindungen und Ausschlusserfahrungen. Sie beschreibt, wie Leute ih- 
re eingekauften Waren teilweise absichtlich nicht aufs Band legen, damit sie es für sie erledigen muss oder wie sie in anderen Sprachen angesprochen wird und dann sagen muss: »sorry, ähm, können- geht es auch auf Deutsch?« (Duaa lachend, A 34). Wenn sie auf solche Fragen auf Schweizerdeutsch antwortet, wird sie, wie sie erzählt, schockiert angeschaut und mit erstaunten Aussagen konfrontiert: »Sie können ja Schweizerdeutsch, eh, das gibt's ja nicht!« (Duaa äfft die Kunden mit verstellter Stimme nach, was als Ausdruck der mangelnden Anerkennung, die sie erlebt, gedeutet werden kann, Duaa, A 34). Ihre Sichtbarkeit für die Kundschaft und die Arbeit an der Kasse, quasi in der »der ersten Reihe« macht Duaa hinsichtlich Ausschlusserfahrungen aufgrund eines intersektionellen Zusammenspiels der Differenzdimensionen besonders vulnerabel. Trotz dieses nicht immer einfachen Verlaufs ihrer Lehrzeit schloss Duaa ihre Ausbildung mit hervorragenden Noten $a b$. Als der Lehrmeister sie fragte, ob sie "weitermachen« wolle, winkte sie jedoch ab. Nach ihren Erfahrungen mit dem Bildungssystem war Duaa für einen weiterbildenden berufsbiografischen Schritt nicht $\mathrm{zu}$ motivieren. Nach Abschluss ihrer Ausbildung und nachdem sie die Erfahrung eines stark fremdbestimmten Übertritts von der obligatorischen zur nachobligatorischen Ausbildung machte, sah sich Duaa nun in der Lage, einen eigenständigen Lebensentwurf nicht nur zu entwerfen, sondern auch durchzusetzen. Der private Lebensentwurf stellte den einzigen Bereich in Duaas bisheriger Biografie dar, wo sie fernab von Fremdbestimmung eine Zukunftsvision entwerfen und einen »Plan vor (...) Augen haben kann«. Die Eltern waren anfänglich gegen eine so frühe Heirat, doch Duaa liess sich diesen eigenständigen Traum von niemandem nehmen. Er gab ihr die Kraft, die Schule durchzustehen und stellte eine Art Gegenwelt zur Realität dar, in die sie sich flüchten konnte: »wenn wir in der Schule irgendetwas schreiben mussten, habe ich immer gesagt, mit zwanzig ein Kind, verheiratet, einfach Familie«. Mit einer ausserordentlichen Zielstrebigkeit setzte sie nun diesen Plan um - gegen den Wunsch der Eltern, welche die Ansicht vertraten, dass sie eine Weiterbildung machen solle. Mit achtzehn Jahren lernte sie auf einer Hochzeit ihren heutigen Mann kennen, der damals selbst noch in Ausbildung war. Sie drängte ihn, baldmöglichst beim Vater um ihre Hand anzuhalten. Den Eltern war das zu voreilig und sie hatten grosse Bedenken:

»Die sind beide schockiert gewesen, weil äh, sie haben gesagt, nein, das kannst du doch noch nicht machen, du kannst, es ist doch, das geht doch 
jetzt alles gerade viel zu schnell, dann habe ich gesagt doch, das ist mein Plan, das ist mein Mann für die Zukunft fertig«(Duaa, A 38).

Duaas Schilderung unterstreicht nochmals, wie ernst es ihr ist, ihren »Plan« durchzuziehen und sich dabei von niemandem reinreden zu lassen. Die Eltern gaben schliesslich nach. Nachdem sie sich knapp drei Monate kannten, heirateten die beiden. Mit zwanzig brachte Duaa dann tatsächlich ihr erstes Kind zur Welt.

Heute, als mehrfache Mutter, arbeitet sie nach wie vor Vollzeit bei dem Detailhändler, bei dem sie ihre Ausbildung absolvierte. Das vom Vater erwünschte familiäre Aufstiegsprojekt verschiebt sie in die nächste Generation, auf die Ebene ihrer Kinder. Diese unterstützt sie schulisch mit Rat und Tat, erstellt ihnen zusätzliche Rechenaufgaben und übt in der Freizeit mit ihnen - sie sollen es einmal besser haben und mehr Geld verdienen können als sie. Ihre Entscheidung, das familiäre Aufstiegsprojekt in die nächste Generation zu verlegen, ändert auch nicht, dass ihr Vater ihr fast täglich in den Ohren liegt, sie solle noch eine weiterführende Ausbildung machen. Diesen Wunsch verweigert Duaa ihm standhaft; ein Umstand, der zu regelmässigen Konflikten zwischen ihr und ihrem Vater führt. In einem gewissen Sinne ist die Weigerung Duaas ebenfalls als »Taktik« einer widerständigen Mikropraktik zu lesen: Endlich in der Lage einen eigenständigen Lebensentwurf zu leben, wiedersetzt sie sich dem väterlichen und lehrmeisterlichen Insistieren auf »fremdbestimmte« Weiterbildung, um einen eigenständigen Lebensentwurf zu verfolgen.

\section{Zusammenfassung "Taktik« Typus 4}

Wie am prototypischen Beispiel von Duaa illustriert werden sollte, ist der berufsbiografische Handlungsspielraum von Frauen, bei denen die »Taktik « der widerständigen Mikropraktiken identifiziert werden konnte, aufgrund eines ausgesprochen starken Zusammenspiels der Differenzdimensionen Gender, »Migrationshintergrund «, »class « und Religion im Vergleich zu den anderen drei Typen weitaus am stärksten eingeschränkt. Der Grund hierfür dürfte nicht zuletzt in der Differenzdimension Körper (Hautfarbe) zu suchen sein, welche im Zusammenspiel mit den anderen Differenzdimensionen intersektionell zusätzlich verstärkend wirkt: Sowohl im öffentlichen Raum wie auch hinsichtlich der Berufsbiografie machen diese Frauen vergleichsweise einschneidende Ausschlusserfahrungen. Mehr Agency erlangen sie nur punktuell, indem sie einerseits direkte Konfrontationen mit Repräsentierenden der hege- 
monialen Strukturen vermeiden und sich andererseits, wo es der strukturelle Druck erlaubt, mittels der »Taktik« widerständiger Mikropraktiken wehren.

Auch im Bereich der religiösen Selbstrepräsentation ist der Spielraum der Frauen stark begrenzt. Trotzdem geben sie ihre äusserliche religiöse Selbstrepräsentation als Teil ihrer religiösen Identifikation nicht auf. Indes greifen sie zu widerständigen Mikropraktiken, mittels derer sie ihre religiöse Selbstrepräsentation gerade so weit anpassen, dass sie in der hegemonialen Mehrheitsgesellschaft als Muslima bestehen können. Diese Anpassung erfolgt, wie anhand des Fallbeispiels von Duaa verdeutlicht werden konnte, insbesondere im Bereich der sichtbaren religiösen Selbstrepräsentation. So eignen sie sich teilweise religiöse Alltagspraktiken in De Certeaus Sinne an. Zum Beispiel indem das Kopftuch in der Öffentlichkeit hinten herum geknüpft wird, damit es auch als Modeaccessoire durchgehen könnte, oder indem auf das Beten am Arbeitsplatz bzw. im öffentlichen Raum verzichtet wird. Alltagspraktiken sind nach De Certeau immer auch Aneignungspraktiken, die auf dem eigensinnigen »Gebrauch« des Gegebenen basieren (De Certeau 1988:13).

Zentral für die Bildungsbiografien dieser Frauen sind wiederkehrende Momente starker Fremdbestimmung. Besonders einschränkend erfahren sie die Wirkmächtigkeit des intersektionellen Zusammenspiels der Differenzdimensionen am Übergang von obligatorischer zu nachobligatorischer Ausbildung. Einerseits sind die Eltern aufgrund der eigenen gesellschaftlichen Positionierung (Verschränkung »class«, »Migrationshintergrund«) nicht in der Lage, ihre Töchter in ihren Bildungszielen zu unterstützen. Andererseits wirken genderbedingte Vorstellungen der Eltern (bspw. bezüglich des Arbeitswegs) zusätzlich intersektionell. Aufgrund dieser Ausgangslage sowie der reproduktiven Wirkung des Bildungssystems (vgl. z.B. Kronig 2005) gelingt den jungen Frauen der Übergang von obligatorischer zu nachobligatorischer Ausbildung lediglich mithilfe sogenannter »Brückenangebote«. Infolge dieser engen Verzahnung von wenig privilegierter Ausgangslage mit den voranstehend genannten Differenzdimensionen kommt schliesslich eine forcierte berufliche Platzierung zum Zuge. Hierbei werden sie entweder von Lehrpersonen, Bezugspersonen oder Eltern dazu gedrängt, unbeliebte Arbeitswege einzuschlagen, die kaum ihren Bedürfnissen entsprechen und tendenziell die wenig privilegierte soziale Stellung der Eltern reproduzieren. Begründet wird dieses »Hineindrängen« in der Regel mit einer potenziell drohenden Arbeitslosigkeit (vgl. hierzu auch Mey 2015: 256). Den Wunsch nach Eigengestaltung der Bildungsbiografie und nach autonomen Lebensentwürfen müssen die Frauen schliesslich weitgehend aufgeben. 
Dennoch ergeben sie sich diesen starken intersektionellen Zwängen nicht einfach nur passiv. Sie versuchen, wenn der strukturelle Druck es erlaubt, in »minimalen Möglichkeitsräume[n]« (Mey 2015: 250) mittels der »Taktik« der widerständigen Mikropraktiken mehr Agency zu erlangen. Exemplarisch für eine solche widerständige Mikropraktik hinsichtlich der Bildungsbiografie ist bspw. das absichtliche Verfassen von einer fehlerhaften Bewerbung. Wie sich rekonstruieren liess, waren die widerständigen Praktiken nicht immer durchschlagskräftig. Teilweise war der intersektionelle wirkende Druck so stark, dass selbst diese versagten und einzig eine Anpassung an die hegemonialen Strukturen blieb, um bildungsbiografisch zu bestehen und im Arbeitsmarkt zu verbleiben. 



\section{Exkurs: Religionsverständnis, religiöse Praxis und religiöse Selbstrepräsentation junger Secondas muslimischen Glaubens im Wandel}

Dass sich der Diskurs über >den Islam konstitutiv auf das Islamverständnis von Muslim*innen auswirkt (Behloul 2009:264) gilt mittlerweile als unbestritten. Im Einklang mit einschlägigen Forschungsergebnissen (vgl. hierzu u.a. Baghdadi 2012, 2010, Schild 2010; in Bezug auf Deutschland: Bendixsen 2013, 2005, Nökel 2002, 1999; in Bezug auf Frankreich bspw. Kilian/Johnson 2006, in Bezug auf die Niederlande bspw. Bracke 2011) konnte auch in den Daten der vorliegenden Studie ein Zusammenhang zwischen dem Religionsverständnis junger Frauen muslimischen Glaubens und dem Diskurs über >den Islam konstruiert werden, insbesondere hinsichtlich der Differenzkategorie »Muslimin«. Dieser Zusammenhang wurde - obwohl dies nicht den Hauptfokus der Fragestellung bildete - in unterschiedlichsten Fallbeispielen und Kontexten in der vorliegenden Arbeit immer wieder implizit, aber auch explizit zum Thema. Im Folgenden möchte ich deshalb, bevor ich zur Schlussdiskussion komme, in einem Exkurs zusammenfassend sieben datenbasierte, teilweise genderspezifische Thesen zum Wandel des Religionsverständnisses, der religiösen Praxis und Vergemeinschaftung sowie der religiösen Selbstrepräsentation von jungen muslimischen Secondas in Bezug auf ihre Elterngeneration aufstellen. Es handelt sich hierbei jedoch um Thesen, die durch weiterführende Forschung zu erhärten wären.

1 Bei Secondas muslimischen Glaubens finden Prozesse der Systematisierung und Intellektualisierung von Religion statt

Hinsichtlich der Religiosität junger muslimischer Secondas in der Deutschschweiz lässt sich rekonstruieren, dass in identifikatorischen Aushandlungs- 
prozessen eine Abgrenzung von der Religiosität der Elterngeneration stattfindet, die mit einer zunehmenden Intellektualisierung bzw. Systematisierung der eigenen Religiosität einhergeht (vgl. zu diesem Prozess bei tibetischen Migrant*innen der zweiten und dritten Generation in der Schweiz, Schlieter et al. 2011: 8). Diese Intellektualisierung bzw. Systematisierung hängt so argumentiere ich - mit dem verschiedentlich konstatierten kollektiven Rechtfertigungsdruck (vgl. u.a. Baumann 2015: 17, Tunger-Zanetti 2013a: 224, Schild 2010: 181) bzw. dem Umstand zusammen, dass junge Musliminnen in besonderem Masse als Frauen - immer wieder in die Pflicht kommen, Glaubensinhalte argumentativ und reflektiert darzulegen und in ein plausibles Verhältnis bspw. zum erforderten säkularen Schulwissen zu bringen (vgl. Schild 2010: 181, Nökel 2002: 54ff.). Die Systematisierungs- und Intellektualisierungstendenzen manifestieren sich in Abgrenzung zu dem oft auf oralen Überlieferungen beruhenden Religionsverständnis der Elterngeneration. So behilft sich bspw. Zara (Fallbeispiel Kap. 5.1) bei Fragen zu religiösen Praxen mit (Lehr-)Büchern über den Islam. Ihr Vorgehen zur Beantwortung einer für sie persönlich hochrelevanten Frage zu einer religiösen Praxis schildert sie wie folgt:

»Nachher habe ich gedacht: Komm, [Name einer bekannten schweizerischen Buchhandlungskette], neutrale Person, Literatur von dort, das bringt's (schmunzelt). Und dann habe ich wirklich so ein bisschen Büchlein angefangen zu suchen und zu lesen, (...) also Anne-Marie Schimmel kann ich mich noch erinnern, habe ich damals gekauft, die das sehr gut erklärt hat« (Zara, A 229).

In einem religiösen Dilemma fragt Zara weder Eltern noch enge Bezugspersonen, auch nicht religiöse Autoritäten, sondern geht in ein Buchgeschäft, wo sie nach den Ausführungen einer "neutralen Person«, also keiner Theologin sondern einer Islamexpertin sucht. Das Anliegen sich »neutrale Informationen« ausserhalb ihres Beziehungsnetzes zu beschaffen, ist gleichfalls im $\mathrm{Zu}$ sammenhang mit der Ablösung vom elterlichen als "traditionell« verorteten Religionsverständnis zu sehen. Auch Klinkhammer stellte in einer Studie zu jungen Secondas muslimischen Glaubens in Deutschland fest, dass viele die religiöse Praxis der Eltern als zu wenig fundiert und »oberflächlich« oder gar als "für die Nachbarn« kritisieren, da diese mit Bewahrung althergebrachter Traditionen zu tun habe und nicht mit einer aktiven Selbstaneignung des Islam (Klinkhammer 2006: 85, 87). 
2 Eine diskursive Trennung von »Religion « und »Kultur « dient der Loslösung vom elterlichen Religionsverständnis

Bei der Thematisierung des eigenen Religionsverständisses gegenüber dem der Elterngeneration wird auffällig oft auf den als »traditionell« bzw. »kulturell« identifizierten Glauben der Eltern verwiesen. Hierbei wird von den jungen Frauen eine diskursive Trennung zwischen »Religion « und »Kultur « ${ }^{1}$ vorgenommen. In dieser Vorstellung wird der selterliche Islam« »der Kultur« zugeordnet, während die eigene religiöse Praxis im Gegensatz dazu, als »die (wahre) Religion« bzw. »der wahre Islam« dargestellt wird. Die jungen Frauen nehmen für sich in Anspruch, im Gegensatz zur Elterngeneration, einen »reinen «, nicht-traditionalen, von »Kultur« losgelösten und in dieser Hinsicht »universellen« Islam zu praktizieren. Hierbei besteht die Vorstellung von »Religion« als »etwas Reinem« und »Kultur« als »etwas die Religion Verunreinigendem« (Feldprotokoll 28.11.2014).

Die diskursive Trennung von (eigener) »Religion« und (elterlicher) »Kultur« dient primär, so argumentiere ich, einer Ablösung vom elterlichen Religionsverständnis ohne in einen offenen Konflikt mit der Elterngeneration zu treten (vgl. Fallbeispiele Zara und Esma Kap. 5.1.2 bzw. 5.3.2). Sie ist als emanzipatorisches Moment zu verstehen, das quasi eine »sanfte Emanzipation « (Strahm 2007: 13) vom Elternhaus ermöglicht. Diese zeigt sich besonders deutlich in der Distanzierung zur elterlichen Geschlechterrollenauffassung (vgl. Fallbeispiel Zara Kap. 5.1.2, aber auch Bendixsen 2013, Klinkhammer 2006). Auf der anderen Seite zeigt sich in dieser Trennung meines Erachtens jedoch auch die in These eins skizzierte zunehmende Intellektualisierung und Systematisierung des Religionsverständnisses von religiösen Secondas muslimischen Glaubens. Strahm vertritt die Ansicht, dass die »reflektierte, selbständige Aneignung von Wissen über den Islam« den Frauen »den Status von Expertinnen »vermittelt, mittels dessen sie eine sanfte Ablösung vom Elternhaus durchsetzen können (ebd.).

Die Vorstellung von Muslim*innen der »zweiten Generation« eines »traditionellen, elterlichen Islam« vs. eines eigenen »von Kultur losgelösten« Islam

1 Die Akteurinnen verwenden fast ausschliesslich geschlossene Begrifflichkeiten von »Kultur« und »Religion« bzw. »Islam«. Um dies zu verdeutlichen, verwende ich Akteur*innenkonzepte hier in doppelten Anführungsstrichen. Auf der Ebene der Analyse wird selbstverständlich eine offene Konzeption von Kultur, Religion und Islam verfolgt. Zur Unterscheidung von Begrifflichkeiten als `Kategorien der Praxisı einerseits und Kategorien der Analyse andererseits vgl. Brubaker \& Cooper (2007). 
wurde bereits in verschiedenen europäischen Studien ausserhalb der Schweiz beschrieben (vgl. bspw. Roy 2010, 2006, Bendixsen 2013, John 2007).

Die norwegische Sozialanthropologin Bendixsen (2013) stellt in ihrer ethnografischen Studie zum Religionsverständnis junger muslimischer Frauen in Berlin ähnliches fest:

»The youth that were part of this study belong to a generation of Muslims who differentiate between their parents' ethnic, traditional Islam and what they describe as a pure Islam. By distinguishing between traditional and authentic religious knowledge, values, and practices, the youth make a discursive differentiation between the behaviour, customs, dress and tastes that are religiously proximate versus those they view as defined by ethnic culture or habitus« (ebd.: 281, Herv. d. Verfasserin).

Bendixsen beobachtet die Trennung zwischen »Kultur« und »Religion« vor allem im Kontext von Diskussionen um das angemessene Rollenverhalten von Frauen und Männern (ebd.).

Roy (2010: 54), der eine solche diskursive Trennung ebenfalls konstatiert, erklärt sie als Folge der Globalisierung. Er vertritt die Meinung, dass eine Religion unter den Bedingungen der Globalisierung nur bestehen kann, wenn sie »abstrakt « gedacht wird (ebd.). Er ist der Ansicht, dass ein solch »dekulturalisierte[r]< Islam« (Roy 2006: 41), im Zeitalter der Globalisierung insbesondere für Migrant*innen und Secondas*os ein immer attraktiver werdendes Identifikationsangebot darstellt. Die Vorstellung eines »dekulturalisierten Islams« ist Roy zu Folge eine Möglichkeit, in einem nicht-muslimischen, »westlichen« Kontext eine »religiöse Identität« zu konstruieren, die nicht mit einer bestimmten »Kultur« verknüpft ist (ebd.).

Aufgrund meiner Daten lässt sich ein weiteres Feld erkennen, innerhalb dessen sich bei den jungen Frauen eine diskursive Trennung zwischen »Kultur« und »Religion« in Abgrenzung zum elterlichen Religionsverständis manifestiert: Diese Unterscheidung wird auffällig oft dann unterstrichen, wenn es darum geht, »den Islam« in einem Kontext zu verteidigen, in dem diesem auf irgendeine Weise negative Praktiken zugeschrieben werden. Es kann sich also bei der der Trennung von »Religion« und »Kultur« meines Erachtens auch um eine »Taktik« im Sinne De Certeaus (1988: 89) handeln, zu welcher die jungen Musliminnen greifen, um die Differenzlinien des dominanten Diskurses zwischen Etablierten und Aussenseitern zurückzuweisen und einen Gegendiskurs zu generieren (vgl. hierzu auch Oester/Brunner 2014: 101,105 in Bezug auf transnationalisierte Peer-Communities). Dieser Gegendiskurs fokussiert 
dann auf eine generationale Trennungslinie (quasi »erste vs. zweite Generation«) und versucht mittels jener die diskursive Trennlinie »Islam vs. westliche Werte« zurückzuweisen: Die negativ aufgeladenen Islamstereotypen werden von den jungen Musliminnen mithilfe dieser "Taktik« schlicht dem »traditionellen, kulturellen Islam《 ihrer Elterngeneration zugeschrieben, während sie für sich in Anspruch nehmen eine neuere, »reinere« Form des Islam, der mit »schweizerischen Normen« »kompatibler« ist, zu vertreten. Das Negativbild, das sich in Bezug auf den Islam aufgebaut habe, so lautet die Argumentationslinie, sei vornehmlich alten, »kulturellen« Traditionen geschuldet, die fälschlicherweise (von der Gesellschaft, aber auch von der eigenen Elterngeneration) dem Islam zugeschrieben werden.

Die Vorstellung einer Trennung von »Kultur« und »Religion« spiegelt sich auch in der Vereinsorganisation von Secondas"os wider. Moschee-ungebundene Organisationen, welche primär von jugendlichen, religiös orientierten Secondas*os frequentiert werden, werden explizit nicht entlang ethnischsprachlicher Gruppierungen organisiert, sondern als Vereine junger Schweizer Muslim"innen ${ }^{2}$, die ggf. in Zusammenhang mit einer Ausbildung stehen können (Student"innenvereine, vgl. bspw. MSAB, Muslim Student and Alumni Association of Bern) oder sich schlicht an die "muslimische Jugend Schweiz" (vgl. Ummah.ch) richten (vgl. ausführlich in Kap. 5.1.2c). In diesen wird ein »supra-ethnisches«, »universelles« Islamverständnis propagiert und Deutsch dominiert als Kommunikationssprache.

Es stellt sich hier die Frage - und dem sollte in weiterführender Forschung nachgegangen werden - inwiefern es sich bei der diskursiven Trennung von »Religion « und »Kultur« um eine spezifische Deutung von Religion unter der Bedingung von transnationaler Migration handelt und ob diese primär als spezifische, intellektualisierte Auslegung von Religiosität muslimischer Secondas" os im Lichte des laufenden, stigmatisierenden Islamdiskurses zu verstehen ist.

2 In Abgrenzung zur Elterngeneration ist ebenfalls eine selbstbewusstere Haltung in Bezug auf die gesellschaftliche Positionierung von Secondas muslimischen Glaubens rekonstruierbar (vgl. hierzu auch Baumann 2019:16, im Erscheinen); diese äussert sich auch in der Forderung nach einer öffentlich sichtbaren, angemessenen, religiösen Selbstrepräsentation. Zoja drückt dies wie folgt aus: Sie wolle sich nicht bedanken für die Moschee im Keller, sondern wünsche sich für ihre Kinder, dass diese zukünftig nicht »in den Keller beten gehen« müssen »oder in den Hinterhof oder in einer Garage"(Zoja, A 82), sondern fordert Moscheen, die den »Namen als ein Cotteshaus «verdienen, und welche die Schweizer Muslim*innen angemessen repräsentieren. 
3 Die Manifestation von »Muslimin« als Kategorie der Differenz führt zu einem Rechtfertigungs- und Positionierungszwang. Dieser kann seinerseits zu einer verstärkten aktiven Selbstaneignung des Islam führen

Dass mittels Religion als Kategorie der Differenz in (Bildungs-)Biografien insbesondere im Zusammenspiel mit anderen Differenzdimensionen wie Gender, »Migrationshintergrund «, »class«, Körper etc. nicht nur im Kontext von Bildung Differenz hergestellt wird, wurde in der vorliegenden Arbeit hinsichtlich der Differenzkategorie »Muslimin« ausführlich dargelegt und empirisch begründet (vgl. u.a. Kap. 2.1.2, 5, 7).

Die Manifestation von »Muslimin« als Kategorie der Differenz führt bei den jungen Secondas nicht zuletzt, so die These, zu einem verschiedentlich konstatierten, dauernden kollektiven gesellschaftlichen Rechtfertigungsdruck $^{3}$ (vgl. u.a. Baumann 2015: 17, Tunger-Zanetti 2013a: 224, Schild 2010: 181), der zudem mit einem »Positionierungszwang« (Riegel 2004: 338) einhergeht, wonach sich junge Frauen gezwungen sehen, sich ständig als »muslimische Frauen« zu positionieren und zu legitimieren (vgl. Kap. »Expertin für Islam«, S. 178ff., 7.1). Diese Konstellation manifestiert sich nicht nur, aber besonders deutlich im Bildungssystem und wird insbesondere dann augenfällig, wenn die jungen Frauen in die Rolle einer »Expertin für Islam« gedrängt werden (vgl. ebd.) und sich in einem pädagogisierenden Kontext zu jeglichen, dem Islam zugeschriebenen Belangen positionieren und Auskunft geben sollen. Dieser Rechtfertigungs- und Positionierungszwang führt nicht selten zu einer verstärkten »aktiven Selbstaneignung des Islam« (Strahm 2007: 13), sprich dazu, dass die jungen Frauen sich intensiver mit der (zugeschriebenen) Religion befassen und auseinandersetzen (vgl. Fallbeispiel Velika, S. 123ff.).

4 In Selbstbeschreibungen rekurrieren junge religiös orientierte Secondas muslimischen Glaubens auf den Islamdiskurs

Untersuchungen zu Anerkennung und Zugehörigkeiten sowie zu Repräsentationsstrategien der sogenannten »ersten Generation« von zugewanderten Frauen muslimischen Glaubens zeigen, dass sich muslimische Frauen in der Schweiz in ihren identifikatorischen Aushandlungsprozessen auf den laufenden Islamdiskurs beziehen (Baghdadi 2012, 2010, Schild 2010). Baghdadi 
$(2012,2010)$ stellte bspw. fest, dass die meisten ihrer Interviewpartnerinnen ausdrücklich Abstand vom diskursiv kursierenden Bild der »typischen« Muslimin nehmen (Baghdadi 2012: 380). Auch Schild (2010: 181) konstatierte, dass herrschende Diskursivierungsprozesse gewisse Zwänge für Muslim*innen mit sich bringen. Sie behauptet, muslimische Frauen in der Schweiz seien in der Ausformulierung einer "positiven >muslimischen Identität«", deren Anerkennung durch die Mehrheitsgesellschaft sie anstreben«, nicht »frei««. Vielmehr müssten sie sich »in der Konstruktion und Repräsentation eines positiven Eigenbildes auf die negativen Zuschreibungen beziehen, diese unablässig berichtigen, korrigieren und entkräften« (ebd.).

Was einschlägige Forschungsergebnisse zum Selbstbeschrieb von zugewanderten Frauen muslimischen Glaubens der »ersten Generation« aufzeigen (Baghdadi 2012, 2010, Schild 2010), lässt sich in den erhobenen Daten auch für religiös orientierte Secondas muslimischen Glaubens rekonstruieren. Auch Secondas beziehen sich in ihren Selbstbeschreibungen auffällig oft implizit oder explizit auf den Islamdiskurs. Ein besonders gängiges und deutliches Element in den Selbstbeschreibungen lässt sich in der Betonung der autonom gefällten, freien Entscheidung des Bedeckens des Kopfhaars rekonstruieren. Sahar drückt dies bspw. so aus:

»Eben zum Beispiel ich ziehe das Kopftuch an, das ziehen bei uns wirklich fast alle an. Also es ist ja nicht, es ist ja nicht so, dass es alle anziehen, weil es ist ja nicht, wir (...) zwingen hier bei uns ja niemanden (...), du musst ein Kopftuch anziehen« (Sahar, A 21).

Auffällig oft betonen junge Secondas die selbst gewählte Entscheidung ihrer religiösen Orientierung und stellen diese in den Mittelpunkt in Beschreibungen ihrer religiösen Sozialisation. Mirjeta unterstreicht im Kontext einer biografischen Erzählung gleich mehrmals (vgl. zu diesem Punkt auch Baghdadi 2010: 213):

»Und in dieser Zeit habe ich mich dann eben auch mit dem Islam ... mit dem Islam auseinandergesetzt aus freien Stücken. (...) Also meine Eltern haben es vorgelebt, aber wir sind frei gewesen eigentlich ähm ob wir islamischer werden wollen oder nicht, wir sind frei gewesen « (Mirjeta, A 44, A 67).

Wie in den Aussagen von Mirjeta und Sahar und ihren unterschiedlich kontextualisierten Betonungen des »freien Entscheidens« verdeutlicht werden sollte, rekurrieren die jungen Frauen oft direkt oder indirekt auf das stereotype Bild einer >(durch Eltern oder Mann) fremdbestimmten<, »unterdrückten 
Muslimin« (vgl. hierzu Kaya 2012: 120). Die Rekurrierung auf das Genderbild im Islamdiskurs in Selbstbeschreibungen von jungen Secondas dürfte nicht zuletzt damit konnektiert sein, dass die diskursive Abgrenzung gegen >den Islam` immer stärker mit dem Verweis auf hierarchische Geschlechterverhältnisse begründet wird, die als Wesensmerkmal >des Islam< dargestellt werden (Allenbach/Müller 2017: 273, in Bezug auf Deutschland: Marx 2008: 55). Wie Allenbach und Müller (2017: 289) bilanzieren, stehen Geschlechtsdiskurse »im Brennpunkt des Kampfs um Anerkennung von religiösen Minderheiten « und müssen »als Argument für den Ausschluss von Zugewanderten herhalten « (ebd.: 273). Deshalb erstaunt es auch nicht, dass sich (diskursive) Differenzziehungsprozesse und die Differenzkategorie »Muslimin « besonders deutlich anhand des Kopftuchs als genderspezifisches, sichtbares religiöses Symbol manifestieren (vgl. Lüddeckens/Grigo 2016: 180, Grigo 2015, Klinkhammer 2013: 114). Diese Entwicklung des Islamdiskurses spiegelt sich denn auch besonders deutlich in den Selbstbeschreibungen der jungen Secondas wider. Ein direkter Bezug auf den Islamdiskurs und ihre Rolle als Kopftuch tragende Muslima in der Schweizer Gesellschaft in ihrem Selbstbeschrieb nimmt bspw. Aieta:

»Aber ich weiss, ich als Mensch falle dadurch auf [gemeint ist hier durch das Kopftuchtragen]. Und ich habe die Möglichkeit ähm zu beweisen, dass ich halt nicht nur eine Muslima bin, die anscheinend unterdrückt wird. Also, dass ich meine eigene Meinung habe...ich bin auch leicht feministisch « (Aieta, A 50).

Wie die Aussage verdeutlichen soll, sieht Aieta ihre Rolle als Kopftuch tragende Muslima auch als Chance (fast tribunalsgleich, in der Rolle der >Angeklagten`), der Gesellschaft »zu beweisen«, dass sie keine Muslimin ist, »die anscheinend unterdrückt wird «, sondern eine, die eine eigene Meinung hat und gar »leicht feministisch« ist (»Die Feministin« stellt in der gängigen Diskursformation DEN Gegensatz per se zur diskursiven Figur der »unterdrückten Muslimin« dar (vgl. Kap. 2.1.2)).

Aufgrund solcher und ähnlicher Aussagen junger Secondas ist Baghdadi ebenso beizupflichten, wenn sie argumentiert, dass durch solche Rückgriffe auf diskursive Zuschreibungen das gängige Stereotyp jedoch weiter zementiert wird (2010: 213). 
5 Frauen entwickeln zahlreiche, produktive »Taktiken« im Umgang mit der Differenzkategorie »Muslimin« Junge Secondas entwickeln zahlreiche »Taktiken« (De Certeau 1988: 89) auf verschiedenen Ebenen um mit der Differenzkategorie »Muslimin« umzugehen bzw. den damit einhergehenden, sozialen Ausschlusspraxen etwas entgegenzusetzen. Vier zentrale »Taktiken« hinsichtlich (Bildungs-)Biografien wurden in dieser Arbeit analysiert (ausführlich in Kap. 5). Zudem konnten zahlreiche alltägliche kleine Mikrotaktiken, welche die Frauen benutzen, um gegenderten Grenzziehungsprozessen und den damit einhergehenden Machtkonstellationen entgegenzutreten, rekonstruiert werden. Auffällig oft betreffen diese die Umgehung der Sichtbarkeit bzw. öffentliche Identifizierbarkeit als Muslima und somit ein Ausweichen der stigmatisierenden Ausschlusserfahrungen. Sie dienen aber auch dazu, sich dem mehrfach beschriebenen kollektiven sozialen »Rechtfertigungsdruck « (vgl. u.a. Baumann 2015: 17, Tunger-Zanetti 2013a: 224, Tunger-Zanetti 2013c, Schild 2010: 181) zu entziehen, welcher die Frauen zwingt, sich ständig als muslimische Frauen legitimieren und erklären zu müssen.

Eine zentrale »Taktik« hierbei bezieht sich auf die »Sichtbarkeit«bzw. das Einschränken einer quasi-öffentlichen Identifizierbarkeit als Muslima: Nicht unüblich ist es beispielweise, dass bedeckte Muslimas, um der Sichtbarkeit und Eindeutigkeit ihrer Haarbedeckung als eines religiösen Symbols zu entgehen und somit nicht »als Muslimin« aufzufallen, das Kopftuch im Nacken knüpfen, so dass es auch als Modeaccessoire durchgehen könnte. Sie sind somit - zumindest auf den ersten Blick - nicht »als Musliminnen« identifizierbar. Eine weitere »Taktik« ist, dass sich einige der interviewten Frauen im Kontext ihres Berufsfelds als Veganerin ${ }^{4}$ oder konsequente Vegetarierin ausgeben, um muslimische Speisegebote einhalten zu können, ohne »als Muslimin« identifizierbar zu sein.

Auch in Bezug auf die Konstruktion von Zugehörigkeiten lassen sich situative »Taktiken« des Umgangs mit der Differenzkategorie »Muslimin« ana-

Wie mir eine junge Frau erklärte, ist für sie das sich Ausgeben als Veganerin einfacher als das sich Ausgeben als Vegetarierin. Erstens, weil »vegan sein« im Moment sowieso »in«sei und dadurch kaum auffalle und zweitens, weil die Veganer*innen als äussert konsequent gelten würden, und sie als Muslimin unter diesem Vorwand so ohne Erklärungen abzugeben auf Süssigkeiten, in denen manchmal auf Schweinefleisch basierte Gelatine enthalten sei, verzichten könne. Zudem kaufe sie gerne in veganen Läden ein, weil sie da in relativ grosser Auswahl halal Essen einkaufen könne, ohne sich zuvor in die Verpackungen vertiefen zu müssen. 
lysieren. So liess sich rekonstruieren, dass die jungen Frauen ihre Selbstrepräsentation als »Muslimin«bzw. »nicht Muslimin« situativ konstruieren und einsetzen. Ein Beispiel hierfür ist Lane (ausführlich Kap. 4.1), die sich in den dezidiert religiösen Kreisen, in denen ihre Schwester verkehrt, als "nichtMuslimin« positioniert, um den Ansprüchen, die ihrer Ansicht nach seitens dieser Kreise an sie »als Muslimin« gestellt werden würden, zu entgehen (z.B. das Bedecken des Kopfhaars oder das Verzichten auf Schminke, beides Dinge, die Lane widerstreben). In anderen Kontexten, wie z.B. in ihrem beruflichen Umfeld, positioniert sich Lane hingegen »als Muslimin« in Abgrenzung zu den »nicht-Muslim*innen« ihres beruflichen Umfelds. Andere von mir interviewte Frauen handhaben die Selbstrepräsentation genau umgekehrt, und >outen sich im beruflichen Kontext nicht als Muslimin, weil sie stigmatisierende Ausschlusserfahrungen befürchten.

Dass junge Secondas*os als Reaktion auf Ausschlusserfahrungen aufgrund ihrer Religionszugehörigkeit verschiedenste Strategien entwickeln, um ihren multiplen Zugehörigkeiten (multiple belonging) Sinn zu verleihen, stellte die Forschungsgruppe um Giordano (Allenbach et al. 2010: 9) ebenfalls fest. Diese untersuchte, wie junge Muslim*innen unterschiedliche Aspekte ihrer Zugehörigkeiten (»Muslim*in«; »Ausländer"in«, »eingebürgert« etc.) flexibel einsetzen, um sie je nach Kontext und Situation zu betonen und sich $\mathrm{zu}>$ Insidern $\mathrm{zu}$ machen (ebd.: 10). Auch Allenbach (2016) kommt in einer Untersuchung über muslimische Mädchen im obligatorischen Schwimmunterricht zum Schluss, dass die jungen Frauen vielfältige Strategien finden, dominante (gegenderte) Differenzlinien und damit einhergehende Machtkonstellation infrage $\mathrm{zu}$ stellen, ihre Positionierung dazu auszuhandeln (ebd.: 43f.) und so mehr Agency entwickeln.

6 Frauengruppen stellen soziale Räume dar, in denen identifikatorische Aushandlungsprozesse stattfinden

Teil der ethnografischen Untersuchung dieses Projekts bildete die teilnehmende Beobachtung unterschiedlicher Gefässe religiöser Vergemeinschaftung (sowohl in virtuellen ${ }^{5}$ wie in nicht-virtuellen Feldern). Obwohl nicht ausschliesslich frauenspezifische, religiöse Vergemeinschaftung beobachtet funktion, aber auch Beobachtung der Vergemeinschaftung in Social-Media-Cefässen wie Whats-App-Gruppen, Facebookseiten etc. 
wurde, bildete diese jedoch aufgrund des Samples der Untersuchung (vgl. Kap 4.1) den Fokus.

Die religiöse Vergemeinschaftung in Frauengruppen dient den Secondas in erster Linie dazu, soziale Anerkennung und Zugehörigkeit zu erfahren, dies in einem gegenüber Musliminnen gesellschaftlich eher rauen Klima. Frauengruppen, so die These, stellen soziale Räume dar, in denen quasi in einem sgeschützten Rahmen< identifikatorische Aushandlungsprozesse stattfinden. Hierbei werden ganz unterschiedliche Themenfelder diskutiert und ausgehandelt. Einerseits werden (frauenspezifische) gesellschaftliche Ausschlusserfahrungen aufgearbeitet und Strategien des Umgangs damit diskutiert, bspw. wie mit einer Anfeindung im öffentlichen Raum bezüglich des Kopftuchs umgegangen werden könnte. Ähnliches stellen Endres et al. (2013: 63ff.) hinsichtlich muslimischer Jugendgruppen fest. Andererseits werden aber durchaus auch andere lebenspraktische Belange, wie bspw. bevorstehende Geburten, beruflich relevante Fragen oder Themen, welche die Freizeit betreffen, diskutiert.

Neben lebenspraktischen Belangen werden in muslimischen Frauengruppen selbstredend auch Fragen religiöser Praxis (mitunter kontrovers) diskutiert, insbesondere auch frauenspezifische Auslegungen religiöser Gebote, die unter Ausschluss der >männlichen Welt besprochen werden sollen (Feldprotokolle Nov 2014), so auch Fragen, welche bspw. die >Reinheit der Frau <etreffen. Andererseits werden aber auch allgemeine Fragen bezüglich der Legitimität und Anwendung religiöser Praxen diskutiert (vgl. hierzu auch Bleisch Bouzar 2012: 292-294), in diesem Sinne sind diese Gefässe auch als Orte der religiösen Selbstsozialisation zu verstehen (vgl. Saba 2012: 128).

Ebenso konnte ich mehrfach beobachten, wie im Rahmen dieser Diskussionen männliche religiöse Autorität oder Entscheide von (männlichen) religiösen Autoritäten infrage gestellt wurden, beziehungsweise auf ihre lebensweltliche »Tauglichkeit« geprüft und kritisch hinterfragt wurden (Feldprotokolle Nov 2014). Gegenteilig zur Rezeption im öffentlichen Islamdiskurs können solche Gefässe durchaus emanzipatorischen Charakter haben und Raum für autonome kritische Fragen bilden. Zudem bilden Frauengruppen soziale Räume - wie anhand des Fallbeispiels von Esma exemplarisch verdeutlicht wurde (vgl. Kap. 5.3.2 c) - wo soziales Kapital (in der Regel) unabhängig von der Herkunftsfamilie akkumuliert werden kann. Dies kann die jungen Frauen unter Umständen darin bestärken, einen eigenständigeren (bildungs-)bio- 
grafischen Weg zu gehen (vgl. Fallbeispiel Esma ${ }^{6}$ Kap. 5.3.2 c.). In dem Sinne stellen Religionsgemeinschaften »Netzwerke dar, also eine soziale Infrastruktur, mit deren Hilfe sich auch ausserreligiöse Ziele verwirklichen lassen « (Coleman 1990 zit.n. Traunmüller 2018: 917). Hierbei kommt die gesellschaftlich integrierende Funktion religiöser Netzwerke von Migrant*innen zum Zuge, auf die bereits verschiedentlich hingewiesen worden ist (vgl. u.a. Baumann 2015, 2012; Endres et al. 2013, Nagel 2015, 2013, Pickel 2014, Weissköppel 2008, Spickard 2005).

Wie anhand des Fallbeispiels Duaa in Kapitel 5.4.1 verdeutlicht werden konnte, zeigt sich umgekehrt auch, dass Frauen, die sich weder in Vereinen noch in virtuellen Feldern religiös vergemeinschaften, gesellschaftlichen Ausschlusserfahrungen ungleich weniger entgegenzusetzen haben.

7 Deutsch gewinnt an Relevanz als Sprache für religiöse Handlungsfelder (in der virtuellen und nicht-virtuellen Welt)

Wie bereits ausgeführt (vgl. Kap. 5.1.2) verstehen sich die überwiegend meisten der von mir interviewten Frauen als vom elterlichen Religionsverständnis emanzipierte "Schweizer Muslimas« der zweiten Generation. Als solche vergemeinschaften sie sich in religiösen Vereinen, arbeiten teilweise innerhalb dieser neue Strukturen (z.B. Frauengruppen), die auf die Bedürfnisse von Secondas ausgerichtet sind. So unterstützen und portieren sie in ihren jeweiligen Vereinen auch dezidiert Deutsch als Sprache für religiöse Handlungsfelder. Wie ich beobachten konnte, finden die meisten Veranstaltungen, welche ich mit Frauen meines Samples gemeinsam besucht habe und welche sich an jüngere Muslim*innen richten, in deutscher Sprache statt. Ebenso konnte ich in einigen Moscheen beobachten, dass Deutsch für religiöse Handlungsfelder an Relevanz gewinnt. So werden bspw. in einigen Moscheen gezielt Deutsch sprechende Vertreter*innen der zweiten Generation (oder Konvertit*innen) eingesetzt, um die Moschee nach aussen sichtbar zu machen oder deren Internet- und/oder Social-Media-Auftritt zu stärken. Deutsch als Spra-

6 Durch die von der Herkunftsfamilie unabhängige Akkumulation von sozialem Kapital gelang es bspw. Esma sich bis zu einem gewissen Grade von den durch das Elternhaus geprägten strukturellen Bildungsbarrieren zu distanzieren und zu emanzipieren (z.B. von der vom elterlichen Cenderbild geprägten Hinfälligkeit einer nachobligatorischen Ausbildung wegen einer frühen Heirat) und eine weniger durch Fremdbestimmung geprägte Berufslaufbahn einzuschlagen (vgl. ausführlich Kap. 5.3.2 c). 
che scheint aber auch zunehmend an Relevanz beim religiösen Unterricht in Moscheen für Kinder der zweiten (oder dritten) Generation zu gewinnen. 



\section{Zusammenfassung und Schlussdiskussion: Die doppelte Rolle der Religion in Bildungsbiografien junger Secondas muslimischen Glaubens}

In diesem Kapitel gehe ich nach einer kurzen Zusammenfassung des Untersuchungsprojekts in Kapitel 7.1 und 7.2 auf die doppelte Rolle von »Religion« in Bildungsbiografien ein, um mit einem Fazit und einem Ausblick (7.3) zu schliessen.

Im Zentrum der vorliegenden Untersuchung stand die Fragestellung, ob und wie Bildungsbiografien von jungen Secondas muslimischen Glaubens (intersektionell) im Kontext des gegenwärtigen Islamdiskurses vorstrukturiert bzw. eingeschränkt werden und wie es ihnen gelingt, im bildungsbiografischen »Möglichkeitsraum« (Holzkamp 1983) »einen Weg zu finden«.

Hierbei waren folgende Teilfragen leitend:

- Wie wirken (diskursive) Zuschreibungsprozesse auf junge religiös orientierte Secondas im Kontext von Schule und (Berufs-)Ausbildung?

- Welche Differenzdimensionen wirken in Bildungsbiografien? Wirken sie intersektionell?

- Wie konstituiert und manifestiert sich die Differenzkategorie »Muslimin« in Bildungsbiografien?

- Wie gelingt es den jungen Secondas muslimischen Glaubens bildungsbiografisch »einen Weg zu finden«? Wie erlangen sie (mehr) Agency in Bildungsbiografien?

Um den Akteur*innen Raum für die Darstellung eigener Relevanz- und Deutungssysteme innerhalb ihrer (sozialen) Räume zu geben, wurde für das Forschungsvorhaben ein ethnografischer Ansatz gewählt. Kern des Zugangs zum 
Feld bildete die Methodik der multi-sited Ethnography, wie Marcus (1995) sie in Abgrenzung zur klassisch ethnografischen Vorgehensweise vorschlug. Wie bei einer ethnografischen Herangehensweise üblich, kam bei der Datenerhebung ein Methodenmix zum Zuge: Kern der Untersuchung bildete ein zirkuläres Verfahren von teilnehmender Beobachtung in multiplen sozialen, aber auch virtuellen Feldern - verbunden mit themenzentrierten (bildungs-)biografischen Interviews sowie einer diskursiven Dokumentenanalyse in Bezug auf die Differenzkategorie »Muslimin«. Das Sample bestand aus jungen religiös orientierten, muslimischen Frauen ${ }^{1}$ mit »Migrationshintergrund «, die in der Schweiz geboren resp. als Kleinkinder mit ihren Eltern zugewandert waren. Die dem Sample angehörenden Frauen waren zum Zeitpunkt der Untersuchung zwischen 18 und 32 Jahre alt und wohnten in der Deutschschweiz.

Um die subjektiven Perspektiven der befragten Frauen im Einzelfall wie auch fallübergreifend zu untersuchen, wurde ein induktiv-iteratives Vorgehen gewählt, welches sich an der Grounded Theory (Strauss/Corbin 1996) orientiert. Dabei wurden sowohl Interviews als auch Feldprotokolle in einem datengeleiteten Codierungsprozess einerseits biografisch-fallrekonstruktiv (vertikale Dimension) und andererseits fallvergleichend (horizontale Dimension) im Hinblick auf die Erarbeitung transversaler Themen untersucht (für eine ausführliche Beschreibung der Methodik siehe Kap.4).

Theoretisch wurde aus einer doppelten Perspektive argumentiert: Zur Erklärung der strukturellen Beschränkungen in Bezug auf den Bildungsweg wurde zum einen eine intersektionelle Perspektive eingenommen, welche das Wechselspiel divergierender Differenzdimensionen untersucht; zur Beleuchtung der Handlungsstrategien der Frauen wurde zum anderen ein Ansatz verfolgt, der die Handlungsfähigkeit (Agency) der jungen Frauen in den Blick nimmt, ohne jedoch deren strukturelle Einschränkungen zu negieren.

Während sich eine intersektionelle Perspektive besonders dazu eignet, gesellschaftliche Einschränkungen aufzuzeigen, fokussieren Agency-Theorien das Gegenteil, nämlich den Handlungsspielraum bzw. die -fähigkeit der Akteur*innen. Es war mir ein zentrales Anliegen, nicht nur die intersektionellen Einschränkungen der bildungsbiografischen Wege von jungen Secondas muslimischen Glaubens aufzuzeigen, sondern insbesondere auch

1 Zur Beschreibung und Problematik der Bezeichnung »Musliminnen« als Zielgruppe im Spannungsfeld zwischen »methodological Islamism« (Brubaker 2012: 6) und einem »strategic use of (...) essentialism«(Spivak 1993: 5, Herv. im Orig.) vergleiche Kap. 4.1. 
die (oft sehr kreativ genutzten) Handlungsspielräume innerhalb des gegebenen »Möglichkeitsraums «² (Holzkamp 1983: 334ff.). Durch die Kombination der beiden theoretischen Perspektiven sollte vermieden werden, die jungen Frauen ausschliesslich sals passive Opfer intersektionell wirkender gesellschaftlicher Einschränkungen zu betrachten.

Aus der Kombination der beiden Perspektiven entwickelte ich das folgende theoretische Rahmenmodell:

\section{Abbildung 2}

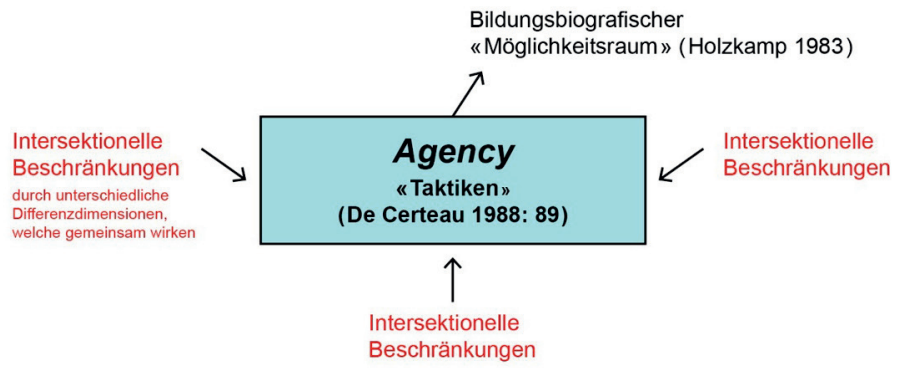

Mittels einer intersektionellen Perspektive als sensitizing concept (Riegel: 2016a: 137) wurde einerseits eine Analyseperspektive auf die empirischen Daten eingenommen, welche die (potenziell) intersektionell wirkenden Einschränkungen der Bildungsbiografien in den Fokus nimmt (vgl. Kap.2.2).

Andererseits wurde der Blick auf die Handlungsfähigkeit der Frauen ausgerichtet: Die Art, wie die jungen Frauen innerhalb ihres intersektionell beschränkten »Möglichkeitsraums« (Holzkamp 1983) Agency in ihren Bildungsbiografien erlangen, wurde mittels De Certeaus Theorie der »Kunst des Handelns« als habituell verankerte »Taktiken« (De Certeau 1988: 89) theoretisiert. De Certeau versteht unter »Taktiken« die eigensinnige Aneignung alltäglicher Handlungsweisen, die durch dominante Strukturen vorgegeben und begrenzt

2 Das Konzept des »Möglichkeitsraums «stammt aus der kritischen Psychologie und geht auf Holzkamp (1983) zurück. Holzkamp geht davon aus, dass die soziale Positionierung eines Individuums einerseits durch objektive, anderseits durch subjektive Handlungsmöglichkeiten und -einschränkungen geprägt ist (ssubjektiver und objektiver Möglichkeitsraum々) (ebd.: 334ff.). Speziell zur Analyse von Möglichkeitsräumen adoleszenter Migrant*innen vgl. bspw. King/Koller 2009b, Riegel 2004: 72ff. und 118ff.). 
sind (vgl. ebd.). Er spricht von der »Kunst des Handelns« (1988) als »Kunst des Gebrauchs derjenigen Produkte, die ihr aufgezwungen werden« (ebd.: 81). ${ }^{3}$

Mithilfe dieser beiden kombinierten theoretischen Perspektiven konnten einerseits die folgenden wirksamen Differenzdimensionen rekonstruiert werden, die in ihrem Zusammenspiel intersektionell einschränkend auf die Bildungsbiografien wirken: Gender, »class«, »Migrationshintergrund«, Religion, Körper. Die Konstellation der intersektionellen Differenzdimensionen gibt in dem voranstehend skizzierten theoretischen Modell den »Möglichkeitsraum « (Holzkamp 1983) vor, innerhalb dessen die jungen Frauen mehr Agency hinsichtlich ihres Bildungswegs erlangen können bzw. bildungsbiografisch »einen Weg finden«. Dieser »Möglichkeitsraum« gestaltet sich unterschiedlich gross, je nachdem, wie einschneidend und in welcher Kombination die Differenzdimensionen gemeinsam wirken.

Die untersuchten Frauen reagierten mit unterschiedlichen, habituell verankerten »Taktiken« (De Certeau 1988: 89) auf dominante Diskurse, zugeschriebene Differenzen und intersektionelle Beschränkungen ihres bildungsbiografischen »Möglichkeitsraums« (Holzkamp 1983). Es konnten vier derartige habituell verankerte »Taktiken « typisiert werden (für eine ausführliche empirische Rekonstruktion dieser »Taktiken« vergleiche Kapitel 5). Diese »Taktiken« stellen die relationale Handlungsfähigkeit (Agency) dar, mittels welcher es den jungen Frauen gelang, sich den intersektionellen Beschränkungen ihrer Bildungsbiografien bis zu einem gewissen Grad zu widersetzen und ihren Einfluss auf deren Verlauf zu vergrössern:

3 In De Certeaus Terminologie würden sich die rekonstruierten Differenzdimensionen auf der Ebene der »Strategien« (De Certeau 1988: 87) bewegen. De Certeau versteht unter »Strategien « in der Regel Strukturen, die auf Kontrolle zielen und mittels derer soziale Ordnung hergestellt werden soll. Hierbei kann es sich jedoch auch um kurzfristig festgelegte Anordnungen handeln (Winter 2018). Sie bilden den Referenzrahmen, bzw. das » Kräfteverhältnis« (De Certeau 1988: 87) innerhalb dessen sich die »Taktiken« verorten. Sie verhalten sich relational zu »Taktiken« (ebd.: 89). »Taktiken« sind zunächst soziale Praktiken, die von Individuen oder Cruppen ergriffen werden können (Winter 2018). Da sich eine intersektionelle Perspektive als analytisch sensibilisierendes Konzept meines Erachtens besser eignet, um die subtilen Machtverhältnisse, welche einschränkend auf Bildungsbiografien wirken, zu rekonstruieren, habe ich auf die Weiterführung des»Strategie«-Begriffs als Cegensatz zum Begriff der»Taktik«nach De Certeau (De Certeau 1988: 87) verzichtet. Als referenziellen Rahmen der »Taktiken «auf der Ebene der »Strategien «verwende ich die intersektionellen Differenzdimensionen. Dies jedoch ohne den relationalen Aspekt zwischen »Taktiken« und intersektionellen Einschränkungen (bzw. »Strategien«) zu vernachlässigen (vgl. Kap. 2.3). 
1 Die »Taktik« des bildungsbiografischen Bestehens durch kämpferische Selbstbehauptung als Muslima

Im Zentrum dieser »Taktik« steht die Aneignung im De Certeau'schen Sinne bzw. das sich Zunutze machen der Differenzkategorie »Muslimin«, um bildungsbiografisch einen Weg zu finden. Bei dieser »Taktik« konnten zwei Ausprägungen im Bereich, wie sich die Frauen hierbei religiös selbst repräsentieren, ermittelt werden: einerseits eine religiöse Selbstrepräsentation als »emanzipierte«, anderseits eine religiöse Selbstrepräsentation als »dezidiert religiöse« Muslima. Durch beide Arten der religiösen Selbstrepräsentation erlangen die Frauen mehr Handlungsfähigkeit (Agency). Der ersteren Ausprägung gelingt es, sich mithilfe (religiöser) Selbstrepräsentation als emanzipierte Muslima gesellschaftspolitisch zu positionieren und eine Alternativkarriere in interreligiösen und/oder interkulturellen NGOs zu machen oder sich durch berufliche Selbstständigkeit mittels eines (religionsrelevanten) Nischenangebots (z.B. Hijab-Verkäuferin, Fahrlehrerin für muslimische Frauen) zu positionieren. Kraft der »Taktik« letzterer Ausprägung (Selbstrepräsentation als dezidiert religiöse Muslima) wird Bildungszugang auf Umwegen erlangt: Der durch die Stigmatisierung als Kopftuch tragende Muslima erzwungene berufliche Umweg führt zur Politisierung. Die »Taktik« der kämpferischen Selbstbehauptung als dezidiert religiöse Muslima beinhaltet die islamisch begründete Bildungsaspiration als Teil des »Kampfes gegen die Islamophobie«: Der Bildungsweg als politisierte Muslima wird konsequent weiterverfolgt - islamisch begründete grösstmögliche Bildungsaspiration stellt neben der Politisierung einen » sozialisatorische[n] Effekt szeneinterner Vergemeinschaftung« (Meinert/Seeliger 2013: 49) dar (vgl. ausführlich in Kapitel 5.1).

2 Die "Taktik« des bildungsbiografischen Bestehens durch zielstrebiges Aufsteigen Im Zentrum der zweiten »Taktik« steht die Aneignung des »meritokratischen Prinzips« (vgl. Becker/Hadjar 2017). Mehr Agency erlangen die jungen Frauen paradoxerweise dadurch, dass sie sich dasjenige Prinzip aneignen, mittels dessen Bildungsungleichheit in modernen Gesellschaften normativ gerechtfertigt wird (Solga 2005). Es gelingt ihnen, mithilfe - im Vergleich zu privilegierten Lernenden - ungleich grösserer Anstrengung aus ihren subalternen Positionen heraus nach meritokratischem Prinzip die intersektionell wirkenden Barrieren auszuhebeln und ihre habituell verankerte Bildungsaspiration in einer tertiären Bildung umzusetzen (vgl. ausführlich in Kapitel 5.2). 
3 Die »Taktik« des bildungsbiografischen Bestehens durch religiöse Vergemeinschaftung

Im Zentrum der dritten »Taktik« steht die Aneignung des akkumulierten sozialen Kapitals (Bourdieu 1983b) der religiösen Gemeinschaft, mittels derer die Frauen Zugang zum Arbeitsmarkt oder zu Bildung (wieder-)erlangen konnten. Durch die von der Herkunftsfamilie unabhängige Akkumulation von sozialem Kapital gelang den Frauen eine berufliche (Weiter-)Entwicklung, die ihnen ansonsten aufgrund intersektioneller Beschränkungen verwehrt geblieben wäre (vgl. ausführlich in Kapitel 5.3).

4 Die »Taktik« des bildungsbiografischen Bestehens durch widerständige Mikropraktiken

Der berufsbiografische Handlungsspielraum von diesen Frauen ist aufgrund eines ausgesprochen starken Zusammenspiels der Differenzdimensionen Gender, »Migrationshintergrund«, »class« und Religion im Vergleich zu den anderen drei Typen weitaus am stärksten eingeschränkt. Der Grund dafür dürfte nicht zuletzt in der sich zusätzlich manifestierenden Differenzdimension Körper (Hautfarbe), die im Zusammenspiel mit den anderen Differenzdimensionen intersektionell verstärkend wirkt, liegen. Im Zentrum der vierten »Taktik« steht die Aneignung eines "minimalen Möglichkeitsraums« (Mey 2015: 230) durch widerständige Mikropraktiken, deren Ziel es ist, Repräsentant*innen der hegemonialen Gesellschaft etwas entgegenzusetzen, ohne aus der subalternen Position heraus direkte Konfrontationen eingehen zu müssen. Exemplarisch für eine solche widerständige Mikropraktik der jungen Frauen hinsichtlich ihrer Bildungsbiografie ist bspw. das absichtliche Verfassen von fehlerhaften Bewerbungen auf eine Stelle, zu deren Bewerbung sie forciert wurden (vgl. ausführlich in Kapitel 5.4).

Es kann resümiert werden, dass Secondas muslimischen Glaubens im Kontext des gegenwärtigen Islamdiskurses bildungsbiografisch durch unterschiedliche, relationale Konstellationen der Differenzdimensionen (Gender, Religion, »class«, »Migrationshintergrund«, Körper etc.), die gemeinsam wirken, eingeschränkt werden (vgl. ausführlich Kap. 7.1) und durch unterschiedliche habituell verankerte »Taktiken« versuchen, innerhalb dieser Einschränkungen mehr Agency (Handlungsfähigkeit) in ihren Bildungswegen zu erlangen. Die Art wie sich diese Agency ausgestalten kann, wird durch einen intersektionell begrenzten bildungsbiografischen »Möglichkeitsraum« (Holzkamp 1983) vorgegeben. 
Mittels des gewählten theoretischen Rahmenmodells, das einerseits die intersektionellen Einschränkungen in den Blick nimmt, andererseits die Agency der jungen Frauen in Bildungsbiografien fokussiert, lässt sich, so das zentrale Ergebnis der Studie hinsichtlich »Religion« eine doppelte Rolle in Bildungsbiografien junger muslimischer Secondas nachzeichnen, die in den folgenden Kapiteln ausgeführt werden soll:

Auf struktureller Ebene wirkt Religion als Differenzkategorie im intersektionellen Zusammenspiel mit anderen Differenzkategorien einschränkend. Dies wird in Kapitel 7.1 ausgeführt und diskutiert.

Auf der Ebene der Agency hingegen zeigte sich auf der anderen Seite, dass Religion verstanden als religiöse Praxis, religiöse Selbstrepräsentation und religiöse Vergemeinschaftung auf der anderen Seite eine wichtige sowie produktive Ressource sein kann, mithilfe derer die jungen Frauen mehr Handlungsfähigkeit hinsichtlich ihrer Bildungsbiografien erlangen. Dieser Aspekt wird in Kapitel 7.2 dargelegt.

Begrifflich unterscheide ich zwischen Religion als Differenzkategorie bzw. -dimension und Religion als "gelebter Religion« (vgl. »lived religion«, McGuire 2008: 12-13). Verwende ich den Begriff Religion im Sinne einer Differenzkategorie bzw. -dimension, wird das Wort kursiv geschrieben, wo ich Religion hingegen im Sinne einer gelebten sozialen Praxis verstehe, wird der Begriff nicht-kursiv geschrieben.

\subsection{Religion als Differenzkategorie: Manifestationen der Differenzkategorie »Muslimin« in Bildungsbiografien}

Im Folgenden möchte ich nun zunächst auf die bildungsbiografisch einschränkende Rolle von Religion in Bildungsbiografien eingehen, also auf die Rolle der Religion als intersektionelle Differenzkategorie. Anschliessend möchte ich vorschlagen, Religion theoretisch als interdependente Kategorie (vgl. Walgenbach 2012c) zu denken. Dieser Vorschlag soll dazu beitragen, in der Religionswissenschaft einen intersektionellen Blick auf die biografische Bedeutung und Funktion von Religion als Differenzdimension im Zusammenspiel mit anderen Differenzdimensionen einzunehmen.

In den Rekonstruktionen der Bildungsbiografien der jungen Secondas wird der sich gegenseitig bedingende Zusammenhang zwischen der diskursiven und sozial konstruierten Differenzkategorie "Muslimin« deutlich. Die 
kritische Diskursanalytikerin Wodak (Wodak 2002: 8) führt die Auswirkungen von diskursiven auf soziale Praktiken wie folgt aus:

»Discursive practices may have major ideological effects - that is, they can help produce and reproduce unequal power relations between (for instance) social classes, women and men, and ethnic/cultural majorities and minorities through the ways in which they represent things and position people« (Wodak 2002: 8).

Es zeigte sich, dass unter den Bedingungen des gegenwärtigen Islamdiskurses die diskursive Differenzkategorie »Muslimin« (vgl. Kap 2.1.2) als soziale Deutungskategorie (re-)produziert wird und dass dieser Prozess mit wirkmächtigen, die soziale Praxis strukturierenden Machtbeziehungen einhergeht. Diese Machtbeziehungen bringen strukturelle Dominanzverhältnisse hervor, welche selbst (Bildungs-)Biografien (zumindest mit) zu prägen vermögen.

Wie in Kapitel 2.2 beschrieben, folgte ich bei der Analyse der Einschränkungen der Bildungsbiografien weitgehend Riegels vorgeschlagener intersektionaler Heuristik (Riegel 2016a: 61ff., 136ff., 2010a: 67ff.). Riegel geht von der Annahme aus, dass Intersektionalität im Sinne eines sensitizing concepts (2016a: 137) zu betrachten sei und sieht diese Perspektive als »eine offen fragende, wie auch als eine (vorherrschende Verhältnisse) kritisch-hinterfragende Perspektive« (ebd.) an.

Im Zentrum der vorliegenden Untersuchung stand die Frage, ob und inwiefern sich Religion (hier: Islam) im Zuge des gegenwärtigen Islamdiskurses als Differenzdimension ${ }^{4}$, (ggf. im Zusammenspiel mit anderen Differenzdimensionen), in Bildungsbiografien junger muslimischer Secondas manifestiert:

Als entscheidend für die konkreten bildungsbiografischen »Möglichkeitsräume« (Holzkamp 1983) der jungen Frauen erwies sich die Kombination bzw. Formationen der Differenzdimension Religion im Zusammenspiel mit mehr oder weniger stark wirksamen und sich überlagernden und gegenseitig verstärkenden oder abschwächenden weiteren Differenzdimensionen wie Gen-

Ich spreche von Differenzdimensionen als »historisch, sozial, politisch und kulturell tradiert[en] Dominanzverhältnis[sen]« (Walgenbach 2012c: 56), welche soziale Praktiken hervorbringen. Mit Walgenbach (2012c: 51) gehe ich von einer »dialektischen Beeinflussung zwischen sozialen Strukturen und Interaktionen« aus, welche sich in der Praxis artikulieren und empirisch rekonstruiert werden können. 
der, »Migrationshintergrund«, »class« und Körper ${ }^{5}$. Massgeblich für die Strukturierung und den Verlauf der Bildungsbiografien war hierbei, inwiefern sich diese Differenzdimensionen überlagern, verstärken oder abschwächen (vgl. Kapitel 5). Da es sich bei der multiperspektivischen Herangehensweise der Intersektionalität um ein komplexes Forschungsparadigma handelt, ist eine solche Analyse zwangsläufig offen und unabgeschlossen. Die Notwendigkeit eines »analytischen Spotlights (Walgenbach 2012c: 63) bei der Ausleuchtung der Komplexität von intersektionellen Differenzdimensionen ergibt sich nicht zuletzt dadurch, dass wie Becker-Schmidt betont, Intersektionalität ein solch hybrides Forschungsparadigma darstellt, dass es sich nur »arbeitsteilig bewältigen lässt « (2007: 57). Will man sich nicht in der Komplexität der gemeinsamen Verschränkung und Durchdingung der intersektionellen Differenzdimensionen, welche sich gegenseitig beeinflussen, verlieren, kommt man als Forschende nicht umhin, einen Fokus zu definieren. In der vorliegenden Untersuchung bildet der Fokus die Manifestation der Differenzkategorie »Muslimin« in Bildungsbiografien sowie deren institutionelle Reproduktion.

Die strukturellen Einschränkungen der Bildungswege der jungen Secondas, so konnte im Einklang mit anderen bildungsbiografischen Forschungen konstatiert werden, zeigten die Wirkmächtigkeit von unterschiedlichen leistungsfremden Differenzkategorien auf Bildungsverläufe. Diese institutionellen Schliessungsprozesse beschränkten sich selbstredend nicht auf diejenigen bildungsbiografischen Einschränkungen, welche die Differenzkategorie »Muslimin « hervorbringt. Habituelle Faktoren wie bspw. das elterliche Genderbild ${ }^{6}$ sowie der elterliche Bildungshintergrund und die gesellschaftliche sowie arbeitsmarktliche Positionierung der Eltern hatten ebenso bedeutenden, teilweise gar bedeutenderen Einfluss auf die Bildungswege der untersuchten Frauen (vgl. ausführlich Kap. 5). In bildungsbiografischen Übergängen manifestierten sich unterschiedliche Mechanismen der Reproduktion sozialer Ungleichheit besonders deutlich (vgl. hierzu auch Hadja/HupkaBrunner 2013, Becker et al. 2013, Becker/Solga 2012, Kronig 2013, Kronig 2007, Kronig et al. 2000, Solga 2005, Bourdieu/Passeron 1971). Die empirischen Rekonstruktionen der Bildungsbiografien zeigen, wie sich verschiedene Diffe-

5 In der vorliegenden Arbeit habe ich mich auf die intersektionellen Differenzdimensionen Cender, Religion, »lass «, »Migrationshintergrund« und Körper konzentriert. Diese kategoriale Auflistung betrachte ich jedoch als offen und unabgeschlossen. aus folgende Hinfälligkeit einer nachobligatorischen Ausbildung aufgrund eines traditionellen Rollenbilds. 
renzkategorien überlagern können und wie sie vom Bildungssystem nicht etwa ausbalanciert, sondern im Gegenteil reproduziert, stabilisiert und teilweise gar verstärkt werden (vgl. Kap. 5, Solga 2005, Bourdieu/Passeron 1971). So wurde in den bildungsbiografischen Erzählungen der jungen Secondas bspw. deutlich, dass Eltern, welche nicht im schweizerischen Bildungssystem sozialisiert wurden, ungeachtet sprachlicher Übersetzungsbemühungen vonseiten der Institutionen, die weitreichende Bedeutung von komplexen Selektionsprozessen auf Bildungslaufbahnen lediglich unvollständig nachvollziehen können. Insbesondere konnte in den Erzählungen der jungen Frauen die fehlende Unterstützung der Eltern an der ersten Selektionschwelle und die reproduktive Wirkung des Bildungssystems hinsichtlich des tendenziell wenig privilegierten gesellschaftlichen Status der Eltern rekonstruiert werden - diese Erkenntnis zieht sich durch das ganze Sample, unabhängig von den Typen der bildungsbiografischen »Taktiken«. Dass leistungsfremde Differenzdimensionen wie »Migrationshintergrund «, »class« oder aber auch Gender einen strukturierenden Einfluss auf Bildungsbiografien haben, stellt für sich keine neue Erkenntnis dar und ist bereits breit untersucht worden (u. v. A. Felouzis/Charmillot 2017, Mey 2015, Hadja/Hupka-Brunner 2013, Becker et al. 2013, Becker/Solga 2012, Kronig 2013, Kronig 2007, Kronig et al. 2000, Gomolla/Radke 2009, Solga 2005, Bourdieu/Passeron 1971). Was sich jedoch zeigte, ist, dass die Differenzkategorie Religion ebenso wie andere Differenzkategorien im intersektionellen Zusammenspiel zusätzlich einen strukturierenden Einfluss auf Bildungsbiografien haben kann. Dieses bildungsbiografisch einschränkende, intersektionelle Zusammenspiel wurde in den Bildungsbiografien nicht nur, aber besonders deutlich anhand der Differenzkategorie »Muslimin«.

Im Folgenden werde ich nun zusammenfassend auf zentrale (strukturelle) Manifestationen der Differenzkategorie »Muslimin« in Bildungsbiografien junger Secondas muslimischen Glaubens eingehen, sowie deren institutionelle Reproduktion und Verstärkung nachzuzeichnen versuchen. Die Differenzkategorie »Muslimin«, so kann resümiert werden, manifestiert sich in den Bildungsbiografien der jungen Frauen besonders deutlich in den folgenden zwei bildungsbiografischen Lagen: 1.) als wirkmächtige, strukturelle Bildungsbarriere in der Berufsbildung anhand der Sichtbarkeit des religiösen Symbols Hijab, 2.) als soziale Deutungspraxis im schulischen Feld (vgl. hierzu auch Lingen-Ali/Mecheril 2016). 
1 Die Differenzkategorie »Muslimin« als wirkmächtige Bildungsbarriere

in der Berufsbildung

Die erhobenen Daten legen nahe, dass sich das Tragen eines Kopftuchs als sichtbares religiöses Symbol bei jungen Secondas im Zuge des gegenwärtigen Islamdiskurses im Berufsbildungsbereich als wirkmächtige Bildungsbarriere manifestiert. Derweil glaubensgewisse Männer nicht in gleichem Masse der beruflich hindernden Wirkmächtigkeit religiöser Symbole ausgesetzt $\operatorname{sind}^{7}$, können sich insbesondere Kopftuch tragende Frauen in der Berufsbildung dem intersektionellen Zusammenspiel der Differenzdimensionen Gender und Religion (und potenziell weiteren Differenzkategorien) kaum entziehen. Während die Hijab tragenden Frauen meines Samples, die den tertiären Bildungsbereich durchlaufen haben, kaum bildungsbiografisch relevante Ausschlusserfahrungen hinsichtlich der Differenzkategorie »Muslimin« schilderten $^{8}$, zeichnen junge Frauen wie Zara, Mirjeta oder Duaa, die eine Berufsbildung absolvierten, ein gänzlich anderes Bild: In der Berufsbildung manifestiert sich die Differenzkategorie »Muslimin« bei Kopftuch tragenden Musliminnen als wirkmächtige Bildungsbarriere. Junge Frauen, für die das Tragen eines Kopftuchs ein unverzichtbarer Teil ihrer religiösen Selbstidentifikation ist, müssen mit erheblichen Einschränkungen bei der Berufswahl rechnen, Bildungsumwege in Kauf nehmen oder gänzlich auf ihr angestrebtes Bildungsziel verzichten und eine Neuorientierung vornehmen (vgl. exemplarisch Fallbeispiel von Zara, Kap. 5.1). Kommen weitere Differenzdimensionen wie Körper (z.B. Hautfarbe), »class« und »Migrationshintergrund« hinzu, er-

7 Selbst wenn Männer gewisse vergleichbare religiöse Symbole tragen, wie z.B. einen Bart, werden sie gemäss Erzählungen der jungen Frauen meines Sampels nicht in gleichem Masse wie Kopftuch tragende Frauen als Muslime sichtbar. Das Tragen eines längeren Barts ist gegenwärtig stark in der Populärkultur verankert, so dass Muslime, die aus religiösen Cründen einen Bart tragen, in der Öffentlichkeit von Repräsentant*innen der hegemonialen Mehrheitsgesellschaft kaum eindeutig als Muslime identifiziert werden können (Feldprotokoll 2016).

8 Eine Ausnahme bildet hierbei die Lehrerinnen- und Lehrerbildung. Zwar existieren an den unterschiedlichen pädagogischen Hochschulen der Deutschschweiz unterschiedliche rigide institutionelle Richtlinien hinsichtlich des Kopftuchtragens von Studentinnen in Praktika; dennoch sehen sich Hijab tragende Studierende bei der Suche nach Praktikumsstellen mit ähnlichen Schwierigkeiten konfrontiert wie Lehrstellensuchende (vgl. Interview Rhea Juni 2018). Es erweist sich nahezu als unmöglich, mit Hijab eine Praktikumsstelle als Lehrperson zu finden. Weil die Absolvierung der Praktika Bedingung für einen erfolgreichen Abschluss der Ausbildung ist, legen meinen Daten nahe, dass auch hier der Hijab als Bildungsbarriere wirkt. 
schwert dies den Bildungszugang zusätzlich (vgl. exemplarisch Fallbeispiel von Duaa Kap. 5.4).

Es erweist sich gemäss den Narrationen der jungen Secondas als äusserst schwierig, als Hijab tragende Frau eine Lehrstelle zu finden - auch mit besten Zeugnissen. Aufgrund der gegebenen qualitativen Datenerhebung können zwar keine generalisierten Aussagen gemacht werden, es ist jedoch augenfällig, dass keine der Kopftuch tragenden Frauen des Samples, die eine nachobligatorische Ausbildung in der Berufsbildung anstrebte, in dem von ihr angestrebten Berufsbereich eine Lehrstelle fand, die sie mit Hijab hätte antreten können - auch nicht bei besten schulischen Qualifikationen und beruflichen Eignungstests. Hijab tragende Frauen des Samples sahen sich im Berufsbildungsbereich vor die Wahl gestellt, sich entweder dafür zu entscheiden, das Kopftuch (zumindest während der Arbeitszeit) abzulegen oder berufliche Umwege in Kauf zu nehmen bzw. ihre Bildungsziele/-wünsche anzupassen oder gar eine berufliche Neuorientierung vorzunehmen. Meist wurden Absagen auf (Lehrstellen-)Bewerbungen gegenüber den Frauen mit der antizipierten Reaktion »der Kundschaft« begründet, dies insbesondere in Berufen, wo Sichtbarkeit in irgendeiner Form gegeben ist, z.B. in Dienstleistungsberufen oder im Verkauf. Diese antizipierten negativen »Kundenreaktionen« wurden jedoch in den vorliegenden Fällen gemäss den Erzählungen der Frauen nicht durch tatsächliche Kundenbefragungen gestützt, sondern lassen sich viel eher als Vorbehalte der potenziellen Vorgesetzten deuten (vgl. hierzu auch Scherr et al. 2015: 154). In Gesundheitsberufen werden Absagen im Gegensatz zu anderen Bereichen auffällig oft mit Hygienebedenken begründet. Auch hier wird laut den Erzählungen der Frauen nicht mit empirisch gestützten Befunden argumentiert. Aieta, die seit ihrer Kindheit einen Hijab trägt und deren grösster Wunsch es war, eine Lehre im Gesundheitsbereich zu machen, fand trotz einwandfreier Qualifikationen nicht einmal eine Praktikumsstelle. Auch Illana, eine andere Frau, die ich im Kontext der Forschung traf, wurde mittels des Arguments der fehlenden Hygiene vor die Wahl gestellt, das Kopftuch auszuziehen oder sich ausserhalb des Gesundheitsbereichs zu orientieren. Das Kopftuch, insbesondere die Bedeckung des Halses, entspreche nicht den Hygienevorschriften. Wälthy gelangt in einer neueren Studie, welche die Problematik des Kopftuch- und Piercing-Tragens in der Schweiz aus arbeitsrechtlicher Sicht beleuchtet (Wälthy 2018), ebenfalls zum Schluss, dass Hygienevorschriften »manchmal etwas exzessiv ausgelegt werden, um sich gar nicht erst mit der Problematik eines Kopftuch-oder Piercing tragenden Arbeitnehmer [sic!] auseinanderzusetzen« (ebd.: 75). Während Il- 
lana sich entschied, das Kopftuch während der Arbeitszeit auszuziehen, war für Aieta hingegen das Bedecken des Haars ein unverzichtbarer Teil ihrer religiösen Selbstidentifikation. Sich unbedeckt öffentlich zu zeigen, kam für sie nicht infrage. Sie musste deswegen schliesslich davon absehen, eine Lehrstelle im Gesundheitsbereich zu finden. Die Differenzkategorie »Muslimin« konnte somit im intersektionellen Zusammenspiel ihre Wirksamkeit als Bildungsbarriere voll entfalten: Wäre Aieta ein Mann muslimischen Glaubens, hätte sie bei hypothetisch ähnlicher religiöser Ausrichtung (und ähnlich guten Zeugnissen) vermutlich eine Ausbildung im Gesundheitsbereich finden und antreten können. Im Telefonmarketing hingegen, wo die Sichtbarkeit nicht gegeben ist, fand Aieta schliesslich auf Anhieb eine Stelle.

Dass es in beruflichen Bereichen, wo sie als Dienstleistende nicht in Erscheinung treten müssen, für Kopftuch tragende Frauen ungleich einfacher ist, eine Stelle zu finden, konstatieren auch Scherr, Janz und Müller (2015) in Bezug auf deutsche Anstellungspraxen. Ihre Befunde ergaben, dass bei Personalverantwortlichen ein gängiges Muster des Umgangs mit Kopftuch tragenden Muslimas darin besteht, sie in denjenigen Bereichen anzustellen, in denen sie für Kund"innen nicht sichtbar sind (Scherr et al. 2015: 156).

Systematische Studien zur Wirkmächtigkeit des Kopftuchs als Bildungsbarriere liegen in der Schweiz meines Wissens (noch) keine vor ${ }^{9}$. Scherr, Janz und Müller weisen jedoch in Bezug auf Deutschland nach, dass 29 bis 46 Prozent der Betriebe (abhängig von der Betriebsgrösse) das Tragen eines Kopftuchs als Ausschlusskriterium bei einer Lehrstellenvergabe werten. Obwohl faktisch nach deutschem Recht rechtswidrig, reicht diese Ablehnung in $\mathrm{Ab}$ hängigkeit von der Betriebsgrösse von 29 bis 46 Prozent - sie ist bei Kleinbetrieben signifikant höher als bei Grossbetrieben (2015: 150-151). Meine Daten legen die Vermutung nahe, dass sich in der Schweiz bezüglich der Vergabe der Lehrstellen ein ähnliches Bild ergeben dürfte.

In den erhobenen bildungsbiografischen Erzählungen konnte rekonstruiert werden, dass bei Lehrstellenvergaben insbesondere beruflich bildende Gatekeeper wie Lehrmeister"innen und Berufsbildende verhindernd wirken. Der Grund hierfür dürfte nicht zuletzt in der Struktur des schweizerischen Berufsbildungssystems liegen: Beim Dualen Berufsbildungssystem in der Schweiz können Betriebe nämlich quasi in Eigenregie ohne staatliche die Problematik des Kopftuch- und Piercing-Tragens am Arbeitsplatz aus rechtlicher Sicht untersucht wird. 
Regulierung über die Abschlüsse von Ausbildungsverträgen entscheiden (vgl. hierzu Imdorf 2011: 274). Während grössere Betriebe und staatliche bzw. kantonale Stellen über Diversity-Konzepte und -Beauftragte verfügen, die eine gewisse (soziokulturelle) Heterogenität bei Anstellungen sicherstellen sollen, kann sich bei kleineren Betrieben, wie anhand meiner Daten angenommen werden kann, die von Imdorf (2011) geortete Eigenlogik der Betriebe bei der Lehrstellenvergabe ungebremst entfalten. Mangels staatlicher Regulationen bei der Lehrstellenvergabe stellt das Kopftuch eine »Projektionsfläche« (Scherr et al. 2015) dar, welche für die Hijab tragenden muslimischen Bewerberinnen folgenreich ist: Sie sind abhängig von der jeweils gearteten Logik ihres zukünftigen Betriebs und der (gesellschaftspolitischen) Haltung ihrer zukünftigen Lehrmeister*innen bzw. Arbeitgeber"innen. Wie sich anhand der vorliegenden Erhebung vermuten lässt, verhindert diese Konstellation bei Hijab tragenden Frauen wohl in den allermeisten Fällen den Abschluss von Ausbildungsverträgen. Gemäss den erhobenen Daten müssen auch Frauen, die sich bereits in gut etablierten Lehr- oder Arbeitsverhältnissen befinden und die sich im Laufe der Adoleszenz dazu entscheiden ein Kopftuch anzuziehen, mit einer Kündigung rechnen oder die Lehrstelle wechseln (vgl. hierzu exemplarisch die Fallbeispiele von Zara und Mirjeta (Kap. 5.1)).

Wie die (Bildungs-)Biografien der jungen Frauen zeigen, ist das Zusammenfallen der Adoleszenz mit dem Entschluss, sich zu bedecken, für junge Frauen weder untypisch noch zufällig. So beschreibt King (2004: 28ff.) die Phase der Adoleszenz denn auch als Phase der Auseinandersetzung mit dem >bisherigen eigenen Leben einerseits, andererseits aber insbesondere auch mit der familialen Herkunft(-sgeschichte) im Zuge derer in Umgestaltungsprozessen potenziell neue, eigene Lebensentwürfe entwickelt werden können (ebd.). Der Entscheid, sich zu bedecken, fand bei einem Teil der jungen untersuchten Secondas, (auch bei solchen aus sog. säkularen Elternhäusern) genau im Zuge dieser von King und Koller beschriebenen adoleszenten Auseinandersetzung mit »Welt-, Selbst- und Sachbezügen« (King/Koller 2009b, Hummrich 2009: 28) statt. Dass die Phase der Adoleszenz ebenso berufsbiografisch einen wichtigen (Neu-)Orientierungspunkt darstellt, macht die Entscheidung, sich fortan $\mathrm{zu}$ bedecken, $\mathrm{zu}$ einem äusserst komplexen und mit weitreichenden (berufs-)biografischen Folgen verbundenem Unterfangen (vgl. exemplarisch Fallbeispiel Zara 5.1). Im Dualen Berufsbildungssystem wird sie gar nicht selten zum entscheidenden bildungsbiografischen Faktor. Wie sich in den Bildungsbiografien der jungen Frauen zeigt, gilt dies nicht nur für den Bereich der Berufsbildung, sondern auch für jenen der Berufsausübung. 
Der in der Adoleszenz gefällte Entscheid zum Tragen eines Kopftuchs stellte sich für die überaus meisten Frauen im Berufsbildungsbereich als entscheidender Faktor für die Verhinderung einer weiteren Anstellung sowie das Verfolgen einer weiterführenden beruflichen Karriere heraus.

Anhand der Manifestationen der Differenzkategorie »Muslimin« im Berufsbildungsbereich zeigt sich meines Erachtens besonders deutlich, dass Religion zur Kategorie der Differenz wird und mit anderen Differenzkategorien zusammen gedacht werden muss, um nicht spezifisch privilegierte Lebenslagen, wie bspw. jene einer christlich sozialisierten, weissen Mittelschichtsfrau zu bevorzugen und ins Zentrum der theoretischen Überlegungen zu stellen. Die Differenzkategorie "Muslimin« konstruiert sich zwar in erster Linie aus einer dialektischen Wechselwirkung von Religion und Gender. Ein besonders deutliches Beispiel hierfür - jedoch bei weitem nicht das einzige - ist das Tragen des sichtbaren religiösen Symbols Hijab, das eine grosse Wirkmächtigkeit als Bildungsbarriere in der Berufsbildung und Ausübung entfalten kann und sich genderspezifisch bei religiös orientierten Frauen (Zusammenwirken Religion und Gender) wirkt. Die Differenzkategorie "Muslimin« ist jedoch, wie sich zeigte, in sich heterogen strukturiert, dabei stehen - wie Riegel für Otheringprozesse feststellt - je nach Kontext »verschiedene Dominanzverhältnisse und Differenzkonstruktionen « im Vordergrund und werden in Verbindung mit anderen wirksam (Riegel 2017: 310): Je nachdem ob und auf welche Weise weitere Differenzdimensionen wie »Migrationshintergrund «, Körper (z.B. Hautfarbe) oder »class « in Wechselwirkung mit Gender und Religion treten, kann die Manifestation der Differenzkategorie »Muslimin « auf Bildungsbiografien unterschiedlich ausfallen und bildungsbiografische Wege sowie Chancen unterschiedlich beeinflussen. So ist die Bildungsbiografie von Duaa als schwarze, Kopftuch tragende Frau und Tochter von anerkannten Geflüchteten, deren Vater über eine in der Schweiz nicht anerkannte Tertiärbildung verfügt (vgl. Kap 5.4) anders strukturiert als die von Xhemile als weisse, nicht bedeckte Tochter eines Imam (ebenfalls mit nicht anerkannter Tertiärbildung), der als Gastarbeiter in die Schweiz kam (Kap. 5.2). Beide werden im Laufe ihrer Bildungsbiografie mit der Differenzkategorie »Muslimin« konfrontiert, aber auf eine andere Weise und innerhalb anderer institutioneller Bedingungen. Bei Duaa, welche durch die Sichtbarkeit der Differenzmarke Hautfarbe (Körper) und Kopftuch (Gender und Religion) intersektionell mehrfach belastet ist, und zusätzlich in ihrer nachobligatorischen Ausbildung auf das Berufsbildungssystem trifft, wirkt die Differenzkategorie »Muslimin« ungleich stärker und bildungsbiografisch einschneidender als bei Xhemile (vgl. Kap. 
5.2, 5.4), welche eine Tertiärbildung absolviert. Dies bedingt sich einerseits durch die Potenzierung und gegenseitige Durchdringung verschiedener intersektionell wirkender Differenzkategorien, andererseits aber auch durch die unterschiedlichen Logiken und Strukturen des Dualen Berufsbildungssystems gegenüber dem (mittel-)schulischen und tertiären Umfeld. Die Manifestation der Differenzkategorie »Muslimin«, wie sie sich in den bildungsbiografischen Erzählungen der Interviewten präsentiert, variiert nämlich in der schulischen Bildung im Vergleich zur Berufsbildung deutlich: Sie manifestiert sich im schulischen Feld in erster Linie als soziale Deutungspraxis, während sie im Dualen Berufsbildungssystem insbesondere für Kopftuch tragende Musliminnen zur Bildungsbarriere wird. Im Folgenden wird nun die Manifestation der Differenzkategorie »Muslimin« im schulischen Feld beschrieben.

2 Die Differenzkategorie »Muslimin« als soziale Deutungspraxis im schulischen Feld Dass der dominante Diskurs um Religion als diskursive Semantik auch den schulischen Raum erfasst hat, dürfte angesichts des laufenden Islamdiskurses nicht weiter erstaunen. Lingen-Ali und Mecheril sprechen gar von einer »Muslimisierung« des schulischen Raums, welche Subjekte hervorbringt und diese positioniert (Lingen-Ali/Mecheril 2016: 18).

Während in der Dualen Berufsbildung Differenz primär anhand sichtbarer religiöser Symbolik (in erster Linie anhand der Kopfbedeckung) konstruiert wird, manifestiert sich die Differenzkategorie »Muslimin« in der schulischen, insbesondere in der mittelschulischen und gymnasialen Bildung vielmehr als soziale Deutungspraxis. Beispielsweise über die pädagogisierte Zuschreibung einer Expertinnenrolle, quasi einer »Expertin für Islam« seitens der Lehrpersonen, aber auch seitens der Peers. Diese zugeschriebene Expertinnenrolle führt zu einer allgemeinen Erwartungshaltung gegenüber den Frauen, gemäss der sie nicht nur über sämtliche religiöse Belange, sondern auch über jegliche, »dem Islam « und der »arabischen Kultur « zugeschriebene Relevanz ${ }^{10}$ Auskunft geben können sollten. Verstärkt in diese Rolle hineingedrängt werden die Secondas jeweils, wenn gesellschaftspolitische Ereignisse oder Debatten (wie bspw. die sog. »Burka-Debatte«), aber auch terroristische Anschläge die Tagespresse beherrschen. Wie aus den biografischen Erzählungen

10 Diese können religiöse Pflichten und Praxen, Koraninhalte aber auch andere »der arabischen Kultur«zugeschriebene Themen wie Mädchenbeschneidung, Frauenunterdrückung und nicht zuletzt auch weltpolitische Konflikte und tagespolitische (terroristische) Ereignisse umfassen. 
der jungen Frauen deutlich wird, besteht die Erwartung seitens der Lehrpersonen und Peers nicht nur darin, dass sie zu sämtlichen Themen Auskunft geben können, sondern auch dass sie sich jeweils dazu positionieren (quasi stellvertretend für »den Islam« oder »die arabische Kultur«). Dieser Zuschreibungsprozess reproduziert den bereits mehrfach beschriebenen kollektiven sozialen »Rechtfertigungsdruck« (vgl. u.a. Baumann 2015: 17, Tunger-Zanetti 2013a: 224, Tunger-Zanetti 2013c, Schild 2010: 181), sich ständig als muslimische Frauen rechtfertigen bzw. legitimieren zu müssen. Der beschriebene Erwartungsdruck und der "Positionierungszwang «" (Riegel 2004: 338) führen ihrerseits nicht selten $\mathrm{zu}$ einem erhöhten Anspruch der Frauen an sich selbst, und zu einer intensiveren Befassung mit der zugeschriebenen Religion. In diesem Prozess wird eine dialektische Wechselwirkung von Religion als Differenzkategorie und Religion als gelebter sozialer Praxis (>lived religion McGuire 2008) besonders deutlich: Die zugeschriebene Rolle der »Expertin für Islam« (Religion als Differenzkategorie) führte bspw. bei Velika dazu, dass sie sich gezwungen sah, sich vermehrt mit dem Islam auseinanderzusetzen (Religion als gelebter sozialer Praxis). Die daraus folgende Akkumulierung von Wissen sollte ihr letztlich dazu dienen, eine fremdzugeschriebene Rolle auszufüllen, die sie sich gar nicht aussuchte.

Auf der anderen Seite wird die auf sie wirkende Erwartungshaltung von den betroffenen Frauen als äusserst ungerecht empfunden, insbesondere im Vergleich mit den Ansprüchen, die seitens der Lehrpersonen an ihre christlich sozialisierten Peers gestellt werden. Wie aus den Erzählungen der jungen Frauen deutlich wird, werden ihre Lebenswelten von den Lehrpersonen tendenziell als stereotyp und essenzialistisch rezipiert, während sie die Lebenswelten ihrer christlich sozialisierten Schüler*innen und deren Verhältnis zu Religion als selbstverständlich plural und pluralisiert ansehen. Von den christlich sozialisierten Schüler*innen wird nicht erwartet, dass sie auch nur Grundzüge »ihrer Religion« - falls sie überhaupt einer solchen zugschrieben werden - kennen. Ebenso stellt bei christlich sozialisierten Peers die Möglichkeit, nicht religiös zu sein, aus Sicht der Lehrpersonen und Peers eine selbstverständliche hypothetische Option dar, während gemäss den Narrationen der jungen Frauen auch bei säkular orientierten Secondas, deren Eltern aus einem gemeinhin mit »Islam« assoziierten Land eingewandert sind, von mit Geschlechterrollen von jungen Migrantinnen den Begriff »Positionierungszwang« (2004: 338). 
einem »religiösem Selbst « ausgegangen wird. Der ungleiche Anspruch an sie vs. ihre Peers wird von den jungen Frauen als äusserst ungerecht empfunden, führt er doch zu einer Reproduktion gesellschaftlicher Ungleichheitsverhältnisse im schulischen Kontext.

Eine Rezeption von Religion, wie sie von Lehrpersonen und Peers in diesem Kontext von den Interviewten beschrieben wird, so argumentiere ich, beruht auf einem geschlossenen Religionsbegriff. Ein geschlossener, essenzialisierter Religionsbegriff verhindert - analog zu den von Kalpaka (2006) beschriebenen ausschliessenden Effekten eines statischen Kulturbegriffs im pädagogischen Feld, dass Personen und ihre Handlungsgründe differenziert wahrgenommen werden (vgl. ausführlich Kap. »Expertin für Islam«, S. 178ff.). Er verschliesst zudem den Blick auf reale Lebensumstände bzw. lebensweltliche religiöse Praxen. Dass sich neben der von Kalpaka georteten »Kulturalisierungsfalle« (2006) auch eine »Religiosierungsfalle« im pädagogischen Feld zu eröffnen scheint, erstaunt angesichts des gesellschaftspolitischen, diskursiven Trends, dass Differenzen vermehrt entlang religiöser Grenzen konstruiert werden (Sökefeld 2011: 271), kaum. Dennoch wird die Zuschreibung der Rolle einer »Expertin für Islam« oder »Anwältin des Islam« von Lehrpersonen und Peers meist nicht etwa in einer ausschliessenden Intention vorgenommen, wohl eher im Gegenteil: Das Pädagogisieren der Differenzkategorie »Muslimin« in Form der Zuweisung einer Expertinnenrolle kann vielmehr als »eine Form des Verstehen-Wollens« (vgl. Kalpaka 2006: 396 hinsichtlich des Kulturbegriffs) gedeutet werden. Wie anhand des Fallbeispiels von Esma verdeutlicht wurde (Kap. 5.3.2 c), erfolgt bspw. die Zuschreibung zur Differenzkategorie »Muslimin« oft bereits auf der Primarstufe. Durch die Herstellung religiöser Differenz im Unterricht und deren Pädagogisierung seitens der Lehrperson wurde die Schülerin in ihrer Wahrnehmung überhaupt erstmals mit der Kategorie »Religionszugehörigkeit« bzw. mit der Kategorie »Muslimin« konfrontiert - im Sinne einer Differenzkategorie. Die hergestellte Differenz sollte im Unterricht einer pädagogischen Kontrastierung >Muslimin bzw. mit Migrationshintergrund (>nicht von hier) vs. >schweizerische Christin (>von hier ) dienen (hier wirken verschiedene Differenzkategorien im Zusammenspiel Religion, Gender, »Migrationshintergrund«). Wie am Beispiel dieser zugewiesenen Subjektpositionierung von Esma exemplarisch verdeutlicht wurde (ausführlich Kap. 5.3.2 c), verschliesst ein solch fremdzugeschriebener, stereotyper Antagonismus den Blick auf reale lebensweltliche (religiöse) Praxen. Er dient vielmehr in erster Linie dazu, die Lernenden im pädagogischen Kontext zu kategorisieren und suggeriert zudem die religiöse Zuordnung bzw. 
Markierung von Menschen als eindeutig (vgl. hierzu auch Lingen-Ali/Mecheril 2016: 22). Ein nahezu analoges Pädagogisieren von Differenz in Bezug auf die Kategorie Religion beschreibt Buchhardt (2014) in dänischen Schulen. Buchhardt betitelt ihre ethnografische Schulforschung in Dänemark gar mit »Pedagogized Muslimness« (2014).

Mit Lingen-Ali und Mecheril (2016: 22) gehe ich davon aus, dass pädagogische Angebote, die von einer gegebenen Differenz von »Kulturen« und »Religionen« ausgehen, als Machtkonstellationen zu verstehen sind. In diesem Sinne wird die Differenzkategorie »Muslimin« im Unterricht zur sozialen Deutungspraxis (vgl. ebd.: 17). Die Differenzkategorie »Muslimin« als soziale Deutungskategorie im pädagogischen Feld ist mit »Praktiken der Ausgrenzung, Zuschreibung, Hierarchisierung, Differenzierung, Homogenisierung und Essentialisierung (ebd.: 19) verbunden. Was Lingen-Ali und Mecheril für die Kategorie »Religion« im Allgemeinen feststellen, gilt ebenso für die Differenzkategorie »Muslimin«:

»Die Kategorie Religion kann mithin als normative Orientierung aufgefasst werden, die die soziale Praxis ordnet und reglementiert. Damit ist Religion eine - auch in pädagogischen Kontexten situierte - Handlungs- und Interpretationsoption der Bezeichnung und Herstellung von Anderen« (ebd.: 20).

Die Differenzkategorie »Muslimin« wird - so kann resümiert werden - im pädagogischen Kontext als soziale Deutungspraxis zu einer Kategorie der Zugehörigkeit (vgl. ebd. 20), die auf einem Antagonismus zwischen einem westlich-(säkularen)-heimischen »Wir« gegenüber einem (vermeintlich) muslimisch-(religiösen)-migrantischen »Andern« konstruiert und markiert (vgl. ebd.: 19). Sie fungiert »als hegemoniale Zuordnungspraxis, die symbolischen Raum schafft, in dem Exklusion und Dominanz legitimiert werden können« (ebd. 22).

In diesem Sinne kann Buchhardt (2014: 179) beigepflichtet werden, dass Religion im Kontext der Institution Schule (mit-)produziert wird.

Was bedeutet dies nun für die theoretische Betrachtung von Religion als Kategorie der Differenz? Theoretisch kann meines Erachtens aus der Manifestation der Differenzkategorie »Muslimin« in Bildungsbiografien gefolgert werden, dass bei der Differenzdimension Religion nicht von einem essenzialistischen "genuinen Kern« (Walgenbach 2012c: 59), welcher sich mit anderen Kategorien verschränkt, ausgegangen werden kann, sondern dass vielmehr verschiedene Differenzdimension von Beginn an zusammen gedacht werden 
müssen, wie dies Walgenbach hinsichtlich der Kategorie Gender mit dem Konzept der »interdependenten Kategorie« (2012c: 63) vorschlägt.

Im Einklang mit der theoretischen Kritik an additiven intersektionellen Modellen, wie sie in Kapitel 2.2. ausführlich dargelegt worden ist, lässt sich feststellen, dass sich Differenzkategorien bzw. -dimensionen nicht nur überschneiden, sondern sich gegenseitig durchdringen (Walgenbach 2012b: o. S.). Es kann Riegel folglich beigepflichtet werden, wenn sie feststellt, dass »die Konstruktion von Andern (...) durch den Bezug auf verschiedene Differenzkonstruktionen « (Riegel 2017: 17) erfolgt und dass sich hierbei verschiedene Dominanz- und Machtverhältnisse überlagern (ebd.). Welche Formationen sich hierbei herausbilden und inwiefern Differenzkonstruktionen miteinander interagieren, sich gegenseitig verstärken, abschwächen oder überlagern (ebd.), muss empirisch rekonstruiert werden. Riegel spricht in Bezug auf diese Formationen von »Modi des intersektionalen Zusammenspiels« (Riegel 2017: 17). Wie Wellgraf betont, existieren intersektionelle Differenzen nicht in »einem quasi isolierten Rohzustand, sondern sie artikulieren sich in der Praxis« (Wellgraf 2015: 168).

Walgenbach schlägt in Bezug auf die Kategorie Gender vor, eine integrale Perspektive einzunehmen - Gender als interdependente Kategorie zu denken (Walgenbach 2012c):

»Das heisst, es wird nicht mehr allein von Interdependenzen bzw. wechselseitigen Abhängigkeiten zwischen Kategorien bzw. Machtverhältnissen ausgegangen, sondern soziale Kategorien werden zugleich als in sich heterogen strukturiert konzeptualisiert (...). Damit haben soziale Kategorien keinen >genuinen< Kern mehr, (...) vielmehr werden sie selbst als interdependente Kategorie gefasst. (Walgenbach 2012b: o. S., Herv. im Orig.).

Im Anschluss an Walgenbach möchte ich deshalb hier vorschlagen, Religion in intersektionellen Analysen theoretisch ebenfalls als interdependente Kategorie $\mathrm{zu}$ denken, d.h., empirisch "nach den relevanten Feldern und Ebenen $\mathrm{zu}$ suchen« (ebd.), welche die »interdependente Struktur« (Walgenbach 2012c: 63) von Religion »in dem ausgewählten Kontext aufspannen« (ebd.). Wie Walgenbach verdeutlicht:

»Um die interdependente Struktur einer Kategorie zu fassen gilt es, deren interne Architektur in ihrer Komplexität möglichst umfassend auszuleuchten. Dabei hebt unser >analytischer Spotlight < zeitweise bestimmte Aspekte 
hervor, während andere in den Hintergrund treten müssen« (ebd., Herv. im Orig.).

Walgenbach schlägt mit ihren Überlegungen kein analytisches Modell vor, sie plädiert jedoch dafür, strukturelle Dominanzverhältnisse ins Zentrum der Analyse zu stellen:

»Wenn man deutlich machen will, dass einige Kategorien unsere Cesellschaft grundlegend strukturieren und die Lebenschancen von Individuen prägen, müsste man m.E. deren strukturelle Dominanz in das Zentrum der Analyse stellen (...). Unter struktureller Dominanz verstehe ich, dass ein interdependentes Dominanzverhältnis bzw. eine interdependente Kategorie gleichzeitig auf diversen Ebenen und Feldern (re-)produziert wird. Es handelt sich mit anderen Worten um ein historisch, sozial, politisch und kulturell tradiertes Dominanzverhältnis, das mehrere gesellschaftliche Bereiche durchzieht und Lebensrealitäten auf fundamentale Weise prägt. Wobei diese Prägung nicht als deterministisch verstanden wird, sondern als Produkt von sozialen Kämpfen bzw. Kräfteverhältnissen« (Walgenbach 2012c: 56, Herv. im Orig.).

Ein solches Dominanzverhältnis stellt die Differenzkategorie »Muslimin« dar. Anhand der Rekonstruktion der Manifestation der Differenzkategorie »Muslimin« in Bildungsbiografien wird deutlich, dass diese »gleichzeitig auf diversen Ebenen und Feldern (re-)produziert « (ebd.) wird, und dass es sich bei deren Bedeutung um ein »historisch, sozial, politisch und kulturell tradiertes Dominanzverhältnis« handelt, welches »mehrere gesellschaftliche Bereiche durchzieht und Lebensrealitäten auf fundamentale Weise prägt« (ebd.) (vgl. Kap. 5).

Religion als intersektionell wirksame Kategorie der Differenz ist meines Erachtens bisher sowohl in religionswissenschaftlichen Untersuchungen als auch in der feministischen Intersektionalitätsforschung nur unzureichend im Zusammenspiel mit anderen Differenzdimensionen beachtet worden.

Wie Höpflinger, Lavanchy und Dahinden in ihrem Artikel Linking Gender and Religion (2012) skizzieren, sind bspw. bisher schon die beiden Differenzdimensionen >Gender $<$ und >Religion nur unzureichend verbunden worden. Das mag an dem Problem liegen, das King und Beattie (2004) als >doppelte Blindheit< bezeichnen: »on one hand most contemporary gender studies (...) remain extraordinarily sreligion-blind; on the other hand many studies in religion continue to be profoundly >gender-blind (King/Beattie 2004 zit.n. 
Höpflinger et al. 2012: 617). ${ }^{12}$ Ebenso ist in der Intersektionalitätsforschung auffallend, dass Religion als Differenzkategorie bzw. -dimension in den überwiegend meisten intersektionalen theoretischen Analysemodellen fehlt (vgl. hierzu ausführlich Kap. 2.2). Bei Lutz und Leiprechts kategorialer Übersicht kommt Religion zwar in späteren Publikationen als "soziale Ordnungskategorie« vor, allerdings einzig in der Dichotomie religiös-säkular (Lutz/Leiprecht 2003: 121). Die intersektionelle Wirkung der Differenzkategorie Religion im Kontext von Bildung im Zusammenhang mit anderen Differenzdimensionen hingegen ist meines Wissens, mit Ausnahme vielleicht von Riegel (2011) ${ }^{13}$ und Knauth/Joachimsen (2017, in Bezug auf religiöse Bildung), kaum je qualitativ empirisch untersucht worden. Wie Wellgraf treffend feststellt, existieren intersektionelle Dimensionen jedoch nicht vorhergehend in »einem quasi isolierten Rohzustand, sondern sie artikulieren sich in der Praxis« (2015:168) und können also somit nur empirisch untersucht werden. Zahlreiche Autor*innen haben jedoch in anderen Kontexten bereits darauf hingewiesen, dass $>$ Religion ebenso wie >Ethnizität als Differenzmarker funktionieren und Einund Ausschlussprozesse bewirken können (Lingen-Ali/Mecheril 2016, Gilliam 2015, Lingen-Ali 2012, Riegel 2011, Sökefeld 2007, Modood 1997 etc.). Religion

12 Benthaus-Apel et al. (2017: 8) sind jedoch der Ansicht, dass das Problem der »doppelten Blindheit« zumindest für die Religionssoziologie aktuell nicht mehr gelte.

13 Die deutsche Erziehungswissenschaftlerin Riegel (2011) befasste sich speziell mit Religion als Differenzmarker im pädagogischen Kontext. Sie untersuchte die Herstellungsprozesse von Differenz im (sozial-)pädagogischen Sprechen über Jugendliche mit»Migrationshintergrund « (2011: 319). Hierbei nahm sie auf die theoretischen Konzepte der Intersektionalität und Interdependenz Bezug und kam zum Schluss, dass »Prozesse des Othering sowie anti-muslimische, rassistische, heterosexistische Diskurse und Repräsentationen « (ebd.: 337) in (sozial-)pädagogischen Prozessen allgegenwärtig sind und dass diese Differenzmarker nicht einzeln, sondern ineinander verschränkt auftreten und sich so "gegenseitig beeinflussen und bestärken« (ebd.). Als ein weiteres Ergebnis strich sie heraus, dass in den von ihr untersuchten Erzählungen der Jugendarbeiter*innen über Jugendliche mit »Migrationshintergrund« Differenzlinien vor allem entlang kulturell-religiöser Grenzen konstruiert werden. Riegel zeigte auf, wie in diesem Kontext Religion zum Differenzmarker wird: Sie konnte feststellen, dass in Erzählungen von Jugendarbeiter*innen speziell muslimische Jugendliche als »von der >deutschen Kultur (...) abweichend « (ebd.: 321) konstruiert wurden. Ebenso verdeutlicht sie, wie sich diese Differenzen anhand im gegenwärtigen Islamdiskurs gängigen Differenzmarkern manifestieren, so zum Bespiel anhand von Erzählungen über >unterdrückteく muslimische Mädchen, patriarchale Geschlechterrollenvorstellungen und gewalttätige Konflikte. 
als Differenzdimension ist demgegenüber in den überwiegend meist kategorialen Aufzählungen von Intersektionalität nicht berücksichtigt worden. Auch Müller (2013: 132) fragt sich, inwiefern Religion als weiterer Differenzfaktor eine Rolle bei sozialen Positionierungsprozessen spielen könnte und »die Liste ergänzen « (ebd.) sollte. Lingen-Ali und Mecheril plädieren gar dafür, die Differenzkategorie Religion als Substitut für »race« zu betrachten (Lingen-Ali/Mecheril 2016: 20ff.). Aus einer konsequent intersektionellen Perspektive greift eine solche Deutungspraxis meines Erachtens jedoch zu kurz, da sie eine Analyse spezifischer (Diskriminierungs-)Erfahrungen wie bspw. jener von Duaa (vgl. Kap. 5.4) als schwarze, Kopftuch tragende Frau unterschlagen würde (Verflechtung der Differenzdimensionen Gender/»race«/Religion).

Wie Walgenbach aufzeigt, ist auch die feministische Theoriebildung, ebenso wie der politische Feminismus von komplexen Dominanzverhältnissen geprägt. Sie arbeitet diese differenziert auf und resümiert, dass "schwarze Frauen, Migrantinnen, Jüdinnen und Frauen mit Behinderungen« gemeinsam die Erfahrung machten, »dass sie im feministischen Mainstream als >die Andern r repräsentiert und verobjektiviert wurden« (2012b: o. S.). Wie meine Daten vermuten lassen, dürften zurzeit (Kopftuch tragende) Frauen, welche sich als Musliminnen und Feministinnen verstehen, ähnliche Erfahrungen machen. Um die wirkmächtigen Machtverhältnisse zu illustrieren, welche mit der Differenzkategorie »Muslimin« gar in feministischen Diskursen einhergehen, sei kurz ein Beispiel angeführt: Zoya schilderte mir in diesem Zusammenhang, wie sie auf YouTube ein Interview mit der Feministin Alice Schwarzer gesehen hatte und ihr gerade gedanklich von ganzem Herzen beipflichten wollte, als diese gegen Ende des Gesprächs verlauten liess, alle Kopftuch tragenden Musliminnen seien unterdrückt. Entrüstet macht Zoya ihren Gefühlen wie folgt Luft:

»Aber an einer Muslima sagst du dann, nein nein, du weisst nicht, was gut ist für dich, ich befreie dich jetzt von deinem Kopftuch: Das ist dann auch Zwang, das ist auch eine Vergewaltigung!«(Zoya, A 112).

Dass sie gerade von einer Feministin einem »entmündigenden Kollektiv [von] Unterdrückten « zugewiesen wird (Marx 2008: 57), versteht Zoya als »Zwang« und »Vergewaltigung« (Zoya, A 112). Sie bemängelt an anderer Stelle, dass sie nicht verstehe, wieso eines der Grundpostulate des Feminismus, nämlich dasjenige der weiblichen Selbstbestimmung, für sie als Hijab tragende Frau nicht gelten solle (Feldtagebuch Dezember 2015). 
Wie in Kapitel 2.1.2 dargelegt, wird Kopftuch tragenden Frauen in der Tat in einer bestimmten feministischen Tradition, der Alice Schwarzer zugerechnet wird (vgl. Rommelspacher 2009b: 395), quasi kollektiv die Selbstbestimmung abgesprochen. Zwar bleibt diese Position innerhalb des Feminismus nicht unwidersprochen, dennoch steht Schwarzer mit ihrer Ansicht nicht alleine da, sondern geniesst mit dieser Haltung zum Kopftuchtragen in der Gesellschaft breiten Rückhalt (ebd.). Rommelspacher bezeichnet diese feministische Tradition als »orthodoxen Feminismus« (ebd.). Anlehnend an die ägyptisch-amerikanische Genderforscherin Ahmed könnte jedoch auch von einem »colonial feminism« (Ahmed 1992: 244) gesprochen werden. Rommelspacher kritisiert die »Selbstverständlichkeit, mit der ein solcher Feminismus vor vornherein zu wissen glaubt, was Emanzipation ist und wie sie umgesetzt werden muss « und wie dieser »schon seit Beginn der Moderne das Verhältnis zwischen den westlichen Frauen und denen der übrigen Welt bestimmt hat « (Rommelspacher 2009b: 398). Wie sie darlegt, besitzt insbesondere das Motiv der »Befreiung « der muslimischen Frau vor ihren männlichen Unterdrückern eine lange, europäische Tradition. Bereits Kreuzfahrer legitimierten ihre Mission damit, »die orientalische Prinzessin zu befreien « (ebd.: 399). Auch in der Kolonialzeit stellte die Befreiung der Frauen, wie Ahmed erörtert, ein wesentliches Element kolonialer Legitimationsstrategie dar (Ahmed 1992).

Rommelspacher bezeichnet Feminismus dann als westlich, wenn er »den Anspruch erhebt, objektiv und universal gültig zu sein« (Rommelspacher 2009b: 399, Herv. im Orig.) und die Kriterien definiert, »die erfüllt sein müssen, um ebenbürtig mitreden zu können« (ebd.). Diese Art von westlichem, »kolonialem Feminismus« kann also als Ausdruck eines komplexen, historisch tradierten Dominanzverhältnisses im Sinne Walgenbachs (2012c: 56) gedeutet werden. Ein Dominanzverhältnis, das sich auf die Konstruktion der Differenzkategorie »Muslimin« auswirkt und, wie in dieser Arbeit hinsichtlich von Bildungsbiografien dargelegt wurde, »Lebensrealitäten auf fundamentale Weise prägt « (Walgenbach 2012c: 56, Herv. im Orig.).

Zoya verwehrt sich gegen eine solche, von strukturellen Dominanzverhältnissen geprägte Sichtweise wie die eines »orthodoxen Feminismus« (Rommelspacher 2009b: 395). Sie verfügt wie auch Aieta über ein ermächtigendes Verständnis von Feminismus. Aieta schildert ihr Verständnis von Feminismus wie folgt:

»Weil, ich bin feministisch aus dem Grund, weil ich entscheiden tue, dass ich den Hijab trage...in dieser Richtung. Ich bin emanzip[iert]...also ich entschei- 
de (...). Feminismus ist für mich, sich für seine Rechte einsetzen« (Aieta, A 71).

Wie aus dem Zitat deutlich wird, verbinden sowohl Aieta als auch Zoya Feminismus mit Selbstbestimmung und Selbstermächtigung. Ihr Verständnis von Feminismus sehen sie durchaus im Einklang resp. als Mitbegründung ihres Hijab-Tragens. Diese Sichtweise steht in krassem Gegensatz zu dem feministischen Rettungsdiskurs - dem Diskurs >der unterdrückten Muslimin`, welche vor dem >orientalistischen Patriarchat« " gerettet werden muss (Marx 2008: 57) - wie er in einigen feministischen Traditionen rekonstruierbar ist (vgl. Kap.2.1.2). Die Erfahrung, wie sie Zoya und Aieta machten, nämlich von Exponentinnen des feministischen Mainstream »als Unterdrückte« markiert und als »die Andern« verobjektiviert zu werden (vgl. Walgenbach 2012b: o. S.), zeugt von den komplexen interdependenten Dominanzverhältnissen, mit welchen die Differenzkategorie »Muslimin« einhergeht. Es handelt sich hierbei um ein »historisch, sozial, politisch und kulturell tradiertes Dominanzverhältnis, das mehrere gesellschaftliche Bereiche durchzieht und Lebensrealitäten auf fundamentale Weise prägt « Walgenbach (2012c: 56). Gerade solch komplexe Dominanzverhältnisse sind nach Walgenbach ins Zentrum der Analyse von interdependenten Kategorien zu stellen (vgl. ebd.):

Eine intersektionale, postkoloniale Perspektive kombiniert mit einer Agency-Perspektive, wie sie in dem vorliegenden Projekt eingenommen wurde, lehnt eine kollektive Viktimisierung und Entsubjektivierung muslimischer Frauen ${ }^{14}$ ab und ermöglicht es, soziale Praktiken wie bspw. das Tragen eines Hijabs auch "gegen den Strich« zu lesen, bspw. als ein sich Verwehren gegen (westliche) Dominanz- und Assimilationsansprüche (vgl. hierzu Strahm 2007: 7).

Ein intersektioneller Analyserahmen könnte demnach in der Religionswissenschaft dahingehend fruchtbar gemacht werden, dass er einen feministischen, postkolonialen und gesellschaftskritischen theoretischen Fokus darstellt, der (Diskriminierungs-)Erfahrungen sowie Selbstpositionierungen von intersektionell belasteten Frauen sichtbar machen kann. Eine solche Perspektive ermöglicht es, die Heterogenität der Erfahrungen mit Differenzkategorien in den Blick zu nehmen und zu rekonstruieren, inwiefern die Differenzkategorie Religion eine spezifische Rolle bei sozialen

14 Selbstredend gilt das auch für die kollektive Viktimisierung mittels anderer Differenzkategorien. 
Positionierungsprozessen insbesondere auch von Frauen spielen kann und inwiefern diese Kategorie mit anderen Differenzkategorien bzw. -dimensionen einhergeht sowie gemeinsam wirkt. Das Potenzial einer intersektionellen Perspektive besteht primär darin, dass soziale (Selbst-)Positionierungen von Subalternen im wissenschaftlichen (und gesellschaftlichen) Diskurs sichtbar gemacht werden können. Mittels eines intersektionellen Ansatzes in Bezug auf Religion können spezifische soziale Ungleichheitsverhältnisse und strukturelle Diskriminierungen sowie (Ausschluss-)Erfahrungen differenzierter analysiert und benannt werden und laufen weniger in Gefahr, unterschlagen oder unter andere Kategorien subsumiert zu werden. Wird Religion jedoch quasi isoliert und nicht als intersektionelle Kategorie gedacht, besteht die Gefahr, dass gerade genderspezifische (Diskriminierungs-)Erfahrungen religiöser Frauen wie bspw. die religiös orientierter Musliminnen (Differenzdimensionen Religion/Gender) unzureichend in Betracht gezogen werden. Verfügen diese gegebenenfalls zusätzlich über einen sog. »Migrationshintergrund (Differenzdimension (»Migrationshintergrund«) und/oder sind sie ggf. Angehörige der Unterschicht (»class«) und/oder People of Color (»Körper«), steigt die Wahrscheinlichkeit, dass deren spezifische Erfahrungen und soziale Lagen aufgrund einer komplexen Überlagerungen struktureller Dominanzverhältnisse unterschlagen werden. Schliesslich trägt eine intersektionelle, interdependente Perspektive dazu bei, essenzialistische Konstruktionen von Identität zu vermeiden und wie Davis (2008: 30) es ausdrückt »situated, critically reflexive feminist knowledge« (2008: 30) zu produzieren.

\subsection{Religion als Ressource: Manifestation von religiöser Praxis, religiöser Selbstrepräsentation und religiöser Vergemeinschaftung als Ressource in Bildungsbiografien}

Die theoretische Herangehensweise, eine intersektionale Perspektive mit einer Agency-Perspektive zu verknüpfen, wie sie in vorliegender Untersuchung gewählt wurde, ermöglichte es, nicht nur die Einschränkungen der Bildungsbiografien $\mathrm{zu}$ rekonstruieren, sondern $\mathrm{zu}$ erkennen, dass Religion in Bildungsbiografien junger Secondas muslimischen Glaubens eine doppelte Rolle zukommt: Nämlich einerseits die einer intersektionell einschränkenden bzw. interdependenten Differenzkategorie, auf der anderen Seite jedoch ebenso auf der 
Ebene der "gelebten Religion « $^{15}$ (»lived religion«, McGuire 2008: 12-13) die einer ermächtigenden Ressource, mittels derer die jungen Frauen mehr Agency über ihre Bildungsbiografien erlangen können. Die Rolle der Religion als ermächtigende Ressource soll im Folgenden ausgeführt werden.

Hummrich wies in ihrer Studie Bildungserfolg und Migration (2009) bereits darauf hin, dass Religiosität in Biografien von Migrantinnen auch die Bedeutung eines produktiven Umgangs mit Ressourcen zukommen kann (Hummrich 2009: 240ff.). Sie kritisierte, dass in der Migrationsforschung bisher »vor allem auf die problematischen Aspekte der Religiosität « bei Migrantenjugendlichen verwiesen wird, dies insbesondere bei muslimischen Mädchen (ebd.: 240) und stellte die These auf, dass die »individuelle Auseinandersetzung mit Religiosität« von Migrantinnen ebenso »als Ausdrucksgestalt der Bearbeitung ihrer Individuationsproblematik gesehen werden« kann (ebd.).

Dass Religion nicht nur als Kategorie der Differenz bei gesellschaftlichen Selbstpositionierungsprozessen von jungen Secondas manifest wird, sondern durchaus auch Quelle der Entwicklung von mehr Agency sein kann, stellte auch die niederländische Religionssoziologin Bracke in einer empirischen Untersuchung zu akademisch gebildeten Anhängerinnen der Milli-Görüş-Bewegung fest. Im Kontext der politischen Narration eines "Dutch exceptionalism «" ${ }^{16}$ (Bracke 2011: 29) sowie des laufenden Islamdiskurses beschreibt sie Strategien, mittels derer die von ihr untersuchten Frauen Handlungsfähigkeit entwickeln, um dem dominanten Diskurs entgegenzutreten. Sie spricht hierbei - rekurrierend auf Althussers Konzept der Interpellation - von »talking back«, ebd.: 37-38). Bracke nennt vier Strategien, wie die jungen Frauen durch »talking back« Agency entwickeln (ebd.: 38ff.). Diese Strategien sind teilweise den von mir rekonstruierten »Taktiken«,

15 »Gelebte Religion « (»lived religion«, McGuire 2008: 12-13) verstehe ich hier als Cegensatz zu Religion als zugeschriebene Differenzkategorie.

16 Bracke (2011) rekonstruiert, wie das niederländische politische System auf der Narration eines »Dutch exceptionalism« (ebd.: 29) hinsichtlich aussergewöhnlicher »Toleranz« beruht und historisch auf einem institutionalisierten Management (religiöser) Differenz gründet (ebd.). Die Narration eines »Dutch exceptionalism «bezieht sich, wie Bracke ausführt, in erster Linie auf die beiden Prinzipien des Säkularismus einerseits und der sexuellen Freiheit und Emanzipation andererseits. Bracke zeigt auf, wie fromme Musliminnen in dieser diskursiven Anordnung zur Kontrastfigur stilisiert werden und zu zentralen »Subjekten der Debatte« werden (ebd.: 28, 29). 
mittels derer sich Frauen in ihren Bildungsbiografien zu behaupten versuchen, nicht unähnlich. Als erste Strategie des »talking back« führt Bracke die Kritik am öffentlichen Islamdiskurs durch die eigene Selbstpositionierung als »emanzipierte fromme Muslimin (ebd.) an; dieser erste Typus von Bracke ähnelt in gewisser Weise der »Taktik der kämpferischen Selbstbehauptung« (»Taktik«1), in der Ausprägung »emanzipierte« Muslima. Als zweite Strategie analysiert Bracke das scheinbare Akzeptieren der Behauptungen des öffentlichen Diskurses durch die gesellschaftliche Selbstpositionierung als ostentativ »unemanzipiert « (ebd.: 4off.); diese Strategie ist der »Taktik der kämpferischen Selbstbehauptung« in der Ausprägung ostentative Muslima ähnlich. Als dritte Strategie des »talking back« verortet Bracke die Selbstorganisation der jungen Frauen in Grass-root-Vereinen zur Aus- und Weiterbildung von Glaubensschwestern und somit als Beitrag zu deren Selbstermächtigung (ebd.: 42ff.), diese Strategie ähnelt in der ermächtigenden Bedeutung der religiösen Vergemeinschaftung der »Taktik«3. Schliesslich stuft sie als vierte Strategie das resignierte Verstummen (ebd.: 44) ein, das auch ein Element der »Taktik der widerständigen Mikropraktiken« darstellt.

Es ist interessant zu sehen, wie sich - auch innerhalb politisch, historisch und gesellschaftlich (leicht) unterschiedlicher Kontexte - ähnliche Strategien rekonstruieren lassen, mittels derer religiös orientierte Secondas muslimischen Glaubens dem dominanten Diskurs entgegentreten und so versuchen mehr Agency zu entwickeln. Allerdings gilt es zu betonen, dass Brackes Sample mit der Fokussierung auf akademisch gebildete Anhängerinnen einer dezidierten religiösen Bewegung ganz anders strukturiert ist als das der vorliegenden Untersuchung.

Auch in der vorliegenden Untersuchung wurde jedoch deutlich, dass der Islam als "gelebte Religion« (»lived religion« McGuire 2008: 12-13) - trotz oder gerade auch wegen seiner gesellschaftlichen Manifestation als Differenzkategorie - eine Ressource zur Entwicklung von Agency in Bildungsbiografien darstellen kann (vgl. Kapitel 5, Fallbeispiele). Dieser Aspekt wird immer wieder implizit und explizit in den habituell verankerten »Taktiken« manifest (vgl. Kap. 5) und soll im Folgenden kurz anhand der unterschiedlichen Typen resümierend dargestellt werden: 
Typus 1: Religiöse Selbstrepräsentation als Ressource

zur gesellschaftlichen Selbstpositionierung

Diese Frauen nutzen ihre religiöse Selbstrepräsentation dahingehend als Ressource, dass sie versuchen, die Differenzkategorie "Muslimin« und das damit einhergehende gesellschaftliche Stigma emanzipatorisch umzudeuten (vgl. Kap 5.1). Dies erreichte bspw. Zara dadurch, dass sie sich durch eine dezidierte Loslösung vom elterlichen Genderbild als Kopftuch tragende, »emanzipierte« Muslima gesellschaftlich als Kontrastfigur zur diskursiv konstruierten »armen, unterdrückten Muslimin« (Kaya 2012: 120) $\mathrm{zu}$ positionieren versucht. Zara entfachte durch ihre religiöse Selbstrepräsentation im Zuge des gegenwärtigen Islamdiskurses und des damit einhergehenden gesellschaftspolitischen Klimas eine dialektische Dynamik, welche ihr schlussendlich (bildungs-)biografisch zugute kam. Durch ihre dem gängigen Stereotyp widersprechende, religiöse Selbstrepräsentation bediente Zara indirekt die politischen Interessen gewisser gesellschaftlicher Akteure, und wurde zu einer Art "Vorzeige-Muslima « von Integrationspolitikern, Bildungsinstitutionen und NGOs. Anhand der Rekonstruktion von Zaras Bildungsbiografie (Kap. 5.1) wird besonders deutlich, dass die Rolle der "gelebten Religion" als Ressource in einem dialektischen Verhältnis mit der Rolle der Religion als Differenzkategorie (in Bildungsbiografien) steht: Ihre Selbstrepräsentation als »emanzipierte Muslima« wurde im gegenwärtigen gesellschaftspolitischen Kontext zur Ressource, um eine Alternativkarriere einzuschlagen (vgl. Kap. 5.1) und ihr ein berufliches Weiterkommen zu ermöglichen. Ein Werdegang, welcher ihr als Kopftuch tragende Frau im Dienstleistungsbereich trotz exzellenter Zeugnisse verwehrt blieb.

Anderen Frauen gelang die Umdeutung der Differenzkategorie Religion als Ressource zur gesellschaftlichen Selbstpositionierung damit, dass sie das Stigma des Kopftuchtragens (vgl. Kreutzer/Demir, Sümeyye 2015) im Arbeitsmarkt als Ressource nutzten. Sie suchten berufsbiografisch nach Nischen, in welchen ihnen ihre religiöse Selbstrepräsentation als bspw. als Kopftuch tragende Muslima zunutze kam, resp. zur bevorteilenden Ressource wurde, anstatt zum Stigma: Sie eigneten sich also die Differenzkategorie "Muslimin« im De Certeau'schen Sinne (1988: 89) an, indem sie sich bspw. als Fahrlehrerin für muslimische Frauen oder als Gründerinnen muslimischer Modelabels oder Hijab-Boutiquen selbstständig machten.

Bei der Ausprägung der religiösen Selbstrepräsentation als »ostentative« Muslima zeigte sich die "gelebte Religion« (McGuire 2008: 12-13) indirekt 
als Ressource und zwar indem sich die Frauen durch die Art ihrer religiösen Selbstrepräsentation politisierten und in der Vergemeinschaftung mit Gleichgesinnten eine islamisch begründete, grösstmögliche Bildungsaspiration entwickelten. So bspw. Mirjeta, welcher der ursprünglich eingeschlagene Bildungsweg wie Zara ebenfalls aufgrund des Hijab Tragens verwehrt wurde, und die sich durch diese Bildungsbarriere politisierte. Durch die Vergemeinschaftung mit Gleichgesinnten setzte Mirjeta ihren eingeschlagenen Bildungsweg - notfalls mittels juristischer Mittel - entschieden fort und versteht ihn als Teil des »Kampfes gegen die Islamophobie« (vgl. Kap.5.1.2.c).

Bei Frauen, bei denen die »Taktik« des Typus eins rekonstruiert werden konnte, kann zusammengefasst werden, stellt die religiöse Selbstrepräsentation eine Ressource zur gesellschaftlichen Selbstpositionierung dar, die positive Auswirkungen auf deren bildungsbiografischen Verlauf hat. Die religiöse Selbstrepräsentation als Teil »gelebter Religion« (McGuire 2008: 12-13) steht in ihren Bildungsbiografien in einem dialektischen Verhältnis zu der Rolle der Religion als Differenzkategorie, wie sie sich gesellschaftlich manifestiert.

Typus 2: Religiöse Praxis als Ressource im Privaten

Für diese Frauen stellt deren religiöse Sozialisation eine Ressource in ihren Bildungsbiografien dar. Die religiöse Sozialisation von Frauen, bei denen die habituell verankerte »Taktik des zielstrebigen Aufsteigens« rekonstruiert werden konnte, zeichnet sich durch eine starke Vereinsgebundenheit und grosses formelles, religiöses Wissen aus (vgl. Kap. 5.2.2 c). So auch diejenige von Xhemile, Sahar und Hannan.

Die religiöse Praxis wie auch die Nähe zum elterlichen Religionsverein wurde bei diesen Frauen in zwei unterschiedlichen Ausprägungen tradiert: die eine Ausprägung, wie sie sich bspw. bei Xhemile zeigt, zeichnet sich durch eine Pragmatisierung der religiösen Praxis und des Vereinsengagements der Eltern aus (Ausprägung "pragmatische« Muslima, vgl. Kap. 5.2). Die andere Ausprägung zeigt sich in der weitgehenden Tradierung des elterlichen Engagements und der elterlichen religiösen Praxis (Ausprägung »engagierte« Muslima bspw. Sahar, Hannan). Hinsichtlich der Manifestation der »gelebten Religion « (McGuire 2008: 12-13) als Ressource spielt jedoch, wie sich rekonstruieren liess, die Ausprägung der Tradierung keine Rolle. Als prägend für die Bildungsbiografie erwies sich vielmehr die religiöse Sozialisation und das damit einhergehende Religionsverständnis: Sowohl Xhemile wie auch Sahar und Hannan gelang es, mittels ihres sozialisatorisch erworbenen, intellektu- 
ellen Islamverständnis ihre Religiosität in ein plausibles Verhältnis zum säkularen Schulwissen zu bringen. Bei Glaubenskonflikten in beruf- und ausbildungsbezogenen Situationen waren sie in der Lage, sich von religiösen Dogmen zu distanzieren und - nicht zuletzt zwecks der zielstrebigen Verfolgung des Bildungswegs - Kompromisse zu finden.

Im privaten Bereich kommt jedoch der "gelebten Religion« eine nicht $\mathrm{zu}$ unterschätzende Bedeutung als persönliche Ressource zu: Die habituell verankerte, mehr oder weniger pragmatisch tradierte religiöse Praxis wie auch die familiäre Eingebundenheit in den Religionsverein stiftet Sinn und gibt Rückhalt im täglichen Leben und bei Krisen (vgl. Kap. 5.2.2b).

Religion und religiöse Praxis übernehmen in Bildungsbiografien von diesen Frauen also die Rolle einer Ressource im Privaten. Sie dient schliesslich unter anderem nicht zuletzt auch der konsequenten Verfolgung der »Taktik des zielstrebigen Aufsteigens", mittels der sie - im Vergleich zu privilegierten Lernenden - ungleich grössere Anstrengungen zur Erreichung ihrer Bildungsziele in Kauf nehmen müssen.

Typus 3: Religiöse Vergemeinschaftung als Ressource zur gesellschaftlichen Selbstpositionierung

Für diese Frauen stellt die religiöse Vergemeinschaftung die entscheidende Ressource dar, mittels derer ein (bildungs-)biografisches Scheitern verhindert werden kann.

Aufgrund des genderbasierten Rollenbilds ${ }^{17}$ und der fehlenden Unterstützung des Elternhauses blieb Frauen wie Esma, bei denen die »Taktik der religiösen Vergemeinschaftung« rekonstruiert werden konnte, eine nachobligatorische Ausbildung verwehrt. Konstitutiv für die Lebensbeschreibungen dieser jungen Frauen ist das Moment, in dem sie sich (bildungs-)biografisch in einer Sackgasse befinden und aufgrund eines massiven strukturellen Drucks in eine scheinbar ausweglose (berufs-)biografische Krise geraten (vgl. Kap. 5.3). Auch Esma schildert ein solches Moment, in dem sie weder ein noch aus wusste. Durch die Vergemeinschaftung im Religionsverein konnte sie für ihre Berufsbiografie entscheidendes, von den Eltern unabhängiges, soziales

17 Dem Rollenbild der Eltern von Frauen, bei denen diese »Taktik« rekonstruiert werden konnte, zu folge ist eine nachobligatorische Ausbildung ihrer Töchter obsolet, da sieso der elterliche Wunsch - nach einer frühen Heirat eine klassische Hausfrauenrolle übernehmen sollten. 
Kapital (Bourdieu 1983b) akkumulieren und dadurch mehr Handlungsfähigkeit (Agency) hinsichtlich ihrer (Bildungs-)Biografie erlangen.

Die Vergemeinschaftung wirkte bei ihr und bei den anderen Frauen der "Taktik« 3 gesellschaftlich integrierend und fing auf, wo Sozialstaat, Elternhaus und Bildungssystem versagten und die Frauen durch das wirkmächtige Zusammenspiel struktureller Differenzdimensionen davon bedroht waren, (bildungs-)biografisch »aus dem System zu fallen«. Die religiöse Vergemeinschaftung diente ihnen als »religiöses Sozialkapital« (Pickel 2014:50) und stellte die entscheidende Ressource zu einer gesellschaftlichen Neu- und Selbstpositionierung dar.

Typus 4: »Gelebte Religion« als Stigma

In Bildungsbiografien dieser Frauen wirkt Religion als interdependente Differenzkategorie im Zusammenspiel mit Gender, »Migrationshintergrund «, »class«, und zusätzlich noch Körper intersektionell so stark einschränkend, dass "gelebter Religion« (»lived religion«, McGuire 2008: 12-13) als Ressource hinsichtlich der Bildungsbiografie kaum noch Bedeutung zukommen kann.

Auch bei dieser »Taktik« steht Religion als Differenzkategorie und Religion als Ressource in einem dialektischen Verhältnis, allerdings in einem von starker Ungleichheit geprägten: Religion als interdependente Differenzkategorie überlagert "gelebte Religion« als potenzielle Ressource so stark, dass dieser in den (Bildungs-)Biografien der Frauen in erster Linie die Rolle eines Stigmas zukommt (vgl. Kap. 5.4).

Zusammenfassend kann formuliert werden, dass bei drei von vier rekonstruierten bildungsbiografischen »Taktiken« junger Musliminnen »gelebter Religion « (McGuire 2008: 12-13) die Rolle einer Ressource im Hinblick auf ihre Bildungsbiografien zukommt.

Ebenso wird deutlich, dass die Rolle von "gelebter Religion«wie bspw. religiöse Selbstrepräsentation, religiöse Praxis und religiöse Vergemeinschaftung als Ressource in Bildungsbiografien in einem dialektischen Verhältnis zur Rolle der Religion als Differenzkategorie steht (vgl. Kap. 5). „Gelebte Religion« kann also auch - oder vielleicht sogar ganz besonders - unter den soziopolitischen Bedingungen des laufenden Islamdiskurses zur Ressource werden. 


\subsection{Fazit und Ausblick}

Aus der Rekonstruktion der Bildungsbiografien der jungen Frauen in der vorliegenden Arbeit geht als zentrale Erkenntnis hervor, dass »Religion« im Zuge des gegenwärtigen Islamdiskurses in Bildungsbiografien eine doppelte Rolle einnimmt: Einerseits wirkt sie als interdependente Differenzkategorie strukturell einschränkend und andererseits - das mag angesichts des laufenden Islamdiskurses mehr erstaunen - kommt "gelebter Religion« (»lived religion«, McGuire 2008: 12-13) in den Bildungsbiografien der untersuchten Frauen die Rolle einer Ressource zu, mittels derer sie mehr Agency erlangen können.

Es zeigte sich, dass die jungen Secondas auch in intersektionell teilweise äusserst begrenzten, bildungsbiografischen »Möglichkeitsräumen« (Holzkamp 1983) Handlungsfähigkeit entwickeln können. Hierbei war die Theoretisierung von Agency durch De Certeaus Konzept der »Taktiken« (vs. »Strategien«) (1988: 89) hilfreich. Anstatt jedoch die De Certeau'sche Gegenüberstellung von »Taktiken« vs. »Strategien« zu übernehmen, verwandte ich auf der Ebene der »Strategien « intersektionelle Differenzdimensionen als »referenziellen Rahmen«, innerhalb dessen sich die »Taktiken« verorten. Eine intersektionelle Perspektive als analytisch sensibilisierendes Konzept erwies sich zudem als sehr nützlich, um die subtilen Machtverhältnisse, die einschränkend auf Bildungsbiografien wirken, zu analysieren. Von De Certeau wurde jedoch der Fokus auf den relationalen Aspekt zwischen »Taktiken«, die ich als habituell verankert sehe (vgl. Winter 2018, 2017), und den intersektionell wirkenden Einschränkungen übernommen (vgl. Kap. 2.3). Der relationale Aspekt zwischen »Taktiken« und intersektionellen Einschränkungen zeigt sich bspw. in dem dialektischen Verhältnis »gelebter Religion« (McGuire 2008: 12-13) als Ressource und Religion als interdependente Kategorie in den Bildungsbiografien der jungen Frauen (vgl. Kap. 7.2). De Certeaus Konzept der »Taktiken« eignete sich durch seine relationale Konstruiertheit zudem ideal, um den potenziell machtsubversiven Gehalt von Agency junger muslimischer Secondas als subalterne Akteurinnen hinsichtlich interdependenter Dominanzverhältnissen zu analysieren.

Die intersektionelle Perspektive auf die Bildungsbiografien der jungen Frauen war insofern erkenntnisreich, da sie gleichzeitig - wie Riegel (2016: 311) es formuliert - eine Perspektive der Reflexion, der Kritik und der Veränderung bzw. des Hinterfragens, »eigener zuschreibender Deutungsmuster« darstellt (2017: 25ff.) und Weg für eine postkoloniale Analyse sozialer Praktiken im Kontext struktureller Dominanzverhältnisse bereitete. 
Auch die ethnografische Herangehensweise (vgl. Kap 4) verhalf zu Einsicht. Sie diente unter anderem dazu - wie Breidenstein et al. es formulieren - den jungen Frauen »in ihren Relevanzen zu folgen« (Breidenstein et al. 2015: 38) und Aspekte der (religiösen) Selbstrepräsentation zu erfassen, die in Interviews und Dokumenten nicht in derselben Weise zugänglich geworden wären (vgl. bspw. Lane Kap.4.1, 6). Zudem bereitete die ethnografische Forschungsstrategie anlehnend an Marcus' Vorschlag einer multi-sited Ethnography (1995) auch Weg für eine systematische Verknüpfung unterschiedlicher Felder, d.h. nicht nur geografischer sondern auch sozialer sowie insbesondere virtueller Felder.

Das vorliegende Projekt befand sich an einer interdisziplinären Schnittstelle zwischen religionswissenschaftlicher Forschung und ethnografischer Bildungsforschung. Aus den beiden disziplinären Perspektiven heraus ergeben sich meines Erachtens unterschiedliche Felder und Anknüpfungspunkte für weiterführende Forschung.

Im Einklang mit Forschungsergebnissen zu jungen religiös orientierten Secondas muslimischen Glaubens in Europa, insbesondere auch in Deutschland (vgl. bspw. Bendixsen 2013, Klinkhammer 2006) konnte festgestellt werden, dass sich deren Geschlechterrollenbild im Vergleich zu dem ihrer Elterngeneration tendenziell im Wandel befindet: Die Hinwendung zur Religion geht für viele der jungen Secondas mit der Emanzipation von dem Genderbild ihrer Eltern einher und wird teilweise gar religiös begründet (vgl. hierzu Fallbeispiel Zara Kap. 5.1.2, vgl. These diskursive Trennung von »Religion« und »Kultur« Kap. 6). Zum Wandel des Genderbildes religiös orientierter (aber unbedingt auch nicht religiös orientierter) Secondas und dem damit einhergehenden generationalen Aushandlungsprozess wäre weiterführende Forschung anzuregen.

In der ethnografischen Feldforschung fiel zudem auf, dass Frauen in diversen Religionsvereinen zentrale Aufgabenfelder innerhalb der Moschee abdecken und/oder als deutschsprechende Secondas in der Öffentlichkeitsarbeit tätig sind (vgl. bspw. 5.1. Zara, oder 5.2.2 b) Sahar). Baumann (2012:61) konnte bereits hinsichtlich der religiösen Organisation von zugewanderten vietnamesischen Buddhist*innen und tamilischen Hindus aufzeigen, dass ein Mangel an religiösen Spezialisten neue Räume für Frauen im rituellen Bereich öffnet (ebd.). Auch Allenbach und Müller stellen zudem ein zunehmendes Eindringen von Frauen in die »institutionelle Sphäre von Religion « fest (Allenbach/Müller 2017: 287). Es wäre interessant, mittels eines ethnografischen Ansatzes weiter zu verfolgen, inwiefern junge Muslimas im schweizeri- 
schen Kontext informell mit Macht ausgestattete Positionen in Vereinen einnehmen, sei dies im sozialen, rituellen oder aber auch im Bereich der Öffentlichkeitsarbeit.

Der Islamdiskurs, dessen inhärentes »religiöses Othering" (Mecheril/Thomas-Olalde 2011: 45) soziale Deutungspraxen hervorbringt (vgl. Lingen-Ali/Mecheril 2016), so konnte in der vorliegenden Untersuchung gezeigt werden, strukturiert die Bildungsbiografien vieler religiös orientierter Secondas muslimischen Glaubens. Ein weiteres Forschungsdesiderat wäre es, zu untersuchen, ob und inwiefern sich Religion in Bildungsbiografien als interdependente Kategorie auch bei Angehörigen anderer religiöser Gruppierungen, losgelöst vom Rahmen des Islamdiskurses, manifestiert; bspw. bei Secondas*os hinduistischen Glaubens, Buddhist*innen oder aber auch bei Angehörigen evangelikaler Gruppierungen.

Ein weiteres Desiderat zu weiterführender Forschung resultiert daraus, dass dem Design entsprechend nur Frauen untersucht wurden, welche sich im weitesten Sinne als religiös orientierte Musliminnen verstehen (vgl. Kap. 4.1). Nicht untersucht wurden Frauen, die im Vergleich zur ihrer Elterngeneration ein dezidiert distanziertes Verhältnis zum Islam entwickelt haben. Es wäre jedoch äusserst spannend, zu erforschen, ob auch Secondas, welche sich selbst nicht als Musliminnen verstehen, in ihren Bildungsbiografien mit der Differenzkategorie »Muslimin« konfrontiert werden.

Aus Sicht ethnografischer Bildungsforschung wäre es zudem interessant Begründungen und Befürchtungen der Arbeitgebenden zu erforschen, Hijab tragende Musliminnen anzustellen. Weiter fiel auf, dass viele der befragten Frauen in ihren Erzählungen die unzureichende Kenntnis der Eltern der Bedeutung des frühen Selektionsprozesses in Bezug auf eine zukünftige Berufs- oder Ausbildungswahl schilderten und als eine Bildungsbarriere erachteten. Vorstellungen von traditionalen Geschlechterrollen, die unter den Eltern der untersuchten Frauen stark verbreitet waren, scheinen zusätzlich einen starken genderspezifischen Einfluss auf Bildungsentscheidungen auszuüben. Auch hier wäre weiterführende Forschung wünschenswert.

Abschliessend gilt es festzuhalten - und das kann nicht genug unterstrichen werden - dass die intersektionellen Strukturierungen der bildungsbiografischen »Möglichkeitsräume« der jungen Secondas muslimischen Glaubens vor dem Hintergrund eines Bildungssystems gedacht werden müssen, das von Jugendlichen nach wie vor »kulturelle Assimilation« erwartet (Oester/Brunner 2015: IV, vgl. hierzu auch Kap. 3.3). Es ist Riegel beizupflichten, wenn sie betont, dass der »Kampf um Anerkennung und Zugehörigkeit« 
(Riegel 2004), obwohl er von den jungen Frauen meist individuell geführt wird, doch eine »Bereitschaft der [hegemonialen] Mehrheitsgesellschaft« voraussetzt, »die eigene Dominanz und damit verbundene Normalitätsvorstellungen aufzugeben und einem gleichberechtigten Aushandlungsprozess freizugeben « (ebd.: 358). In Bezug auf die Thematik der vorliegenden Untersuchung könnte sich das bspw. dadurch zeigen, dass hegemoniale, gegenderte Deutungspraxen gerade auch von Akteur*innen des Bildungssystems einem gleichberechtigten Aushandlungsprozess freigegeben würden. Das Tragen eines Hijabs würde so bspw. nicht länger primär als Symbol von Unterdrückung und mangelnder Handlungsfähigkeit gedeutet, sondern könnte genauso gut als Ausdruck gelebter religiöser Selbstrepräsentation von handlungsund entscheidungsfähigen jungen Frauen gelesen werden, die gleichberechtigt neben anderen Formen religiöser und nicht religiöser Selbstrepräsentation stehen und so als Bildungsbarriere strukturell keine Wirkmächtigkeit entfalten könnte.

Es ist bemerkenswert, dass sich die untersuchten Frauen trotz der teilweise sehr schwierigen strukturellen Bedingungen durchgängig im Rahmen ihres »Möglichkeitsraums« als aktive Gestalterinnen ihrer Bildungsbiografien erwiesen. Sie liessen sich selbst von stark wirksamen Bildungsbarrieren nicht entmutigen und suchten nach Ausweichstrategien, um bildungsbiografisch einen Weg zu finden. 


\section{Dank}

Zuallererst möchte ich den Frauen danken, die hinter den Pseudonymen Zara, Xhemile, Esma, Duaa, Ardita, Velika, Adea, Aieta, Maide, Suad, Sahar, Zoya, Rahima, Lane, Malia, Raime, Fijona, Illana, Rhea, Hannan und Mira stehen. Vielen Dank, dass Ihr mich in Eure Lebenswelten habt blicken lassen und mich an für Euch relevante Orte mitgenommen habt. Eine Teilnahme an einer ethnografischen Forschung ist gerade für Menschen, die immer wieder mit gesellschaftlichen Ausschlusserfahrungen konfrontiert sind, keineswegs selbstverständlich. Ich hoffe, ich bin mit dem Vertrauen, das Ihr mir entgegengebracht habt, sorgsam umgegangen.

Besonders herzlich möchte ich auch meinem Betreuer Martin Baumann danken, der mir stets unkompliziert und schnell mit hilfreichem Rat sowie Literaturhinweisen beiseite stand, wenn sich ein (religions-)wissenschaftliches Problemfeld auftat. Mein ganz herzlicher Dank richtet sich ebenso an Angela Stienen, meine Zweitbetreuerin, die mich immer gefördert, auf meinen intellektuellen Wegen unterstützt und mich in die Gefilde der postkolonialen Studien hineinsozialisiert hat. Auch bei Fragen und Dilemmata hinsichtlich der ethnografischen Feldforschung war sie stets für ein unkompliziertes, zeitnahes Gespräch zu haben.

Einen ganz speziellen Dank möchte ich an Andreas Tunger-Zanetti vom Zentrum für Religionsforschung der Universität Luzern (ZRF) richten, der die thematische Initialzündung zu diesem Projekt gab. Er stellte seinen Erfahrungsschatz zu Lebenswelten junger Muslim*innen in der Schweiz und anderswo, aber auch sein schier unendliches Faktenwissen zum Islam stets grosszügig zur Verfügung. Auch Jürgen Endres danke ich für die wertvollen Hinweise und für die gemeinsamen Feldbesuche.

Gebührender Dank gilt auch Kathrin Oester, die mit ihrem klugen, analytischen Blick, ihren Arbeiten über Schulen und Peergroups in transnationalen Lebenswelten sowie hilfreichen Literaturtipps viel zu meiner geistigen 
Sozialisation in die ethnografische Bildungsforschung beigetragen hat. $\mathrm{Zu}$ dem möchte ich Caroline Bühler danken, meiner Mentorin im Hintergrund, ohne die dieses Projekt nicht zustande gekommen wäre und die mich grosszügig von administrativen Assistentinnenpflichten befreit hat, damit ich an dessen Ausarbeitung arbeiten konnte.

Gerne danke ich der PHBern für die grosszügige Finanzierung des Projekts. Ebenso möchte ich dem Berufsberatungs- und Informationszentrum Bern (BIZ Bern) für die zahlreichen Auskünfte zu möglichen Bildungswegen danken und für die Mithilfe bei der Rekonstruktion von Bildungsbiografien, die auf älteren, nicht mehr aktuellen Bildungsstrukturen beruhen.

Ein spezieller Dank geht an meine Lektorin Franziska Geiser, die von meiner ersten Seminararbeit an jede meiner universitären Arbeiten gegengelesen hat und mit ihrem scharfen Blick nebst Schreibfehlern stets auch inhaltliche Ungenauigkeiten aufzuspüren vermag. Jegliche verbliebene Nachlässigkeiten sind allein mir selbst zuzuschreiben. Ganz lieben Dank auch an Mira Ducommun, die mir ebenso immer wieder einzelne Kapitel gegengelesen hat und im richtigen Moment wichtige Hinweise beim Entwickeln der Typologie geliefert hatte. Danken möchte ich ebenfalls Brigit Allenbach, Eva Mey, Karénina Kollmar-Paulenz, Judith Hangartner, Simone Marti, Daniel Steiner, Christine Beckert, Anne-Seline Moser, Jessica Bollag, Jonathan Hoppler, Rachel Imboden, Luisa Genovese und den Forschungspraktikannt*innen sowie allen, die hier namentlich nicht aufgeführt sind und auf unterschiedliche Art und Weise zu diesem Projekt beigetragen haben.

Herzlich danken möchte ich unbedingt auch meinen Freund*innen, die hier ebenfalls namentlich unerwähnt bleiben, für ihr Dasein und die gemütlichen Nachtessen, die mich stets auch auf andere Gedanken gebracht haben.

Schliesslich danke ich Simone Suter, die mir als verlässliche Weggefährtin während der Dissertation sowohl in fachlichen als auch persönlichen Belangen stets humorvoll und klug beiseite stand und mich durch alle Höhen und Tiefen dieses Projekts eng begleitet (und ausgehalten) hat.

Ganz vielen lieben Dank gebührt natürlich den fünf Grosseltern meiner Kinder sowie Heidy Weil, Lukas Gasser, Liselotte Jordi und allen anderen lieben Menschen meiner Familie. Merci für Eure vielfältige Unterstützung, Euren Rückhalt und nicht zuletzt auch: Merci für die vielen Extrahütestunden in der Endphase dieser Arbeit!

Mein allergrösster Dank geht jedoch an meinen Partner Markus Kreis und meine Kinder Lennart und Hannes, die mir immer wieder mit viel Liebe, Ge- 
duld und Humor gezeigt haben, worum es im Leben wirklich geht und dabei stets an das Gelingen dieses Projekts geglaubt haben. 



\section{Literaturverzeichnis}

Aarburg, Hans-Peter von/Gretler, Sarah Barbara (2011): Kosova-Schweiz. Die albanische Arbeits- und Asylmigration zwischen Kosovo und der Schweiz (1964-2000). 2. Aufl. Wien u.a.: LIT.

Abu-Lughod, Lila (2013): Do Muslim women need saving? Cambridge MA: Harvard University Press.

Abu-Lughod, Lila (2002): Do Muslim Women Really Need Saving? Anthropological Reflections on Cultural Relativism and Its Others. American Anthropologist 104(3).

Allenbach, Brigit/Müller, Monika (2017): Doing gender in religiösen Organisationen von Zugewanderten in der Schweiz: Inkorporation und vielfältige Zugehörigkeit. In: Sammet, Kornelia/Benthaus-Apel, Friederike/Gärtner, Christel (Hg.): Religion und Geschlechterordnungen. Wiesbaden: Springer VS, 273-292.

Allenbach, Brigit (2016): Do Muslim Girls Really Need Saving? BoundaryMaking and Gender in Swiss Schools. In: Hunner-Kreisel, Christine/Bohne, Sabine (Hg.): Childhood, Youth and Migration. Connecting Global and Local Perspectives. Cham: Springer International Publishing, 31-47.

Allenbach, Brigit (2012): Bairam, Balkanslang, Basketball... Die vielfältigen $\mathrm{Zu-}$ gehörigkeiten von muslimischen Jugendlichen in der Schweiz. Tsantsa 17, 86-95.

Allenbach, Brigit (2011): Made in Switzerland. Erzählungen über Religion und Zugehörigkeit von Secondos/Secondas aus Südosteuropa. In: Allenbach, Brigit/Goel, Urmila/Hummrich, Merle/Weisköppel, Cordula (Hg.): Jugend, Migration und Religion. Interdisziplinäre Perspektiven. BadenBaden: Nomos, 199-224. 
Allenbach, Brigit/Herzig, Pascale (2010): Der Islam aus der Sicht von Kindern und Jugendlichen. In: Allenbach, Brigit/Sökefeld, Martin (Hg.): Muslime in der Schweiz. Zürich: Seismo, 296-330.

Allenbach, Brigit/Sökefeld, Martin (2010): Einleitung. In: Allenbach, Brigit/Sökefeld, Martin (Hg.): Muslime in der Schweiz. Zürich: Seismo, 9-40.

Allenbach, Brigit/Herzig, Pascale/Müller, Monika (2010): Migration und Religion. Perspektiven von Kindern und Jugendlichen in der Schweiz. Schlussbericht. Bern: Schweizerischer Nationalfonds (SNF), Nationales Forschungsprogramm NFP 58). URL: www.snf.ch/ SiteCollectionDocuments/nfp/nfp58/NFP58_Schlussbericht_Giordano. pdf [Stand: 24. Januar 2019].

Ahmed, Leila (1992): Women and Gender in Islam. Historical Roots of a modern Debate. New Haven CT: Yale University Press.

Amit, Vered (Hg.) (2000): Constructing the field. Ethnographic fieldwork in the contemporary world. London u.a.: Routledge.

Anthias, Floya (2009a): Intersectionality, belonging and transnational positionality. Thinking about transnational identities. In: Rosenthal, Gabriele/Bogner, Artur (Hg.): Ethnicity, belonging and biography. Ethnographical and biographical perspectives. Berlin: Lit, 229-249.

Anthias, Floya (2009b): Translocational Belonging, Identity and Generation. Questions and Problems in Migration and Ethnic Studies. Finnish Journal of Ethnicity and Migration 4(1), 6-15.

Anthias, Floya (2008): Thinking through the lens of translocational positionality: an intersectionality frame for understanding identity and belonging. Translocations 4(1), 5-20.

Anthias, Floya (2003): Erzählungen über Zugehörigkeit. In: Apitzsch, Ursula/Jansen, Mechtild M./Löw, Christine (Hg.): Migration, Biographie und Geschlechterverhältnisse. Münster: Westfälisches Dampfboot, 20-37.

Anthias, Floya/Yuval-Davis, Nira (1992): Racialized boundaries. Race, nation, gender, colour and class and the anti-racist struggle. New York NY: Routledge.

Anzaldúa, Gloria/Moraga, Cherríe (Hg.) (1981): This bridge called my back. Writings by radical women of color. New York NY: Kitchen Table.

Arlettaz, Silvia (2012): "Saisonniers«. In: Historisches Lexikon der Schweiz (Internetversion). Historisches Lexikon der Schweiz (HLS). URL: www. hls-dhs-dss.ch/textes/d/D25738.php [Stand: 26. Januar 2019].

Augsburger, Jaqueline (2005): Die rechtliche Behandlung des Kopftuchs im Spannungsfeld von Religionsfreiheit, religiöser Neutralität, Ge- 
schlechtergleichheit und Integration. Bern: Humanrights.ch/MERS. URL: https://www.humanrights.ch/cms/upload/pdf/o60117_augsburger_ kopftuchverbot.pdf [Stand: 26. Januar 2019].

Aumüller, Jutta (2010): Wie viele Generationen dauert Integration? Wie Begriffe unser Bild von Gesellschaft prägen. Berlin: Heinrich Böll Stiftung. URL:www.migration-boell.de/web/integration/47_2685.asp [Stand: 29. Januar 2019].

Bader, Dina/Fibbi, Rosita (2012): Kinder mit Migrationshintergrund: ein grosses Potenzial. Institut Swiss Forum for Migration and Populations Studies. Neuenburg: Universität Neuenburg, Swiss Forum for Migration and Population Studies (SFM). URL: https://www.unine.ch/files/live/sites/ sfm/files/nouvelles \%20publications/fibbi_bader_2012.pdf [Stand: 29. Januar 2019].

Badouard, Romain (2016): Je ne suis pas Charlie. Pluralité des prises de parole sur le web et les réseaux sociaux. Le Défi Charlie. Les médias à l'épreuve des attentats. In: HAL. Archives-ouvertes.fr (Onlinearchiv). HAL-ID: hal-01251253. URL: https://hal.archives-ouvertes.fr/hal-01251253/ document [Stand: 29. Januar 2019].

Baghdadi, Nadia (2012): Und plötzlich bist du DIE Muslimin. Migrantinnen zwischen Karrieresprung und Ausschlusserfahrung. Berlin: Frank \& Timme.

Baghdadi, Nadia (2010): "Die Muslimin« im Spannungsfeld von Zuschreibung, Abgrenzung und Umdeutung. In: Allenbach, Brigit/Sökefeld, Martin (Hg.): Muslime in der Schweiz. Zürich: Seismo, 213-240.

Baumgartner, Fabian (2016): Nach Razzia in Winterthur. Stadt kann AnNur-Moschee nicht schliessen. In: NZZ (Internetversion), 3.11.2016. URL: https://www.nzz.ch/zuerich/aktuell/razzia-in-winterthur-niemand-willden-schluessel-zur-an-nur-moschee-ld.126218 [Stand: 28. Januar 2019].

Baumann, Martin (2019): Generational Changes of Religion and Civic Participation among Immigrant Minorities: Studying Tamil Hindu and Sunni Muslim Youths in Switzerland (im Erscheinen). In: Irene Becci (Hg.): Religion, diversité, reconnaissance. Rennes: Presses universitaires de Rennes.

Baumann, Martin/Endres, Jürgen/Martens, Silvia/Tunger-Zanetti, Andreas (2017): »Hallo es geht um meine Religion!«. Muslimische Jugendliche in der Schweiz auf der Suche nach ihrer Identität. Forschungsbericht des Projektes Imame, Rapper, Cybermufties. Luzern: Universität Luzern, Zentrum für Religionsforschung. URL: https://www.unilu.ch/fileadmin/ 
fakultaeten/ksf/institute/zrf/dok/Forschungsbericht_Hallo_es_geht_um_ meine_Religion.pdf [Stand: 24. Januar 2019].

Baumann, Martin (2015): Religion als Ressource und Konfliktpotential in Europa. Analytische Perspektiven auf Immigration, Gemeinschaft und Gesellschaft. In: Polak, Regina/Reiss, Wolfram (Hg.): Religion im Wandel. Transformation religiöser Gemeinschaften in Europa durch Migration interdisziplinäre Perspektiven. Göttingen: V \& R Unipress, Vienna University Press, 49-74.

Baumann, Martin (2012): Religionsgemeinschaften im Wandel: Identitäten, Strukturen, interreligiöse Beziehungen. In: Bochinger, Christoph (Hg.): Religionen, Staat und Gesellschaft. Die Schweiz zwischen Säkularisierung und religiöser Vielfalt. Zürich: Verlag Neue Zürcher Zeitung, 21-75.

Baumann, Martin (1998): Qualitative Methoden in der Religionswissenschaft. Hinweise zur religionswissenschaftlichen Feldforschung. 2. Aufl. Marburg: Religionswissenschaftlicher Medien- und Informationsdienst (REMID).

Baumann, Martin/Tunger-Zanetti, Andreas (2011): Wenn Religionen Häuser bauen: Sakralbauten, Kontroversen und öffentlicher Raum in der Schweizer Demokratie. In: Baumann, Martin/Neubert, Frank (Hg.): Religionspolitik - Öffentlichkeit - Wissenschaft. Studien zur Neuformierung von Religion in der Gegenwart. Zürich: Pano, 151-188.

Bauschke-Urban, Carola (2010): Im Transit. Transnationalisierungsprozesse in der Wissenschaft. Wiesbaden: VS Verlag für Sozialwissenschaften.

Beck, Charlotte/Büchel, Romana/Galizia, Michele (2005): Fremde Freunde. Gewährsleute der Ethnologie. Wuppertal: Peter Hammer Verlag.

Becker, Rolf (2010): Soziale Ungleichheit im Schweizer Bildungssystem und was man dagegen tun kann. In: Neuenschwander, Markus P./Grunder, Hans-Ulrich (Hg.): Schulübergang und Selektion. Forschungsbefunde - Praxisbeispiele - Umsetzungsperspektiven. Internationale Tagung "Schulübergang und Selektion«. Zürich: Rüegger Verlag, 91-108.

Becker, Rolf/Beck, Michael/Jäpel, Franziska (2013): Geschlechterunterschiede im Bildungserfolg. Eine empirische Analyse für Schulkinder im Deutschschweizer Schulsystem unter besonderer Berücksichtigung ihres Migrationshintergrundes. In: Hadjar, Andreas/Hupka-Brunner, Sandra (Hg.): Geschlecht, Migrationshintergrund und Bildungserfolg. Weinheim: Beltz Juventa, 77-101.

Becker, Rolf/Hadjar, Andreas (2017): Meritokratie - Zur gesellschaftlichen Legitimation ungleicher Bildungs-, Erwerbs- und Einkommenschancen in 
modernen Gesellschaften. In: Becker, Rolf (Hg.): Lehrbuch der Bildungssoziologie. 3. Aufl. Wiesbaden: Springer VS.

Becker, Rolf/Solga, Heike (2012): Soziologische Bildungsforschung. Wiesbaden: Springer VS.

Becker-Schmidt, Regina (2007): »Class«, »Gender«, »Ethnicity«, »Race«. Logiken der Differenzsetzung, Verschränkungen von Ungleichheitslagen und gesellschaftliche Strukturierung. In: Klinger, Cornelia/Knapp, GudrunAxeli \& Sauer, Birgit (Hg.): Achsen der Ungleichheit. Zum Verhältnis von Klasse, Geschlecht und Ethnizität. Frankfurt a.M.: Campus, 56-83.

Behloul, Samuel M. (2011): Vom öffentlichen Thema zur öffentlichen Religion? Probleme und Perspektiven des Isam im Westen am Beispiel Schweiz. In: Baumann, Martin/Neubert, Frank (Hg.): Religionspolitik - Öffentlichkeit - Wissenschaft. Studien zur Neuformierung von Religion in der Gegenwart. Zürich: Pano, 127-150.

Behloul, Samuel M. (2010): Religion und Religionszugehörigkeit im Spannungsfeld von normativer Exklusion und zivilgesellschaftlichem Bekenntnis. Islam und Muslime als öffentliches Thema in der Schweiz. In: Allenbach, Brigit/Sökefeld, Martin (Hg.): Muslime in der Schweiz. Zürich: Seismo, 43-65.

Behloul, Samuel M. (2009a): Minarett-Initiative. Im Spannungsfeld zwischen Abwehrreflex und impliziter Anerkennung neuer gesellschaftlicher Fakten. In: Tanner, Mathias/Müller, Felix/Mathwig, Frank/Lienemann, Wolfgang (Hg.): Streit um das Minarett. Zusammenleben in der religiös pluralistischen Gesellschaft. Zürich: TVZ Theologischer Verlag Zürich, 103-122.

Behloul, Samuel M. (2009b): Islam-Diskurs nach 9/11. Die Mutter aller Diskurse? Zur Interdependenz von Religionsdiskurs und Religionsverständnis. In: Müller, Wolfgang W. (Hg.): Christentum und Islam. Plädoyer für den Dialog. Zürich: TVZ Theologischer Verlag Zürich, 229-268.

Behloul, Samuel M. (2009c): Discours total! Le débat sur l'Islam en Suisse et le positionnement de l'Islam comme religion publique. In: Schneuwly Purdie, Mallory/Gianni, Matteo/Jenny, Magali (Hg.): Musulmans d'aujourd'hui. Identités plurielles en Suisse. Genève: Labor et Fides, 53-72.

Behloul, Samuel M./Lathion, Stéphane (2007): Muslime und Islam in der Schweiz. Viele Gesichter einer Weltreligion. In: Baumann, Martin/Stolz, Jörg (Hg.): Eine Schweiz - viele Religionen. Risiken und Chancen des $\mathrm{Zu}$ sammenlebens. Bielefeld: transcript, 193-207.

Behloul, Samuel M. (2005): Religionspluralismus: Europäischer »Normal«oder »Notfall«? Muslimische Migranten in der Schweiz und die Einbet- 
tung in den öffentlichen Raum. In: Baumann, Martin/Behloul, Samuel M. (Hg.): Religiöser Pluralismus. Empirische Studien und analytische Perspektiven. Schweizerische Gesellschaft für Religionswissenschaft. Bielefeld: transcript, 145-169.

Behloul, Samuel M. (2004): Muslims in Central Switzerland. From Migrants to Diaspora-Muslims (unpublished Research Report). Department for the Study of Religions of University of Lucerne.

Belloni, Milena (2016): My uncle cannot say »no« if I reach Libya: Unpacking the social dynamics of border-crossing among Eritreans heading to $\mathrm{Eu}$ rope. Human Geography 9(2), 47-56.

Belloni, Milena (2015): Cosmologies of Destinations: Roots and routes of Eritrean forced migration towards Europe. Dissertation. Trento: University of Trento. URL: http://eprints-phd.biblio.unitn.it/1625/ [Stand: 28. Januar 2019].

Bergman, Manfred Max/Hupka-Brunner, Sandra/Meyer, Thomas/Samuel, Robin (Hg.): (2012): Bildung - Arbeit - Erwachsenwerden. Ein interdisziplinärer Blick auf die Transition im Jugend- und jungen Erwachsenenalter. Wiesbaden: Springer VS.

Bendixsen, Synnøve K.N (2013): The religious identity of young Muslim women in Berlin. An ethnographic study. Leiden: Brill.

Bendixsen, Synnøve (2005): Being Young, Muslim and Female. Creating Space of Belonging in Berlin. In: Hotel Berlin. Formen urbaner Mobilität und Verortung. Berliner Blätter. Ethnographische und ethnologische Beiträge 37, Berlin: Lit, 88-98.

Benthaus-Apel, Frederike/Gärtner, Christel/Sammet, Kornelia (2017): Einleitung. In: Sammet, Kornelia/Benthaus-Apel, Friederke/Gärtner, Christel (Hg.): Religion und Geschlechterordnungen. Wiesbaden: Springer VS, 733.

BFS (2017a): Bundesamt für Statistik. Bildungssystem (Webseite). Bundesamt für Statistik (BFS). URL: https:/www.bfs.admin.ch/bfs/de/home/ statistiken/bildung-wissenschaft/bildungssystem.html [Stand: 28. Januar 2019].

BFS (2017b): Bevölkerung nach Migrationsstatus (Webseite). Bundesamt für Statistik (BFS). URL: https://www.bfs.admin.ch/bfs/de/home/statistiken/ bevoelkerung/migration-integration/nach-migrationsstatuts.html [Stand: 28. Januar 2019]. 
BFS (2017c): Religionen (Webseite). Bundesamt für Statistik (BFS). URL: https:/www.bfs.admin.ch/bfs/de/home/statistiken/bevoelkerung/ sprachen-religionen/religionen.html [Stand: 28. Januar 2019].

BFS (2017d): Lohnniveau Schweiz. Nach Berufsgruppen (Webseite). Bundesamt für Statistik (BFS). URL: https://www.bfs.admin.ch/bfs/de/home/ statistiken/arbeit-erwerb/loehne-erwerbseinkommen-arbeitskosten/ lohnniveau-schweiz/berufsgruppen.html [Stand: 28. Januar 2019].

Blanes, Ruy Llera (2006): The Atheist Anthropologist. Believers and Non-believers in Anthropological Fieldwork. Social Anthropology 14(2), 223-234.

Bleisch, Petra (2016): Der »Fall Therwil« - (nicht)-Händeschütteln als Frage berufsethischen Handelns. Zeitschrift für Religionskunde (3), 102-107.

Bleisch Bouzar, Petra (2012): »She is Simply Present«: Female Leadership and Informal Authority in a Swiss Muslim Women's Association. In: Bano, Masooda/Kalmbach, Hilary (Hg.): Women, leadership and mosques. Changes in contemporary Islamic authority. Leiden: Brill, 279-300.

Bolzman, Claudio/Fibbi, Rosita/Vial, Marie (2003): Secondas - secondos. Le processus d'intégration des jeunes adultes issus de la migration espagnole et italienne en Suisse. Zurich: Seismo.

Bourdieu, Pierre/Wacquant, Loïc J. D. (2006): Reflexive Anthropologie. Frankfurt a.M.: Suhrkamp.

Bourdieu, Pierre (1997): Verstehen. In: Bourdieu, Pierre et al. (Hg.): Das Elend der Welt. 2. Aufl. Konstanz: UVK Verlagsgesellschaft, 779-802.

Bourdieu, Pierre (1993): Sozialer Sinn. Kritik der theoretischen Vernunft. Frankfurt a.M.: Suhrkamp.

Bourdieu, Pierre (1983a): Die feinen Unterschiede. Kritik der gesellschaftlichen Urteilskraft. 2. Aufl. Frankfurt a.M.: Suhrkamp.

Bourdieu, Pierre (1983b): Ökonomisches Kapital, kulturelles Kapital, soziales Kapital. In: Kreckel, Reinhard (Hg.): Soziale Ungleichheiten. Göttingen: Schwartz, 183-198.

Bourdieu, Pierre (1979): Entwurf einer Theorie der Praxis auf der ethnologischen Grundlage der kabylischen Gesellschaft. Frankfurt a.M.: Suhrkamp.

Bourdieu, Pierre/Passeron, Jean-Claude (1987): La reproduction. Éléments pour une théorie du systéme d'enseignement. Paris: Les Éditions de Minuit.

Bourdieu, Pierre; Passeron, Jean-Claude (1971): Die Illusion der Chancengleichheit. Untersuchungen zur Soziologie des Bildungswesens am Beispiel Frankreichs. Stuttgart: Klett. 
Bovay, Claude (2004): Eidgenössische Volkszählung 2000. Religionslandschaft in der Schweiz. Bern: Bundesamt für Statistik (BFS). URL: https:// www.bfs.admin.ch/bfsstatic/dam/assets/341873/master [Stand: 29. Januar 2019].

Bracke, Sarah (2011): Subjects of Debate. Secular and Sexual Exceptionalism, and Muslim Women in the Netherlands. Feminist Review 98, 28-46.

Breidenstein, Georg/Hirschauer, Stefan/Kalthoff, Herbert/Nieswand, Boris (2015): Ethnografie. Die Praxis der Feldforschung. 2. Aufl. Konstanz: UVK Verlagsgesellschaft.

Brubaker, Rogers (2012): Categories of analysis and categories of practice: a note on the study of Muslims in European countries of immigration. Ethnic and Racial Studies 36(1), 1-8.

Brubaker, Rogers/Cooper, Frederick (2007): Jenseits von Identität. In: Brubaker, Rogers (Hg.): Ethnizität ohne Gruppen. Hamburg: Hamburger Edition, 46-95.

Bryceson, Deborah Fahy/Vuorela, Ulla (Hg.) (2002): The transnational family. New European frontiers and global networks. Oxford: Berg.

Buchardt, Mette (2014): Pedagogized Muslimness. Religion and Culture as Identity Politics in the Classroom. Münster: Waxmann.

Der Bundesrat - Portal der Schweizer Regierung (2017): Volksabstimmung vom 12. Februar 2017. Resultate (Webseite). Schweizerische Eidgenossenschaft. URL: https://www.admin.ch/gov/de/start/dokumentation/ abstimmungen/20170212.html [Stand. 29. Januar 2019].

Der Bundesrat - Portal der Schweizer Regierung (2014): Bundesrat beantragt Gewährleistung von geänderten Kantonsverfassungen. Medienmitteilung (Webseite). Schweizerische Eidgenossenschaft. URL: https:// www.admin.ch/gov/de/start/dokumentation/medienmitteilungen.msgid-55185.html [Stand. 29. Januar 2019].

Bundesverfassung der Schweizerischen Eidgenossenschaft vom 18. April 1999 (Internetversion). Bern: Schweizerische Eidgenossenschaft. URL: https:// www.admin.ch/opc/de/classified-compilation/19995395/201601010000/ 101.pdf [Stand: 28. Januar 2019].

Bundesversammlung - Schweizer Parlament (2011a): Motion Fehr Hans. Nationales Vermummungsverbot (Webseite). Parlamentsdienste. URL: https:/www.parlament.ch/de/ratsbetrieb/suche-curia-vista/geschaeft? AffairId=20113043 [Stand: 28. Januar 2019].

Bundesversammlung - Schweizer Parlament (2011b): Motion Freysinger Oskar. Runter mit den Masken! (Webseite). Parlamentsdienste. URL: 
https://www.parlament.ch/de/ratsbetrieb/amtliches-bulletin/amtlichesbulletin-die-verhandlungen?SubjectId=20201 [Stand: 28. Januar 2019].

Bundesversammlung - Schweizer Parlament (2010): Standesinitiative eingereicht von Kanton Aargau. Nationales Verhüllungsverbot im öffentlichen Raum (Webseite). Parlamentsdienste. URL: https://www. parlament.ch/de/ratsbetrieb/suche-curia-vista/geschaeft?AffairId= 20100333 [Stand: 23. Januar 2017].

Bundesversammlung - Schweizer Parlament (2009): Interpellation Darbellay Christophe. Verschleierung und Integration (Webseite). Parlamentsdienste. URL: https://www.parlament.ch/de/ratsbetrieb/suchecuria-vista/geschaeft?AffairId=20094308 [Stand: 28. Januar 2019].

Burkard, Stephan (2018): »chrampfe«. In: Berndeutsch.ch/Wörterbuch (Webseite). Berndeutsch.ch. URL: https://www.berndeutsch.ch/web/words/ view/12509 [Stand: 28. Januar 2019].

Butler, Judith (1991): Das Unbehagen der Geschlechter. Frankfurt a.M.: Suhrkamp.

Chebout, Lucy N. (2016): Wo ist Intersectionality in bundesdeutschen Intersektionalitätsdiskursen? Exzerpte aus dem Reisetagebuch einer »Traveling Theory«. In: Smykalla, Sandra/Vinz, Dagmar (Hg.): Intersektionalität zwischen Gender und Diversity. Theorien, Methoden und Politiken der Chancengleichheit. 4. Aufl. Münster: Westfälisches Dampfboot, 46-60.

Collins, Patricia Hill (1990): Black Feminist Thought. Knowledge, Consciousness, and the Politics of Empowerment. Boston: Unwin Hyman.

Combahee River Collective (1981): A Black Feminist Statement. In: Anzaldúa, Gloria/Moraga, Cherríe (Hg.): This bridge called my back. Writings by radical women of color. New York NY: Kitchen Table, 210-231.

Coppola, Maurizio (2013): Prekariat, Migration, Widerstand - am Beispiel der Schweiz. Sozial. Geschichte Online (10), 119-146. URL: https://duepublico. uni-duisburg-essen.de/servlets/DerivateServlet/Derivate-32891/07_ Coppola_Migration.pdf [Stand: 29. Januar 2019].

Crenshaw, Kimberele (1989): Demarginalizing the intersection of race and sex: A black feminist critique of antidiscrimination doctrine, feminist theory and antiracist politics. The University of Chicago Legal Forum 4, 139-167.

Dahinden, Janine/Duemmler, Kerstin/Moret, Joëlle (2012): Islam and Gender in the Boundary Work of Young Adults in Switzerland. Neuchâtel: University of Neuchâtel, Maison d'analyse des processus sociaux (MAPS). URL: $\quad$ www.unine.ch/files/live/sites/maps/files/shared/documents/wp/ WPMAPS_1_2012_E_DaDuMo.pdf [Stand: 29. Januar 2019]. 
Dahinden, Janine/Moret, Joëlle/Duemmler, Kerstin (2011): Die Herstellung sozialer Differenz unter der Bedingung von Transnationalisierung. Religion, Islam und boundary work unter Jugendlichen. In: Allenbach, Brigit/Goel, Urmila/Hummrich, Merle/Weisköppel, Cordula (Hg.): Jugend, Migration und Religion. Interdisziplinäre Perspektiven. Baden-Baden: Nomos, 225-248.

Dahinden, Janine/Duemmler, Kerstin/Moret, Joëlle (2010): Schlussbericht Religion und Ethnizität: Welche Praktiken, Identitäten und Grenzziehungen? Eine Untersuchung mit jungen Erwachsenen. Bern: Schweizerischer Nationalfonds (SNF), Nationales Forschungsprogramm »Religionsgemeinschaften Staat und Gesellschaft« (NFP 58). URL: www.snf.ch/SiteCollectionDocuments/nfp/nfp58/NFP58_Schlussbericht_ DahindenJanine.pdf [Stand: 26. Januar 2019].

Dahinden, Janine/Stants, Fabienne (2006): Arbeits- und Lebensbedingungen von Cabaret-Tänzerinnen in der Schweiz. Neuchâtel: Swiss Forum for Migration and Population Studies (SFM). URL: https://core.ac.uk/download/ pdf/20641529.pdf [Stand: 29. Januar 2019].

D'Amato, Gianni (2015): How Foreigners Became Muslims. Switzerland's Path to Accommodating Islam as a New Religion. In: Burchardt, Marian/Michalowski, Ines (Hg.): After integration. Islam, conviviality and contentious politics in Europe. Wiesbaden: Springer VS, 285-301.

D’Amato, Gianni (2010): Die Secondos. Von tickenden Zeitbomben zu »Overperformern«. In: Ritter, Christian (Hg.): Magische Ambivalenz. Visualität und Identität im transkulturellen Raum. Zürich: Diaphanes, 177-185.

D’Amato, Gianni (2005): Vom Ausländer zum Bürger. Der Streit um die politische Integration von Einwanderern in Deutschland, Frankreich und der Schweiz. 3. Aufl. Münster: LIT.

Davis, Kathy (2008): Intersectionality in Transatlantic Perspective. In: Klinger, Cornelia/Knapp, Gudrun-Axeli (Hg.): ÜberKreuzungen. Fremdheit, Ungleichheit, Differenz. Münster: Westfälisches Dampfboot, 19-35.

De Certeau, Michel (1988): Kunst des Handelns. Berlin: Merve.

De Flaugergues, Amélie (2016): Religiöse und spirituelle Praktiken und Glaubensformen in der Schweiz. Erste Ergebnisse der Erhebung zur Sprache, Religion und Kultur 2014. Neuenburg: Bundesamt für Statistik (BFS). URL: https://www.bfs.admin.ch/bfs/de/home/statistiken/bevoelkerung/ sprachen-religionen/religionen.assetdetail.350455.html [Stand: 28. Januar 2019]. 
Dietze, Gabriele (2006): Critical Whiteness Theory und Kritischer Okzidentalismus. In: Tissberger, Martina/Dietze, Gabriele/Hrzán, Daniela/Husmann, Jana (Hg.): Weiss - Weisssein - whiteness. Kritische Studien zu Gender und Rassismus. Frankfurt a.M.: Lang, 232-250.

EDK (2017a): Das Bildungssystem Schweiz. Grafik (Internetversion). Schweizerische Konferenz der kantonalen Erziehungsdirektoren (EDK). URL: www.edudoc.ch/static/web/bildungssystem/grafik_bildung_d.pdf [Stand: 28. Januar 2019].

EDK (2017b): Bildungssystem Schweiz (Webseite). Schweizerische Konferenz der kantonalen Erziehungsdirektoren (EDK). URL: www.edk.ch/dyn/ 14798.php [Stand: 28. Januar 2019].

Educa.ch (2017a): Bildungssystem. Obligatorische Schule (Webseite). Schweizer Medieninstitut für Bildung und Kultur (educa.ch). URL: https:// bildungssystem.educa.ch/de/obligatorische-schule-1 [Stand: 28. Januar 2019].

Educa.ch (2017b): Bildungssystem. Sekundarstufe II (Webseite). Schweizer Medieninstitut für Bildung und Kultur (educa.ch). URL: https:// bildungssystem.educa.ch/de/sekundarstufe-ii-4 [Stand: 28. Januar 2019]. Educa.ch (2017c): Bildungssystem. Tertiärstufe (Webseite). Schweizer Medieninstitut für Bildung und Kultur (educa.ch). URL: https:// bildungssystem.educa.ch/de/tertiaerstufe-1 [Stand: 28. Januar 2019].

Educa.ch (2017d): Bildungssystem. Sonderpädagogik (Webseite). Schweizer Medieninstitut für Bildung und Kultur (educa.ch). URL: https:// bildungssystem.educa.ch/de/sonderpaedagogik [Stand: 28. Januar 2019].

Egerkinger Komitee/Wobmann, Walter (2015): Warum eine Volksinitiative für ein nationales Verhüllungsverbot? (Webseite). Website Walter Wobmann. URL: www.walter-wobmann.ch/aktuell/reden-referate/warumeine-volksinitiative-fuer-ein-nationales-verhuellungsverbot/ [Stand: 26. Januar 2019].

Endres, Jürgen/Tunger-Zanetti, Andreas/Behloul, Samuel-Martin/Baumann, Martin (2013): Jung, muslimisch, schweizerisch. Muslimische Jugendgruppen, islamische Lebensführung und Schweizer Gesellschaft. Ein Forschungsbericht. Luzern: Universität Luzern, Zentrum Religionsforschung.

Erziehungsdirektion des Kantons Bern (ERZ) (2018a): Brückenangebote Kanton Bern (Webseite). Erziehungsdirektion des Kantons Bern (ERZ). URL: www.erz.be.ch/erz/de/index/berufsbildung/brueckenangebote.html [Stand: 28. Januar 2019]. 
Erziehungsdirektion des Kantons Bern (ERZ) (2018b): Berufsvorbereitende Schuljahr Praxis und Allgemeinbildung BPA (Webseite). Erziehungsdirektion des Kantons Bern (ERZ). URL: www.erz.be.ch/erz/de/index/ berufsbildung/brueckenangebote/berufsvorbereitendesschuljahr.html [Stand: 28. Januar 2019].

Ettinger, Patrik/Imhof, Kurt (2011): Ethnisierung des Politischen und Problematisierung religiöser Differenz. Religionsgemeinschaften Staat und Gesellschaft. Schlussbericht. Bern: Schweizerischer Nationalfonds (SNF), Nationales Forschungsprogramm »Religionsgemeinschaften Staat und Gesellschaft« (NFP 58). URL: www.snf.ch/SiteCollectionDocuments/ nfp/nfp58/NFP58_Schlussbericht_Ettinger_Imhof.pdf [Stand: 26. Januar 2019].

Falzon, Mark-Anthony (2009): Multi-sited ethnography. Theory, praxis and locality in contemporary research. Introduction. In: Falzon, Mark-Anthony (Hg.): Multi-sited ethnography. Theory, praxis and locality in contemporary research. Farnham: Ashgate, 1-23.

Felouzis, Geoges/Charmillot, Samuel (2017): Schulische Ungleichheit in der Schweiz. Social Change in Switzerland (8), 1-12.

Fibbi, Rosita/Bülent, Kaya/Piguet, Etienne (2003: Le passeport ou le diplôme? Etudes des discriminations à l'embauche des jeunes issus de la migration. Rapport de recherche 31 du Forum suisse pour l'étude des migration et de la population. Neuchâtel: Swiss Forum for Migration and Population Studies.

FIDS (2017): Website der Föderation der Islamischen Dachorganisationen Schweiz (FIDS). URL: www.fids.ch/?page_id=545 [Stand: 28. Januar 2019]. Flick, Uwe (2010): Qualitative Sozialforschung. Eine Einführung. 3. Aufl. Reinbek bei Hamburg: Rowohlt.

Foucault, Michel (1976a): Überwachen und Strafen. Die Geburt des Gefängnisses. Frankfurt a.M.: Suhrkamp.

Foucault, Michel (1976b): Mikrophysik der Macht. Über Strafustiz, Psychiatrie und Medizin. Berlin: Merve.

Franke, Edith/Maske, Verena (2011): Teilnehmende Beobachtung als Verfahren in der Religionsforschung. Der Verein »Muslimische Jugend in Deutschland e.V.«. In: Kurth, Stefan/Lehmann, Karsten (Hg.): Religionen erforschen. Kulturwissenschaftliche Methoden in der Religionswissenschaft. Wiesbaden: VS Verlag für Sozialwissenschaften, 105-134.

Frigerio Martina (2014): Verbotene Kinder. Die Kinder der italienischen Saisonniers erzählen von Trennung und Illegalität. Zürich: Rotpunktverlag. 
Frisina, Annalisa (2010): Young Muslims' Everyday Tactics and Strategies. Resisting Islamophobia, Negotiating Italianness, Becoming Citizens. Journal of Intercultural Studies 31(5), 557-572.

Füssel, Marian (2018): Zur Aktualität Von Michel de Certeau. Einleitung in Sein Werk. Wiesbaden: Springer VS.

Füssel, Marian (2001): Von der Produktion der Geschichte zur Geschichte der Praktiken: Michel de Certeau S.J. In: Angermüller, Johannes/Bunzmann, Katharina/Nonhoff, Martin (Hg.): Diskursanalyse: Theorien, Methoden, Anwendungen. Argument Verlag: 99-110.

Gafner, Beni (2017): Von gegenseitigen Kontrollen keine Spur. In: Basler Zeitung (Internetversion), 13.1.2017. URL: http://bazonline.ch/schweiz/vongegenseitigen-kontrollen-keine-spur/story/21788048 [Stand: 29. Januar 2019].

Gebhardt, Winfried (2018): Religiöse Szenen und Events. In: Detlef, Pollack/Volkhard, Krech/Olaf Müller/Markus, Hero (Hg.): Handbuch Religionssoziologie. Wiesbaden: Springer VS, 591-610.

Gebhardt, Winfried/Engelfried-Rave, Ursula/Hepp, Andreas (2007): Megaparty Glaubensfest. Weltjugendtag: Erlebnis - Medien - Organisation. Wiesbaden: VS Verlag für Sozialwissenschaften.

Geertz, Clifford (1983): Religion als kulturelles System. In: Dichte Beschreibung. Beiträge zum Verstehen kultureller Systeme. Frankfurt a.M.: Suhrkamp, 44-95.

Gerlach, Julia (2010): Pop-Islam revisited: Wohin entwickelt sich die transnationale Jugendbewegung der »neuen Prediger« in Europa und in der Arabischen Welt? In: Hunner-Kreisel, Christine/Andresen, Sabine (Hg.): Kindheit und Jugend in muslimischen Lebenswelten. Aufwachsen und Bildung in deutscher und internationaler Perspektive. Wiesbaden: VS Verlag für Sozialwissenschaften, 109-124.

Gianni, Matteo (2010): Muslime in der Schweiz. Identitätsprofile, Erwartungen und Einstellungen. Eine Studie der Forschungsgruppe »Islam in der Schweiz« (GRIS). 2. Aufl. Bern: Eidgenössische Komission für Migrationsfragen (EKM). URL: https://www.ekm.admin.ch/dam/data/ ekm/dokumentation/materialien/mat_muslime_d.pdf [Stand: 29. Januar 2019].

Gianni, Matteo (2009): Citoyenneté et intégration des musulmans en Suisse: adaptation aux normes ou participation à leur défintion? In: Schneuwly Purdie, Mallory/Gianni, Matteo/Jenny, Magali (Hg.): Musulmans d'aujourd'hui. Identités plurielles en Suisse. Genève: Labor et Fides, 73-92. 
Gianni, Matteo/Giugni, Marco/Michel, Noémi (2015): Les musulmans en Suisse. Profils et intégration. Lausanne: Presses Polytechniques et Universitaires Romandes.

Giddens, Anthony (1997): Die Konstitution der Gesellschaft. Grundzüge einer Theorie der Strukturierung. 3. Aufl. Frankfurt a.M.: Campus.

Giliam, Laura (2015): Being a Good, Relaxed or Exaggerated Muslim. Religiosity and Masculinity in the Social Worlds of Danish Schools. In: Sedgwick, Mark J. (Hg.): Making european muslims. Religious socialization among young muslims in Scandinavia and Western Europe. New York NY u.a.: Routledge, 165-186.

Girtler, Roland (1989): Die "teilnehmende, unstrukturierte Beobachtung« ihr Vorteil bei der Erforschung des sozialen Handelns und des in ihm enthaltenen Sinns. In: Aster, Reiner (Hg.): Teilnehmende Beobachtung. Werkstattberichte und methodologische Reflexionen. Frankfurt a.M. u.a.: Campus, 103-113.

Glarner, Andreas (2017): Unkontrolliert einbürgern? Nein! In: Schweizerzeit (Internetversion), 9.1.2017. URL: www.schweizerzeit.ch/cms/index. php?page=/news/unkontrolliert_einbuergern_nein-2970 [Stand: 28. Januar 2019].

Glaser, Barney G. with the assistance of Judith Holton (2004): Remodeling Grounded Theory. Forum: Qualitative Social Research 5(2).

Glaser, Barney G./Strauss, Anselm L. (1967): The Discovery of Grounded Theory. Strategies for Qualitative Research. New York NY u.a.: Aldine de Gruyter.

Granato, Mona (2006): Junge Frauen mit Migrationshintergrund - wenig Aussichten auf eine berufliche Ausbildung? In: Granato, Mona/Degen Ulrich (Hg.): Berufliche Bildung von Frauen. Bielefeld: Bertelsmann, 98-114.

Granato, Mona (2003): Jugendliche mit Migrationshintergrund - auch in der beruflichen Bildung geringere Chancen? In: Auernheimer, Georg (Hg.): Schieflagen im Bildungssystem. Die Benachteiligung der Migrantenkinder. Opladen: Leske + Budrich, 113-135.

Gomolla, Mechtild/Radtke, Frank-Olaf (2009): Institutionelle Diskriminierung. Die Herstellung ethnischer Differenz in der Schule. 3. Aufl. Wiesbaden: VS Verlag für Sozialwissenschaften/GWV Fachverlage.

Gujer, Eric (2016): Burkadebatte in der Schweiz. Ein Gefängnis aus Stoff. Kommentar. In: NZZ (Internetversion), 19.8.2016. URL: https://www. nzz.ch/meinung/burkadebatte-in-der-schweiz-ein-gefaengnis-ausstoff-ld.1118733 [Stand: 28. Januar 2019]. 
Gustavson, Leif C./Cyntrynbaum, Joseph C. (2003): Illuminating Spaces: Relational Spaces, Complicity, and Multisited Ethnography. Field Methods 15(3), 252-270.

Haeberlin, Urs/Imdorf, Christian/Kronig, Winfried (2004): Chancenungleichheit bei der Lehrstellensuche. Der Einfluss von Schule, Herkunft und Geschlecht. Aarau: Schweizerische Koordinationsstelle für Bildungsforschung.

Hadjar, Andreas (2008): Meritokratie als Legitimationsprinzip. Die Entwicklung der Akzeptanz sozialer Ungleichheit im Zuge der Bildungsexpansion. Wiesbaden: VS Verlag für Sozialwissenschaften.

Hadjar, Andreas/Hupka-Brunner, Sandra (Hg.) (2013a): Geschlecht, Migrationshintergrund und Bildungserfolg. Weinheim: Beltz Juventa.

Hadjar, Andreas/Hupka-Brunner, Sandra (2013b): Überschneidungen von Bildungsungleichheiten nach Geschlecht und Migrationshintergrund. Eine theoretische und empirische Hinführung. In: Hadjar, Andreas/HupkaBrunner, Sandra (Hg.): Geschlecht, Migrationshintergrund und Bildungserfolg. Weinheim: Beltz Juventa, 7-35.

Haenni Hoti, Andrea (Hg.) (2015): Equity - Diskriminierung und Chancengerechtigkeit im Bildungswesen. Migrationshintergrund und soziale Herkunft im Fokus. Bern: Schweizerische Konferenz der kantonalen Erziehungsdirektoren (EDK). URL: https://edudoc.ch/record/120065/files/ StuB_37A.pdf [Stand 29. Januar 2019].

Hagedorn, Jörg (2008): Jugendkulturen als Fluchtlinien. Zwischen Gestaltung von Welt und der Sorge um das gegenwärtige Selbst. Wiesbaden: VS Verlag für Sozialwissenschaften.

Halbmayer, Ernst (2017): Ausgewählte Weiterentwicklungen der ethnographischen Forschung. Globale Welt und multi-sited Ethnography (Webseite). Universität Wien, Institut für Kulturanthropologie. URL: www.univie.ac.at/ksa/elearning/cp/ksamethoden/ksamethoden-84.html [Stand: 24. Januar 2019].

Hall, Stuart (2004): Das Spektakel der Anderen. In: Hall Stuart [Koivisto, Juha/Merkens, Andreas (Hg)]: Ideologie, Identität, Repräsentation. Hamburg: Argument Verlag, 108-166.

Hall, Stuart (1996): Encoding/Decoding. In: Hall, Stuart/Hobson, Dorothy/Lowe, Andrew/Willis, Paul (Hg.): Culture, media, language. London: Routledge, 128-138.

Hannerz, Ulf (2003): Being there...and there...and there! Reflections on multisited ethnography. In: Ethnography 4 (2), 201-216. 
Helsper, Werner/Busse, Susann/Hummrich, Merle/Kramer, Rolf-Torsten (2009): Jugend zwischen Familie und Schule. Eine Studie zu pädagogischen Generationsbeziehungen. Wiesbaden: VS Verlag für Sozialwissenschaften.

Herding, Maruta (2013): Inventing the Muslim Cool. Islamic Youth Culture in Western Europe. Bielefeld: transcript.

Hitzler, Ronald/Niederbacher, Arne (2010): Leben in Szenen. Formen juveniler Vergemeinschaftung heute. 3. Aufl. Wiesbaden: VS Verlag für Sozialwissenschaften.

Hofstetter, Daniel (2017): Die schulische Selektion als soziale Praxis. Aushandlungen von Bildungsentscheidungen beim Übergang von der Primarschule in die Sekundarstufe I. Weinheim, Basel: Beltz Juventa.

Holzkamp, Klaus (1983): Grundlegung der Psychologie. Frankfurt a.M. u.a.: Campus.

Hooks, Bell (1981): Ain't I a woman. Black Women and Feminism. London: Pluto Press.

Hooks, Bell (1984): Feminist theory. From margin to center. New York NY u.a.: South End Press.

Höpflinger, Anna-Katharina/Lavanchy, Anne/Dahinden, Janine (2012): Introduction. Linking Gender and Religion. Women's Studies 41(6), 615-638.

Huber, Stefan (2007): Are Religious Beliefs Relevant In Daily Life? In: Heinz Streib (Hg.): Religion inside and outside Traditional Institutions: Leiden: Brill, 209-230.

Hull, Gloria T./Bell Scott, Patricia, Smith Barbara (Hg.) (2010): All the Woman are White, All the Blacks Are Men, But Some of Us are Brave. Black Women's Studies. New York NY: Feminist Press.

humanrights.ch (2016): Das Kopftuch an öffentlichen Schulen (Webseite). Informationsplattform humanrights.ch. URL: www.humanrights.ch/de/ menschenrechte-schweiz/inneres/gruppen/religioese/kopftuchverbotoeffentlichen-schulen [Stand: 28. Januar 2019].

Hummrich, Merle (2009): Bildungserfolg und Migration. Biografien junger Frauen in der Einwanderungsgesellschaft. 2. Aufl. Wiesbaden: VS Verlag für Sozialwissenschaften.

Hupka-Brunner, Sandra/Meyer, Thomas/Stalder, Barbara E./Keller, Anita (2011a): Pisa-Kompetenzen und Übergangswege: Egebnisse aus der Schweizer TREE-Studie. In: Krekel, Elisabeth M./Lex, Tilly (Hg.): Neue Jugend, neue Ausbildung? Beiträge aus der Jugend- und Bildungsforschung. Bielefeld: Bertelsmann, 173-188. 
Hupka-Brunner, Sandra/Meyer, Thomas/Stalder, Barbara E./Keller, Anita (2011b): Transition from Lower to Upper Secondary Education in Switzerland and Germany: Chances for Young Adults from Lower Secondary Schools with Basic Intellectual Requirements. Zeitschrift für Soziologie der Erziehung und Sozialisation 31 (1), 62-78.

IZRS (2010): Pressekommuniqué vom 15.1.2010. (Webseite). IZRS. URL: www.izrs.ch/zusammenfassung-der-pressekonferenz-vom-15-1-2010-inbern.html [Stand: 18. Januar 2017].

Initiativkomitee »Ja zum Verhüllungsverbot « (2015): »Ja zum Verhüllungsverbot« (Website). URL: www.verhuellungsverbot.ch/ [Stand: 28. Januar 2019].

Imdorf, Christian (2011): Wie Ausbildungsbetriebe soziale Ungleichheit reproduzieren: Der Ausschluss von Migrantenjugendlichen bei der Lehrlingsselektion. In: Krüger, Heinz-Hermann (Hg.): Bildungsungleichheit revisited. Bildung und soziale Ungleichheit vom Kindergarten bis zur Hochschule. 2. Aufl. Wiesbaden: VS Verlag für Sozialwissenschaften, 261-27.

Imdorf, Christian (2005): Schulqualifikation und Berufsfindung. Wie Geschlecht und nationale Herkunft den Übergang in die Berufsbildung strukturieren. Wiesbaden: VS Verlag für Sozialwissenschaften.

Jaffe-Walter, Reva (2016): Coercive concern. nationalism, liberalism, and the schooling of Muslim youth. Stanford CA: Stanford University Press.

Janmohamed, Shelina (2016): Generation M. Young Muslims Changing the World. London: I.B. Tauris.

Jenny, Zoé (2016): Burka - der Stoff, aus dem Unterdrückung ist. Kommentar der Anderen. In: Der Standard (Internetversion), 14. Oktober 2016. URL: http://derstandard.at/2000045908285/Burka-der-Stoffaus-dem-Unterdrueckung-ist [Stand: 16. Januar 2017].

John, Barbara (2007): Kulturelle Anpassungsleistungen muslimischer Jugendlicher in Deutschland unter Wahrung der religiösen Identität. In: Dettling, Daniel (Hg.): Vorteil Vielfalt. Herausforderungen und Perspektiven einer offenen Gesellschaft. Wiesbaden: VS Verlag für Sozialwissenschaften, 56-65.

Jürgensen, Nadine (2016): Simonetta Sommaruga: »Der Händedruck gehört zu unserer Kultur«. In: NZZ (Internetversion), 5.4.2016. URL: www.nzz.ch/schweiz/aktuelle-themen/simonetta-sommaruga-derhaendedruck-gehoert-zu-unserer-kultur-ld.11627 [Stand: 28. Januar 2019]. 
Jurinak, Irena (2015): IZRS-Vorstand interviewt Jihadisten-Chef in Syrien. In: Tages-Anzeiger (Internetversion), 29. November 2015. URL: www.tagesanzeiger.ch/ausland/naher-osten-und-afrika/izrsvorstandinterviewt-alqaidafuehrer-in-syrien/story/15880667 [Stand: 28. Januar 2019].

Juhasz, Anne/Mey, Eva (2003): Die zweite Generation: Etablierte oder Aussenseiter? Biographien von Jugendlichen ausländischer Herkunft. Wiesbaden: Westdeutscher Verlag.

Kälin, Walter (2000): Grundrechte im Kulturkonflikt. Freiheit und Gleichheit in der Einwanderungsgesellschaft. Zürich: Verlag Neue Zürcher Zeitung.

Kalpaka, Annita (2006): Pädagogische Professionalität in der Kulturalisierungsfalle. Über den Umgang mit »Kultur« in Verhältnissen von Differenz und Dominanz. In: Leiprecht, Rudolf/Kerber, Anne (Hg.): Schule in der Einwanderungsgesellschaft. Ein Handbuch. 2. Aufl. Schwalbach a. T.: Wochenschau Verlag, 387-405.

Kamp, Melanie (2007): Mehr als Vorbeter: Zur Herkunft und Rolle von Imamen in Moscheevereinen (Webseite). Heinrich Böll Stiftung. URL: https://heimatkunde.boell.de/2007/05/01/mehr-als-vorbeterzur-herkunft-und-rolle-von-imamen-moscheevereinen [Stand: 15. Mai 2018].

Karakaşoğlu-Aydin, Yasemin (2000): Muslimische Religiosität und Erziehungsvorstellungen. Eine empirische Untersuchung zu Orientierungen bei türkischen Lehramts- und Pädagogik-Studentinnen in Deutschland. Frankfurt a.M.: IKO.

Kaya, Meral (2012): Geschlecht im Schweizer Migrationsdiskurs. Die postkoloniale Konstruktion der »unterdrückten Muslimin« und die rassistische Verwendung des Schleiers. In: Purtschert, Patricia/Falk, Francesca/Lüthi, Barbara (Hg.): Postkoloniale Schweiz. Formen und Folgen eines Kolonialismus ohne Kolonien. Bielefeld: transcript, 117-132.

Kelek, Neclá (2002): Islam im Alltag. Islamische Religiosität und ihre Bedeutung in der Lebenswelt von Schülerinnen und Schülern türkischer Herkunft. Münster, New York NY: Waxmann.

Kelle, Udo/Kluge, Susann (2010): Vom Einzelfall zum Typus. Fallvergleich und Fallkontrastierung in der qualitativen Sozialforschung. 2. Aufl. Wiesbaden: VS Verlag für Sozialwissenschaften.

Khawaja, Iram/Lerche Mørck, Line (2009): Researcher positioning: Muslim otherness and beyond. Qualitative Research in Psychology 6(1), 28-45. 
Killian, Caitlin/Johnson, Cathryn (2006): »I'am Not an Immigrant!« Resistance, Redefinition, and the Role of Ressources in Identity Work. In: Social Psychology Quarterly 69(1), 60-80.

King, Deborah K. (1988): Multiple jeopardy, multiple consiousness: the context of Black Feminist Ideology. Signs: Journal of Women Culture and Society 14(1), 42-72.

King, Vera (2004): Die Entstehung des Neuen in der Adoleszenz. Individuation, Generativität und Geschlecht in modernisierten Gesellschaften. Opladen: Leske + Budrich.

King, Vera/Koller, Hans-Christoph (Hg.) (2009a): Adoleszenz - Migration - Bildung. Bildungsprozesse Jugendlicher und junger Erwachsener mit Migrationshintergrund. 2. Aufl. Wiesbaden: VS Verlag für Sozialwissenschaften.

King, Vera/Koller, Hans-Christoph (2009b): Adoleszenz als Möglichkeitsraum für Bildungsprozesse unter Migrationsbedingungen. Eine Einführung. In: King, Vera/Koller, Hans-Christoph (Hg.): Adoleszenz - Migration Bildung. Bildungsprozesse Jugendlicher und junger Erwachsener mit Migrationshintergrund. 2. Aufl. Wiesbaden: VS Verlag für Sozialwissenschaften, 9-26.

Klinger, Cornelia/Knapp, Gudrun-Axeli/Sauer, Birgit (Hg.) (2007): Achsen der Ungleichheit. Zum Verhältnis von Klasse, Geschlecht und Ethnizität. Frankfurt a.M. Campus.

Klinger, Cornelia/Knapp, Gudrun-Axeli (2005): Achsen der Ungleichheit Achsen der Differenz. Verhältnisbestimmungen von Klasse, Geschlecht, »Rasse«./Ethnizität. Transit. Europäische Revue (29), 72-96.

Klinger, Cornelia (2003): Ungleichheit in den Verhältnissen von Klasse, Rasse und Geschlecht. In: Knapp, Gudrun-Axeli/Wetterer, Angelika (Hg.): Achsen der Differenz. Münster: Verlag Westfälisches Dampfboot, 14-48.

Klinkhammer, Gritt (2013): Islamic Style - die Sichtbarkeit des »unsichtbaren« Islams. In: Dorothea Lüddeckens, Uehlinger Christoph und Rafael Walthert (Hg.): Die Sichtbarkeit religiöser Identität. Repräsentation - Differenz - Konflikt. Zürich: Pano, 111-136.

Klinkhammer, Gritt (2006): Emanzipation und Islam in der Diaspora. Zur Religiosität von Musliminnen der zweiten Generation in Deutschland. In: Doris Strahm und Manuela Kalsky (Hg.): Damit es anders wird zwischen uns. Interreligiöser Dialog aus der Sicht von Frauen. Mainz: MatthiasGrünewald-Verlag, 84-97. 
Klinkhammer, Gritt Maria (2000): Moderne Formen islamischer Lebensführung. Eine qualitativ-empirische Untersuchung zur Religiosität sunnitisch geprägter Türkinnen der zweiten Generation in Deutschland. Marburg: Diagonal.

Knapp, Gudrun-Axeli (2013): Über Kreuzungen: Zu Produktivität und Grenzen von »Intersektionalität« als »Sensitizing Concept«. In: Bereswill, Mechthild (Hg.): Geschlecht (re)konstruieren. Zur methodologischen und methodischen Produktivität der Frauen- und Geschlechterforschung. Münster: Westfälisches Dampfboot, 242-262.

Knapp, Gudrun-Axeli (2005): »Intersectionality« - ein neues Paradigma feministischer Theorie? Zur transatlantischen Reise von »Race, Class, Gender«. Feministische Studien 23(1), 68-81.

Knauth, Thorsten/Jochimsen, Maren A. (Hg.) (2017): Einschliessungen und Ausgrenzungen. Zur Intersektionalität von Religion, Geschlecht und sozialem Status für religiöse Bildung. Münster: Waxmann.

Korteweg, Anna C./Yurdakul, Gökçe (2016): Kopftuchdebatten in Europa. Konflikte um Zugehörigkeit in nationalen Narrativen. Bielefeld: transcript.

Kreutzer, Florian/Demir, Sümeyye (2015): Stigma »Kopftuch«. Zur rassistischen Produktion von Andersheit. Bielefeld: transcript.

Krönert, Veronika (2009): Michel de Certeau: Alltagsleben, Aneignung und Widerstand. In: Hepp, Andreas/Krotz, Friedrich/Thomas, Tanja (Hg.): Schlüsselwerke der Cultural Studies. Wiesbaden: VS Verlag für Sozialwissenschaften, 47-57.

Kronig, Winfried (2013): Die faktische Definition des schulischen Scheiterns. In: Hadjar, Andreas/Hupka-Brunner, Sandra (Hg.): Geschlecht, Migrationshintergrund und Bildungserfolg. Weinheim: Beltz Juventa, 36-51.

Kronig, Winfried (2007): Die systematische Zufälligkeit des Bildungserfolgs. Theoretische Erklärungen und empirische Untersuchungen zur Lernentwicklung und zur Leistungsbewertung in unterschiedlichen Schulklassen. Bern: Haupt.

Kronig, Winfried (2005): Irrtümer der Selektion. Über die Tücken eines hierarchisch gestuften Bildungssystems. vpod - bildungspolitik, (143/144), 12-14.

Kronig, Winfried/Haeberlin, Urs/Eckhart, Michael (2007): Immigrantenkinder und schulische Selektion. Pädagogische Visionen, theoretische Erklärungen und empirische Untersuchungen zur Wirkung integrierender und separierender Schulformen in den Grundschuljahren, 2. Aufl. Bern u.a.: Haupt. 
Kucera, Andrea (2016): Islam. Walliser SVP fordert Kopftuchverbot an Schulen. In: NZZ (Internetversion), 22.2.2016. URL: https://www.nzz.ch/ schweiz/walliser-svp-fordert-kopftuchverbot-an-schulen-1.18699499 [Stand: 28. Januar 2019].

Kurt, Stefanie/Shy Chau, Huey (2013): Heirat und Migration. Bern: Schweizerische Beobachtungsstelle für Asyl- und Ausländerrecht. URL: https://beobachtungsstelle.ch/fileadmin/Publikationen/2013/Bericht_ Heirat_Migration_D.pdf [Stand: 28. Januar 2019].

Kurth, Stefan/Lehmann, Karsten (2011): Narrativ fundierte Interviews mit religiösen Subjekten. Individualsynkretismus als Typus moderner Religiosität. In: Kurth, Stefan/Lehmann, Karsten (Hg.): Religionen erforschen. Kulturwissenschaftliche Methoden in der Religionswissenschaft. Wiesbaden: VS Verlag für Sozialwissenschaften, 135-168.

Landolt, Noëmi (2016a): Zieht euch gefälligst an, ihr Schlampen! Kommentar zum »Burkaverbot«. In: WOZ - Die Wochenzeitung (Internetversion), 25.8.2016 34. URL: https://www.woz.ch/-7099 [Stand: 28. Januar 2019].

Landolt, Noëmi (2016b): Adios, Second@s Plus. In: WOZ - Die Wochenzeitung (Internetversion), 16.6.2016. URL: https://www.woz.ch/1624/ migrationspolitik/adios-seconds-plus [Stand: 28. Januar 2019].

Le Breton, Maritza (2011): Sexarbeit als transnationale Zone der Prekarität. Migrierende Sexarbeiterinnen im Spannungsfeld von Gewalterfahrungen und Handlungsoptionen. Wiesbaden: VS Verlag für Sozialwissenschaften. Lenz, Ilse (1995): Geschlecht, Herrschaft und internationale Ungleichheit. In: Becker-Schmidt, Regina/Knapp, Gudrun-Axeli (Hg.): Das Geschlechterverhältnis als Gegenstand der Sozialwissenschaften. Frankfurt a. M; New York NY: Campus, 19-46.

Lingen-Ali, Ulrike (2012): »Islam« als Zuordnungs- und Differenzkategorie. Antimuslimische Ressentiments im Bereich von Bildung und sozialer Arbeit. Sozial extra (9/10), 24-27.

Lingen-Ali, Ulrike/Mecheril, Paul (2016): Religion als soziale Deutungspraxis. Österreichisches Religionspädagogisches Forum 24(2), 17-24.

Lipp, Wolfgang (2010): Stigma und Charisma. Über soziales Grenzverhalten. 2. Aufl. Würzburg: Ergon.

Lübcke, Claudia (2007): Jugendkulturen junger Muslime in Deutschland. In: Wensierski, Hans-Jürgen von/Lübcke, Claudia (Hg.): Junge Muslime in Deutschland. Lebenslagen, Aufwachsprozesse und Jugendkulturen. Opladen: Verlag Barbara Budrich, 285-318. 
Lucius-Hoene, Gabriele/Deppermann, Arnulf (2002): Rekonstruktion narrativer Identität. Ein Arbeitsbuch zur Analyse narrativer Interviews. Opladen: Leske + Budrich, 285-318.

Lüders, Christian (2011): Teilnehmende Beobachtung. In: Bohnsack, Ralf/Marotzki, Winfried/Meuser, Michael (Hg.): Hauptbegriffe qualitativer Sozialforschung. 3. Aufl. Opladen: Leske + Budrich, 151-153.

Lutz, Helma/Vivar, Maria Teresa Herrera/Supik, Linda (2013): Fokus Intersektionalität - eine Einleitung. In: Lutz, Helma/Vivar, Maria Teresa Herrera/Supik, Linda (Hg.): Fokus Intersektionalität. Bewegungen und Verortungen eines vielschichtigen Konzeptes. 2. Aufl. Wiesbaden: Springer VS, 9-31.

Lutz, Helma/Davis, Kathy (2005): Geschlechterforschung und Biografieforschung. Intersektionalität als biografische Ressource am Beispiel einer aussergewöhnlichen Frau. In: Völter, Bettina/Dausien, Bettina/Lutz, Helma/Rosenthal, Gabriele (Hg.): Biographieforschung im Diskurs. Wiesbaden: VS Verlag für Sozialwissenschaften, 228-247.

Lutz, Helma/Leiprecht, Rudolf (2003): Heterogenität als Normalfall. Eine Herausforderung für die Lehrerbildung. In: Gogolin, Ingrid/Helmchen, Jürgen/Lutz, Helma/Schmidt, Gerlind (Hg.): Pluralismus unausweichlich? Blickwechsel zwischen vergleichender und interkultureller Pädagogik. Münster u.a.: Waxmann, 115-128.

Lutz, Helma/Wenning, Norbert (Hg.) (2001): Unterschiedlich verschieden. Differenz in der Erziehungswissenschaft. Opladen: Leske + Budrich; VS Verlag für Sozialwissenschaften.

Mahnig, Hans/Piguet, Etienne (2003): Die Immigrationspolitik der Schweiz von 1948 bis 1998: Entwicklung und Auswirkungen. In: Wicker, HansRudolf (Hg.): Migration und die Schweiz. Ergebnisse des Nationalen Forschungsprogramms »Migration und interkulturelle Beziehungen«. Zürich: Seismo, 65-108.

Mahmood, Saba (2012): Politics of piety. The Islamic revival and the feminist subject. Princeton NJ: Princeton University Press.

Marcus, Georg E. (1995): Ethnography in/of the World System: The Emergence of Multi-Sited Ethnography. Annual Review of Anthropology 24, 95-117.

Martens, Silvia (2010): Wohltätiges Engagement von Muslimen in der Schweiz. In: Allenbach, Brigit/Sökefeld, Martin (Hg.): Muslime in der Schweiz. Zürich: Seismo, 145-178.

Marti, Michael/Kraft, Eliane/Walter, Felix (2010): Dienstleistungen, Nutzen und Finanzierung von Religionsgemeinschaften in der Schweiz. Synthese 
des Projekts FAKIR. Schlussbericht. Bern: Schweizerischer Nationalfonds (SNF), Nationales Forschungsprogramm »Religionsgemeinschaften Staat und Gesellschaft« (NFP 58). URL: www.snf.ch/SiteCollectionDocuments/ nfp/nfp58/NFP58_Schlussbericht_Marti.pdf [Stand: 29. Januar 2019].

Martin, Emily (1994): Flexible bodies. Tracking immunity in American culture; from the days of polio to the age of AIDS. Boston, MA: Beacon Press.

Marx, Daniela (2008): Mission: impossible? Die Suche nach der »idealen Muslimin«. Feministische Islamdiskurse in Deutschland und den Niederlanden. FEMINA POLITICA - Zeitschrift für feministische Politikwissenschaft 17(1), 55-67.

McCall, Leslie (2005): The complexity of intersectionality. Signs: Journal of Women Culture and Society 30(3), 1771-1800.

McGuire, Meredith B. (2008): Lived religion. Faith and practice in everyday life. Oxford; New York NY: Oxford University Press.

Mecheril, Paul/Thomas-Olalde, Oscar (2018): Religion und die Identifikation der Andern. In: Dirim, Inci/Mecheril, Paul (Hg.): Heterogenität, Sprache(n) und Bildung. Eine differenz- und diskriminierungstheoretische Einführung. Bad Heilbrunn: Julius Klinkhardt, 179-196.

Mecheril, Paul/Thomas-Olalde, Oscar (2011): Die Religion der Anderen. Anmerkungen zu Subjektivierungspraxen der Gegenwart. In: Allenbach, Brigit/Goel, Urmila/Hummrich, Merle/Weisköppel, Cordula (Hg.): Jugend, Migration und Religion. Interdisziplinäre Perspektiven. Baden-Baden: Nomos, 35-66.

Meer, Nasar/Modood, Tariq (2013): Beyond »Methodological Islamism«? A Thematic Discussion of Muslim Minorities in Europe. Advances in Applied Sociology 3(7), 307-313.

Metzger, Michael (2013): Urban Games. Die Stadt als Spielfeld (unveröffentlichte Magisterarbeit). Berlin: Humboldt-Universität zu Berlin, Institut für Europäische Ethnologie.

Mey, Eva (2015): Wege in die Arbeitswelt - dorthin, wo noch Platz ist. Mechanismen und Bedeutung stark fremdbestimmter Berufswahl bei jungen Menschen mit Migrationshintergrund. In: Geisen, Thomas/Ottersbach, Markus (Hg.): Arbeit, Migration und Soziale Arbeit. Prozesse der Marginalisierung in modernen Arbeitsgesellschaften. Wiesbaden: Springer VS, 235-261.

Mey, Eva/Rorato, Miriam (2010): Jugendliche mit Migrationshintergrund im Übergang ins Erwachsenenalter - eine biografische Längsschnittstudie. Schlussbericht zuhanden des Praxispartners Bundesamt für 
Migration. Luzern: Hochschule Luzern - Soziale Arbeit. URL: https:// www.sem.admin.ch/dam/data/sem/publiservice/service/forschung/bersecondos-d.pdf [Stand 29. Januar 2019].

Mey, Eva/Rorato, Miriam/Voll, Peter (2005): Die soziale Stellung der zweiten Generation. Analysen zur schulischen und beruflichen Integration der zweiten Ausländergeneration. In: Eidgenössische Volkszählung 2000, Neuenburg: Bundesamt für Statistik, 61-152.

Mey, Günter/Mruck, Katja (2011): Grounded-Theory-Methodologie. Entwicklung, Stand, Perspektiven. In: Mey, Günter/Mruck, Katja (Hg.): Grounded Theory Reader. 2. Aufl. Wiesbaden: VS Verlag für Sozialwissenschaften, 11-48.

Mey, Günter/Mruck, Katja (2009): Methodologie und Methodik der Grounded Theory. In: Kempf, Wilhelm/Kiefer, Marcus (Hg.): Forschungsmethoden der Psychologie. Zwischen naturwissenschaftlichem Experiment und sozialwissenschaftlicher Hermeneutik. Berlin: Regener, 100-152.

Mruck, Katja/Mey, Günter (2007): Grounded Theory and Reflexivity. In: Bryant, Antony/Charmaz, Kathy (Hg.): The SAGE Handbook of Grounded Theory. Los Angeles, London: Sage, 487-510.

Meinert, Philipp/Seeliger, Martin (2013): Punk in Deutschland. Sozial- und kulturwissenschaftliche Perspektiven. In: Meinert, Philipp/Seeliger, Martin (Hg.): Punk in Deutschland. Sozial- und kulturwissenschaftliche Perspektiven. Bielefeld: transcript, 9-54.

Meyer, Thomas (2009): Wer hat, dem wird gegeben: Bildungsungleichheit in der Schweiz. In: Suter, Christian/Perrenoud, Silvia/Levy, René/Kuhn, Ursina/Joye, Dominique/Gazareth, Pascale (Hg.): Sozialbericht 2008. Die Schweiz vermessen und verglichen. Zürich: Seismo, 60-81.

Mintz, Sidney Wilfred (1985): Sweetness and power. The place of sugar in modern history. New York NY: Penguin Books.

Mir, Shabana (2014): Muslim American Women on Campus. Undergraduate Social Life and Identity. Chapel Hill: University of North Carolina Press.

Modood, Tariq (2013): Multiculturalism. A civic idea. 2. Aufl. Cambridge, Malden MA: Polity.

Modood, Tariq (2011): Multiculturalism and integration. Struggling with confusions. In: Mahamdallie, Hassan (Hg.): Defending multiculturalism. A guide for the movement. London: Bookmarks Publications, 61-76.

Modood, Tariq (2010): Still not easy being British. Struggles for a multicultural citizenship. Stoke-on-Trent: Trentham Books. 
Modood, Tariq (1998): Anti-Essentialism, Multiculturalism and the »Recocnition« of Religious Groups. The Journal of Political Philosophy 6(4) 378-399.

Modood, Tariq (1997): Introduction. The Politics of Multiculturalism in the New Europe. Racism, Identity and community. In: Modood, Tariq (Hg.): The Politics of Multiculturalism in the New Europe. Racism, Identity and Community. London u.a.: Zed Books, 1-25.

Mruck, Katja/Mey, Günter (2007): Grounded Theory and Reflexivity. In: Bryant, Antony/Charmaz, Kathy (Hg.): The SAGE Handbook of Grounded Theory. Los Angeles, London: Sage, 87-510.

Müller, Jochen/Nordbruch, Götz/Berke, Tataroglu (2010): Jugendkulturen zwischen Islam und Islamismus. Lifestyle, Medien, Musik. Berlin: Bundeskoordination Schule ohne Rassismus - Schule mit Courage.

Müller, Monika (2013): Migration und Religion. Junge hinduistische und muslimische Männer in der Schweiz. Wiesbaden: Springer VS.

Müller, Monika (2010): Perspektiven männlicher Jugendlicher auf den Islam: Eine Gratwanderung zwischen Identifikation und Ausschluss. In: Allenbach, Brigit/Sökefeld, Martin (Hg.): Muslime in der Schweiz. Zürich: Seismo, 266-295.

Müller, Felix (2009): Rechtliche und politische Aspekte der eidgenössischen Volksinitiative »Gegen den Bau von Minaretten«. In: Tanner, Mathias/Müller, Felix/Mathwig, Frank/Lienemann Wolfgang (Hg.): Streit um das Minarett. Zusammenleben in der religiös pluralistischen Gesellschaft. Zürich: TVZ Theologischer Verlag Zürich, 61-86.

Müller, Romano (2009): Berufswahl und Lehre. Berufliche Orientierungs- und Entscheidungsprozesse ausländischer und schweizerischer Jugendlicher. Bern: hep.

Nagel, Alexander-Kenneth (2015): Religiöse Netzwerke: Die zivilgesellschaftlichen Potentiale. In: Nagel, Alexander-Kenneth (Hg.): Religiöse Netzwerke. Die zivilgesellschaftlichen Potentiale religiöser Migrantengemeinden. Berlin, Bielefeld: De Gruyter, transcript, 11-35.

Nagel, Alexander-Kenneth (2013): Diesseits der Parallelgesellschaft. Religion und Migration in relationaler Perspektive. In: Nagel, Alexander-Kenneth (Hg.): Diesseits der Parallelgesellschaft. Neuere Studien zu religiösen Migrantengemeinden in Deutschland. Bielefeld: transcript, 11-35.

Neuenschwander (2011): Selektionsprozesse beim Übergang in die Berufsbildung. In: Verband Dyslexie Schweiz (Hg.): Keine Pole-Position? Wie der Start ins Berufsleben aus der 2. Reihe gelingen kann. Zürich: Verband Dyslexie Schweiz, 7-17. 
Nielsen, Jørgen S./Akgönül, Samim/Alibašić, Ahmet/Racius, Egdunas (Hg.) (2012): Yearbook of Muslims in Europe. Vol. 4. Leiden: Brill.

Nökel, Sigrid (2002): Die Töchter der Gastarbeiter und der Islam. Zur Soziologie alltagsweltlicher Anerkennungspolitiken: eine Fallstudie. Bielefeld: transcript.

Nökel, Sigrid (1999): Islam und Selbstbehauptung - alltagsweltliche Strategien junger Frauen in Deutschland. In: Klein-Hessling, Ruth/Nökel, Sigrid/Werner, Karin (Hg.): Der neue Islam der Frauen. Weibliche Lebenspraxis in der globalisierten Moderne: Fallstudien aus Afrika, Asien und Europa. Bielefeld: transcript.

Oester, Kathrin (2008): Die doppelte Funktion des Bildungssystems - theoretische Grundlagen zu Schule und Migration. In: Oester, Kathrin/Fiechter, Ursula/Kappus, Elke-Nicole (Hg.): Schulen in transnationalen Lebenswelten. Integrations- und Segregationsprozesse am Beispiel von Bern West. Zürich: Seismo, 49-68.

Oester, Kathrin/Brunner, Bernadette (2015): Von Kings und Losern. Eine Performance-Ethnografie mit Schülerinnen und Schülern im transnationalisierten Stadtteil Bern West. Wiesbaden: Springer VS.

Oester, Kathrin/Brunner, Bernadette (2014): Transnationalisierte PeerCommunities. Eine Performance Ethnografie mit Schülerinnen und Schülern aus Bern West (unveröffentlichter Forschungsbericht). Institut für Forschung, Entwicklung und Evaluation der Pädagogischen Hochschule Bern.

Online Marketing Lexikon (2018): »Influencer Marketing« (Webseite). OnlineMarketing.de. URL: https://onlinemarketing.de/lexikon/definitioninfluencer-marketing [Stand: 09. Januar 2018].

Pädagogische Hochschule Zürich (PH Zürich) (2014): Merkblatt - Tragen von religiös motivierter Kleidung. Zürich: Pädagogische Hochschule Zürich, Prorektorat Ausbildung. URL: https://stud.phzh.ch/globalassets/stud. phzh.ch/bpa/kiga-kust-primar-sek1_merkblatt-religioes-motiviertekleidung.pdf [Stand: 29.1.2019].

Pastega, Nadja (2010): Burkini für Schülerinnen. In: Schweiz am Sonntag (Internetversion), 2.4.2010. URL: https://www.schweizamwochenende.ch/ aktuell/burkini-fuer-schuelerinnen-131036693 [Stand: 28. Januar 2019].

Pelizzari, Alessandro (2009): Dynamiken der Prekarisierung. Atypische Erwerbsverhältnisse und milieuspezifische Unsicherheitsbewältigung. Konstanz: UVK. 
Pfaff-Czarnecka, Joanna (2009): Accommodating religious diversity in Switzerland. In: Bramadat, Paul/Koenig, Matthias (Hg.): International migration and the governance of religious diversity. Queens's University. Kingston ON: Queen's University, School of Policy Studies, 225-257.

Phoenix, Ann (2013): Psychosoziale Intersektionen. Zur Kontextualisierung von Lebenserzählungen Erwachsener aus ethnisch sichtbar differenten Haushalten. In: Lutz, Helma (Hg.): Fokus Intersektionalität. Bewegungen und Verortungen eines viel-schichtigen Konzeptes. 2. Aufl. Wiesbaden: Springer VS, 181-200.

Pickel, Gert (2014): Religiöses Sozialkapital - Integrationsressource für die Gesellschaft und die Kirchen? In: Arens, Edmund/Baumann, Martin/Liedhegener, Antonius/Müller, Wolfgang W./Ries, Markus (Hg.): Integration durch Religion? Geschichtliche Befunde, gesellschaftliche Analysen, rechtliche Perspektiven. Baden-Baden: Nomos, 41-61.

Polizei und Militärdirektion Kanton Bern (POM) (2017): Aufenthalt (Webseite). Kanton Bern, Polizei und Militärdirektion (POM). URL: www.pom.be.ch/ pom/de/index/migration/einreise/die_aufenthaltsbewilligung.html

[Stand: 23. Oktober 2017].

Portes, Alejandro/Rumbaut, Rubén G. (2001): Legacies. The story of the immigrant second generation. Berkeley CA: University of California Press.

Pries, Ludger (2008): Die Transnationalisierung der sozialen Welt. Sozialräume jenseits von Nationalgesellschaften. Frankfurt a.M.: Suhrkamp.

Purtschert, Patricia (2012): »De Schorsch Gaggo reist uf Afrika«. Postkoloniale Konstellationen und diskursive Verschiebungen in Schweizer Kindergeschichten. In: Purtschert, Patricia/Falk, Francesca/Lüthi, Barbara (Hg.): Postkoloniale Schweiz. Formen und Folgen eines Kolonialismus ohne Kolonien. 2. Aufl. Bielefeld: transcript Verlag, 89-116.

Repubblica e Cantone Ticino, Dipartimento delle istituzioni (2016): Comunicato stampa: 1. luglio 2016: entrano in vigore le nuove disposizioni sulla dissimulazione del viso nei luoghi pubblici (Internetversion). Repubblica e Cantone Ticino. URL: http://www3.ti.ch/CAN/comunicati/30-06-2016comunicato-stampa-617595990261.pdf [Stand: 28. Januar 2019].

Riegel, Christine (2017): Intersektionalität in Forschung und pädagogischer Praxis (unpublizierter Gastvortrag). Institut für Forschung und Entwicklung (IFE) der Pädagogischen Hochschule Bern (PHBern), 1-32.

Riegel, Christine (2016a): Bildung - Intersektionalität - Othering. Pädagogisches Handeln in widersprüchlichen Verhältnissen. Bielefeld: transcript. 
Riegel, Christine (2016b): Subjektwissenschaftliche und intersektionale Perspektiven - Konzeptionelle Überlegungen für eine kritische Forschung zu Bildungswegen in migrationsgesellschaftlichen Verhältnissen. In: Dausien, Bettina/Rothe, Daniela/Schwendowius, Dorothee (Hg.): Bildungswege. Biographien zwischen Teilhabe und Ausgrenzung, Frankfurt a.M.: Campus, 97-122.

Riegel, Christine (2011): Religion als Differenzmarker. Zu Herstellungsprozessen von Differenz im (sozial-)pädagogischen Sprechen über jugendliche Migrations-Andere. In: Allenbach, Brigit/Goel, Urmila/Hummrich, Merle/Weisköppel, Cordula (Hg.): Jugend, Migration und Religion. Interdisziplinäre Perspektiven. Baden-Baden: Nomos, 319-341.

Riegel, Christine (2010a): Intersektionalität als transdisziplinäres Projekt: Methodologischen Perspektiven für die Jugendforschung. In: Riegel, Christine/Scherr, Albert/Stauber, Barbara (Hg.): Transdisziplinäre Jugendforschung. Grundlagen und Forschungskonzepte. Wiesbaden: VS Verlag für Sozialwissenschaften, 65-87.

Riegel, Christine (2010b): Zwischen Kämpfen und Leiden. Handlungsfähigkeit im Spannungsfeld ungleicher Geschlechter-, Generationen- und Ethnizitätsverhältnisse. In: Riegel, Christine/Geisen, Thomas (Hg.): Jugend, Zugehörigkeit und Migration. Subjektpositionierung im Kontext von Jugendkultur, Ethnizitäts- und Geschlechterkonstruktionen. 2. Aufl. Wiesbaden: VS Verlag für Sozialwissenschaften, 249-273.

Riegel, Christine (2004): Im Kampf um Zugehörigkeit und Anerkennung. Orientierungen und Handlungsformen von jungen Migrantinnen; eine soziobiografische Untersuchung. Frankfurt a.M.: IKO.

Riphahn, Regina/Bauer, Philipp (2007): Intergenerationale Bildungs- und Einkommensmobilität in der Schweiz. Die Volkswirtschaft 80(7/8), 18-21.

Rommelspacher, Birgit (2011): Was ist eigentlich Rassimus? In: Melter, Claus/Scharathow, Wiebke (Hg.): Rassismuskritik. 2. Aufl. Schwalbach a. T.: Wochenschau Verlag, 25-38.

Rommelspacher, Birgit (2009a): Intersektionalität - über die Wechselwirkung von Machtverhältnissen. In: Kurz-Scherf, Ingrid (Hg.): Feminismus. Kritik und Intervention. Münster: Westfälisches Dampfboot, 81-96.

Rommelspacher, Birgit (2009b): Feminismus und kulturelle Dominanz: Kontroversen um die Emanzipation der muslimischen Frau. In: Berghahn, Sabine/Rostock, Petra (Hg.): Der Stoff, aus dem Konflikte sind: Debatten um das Kopftuch in Deutschland, Österreich und der Schweiz. Bielefeld: transcript, 395-411. 
Rosenthal, Gabriele (1995): Erlebte und erzählte Lebensgeschichte. Gestalt und Struktur biographischer Selbstbeschreibungen. Frankfurt a.M., New York NY: Campus.

Rothfuss, Eberhard (2012): Exklusion im Zentrum. Die brasilianische Favela zwischen Stigmatisierung und Widerständigkeit. Bielefeld: transcript Verlag.

Roy, Olivier (2010): Heilige Einfalt. Über die politischen Gefahren entwurzelter Religionen. München: Siedler.

Roy, Olivier (2006): Der islamische Weg nach Westen. Globalisierung, Entwurzelung und Radikalisierung. München: Pantheon.

Ryser, Mirjam/Erlach, Emanuel von (2007): Bildungsmosaik Schweiz. Bildungsindikatoren 2007. Neuenburg: Bundesamt für Statistik.

Said, Edward W. (1995): Orientalism. Western conceptions of the Orient. London u.a.: Penguin.

Scharenberg, Katja/Hupka-Brunner, Sandra/Meyer, Thomas/Bergmann, Manfred Max (2016): Transitionen im Jugendalter: Ergebnisse der Schweizer Längsschnittstudie TREE. Zürich: Seismo.

Scherr, Albert/Janz, Caroline/Müller, Stefan (2015): »Ich würde dann die Frau nehmen ohne Kopftuch«. Das muslimische Kopftuch als Projektionsfläche für Fremdheitszuschreibungen. In: Scherr, Albert/Janz, Caroline/Müller, Stefan (Hg.): Diskriminierung in der beruflichen Bildung. Wiesbaden: Springer VS, 49-160.

Schiffauer, Werner (2004): Vom Exil- zum Diaspora-Islam. Muslimische Identitäten in Europa. Soziale Welt 55(4), 347-368.

Schild, Pascale (2010): Situationen, Widersprüche und Konflikte muslimischer Identitätspolitik im diskursiven Kontext der Schweiz. In: Allenbach, Brigit/Sökefeld, Martin (Hg.): Muslime in der Schweiz. Zürich: Seismo, 181-212.

Schittenhelm, Karin (2010): Statuspassagen in akademischen Laufbahnen der zweiten Generation. In: Nohl, Arnd-Michael/Schittenhelm, Karin/Schmidtke, Oliver/Weiss, Anja (Hg.): Kulturelles Kapital in der Migration. Hochqualifizierte Einwanderer und Einwandererinnen. Wiesbaden: VS Verlag für Sozialwissenschaften, 39-51.

Schittenhelm, Karin (2005): Soziale Lagen im Übergang. Junge Migrantinnen und Einheimische zwischen Schule und Berufsausbildung. Wiesbaden: VS Verlag für Sozialwissenschaften.

Schlieter, Jens/Kind Furger, Marietta/Lauener, Tina (2011): Buddhistische Identität im Wandel. Eine Untersuchung der zweiten und dritten Genera- 
tion tibetischer Migrantinnen und Migranten in der Schweiz. Schlussbericht. Bern: Schweizerischer Nationalfonds (SNF), Nationales Forschungsprogramm »Religionsgemeinschaften Staat und Gesellschaft» (NFP 58). URL: www.snf.ch/SiteCollectionDocuments/nfp/nfp58/NFP58_ Schlussbericht_Schlieter.pdf [Stand: 28. Januar 2019].

Schneuwly Purdie, Mallory/Tunger-Zanetti, Andreas (2017): Switzerland. In: Scharbrodt, Oliver/Akgönül, Samim/Alibašić, Ahmet/Nielsen, Jørgen S./Racius, Egdunas (Hg.): Yearbook of Muslims in Europe. Volume 8. Leiden, Boston: Brill, 669-687.

Schneuwly Purdie, Mallory/Tunger-Zanetti, Andreas (2015): Switzerland. In: Scharbrodt, Oliver/Akgönül, Samim/Alibašić, Ahmet/Nielsen, Jørgen S./Racius, Egdunas (Hg.): Yearbook of Muslims in Europe. Vol. 7. Leiden, Boston: Brill, 562-578.

Schneuwly Purdie, Mallory (2010): De l'étranger au musulman. Immigration et intégration de l'islam en Suisse. Saarebruck: Editions universitaires européennes, 2010.

Schneuwly Purdie, Mallory/Gianni, Matteo/Jenny, Magali (Hg.) (2009): Musulmans d'aujourd'hui. Identités plurielles en Suisse. Genève: Labor et Fides.

Schröter, Hiltrud (2002): Mohammeds deutsche Töchter. Bildungsprozesse, Hindernisse, Hintergründe. Königstein/Taunus: Ulrike Helmer Verlag.

Schutzfaktor-m.ch (2017): EGMR stützt Schweizer Praxis: Verpflichtung zum Schwimmunterricht zweier Mädchen muslimischen Glaubens verletzt Religionsfreiheit nicht. Medienmitteilung (Webseite). Verein Dialog EMRK. URL: www.schutzfaktor-m.ch/mm-urteil-schwimmunterricht10012017 [Stand: 28. Januar 2019].

Schwarzer, Alice (2017): Emma. Themenseite Burka (Webseite). Emma Frauenverlag. URL: https://www.emma.de/thema/burka [Stand: 28. Januar 2019].

Schweizerische Bundeskanzlei (2017): Eidgenössische Volksinitiative »Ja zum Verhüllungsverbot« (Webseite). Schweizerische Eidgenossenschaft, Bundeskanzlei (BK). URL: https:/www.admin.ch/ch/d/pore/vi/vis465t.html [Stand: 28. Januar 2019].

Schweizerischer Gewerkschaftsbund (SGB) (2014): Saisonnierstatut - einmal und nie wieder! Eine lange Liste von Diskriminierungen (Webseite). Schweizerischer Gewerkschaftsbund (SGB). URL: https://www. sgb.ch/themen/migration/artikel/details/saisonnierstatut-einmal-undnie-wieder/ [Stand: 28. Januar 2019]. 
SKBF (2014): Bildungsbericht Schweiz 2014. Aarau: Schweizerische Koordinationsstelle für Bildungsforschung (SKBF).

Sökefeld, Martin (2011): Religion, Grenzen, Identitäten. In: Allenbach, Brigit/Goel, Urmila/Hummrich, Merle/Weisköppel, Cordula (Hg.): Jugend, Migration und Religion. Interdisziplinäre Perspektiven. Baden-Baden: Nomos, 270-286.

Sökefeld, Martin (2007): Zum Paradigma kultureller Differenz. In: Johler, Reinhard/Thiel, Ansgar/Schmid, Josef/Treptow, Rainer (Hg.): Europa und seine Fremden. Die Gestaltung kultureller Vielfalt als Herausforderung. Bielefeld: transcript, 41-57.

Solga, Heike (2005): Meritokratie - die moderne Legitimation ungleicher Bildungschancen. In: Berger, Peter A./Kahlert, Heike (Hg.): Institutionalisierte Ungleichheiten. Wie das Bildungswesen Chancen blockiert. Weinheim u.a.: Belt Juventa, 19-38.

Soysal, Yasemin Nuhoglu (1994): Limits of citizenship. Migrants and postnational membership in Europe. Chicago: The University of Chicago Press.

Spescha, Stefan (2011): Verdammt zum Eheglück. Paarleben unter dem Damoklesschwert der Migrationsbehörden. In: Bannwart, Bettina/Cottier, Michelle/Durrer, Cheyenne/Kühler, Anna/Küng, Zita/Vogler, Annina (Hg.): Keine Zeit für Utopien? Perspektiven der Lebensreformpolitik im Recht. Zürich, St. Gallen: Dike, 299-320.

Spickard, James (2005): Networks, Homes or Congragations? Exploring the Locus of Immigrant Religiosity. In: Adogame, Afe/Weissköppel, Cordula (Hg.): Religion in the context of African migration. Bayreuth: Breitinger, 23-42.

Spivak, Gayatri Chakravorty (1993): Outside in the Teaching Machine. New York NY: Routledge.

Spivak, Gayatri Chakravorty (1988): Can the Subaltern Speak? In: Nelson, Cary/Grossberg, Lawrence (Hg.): Marxism and the Interpretation of Culture. Basingstoke: Macmillan Education UK, 66-111.

Stienen, Angela (2016): Fieldwork under Forced Protection. The Suspicious Gaze of Children in Columbia's Medellín. Zeitschrift für Ethnologie (141), 233256.

Stienen, Angela/Bühler, Caroline/Gasser, Nathalie (2012): Weltdeutungen im Selbstverständnis von Lehramtsstudierenden. Journal für Lehrerinnenund Lehrerbildung 12(4), 10-20.

Stienen, Angela, Bühler, Caroline, Gasser, Nathalie \& Tamcan, Özgür (2011): Beruf oder Berufung? Deutungskonflikte in der Lehrerinnen- und Leh- 
rerbildung. Schlussbericht. Bern: Schweizerischer Nationalfonds (SNF), Nationales Forschungsprogramm $»$ Religionsgemeinschaften Staat und Gesellschaft« (NFP 58). URL: www.snf.ch/SiteCollectionDocuments/nfp/ nfp58/NFP58_Schlussbericht_Stienen_de.pdf [Stand: 26. Januar 2019].

Stolz, Jörg (2012): Religion und Individuum unter dem Vorzeichen religiöser Pluralisierung. In: Bochinger, Christoph (Hg.): Religionen, Staat und Gesellschaft. Die Schweiz zwischen Säkularisierung und religiöser Vielfalt. Zürich: Verlag Neue Zürcher Zeitung, 77-107.

Stolz, Jörg/Könemann, Judith/Schneuwly Purdie, Mallory/Englberger, Thomas/Krüggeler, Michael (2014): Religion und Spiritualität in der IchGesellschaft. Vier Gestalten des (Un-)Glaubens. Zürich: TVZ Theologischer Verlag Zürich.

Stolz, Jörg/Könemann, Judith/Schneuwly Purdie, Mallory/Engelberger, Thomas/Krüggeler, Michael (2011): Religiosität in der modernen Welt. Bedingungen, Konstruktionen und sozialer Wandel. Bern: Schweizerischer Nationalfonds (SNF), Nationales Forschungsprogramm »Religionsgemeinschaften Staat und Gesellschaft" (NFP 58). URL: www.snf.ch/ SiteCollectionDocuments/nfp/nfp58/NFP58_Schlussbericht_Stolz.pdf [Stand: 26. Januar 2019].

Stolz, Jörg/Baumann, Martin (2007): Religiöse Vielfalt in der Schweiz: Zahlen, Fakten, Trends. In: Baumann, Martin/Stolz, Jörg (Hg.): Eine Schweiz viele Religionen. Risiken und Chancen des Zusammenlebens. Bielefeld: transcript, 21-38.

Strahm, Doris (2007): Schleiersichten. Feministische Debatten um das Kopftuch, Geschlechterkonzepte und Religion (unveröffentlichtes Vorlesungsmanuskript). Theologische Fakultät der Universität Luzern. URL: https:// www.ncbi.ch/uploads/Files/pdf/Artikel_Strahm_4_02.pdf [Stand: 29. Januar 2019].

Strauss, Anselm L./Corbin, Juliet M. (1996): Grounded Theory. Grundlagen qualitativer Sozialforschung. Weinheim: Beltz Psychologie Verlags Union.

Strauss, Anselm L. (1994): Grundlagen qualitativer Sozialforschung. Datenanalyse und Theoriebildung in der empirischen soziologischen Forschung. München: Fink.

Strübing, Jörg (2011): Theoretisches Sampling. In: Bohnsack, Ralf/Marotzki, Winfried/Meuser, Michael (Hg.): Hauptbegriffe qualitativer Sozialforschung. 3. Aufl. Opladen, Farmington Hills MI: Verlag Barbara Budrich, 154-156. 
Talal, Asad (1990): Multiculturalism and Brithish identity in the wake of the Rushdie affair. Politics and Society 18(4), 452-480.

Tezcan, Levent (2007): Kultur, Gouvernalität der Religion und der Integrationsdiskurs. In: Wohlrab-Sahr, Monika/Tezcan, Levent (Hg.): Konfliktfeld Islam in Europa. Baden-Baden: Nomos, 51-74.

Tietze, Nikola (2001): Islamische Identitäten. Formen muslimischer Religiosität junger Männer in Deutschland und Frankreich. Hamburg: Hamburger Edition.

Traunmüller, Richard (2018): Religion und Sozialkapital. In: Pollack, Detlef/Krech, Volkhard/Müller, Olaf/Hero, Markus (Hg.): Handbuch Religionssoziologie. Wiesbaden: Springer VS, 911-933.

Tunger-Zanetti, Andreas (2017): Zahlen zu Mitgliedern in Moscheevereinen. Emailkorrespondenz, 23. März 2017.

Tunger-Zanetti, Andreas (2013a): The many facing the »other« (within). In: Behloul, Samuel M./Leuenberger, Susanne/Tunger-Zanetti, Andreas (Hg.): Debating Islam. Negotiating Religion, Europe, and the Self. Bielefeld: transcript, 223-226.

Tunger-Zanetti, Andreas (2013b): »Against Islam, but not against Muslims«. Actors and attitudes in the Swiss minarett vote. In: Behloul, Samuel M./Leuenberger, Susanne/Tunger-Zanetti, Andreas (Hg.): Debating Islam. Negotiating Religion, Europe, and the Self. Bielefeld: transcript, 285312.

Tunger-Zanetti Andreas (2013C) in Linder, Karin (2013): Zwischen Moschee und Matterhorn. Radio SRF DRS2 (= Kontext). URL: www.srf.ch/sendungen/kontext/zwischen-moschee-und-matterhorn-5 [Stand: 23. April 2013].

Udem, Peter (2018): Redensarten-Index. Wörterbuch für Redensarten, Redewendungen, idiomatische Ausdrücke, Sprichwörter, Umgangssprache (Website). Peter Udem Internet-Dienstleistungen. URL: https://www. redensarten-index.de/suche.php [Stand: 28. Januar 2019].

Unesco (2012): International Standard Classification of Education (ISCED) 2011. Paris: United Nations Educational, Scientific and Cultural Organization (UNESCO).

Urban Dictionary (2017): »diss« (Webseite). Urban Dictionary Online. URL: www.urbandictionary.com/define.php?term=diss [Stand: 26. Januar 2019].

Wäckerlig, Oliver (2014): Das Fanal von Wangen. Der Schweizer Minarettdiskurs - Ursachen und Folgen. Saarbrücken: AV Akademikerverlag. 
Walgenbach, Katharina (2016): Von Differenz und Differenzen: Methodologische Herausforderungen und Chancen einer Komplexitätssteigerung in der Historischen Bildungsforschung. In: Groppe, Carola/Kluchert, Gerhard/Matthes, Eva (Hg.): Bildung und Differenz. Historische Analysen zu einem aktuellen Problem, 39-62.

Walgenbach, Katharina (2014): Heterogenität - Intersektionalität - Diversity in der Erziehungswissenschaft. Opladen u.a.: Verlag Barbara Budrich.

Walgenbach, Katharina (2013): Postscriptum: Intersektionalität - Offenheit, interne Kontroversen und Komplexität als Ressourcen eines gemeinsamen Orientierungsrahmens. In: Lutz, Helma/Vivar, Maria Teresa Herrera/Supik, Linda (Hg.): Fokus Intersektionalität. Bewegungen und Verortungen eines vielschichtigen Konzeptes. 2. Aufl. Wiesbaden: Springer VS, 265-277.

Walgenbach, Katharina (2012a): Intersektionalität als Analyseperspektive heterogener Stadträume. In: Scambor, Elli/Zimmer, Fränk (Hg.): Die intersektionelle Stadt. Geschlechterforschung und Medienkunst an den Achsen der Ungleichheit. Bielefeld: transcript, 81-92.

Walgenbach, Katharina (2012b): Intersektionalität - eine Einführung (Webseite). Bergische Universität Wuppertal, Portal Intersektionalität. URL: http://portal-intersektionalitaet.de/theoriebildung/ueberblickstexte/ walgenbach-einfuehrung/ [Stand: 28. Oktober 2019].

Walgenbach, Katharina (2012c): Gender als interdependente Kategorie. In: Walgenbach, Katharina/Dietze, Gabriele/Hornscheidt, Antje/Palm, Kerstin (Hg.): Gender als interdependente Kategorie. Neue Perspektiven auf Intersektionalität, Diversität und Heterogenität. 2. Aufl. Opladen: Verlag Barbara Budrich, 23-64.

Walgenbach, Katharina/Dietze, Gabriele/Hornscheidt, Antje/Palm, Kerstin (Hg.) (2012): Gender als interdependente Kategorie. Neue Perspektiven auf Intersektionalität, Diversität und Heterogenität. Opladen: Verlag Barbara Budrich.

Walthert, Rafael (2010): Ritual, Individuum und religiöse Gemeinschaft. Das International Christian Fellowship Zürich. In: Lüddeckens, Dorothea/Walthert, Rafael (Hg.): Fluide Religion. Neue religiöse Bewegungen im Wandel; theoretische und empirische Systematisierungen. Bielefeld: transcript, 243-268.

Wälty, Carla Sophia (2018): Verbot zum Tragen von Kopftuch oder Piercing durch den Arbeitgeber. Zürich: Dike. 
Weber, Max (1995 [1904]): Die »Objektivität« sozialwissenschaftlicher und sozialpolitischer Erkenntnis. Schutterwald/Baden: Wissenschaftlicher Verlag.

Weiss, Hilde (Hg.) (2007): Leben in zwei Welten. Zur sozialen Integration ausländischer Jugendlicher der zweiten Generation. Wiesbaden: VS Verlag für Sozialwissenschaften.

Weiss, Hilde/Ates, Gülay/Schnell, Philipp (Hg.) (2016): Muslimische Milieus im Wandel? Religion, Werte und Lebenslagen im Generationenvergleich. Wiesbaden: Springer VS.

Weiss, Hilde/Schnell, Philipp/Ateş, Gülay (Hg.) (2014): Zwischen den Generationen. Transmissionsprozesse in Familien mit Migrationshintergrund. Wiesbaden: Springer VS.

Weissköppel, Cordula (2008): "You don't get lost«. Transnationales Handeln von Sudanesen in einer protestantischen Kirchgemeinde. In: Lauser, Andrea/Weissköppel, Cordula (Hg.): Migration und religiöse Dynamik. Ethnologische Religionsforschung im transnationalen Kontext. Bielefeld: transcript Verlag, 75-103.

Weissköppel, Cordula (2005): »Kreuz und quer. Zur Theorie und Praxis der multi-sited-ethnography«. Zeitschrift für Ethnologie 130(1), 45-68.

Wellgraf, Stefan (2015): Der Boxerstil: Zu Ungleichheitsdimensionen alltagsästhetischer Praktiken. In: Bereswill, Mechthild/Degenring, Folkert/Stange, Sabine (Hg.): Intersektionalität und Forschungspraxis - wechselseitige Herausforderungen. Münster: Westfälisches Dampfboot, 154-171.

Welsch, Wolfgang (2010): Was ist Was ist eigentlich Transkulturalität? In: Darowska, Lucyna/Lüttenberg, Thomas/Machold, Claudia (Hg.): Hochschule als transkultureller Raum? Kultur, Bildung und Differenz in der Universität. Bielefeld: transcript, 39-66.

Wensierski, Hans-Jürgen von/Lübcke, Claudia (2012): Als Moslem fühlt man sich hier auch zu Hause. Biographien und Alltagskulturen junger Muslime in Deutschland. Opladen u.a.: Verlag Barbara Budrich.

Wensierski, Hans-Jürgen von/Lübcke, Claudia (2011): In Deutschland habe ich mit meinem Kopftuch nie Probleme gehabt. Zur Religiosität junger Muslime der Zweiten Generation in Deutschland. In: Allenbach, Brigit/Goel, Urmila/Hummrich, Merle/Weisköppel, Cordula (Hg.): Jugend, Migration und Religion. Interdisziplinäre Perspektiven. Baden-Baden: Nomos, 3-114. 
Wensierski, Hans-Jürgen von/Lübcke, Claudia (Hg.) (2007): Junge Muslime in Deutschland. Lebenslagen, Aufwachsprozesse und Jugendkulturen. Opladen: Verlag Barbara Budrich.

West, Candance/Fenstermaker, Sarah (1995): Doing Difference. Gender \& Society 9(1), 8-37.

Wicker, Hans-Rudolf (2003): Einleitung: Migration, Migrationspolitik und Migrationsforschung. In: Wicker, Hans-Rudolf (Hg.): Migration und die Schweiz. Ergebnisse des Nationalen Forschungsprogramms »Migration und interkulturelle Beziehungen«. Zürich: Seismo, 12-62.

Wiedl, Nina (2008): Da'wa - der Ruf zum Islam in Europa. Berlin: Schiler.

Wimmer, Andreas/Glick Schiller, Nina (2002): Methodological nationalism and beyond: nation-state building, migration and the social sciences. Global Networks 2(4), 301-334.

Winker, Gabriele/Degele, Nina (2009): Intersektionalität. Zur Analyse sozialer Ungleichheiten. Bielefeld: transcript.

Winter, Rainer (2018): De Certeau und habituelle Verankerung von Taktiken, 2. Teil. Emailkorrespondenz, 21. September 2018.

Winter, Rainer (2017): De Certeau und habituelle Verankerung von Taktiken, 1. Teil. Emailkorrespondenz, 15. März 2017.

Winter, Rainer (2008): Widerständige Sozialität im postmodernen Alltagsleben. Das Projekt der Cultural Studies und die post-strukturalistische Diskussion. In: Thomas, Tanja/Höhn, Marco (Hg.): Medienkultur und soziales Handeln. Wiesbaden: VS Verlag für Sozialwissenschaften, 302-315.

Winter, Rainer (2007): Das Geheimnis des Alltäglichen. Michel de Certeau und die Kulturanalyse. Östereichische Zeischrift für Soziologie 32(4), 21-39.

Wodak, Ruth (2002): Aspects of Critical Discourse Analysis. Zeitschrift für angewandte Linguistik 36, 5-31.

Wyttenbach, Judith (2013): To swim or not to swim: Grundrechte und Integration - Rückblick auf zwei Bundesgerichtsentscheide. In: Kaya, Bülent/D'Amato, Gianni (Hg.): Kulturelle Vielfalt und die Justiz. Zürich: Seismo, 93-107.

Young, Michael Dunlop (1961): The rise of the meritocracy, 1870-2023. An essay on education and equality. Harmondsworth: Penguin.

Yuval-Davis, Nira (2013): Jenseits der Dichotomie von Anerkennung und Umverteilung: Intersektionalität und soziale Schichtung. In: Lutz, Helma/Vivar, Maria Teresa Herrera/Supik, Linda (Hg.): Fokus Intersektionalität. Bewegungen und Verortungen eines vielschichtigen Konzeptes. 2. Aufl. Wiesbaden: Springer VS, 203-221. 
Ziegler, Holger (2008): Soziales Kapital und Agency. In: Homfeldt, Günther/Schröer, Wolfgang/Schweppe, Cornelia (Hg.): Vom Adressaten zum Akteur. Soziale Arbeit und Agency. Opladen: Verlag Barbara Budrich, 83106.

Zhou, Min; Lee, Jennifer; Agius Vallejo, Jody; Tafoya-Estrada, Rosaura; Xiong Sao, Yang (2008): Success Attained, Deterred, and Denied: Divergent Pathways to Social Mobility in Los Angeles's New Second Generation. The Annals of the American Academy of Political and Social Science 620(1), 37-61.

Zurlinden, Melanie (2015): Religionsgemeinschaften in der direkten Demokratie. Handlungsräume religiöser Minderheiten in der Schweiz. Wiesbaden: Springer VS. 



\section{Transkriptionsregeln Interviews}

\section{Schweizerdeutsch-Hochdeutsch}

Der schweizerdeutsche Text der Interviews wird ins Hochdeutsche übersetzt. Unschöne Satzkonstruktionen werden bewusst beibehalten. Grammatikalische Unterschiede zwischen Schweizerdeutsch und Hochdeutsch werden grundsätzlich nicht angepasst. Unübersetzbare Formulierungen werden so belassen und kursiv geschrieben (z.B. momou, oder Gymer, Gstürm, schräg iifahre).

\section{Sprechpausen}

Kürzere Sprechpausen drei Pünktchen ...

Längere Sprechpause drei Pünktchen in Klammer (...)

\section{Gleichzeitig Gesprochenes}

Gleichzeitig Gesprochenes Doppelschrägstrich //

Bsp.: $\mathrm{N}$ spricht $\mathrm{mhm}$ gleichzeitig wie die Interviewte aus:

D: und ausserdem ist das Wetter sehr schön heute, //N: $\mathrm{mhm} / /$ D: finden Sie nicht?

\section{Laut Gesprochenes/Betontes}

Laut Gesprochenes und Betontes unterstreichen

\section{Unsicher in Verschriftung}

Unsicher in der Verschriftung: Doppelklammer (()).

Wenn man meint, etwas verstanden zu haben, aber man ist nicht sicher, Wörter oder Wort in Doppelklammer, falls man jedoch gar nichts verstehen kann, leere Doppelklammer

Bsp.: D: ((und ausserdem)) ist das Wetter sehr schön heute

Bsp.: D: (0) ist das Wetter sehr schön heute 


\section{Averbale Ausdrücke}

Averbale Ausdrücke wie schweres Ausatmen oder Einatmen oder ähnliches in Klammern notieren.

schweres Ausatmen (D atmet schwer aus)

Lachen (D lacht)

Angedeutetes Lachen oder Lächeln (D halbes Lachen)

\section{Lautstärke/Tempo}

Falls auffällig, Lautstärke in Klammer

D: (sehr leise) und ausserdem ist das (lauter) Wetter sehr schön heute, (normale Lautstärke) jedenfalls (langsam) spielen die Kinder draussen 


\section{Kulturwissenschaft}

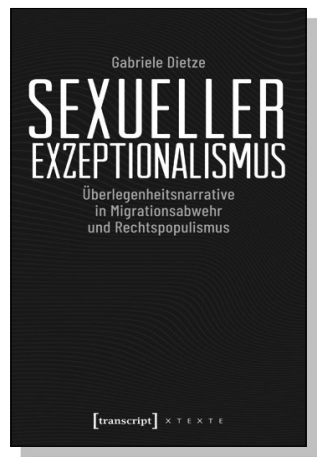

Gabriele Dietze

\section{Sexueller Exzeptionalismus}

Überlegenheitsnarrative in Migrationsabwehr und

Rechtspopulismus

2019, 222 S., kart., Dispersionsbindung, 32 SW-Abbildungen $19,99 €(D E), 978-3-8376-4708-2$

E-Book: 17,99 € (DE), ISBN 978-3-8394-4708-6

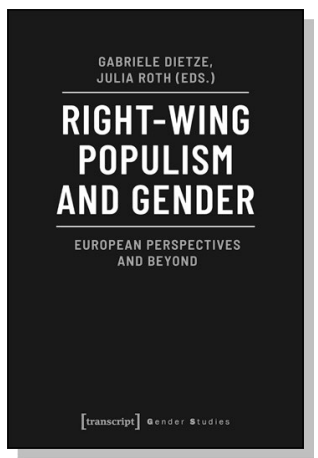

Gabriele Dietze, Julia Roth (eds.)

Right-Wing Populism and Gender

European Perspectives and Beyond

April 2020, 286 p., pb., ill.

35,00 € (DE), 978-3-8376-4980-2

E-Book: 34,99 € (DE), ISBN 978-3-8394-4980-6

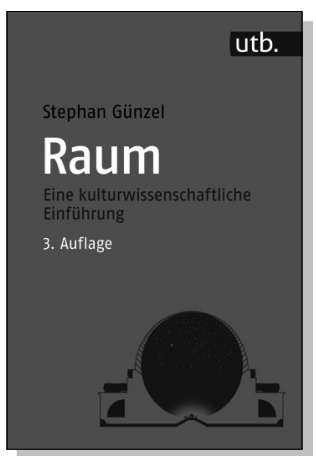

Stephan Günzel

\section{Raum}

Eine kulturwissenschaftliche Einführung

März 2020, 192 S., kart.

20,00€ (DE), 978-3-8376-5217-8

E-Book: 17,99 € (DE), ISBN 978-3-8394-5217-2 


\section{Kulturwissenschaft}

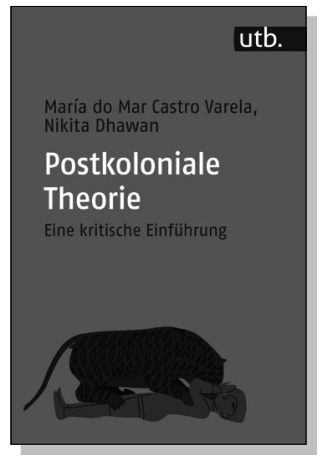

María do Mar Castro Varela, Nikita Dhawan

Postkoloniale Theorie

Eine kritische Einführung

Februar 2020, 384 S., kart.

25,00€ (DE), 978-3-8376-5218-5

E-Book: 22,99 € (DE), ISBN 978-3-8394-5218-9

\section{POP}

Thomas Hecken, Moritz Baßler, Elena Beregow,

Robin Curtis, Heinz Drügh, Mascha Jacobs,

Annekathrin Kohout, Nicolas Pethes, Miriam Zeh (Hg.)

\section{POP}

Kultur \& Kritik (Jg. 9, 1/2020)

April 2020, 180 S., kart.

$16,80 €(D E), 978-3-8376-4936-9$

E-Book: 16,80€ (DE), ISBN 978-3-8394-4936-3

[transcript]

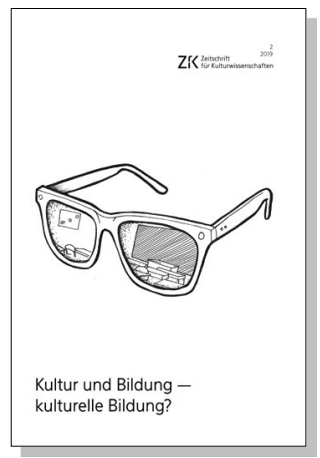

Birgit Althans, Kathrin Audehm (Hg.)

Kultur und Bildung - kulturelle Bildung?

Zeitschrift für Kulturwissenschaften, Heft 2/2019

2019,144 S., kart.

$14,99 €(D E), 978-3-8376-4463-0$

E-Book: 14,99 € (DE), ISBN 978-3-8394-4463-4 

